UNIVERSIDAD POLITÉCNICA DE MADRID

ESCUELA TÉCNICA SUPERIOR DE ARQUITECTURA

\title{
ANÁLISIS DE DATOS ESPACIALES PARA LA ERRADICACIÓN DE LA POBREZA ENERGÉTICA EN LA REHABILITACIÓN URBANA. EL CASO DE MADRID
}

TESIS DOCTORAL

ARQUITECTO FERNANDO MARTÍN-CONSUEGRA ÁVILA

MÁSTER UNIVERSITARIO EN PLANEAMIENTO URBANO Y TERRITORIAL 

DEPARTAMENTO DE URBANISMO Y ORDENACIÓN DEL TERRITORIO ESCUELA TÉCNICA SUPERIOR DE ARQUITECTURA DE MADRID

\title{
ANÁLISIS DE DATOS ESPACIALES PARA LA \\ ERRADICACIÓN DE LA POBREZA ENERGÉTICA EN LA \\ REHABILITACIÓN URBANA. EL CASO DE MADRID
}

\author{
AUTOR: \\ FERNANDO MARTÍN-CONSUEGRA ÁVILA \\ DIRECTORES DE TESIS: \\ DOCTOR ARQUITECTO AGUSTÍN HERNÁNDEZ AJA \\ (ESCUELA TÉCNICA SUPERIOR DE ARQUITECTURA DE MADRID) \\ DOCTOR ARQUITECTO IGNACIO OTEIZA SANJOSÉ \\ (INSTITUTO EDUARDO TORROJA DE CIENCIAS DE LA CONSTRUCCIÓN)





\section{(3.) \\ POLITÉCNICA}

Tribunal nombrado por el Magfco. y Excmo. Sr. Rector de la Universidad Politécnica de Madrid, el día

Presidente

Vocal

Vocal

Vocal

Secretario

Suplente

Realizado el acto de defensa y lectura de la Tesis el día en la E.T.S. Arquitectura.

CALIFICACIÓN:

EL PRESIDENTE

LOS VOCALES

EL SECRETARIO 



\section{Agradecimientos}

En especial a Fernando de Frutos García por su ayuda en la programación Python para la automatización de los procesos de análisis en la herramienta MEPEC. Al Programa de Cooperación Europea en Ciencia y Tecnología (COST) por la financiación para la realización de una estancia predoctoral de investigación en la Faculdade de Ciências e Tecnologia / Universidade Nova de Lisboa, a través de la Acción European Energy Poverty: Agenda Co-Creation and Knowledge Innovation (ENGAGER 2017-2021), y en especial al investigador João Pedro Gouveia por su dirección científica. Al Programa Estatal de I+D+i por la financiación al proyecto BIA2017-83231-C2-1-R: HABITARES- Nueva herramienta integrada de evaluación para áreas urbanas vulnerables. Hacia la autosuficiencia energética y a favor de un modelo de habitabilidad biosaludable. Al arquitecto Pedro Ramírez Perea por compartir su experiencia en el diseño de métodos simplificados para el predimensionado de la demanda de climatización. A los arquitectos Francisco Botella y Carmen Alonso Ruiz-Rivas. A los compañeros del Grupo de Investigación de Sistemas Constructivos y Habitabilidad en la Edificación del Instituto Eduardo Torroja de ciencias de la construcción. A Mariano Sanz (DELETEC) por su ayuda con el diseño de fichas. A la Secretaría de Estado de Infraestructuras, Transporte y Vivienda del Ministerio de Fomento y al equipo de Barrios Vulnerables del DUyOT por facilitar información necesaria para la investigación. A Iván Rodríguez Suarez por su ayuda para la comprensión de la estructura de los datos catastrales. A mi familia por su impulso incondicional a mis estudios. 

RESUMEN: La tesis se basa en el desarrollo conceptual de un Modelo de Análisis de Datos Espaciales capaz de recoger y procesar grandes cantidades de información acerca de la eficiencia energética del parque edificado. El modelo incorpora datos procedentes de diversas fuentes y a varias escalas, con objeto de evaluar las necesidades de barrios enteros y priorizar las actuaciones. Facilita el planeamiento y la gestión de estrategias de rehabilitación energética basadas en la reducción de la demanda desde una perspectiva integral, teniendo en cuenta los aspectos medioambientales, sociales y económicos implicados y el problema de la pobreza energética como elemento vertebrador.

Se proponen dos herramientas complementarias para el proceso de información de las principales bases de datos de la edificación existentes en España: el Catastro y los Censos de Población y Viviendas. Estas herramientas generan indicadores energéticos que se utilizan para caracterizar el desempeño térmico de los edificios, los barrios y las ciudades. Los resultados se vuelcan en el modelo, que permite visualizarlos y detectar las áreas residenciales de la ciudad afectadas por problemas de desigualdad asociada al uso de la energía. Se trata de barrios desfavorecidos en los que la ineficiencia de la edificación se convierte en un vector de riesgo de pobreza energética para sus ocupantes.

El modelo se valida para el caso de Madrid, evaluando el potencial de mejora de la envolvente térmica de la edificación contenida en los tejidos urbanos característicos de los barrios vulnerables e ineficientes de la ciudad. Para ello se han utilizado Sistemas de Información Geográfica y tecnología de procesos de datos inspirada en la Ciencia de Datos Urbanos.

PALABRAS CLAVE: datos urbanos, eficiencia energética, equidad, rehabilitación de barrios, envolvente 

ABSTRACT: The thesis proposes the conceptual development of a Spatial Data Analysis Model that can collect large amounts of information about the energy efficiency of the building stock. The model contains information from different databases at various scales, in order to assess the refurbishment needs of entire neighborhoods. It gives the possibility of planning rehabilitation strategies based on energy needs reduction, taking into account the different environmental, social and economic aspects involved in the process.

Two complementary tools are proposed for the data processing of the main existing bases in Spain: the cadastre and the census. These tools generate energy indicators that are used to characterize the thermal performance of buildings, neighborhoods and cities. The results are inputs for the model, which allows their visualization for the detection of residential areas of the city affected by problems of energy inequality. In these neighborhoods the inefficiency of building becomes a vector of risk of energy poverty for its occupants.

The model is validated for the case of Madrid, by assessing the thermal envelope improvement potential of characteristic urban fabrics from deprived and inefficient neighborhoods of the city. For this purpose, Geographic Information Systems and data processing technologies inspired by the Urban Data Science have been used.

KEYWORDS: urban data, energy efficiency, equity, urban refurbishment, building envelope 

UNIVERSIDAD POLITÉCNICA DE MADRID

ESCUELA TÉCNICA SUPERIOR DE ARQUITECTURA

DEPARTAMENTO DE URBANÍSTICA Y ORDENACIÓN DEL TERRITORIO

TESIS DOCTORAL

ANÁLISIS DE DATOS ESPACIALES PARA LA ERRADICACIÓN DE LA POBREZA

ENERGÉTICA EN LA REHABILITACIÓN URBANA. EL CASO DE MADRID

\section{FE DE ERRATAS}

El título de la Ecuación 3 (página 186) contiene un error en las unidades. El título correcto debería ser:

Ecuación 3. Pérdidas energéticas totales por transmisión (kWh) 
UNIVERSIDAD POLITÉCNICA DE MADRID

ESCUELA TÉCNICA SUPERIOR DE ARQUITECTURA

DEPARTAMENTO DE URBANISMO Y ORDENACIÓN DEL TERRITORIO

TESIS DOCTORAL

ANÁLISIS DE DATOS ESPACIALES PARA LA ERRADICACIÓN DE LA POBREZA

ENERGÉTICA EN LA REHABILITACIÓN URBANA. EL CASO DE MADRID

\section{INDICE}

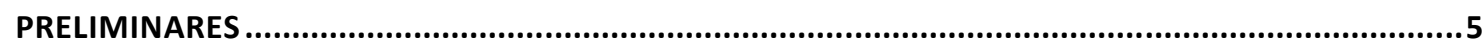

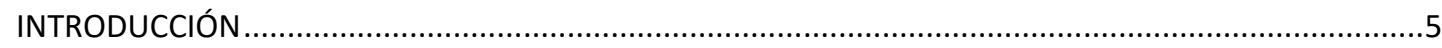

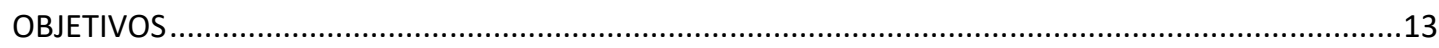

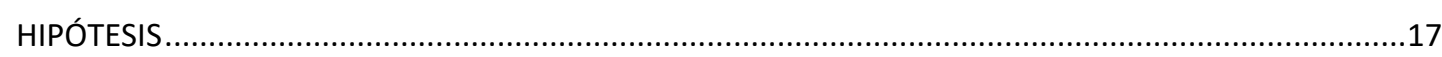

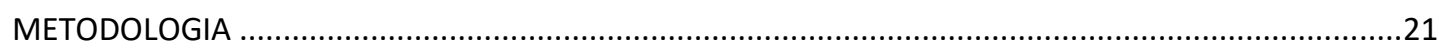

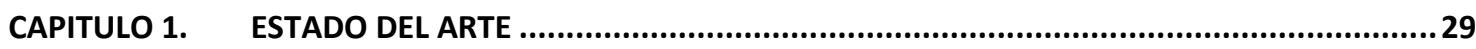

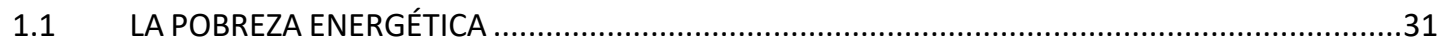

1.1.1 Del derecho a la energía a la justicia energética .........................................................32

1.1.2 La definición del concepto de pobreza energética ...............................................................33

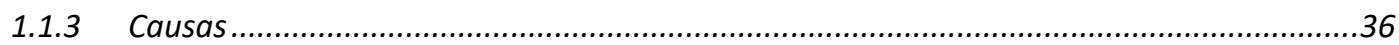

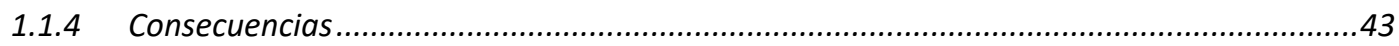

1.1.5 La evaluación de la pobreza energética ...................................................................47

1.1.6 Expectativas de evolución del problema ....................................................................54

1.1.7 Estado del arte de las políticas y soluciones propuestas................................................57

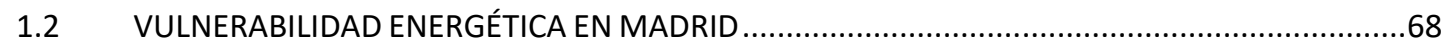

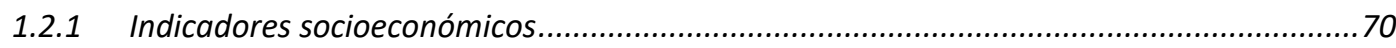

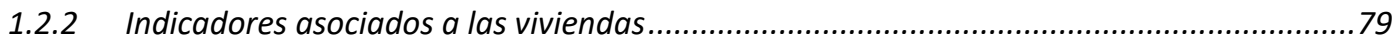

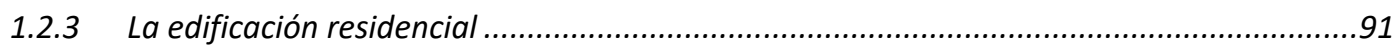

CONSIDERACIONES PARA EL DESARROLLO DEL ESTUDIO ................................................101 
CAPITULO 2. EVALUACIÓN ESTADÍSTICA DE LA POBREZA ENERGÉTICA A LA ESCALA DE LA CIUDAD

2.1 LA DEMANDA ENERGÉTICA DE CALEFACCIÓN A ESCALA URBANA......................................108

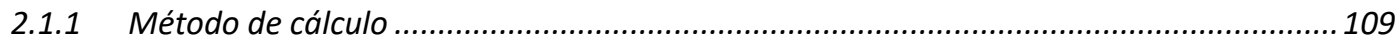

2.1.2 Caracterización energética de la edificación .............................................................. 110

2.1.3 Datos estadísticos residenciales utilizados ............................................................... 116

2.1.4 Indicadores energéticos urbanos obtenidos .............................................................. 116

2.1.5 La clasificación energética de los Barrios Vulnerables...................................................... 120

2.2 DISTRIBUCIÓN DE LA POBREZA ENERGÉTICA EN MADRID ............................................ 122

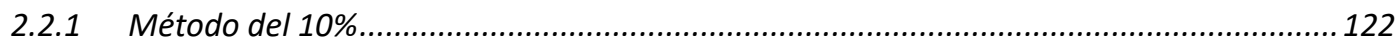

2.2.2 Índice multidimensional de pobreza energética .............................................................. 136

2.3 COMPARATIVA ENTRE MÉTODOS DE ANÁLISIS DE LA POBREZA ENERGÉTICA.......................150

CAPITULO 3. EVALUACIÓN ENERGÉTICA DE BARRIOS UTILIZANDO DATOS CATASTRALES.....155

3.1 ESTIMACIÓN DE PÉRDIDAS ENERGÉTICAS A TRAVÉS DE DATOS CATASTRALES (MEPEC)........158

3.1.1 Las pérdidas energéticas de la edificación..................................................................... 160

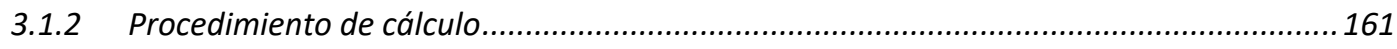

3.1.3 Descarga y procesado de los datos catastrales .......................................................... 162

3.1.4 Caracterización geométrica de la edificación ................................................................ 166

3.1.5 Caracterización constructiva de la envolvente térmica ............................................... 172

3.1.6 Indicadores de transmisión térmica y cómputo de pérdidas energéticas.......................... 185

3.1.7 La evaluación de la eficiencia energética mediante datos catastrales.............................190

3.2 DEMANDA ENERGÉTICA DE CALEFACCIÓN DE LOS BARRIOS RESIDENCIALES.......................194

3.2.1 Simplificaciones para el cálculo a escala urbana .......................................................... 195

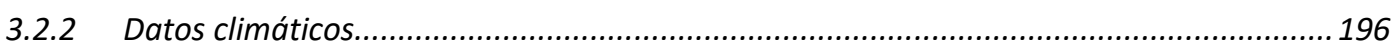

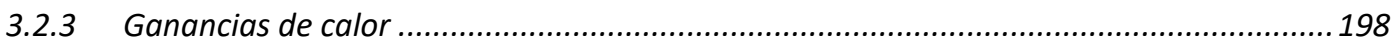

3.2.4 Estimación de las perdidas energéticas totales........................................................204

3.2.5 Resultados de demanda energética de calefacción .....................................................206

3.3 EVALUACIÓN DE MEDIDAS DE MEJORA DE LA ENVOLVENTE..............................................208

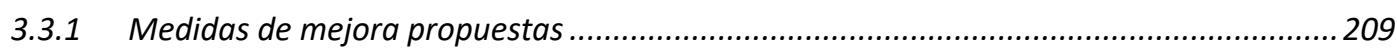

3.3.2 Costes de la inversión inicial ............................................................................. 218

3.3.3 Beneficios medioambientales, sociales y económicos ...............................................225

3.3.4 Comparación de costes y beneficios .....................................................................229

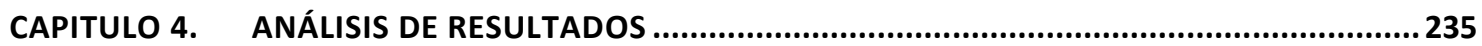

4.1 CARACTERIZACIÓN TÉRMICA DE LOS BARRIOS EN RIESGO DE POBREZA ENERGÉTICA ...........238

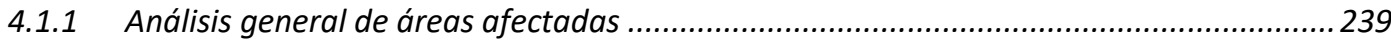

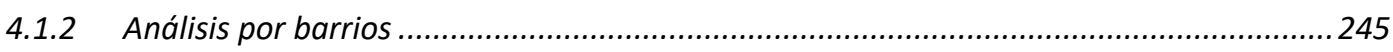

4.1.3 Tejidos urbanos característicos de áreas en riesgo de pobreza energética....................... 248 


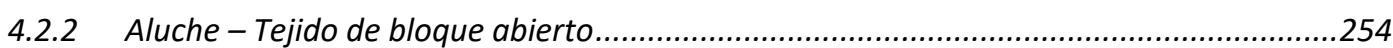

4.2.3 Entrevías Este - Poblado de promoción pública del periodo 40-60 .................................258

4.2.4 Picazo - Tejido de parcelación periférica .....................................................................260

4.2.5 Vicálvaro - Poblado anexionado a Madrid ...............................................................262

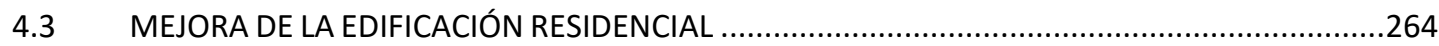

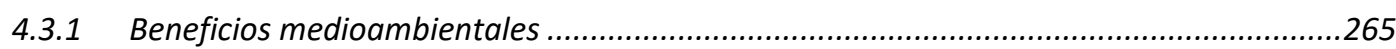

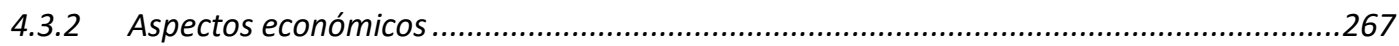

4.3.3 Beneficios sociales por el potencial de creación de empleo .........................................269

4.4 COMPARATIVA DE RESULTADOS OBTENIDOS CON DATOS ESTADÍSTICOS Y CATASTRALES...271 CONCLUSIONES 277

La identificación de la ineficiencia y la pobreza energética en la ciudad ......................................280

Del Método de Evaluación de Pérdidas Energéticas a partir de Catastro .....................................284

La demanda energética de calefacción en los barrios...........................................................286

La rehabilitación de las envolventes, sus costes y beneficios .....................................................289

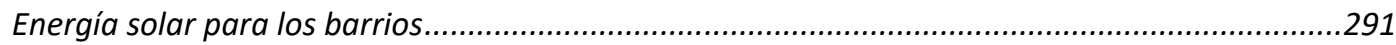

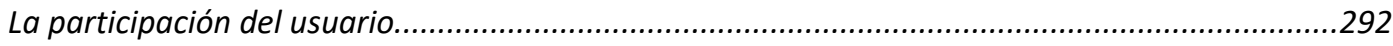

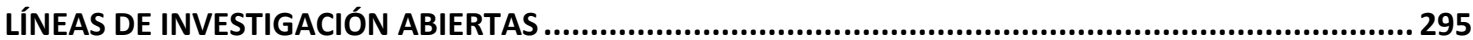

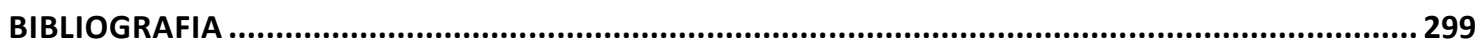

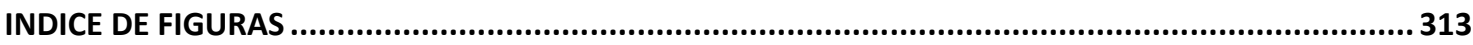

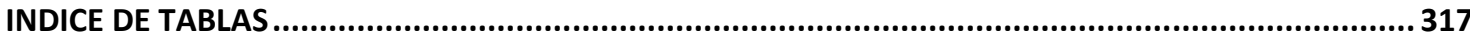

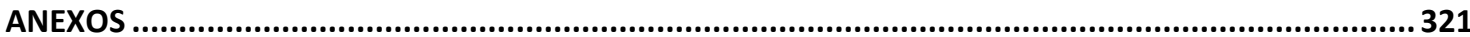





\section{PRELIMINARES}

\section{INTRODUCCIÓN}

La edificación residencial española es consumidora de grandes recursos energéticos y presenta un alto potencial para el ahorro energético. La ineficiencia de nuestros edificios es causante de graves problemas ambientales, sociales y económicos que pueden ser amortiguados en gran parte mediante su rehabilitación. Para lograr la transición a un modelo de ciudad más eficiente y sostenible se deben diseñar operaciones de regeneración urbana que aborden todas las dimensiones del problema respondiendo a criterios de equidad energética. 
La Directiva 2002/91/CE del Parlamento Europeo y del Consejo de 16 de diciembre de 2002, relativa a la eficiencia energética de los edificios identifica al sector de la edificación como uno de los grandes consumidores de energía de Europa. Para abordar el problema, establece un etiquetado energético para todos los países miembros de la Unión Europea, la aplicación de requisitos mínimos de eficiencia energética en los edificios nuevos y apunta por primera vez la necesidad de aplicar esos requisitos a los grandes edificios existentes (Parlamento Europeo y el Consejo de la Unión Europea 2002). Esta Directiva ha sido modificada tres veces ampliando el foco en la rehabilitación energética: en 2010 la Directiva 2010/31/UE establece la obligatoriedad de que los nuevos edificios sean de energía "casi nula" y de mejorar la eficiencia energética de edificios ineficientes en los que se acometan obras importantes. En 2012 la Directiva 2012/27/UE de eficiencia energética marca el objetivo de un 20 \% de ahorro para 2020. En su Artículo 4 insta a los Estados miembros a realizar estrategias a largo plazo para movilizar inversiones en la renovación del parque y señala la función ejemplarizante que deben asumir los organismos públicos en dicha renovación. La Directiva (UE) 2018/844, con el objetivo principal de acelerar la renovación económicamente rentable de los edificios, exige a los países de la UE que elaboren estrategias a largo plazo para apoyar la renovación de los edificios residenciales y no residenciales transformándolos en parques inmobiliarios con alta eficiencia energética y descarbonizados antes de 2050 (Parlamento Europeo y el Consejo de la Unión Europea 2010; 2012; 2018).

Desde el impulso de las instituciones europeas el interés por el tema va creciendo en España. De manera paralela se han ido realizando numerosos estudios independientes dirigidos a evaluar la calidad térmica de la edificación existente en nuestras ciudades, constatando su alta ineficiencia. Estos estudios van detallando la problemática con objeto de señalar aspectos clave y ayudar a trazar estrategias de mejora que respondan a las directivas (Dalle et al. 2010; A. Cuchí y Sweatman 2012; Tragopoulos y Sweatman 2012; Tirado, López Fernández, y Martín García 2012; Santiago 2014; Kurtz, Monzón, y LópezMesa 2015; Oteiza, I. et al. 2018).

El Instituto para la Diversificación y el Ahorro Energético se implica directamente en el análisis del consumo energético del sector residencial en España a través de los proyectos SPAHOUSEC (IDAE 2011b; 2019). 
Desde el Gobierno de España se trata de eliminar trabas y flexibilizar el régimen vigente para mejorar el estado de conservación de los edificios: la Ley 8/2013, de Rehabilitación, Regeneración y Renovación urbanas, con medidas específicas para mejorar la eficiencia energética en la edificación de manera voluntaria y desarrollar fórmulas adicionales de financiación de las obras que se sumen a las tradicionales desde un enfoque medioambiental, social y económico integrador:

“...regular las condiciones básicas que garanticen un desarrollo sostenible, competitivo y eficiente del medio urbano, mediante el impulso y el fomento de las actuaciones que conduzcan a la rehabilitación de los edificios y a la regeneración y renovación de los tejidos urbanos existentes, cuando sean necesarias para asegurar a los ciudadanos una adecuada calidad de vida y la efectividad de su derecho a disfrutar de una vivienda digna y adecuada..." (Gobierno de España 2013)

La Estrategia a largo plazo para la rehabilitación energética en el sector de la edificación en España en desarrollo del artículo 4 de la Directiva 2012/27/UE (ERESEE 2014), elaborada por el Ministerio de Fomento, recoge las obligaciones de los textos legales y se apoya en los estudios citados para determinar enfoques rentables de renovación en relación con el tipo de edificio y la zona climática, mediante cálculos fundados en datos estadísticos del Censo de Población y Viviendas. Ofrece un panorama del parque inmobiliario nacional a la escala provincial y establece como factor determinante la reducción de la demanda por actuaciones sobre la piel del edificio (Ministerio de Fomento 2014). En la actualización de 2017 se abordan aspectos cualitativos para su aplicación y se identifican barreras y oportunidades de actuación (Ministerio de Fomento 2017). La tercera actualización de la estrategia está prevista para 2020, en la que se espera que se incorpore un calendario concreto para la intervención en edificios con objetivos específicos para lograr la descarbonización del parque para el año 2050.

El Estudio de la distribución del consumo energético residencial para la calefacción en España, encargado por el Ministerio de Fomento para disponer de información precisa para actualizar la ERESEE aborda la necesidad de la cuantificación de la pobreza energética. El trabajo señala la calefacción como principal servicio consumidor de energía en los edificios residenciales de España, y en especial en la zona continental. Presenta como principal conclusión "mostrar la necesidad y urgencia de disponer de fuentes de 
datos con la calidad suficiente para sustentar sucesivas actualizaciones de la ERESEE y, en particular, la próxima de 2020" citando expresamente el Catastro como fuente de datos necesaria sobre la morfología urbana (Cuchí, A., Arcas, J., y Pagés-Ramon 2017).

Los trabajos mencionados van recopilando información y evidencias científicas y técnicas de la idoneidad de la regeneración urbana como motor de cambio hacia un modelo más racional, eficiente y sostenible. Pero a pesar de ello la rehabilitación no termina de implantarse con el vigor necesario en España, pudiéndose afirmar que se trata de una actividad marginal. En 2014 se rehabilitaron o se reformaron más de 22.000 viviendas y 28.000 edificios (Figura 1), cifras similares a los años 2012 y 2013. Si lo comparamos con el número de viviendas nuevas finalizadas en el año 2014 que fue de 46.958 unidades, representan el doble que el de las viviendas rehabilitadas, a pesar del pinchazo de la burbuja inmobiliaria que llegó a construir más de 600.000 viviendas en los años 2007 y 2008 (CEPCO 2015). El análisis de la lenta, por no decir casi nula, progresión de la rehabilitación en España, mas aun con un componente de mejora de la eficiencia energética, debe partir de observar una serie de circunstancias socioeconómicas que deben ser tenidas como obstáculos en la consecución de tal objetivo.

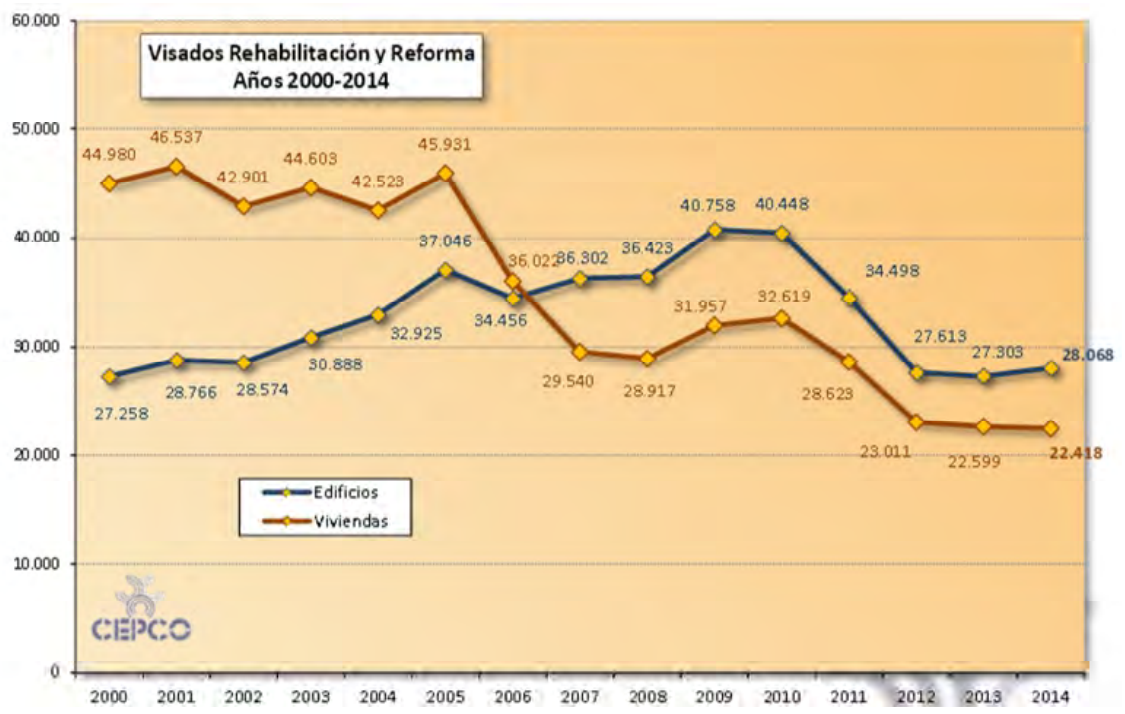

Figura 1. Visados de rehabilitación y reforma 2000 al 2014. Fuente Ministerio de Fomento (CEPCO, 2015). 
Generalmente los edificios que requieren actuaciones de rehabilitación serán aquellos de mayor antigüedad y deficiente calidad constructiva. Muchos de ellos habitados por personas con insuficientes recursos para abordar tales actuaciones. En estos casos, no solo la eficiencia energética será el objetivo, sino que el mantenimiento del edificio puede ser de por si razón que las justifique. En España, según datos del proyecto europeo ENTRANZE $^{1}$, relativos a 2008 , el $83 \%$ de las viviendas estaba ocupado por sus propietarios, de los cuales el $86 \%$ era de bajos ingresos y $12,6 \%$ mayores de 65 años. Por ello, la pretensión de rehabilitar sin hacer un estudio detallado de la distribución de recursos, en el ámbito urbanístico donde se planteen las actuaciones, puede conducir a situaciones problemáticas a la hora de hacer efectivos los pagos de las obras.

Desde el punto de vista económico, se suele argumentar que el resultado de la rehabilitación viene a suponer objetivamente un valor añadido del inmueble. Las casas valen en gran medida por donde están situadas y por el componente de construcción. En lo que se refiere a la eficiencia energética, el supuesto aumento de valor puede ser atribuido al ahorro energético que se consiga. Así pues, una vez realizada la inversión en el inmueble, hay un incremento de valor útil en el uso, que es objetivo y que no puede desdeñarse; pero debe quedar claro que este valor está vinculado a la habitabilidad. En cualquier caso, habrá que hacer llegar de antemano recursos económicos a las actuaciones de rehabilitación.

Un gran problema a la hora de comunicar a la sociedad la idea de los beneficios de la mejora de la eficiencia energética de las viviendas existentes, está en saber transmitir de qué se trata. Tal eficiencia es la relación que existe entre la energía necesaria para conseguir el confort y mantenerlo (demanda), y el combustible que se necesita para ello (consumo). Esto depende del clima local, de la orientación y el factor de forma del edificio (superficie expuesta por volumen), de los elementos constructivos que conforman los límites materiales del espacio a acondicionar, de la naturaleza del combustible y de los dispositivos que lo transforman en servicios energéticos. En lo que respecta al factor social, hay que tener en cuenta que:

\footnotetext{
${ }^{1}$ http://www.entranze.enerdata.eu/
} 
- A personas con recursos limitados, la carga de las actuaciones de rehabilitación no pueden vincularse al ahorro de la factura en la parte de compra del combustible.

- A personas de una edad avanzada, no se les puede convencer con el argumento de la revaloración del inmueble, por no hablar de la amortización de la inversión.

La amortización de los costos de las operaciones de rehabilitación energética a partir de los ahorros conseguidos en la factura no parece estimular suficientemente a los agentes implicados. El enfoque basado en la amortización de la inversión está basado en premisas erróneas debido a que no tiene en cuenta que una buena parte de los hogares no pueden hacer frente a los costes derivados de su factura energética y optan por reducir los niveles de confort y, por tanto, su potencial de ahorro es reducido. Los aspectos sociales son determinantes, puesto que una parte importante de la población sufre privación en el uso de la energía. Las carencias en materia de eficiencia energética que padece la edificación residencial existente producen una vulnerabilidad energética en la población que habita los edificios ineficientes. Cuando a esta problemática se suman unos bajos ingresos en el hogar, la combinación deriva en muchos casos en situaciones de pobreza energética. Si bien existen otras causas de pobreza que no están relacionadas con la edificación, la intervención desde la regeneración urbana es una estrategia que cuenta con un potencial decisivo para la solución del problema.

En ese sentido, la rehabilitación energética puede ser una herramienta de lucha contra la pobreza. La mejora de las viviendas es una solución a largo plazo para los hogares que actualmente se encuentran en situación de pobreza energética, evitando el previsible aumento del número de casos en el futuro. En los casos en los que las viviendas albergan a población vulnerable, el componente de mejora pasiva de la eficiencia energética permite incrementar el confort aunque el consumo energético en muchos casos esté restringido por motivos económicos. El alivio de este problema supone la reducción de uno de los múltiples aspectos de privación en la dimensión de las necesidades básicas que definen la línea de la pobreza en países desarrollados (Pérez Mayo 2004).

La mayor parte de los edificios existentes en España fueron construidos con anterioridad al año 1979 y por tanto presentan una mala calidad térmica, careciendo generalmente de aislamiento o de cualquier otra medida para la limitación de su demanda energética. En este contexto las pérdidas por transmisión a través de la 
envolvente suponen un factor de gran impacto en su demanda de calefacción. La mejora de la eficiencia energética de la edificación debe priorizar como primer paso el comportamiento pasivo de los edificios, en el que la intervención en la envolvente incide directamente. En una segunda etapa será necesario mejorar el rendimiento de las instalaciones térmicas que podrán diseñarse con una menor potencia que redunde en un uso más eficiente de los recursos energéticos. En una tercera fase del proceso será posible cubrir las necesidades de energía, ya sensiblemente reducidas, mediante la incorporación de energías renovables de manera distribuida en los edificios y a la escala de distrito.

La rehabilitación a la escala del barrio presenta un mayor potencial de impacto que la intervención edificio por edificio. La mejora de la eficiencia energética de nuestras ciudades debe ser abordada desde el urbanismo para conseguir un enfoque general del problema que permita observarlo desde su totalidad y en su contexto socioeconómico. A partir de esta visión global será posible ampliar la escala para analizar cada barrio, su morfología, la edificación y hasta las soluciones constructivas existentes. Este conocimiento va a permitir el planeamiento de estrategias dirigidas a la incorporación de soluciones integrales para los problemas derivados del uso ineficiente de la energía en nuestras ciudades. Los planes de ayuda a la rehabilitación energética de edificios aislados están resultando eficaces para lograr mejoras puntuales en algunos de ellos, para fomentar la rehabilitación y dar a conocer el problema, ensayar fórmulas para las subvenciones, etc. (IDAE 2016) (Ayuntamiento de Madrid 2016). Pero su capacidad para influir en el medioambiente urbano es limitada, al tratarse de un reducido número de casos desperdigados por todo el país o la ciudad. El estudio desde la escala urbana facilita el diseño de propuestas de mejora con posibilidades de lograr un impacto importante en la mejora de la calidad de vida de la población. El volumen de estas actuaciones genera la posibilidad de acumular un impacto suficiente que permita reducir drásticamente el consumo energético, aumentar el confort de la población, y mejorar el medioambiente urbano. Mediante la generalización de la rehabilitación energética de barrios es posible conseguir una repercusión suficiente como para que su impacto se aprecie en toda la ciudad. Además, la rehabilitación de barrios es la estrategia que cuenta con mayores conexiones con otras políticas energéticas como es la reducción de la dependencia energética, un problema endémico en España. También incide reduciendo las emisiones 
de $\mathrm{CO}_{2}$ y contiene además un potencial de generación de empleo y desarrollo de la innovación en el sector de la construcción.

Así pues la promoción de la rehabilitación pasa por una planificación, es decir, por unas inversiones preliminares en los estudios socioeconómicos y urbanísticos que procedan. Existe una urgente necesidad de herramientas precisas para el diagnóstico urbano detallado que permitan gestionar, visualizar y comunicar todo el proceso de forma clara. La presente tesis doctoral pretende avanzar en esta línea. 


\section{OBJETIVOS}

El objetivo principal de este estudio es el desarrollo de herramientas coordinadas para el diagnóstico de las necesidades de rehabilitación energética a la escala urbana que posibiliten la evaluación de propuestas de mejora desde una perspectiva integradora. Se busca un método útil para la incorporación de criterios de eficiencia energética y confortabilidad en los desarrollos de programas y planes de rehabilitación del parque residencial existente, mediante el planteamiento de operaciones a escala de barrio.

La inclusión de medidas de mejora de la eficiencia energética de la edificación es una premisa necesaria en las operaciones de regeneración urbana para lograr los siguientes objetivos:

- La reducción del agotamiento de recursos energéticos y sus costes asociados

- La amortiguación de los múltiples problemas sociales derivados de la ineficiencia energética en la edificación, como son la pobreza energética, la privación del confort y los problemas de salud asociados

- La mejora del medioambiente urbano mediante la reducción de emisiones de gases contaminantes a la escala microclimática

- La mitigación de impactos ambientales globales, como el cambio climático, mediante la reducción de las emisiones de $\mathrm{CO}_{2}$ 
Por otro lado, se considera imprescindible incorporar criterios socioeconómicos en la planificación de estas operaciones para lograr diseñar estrategias efectivas adaptadas al usuario final. El propósito es conseguir aumentar el número de edificios rehabilitados actuando a la escala urbana y considerando las circunstancias de la población. Solo así se podrán lograr los objetivos marcados por la tarea propuesta por la Directiva 2018/844/UE de descarbonización del parque edificado para 2050 (Parlamento Europeo y el Consejo de la Unión Europea 2018) y su concreción en España a través de la Estrategia a largo plazo para la rehabilitación energética en el sector de la edificación en España ERESEE (Ministerio de Fomento 2014; 2017).

El trabajo que se presenta está en consonancia directa con los Objetivos de Desarrollo Sostenible del Programa de Naciones Unidas para el Desarrollo, en concreto con el Objetivo 7: "Energía asequible y no contaminante", ya que se trabaja por la reducción de la dependencia de los combustibles fósiles que está generando cambios drásticos en nuestro clima. También toca el Objetivo 11: "Ciudades y comunidades sostenibles". y el Objetivo 1: "Fin de la Pobreza", que exige "...terminar con la pobreza en todas sus formas y dimensiones para 2030. Esto requiere enfocarse en los más vulnerables, aumentar el acceso a los recursos y servicios básicos..." (PNUD 2016). En concreto se pretende trabajar en lo que respecta a la dimensión energética de la pobreza. Para ello se proponen los siguientes objetivos específicos:

1. Se persigue valorar en la escala urbana los edificios, en particular los de viviendas existentes, mediante indicadores de comportamiento energético. Se busca cuantificar las demandas energéticas de calefacción necesarias actualmente para lograr situaciones de confort en las viviendas, y en particular en las situadas en barrios desfavorecidos. Esto va a permitir avanzar en la definición de las necesidades básicas de confort térmico para garantizar una calidad de vida digna. Desde esa conceptualización es posible cuantificar la cantidad de energía que es necesario suministrar a cada barrio, en función de las características de los edificios y los hogares que los habitan.

2. Se pretende volcar en un modelo único la información técnica relativa a las características térmicas de la edificación ineficiente a la vez que se tienen en cuenta las circunstancias sociales, ambientales y económicas en las áreas urbanas que la 
contienen. Avanzar en la sistematización de la recogida de datos de las fuentes existentes acerca de la edificación y la vulnerabilidad energética que genera en los usuarios, incluyendo su referencia espacial. Principalmente se busca explorar en los datos de los censos de población y viviendas y en los datos catastrales, además de otras fuentes complementarias. Mediante el proceso de estos datos se busca obtener resultados que permitan relacionar las múltiples dimensiones del problema de la ineficiencia de las viviendas de nuestras ciudades. El cruce, análisis espacial y visualización de la información recopilada persigue facilitar la gestión y comunicación de las operaciones de rehabilitación de la edificación residencial ineficiente. Este objetivo pretende dar respuesta a la necesidad y urgencia de disponer de fuentes de datos para sustentar sucesivas actualizaciones de la ERESEE que se expresan en las conclusiones del Estudio de la distribución del consumo energético para calefacción en España (Cuchí, A., Arcas, J., y Pagés-Ramon 2017).

3. Facilitar la incorporación de criterios socioeconómicos en los planes de rehabilitación energética de barrios para poder trazar estrategias dirigidas a conseguir la reducción de problemas de pobreza energética en la población, en base a información veraz. La edificación contenida en barrios degradados cuenta con unas peores condiciones constructivas y de mantenimiento. Se pretende profundizar en la cuantificación del problema, en el análisis de sus causas y en la propuesta de soluciones específicas. Se propone identificar la ineficiencia energética de la edificación para analizarla en relación con los problemas de vulnerabilidad urbana en áreas desfavorecidas, partiendo de la premisa de que ambos factores son determinantes de la pobreza energética. Del estudio de la interacción de ambas problemáticas será posible sacar conclusiones relevantes para el planeamiento de operaciones de mejora que sean realistas con las posibilidades de la población. Se debe evitar que la transición a un modelo de ciudad más sostenible agrave todavía más las causas de vulnerabilidad ya existentes en los barrios desfavorecidos. La localización de edificación en barrios vulnerables con envolventes ineficientes permitirá la estimación de los recursos necesarios para su recuperación. Se pretende que el trabajo desarrollado facilite el cálculo de la inversión necesaria para atajar el problema, posibilitando la inclusión de criterios de equidad energética en las políticas públicas. 
4. También se procura que las herramientas desarrolladas permitan su integración en planes de Regeneración Urbana Integrada (Martín-Consuegra, Alonso, y Frutos 2015). Se entiende que la mejora de la eficiencia energética de la edificación no se puede desligar de los procesos de recuperación de la ciudad existente. Para ello se considera prioritario facilitar la comunicación interdisciplinar entre arquitectos, ingenieros, sociólogos, científicos, economistas y otros profesionales trabajando en diferentes áreas de la ecología en la edificación. Para ello se pretende avanzar en la visualización de los datos en mapas inteligentes que permitan manejar fácilmente grandes cantidades de información sobre los edificios en su entorno. 


\section{HIPÓTESIS}

Existe una demanda energética encubierta en el sector residencial, causada por la pobreza energética, que no está siendo satisfecha por parte de los usuarios. Esto es sucede en gran parte por la imposibilidad de costear los suministros necesarios para obtener unos servicios energéticos básicos. Los edificios ineficientes provocan en sus usuarios situaciones de vulnerabilidad energética que, en combinación con otros problemas socioeconómicos, puede derivar en pobreza energética. Desde el punto de vista de la arquitectura, es posible realizar un diagnóstico de las causas de esa ineficiencia para intervenir desde la raíz del problema. Pero su magnitud es extensa y los recursos limitados. Son necesarias herramientas detalladas capaces de analizar gran cantidad de datos para detectar la ineficiencia de manera precisa y en base a información veraz, para poder priorizar las actuaciones en los casos más necesarios. 
El presente trabajo parte de la hipótesis de que mediante la utilización de técnicas inspiradas en la Ciencia de Datos Urbanos es posible desarrollar un método para la determinación de las necesidades energéticas básicas de la edificación residencial para todo el país y que incorpore datos concretos acerca de cada edificación. En el momento presente nos encontramos con la creciente disponibilidad de una gran cantidad de información digital accesible desde las redes. El concepto de Big Data hace referencia al tratamiento y análisis de repositorios de datos desproporcionadamente grandes, difíciles de manejar con las herramientas de bases de datos y analíticas convencionales. Este fenómeno afecta también a la información sobre nuestras ciudades, su población y la edificación existente. La Unión Europea define la transparencia como un elemento clave para fomentar la participación activa de los ciudadanos europeos en su vida democrática y les otorga el derecho a solicitar el acceso a esos documentos y a dar a conocer sus puntos de vista. Esta creciente disponibilidad de información pública accesible en abierto es una oportunidad para los investigadores para realizar estudios precisos.

Mediante la explotación de los datos abiertos se puede obtener información de áreas urbanas desde la escala nacional, provincial y municipal, hasta los barrios y sus edificios con un alto nivel de detalle. Es posible integrar toda esta información en un solo modelo mediante la utilización de Sistemas de Información Geográfica (SIG) para agrupar y contrastar información a diferentes escalas, realizar operaciones de análisis espacial y para su visualización en mapas inteligentes. Utilizando herramientas de software libre es posible automatizar estos procesos y realizar el trabajo en un tiempo razonable. El modelo puede permitir gestionar la información necesaria para auditar la estimación de las necesidades básicas en materia de energía de barrios enteros, atendiendo a los factores medioambientales, sociales y económicos asociados y a las características de los tejidos que los conforman. Para ello se plantean las siguientes sub-hipótesis.

1. Se parte de la premisa de que mediante la construcción de un modelo que recoja la información de la edificación, resultará posible lograr dos objetivos clave para facilitar el diseño y gestión de estrategias de rehabilitación energética:

- Establecer comparaciones entre las bases de datos públicas más importantes a la escala nacional: el Censo de Población y Viviendas y el Catastro. Esta estrategia permite dar un salto cualitativo para afinar en el diagnóstico de la situación inicial. 
- Simular escenarios futuros para estimar los potenciales de reducción de la demanda mediante la incorporación de mejoras de la edificación. Este modelo permitiría realizar estimaciones sobre los costes de intervención y cuantificar los beneficios de la rehabilitación.

2. Las tecnologías digitales citadas pueden permitir el desarrollo de al menos dos herramientas de evaluación energética urbana diseñadas para:

- Determinar áreas ineficientes a la escala de la sección censal mediante la utilización de indicadores basados en datos estadísticos que completen los estudios existentes en los que se basa la estrategia ERESEE (A. Cuchí y Sweatman 2012; Cuchí, A., Arcas, J., y Pagés-Ramon 2017). Es posible superar el nivel de detalle espacial de estos estudios -que hasta el momento han llegado hasta la escala provincial y la clasificación de la edificación en clústeres- logrando una mayor desagregación territorial.

- Desarrollar indicadores energéticos a partir de los datos catastrales para evaluar los edificios de manera pormenorizada, y conseguir un gran nivel de detalle para el análisis de barrios a partir de la agrupación de datos particularizados de cada edificio.

3. El presente estudio parte de la premisa de que la morfología urbana influye en el desempeño térmico de la edificación. Es necesario llegar a un nivel de detalle que contemple la trama urbana y conseguir la incorporación de información sobre la calidad constructiva de las envolventes. Una vez hecho esto resulta posible estimar unos rangos en los valores de la demanda energética de los edificios y plantear soluciones particularizadas para cada tejido urbano.

4. Mediante el correcto diseño de estrategias de eficiencia energética en operaciones de regeneración urbana integrada de áreas ineficientes, se pueden diseñar barrios libres de pobreza energética. Si los edificios residenciales reducen su demanda energética considerablemente, los usuarios dejarán de sentir la presión causada por la vulnerabilidad energética a la que se ven expuestos en la actualidad.

5. Se parte de la suposición de que la población vulnerable es la que habita principalmente en áreas urbanas con la edificación más ineficiente y con mayor 
necesidad de rehabilitación. Mediante la comparación de los datos de la edificación con los datos socioeconómicos se pueden identificar cuáles son los barrios ineficientes que albergan a población vulnerable y por tanto se encuentran en una situación crítica. 


\section{METODOLOGIA}

La idea de integrar en un solo modelo espacial del parque edificado toda la información referente a su eficiencia energética, desde múltiples niveles que van desde la escala nacional hasta la de la edificación, se basa en el trabajo desarrollado en su tesis doctoral por Liane Thuvander en la Chalmers Tekniska Högskola de Göteborg (Suecia) (Thuvander 2008). En su propuesta se plantean las bases conceptuales para el desarrollo de herramientas informáticas aplicadas a la gestión ambiental, y su concreción en un sistema de información integral del parque edificado (Figura 2).

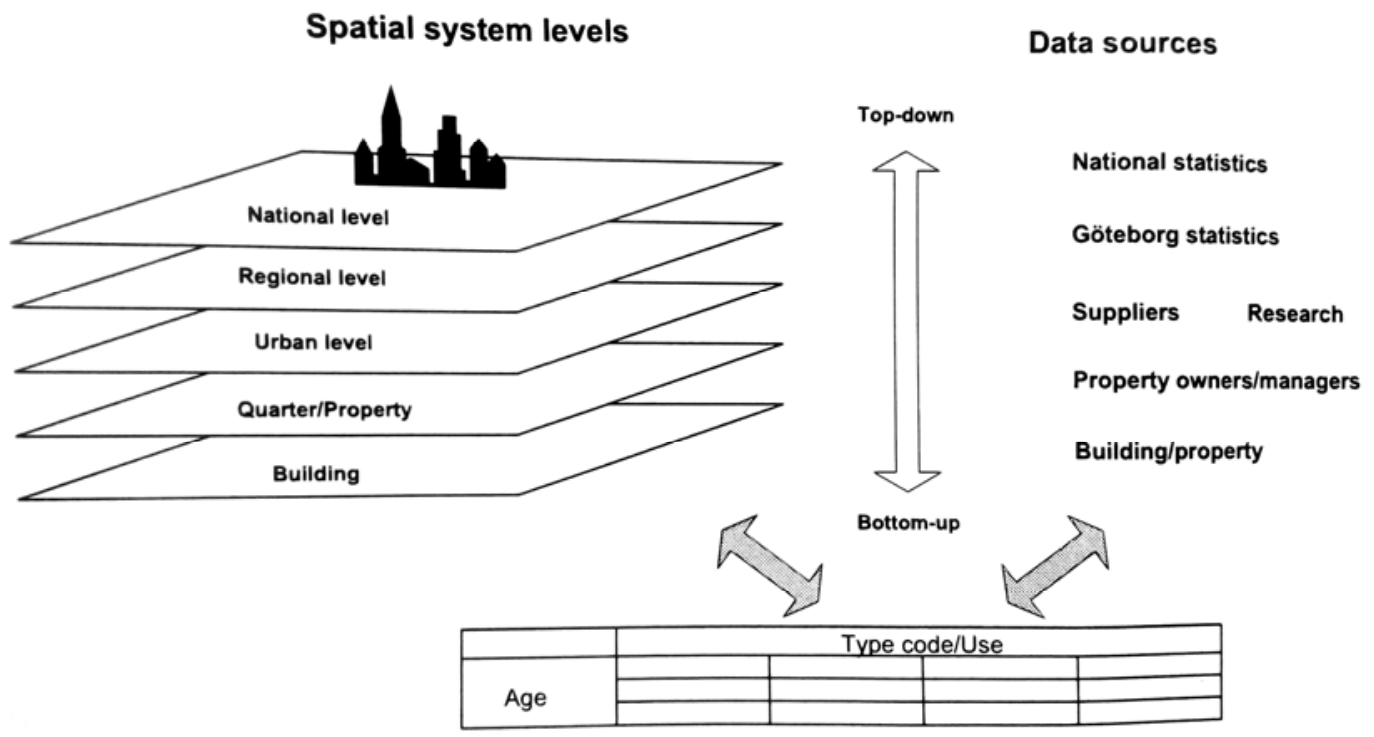

Figura 2. Esquema conceptual del Modelo de Análisis de Datos Espaciales (Thuvander, 2008) 
En este trabajo se aplican las bases conceptuales propuestas por Thuvander con objeto de construir un Modelo de Análisis de Datos Espaciales (MADE) diseñado para la evaluación de la ineficiencia del parque edificado y para la gestión de su rehabilitación energética (Figura 3). Se trata de un modelo que recoge las características físicas de la ciudad y las pone en relación con una gran cantidad de datos geolocalizados. Para facilitar la compatibilidad de este modelo con las fuentes de información disponible, y con otros métodos existentes basados en esta, la estructura de los datos se ha construido utilizando la referenciación espacial propuesta por las bases de datos robustos existentes en España que contienen una mayor información acerca de la edificación: los Censos de Población y Viviendas del Instituto Nacional de Estadística, y el Catastro. A partir del proceso de los datos obtenidos de cada una de ellas se desarrollan dos herramientas concretas para la evaluación energética de edificios residenciales dentro del contexto socioeconómico del barrio en el que se ubican: la Herramienta de Análisis Estadístico de la Pobreza Energética en la Ciudad (HEEPEC, que se desarrolla en CAPITULO 2) y la Metodología de Evaluación de Pérdidas Energéticas con Datos Catastrales (MEPEC, que se desarrolla en el CAPITULO 3). Estas herramientas operan a diferentes escalas según la disponibilidad de datos, y generan una serie de indicadores energéticos que se vuelcan en el MADE, a través del cual es posible visualizar y analizar la integración de los resultados entre sí y con el resto de información georreferenciada existente. El modelo puede albergar todos los registros procedentes de las bases de datos existentes en el país que contienen información relevante relacionada, desde un enfoque amplio, con la eficiencia energética de los edificios y con mayor detalle, del parque residencial.

Los resultados arrojados por las herramientas de análisis y el funcionamiento del modelo se han validado utilizando el estudio de caso del municipio de Madrid. Los estudios a partir de datos estadísticos se han realizado para el ámbito de toda la ciudad y aquellos que utilizan datos catastrales se han aplicado a la escala de barrio, con detalle de cada edificación. Finalmente se cruzan los datos a diferentes escalas para permitir un análisis integral de una serie de barrios. La selección de estos barrios se ha realizado a partir de los indicadores de eficiencia energética y de vulnerabilidad urbana obtenidos de la aplicación de esta metodología. Para la consecución de los objetivos propuestos y el contraste de las hipótesis formuladas se han seguido las etapas que se detallan a continuación. 


\section{METODOLOGÍA}

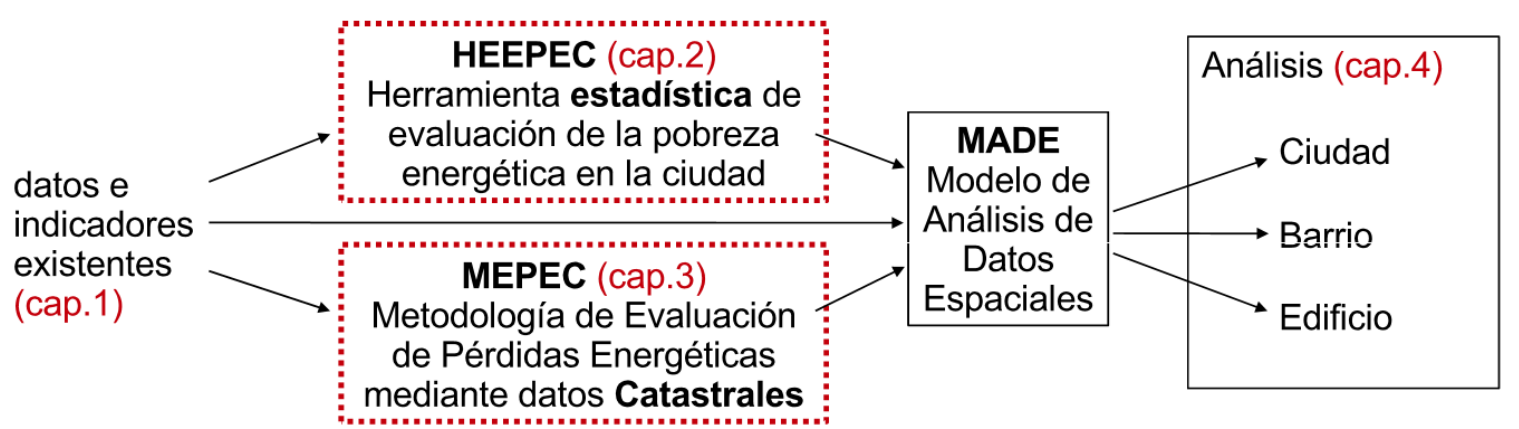

Figura 3. Diagrama conceptual de la metodología propuesta. Elaboración propia

\section{Estado del arte}

En el CAPÍTULO 1 de la tesis se elabora un estado del arte dirigido a enfocar el análisis de la ineficiencia energética de la edificación desde el punto de vista de sus consecuencias sociales y en concreto de la pobreza energética como la más grave de ellas. Utilizando este concepto como vertebrador para la búsqueda de soluciones integrales, se analiza la literatura existente y se pone en relación con la conceptualización de otras definiciones emergentes como son la equidad y la justicia energética.

La primera parte del CAPÍTULO 1 consiste en una revisión de las fuentes existentes acerca de la pobreza energética para pasar a la estructuración ordenada de la información y conseguir una visión general del problema. Se concreta el análisis para detectar los aspectos que están relacionados con la edificación e identificar los conceptos clave.

En una segunda parte se introduce el análisis de la ciudad, en concreto del caso de Madrid, donde se van a testar las herramientas que se generen. Se realiza una búsqueda en los recursos existentes de datos estadísticos relacionados con la pobreza energética y especialmente con los aspectos relativos a la edificación. Se toma la geo-referenciación del Censo de Población y Viviendas para conformar el esqueleto del MADE para la ciudad de Madrid, iniciando su estructura desde la escala de la sección censal. Sobre esta primera referencia se irán volcando los resultados de las herramientas de evaluación que se detallan en los siguientes capítulos. 


\section{Herramienta de evaluación de la pobreza energética a la escala de la ciudad}

En un segundo paso (CAPITULO 2) se construye una herramienta de proceso de datos estadísticos dirigida al análisis de la pobreza energética y de la vulnerabilidad de la edificación y de su distribución espacial dentro de la ciudad. La herramienta es capaz de integrar datos de diferentes fuentes para:

- El cálculo de indicadores útiles para evaluar la eficiencia energética de la edificación residencial en toda la ciudad. En especial se centra en la detección de áreas que contienen edificios ineficientes, una fuente de derroche que provoca presión sobre sus ocupantes. Es lo que se entiende en este trabajo como vulnerabilidad energética asociada a la edificación.

- Contrastar información socioeconómica relacionada con las causas y consecuencias de la pobreza energética. Calcular los valores medios de los costes de la factura energética de la ciudad e incorporar información sobre el nivel de renta.

- Generar indicadores urbanos de pobreza energética a partir de la combinación de la información de los puntos anteriores. En concreto se proponen dos sistemas de evaluación: el indicador del porcentaje de los costes energéticos sobre los ingresos del hogar (regla del 10\%) y el índice multidimensional de pobreza energética (IMPE) que incorpora otros criterios socioeconómicos complementarios.

Toda la información elaborada contiene una geo-referenciación a partir del código de sección censal del Censo de Población y Viviendas del Instituto Nacional de Estadística, de manera que se puede volcar en el MADE con la misma organización espacial y al nivel de resolución de la sección censal.

La aplicación de esta herramienta permite obtener unos primeros resultados parciales para la investigación que se plasman en mapas de pobreza energética. Se identifican las áreas críticas de la ciudad en las cuales la edificación es altamente ineficiente y además albergan a población vulnerable, con lo cual el riesgo de pobreza energética se ve intensificado. Sobre esta selección de áreas se aplicará la herramienta detallada desarrollada en el CAPITULO 3. 


\section{Herramienta de evaluación energética de barrios}

En el CAPITULO 3 se desarrolla un método detallado para la evaluación energética de barrios enteros, con información recopilada edificio por edificio. Se diseña la incorporación al MADE de los datos que pone a disposición la Oficina Virtual del Catastro consistentes en información geométrica en formato vectorial y datos alfanuméricos descriptivos de la edificación. El alto nivel de detalle de esta información permite determinar la influencia de la forma urbana y de la calidad de la edificación en las necesidades energéticas de la ciudad de manera pormenorizada y con una alta definición. El proceso se aplica al estudio de caso del Poblado Dirigido de Canillas, y se organiza en tres etapas:

- En la primera etapa se desarrolla una herramienta automatizada para la estimación de las pérdidas energéticas a través de la envolvente utilizando el proceso masivo de los datos catastrales. Esta herramienta se ha denominado Metodología de Evaluación de Pérdidas Energéticas a partir de datos Catastrales (MEPEC). Permite evaluar la edificación además de desarrollar otros indicadores de eficiencia energética a la escala urbana.

- A partir de esta información es posible completar el cálculo de la demanda energética de calefacción gracias a la incorporación en el MADE de la estimación de otros factores influyentes. Se incluyen unos valores estimados de las ganancias solares, las ganancias internas y las pérdidas por ventilación utilizando el método contemplado en la norma (ISO 13790 2008). Mediante el balance energético de estos conceptos (ganancias-pérdidas) se obtienen valores de demanda para cada edificio y para todo el barrio.

- Conocidos los valores de la demanda energética de la edificación en su estado actual resulta posible generar un escenario rehabilitado simulando medidas de mejora de la eficiencia energética. Se aplica el método para la estimación de los beneficios producidos por la inversión en la mejora de las prestaciones de la envolvente opaca de todos los edificios anteriores a 1979. La definición de estas mejoras permite realizar una estimación de los costes de intervención inicial y de los beneficios medioambientales, sociales y económicos que se obtendrían de su aplicación. 


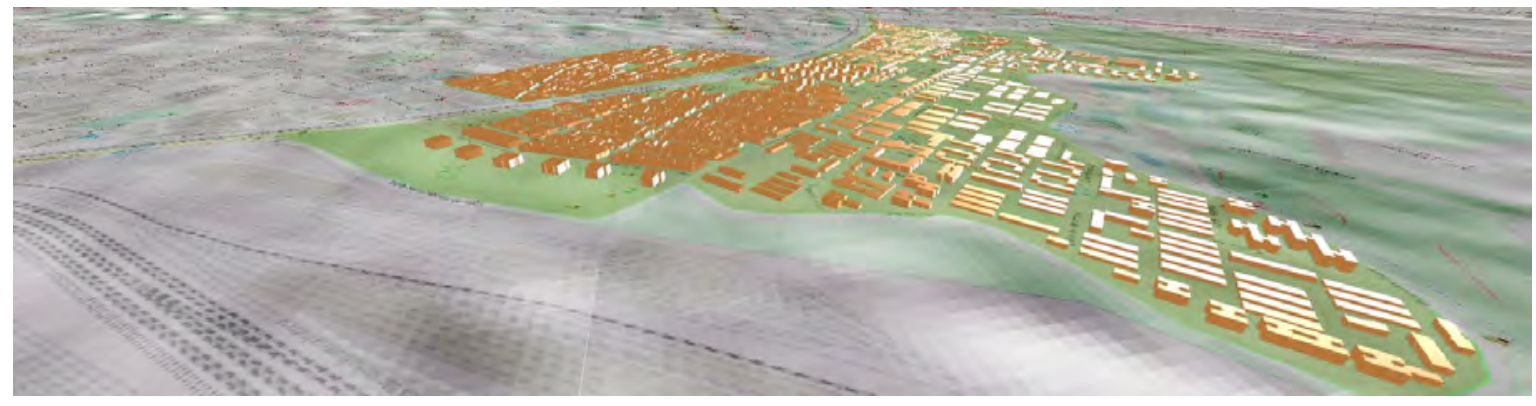

Figura 4. Visualización del soporte de información geométrica del MADE. Ejemplo para los barrios vulnerables e ineficientes en Puente de Vallecas (Madrid). Elaboración propia.

\section{Validación de la herramienta y obtención de resultados}

En el CAPITULO 4, de análisis de resultados, se aplica la metodología catastral MEPEC propuesta en el CAPITULO 3 para la evaluación de la eficiencia energética de los barrios en riesgo de pobreza energética identificados con la herramienta estadística HEEPEC en el CAPITULO 2. Se obtienen resultados clasificados para cada barrio y se determina cuales son los tejidos urbanos característicos de dichos barrios mediante su análisis morfológico. Esto se consigue incorporando al MADE información urbanística de las Normas Zonales incluidas en el Plan General de Ordenación Urbana de Madrid vigente (Ayuntamiento de Madrid 1997).

Mediante la visualización de los resultados utilizando herramientas SIG se comprueba la funcionalidad de la metodología desarrollada y la coherencia de los resultados automatizados. Se utilizan herramientas estadísticas para evaluar la edificación de los barrios vulnerables en mayor riesgo de pobreza energética. También se aplica el MEPEC para el análisis detallado de los barrios vulnerables e ineficientes que contienen tejidos urbanos característicos de las áreas en riesgo de pobreza energética. Se simula un escenario mejorado en el cual se contempla la incorporación de aislamiento térmico en toda la envolvente opaca de la edificación anterior a 1979, obteniendo resultados de la demanda energética resultante en el estado reformado y de otros beneficios medioambientales, sociales y económicos concretos, todo ello de manera comparada con los costes de la inversión necesaria.

Finalmente, como ejemplo de evaluación multi-escala, se realiza una reflexión comparativa de los resultados de demanda energética de calefacción obtenidos de forma simplificada mediante la utilización de la herramienta estadística HEEPEC con los 
resultados detallados obtenidos a partir de datos catastrales con MEPEC agrupados a la escala de la sección censal. Esto permite la realización de una serie de consideraciones finales acerca de la idoneidad de ambos métodos y proponer una serie de mejoras para el método estadístico.

La Figura 4 representa una visualización del soporte geométrico del MADE y la Figura 5 el diagrama de entradas y salidas de los flujos de información. Las partes desarrolladas en esta tesis aparecen resaltadas en gris. El modelo se conceptualiza para permitir la incorporación de los resultados de futuras líneas de investigación relacionadas, como son los desarrollos de cálculo solar que contemplen las obstrucciones solares en barrios (herramienta MESOL) o el volcado de información volumétrica detallada obtenida mediante datos en formato LIDAR (Laser Imaging Detection and Ranging) del Instituto Geográfico Nacional. También se prepara para su calibración a partir de la monitorización del comportamiento energético de edificios y viviendas mediante la instalación de sensores (C. Alonso et al. 2017), que permitirá realizar estimaciones precisas de consumo en los casos concretos de barrios que sufren situaciones de pobreza energética, donde las necesidades básicas no se satisfacen.

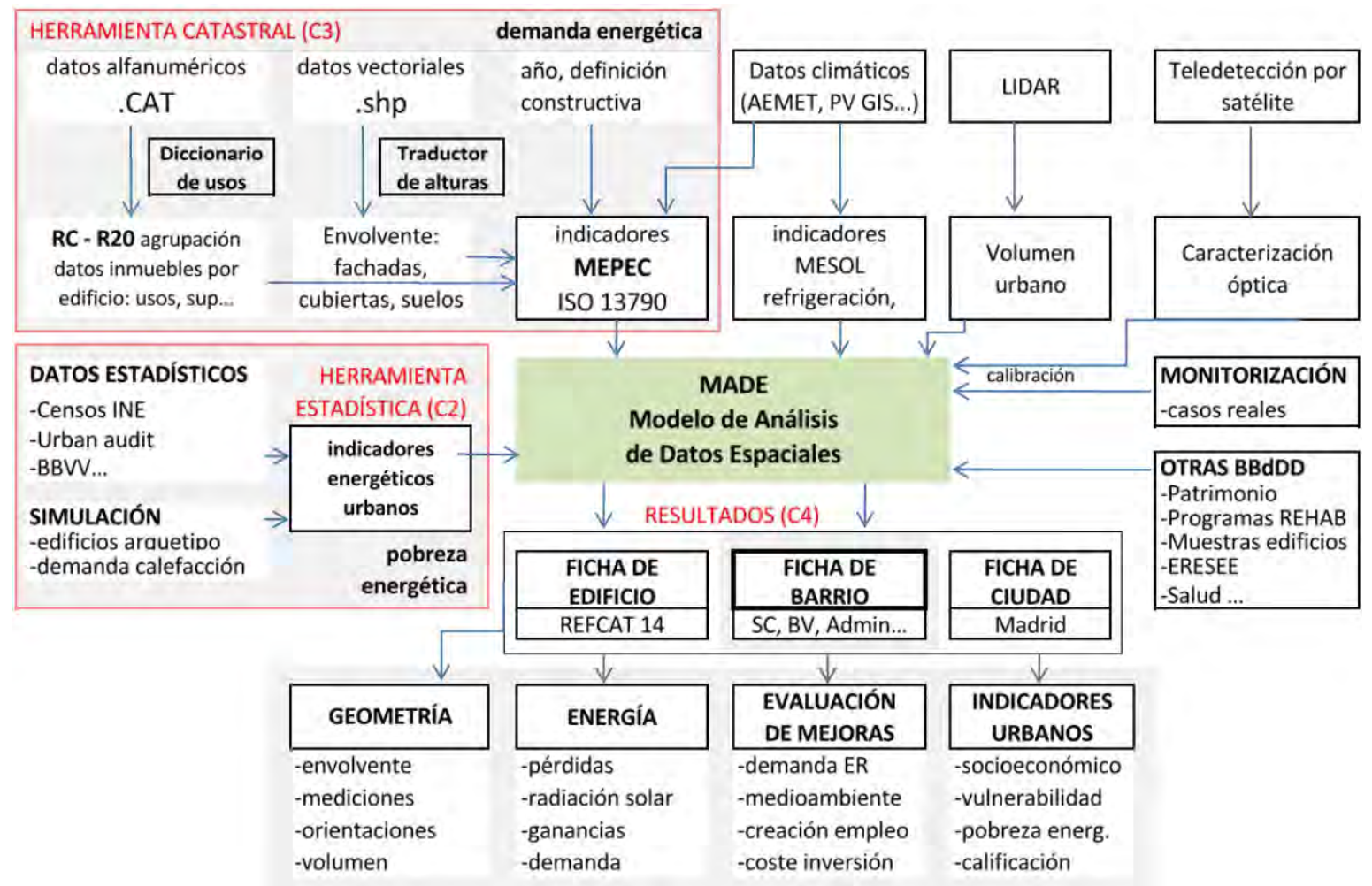

Figura 5. Diagrama de flujos de entradas y salidas de información en el Modelo de Análisis de Datos Espaciales propuesto. Elaboración propia 



\section{CAPITULO 1. ESTADO DEL ARTE}

La energía es descrita a menudo, junto con la alimentación, la vestimenta y la vivienda digna, como una necesidad básica en el sentido en que sin ella la supervivencia se ve amenazada (Bradshaw y Hutton 1983).

Uno de los impactos sociales más adversos del consumo ineficiente de energía en el sector doméstico es la pobreza energética. En el presente capítulo se analiza el estado del arte en torno al problema. En la primera parte se aborda una revisión bibliográfica de los estudios en la materia, principalmente centrada alrededor de los aspectos relacionados con la edificación. En la segunda parte se analizan las bases de datos existentes para realizar una búsqueda de datos estadísticos robustos geo-referenciados. Se trata de recopilar la información relacionada con la ineficiencia energética de la edificación desde su contexto socioeconómico. El estudio se aplica al caso de la ciudad de Madrid. 


\section{CAPÍTULO 1. ESTADO DEL ARTE}

La pobreza energética es un problema social, medioambiental y de salud pública de gran actualidad, que parece destinado a agravarse en España y en Europa en los próximos años. Su origen se produce por la incapacidad de mantener un hogar en condiciones de confort adecuadas para los estándares actuales y disponer de los servicios energéticos necesarios por un precio razonable. Ocurre como una combinación de tres factores definidos en el ámbito del hogar: la ineficiencia energética de la vivienda, una baja renta familiar y elevados precios de la energía. Las consecuencias son una pérdida de calidad de vida, falta de confort y problemas de salud asociados mayoritariamente a personas débiles a las cuales en el peor de los casos puede producirles la muerte (Healey 2004). El sur de Europa padece los niveles más altos de pobreza energética debido principalmente a que contiene las condiciones más precarias en la calidad constructiva de sus edificios (Healy 2003). Se define así el concepto de edificación vulnerable desde el punto de vista de la eficiencia energética: se deduce que existen viviendas de baja calidad térmica que generan unos altos costes para lograr el confort, provocando que en ellas se produzcan situaciones de pobreza energética.

El aumento de la mortalidad en ciertas estaciones del año es algo a tener muy en cuenta, pues si analizamos la pobreza energética en España como parte de su causa, se podría reducir adecuando las viviendas a unas mejores condiciones. Para lograr resultados significativos en la mejora de la calidad energética se entiende que es necesario un acercamiento desde la escala urbana. El estado español tiene unos compromisos en ese aspecto: la trasposición de los artículos de la Directiva Europea de Eficiencia Energética insta a los Estados miembros a establecer una estrategia a largo plazo para movilizar inversiones para la renovación del parque nacional de los edificios residenciales, entre otros (Parlamento Europeo y el Consejo de la Unión Europea 2012). Dicha estrategia debe plantearse de forma integral, poniendo en el foco la solución de los problemas sociales derivados de la ineficiencia energética. 


\subsection{LA POBREZA ENERGÉTICA}

Se trata de un problema que viene detectándose desde los años 70 . Los primeros estudios específicos que tratan las consecuencias negativas del alza de los precios de la energía para el sector doméstico aparecen en el Reino Unido tras la crisis energética de los años 70 (The Energy Commission 1979). Rápidamente se pasa a identificar sus posibles consecuencias sobre la salud de las personas mayores (Wicks 1978) y se empieza a plantear el desarrollo de políticas sociales de prevención (Bradshaw y Hutton 1983). Seguidamente, el desarrollo de la investigación comienza a centrar la atención sobre sus implicaciones políticas particularmente en relación con la privatización de la electricidad, la preocupación por la contaminación ambiental y las tendencias en la legislación europea (Boardman 1991). El primer estudio transeuropeo de pobreza energética que incluye a España es el proyecto EPEE, financiado por la Comisión Europea en el programa Inteligent Energy Europe (Nolay et al. 2009) (ECOSERVEIS 2010). El primer estudio específico para un caso español es el proyecto REPEX "Rehabilitación energética de edificios: una oportunidad de empleo verde en Extremadura, una solución a la pobreza energética", en el cual se sientan las bases para el posterior estudio a escala nacional "Pobreza Energética en España. Potencial de generación de empleo derivado de la rehabilitación energética de viviendas" (Tirado, López Fernández, y Martín García 2012). Este ha contado con sucesivas actualizaciones en las que se profundiza en diversos aspectos del problema en el contexto español (Tirado et al. 2014; Tirado, S. et al. 2016; Tirado et al. 2018). Se advierte que la situación está destinada a agravarse principalmente por la tendencia al alza de los precios de la energía, como se constata a través de estudios específicos (Capros et al. 2010).

El problema se origina desde el momento en el que los hogares con ingresos bajos se ven obligados a restringir el uso de las instalaciones térmicas debido a que los altos costes de la energía necesaria para alcanzar el confort aumentan en exceso la presión sobre sus presupuestos familiares (Thomson y Snell 2013). Al no poder hacer frente al pago de las facturas energéticas, ven reducidos sus estándares de confort por debajo de lo que se considera aceptable (Brunner, Spitzer, y Christanell 2012). Además de la pérdida de calidad de vida por deficiencias en confort, el endeudamiento de los hogares y 


\section{CAPÍTULO 1. ESTADO DEL ARTE}

el deterioro de los edificios, las consecuencias pueden derivar en problemas de salud asociados mayoritariamente a personas débiles a las cuales en el peor de los casos puede producirles la muerte (Christine Liddell y Morris 2010).

A partir de estas premisas comienzan los estudios dirigidos al análisis de la situación de las ciudades para identificar áreas urbanas vulnerables en Inglaterra (Fahmy, Gordon, y Patsios 2011), y dentro de ellas los hogares en situación de pobreza energética (Dubois 2012). Se toma conciencia del riesgo de agravar la situación en los hogares vulnerables que podrían suponen las operaciones de rehabilitación dirigidas a solucionar el problema de la ineficiencia energética de la edificación existente, lo que exige desarrollar soluciones atendiendo a las circunstancias e impactos socioeconómicos (Dresner y Ekins 2006).

\subsubsection{Del derecho a la energía a la justicia energética}

Las consecuencias sociales de la crisis energética de los años 70 obligaron a definir la energía como una necesidad básica para poder garantizar una supervivencia digna (Bradshaw y Hutton 1983). La justicia energética implica el derecho de todas las personas a acceder a los servicios energéticos. El concepto está emergiendo como una nueva línea de investigación de las ciencias sociales que busca aplicar principios de justicia a las políticas, la producción, los sistemas, el consumo y la seguridad energética y el cambio climático (Jenkins et al. 2016).

Analizar la pobreza energética desde un enfoque de derechos humanos permite poner el foco, no en las carencias y necesidades de las personas que la padecen para que el Estado las satisfaga, sino en los resultados de las medidas adoptadas por los titulares de las obligaciones de respetar, proteger y garantizar los derechos esenciales de las personas. Se trata de garantizar tales derechos de tal forma que en caso de no cumplir con el mandato puedan ser reclamados jurídicamente por sus titulares (Sánchez Suarez 2019).

En un primer momento esta perspectiva se genera a partir de los problemas de injusticia medioambiental causados por la producción, extracción de materias primas y transformación de la energía. Un ejemplo de ello es el impacto causado por la energía nuclear (desde la extracción del uranio hasta el tratamiento de sus residuos radioactivos), cuyas consecuencias afectan a determinados sectores de la sociedad a quienes el 
discurso energético ignora o no reconoce (Endres 2009). Estos y otros problemas ambientales causados por la producción y distribución de la energía están conectados de manera inseparable a su consumo. La justicia energética debe garantizar que los permisos y la ubicación de la energía no infrinjan las libertades civiles básicas y que las comunidades estén informadas y representadas de manera significativa en las decisiones sobre energía (Sovacool y Dworkin 2015). Además ofrece un nuevo marco para abordar la investigación existente y futura, y la planificación de la producción y el consumo de energía.

La justicia energética proporciona un hilo conductor para relacionar los impactos sociales, económicos y ambientales de la energía, que pueden ocurrir a todos los niveles en los sistemas energéticos globales (Jenkins et al., 2016). En los últimos años, la investigación está fundamentando que el tema de la pobreza energética es una dimensión clave para formular un paradigma de justicia energética, ya que se trata fundamentalmente de un problema complejo de injusticia distributiva. Los fundamentos teóricos de la justicia energética conectan la pobreza energética con las políticas nacionales en materia de eficiencia energética. Además aportan un valor añadido desde la perspectiva de los derechos sociales proporcionando estrategias para responder a las necesidades específicas de los hogares, y validando el derecho a una serie de servicios básicos de energía, más allá del confort térmico. (Gillard, Snell, y Bevan 2017).

El uso eficiente, equitativo y sostenible de la energía se encuentra actualmente con numerosas barreras sociales, políticas, económicas y tecnológicas, pero implica altos beneficios potenciales para la salud (Wilkinson et al. 2004). La justicia energética presenta una herramienta útil para la toma de decisiones que puede ayudar tanto a planificadores como a consumidores de energía a tomar decisiones energéticas bien informadas (Sovacool y Dworkin 2015).

\subsubsection{La definición del concepto de pobreza energética}

En el contexto europeo se considera que la energía es imprescindible para la movilidad, la climatización o la iluminación; en sectores como la industria, la sanidad, la agricultura, el sector doméstico o el ocio. Los objetivos actuales para la planificación de formas urbanas energéticamente eficientes se centran principalmente en la reducción de 


\section{CAPÍTULO 1. ESTADO DEL ARTE}

los gastos en transporte y los requerimientos energéticos de la edificación (Madlener y Sunak 2011). En el sector residencial, la dificultad de satisfacer las necesidades de transporte aumenta la presión sobre los hogares en situación de dificultad para mantener el hogar en unas condiciones de confort apropiadas.

En el sector transporte, "vulnerabilidad energética es la situación en la cual un hogar es incapaz de pagar la cantidad de energía suficiente para la satisfacción de sus necesidades básicas de transporte y/o cuando se ve obligado a destinar una parte excesiva de sus ingresos a pagar la factura energética de su transporte" (Jiménez Romera, y otros, 2012)

En el contexto europeo, el mayor de los gastos energéticos se corresponde con la necesidad de mantener el hogar caliente. Gran Bretaña es el país europeo que desde su origen ha dedicado más atención a este problema. La primera definición enunciada considera que se sufre una situación de pobreza energética cuando se invierte más del $10 \%$ de los ingresos en mantener la casa a unos niveles de temperatura adecuados (Boardman 1991). Como principal referencia, la Organización Mundial de la Salud considera que la temperatura de confort adecuada es de $21^{\circ} \mathrm{C}$ en la sala de estar y $18^{\circ} \mathrm{C}$ en el resto de estancias. Esta definición permite generar debate científico sobre las causas, componentes, síntomas y consecuencias de la privación de energía doméstica. Hace posible cuantificar las necesidades de energía necesaria para conseguir un confort saludable, y no centra el foco exclusivamente en el coste que supone la factura. La calidad de la edificación pasa a ocupar una posición central en el problema, a través de las necesidades de la vivienda (Boardman 2010). La demanda energética pasa a ser un indicador de la vulnerabilidad asociada a la edificación residencial en el sentido en el que la edificación condiciona la capacidad de sus habitantes para satisfacer sus necesidades de confort (Martín-Consuegra 2014).

Los primeros intentos para desarrollar métodos de medición de la pobreza energética a partir de datos de la Encuesta de Condiciones de Vida desvelan los problemas que presenta utilizar indicadores sensibles a los cambios las facturas energéticas, las suposiciones de lo que se considera que son temperaturas adecuadas, y los ingresos reportados a encuestas que no están enfocadas a la medición del nivel de ingresos de la población. A partir de estas conclusiones el gobierno del Reino Unido encarga un informe oficial para la revisión de la definición existente. El informe Hills, de la London School of Economics, genera una nueva definición al considerar a los hogares en situación de 
pobreza energética aquellos casos en los que (i) sus "costes de combustible necesarios" están por encima del valor medio; y (ii) gastar esa cantidad les situaría "por debajo de la línea de pobreza oficial" (Hills 2012). El informe generó controversia puesto que la aplicación de la metodología propuesta tiende a reducir el número de hogares afectados a una cifra "demasiado" conservadora (Moore 2012).

La identificación pionera del problema en el contexto británico ha hecho que la noción de pobreza energética se asocie comúnmente al uso de energía para calefacción. No obstante, la satisfacción de otras necesidades domesticas también debe ser tenida en cuenta, como son mantener una temperatura de la vivienda adecuada durante el verano, las necesidades de iluminación, de uso de electrodomésticos, agua caliente, etc. Con el objeto de abordar estos conceptos, la Comisión Europea propone una definición de pobreza energética indicando que puede ser completada utilizando también otros criterios que permitan actualizar el concepto según la evolución de la sociedad.

"La dificultad o la incapacidad de mantener la vivienda en unas condiciones adecuadas de temperatura así como de disponer de otros servicios energéticos esenciales a un precio razonable" (Comité Económico y Social Europeo, 2011)

Para el contexto español, en el Proyecto REPEX se propuso fusionar todos los conceptos anteriores en la siguiente definición que incluye la presión de los costes en los ingresos y la satisfacción de necesidades básicas:

\footnotetext{
"Aquella situación que sufren los hogares que son incapaces de pagar una cantidad de servicios de la energía suficiente para la satisfacción de sus necesidades domésticas y/o cuando se ven obligados a destinar una parte excesiva de sus ingresos a pagar la factura energética de sus viviendas (más de un 10\% de sus ingresos anuales)" (Tirado Herrero, y otros, 2012)
}

La incorporación de la perspectiva de la justicia energética da soporte a definiciones centradas en la equidad, permitiendo conceptualizar la pobreza energética desde una enfoque de satisfacción de servicios energéticos básicos para todas las personas (como movilidad, lavado, calefacción, cocina, refrigeración e iluminación). En ese sentido avanzan los trabajos para una correcta conceptualización del término:

"Incapacidad [de un hogar] de alcanzar un nivel social y materialmente necesario de servicios domésticos de la energía" (Bouzarovski y Petrova 2015). 


\section{CAPÍTULO 1. ESTADO DEL ARTE}

El 5 de abril de 2019, el Gobierno de España ha aprobado la Estrategia Nacional contra la Pobreza Energética 2019-2024 para dar cumplimiento al mandato establecido en el artículo 1 del Real Decreto- ley 15/2018, de 5 de octubre, de medidas urgentes para la transición energética y la protección de los consumidores (MITECO 2019). La estrategia adopta la siguiente definición oficial para España, que pone en relieve la importancia de las viviendas como vector de pobreza energética:

"La pobreza energética es la situación en la que se encuentra un hogar en el que no pueden ser satisfechas las necesidades básicas de suministros de energía como consecuencia de un nivel de ingresos insuficiente y que, en su caso, puede verse agravada por disponer de una vivienda ineficiente en energía". (MITECO 2019).

\subsubsection{Causas}

Actualmente está bastante consensuado que las situaciones de pobreza energética resultan principalmente como consecuencia de la combinación de tres factores que se producen en el ámbito del hogar: un bajo nivel de renta, una calidad térmica de la edificación insuficiente y los elevados precios de la energía que repercuten sobre sus facturas energéticas. Son ya numerosos los estudios los que citan estos factores como sus causantes (Nolay et al. 2009; Atanasiu, Kontonastou, y Mariottini 2014; UPV 2016).

En el caso de España, un problema añadido ha sido la falta de percepción de este problema social a todos los niveles, lo que ha impedido que se pongan en marcha políticas efectivas de mejora de la situación. Las políticas nacionales sobre eficiencia energética dirigidas específicamente a combatir la pobreza energética son casi inexistentes. Actualmente empieza a ser un tema de investigación y de interés general, y se está produciendo conocimiento acerca de la materia. Además de en las causas directas, algunos estudios profundizan en los elementos que definen el concepto visibilizando otros condicionantes que pueden impulsar a un hogar a estar en situación de pobreza energética, y lo ponen en relación directa con la realidad del modelo energético y sus deficiencias, visibilizando no solo las causas individuales sino también las causas estructurales del sistema (Sánchez Suarez 2019). 


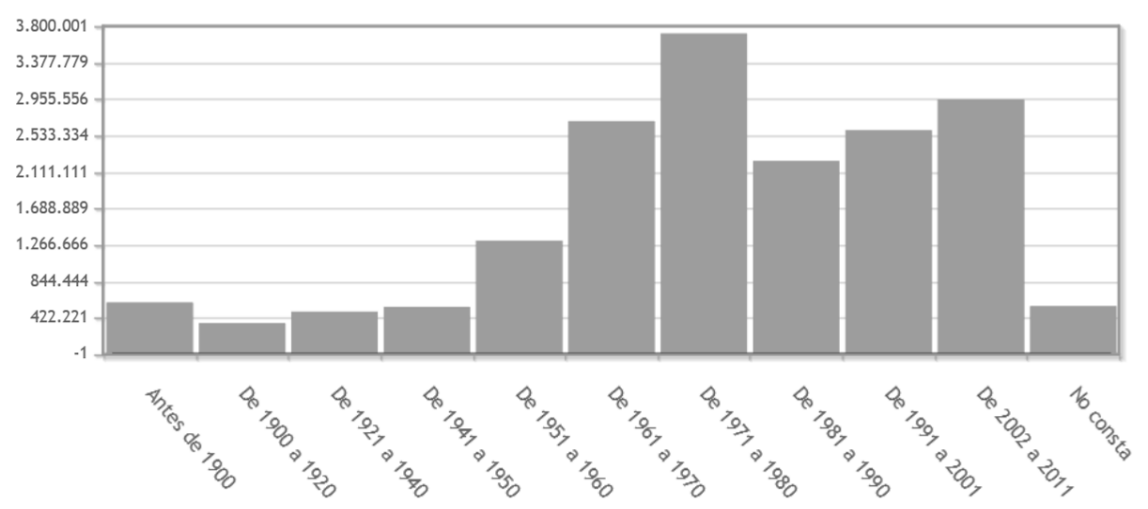

Figura 6. Viviendas principales por año de construcción en España. Fuente INE 2011

\subsubsection{Ineficiencia energética de la edificación}

El parque existente es responsable de altos consumos energéticos debido a sur su ineficiencia. La mala calidad térmica de gran parte de los edificios construidos y las carencias de sus sistemas de climatización generan una situación de vulnerabilidad energética, ya que los hogares necesitan grandes cantidades de energía para lograr mantenerse dentro de un rango de confort aceptable.

En el caso de España el problema viene de un parque edificado con soluciones constructivas de mala calidad en la envolvente térmica. Aproximadamente el $70 \%$ de las viviendas se construyeron con anterioridad a la entrada en vigor de la primera norma que introduce la exigencia de condiciones de eficiencia energética en la edificación (NBE-CT79 1979), y por lo tanto carecen de aislamiento térmico (Figura 6). El mayor volumen de obra construida pertenece al periodo comprendido entre 1951 y 1980, en ese periodo proliferó la construcción de bloques en altura que albergan a su vez un gran número de viviendas de superficie pequeña en comparación con los periodos anteriores (Figura 6). En el periodo posterior encontramos mejoras significativas como la inclusión de materiales aislantes en la envolvente opaca y el doble acristalamiento aislante. No obstante algunos estudios apuntan a que la calidad térmica tampoco está necesariamente garantizada, por ejemplo en los edificios construidos durante la burbuja especulativa de la construcción de los años 90.

"...aunque a priori pueda pensarse que al cumplir la Norma Básica de la Edificación sobre Condiciones Térmicas (NBT CT-79) sus condiciones térmicas sean mejores, esto no es del todo 


\section{CAPÍTULO 1. ESTADO DEL ARTE}

cierto, ya que la velocidad con la que se construyó un gran número de edificios, las pocas calidades de los materiales o la falta de cualificación de los operarios en algunos casos, hacen que estos edificios presenten importantes deficiencias energéticas." (Dalle et al. 2010).

En lo referente a los sistemas de calefacción, se consideran inadecuados los sistemas que tengan bajos rendimientos que necesitan consumos elevados para satisfacer la demanda, y como consecuencia de ello llevan asociadas altas emisiones de CO2 y otros gases contaminantes.

"... el "boom" de la construcción [años 90] coincidió con un momento de auge y desarrollo de las tecnologías especializadas en climatización, y se hizo un uso excesivo de equipos innecesarios, que pretendían suplir las carencias que presentaban las construcciones de baja calidad, por lo que muchas de estas edificaciones presentan equipos e instalaciones sobredimensionados, poco eficientes y que necesitan grandes consumos para climatizar las estancias." (Dalle, y otros 2010)

La mala calidad térmica de los edificios residenciales e instalaciones inadecuadas son determinantes en este sentido. Algunos estudios (Healy, 2003) apuntan la paradoja de que las zonas de Europa con inviernos más suaves, donde las temperaturas medias invernales no son inferiores a 5으, exhiban mayores variaciones de mortalidad estacional. Esta distribución se repite también en el caso de España, donde se puede concluir que hay mayores niveles de pobreza energética en las regiones del sur que en las del norte (Aristondo y Onaindia 2018). Recientemente se ha ampliado estos estudios incluyendo los países del este, concluyendo que en la Unión Europea existe una clara división en la clasificación del tipo de pobreza energética y determina dos áreas: el corazón de la Unión (the Core) y las periferias, que incluirían los países del este y del sur mediterráneo, en los cuales la mala calidad de la edificación sería determinante como causa de pobreza energética (Bouzarovski 2018).

Otros estudios clasifican relacionan los indicadores subjetivos basados en el nivel de insatisfacción térmica declarada por los ocupantes en la Encuesta de Condiciones de Vida con la falta de sistemas de calefacción adecuados (INE 2017) concluyen también que este problema es específico de las regiones cálidas (del sur y este peninsular e islas) de nuestro país, ya que se encuentran en general peor equipadas:

"En estas áreas de clima en general más benigno, que sufren sin embargo algunas semanas de frío al año, las casas están peor aisladas y no disponen siempre de un sistema de calefacción adecuado, sobre todo en el caso de las viviendas de peor calidad ocupadas por las familias de 
pocos ingresos. Estos hogares tienen que utilizar calefactores eléctricos (muy costosos por unidad de calor entregado a la vivienda) u otras formas subóptimas de calefacción que no consiguen caldear el espacio de la vivienda de forma suficiente, pero que aun así pueden suponer una carga importante en el presupuesto de las familias durante ese periodo frío. Aunque a lo largo de todo un año el peso de las facturas de la energía en el presupuesto doméstico es relativamente reducido, muchos hogares habrían estado de hecho en pobreza energética durante las semanas en las que la calefacción era necesaria. Éstos serían precisamente los hogares que en las regiones de clima más templado estarían declarándose incapaces de mantener su vivienda con una temperatura adecuada de acuerdo con la ECV " (Tirado, López Fernández, y Martín García 2012).

\subsubsection{Bajos ingresos en el hogar}

El nivel de ingresos en el hogar parece haber empeorado en los últimos años en España y las situaciones de vulnerabilidad urbana se prolongan en el tiempo, ademas de aparecer nuevas areas vulnerables (Agustín Hernández Aja et al. 2018). El informe UNICEF 2012 ya constataba como una de las consecuencias mas visibles de la crísis en España el aumento de la pobreza, con una mayor repercusión sobre la población menor (Figura 7).

"El importante incremento de este y otros indicadores de pobreza y privación en el contexto de la crisis, especialmente los referidos a la infancia, nos está mostrando realidades muy preocupantes" (González Bueno, y otros, 2012).

A los bajos ingresos del hogar y renta per cápita, el pobre desarrollo económico y la creciente desigualdad social que vive el país, viene a unirse el deterioro de la calidad de vida que están causando las políticas de austeridad puestas en práctica por los países del UE en el contexto de la crisis que en España, según los datos del Instituto Nacional de Estadística, dependiente de la Administración General del Estado, se afirma que concluyó en el año 2014. Sin embargo, hasta la actualidad (2019) la economía española no ha recuperado los valores previos a la crisis, en particular en cuanto a desempleo. Todos estos factores están multiplicando las situaciones de privación en nuestra sociedad. 


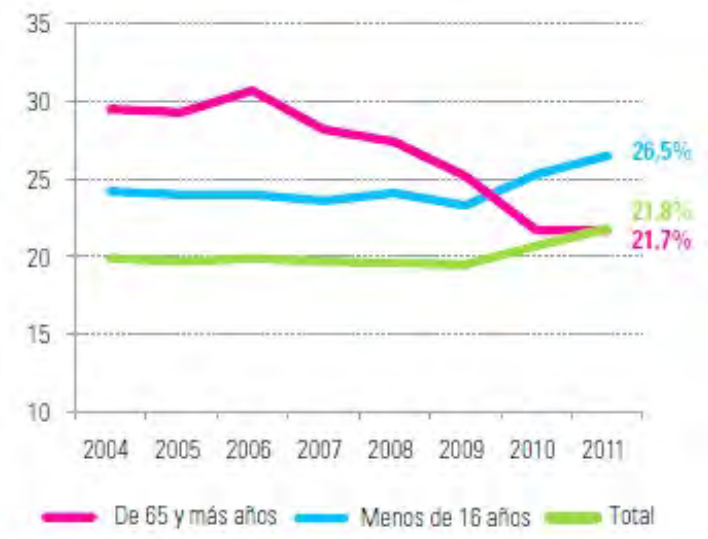

Figura 7. Evolución 2004-2011 de la tasa de riesgo de pobreza por edad. Fuente: UNICEF a partir de datos de la ECV, INE. Datos provisionales para 2011

A pesar del crecimiento económico posterior a 2014, la distribución de la riqueza no se está dirigiendo hacia las clases mas desfavorecidas. El índice de desigualdad en las ciudades ha aumentado desde la salida de la crisis, favoreciendo a la población con más poder adquisitivo y aumentando las brechas de desigualdad y los índices de pobreza y exclusión social, que afectan a un tercio de la población (Martínez Parra 2019).

"Durante las últimas décadas, se ha ido ampliando y haciendo más complejo el término "pobreza". El origen de esta evolución es la necesidad de dar cabida a las distintas formas en las que las carencias o situaciones de privación afectan a las personas. Partiendo del concepto de "pobreza absoluta" (una cuantía económica universal, aplicable a cualquier situación, por debajo de la cual las necesidades no estarían cubiertas), se ha llegado a otros como el de "pobreza relativa" (que dependerá del contexto socioeconómico en el que se quiera medir), "pobreza subjetiva" (que se evaluará en función de la percepción del sujeto sobre su situación económica) o "privación multidimensional", intentando éste último no sólo evaluar una cuestión monetaria, sino las privaciones a las que se ve abocado un sujeto aunque sobrepase los rangos establecidos en las anteriores definiciones. " (Jiménez Romera y Sanz Fernandez 2012)

\subsubsection{Altos precios de la energía}

El resumen de información básica de consumos del sector residencial elaborado por el IDAE para las viviendas en España en 2012 sitúa el gasto energético medio anual por hogar en $990 €$, del cual el $47 \%$ corresponde a consumos de calefacción (IDAE 2011b). Es fácilmente deducible que los hogares en situación de pobreza tendrán gastos inferiores. Además, el gasto en energía va a seguir una tendencia al alza. Autores como Santamarta o Fernández Durán concluyen que el agotamiento de los combustibles fósiles es ya una 
realidad, que hacia el año 2008 se alcanzó el pico de la producción mundial y por tanto el precio de la energía va a aumentar en los próximos años (Figura 8). El fuerte alza del precio del crudo desde el inicio del nuevo milenio y la subida espectacular de la cotización del barril en los últimos tiempos son indicadores de que la era del petróleo barato se ha acabado (Fernández Durán 2008):

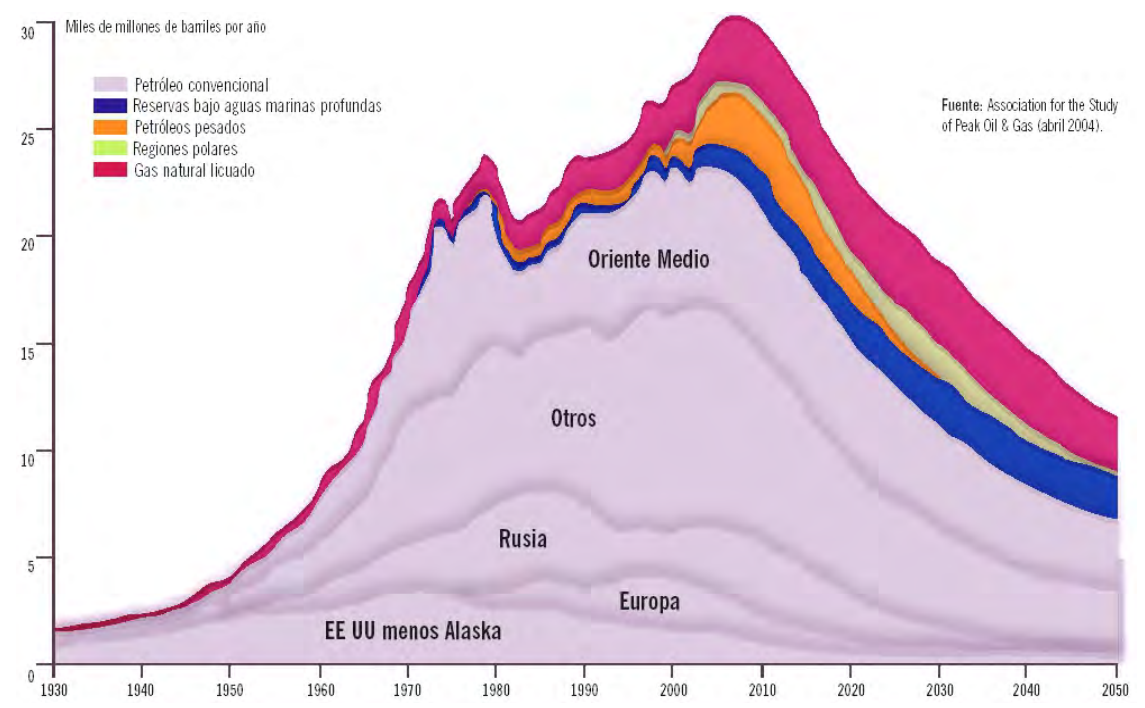

Figura 8. El pico de la producción mundial. Fuente: Ramón Fernández Durán

\begin{abstract}
"Hemos entrado de lleno en el fin de la era del crudo barato, y estamos iniciando el recorrido por territorios desconocidos, propios del próximo declive energético global."... "El llamado pico mundial del petróleo parece que ya está aquí, o estamos a punto de entrar en él. Es decir, el momento a partir del cual ya no será posible poner más crudo adicional en el mercado, por mucho que se hagan nuevas y costosas prospecciones y extracciones, pues habríamos consumido ya grosso modo la mitad de los reservas globales de petróleo" (Fernández Durán 2008).
\end{abstract}

La liberalización del mercado de la energía ha sido una de las políticas centrales de la UE tras el Consejo de Energía de junio de 1987. Las primeras directivas liberalizadoras de los mercados del gas y la electricidad se promulgaron a finales de los 90 del siglo pasado $y$, desde entonces, se han producido múltiples actuaciones en esta dirección. Los objetivos declarados en el proceso de liberalización iban destinados a lograr un sector energético más eficiente y una economía europea más competitiva (Gouardères 2019). No hubo pleno acuerdo entre todos los Estados miembros sobre las medidas y, de hecho, existe una fuerte resistencia en algunos de ellos a la implementación de las políticas correspondientes. Actualmente existe un alto nivel de concentración en la oferta del mercado energético mayorista que no resulta eficaz para la sociedad. Asociaciones como 
Greenpeace o Ecologistas en Acción han denunciado su falta de transparencia y las estructuras discriminatorias en las que se sostiene (Greenpeace 2008; Sánchez Suarez 2019). El argumentario liberal del mercado de la competencia sugiere que las buenas sociedades presentan a las personas un conjunto de oportunidades o libertades sustanciales que se pueden ejercer o no. Pero, como se ha dicho, el uso de la energía no es una opción sino una necesidad básica. Es necesario que esta liberalización del mercado se revise sobre el concepto de equidad para crear estructuras sociales justas que a su vez produzcan una distribución equitativa de bienes y servicios (Sovacool y Dworkin 2015). Numerosos análisis de las políticas llevadas a cabo critican que no hayan servido para fomentar la competencia. En varios Estados miembros como España, los oligopolios privados de la energía han impuesto sus criterios a los consumidores y a los organismos reguladores resultando en precios elevados de la energía (EUROSTAT 2019).

"La liberalización beneficia al consumidor si fomenta realmente la competencia; sin embargo, en varios Estados miembros se ha producido la sustitución de monopolios públicos por oligopolios privados, lo que obliga a intensificar las medidas que tiendan a fomentar la transparencia y la competencia en el ámbito de la energía" ... " insistir en la necesidad de que se hagan efectivas las medidas previstas en el Tercer Paquete de la Energía tendentes a crear un verdadero mercado de la energía basado en la cooperación entre los Estados, entre ellas, la mayor interconexión de las redes, la mejor coordinación de los operadores y el refuerzo de los poderes de los reguladores nacionales." (CESE Comité Económico y Social Europeo 2010).

En el caso de España, además de tener uno de los precios más altos de la energía de Europa, esta situación también se ha producido en el mercado del gas, resultando en precios más elevados para el consumidor que antes de la liberalización (García 2006).

"...El déficit de la tarifa eléctrica surge a finales de la década pasada a consecuencia de la diferencia, regulada legalmente, entre los costes de producción de la electricidad y las tarifas de acceso que se cobran a los consumidores. Esta intervención del Estado sobre el mercado eléctrico desacopló la evolución de los precios de la electricidad de la del resto de bienes y servicios (IPC), de manera que se registró un descenso en la tarifa media de referencia de la electricidad medida en unidades reales (e incluso nominales) desde mediados de la década de los noventa del siglo pasado hasta el año 2005. Se considera que esta decisión, que permitía controlar momentáneamente la inflación (trasladándola en cualquier caso hacia el futuro), ha hecho insostenible el mantenimiento de una tarifa regulada, ha desincentivado la inversión en eficiencia energética por parte de los consumidores y es incompatible con una verdadera liberalización del mercado eléctrico (Energía y Sociedad, 2012)." (Tirado, López Fernández, y Martín García 2012). 


\subsubsection{Consecuencias}

Las consecuencias que una situación de pobreza energética puede desencadenar son múltiples, como por ejemplo problemas de salud, infrautilización del uso de la energía por debajo de los estándares de confort o la acumulación de deuda y desconexiones de la red por parte del suministrador.

"El acceso a una energía suficiente y de calidad para la industria, la agricultura y el resto de los sectores es esencial para la prosperidad y la competitividad de un pais y su carencia puede conducir a la crisis económica, el desempleo y la pobreza en general" (CESE Comité Económico y Social Europeo 2010)

\subsubsection{Problemas de salud}

Numerosos estudios tratan la relación entre salud y pobreza energética. La mayor parte de los trabajos publicados se han centrado principalmente en el exceso de mortalidad en invierno (Atanasiu, Kontonastou, y Mariottini 2014). Estudios como el realizado en Vermont (EEUU) concluyen que en esa localidad hay más muertes por el frío estacional que por accidentes de tráfico (Teller-Elsberg et al. 2016). En España los estudios sobre el impacto de la meteorología en la salud se comienzan a realizar en los años 90, identificando la relación entre temperatura ambiental y mortalidad (Ballester Díez 1996). La mortalidad causada por el frío es un problema grave y prolongado en el tiempo que precisa de planes de prevención específicos, puesto que, a pesar de que la temperatura media se ha incrementado debido al Cambio Climático, su impacto se ha mantenido constante a lo largo del tiempo e incluso ha aumentado en algunos países, y parece ser mayor que el impacto del calor (en muertes / día). (Díaz et al. 2019).

La precariedad energética se debe analizar como un problema de salubridad de las viviendas peor equipadas. En Reino Unido al menos un 10\% de la variación estacional de la mortalidad está causada por situaciones de pobreza energética (Hills, 2012), lo cual significa miles de muertes al año, además del aumento de la hospitalización y altos costes para el sistema nacional de salud. Además, se han identificado los impactos directos sobre la salud asociados a la falta de confort en el hogar en el invierno: el paro cardiaco, accidente cerebro vascular, enfermedad respiratoria, gripe, caídas y lesiones e hipotermia. Al igual que ocurre con el exceso de mortalidad, estos impactos se 


\section{CAPÍTULO 1. ESTADO DEL ARTE}

experimentan a menudo después de la exposición al problema. También se producen impactos negativos indirectos para la salud, incluido el riesgo de intoxicación por monóxido de carbono si las calderas, la cocina y los aparatos de calefacción son inadecuados, no tienen el mantenimiento necesario o no están bien ventilados (Tod y Thomson 2016). Los responsables de la formulación de políticas en el país han comenzado a reconocer las necesidades específicas de determinados grupos sociales, como los ancianos y los enfermos crónicos, a causa de su dependencia de temperaturas de confort superiores a la media (Walker y Day 2012).

En su revisión de evidencias de casos desde 2000 a 2009, (Christine Liddell y Morris 2010) describen los efectos en la salud física de los adultos como modestos, pero observan en cambio un aumento de problemas respiratorios en niños y personas mayores. En cuanto a los problemas psicológicos, impactan en personas adolescentes (absentismo y bajo rendimiento escolar, comportamiento antisocial...) y en adultos (aislamiento social,...). Vivir en una vivienda fría y húmeda contribuye a una variedad de factores estresantes de la salud mental, que incluyen la preocupación persistente por la deuda y la asequibilidad, la incomodidad térmica y la preocupación por las consecuencias del frío y la humedad para la salud (C. Liddell y Guiney 2015).

Además de esto en los países cálidos del sur mediterráneo es necesario señalar también el problema de mortalidad en verano, llegando a resultar necesario el uso de energía para mantener una temperatura de la vivienda adecuada por medio de sistemas de refrigeración. En Europa las condiciones climáticas extremas que causaron la canícula u ola de calor en el 2003 tuvieron como consecuencia un incremento de la mortalidad en verano (Ballester Díez 1996).

\subsubsection{Endeudamiento, cortes de suministro, desahucios}

En los peores casos, las deudas en el pago de las facturas energéticas pueden resultar en cortes de suministro y desahucios por impagos. Además, las personas afectadas por desconexión son privadas de su derecho a la energía, lo que conlleva privaciones que pueden poner en riesgo su salud y provocar la exclusión de su vivienda. Prescindir del uso de la energía no es una opción, y la reducción del consumo es a menudo difícil debido a las circunstancias de los hogares y las condiciones de las viviendas. En su artículo "Social 
causes and consequences of energy poverty", publicado en (Gosztonyi et al. 2019), Sian Jones señala el círculo vicioso que genera el problema de la pobreza energética. Las deudas en facturas energéticas provocan cortes de suministro por parte de las empresas suministradoras que vulneran el derecho a la energía de las personas afectadas. En algunos países de la UE se incluye a las personas con problemas en listados de morosos que dificultan su acceso a una nueva vivienda, al no poder acceder a un nuevo contrato de alquiler.

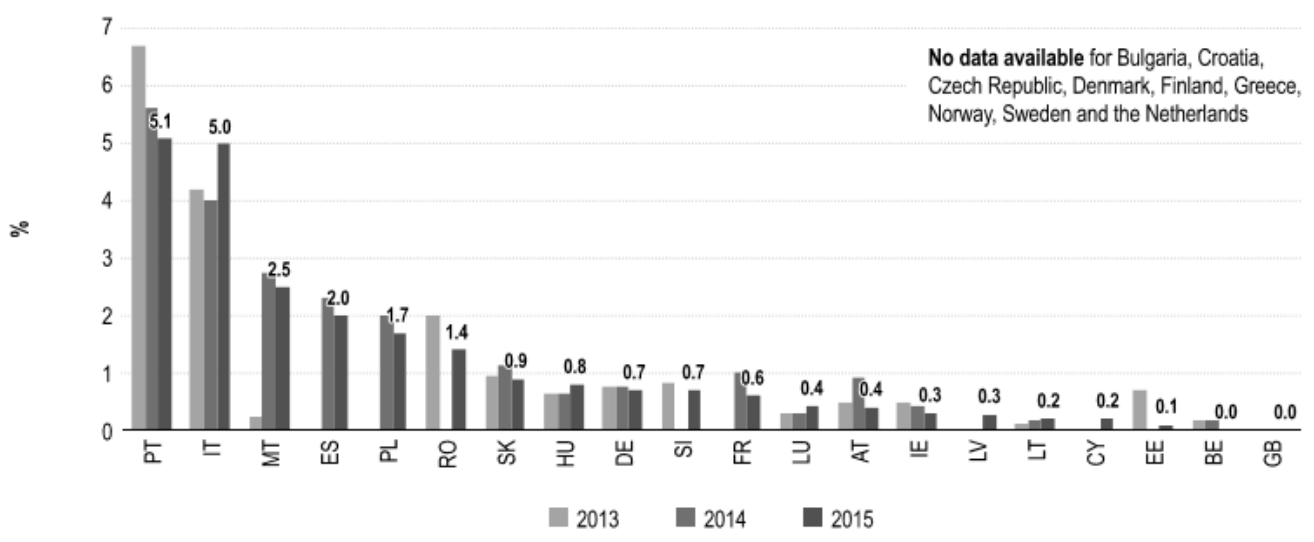

Figura 9. Tasas de desconexión en diferentes países de la UE (ACER/CEER 2017)

España ocupo en 2017 el cuarto puesto más alto en tasas de desconexión (Figura 9). El aumento del precio de la energía repercute especialmente en los hogares más vulnerables. Este problema se va a acrecentar con un previsible aumento de precios, y por tanto también el número de hogares que mantiene deudas con empresas suministradoras de energía.

\subsubsection{Deterioro del parque edificado}

Las viviendas afectadas por situaciones de pobreza tienden a minimizar el uso de la energía para controlar los gastos en el hogar. Además estos hogares reducen el mantenimiento de los edificios y difícilmente podrán llevar a cabo las obras de mejora que necesitan para su adecuación a las exigencias actuales en materia de eficiencia energética. La rehabilitación energética de esos edificios podría contribuir a su conservación y mantenimiento.

En la escala europea, los primeros estudios de pobreza energética dirigidos al parque edificado señalan el sur mediterráneo como zona vulnerable por la mala calidad de su 


\section{CAPÍTULO 1. ESTADO DEL ARTE}

edificación (Healy 2003). Investigaciones acerca de las relaciones entre calidad de las viviendas y el nivel de ingresos relacionan la mala calidad de la edificación con la pobreza, señalando la gravedad de la situación en el este de Europa (Lelkes y Zólyomi 2010). Estudios más recientes concluyen que el problema está ocurriendo en toda la Unión Europea, pero con niveles particularmente altos en los países del este y sur de Europa. La diferenciación entre el corazón de la Unión y las periferias se ha ido consolidando en estudios que señalan que en muchos Estados miembros de la UE del Este, Centro y Sur, existe una tendencia a que la privación de energía doméstica se concentre en áreas periféricas y regiones rurales con vivienda de baja calidad y menor acceso a combustibles asequibles (Thomson y Snell 2013).

En el caso de España, la mala calidad de las viviendas construidas durante ciertos periodos de desarrollo especulativo alimenta la vulnerabilidad residencial y energética de las personas que las habitan. En concreto, las áreas de periferia desarrolladas en el periodo de 1940 al 80 cuentan con la mayor concentración de edificios en mal estado o ruinosos (Oteiza, I. et al. 2018). En las áreas en las que se produce este contexto resulta difícil que los habitantes estén en disposición de costear las operaciones de rehabilitación para el mantenimiento y mejora que necesita la edificación.

\subsubsection{Cambio climático}

La pobreza energética tiene una estrecha relación con un problema ambiental de gran magnitud: el cambio climático. El consumo de energía para usos residenciales es fuente de una parte muy importante de las emisiones de gases de efecto invernadero y otros contaminantes con impactos sobre la salud y los ecosistemas vinculados a la actividad humana. La Comisión Europea estima que el parque de viviendas europeo es responsable de más del $40 \%$ del consumo de energía y del $36 \%$ de las emisiones de $\mathrm{CO}_{2}$ eq (European Parliament and UE Council 2010). Solamente el sector transporte produce mayores impactos ambientales (Sanz Fernández 2012).

La pobreza energética es un aspecto a tener en cuenta a la hora de formular las políticas de reducción de impactos ambientales asociadas al uso de la energía y contra el cambio climático. Su relación con éste es transversal, afectando a sus causas, sus consecuencias y a las expectativas de evolución del problema. El aumento de la 
temperatura media y el aumento de los episodios climáticos extremos elevan el riego de pobreza energética. El aumento de la demanda de refrigeración y de los consumos en momentos pico inciden en un sector de grandes emisiones (por la ineficiencia y el uso de sistemas inadecuados) que supone un enorme impacto ambiental, en una espiral destinada a agravarse.

El caso español presenta un sistema energético con dos desequilibrios fundamentales: el primero es la dependencia de fuentes de energía primaria importadas, principalmente el petróleo. El grado de dependencia energética ha tendido a aumentar (del $66 \%$ en 1990, y de un $80 \%$ en 2008). El otro desequilibrio son las excesivas emisiones de gases de efecto invernadero (a pesar de la caída de la actividad económica el 22,1\% de 2010 se mantiene a un nivel superior del compromiso del 15\% por encima del año base 1990 que adquirió España en el protocolo de Kioto) (José Santamarta y Llorenç Serrano 2009). El sector doméstico es una de las principales fuentes de emisión, debido a su alta ineficiencia. En España su consumo asciende a 14.676 kteps (IDAE 2011b). El uso de sistemas inadecuados en viviendas de calidad térmica precaria, asociadas a situaciones de pobreza energética, se traduce en mayores consumos energéticos y emisiones de $\mathrm{CO}_{2}$ que en viviendas más eficientes y mejor equipadas.

\subsubsection{La evaluación de la pobreza energética}

El desarrollo de indicadores e índices compuestos utilizados para la evaluación de la pobreza energética está íntimamente relacionado con la evolución de su definición. Se han ido estableciendo procedimientos como forma de identificar y cuantificar el problema. El objetivo es, por una parte la elección de distintos acercamientos al problema y por otra la identificación de las personas afectadas con el objeto de darles soporte. En este sentido su volcado en mapas permite la visualización de la distribución geográfica del problema y su análisis geográfico.

\subsubsection{El Observatorio Europeo de Pobreza Energética}

El Observatorio Europeo de Pobreza Energética (EPOV) surge a instancias del Comité Económico y Social Europeo (CESE) para comparar y buscar lugares comunes en los diferentes estudios de pobreza energética llevados en los países de la Unión. A pesar de 


\section{CAPÍTULO 1. ESTADO DEL ARTE}

su rigor metodológico y de las amplias muestras utilizadas, varios autores coinciden con la dificultad de desarrollar métodos validos para todo el continente por la heterogeneidad de los objetivos, sus métodos, tratamientos estadísticos. En ese sentido el CESE recomendó en 2011 que

"...con el objeto de armonizar las estadísticas en el contexto europeo, Eurostat y los institutos estadísticos de los Estados miembros adopten metodologías estadísticas homogéneas para poder cuantificar el alcance del problema de la pobreza energética..." (CESE Comité Económico y Social Europeo 2010)

Respondiendo a estas demandas de la Comisión Europea, ha sido creado recientemente el Observatorio Europeo de Pobreza Energética el objetivo de mejorar la medición, el seguimiento y el intercambio de conocimientos y las mejores prácticas en materia de pobreza energética entre los países miembros (EPOV 2017). Con una duración de 3 años, el proyecto EPOV está formado por un consorcio de entidades europeas lideradas por la Universidad de Manchester. En ella participan Ecofys, el European Policy Centre, Intrasoft International, National Energy Action y Wuppertal Institute como socios. Sus funciones van encaminadas a proporcionar métodos y datos fiables que muestren el alcance de la problemática. Otras de sus funciones son la información a la ciudadanía de las diferentes medidas para luchar contra la Pobreza Energética y su promoción entre las diferentes administraciones y sociedad civil, además de la aplicación y puesta en marcha de esas medidas.

El EPOV asume la clasificación de los indicadores en dos grupos principales: los cuantitativos y los cualitativos. Actualmente la investigación en la materia tiende a proponer índices compuestos mixtos que incorporan indicadores de ambos grupos para tratar de abordar el problema desde sus múltiples dimensiones.

\subsubsection{Indicadores cuantitativos}

Los indicadores cuantitativos más utilizados están basados en la comparación de los costes energéticos con los ingresos del hogar. El primero en desarrollar fue la regla del $10 \%$ y a partir de ella se han desarrollado otros como el LIHC (Low Income-High Cost), que introduce matices en el cálculo. A partir de ellos se han desarrollado otros indicadores, como el 2M (High share of energy expenditure in income). Estos indicadores 
se basan en datos objetivos y son absolutos. Su principal crítica es que no tienen en cuenta la opinión de los afectados.

Indicador del $10 \%$ de gastos e ingresos

Este método se basa en la consideración de que un hogar está en situación pobreza energética cuando en él se da la situación de que el gasto energético supera el umbral del $10 \%$ de los ingresos del hogar (Boardman 1991). Desarrollado en Reino Unido, fue el primero de los indicadores objetivos, resultando el más consolidado hasta el momento. Tiene la ventaja de que ser muy claro y sencillo de incorporar, pero ha sido criticado puesto que no resulta preciso a la hora de definir el grado de confort o calor aceptable o la cantidad de energía necesaria dependiendo de la calidad de la edificación y no aborda cual es el coste razonable para la energía y cómo se definen los ingresos del hogar (Fahmy 2011). En España este indicador ofrece resultados desalentadores.

"En España un 10\% de la población (4 millones de habitantes) se veía afectado por la pobreza energética en 2010. Dada la evolución a peor ... desde ese momento puede aventurarse que en 2012 la cifra será aproximadamente de un 14-15\% ... Desde el comienzo de la crisis (2008) se eleva la pobreza energética, de manera que si en 2010 los ingresos (en unidades corrientes) de una familia promedio en España eran tan sólo un 7\% más elevados que en 2006, el gasto anual en energía había aumentado un 34\%." (Tirado, López Fernández, y Martín García 2012).

\section{El indicador LIHC y la brecha de pobreza energética}

El informe Hills propone un indicador capaz de discriminar los grandes consumidores con gastos excesivos pero altos ingresos, de las situaciones de pobreza. Se considera situación de pobreza energética como aquella en la que un hogar tiene costes energéticos por encima del requerimiento energético medio, y tras pagar sus facturas energéticas sus ingresos quedan por debajo del umbral de la pobreza (Hills 2012). Para ello desarrolla un indicador más complejo que el utilizado hasta el momento: el LIHC (Low Income - High Cost) se define como la superposición entre situaciones con bajos ingresos y altos costes energéticos (Figura 8). La brecha de pobreza energética (fuel poverty gap) describe la profundidad económica de una situación de pobreza energética. 


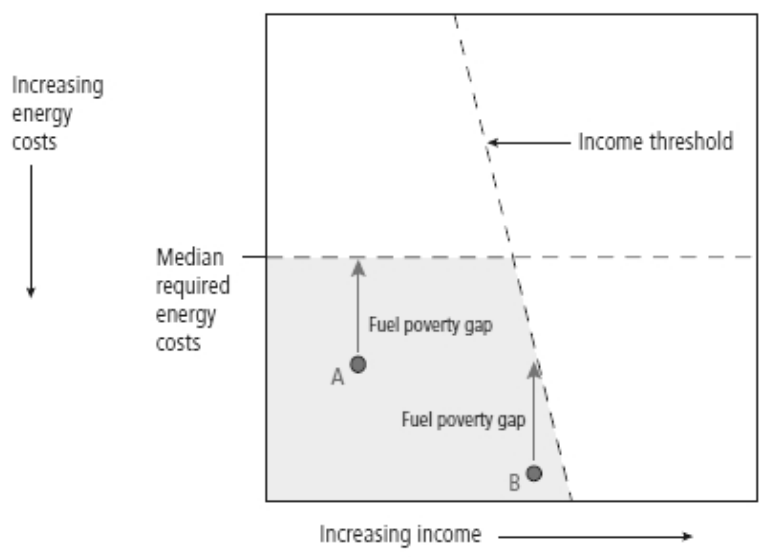

Figura 10. Cálculo de la brecha de pobreza energética. Fuente: J. HILLS. Final report of the Fuel Poverty Review, 2012

En el caso de España, existen ya propuestas de aplicación del indicador LIHC para la rehabilitación de viviendas, como es la desarrollado en la tesis de (Sánchez-Guevara Sánchez 2015). En una propuesta metodológica adaptada al contexto de la Comunidad de Madrid, se profundiza en la clasificación de diferentes grupos de hogares en función de sus necesidades y las características del parque de viviendas que ocupan (SánchezGuevara, Sanz Fernández, y Hernández Aja 2015).

\section{Indicadores propuestos por el EPOV}

El EPOV tiene como misión el desarrollo de indicadores que permita la comparación en todos los países europeos. Se desarrollan en base a la armonización a partir de datos de EUROSTAT. La dificultad para encontrar indicadores europeos adecuados que se ajusten a la realidad de todos los países ha derivado en la propuesta, hasta el momento, de dos indicadores objetivos nuevos: el HEP y el $2 \mathrm{M}$. Se incluyen aquí a modo de ejemplo de otros indicadores basados en gastos e ingresos:

- El indicador 2M: identifica, para cada país, la proporción de hogares en los cuales el coste de la energía en proporción con los ingresos representa más del doble del que representa la proporción de la mediana nacional.

- El HEP (M/2): indicador de pobreza energética oculta determina para cada país, la proporción de los hogares en los cuales el gasto energético absoluto es inferior a la mitad de la mediana nacional. 
Además de estos, el EPOV adopta un indicador cualitativo y un indicador basado en los cortes de suministro por impago.

\subsubsection{Indicadores cualitativos sobre la calidad de vida}

Se observa en la bibliografía otro tipo de indicadores subjetivos, basados en la percepción del usuario, que abordan aspectos cualitativos de la pobreza energética. Se señala la necesidad de recurrir a medidas basadas en la evaluación que los propios hogares hacen de su capacidad para mantener su vivienda a una temperatura adecuada durante el invierno (Healey 2004). En ese sentido se han consolidado los indicadores subjetivos recogidos en la European Survey on Income and Living Conditions (EU SILC) (EUROSTAT s. f.): la incapacidad de mantener el hogar a una temperatura adecuada, el retraso en el pago de facturas del hogar y la existencia de goteras o humedades en la vivienda.

En el caso de España, la primera metodología utilizada en el proyecto EPEE incluye el porcentaje de la población que tiene problemas en el pago de facturas (7 \% en UE-27, EUROSTAT 2007), o que tiene deudas con las empresas suministradoras de energía, y el número de viviendas que tienen goteras, grietas u otros males que afectan al edificio (18 \% en UE-25, Encuesta UE-SILC 2007) (Figura 11).

Comparison between 5 countries

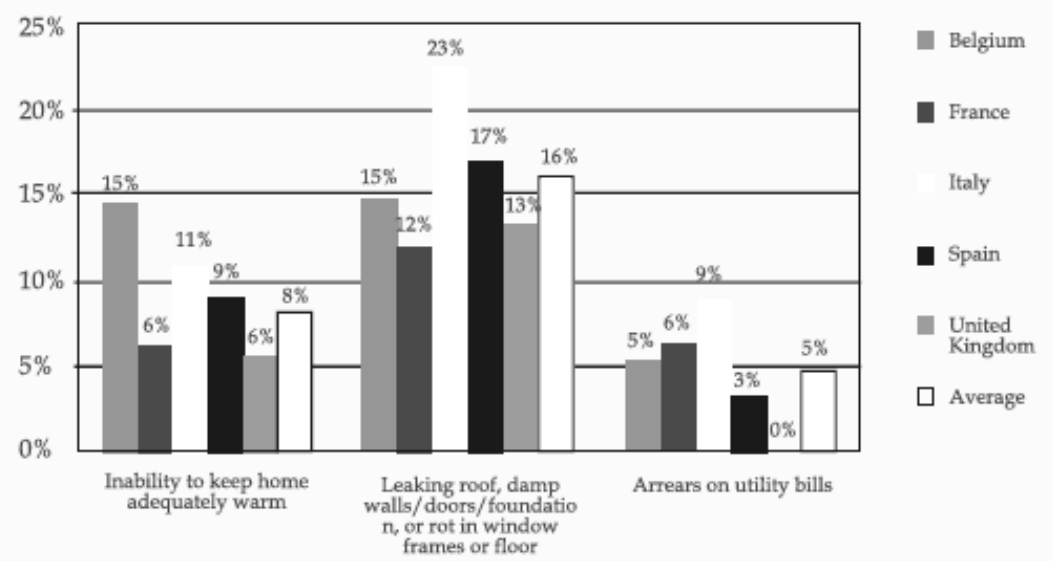

Figura 11. Comparación de indicadores de pobreza energética en 5 países Europeos. Fuente: EPEE project 


\section{CAPÍTULO 1. ESTADO DEL ARTE}

El Proyecto REPEX para su evaluación de la evolución de la situación en España utiliza los indicadores subjetivos de la EU SILC (en España Encuesta sobre Condiciones de Vida$\mathrm{ECV}^{2}$ ), asignando cada interpretación a una zona climática específica (Figura 12).

"...una más convencional, que sufren los hogares de pocos ingresos de las zonas más frías de España (centro y norte peninsular: Castilla y León, Castilla-La Mancha, Extremadura, La Rioja, Navarra o Aragón) y que se manifiesta con el indicador de gastos e ingresos (Encuesta de Presupuestos Familiares); y otra específica, que padecen hogares que habitan en viviendas mal aisladas y sin sistema de calefacción adecuado, típicas de las regiones templadas del país: Canarias, Murcia, Galicia, Andalucía, Extremadura e Islas Baleares. Estos hogares son incapaces de asegurar su confort térmico en las semanas frías el año, si bien el peso de los gastos en energía sobre su presupuesto anual es reducido" (Tirado Herrero, López Fernández y Martín García 2012.)

El concepto de indicador subjetivo de incapacidad de mantener la vivienda a una temperatura adecuada, amplía la dimensión de los indicadores: al contemplar las variables subjetivas se incluyen las preferencias de cada usuario, la libertad de consumo y de elección de sus propias privaciones. Otras aproximaciones han subrayado la importancia de las convenciones y prácticas sociales a la hora de definir lo que se considera en cada momento y lugar como un nivel suficiente de satisfacción de las necesidades básicas de energía en el hogar (Bouzarovski y Simcock 2017).

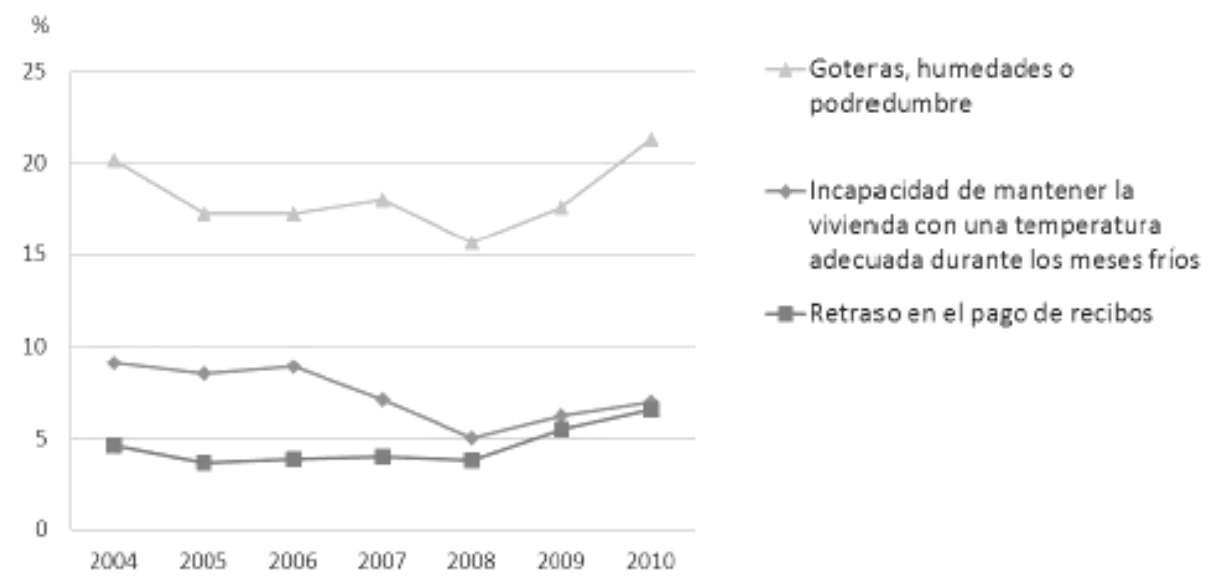

Figura 12.Porcentaje de personas que no pueden permitirse mantener su vivienda a una temperatura adecuada, con retraso en el pago de recibos (excluidos alquiler e hipoteca) y con goteras, humedades o podredumbre en su vivienda (España, 2004-2010). Proyecto REPEX

\footnotetext{
${ }^{2}$ La Encuesta de Condiciones de Vida (ECV) es el equivalente, en España, de la European Survey on Income and Living Conditions (EU SILC) EUROSTAT
} 


\subsubsection{4 Índices compuestos a partir de indicadores multidimensionales}

Una tercera generación de indicadores para identificar los problemas de pobreza energética que se está desarrollando actualmente como respuesta a las críticas realizadas a los dos grupos de indicadores explicados previamente, comprende los llamados índices multidimensionales. Estos tratan de incluir aspectos objetivos (de los indicadores de gastos e ingresos) y subjetivos de manera que se incluyan aspectos cualitativos, incluyendo la satisfacción de los habitantes en los hogares, que se están abordando desde las ciencias sociales.

Un ejemplo de este tipo de índices compuestos en España es el Indicador de Vulnerabilidad en el Hogar IVH (Castaño-Rosa, Solís-Guzmán, y Marrero 2018). Se basa en el análisis de los diferentes indicadores de pobreza energética existentes y su relación con el sector residencial. Evalúa la situación de vulnerabilidad utilizando tres dimensiones: coste monetario, energía y confort térmico y consulta aspectos de satisfacción a través de encuestas a los ocupantes.

\subsubsection{Indicadores adoptados por la Estrategia Nacional contra la Pobreza Energética} 2019-24

El texto aprobado en abril de 2019 adopta los cuatro indicadores primarios oficiales del Observatorio Europeo contra la Pobreza Energética (EPOV). La función prevista es el seguimiento adecuado de las diversas tipologías de pobreza energética.

- Gasto desproporcionado (2M): porcentaje de hogares cuyo gasto energético en relación con sus ingresos es más del doble de la mediana nacional.

- Pobreza energética escondida (HEP, en su acrónimo inglés): porcentaje de los hogares cuyo gasto energético absoluto es inferior a la mitad de la mediana nacional.

- Incapacidad para mantener la vivienda a una temperatura adecuada: porcentaje de la población que no puede mantener su vivienda a una temperatura adecuada.

- Retraso en el pago de las facturas: porcentaje de población que tiene retrasos en el pago de facturas de los suministros de la vivienda. 


\section{CAPÍTULO 1. ESTADO DEL ARTE}

Los indicadores adoptados por la estrategia española apuestan por la integración con el EPOV y la compatibilidad con los datos de EUROSTAT. Se trata de una transposición directa de las directrices europeas sin incluir ninguna especificidad para España. Tampoco incluyen ninguna referencia a la eficiencia energética de la edificación.

\subsubsection{Expectativas de evolución del problema}

Las acciones futuras dirigidas a la solución del problema se deben abordar de manera integral, utilizando marcos de justicia energética de manera simultánea a la generación de conocimiento acerca de los problemas relacionados con la energía, el cambio climático y la pobreza (Walker y Day 2012).

\subsubsection{Empobrecimiento y envejecimiento de la población}

El estancamiento o caída de las retribuciones de los trabajadores europeos, el aumento del paro y las medidas económicas de austeridad que se han ido aplicando en algunos estados miembros para reducir el elevado endeudamiento y déficit público están agravando la situación. Europa carece de una "estrategia de salida" de la crisis suficientemente coordinada (CESE Comité Económico y Social Europeo 2010). Estas medidas afectan a las prestaciones sociales (pensiones, ayudas, prestaciones por desempleo...) y a los servicios públicos. Los grupos sociales más vulnerables coinciden con los de menor nivel de ingresos, como mayores de 65 años, familias monoparentales, personas en paro o aquellas que cobran prestaciones sociales. Coincide además, en la mayoría de los casos, que las personas con bajos niveles de renta viven en edificios con un inadecuado aislamiento térmico (Lelkes y Zólyomi 2010). El número de familias en situación de pobreza energética en Europa puede verse incrementado debido a que aproximadamente el $16 \%$ de los europeos están expuestos al riesgo de pobreza (Informe conjunto sobre protección social e inclusión social, Comisión Europea, 2009). En España, entre 2004 y 2015 el porcentaje de personas pobres ha aumentado en más del 25\%. (Aristondo y Onaindia 2018).

"...los ingresos familiares no cuentan con el mejor escenario a corto y medio plazo, dada la situación actual de crisis y el impacto negativo que provoca el desempleo en cuanto a los ingresos los hogares y al riesgo de padecer pobreza energética. " (Tirado Herrero, y otros, 2012.) 


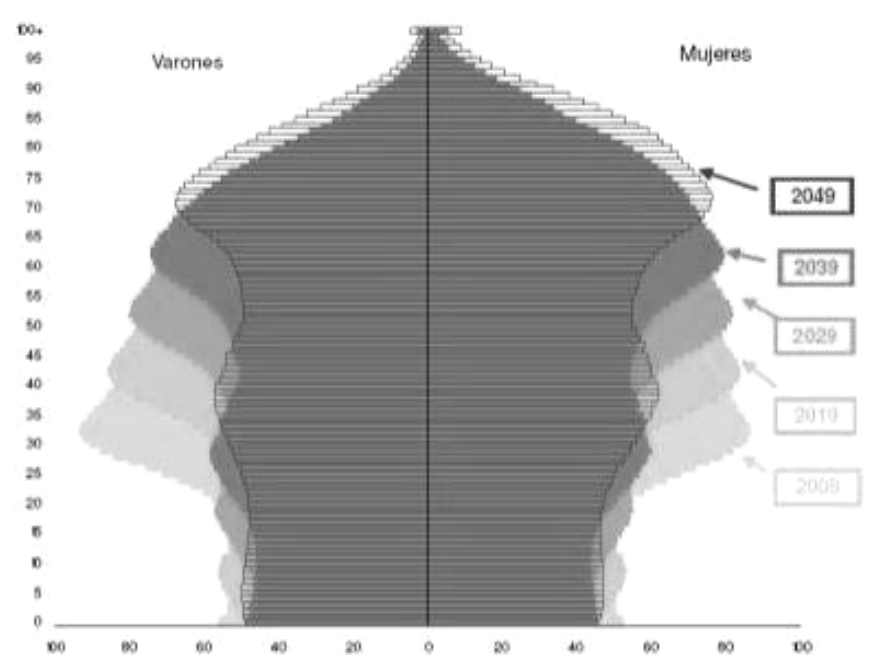

Figura 13.Pirámides de población española en 2009 y estimaciones hasta 2049. Fuente: Instituto Nacional de Estadística

Además del aumento de la pobreza, es necesario tener en cuenta en general en toda Europa, y en particular en el caso de España la tendencia al envejecimiento de la población que reflejan las previsiones. Los bajos índices de natalidad permiten prever un aumento de grupos de población vulnerable por causa de su edad en los próximos años (Figura 13).

\subsubsection{Costes energéticos crecientes}

Existe un preocupante panorama para las familias más vulnerables ante los costes energéticos crecientes. La predicción de tendencias de la Comisión Europea para el escenario base indican que los precios de la energía van a seguir subiendo hasta estabilizarse hacia el año 2030. Los precios de la electricidad, del gas y de otros combustibles, como el carbón, siguen aumentando y parece que va a seguir esta tendencia en los próximos años por lo que el número de consumidores de energía vulnerables también puede crecer de forma importante.

"se está produciendo una escalada de precios sobre la energía, en un sector que experimenta cambios constantes en sus políticas, circunstancia que está afectando, además, al desarrollo de distintas tecnologías y que genera gran incertidumbre entre los usuarios" " (Tirado Herrero, y otros, 2012.)

"es objeto de este Dictamen remarcar la necesidad de proteger a los consumidores vulnerables para evitar situaciones de pobreza energética" (European Commission y Directorate-General for Energy 2010) 


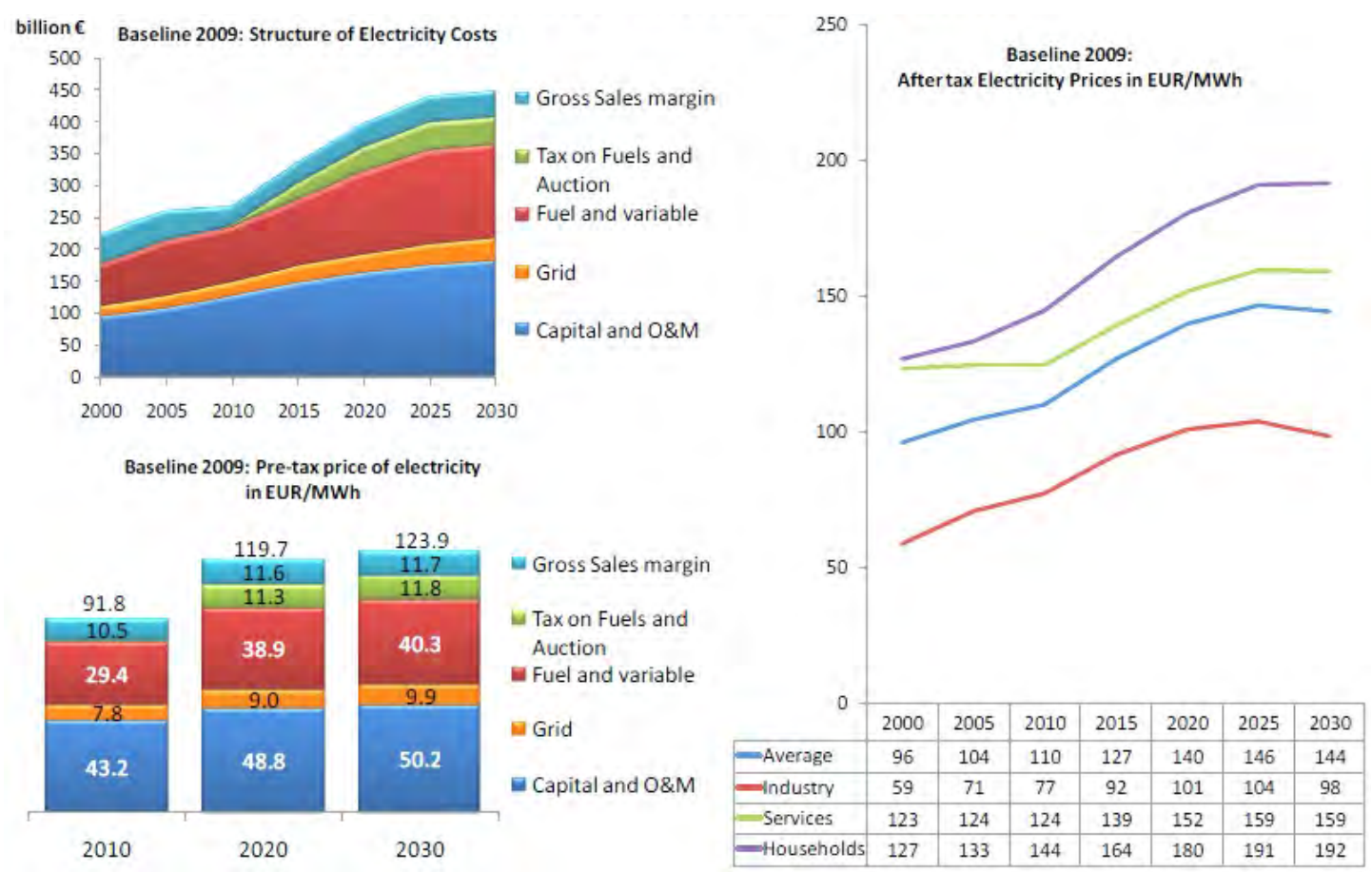

Figura 14. Impactos en costes y precios de la electricidad. Escenario base. Fuente: (European Commission y Directorate-General for Energy 2010)

Cabe destacar que el sector residencial es el que afronta los mayores precios de la energía, en comparación con los sectores servicios e industria, que gozan de precios más reducidos (Figura 14). Además, las actuales estructuras de tarificación también penalizan la pobreza pues resultan en un precio mayor para los consumos reducidos.

"de 2005 a 2007 el precio del gas para consumidores domésticos se incrementó, de media, un 18 \% (Eurostat 2007); de 2005 a 2007 el precio de la electricidad para usuarios domésticos se incrementó, de media, un 14 \% (Encuesta UESILC 2007)" (CESE Comité Económico y Social Europeo 2010).

\subsubsection{Problemas de sobrecalentamiento en verano}

Los hogares en riesgo de pobreza energética, que habitan edificios ineficientes, son además más vulnerables al cambio climático local y global y se ven más afectados por las olas de calor y por tanto a los problemas de salud ocasionados por los golpes de calor (Thomson et al. 2019). Se espera que la demanda de energía para refrigeración aumente en un futuro próximo debido al Cambio Climático. Además, el balance energético positivo en la ciudad, llamado Isla de Calor Urbana (UHI), aumenta todavía más la temperatura en áreas fuertemente urbanizadas (Núñez Peiró et al. 2016). Esto no solo afecta a la 
demanda de energía para refrigeración sino que también tiene un gran impacto en la demanda de electricidad máxima y total, aumentando los costes de la energía para poder garantizar el suministro en horas de demanda pico. También se ha observado una reducción de la eficacia en las técnicas pasivas de enfriamiento utilizadas tradicionalmente, que viene causada por el aumento del número de noches cálidas durante el verano. Esto agrava la problemática en los hogares en situación de pobreza energética, que tendrán dificultades económicas para costear instalaciones de refrigeración eficientes (Mat Santamouris 2016). El proyecto MODIFICA realizó una estimación de la UHI en la ciudad de Madrid concluyendo que los registros de temperatura muestran diferencias de temperatura significativas entre los distintos puntos de la ciudad, llegando a ser de hasta 6 ㅇ C (F.J. Neila et al. 2017).

En España ya se están desarrollando estudios que incorporan las necesidades energéticas para el confort térmico en verano al análisis de la pobreza energética (Sánchez-Guevara, Mavrogianni, y Neila 2017).

\subsubsection{Estado del arte de las políticas y soluciones propuestas}

Las soluciones propuestas hasta la fecha, inciden en las causas de Pobreza Energética, y son de tres tipos; las políticas de renta tienden a compensar las diferencias según el nivel de renta; las políticas de precio inciden en la factura energética y las políticas de eficiencia se orientan a reducir las necesidades energéticas de la edificación, a través de la inversión en el hogar, y con ello prevenir situaciones futuras de pobreza energética en hogares vulnerables (Sánchez Suarez 2019).

La Estrategia Nacional contra la Pobreza Energética 2019-2024, de reciente aprobación, supone la primera política diseñada específicamente para abordar el problema en el país. Está basada en cuatro ejes de actuación y contiene con 19 acciones concretas incluida la creación de un nuevo bono social energético para todos los suministros. Traza el objetivo de reducir en un $50 \%$ el número de personas que viven en situación energética para 2025. Entre las acciones propuestas, en las medidas a largo plazo, se contempla la rehabilitación de edificios (Medida 10) y el análisis detallado del parque en contraste con los indicadores de vulnerabilidad (Medida 11) (MITECO 2019). 


\subsubsection{La mejora de la eficiencia energética para reducir el consumo enla edificación}

Las directivas europeas y los objetivos de la estrategia Europa 2020 apuntan la necesidad urgente de rehabilitar los tejidos urbanos ineficientes con el objetivo de desarrollar una economía social de mercado para el siglo XXI basada en bajas emisiones de carbono y el aprovechamiento de los recursos existentes. La recuperación del patrimonio edificado y la ciudad deben comprender un enfoque transversal basado en términos de integración medioambiental, social y económica (Martín-Consuegra, Alonso, y Frutos 2015). Cada vez son más los estudios oficiales que señalan la rehabilitación de los inmuebles como solución integral al problema de ineficiencia energética y los enormes consumos de la edificación y sus consecuencias sociales (Atanasiu, Kontonastou, y Mariottini 2014). La revisión de la Directiva (UE) 2018/844 incluye por primera vez referencias a la pobreza energética y especifica que los planes de renovación de los estados miembros deben contemplar aspectos sociales:

Para lograr un parque inmobiliario descarbonizado,..., en particular mediante un aumento de las reformas profundas, los Estados miembros deben proporcionar unas orientaciones claras $y$ definir acciones específicas y mensurables y promover un acceso igualitario a la financiación, en particular para los segmentos del parque inmobiliario nacional con peor rendimiento, para los consumidores que sufren pobreza energética, para las viviendas sociales y para las familias que se enfrentan a dilemas causados por la contraposición de incentivos, teniendo en cuenta al mismo tiempo la asequibilidad. (European Parliament and UE Council 2018)

Los estudios científicos sobre pobreza energética recomiendan la implementación de políticas serias en materia de eficiencia energética que supongan un cambio profundo y estructural sobre el problema de la ineficiencia de la edificación existente. La rehabilitación energética se define como una solución definitiva y a largo plazo en el contexto actual de incremento de precios de la energía, empobrecimiento de la población y cambio climático. Los ejes tecnológicos en políticas de innovación en eficiencia energética en edificios apuntan básicamente en tres direcciones: (1) la reducción de la demanda, (2) los suministros limpios y renovables y (3) la gestión inteligente.

Aunque, en su mayoría, suponen inicialmente un notable o elevado desembolso económico, tienen una importante e inmediata repercusión en la erradicación de la pobreza energética ya que contribuyen a lograr importantes ahorros a largo plazo para las familias vulnerables 
solventando el problema con carácter definitivo frente a otras medidas de carácter paliativo. Además constituyen un instrumento básico en la lucha contra el cambio climático al reducir las emisiones de $\mathrm{CO}_{2}$ (Sánchez Suarez 2019).

El "Paquete de Energía Limpia" enmarca los esfuerzos para definir áreas clave de posibles intervenciones innovadoras en materia de "descarbonización" de la Unión Europea: 1) intervenciones para mejorar la eficiencia energética de las viviendas y 2) educación dirigida a los hogares sobre cambios de comportamiento para reducir el consumo de energía. Hace hincapié en las medidas de eficiencia energética de bajo costo para los hogares de bajos ingresos y en las medidas de eficiencia energética a largo plazo y de mayor costo como por ejemplo reformas profundas de edificios (Comisión Europea 2016).

La medida con mayor potencial de ahorro energético es la mejora de la envolvente térmica para reducir las pérdidas en invierno. Algunos autores señalan la necesidad de desarrollar soluciones industrializadas para ello (Pittau et al. 2017). Estudios realizados con posterioridad a operaciones de rehabilitación energética profunda en edificios con viviendas en situación de pobreza energética demuestran que las mejoras en la eficiencia energética de los edificios obsoletos elevan la temperatura del aire interior en invierno, además de ayudar a los hogares a reducir su consumo de energía. Los mayores aumentos de la temperatura interior se producen en los edificios que tenían la calificación energética más baja antes de la intervención, aumentando en mayor medida en las últimas horas de la tarde y por la noche, así como en la sala de estar y el dormitorio principal, lo que sugiere que la rehabilitación provoca el mayor impacto en los espacios en uso (Poortinga et al. 2018).

En cuanto a las soluciones constructivas de bajo coste o de aplicación sencilla, en el trabajo Re-habilitación exprés para hogares vulnerables (soluciones de bajo coste) se han propuesto sistemas económicos de aislamiento térmico por el exterior, insuflados en cámara o reflectantes. También recomiendan la utilización de alfombras, cortinas aislantes y vegetación, la incorporación de laminas de control solar o baja emisividad en los vidrios, o la disposición de burletes de estanqueidad en ventanas y capialzados (Luxán García De Diego et al. 2017). Este trabajo se señala como buena práctica en la Estrategia Nacional contra la Pobreza Energética, que formula en la misma línea su medida 7: 


\section{CAPÍTULO 1. ESTADO DEL ARTE}

Rehabilitaciones exprés en viviendas, con determinadas medidas de bajo coste y rápida ejecución.

\section{La amortización de la inversión inicial}

La mayoría de los hogares de bajos ingresos en Europa están ubicados en edificios de baja eficiencia energética. Esto significa que la población vulnerable tiene una necesidad urgente de rehabilitación energética. La mejora de la calidad térmica puede disminuir la pobreza energética a través de un menor consumo de energía y el costo de funcionamiento de los edificios (Kolokotsa y Santamouris 2015). La inversión en eficiencia energética en la edificación existente puede ser amortizada a partir de los retornos económicos obtenidos por la reducción del gasto en las facturas energéticas. No obstante, el enfoque de la amortización a través del ahorro presenta cierta controversia en el caso de los hogares en riesgo de pobreza energética. En muchos casos el consumo de energía ya es extremadamente limitado antes de la rehabilitación (efecto precondenado). Para una estimación realista de los ahorros que se pueden lograr, resulta necesario tener en cuenta este efecto mediante la calibración de los modelos energéticos con datos de consumos reales obtenidos, por ejemplo, de las facturas energéticas. Teniendo en cuenta estos aspectos, un estudio realizado en Zaragoza ha estimado que el ahorro podría verse reducido entre un 20 y un $30 \%$ por debajo de las estimaciones para un hogar en el que se estuvieran cubriendo las necesidades de confort (Aranda et al. 2017). Otros estudios señalan que no se puede esperar una reducción del consumo después de la renovación, ya que los hogares con poca energía tienden a utilizar los beneficios de la mejora de la eficiencia para aumentar sus niveles de confort en lugar de reducir el consumo (efecto rebote) (Berger y Höltl 2019).

\section{Aumento del valor de los inmuebles}

Algunos estudios han constatado una influencia económica en el aumento del valor de los inmuebles, en el precio de alquiler y venta, por ejemplo de entre un 5 y un $10 \%$ en España (de Ayala, Galarraga, y Spadaro 2016). En el mercado ingles se constatan subidas del $5 \%$ para las viviendas con calificación A y B (Fuerst et al. 2015). Otros estudios demuestran que el efecto de la calificación energética es generalmente mayor cuando las condiciones del mercado son peores (Hyland, Lyons, y Lyons 2013), diluyéndose en zonas 
con altos precios del suelo. El precio de una vivienda y, en general, de un edificio, se calcula en función de la ubicación (valor por m2 por superficie bruta) y la calidad de la construcción. Por lo tanto, la renovación de baja energía solamente podría mejorar este último (Martín-Consuegra et al. 2015).

El aumento del valor de la vivienda se incluye en las "narrativas holísticas" sobre el estudio de los beneficios de la rehabilitación energética, y se considera que podría ayudar a mejorar la condición social de las personas con bajos ingresos propietarias de viviendas (Kerr, Gouldson, y Barrett 2018). No obstante, todo depende de las circunstancias concretas de cada caso. En el caso de viviendas en alquiler, el aumento de la calidad de los inmuebles y la necesidad de financiar la inversión puede producir subidas en el precio del alquiler, con riesgo de causar fenómenos de "gentrificación energética"(Großmann et al. 2014). A pesar de la inclusión de medidas correctoras, como las impulsadas por el gobierno alemán, que limita estos incrementos de precio a un máximo de un $11 \%$, los hogares en situación de pobreza energética se ven afectados desproporcionalmente (Weber y Wolff 2018).

\section{Instrumentos financieros}

La innovación en la optimización de los instrumentos financieros disponibles para combatir la pobreza energética es un requisito de la sociedad para lograr estos objetivos. Se necesita innovación en el modelo de negocio desde una perspectiva de justicia energética. La política debe centrarse en crear condiciones de apoyo para las empresas locales de energía a favor de la equidad. Las políticas de apoyo financiero para la mejora de la eficiencia de los hogares deben dirigirse específicamente a las personas propietarias de viviendas que viven bajo el umbral de la pobreza (Hiteva y Sovacool 2017). Se hace necesario el diseño de modelos de financiación para identificar y priorizar los puntos socioeconómicos críticos en el stock de viviendas y ofrecer a cada sector un producto adaptado a sus necesidades. En trabajos anteriores se han esbozado ideas para crear un modelo equitativo para financiar la renovación energética, en el que el costo real de la inversión inicial puede servir como garantía real para el préstamo para realizar las obras. La constitución de la garantía no afectaría a los propietarios de edad avanzada (esperanza de vida estimada) ni a los propietarios que acreditan la pobreza (hasta que sus circunstancias cambien para mejor) (Martín-Consuegra et al. 2015). 


\section{CAPÍTULO 1. ESTADO DEL ARTE}

\section{Beneficios no energéticos}

Los Beneficios No Energéticos (BNE) aunque difíciles de cuantificar, son tenidos en cuenta cada vez más para evaluar la efectividad de la inversión en eficiencia energética. La estimación de costes y beneficios está ya incorporando no solo a los participantes directos, sino también la utilidad que para la sociedad se genera (Skumatz 2015). La seguridad, la salud humana y ambiental, o los elementos de racionalización de procesos ya son subproductos frecuentes de los programas de eficiencia energética (IEA 2014; Helge Sigurd Næss-Schmidt, Martin Bo Westh Hansen, y Carl von Utfall Danielsson 2012). Las utilidades integradas del beneficio del usuario en aspectos como la comodidad, la salud y el ahorro también se han abordado en trabajos anteriores (Martín-Consuegra et al. 2015). Otros aspectos relacionados con los beneficios socioeconómicos son, por ejemplo, la estimulación del mercado de la Eficiencia Energética, que tiene un impacto en la creación de oportunidades laborales que debería dirigirse a nivel local en la remodelación de barrios desfavorecidos. La creación de empleo también es un beneficio bastante citado en los estudios sobre BNE de la rehabilitación energética desde (Dalle et al. 2010).

La mejora del medioambiente no afecta solamente de forma micro climática, sino que impacta globalmente en el Cambio Climático (WWF et al. 2017). Se debe trabajar para mejorar las definiciones y la cuantificación de los beneficios y costos debidos tanto a las medidas que no son de EE como a las de EE, pero tales esfuerzos no deben obstaculizar el objetivo de lograr la equidad para la mejora de la seguridad y la calidad de vida de los hogares de bajos ingresos (Freed y Felder 2017).

\section{Mejoras en la salud}

Las investigaciones han demostrado que la calidad de la vivienda está asociada con una serie de aspectos psicosociales y de salud. En concreto, las mejoras en la eficiencia energética a menudo se asocian con mejoras significativas en el bienestar térmico y la salud física y mental (C. Liddell y Guiney 2015). Entre los múltiples beneficios que se obtienen de estas operaciones aparecen a menudo las mejoras en la salud tanto de las personas directamente afectadas por situaciones de falta de confort en los hogares, como por la mejora del medioambiente urbano por la reducción de la contaminación 
(Helge Sigurd Næss-Schmidt, Martin Bo Westh Hansen, y Carl von Utfall Danielsson 2012).

Una iniciativa innovadora en este aspecto es el programa "Warmer Homes Scheme" en la República de Irlanda. Este programa ofrece aislamiento térmico gratuito a aquellos propietarios de viviendas que tienen una enfermedad respiratoria o son beneficiarios de ayudas sociales para personas vulnerables. La rehabilitación la realiza el gobierno, sin ningún costo para la propiedad del inmueble, financiando mejoras en la eficiencia energética de los hogares de personas vulnerables en riesgo de pobreza energética, con la intención de reducir el gasto en el Sistema Nacional de Salud por enfermedades relacionadas con la falta de confort (Sustainable Energy Authority Of Ireland 2015).

\subsubsection{Políticas de precio}

Las políticas de renta destinadas a atajar el problema de la pobreza energética pretenden paliar la carga que supone la factura en el hogar. En el Reino Unido se cuenta con el WHD (Warm Home Discount) desde 2011, que apoya directamente el pago de las facturas energéticas a hogares en situación de vulnerabilidad. En Francia, la TPN (Tarifa Eléctrica para las Necesidades Básicas) y TSS (Tarifas Sociales Solidarias de gas) permiten un descuento de entre el 40 y el 60\% a hogares con ingresos reducidos (Sánchez Suarez 2019). El uno de julio de 2009 entró en vigor en España un nuevo sistema de tarifas eléctricas en el que coexistían, por un lado, el mercado libre, y por otro, una tarifa fijada por el gobierno: la denominada Tarifa de Último Recurso. La TUR fue el precio regulado por el gobierno para el suministro obligatorio a los clientes que no querían o no podían buscar otras ofertas en el mercado. Según el gobierno (MINETUR), la TUR "se configura como una tarifa refugio y está reservada para los consumidores que tienen una potencia contratada inferior a $10 \mathrm{Kw}$, segmento en el que se encuentran prácticamente todos los consumidores domésticos."

El ejecutivo eligió cinco empresas, denominadas comercializadoras de último recurso, para dar servicio a los clientes con derecho a la TUR. Esas cinco empresas son filiales de las mismas que integran Unesa. A saber: Endesa Energía XXI, Iberdrola Comercialización de Último Recurso, Gas Natural, HC-Naturgás Comercializadora Último Recurso y E.ON Comercializadora de Último Recurso" (Tirado, López Fernández, y Martín García 2012) 
Con la entrada en vigor de la Tarifa de Último Recurso (TUR) se puso en marcha también el denominado bono social que se concreta en la congelación de la tarifa vigente en el momento de la puesta en marcha de la TUR hasta 2012.

"Se calcula que beneficiará a unos 5 millones de consumidores. Podrán acogerse al bono social cuatro colectivos: a) los clientes domésticos residencias con una potencia contratada inferior a 3 $K W ; b)$ los pensionistas con prestaciones mínimas; c) las familias numerosas y d) los hogares en los que todos sus integrantes se encuentren en situación de desempleo" MINETUR, 2009

Se ha criticado la incertidumbre que causa la caducidad de la medida y su acotación a usuarios de energía eléctrica, se distinguen tres tipos de consumidores: vulnerables, vulnerables severos y en riesgo de exclusión, aplicando un descuento del $25 \%, 40 \%$ y $100 \%$, respectivamente, en la factura.

En España, el bono social "es la única medida definida de forma especifica para paliar los efectos de la pobreza energética. Sin embargo, los colectivos que se benefician de esta ayuda no siempre estarán en pobreza energética, y hay hogares en pobreza energética cuya fuente principal de calor es diferente de la electricidad (por ejemplo, el gas butano)." (Tirado Herrero, y otros, 2012.)

Otros autores han criticado las dificultades burocráticas y de tramitación, y el carácter limitado de la ayuda, además de la reducción del número de beneficiarios con respecto a la TUR hace imposible cubrir a todos los consumidores vulnerables (eliminando de la ayuda a hogares con potencia inferior a $3 \mathrm{kWh}$ y hogares con todos sus miembros en paro) (Sánchez Suarez 2019).

Existe un límite máximo de $\mathrm{kWh}$ consumidos a los que se aplica el descuento por encima de los cuales se facturará sin descuento. Se alegó que así se incentivaba el ahorro y se prevenía el derroche, aunque volvemos a contar con umbrales injustificadamente bajos. Además, no se tienen en cuenta los meses de temperaturas extremas tanto de frío como de calor o, por ejemplo, al grupo de beneficiarios con pensión mínima, que muy probablemente pase más tiempo en el hogar, se le asigna uno de los tramos más bajos de energía de los que se les aplica el descuento (Sánchez Suarez 2019).

\subsubsection{El papel de las nuevas tecnologías en eficiencia energética como solución a la pobreza energética}

Resulta frecuente la invocación a la búsqueda de soluciones tecnológicas al problema de ineficiencia del parque. La incorporación de nuevas tecnologías en los hogares en 
riesgo de pobreza se encuentra, de entrada, con barreras adicionales porque la población vulnerable, en el cuartil de ingresos más bajo, muestra en general una menor propensión a la adopción de nuevas tecnologías (Schleich 2019). Por ejemplo, el rol de las nuevas tecnologías de información y telecomunicaciones (TICS) en el desarrollo de los "edificios inteligentes" de alta eficiencia energética integrados en redes urbanas, precisa de un potente enfoque social si se pretenden incorporar en barrios vulnerables. Resulta indispensable la formación de "usuarios inteligentes" como agentes interesados activos e implicados en los procesos (Wurtz y Delinchant 2017).

El desarrollo de productos de construcción innovadores - como los materiales de cambio de fase, los recubrimientos fríos o termocrómicos, los sistemas HVAC de alto rendimiento, la tecnología de energía solar de película delgada, y la fotovoltaica integrada en los materiales de construcción- presenta muchas posibilidades de mejora basadas en la innovación (Mat Santamouris 2016), pero hasta el momento no se ha encontrado ningún estudio que evidencie alguna influencia en su aplicación en los hogares con problemas de pobreza energética. La innovación en la investigación con el objetivo de "enfriar las ciudades" (cooling the cities) incluye inversiones en las infraestructuras verdes urbanas para aumentar el sombreado y el enfriamiento evaporativo (Moss et al. 2018; Saaroni et al. 2018). En los climas secos la evaporación se puede aumentar mediante la incorporación de láminas de agua y surtidores. Además, se está desarrollando rápidamente la investigación sobre "recubrimientos fríos" tanto en los campos de la ciencia básica como en la aplicada, ya que su efecto para la reducción de la temperatura exterior y su impacto el confort interior y la eficiencia energética de los edificios está claramente establecida (Pisello 2017).

\section{La incorporación de energías renovables en los hogares y la generación distribuida}

La generación distribuida de energía vuelve a posicionarse como una estrategia necesaria para lograr seguridad en el suministro energético y avanzar hacia la equidad energética en España tras el trauma causado por el hachazo a las renovables:

Tras posicionarse en 2008 como uno de los líderes mundiales en el ámbito de la energía fotovoltaica atrayendo a numerosos inversores extranjeros, [...] en 2010, con el inicio de los recortes retroactivos, comenzó una carrera de reclamaciones millonarias ante cortes arbitrales privadas. Actualmente España se sitúa entre los países más demandados con un total de 36 
reclamaciones pendientes a finales de 2017 cuya cuantía superaba los 7.566 millones de euros (Sánchez Suarez 2019).

Joan Herrera, último director del Instituto para la Diversificación y el Ahorro de Energía afirma que "debemos protagonizar una introducción masiva de energías de origen renovable", remarcando la necesidad de la implicación ciudadana en su incorporación, para lo cual hacen falta dos ingredientes que faciliten la transición:

"El primer ingrediente es la necesidad de la participación ciudadana y la inversión múltiple y no sólo concentrada en muy pocas manos., ...

... en segundo lugar necesitamos gestionabilidad. Y ya no de la producción sino de la demanda. Si hasta ahora el modelo lo que hacía era básicamente casar la producción con la demanda prevista, lo que necesitamos en un contexto de fuerte producción renovable es ajustar las curvas de demanda a los momentos de producción de origen renovable" (Herrera 2019).

La incorporación de energías renovables en áreas vulnerables presenta numerosas barreras que sugieren que es necesario un fuerte enfoque social para poder desarrollar con éxito la integración de estas tecnologías. Resulta necesaria la aplicación de acercamientos "socio-tecnológicos" en la investigación en el campo de la energía y el desarrollo de interfaces comprensibles y que permitan la interacción del usuario (McCabe, Pojani, y van Groenou 2018). La utilización de la energía renovable de manera comunitaria en barrios de vivienda social se debe contemplar, desde la perspectiva del derecho a la energía, incluyendo una provisión de energía para grupos de bajos ingresos. En cualquiera de los casos, para el ajuste del potencial de producción de energía renovable a la demanda, es imprescindible la mejora previa de la envolvente térmica para reducirla al máximo y necesitar así una menor infraestructura para cubrirla.

Existen algunos ejemplos de investigación científica que plantean el uso de tecnologías renovables para la lucha contra la pobreza. Se han realizado unas primeras propuestas de trabajo dirigidas a la utilización de energía solar en comunidades vulnerables, como por ejemplo en el caso de la ciudad de Dundee en Escocia (Andreadis, Roaf, y Mallick 2013) o en España con la propuesta para un barrio de viviendas sociales en Sevilla que sufría temperaturas insoportables durante todo el año. Se registraron reducciones de las diferencias de confort entre las viviendas, mediante el uso del excedente de energía 
fotovoltaica, mejorando el confort térmico de los ocupantes (Romero Rodríguez et al. 2018).

La nueva Estrategia Nacional contra la Pobreza Energética incluye también entre las medidas a considerar a medio-largo plazo en el ámbito de la lucha contra la pobreza energética la promoción del autoconsumo térmico y/o eléctrico en asociación (MITECO 2019). 


\subsection{VULNERABILIDAD ENERGÉTICA EN MADRID}

Se han analizado las definiciones existentes, sus causas y consecuencias y las medidas correctoras planteadas hasta la fecha para solucionar el problema de la pobreza energética. En el presente apartado se centra la investigación en los aspectos del urbanismo y la arquitectura que hacen que los edificios sean vectores de riesgo que, unidos a otros problemas socioeconómicos en el hogar, pueden provocar situaciones de pobreza energética en la población que los habita. Esta situación se ha denominado vulnerabilidad energética asociada a la edificación (Martín-Consuegra 2014). Se pretende introducir la dimensión urbana de la investigación, mediante la incorporación de un análisis urbanístico de los factores que influyen en las necesidades y revele como se estructura la inequidad energética de las viviendas de la ciudad. Se utiliza el estudio de caso de la ciudad de Madrid.

Múltiples estudios en materia de eficiencia energética de la edificación residencial existente señalan como conjuntos de viviendas ineficientes las contenidas en las áreas urbanas producidas a partir del periodo de reconstrucción de posguerra hasta la entrada en vigor de la primera Norma Básica de la Edificación (NBE-CT-79 1979), que comienza a incluir exigencias para limitar el consumo energético de los edificios (Dalle et al. 2010; Albert Cuchí, Sweatman, y GTR 2012; Kurtz, Monzón, y López-Mesa 2015; WWF et al. 2017; Oteiza, I. et al. 2018).

Para el abordaje del problema desde la perspectiva del derecho a la energía, se recopila información sobre los grupos sociales más vulnerables, que coinciden con los de menor nivel de ingresos, los mayores de 65 años, familias monoparentales, personas en paro o aquellas que cobran prestaciones sociales. Se incorporan así a los estudios del impacto ambiental del consumo de energía residencial, datos socioeconómicos que permitan realizar un análisis integral.

En este primer acercamiento al problema se analizan recursos estadísticos existentes que pueden aportar información relacionada con estos aspectos, en especial los censos de población y viviendas (INE 2011; 2001; 1991). Se han recopilado datos estadísticos existentes desagregados a la escala de la sección censal para el municipio de Madrid. Se 
pretende incorporar al estudio aquella información contenida en los datos estadísticos que aborda aspectos de eficiencia energética que deben ser tenidos en cuenta a la hora de plantear operaciones de Regeneración Urbana Integrada de barrios degradados e ineficientes desde el punto de vista del uso de la energía. Los indicadores estudiados están relacionados con la edificación, las viviendas y la población que las habita, y se estructuran en los siguientes grupos:

- Indicadores socioeconómicos

- Vulnerabilidad urbana

- Distribución de la renta

- Edad de la población

- Indicadores residenciales

- Viviendas por periodo de construcción

- Instalaciones para el confort en las viviendas

- Vivienda de protección pública

○ Viviendas vacías

- Indicadores de la edificación

- Parque residencial construido durante la época 1940-80

- Estado de la edificación

- Accesibilidad

- Áreas de rehabilitación promovidas por entes públicos

A partir de la recopilación de estos datos se pretenden localizar en la cartografía municipal de Madrid los aspectos que relacionan las viviendas con las necesidades de rehabilitación energética de los edificios y con la vulnerabilidad de las personas que los habitan. Se ha trabajado principalmente con datos que provienen de los Censos del Instituto Nacional de Estadística con el mayor nivel de desagregación posible (a la escala de la sección censal). Para el análisis de la edificación se utilizan datos del último Censo de 2001 y para los de la población el de 2011. La razón es que los datos consolidados del último censo (2011) se han conocido a final de 2014 y están sustentados en una muestra estadística frente a la metodología de muestra universal de los censos anteriores (2001 y 1991). Se considera que se ha ido perdiendo calidad en los datos estadísticos y que esta pérdida de calidad afecta especialmente a los datos de vivienda (Naredo 2014). Por esta razón, los datos estadísticos que se han utilizado en lo referente a la edificación pertenecen al Censo INE 2001, puesto que se entiende que se trata de bienes inmuebles con un periodo de vida prolongado. No obstante, para los estudios relacionados con la 


\section{CAPÍTULO 1. ESTADO DEL ARTE}

población se han utilizado datos del último Censo (2011), puesto que se considera que las circunstancias que rodean a las personas pueden haber sufrido variaciones en una década que deben ser tomadas en consideración.

La representación de los indicadores estadísticos en mapas permite analizar su distribución espacial. Se señalan las secciones censales que superan el valor medio para toda la ciudad para cada indicador. Las áreas en los que el indicador supera el $150 \%$ del valor medio se consideran críticas y se marcan en un color más oscuro. Esta metodología se ha tomado del Análisis Estadístico de Barrios Vulnerables (Agustín Hernández Aja 2011).

\subsubsection{Indicadores socioeconómicos}

Se han recopilado datos existentes relacionados con la población que pueden tener influencia en su relación con el uso de la energía. De acuerdo con los aspectos estudiados en el estado del arte sobre pobreza energética, se han considerado aspectos como los fenómenos de vulnerabilidad urbana, la distribución de la renta o la edad de la población.

\subsubsection{Vulnerabilidad urbana}

Se ha tenido en cuenta la información contenida en el Atlas de la Vulnerabilidad Urbana en España (Agustín Hernández Aja 2011), cedida por el Ministerio de Fomento, y la información sobre áreas preferentes para la rehabilitación urbana (APIRUs) desarrollada y cedida por el ayuntamiento de Madrid (Ayuntamiento de Madrid 2016). Ambos estudios se basan en el análisis de datos estadísticos de los Censos de Población y Viviendas (INE 2011, 2001). El primer estudio desarrolla una metodología a partir de criterios estrictamente técnicos y está dirigido a la identificación de áreas urbanas vulnerables en toda la geografía española, y a la caracterización detallada de las causas de vulnerabilidad. El segundo estudio está dirigido a la rehabilitación energética de barrios de la periferia del municipio de Madrid e incluye criterios políticos además de técnicos para la selección de áreas de rehabilitación preferente. En el caso del Atlas de Vulnerabilidad Urbana, es posible asimilar los datos de los censos utilizando la clasificación de Barrios Vulnerables coincidente con secciones censales completas. 


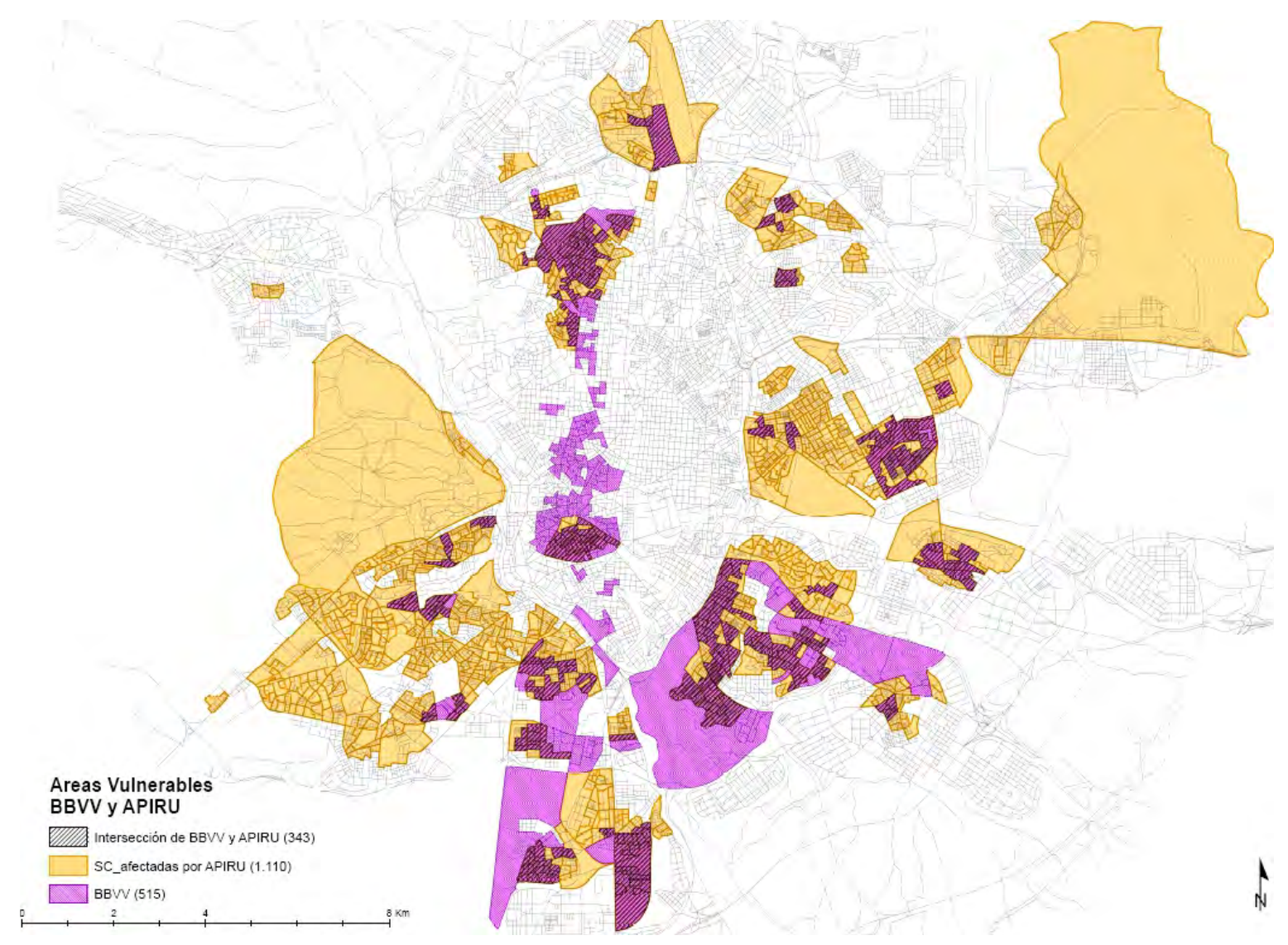

Figura 15. Cruce de datos de vulnerabilidad urbana en Madrid, de las dos metodologías existentes. Elaboración propia

En el plano (Figura 15) se han representado en color magenta la localización de los Barrios Vulnerables de Madrid (Agustín Hernández Aja et al. 2015). Además, se representa en azul la delimitación provisional del Plan Municipal de Impulso a la Regeneración Urbana presentado por el Ayuntamiento de Madrid con el foco puesto en la mejora de la Accesibilidad, Conservación y Eficiencia energética de la edificación residencial a través de las Áreas Preferentes de Impulso a la Regeneración Urbana (APIRU) (Ayuntamiento de Madrid 2016).

Observatorio de la vulnerabilidad urbana $(1991,2001,2011)$

El Observatorio de la Vulnerabilidad Urbana, promovida por el Ministerio de Fomento y desarrollada por el Departamento de Urbanismo y Ordenación del Territorio de la Universidad Politécnica de Madrid, ofrece información estadística y permite analizar datos desagregados a la escala de la sección censal para todos los municipios de España diversas variables socioeconómicas y residenciales utilizadas para la identificación y delimitación de Barrios Vulnerables. 


\section{CAPÍTULO 1. ESTADO DEL ARTE}

...puede entenderse por vulnerabilidad urbana "aquel proceso de malestar en las ciudades producido por la combinación de múltiples dimensiones de desventaja, en el que toda esperanza de movilidad social ascendente, de superación de su condición social de exclusión o próxima a ella, es contemplada como extremadamente difícil de alcanzar. Por el contrario, conlleva una percepción de inseguridad y miedo a la posibilidad de una movilidad social descendente, de empeoramiento de sus actuales condiciones de vida" (Agustín Hernández Aja 2007)

Los indicadores tenidos en cuenta para la selección de secciones censales vulnerables han sido los siguientes:

- $\%$ SIN ESTUDIOS.

Personas analfabetas o sin estudios

- \% PARO.

Personas desempleadas

- \% de viviendas sin aseo. Indicador de vivienda

Al tratarse de un proyecto de largo recorrido en el tiempo, permite observar la evolución de los barrios vulnerables en cada década.

Los fenómenos de segregación espacial tienden a mantenerse en el tiempo hasta que algún acontecimiento extraordinario, o la suma de acciones sostenidas en el tiempo, consiguen reducirla reincorporando el espacio a la ciudad en la que se incluye. (Agustín Hernández Aja et al. 2015).

Se ha contabilizado la población (INE, 2011) residente en estas zonas en 592.240 personas, distribuidas en 515 secciones censales, lo que significa que el 19\% de la población de Madrid vive en áreas con problemas de vulnerabilidad urbana.

\section{Ayuntamiento de Madrid}

La metodología desarrollada por el Ayuntamiento para la delimitación de Áreas Preferentes de Impulso a la Regeneración Urbana (APIRU) es específica para la ciudad de Madrid. El objetivo es gestionar subvenciones públicas con destino a la realización de actuaciones de conservación y eficiencia energética de los edificios residenciales que se encuentren en el interior de estas áreas. Se trata de barrios donde las instituciones públicas van a tratar de promover operaciones de regeneración urbana integrada incluyendo medidas de mejora de la eficiencia energética de la edificación. Los indicadores utilizados por el ayuntamiento para delimitar estas áreas han sido los siguientes: 
- \% ENVEJECIMIENTO.

- \% SIN ESTUDIOS.

- \% V. CATASTRAL.

- $\%$ VIV $<1980$.
Personas mayores

Personas analfabetas o sin estudios

Valor Catastral de los inmuebles

Viviendas construidas antes de 1980

La delimitación de estas áreas no coincide necesariamente con secciones censales. Para la comparación con el resto de datos se han seleccionado todas aquellas secciones censales en las cuales existen zonas coincidentes con la delimitación de APIRUs. Este análisis resulta en 1.110 secciones censales afectadas en mayor o menor medida por estas Áreas Preferentes de Rehabilitación. En estas secciones censales residen 1.324.300 personas, el $42 \%$ de la población de la ciudad.

\subsubsection{Distribución de la renta}

El conocimiento de la distribución espacial del nivel de renta resulta de utilidad para el estudio de las dinámicas sociales y económicas de la población en su relación con el uso de la energía. Se han extraído datos sobre la renta per cápita y del hogar. La base de datos Almudena de la Comunidad Autónoma de Madrid contiene datos de la renta per cápita desde el año 2000. El ayuntamiento ofrece datos de renta media del hogar a escala de barrio, y del tramo de renta desagregados a la escala de la sección censal.

\section{Renta per cápita}

La necesaria protección que rodea la información de ingresos personales, provenientes de encuestas de ingresos y gastos familiares y de los registros de origen fiscal, dificulta la disponibilidad de datos sobre este tema. Los primeros datos que se han podido encontrar fueron publicados en el año 2003 (Moreno Jiménez 2003). La configuración espacial de los niveles de renta en la capital presenta una tendencia general descendente desde el Noroeste al Sureste (Figura 16). El grueso de la parte Norte y la almendra central presentan rentas más altas (Chamartín, Salamanca, Retiro Chamberí y Moncloa-Aravaca), mientras que en todo el arco sur prevalecen las rentas más bajas (Latina, Carabanchel, Usera, Villaverde, Puente de Vallecas, Villa de Vallecas, Moratalaz y San Blas). No obstante, en distritos como Centro y Tetuán se altera este esquema lineal. En estas tendencias se inscriben una serie de variaciones resultantes de 


\section{CAPÍTULO 1. ESTADO DEL ARTE}

la compleja evolución histórica del urbanismo madrileño, por ejemplo áreas de menor renta en la zona norte (Tetuán, Barrio del Pilar) y un centro muy dividido.

Si se analizan los datos de la tendencia de la renta per cápita municipal desde el momento de este estudio se puede observar una subida ocasionada principalmente por el alza del precio de los inmuebles ocasionado por la burbuja inmobiliaria (Vinuesa 2008) y una tendencia a la baja desde el momento de su estallido (Figura 17).

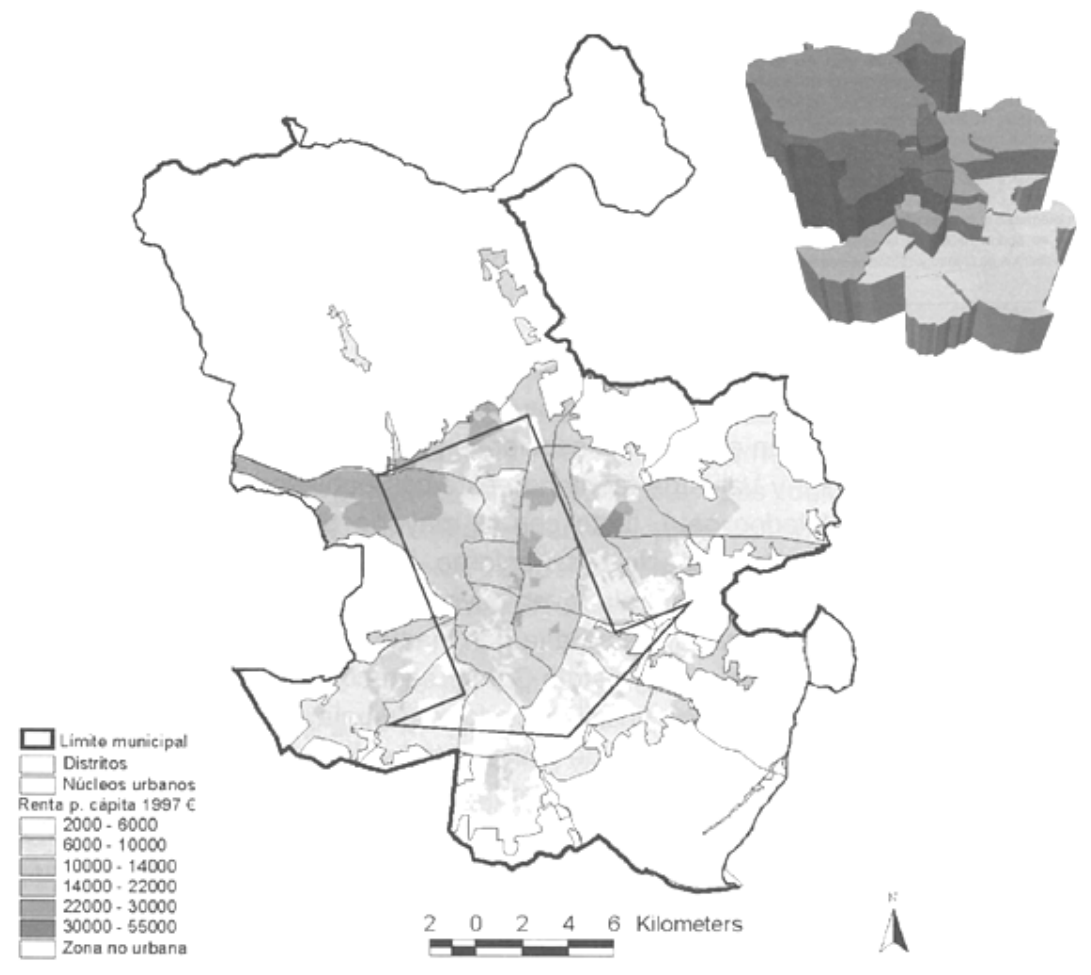

Figura 16.Distribución de la renta per cápita en Madrid capital en 1997 por secciones censales y por distritos (Moreno Jiménez 2003)

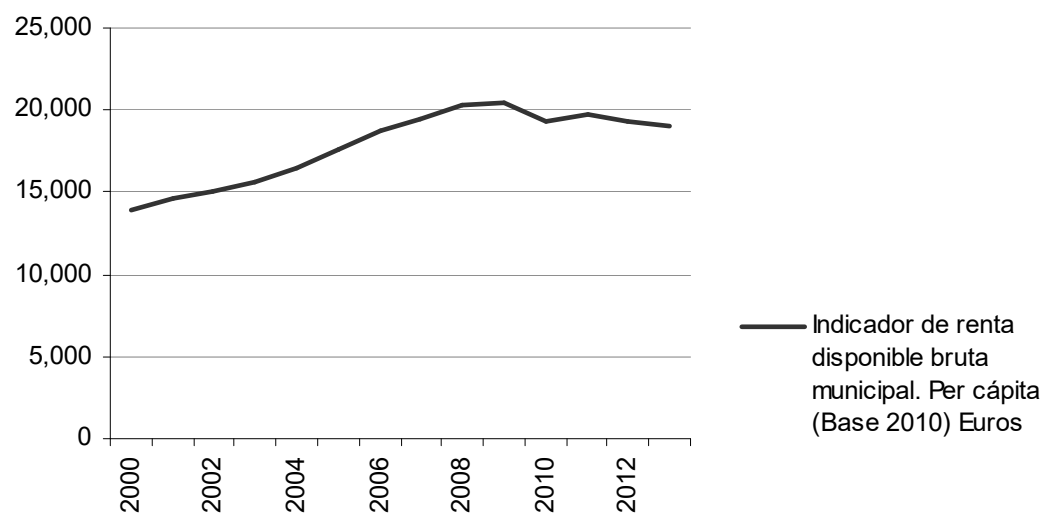

Figura 17. Indicador de renta disponible bruta municipal per cápita (Base 2010) Euros. Elaboración propia a partir del Banco de datos municipal y zonal Almudena, Instituto de Estadística de la Comunidad de Madrid 


\section{Rentas del hogar}

La información utilizada acerca de la renta neta media anual de los hogares por sección censal ha sido facilitada por el Ayuntamiento de Madrid (Ayuntamiento de Madrid 2017). Esta información es fruto de la colaboración del Instituto Nacional de Estadística (INE) con la Agencia Española de Administración Tributaria (AEAT) para la utilización de datos tributarios con fines estadísticos. El estudio tiene en cuenta dos componentes: la renta neta media anual (AEAT), y el número de hogares a partir de una explotación del Padrón Continuo (INE). La recopilación de datos se ha realizado para el proyecto Urban Audit (European Environment Agency 2017) siguiendo la metodología descrita en el manual de Estadística Urbana de Eurostat (European Union 2017) y se distribuyen en 10 tramos de renta. Los valores de renta de este estudio aparecen detallados geográficamente a la escala de la sección censal, permitiendo tener una fotografía de la desigualdad urbana en cuestión de ingresos para los hogares de la ciudad de Madrid. En la Figura 18 se ha representado el tramo de renta en el que se encuentra cada sección censal.

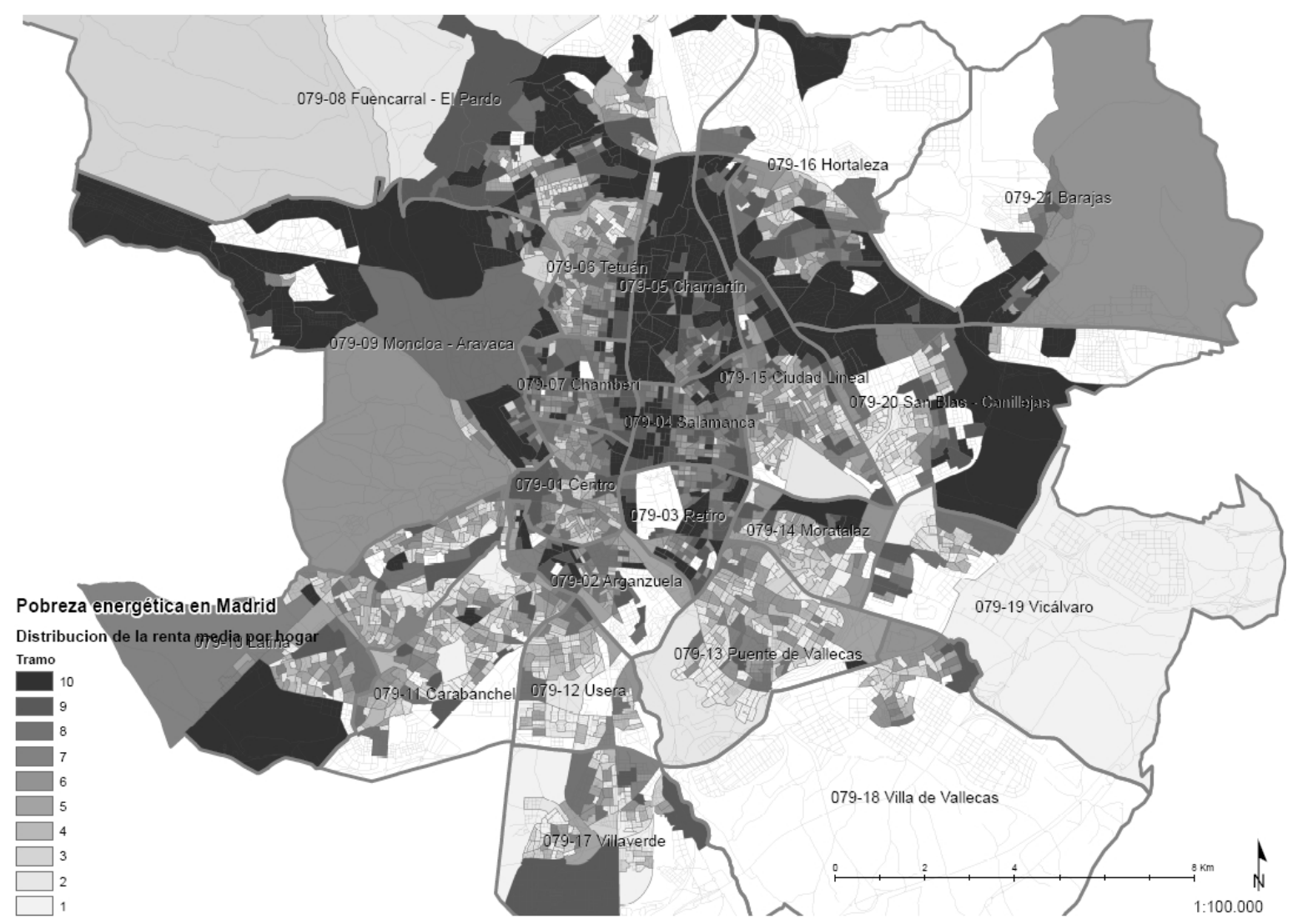

Figura 18. Distribución de la renta por tramos en Madrid (Urban Audit 2013) 


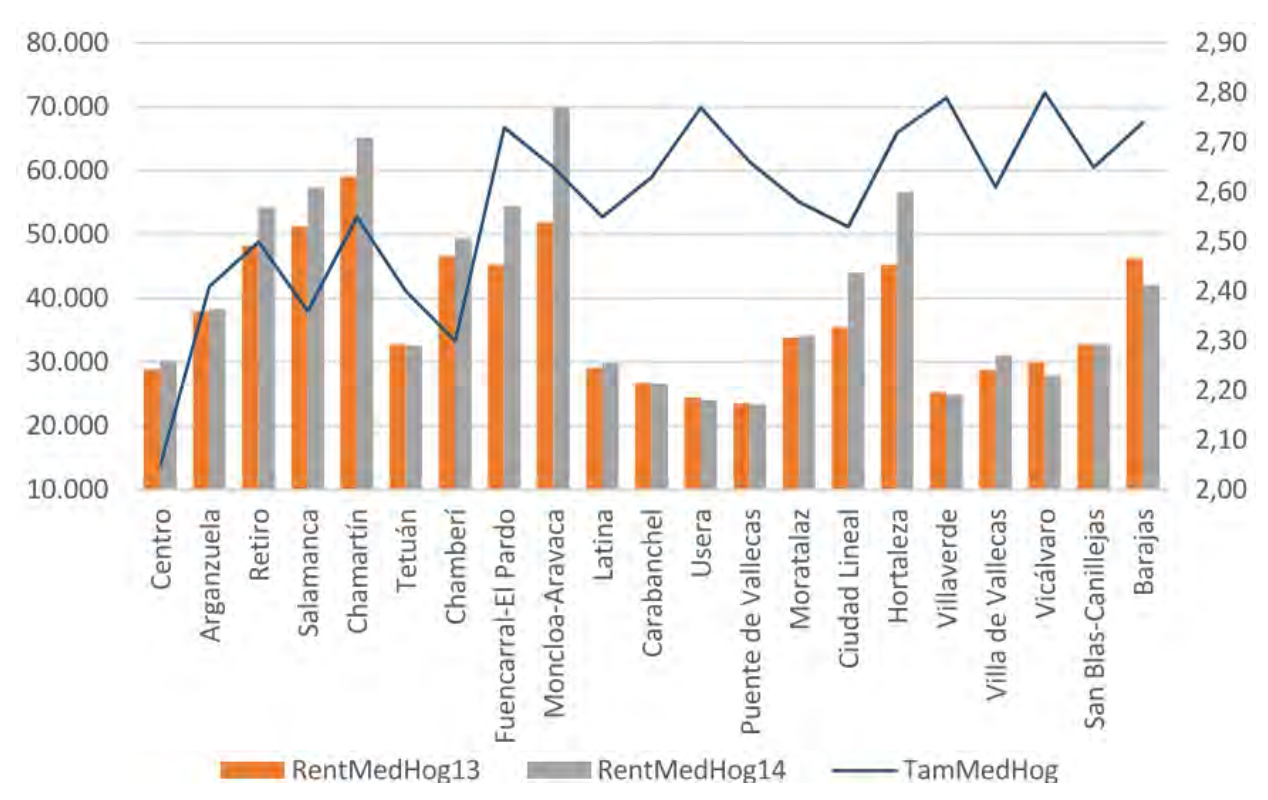

Figura 19. Renta media del hogar por distritos en 2013 y 2014 (Ayuntamiento de Madrid)

Los datos del proyecto Urban Audit apuntan un aumento de las rentas entre el año 2013 y 2014, observándose indicios de desigualdad en el reparto de la riqueza generada. La renta media por hogar aumentó en un año al 110\% de 2013 a 2014. Este aumento no se ha distribuido de manera equitativa. Los distritos con mayores rentas la ven incrementada, mientras los de menor renta se mantienen o ven reducidos sus ingresos. El distrito peor parado es Barajas, que redujo su renta en 2014 al 91\% de 2013, seguido de Vicálvaro. Los distritos más beneficiados de la mejora económica han sido Fuencarral-El Pardo (120\%), Moncloa-Aravaca (135\%), Ciudad Lineal (124\%) y Hortaleza (125\%) (Figura 19). Estos datos evidencian el empeoramiento del nivel de vida en las áreas más desfavorecidas, en línea con los estudios publicados en informes sobre la pobreza en España (Cáritas 2014; Martínez Parra 2019).

\subsubsection{La edad de la población}

El análisis de la distribución espacial de la edad de la población en el contexto de la rehabilitación energética resulta relevante, tal y como indican los estudios acerca de las consecuencias de la pobreza energética. Las razones son la vulnerabilidad ante la falta de confort térmico de los menores y personas mayores. Además, las personas mayores son menos propensas a realizar obras de rehabilitación en sus viviendas, por los siguientes motivos 


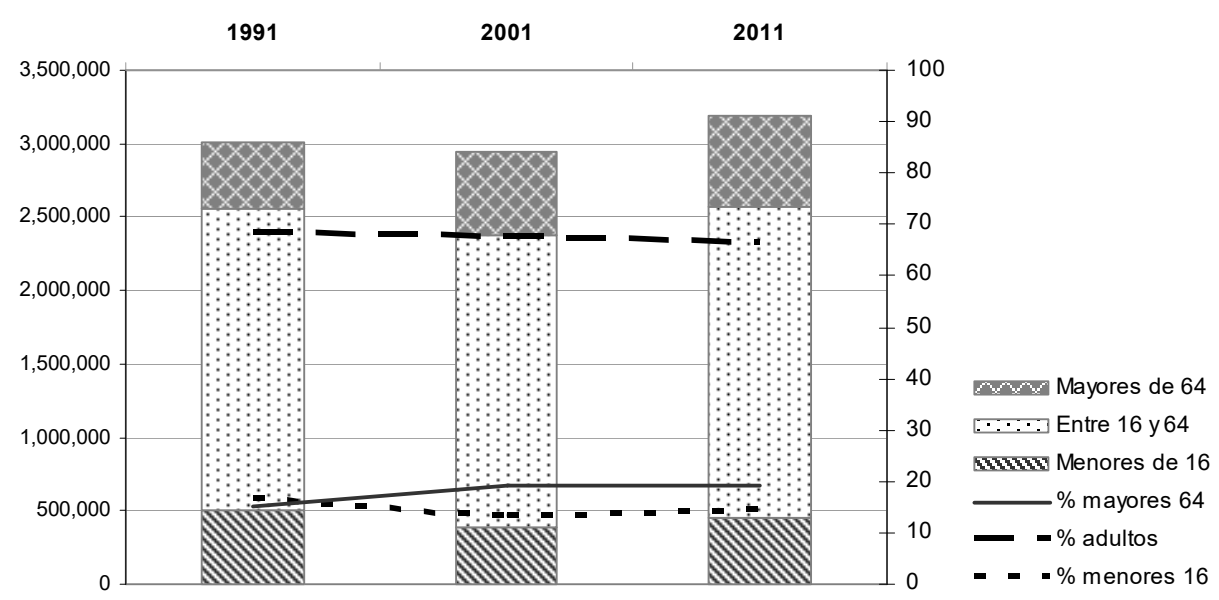

Figura 20. Edad de la población por tramos. Fuente Censos INE 1991, 2001 y 2011

- Motivos de salud. Diversos estudios identifican problemas de salud y un aumento de la mortalidad en invierno asociados a la falta de confort térmico adecuado en las viviendas. Se considera una mayor vulnerabilidad la población mayor de 64 años o menor de 16.

- Amortización de la inversión en rehabilitación energética. En el caso de las personas mayores se consideran además inasumibles las oportunidades de amortización de la rehabilitación mediante el ahorro en las facturas energéticas. Estos modelos de financiación no resultan satisfactorios para convencer a personas de edad avanzada, al margen del perfil sicológico que puedan tener estas personas sobre su realidad.

Se tratan aspectos relativos a la distribución en el municipio de Madrid de estas personas a partir de la base de datos disponible de población más actualizada: el Censo de población y viviendas de 2011 del INE. A partir de la comparación de los datos que aparecen en los Censos de 1991 y 2001 resulta posible observar la evolución de los datos de población (Figura 20). En la Tabla 1 se recogen los datos de población encontrados en los censos consultados para la ciudad de Madrid a partir de los cuales es posible obtener un indicador para localizar aquellas secciones censales con una mayor concentración de población mayor de 64 y menor de 16 años. Este indicador representa aquellas secciones censales cuya población de estas características supera el $150 \%$ del valor medio del municipio. 
Tabla 1. Valores medios de la distribución de la población por edades para el municipio de Madrid.

Fuente Censos INE 1991, 2001 y 2011

\begin{tabular}{|l|l|l|l|l|l|l|}
\hline Censo & Menores de 16 & \% < 16 & Adultos & \% adultos & Mayores de 64 & \% $>64$ \\
\hline 1991 & 502.464 & 16.69 & 2.054 .260 & 68.24 & 453.768 & 15.07 \\
\hline 2001 & 387.724 & 13.19 & 1.984 .185 & 67.52 & 566.814 & 19.29 \\
\hline 2011 & 458.380 & 14.38 & 2.112 .150 & 66.28 & 615.005 & 19.30 \\
\hline
\end{tabular}
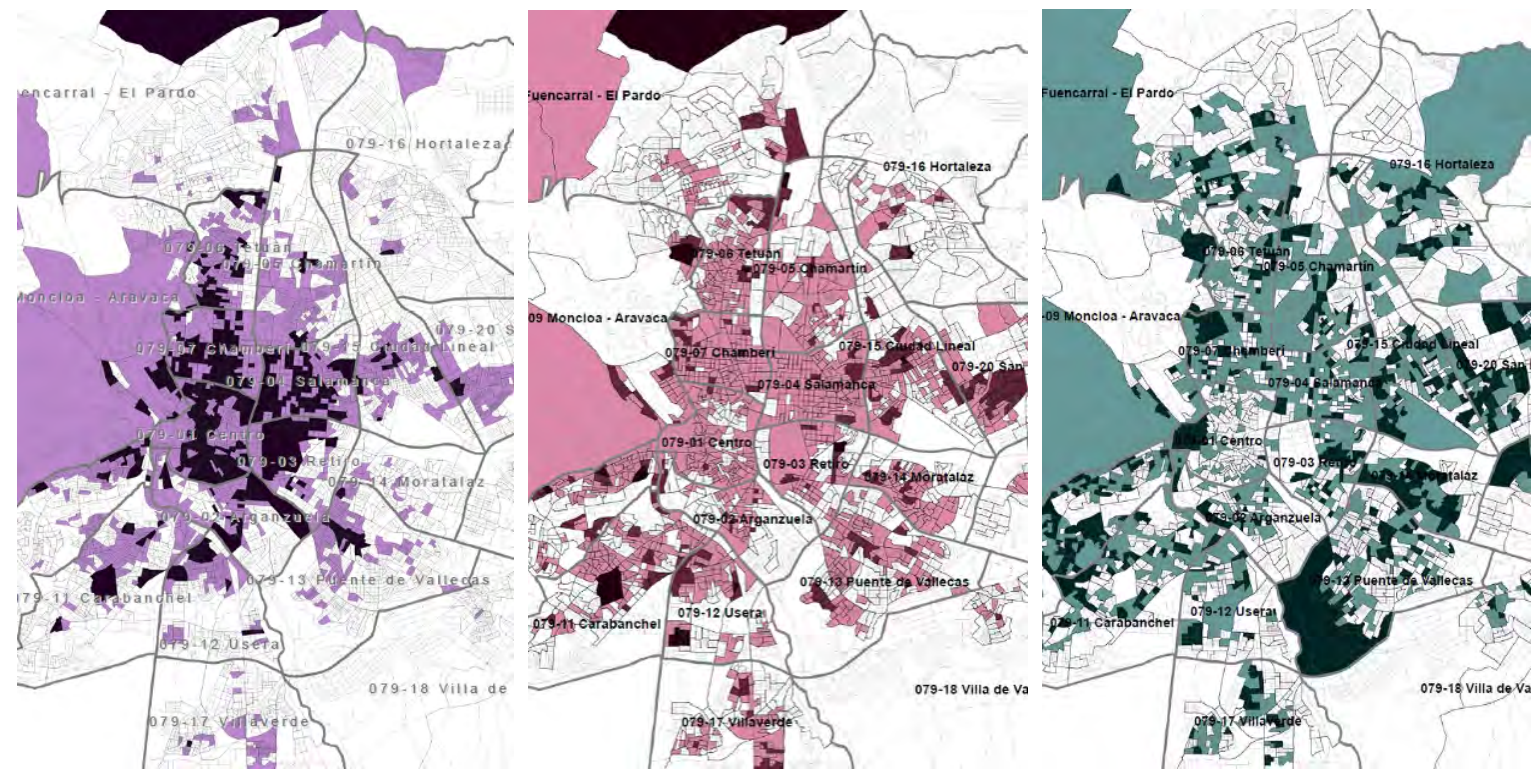

Figura 21. Evolución de la distribución de la población mayor de 65 años. Censos (INE 1991; 2001; 2011)

\section{Población mayor}

La visualización en mapas de la distribución espacial de la población mayor en la ciudad permite analizar la evolución que se ha producido en la concentración de población mayor de 64 años en el municipio de Madrid (Figura 21). Se observa el aumento de concentración de esta población en las zonas de la periferia urbana y un paulatino abandono de la zona centro por parte de la población mayor.

\section{Menores de 16 años}

Para el caso de las personas menores de 16 años (Figura 22), la distribución espacial en la ciudad de Madrid es claramente concéntrica, aumentando al alejarse del centro, a excepción de algunos focos puntuales situados en las primeras periferias, especialmente en la zona sur. Los desarrollos urbanos más recientes, situadas en una segunda periferia de la ciudad en torno a la autopista de circunvalación M40 presentan unos mayores porcentajes de personas menores de edad. 


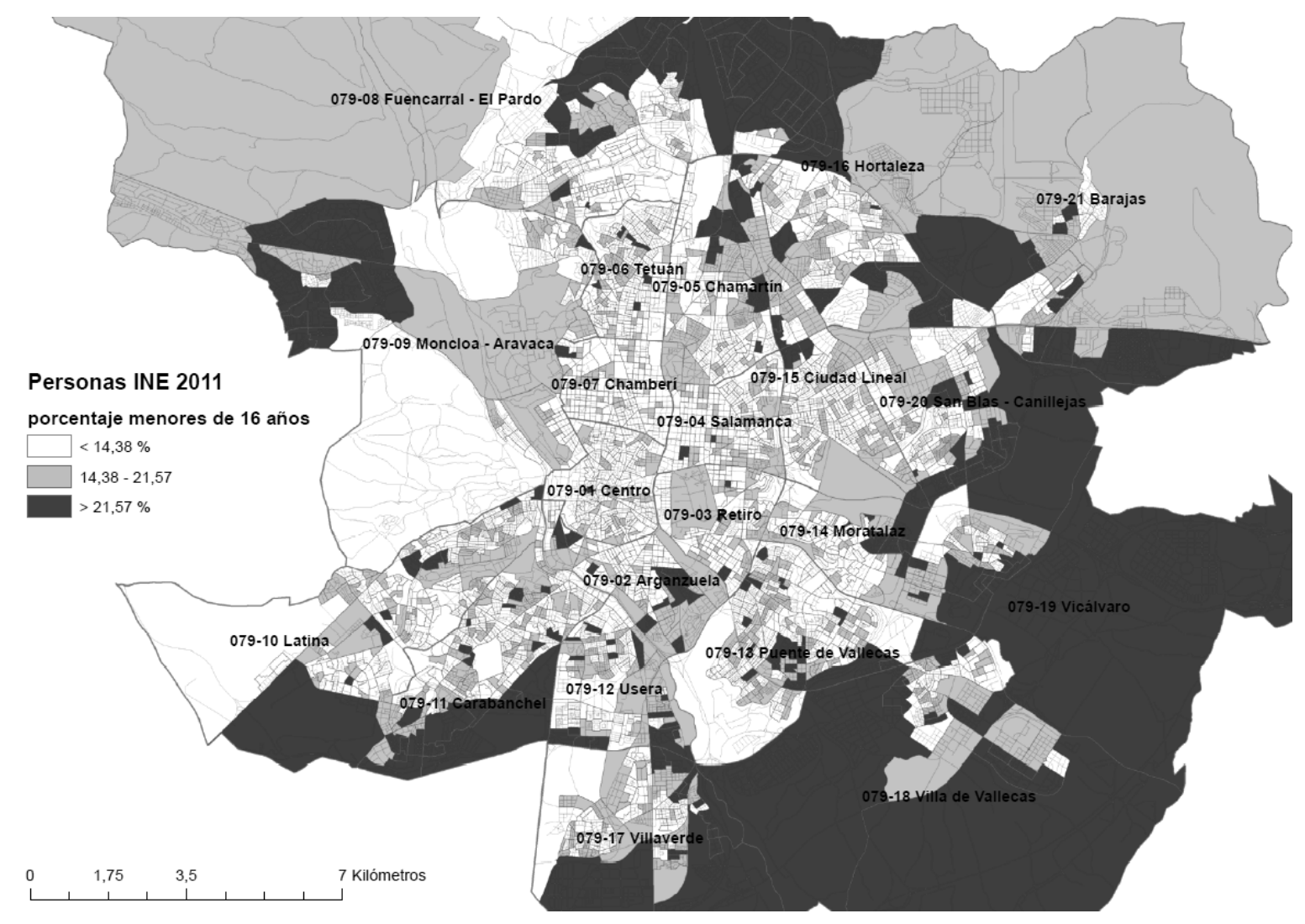

Figura 22. Porcentaje de población menor de 16 años por sección censal en el Censo del INE 2011

\subsubsection{Indicadores asociados a las viviendas}

La escala de la vivienda resulta adecuada para la realización de estudios relativos a la pobreza energética. Como se ha visto, el problema está directamente relacionado con las circunstancias del hogar. Se recogen datos existentes relativos a los hogares de Madrid y se clasifican por su periodo de construcción, factor determinante de la calidad de sus envolventes, poniendo el foco en la edificación realizada durante los años 1940-80. Se analiza también como muchas de estas viviendas fueron realizadas por promoción pública. Además se recogen los datos disponibles en los censos acerca de las instalaciones térmicas de las viviendas y se tienen en consideración las viviendas vacías, puesto que su consumo energético es en principio nulo. Se ha utilizado información obtenida a partir de datos de los Censo INE 2001 o 2011 según disponibilidad.

Del total de las viviendas principales, el 79\% son en régimen de propiedad en 2001 (con pagos pendientes o no) y el 73\% en 2011. En el año 2001 los datos estadísticos registran un 17\% de viviendas principales alquiladas en la ciudad, aumentando en 2011 al 20\% (Tabla 3). 
Tabla 2. Número de viviendas por clases en el municipio de Madrid (INE 2001)

\begin{tabular}{|l|l|l|l|l|l|l|}
\hline Censo & TOTAL & Principales & Alojamientos & Secundarias & Vacías & Otro tipo \\
\hline 2001 & 1.378 .931 & 1.080 .306 & 58 & 106.192 & 178.377 & 13.998 \\
\hline 2011 & 1.530 .955 & 1.320 .530 & - & 57.325 & 153.100 & - \\
\hline
\end{tabular}

Tabla 3. Detalle del régimen de tenencia de vivienda principal en Madrid (INE 2001)

\begin{tabular}{|l|l|l|l|l|l|}
\hline Censo & TOTAL & En propiedad & En alquiler & Cedida & Otra forma \\
\hline 2001 & 1.080 .306 & 848.738 & 178.501 & 23.996 & 29.071 \\
\hline 2011 & 1.320 .530 & 966.565 & 264.130 & - & 89.835 \\
\hline
\end{tabular}

Tabla 4. Distribución de viviendas principales de Madrid por periodo y distrito (INE 2001)

\begin{tabular}{|c|c|c|c|c|c|c|c|c|c|}
\hline DISTRITO & TOTAL & $\begin{array}{l}\text { Anterior } \\
\text { a } 1900\end{array}$ & $\%$ & $\begin{array}{l}1901 \\
\text { a } 1940\end{array}$ & $\%$ & $\begin{array}{l}1941 \\
\text { a } 1980\end{array}$ & $\%$ & $\begin{array}{l}1981 \\
\text { a } 2001\end{array}$ & $\%$ \\
\hline CENTRO & 56.424 & 26.157 & 46,36 & 14.545 & 25,78 & 10.077 & 17,86 & 4.753 & 8,42 \\
\hline ARGANZUELA & 51.954 & 847 & 1,63 & 10.946 & 21,07 & 29.440 & 56,67 & 10.672 & 20,54 \\
\hline RETIRO & 44.845 & 707 & 1,58 & 6.860 & 15,30 & 32.794 & 73,13 & 4.403 & 9,82 \\
\hline SALAMANCA & 55.055 & 1.455 & 2,64 & 14.849 & 26,97 & 35.218 & 63,97 & 2.679 & 4,87 \\
\hline CHAMARTÍN & 49.798 & 157 & 0,32 & 2.486 & 4,99 & 40.171 & 80,67 & 6.712 & 13,48 \\
\hline TETUÁN & 54.242 & 1.103 & 2,03 & 8.577 & 15,81 & 35.620 & 65,67 & 8.662 & 15,97 \\
\hline CHAMBERÍ & 56.820 & 2.972 & 5,23 & 18.131 & 31,91 & 32.104 & 56,50 & 3.092 & 5,44 \\
\hline FUENCARRAL-EL PARDO & 68.083 & 333 & 0,49 & 758 & 1,11 & 48.335 & 70,99 & 18.597 & 27,32 \\
\hline MONCLOA-ARAVACA & 38.848 & 531 & 1,37 & 4.584 & 11,80 & 25.367 & 65,30 & 8.175 & 21,04 \\
\hline LATINA & 89.177 & 200 & 0,22 & 1.180 & 1,32 & 77.500 & 86,91 & 10.148 & 11,38 \\
\hline CARABANCHEL & 78.811 & 29 & 0,04 & 1.617 & 2,05 & 65.103 & 82,61 & 11.718 & 14,87 \\
\hline USERA & 41.799 & 61 & 0,15 & 1.283 & 3,07 & 26.196 & 62,67 & 14.159 & 33,87 \\
\hline PUENTE DE VALLECAS & 81.021 & 992 & 1,22 & 3.582 & 4,42 & 49.277 & 60,82 & 27.022 & 33,35 \\
\hline MORATALAZ & 37.382 & 48 & 0,13 & 575 & 1,54 & 28.644 & 76,63 & 8.096 & 21,66 \\
\hline CIUDAD LINEAL & 81.190 & 159 & 0,20 & 1.012 & 1,25 & 66.323 & 81,69 & 13.476 & 16,60 \\
\hline HORTALEZA & 49.490 & 202 & 0,41 & 567 & 1,15 & 36.155 & 73,06 & 12.469 & 25,19 \\
\hline VILLAVERDE & 44.504 & 96 & 0,22 & 214 & 0,48 & 34.014 & 76,43 & 10.084 & 22,66 \\
\hline VILLA DE VALLECAS & 20.234 & 241 & 1,19 & 62 & 0,31 & 13.312 & 65,79 & 6.565 & 32,45 \\
\hline VICÁLVARO & 18.714 & 25 & 0,13 & 121 & 0,65 & 11.009 & 58,83 & 7.509 & 40,13 \\
\hline SAN BLAS-CANILLEJAS & 49.496 & 73 & 0,15 & 220 & 0,44 & 34.515 & 69,73 & 14.663 & 29,62 \\
\hline BARAJAS & 12.477 & 134 & 1,07 & 188 & 1,51 & 8.465 & 67,84 & 3.659 & 29,33 \\
\hline TOTAL MADRID & 1.080 .364 & 36.522 & 3,38 & 92.357 & 8,55 & 739.639 & 68,46 & 207.313 & 19,19 \\
\hline
\end{tabular}


Para el año 2011, el número total de viviendas era de 1.530.955, se había aumentado el parque de la ciudad en un $11 \%$ con respecto a 2001 , principalmente en el anillo más externo, en los desarrollos conocidos como los PAUs (

Tabla 2). Si tenemos en cuenta las viviendas principales, estos datos arrojaban en 2001 un ratio de 2,7 habitantes por vivienda. Para el censo de 2011 la ocupación había descendido a 2,41 personas por vivienda. Los datos estadísticos indican que el sector residencial de la ciudad de Madrid está organizado en edificios multifamiliares. En el año 2001, del total de las 1.080.306 viviendas familiares principales que existían, 46.953 eran unifamiliares, lo que representa tan solo un 4\% de los hogares (INE 2001).

\subsubsection{Viviendas por periodo de construcción}

Se han recopilado datos del número de viviendas construidas por periodo de construcción, poniendo el foco en las construidas durante el periodo de 1940 a 1980 por tratarse de las más ineficientes (Apartado 1.1.3). Se analiza su distribución espacial en el municipio de Madrid.

En el año 2001, el 68 \% (739.639 Uds.) de las viviendas principales (1.080.206 Uds.) se habían construido durante este periodo, según la distribución que figura en la Tabla 4, en valores absolutos y porcentaje respecto del total. La mayor parte de las viviendas de Madrid fueron edificadas en la década de los 60. Los distritos con mayor número de viviendas son Latina, Carabanchel, Puente de Vallecas y Ciudad Lineal. Los distritos con

mayor porcentaje de viviendas construidas durante los años 40-80 son Latina y Moratalaz. En el mapa aparecen representados estos valores de forma gráfica para cada distrito de Madrid (Figura 23). 


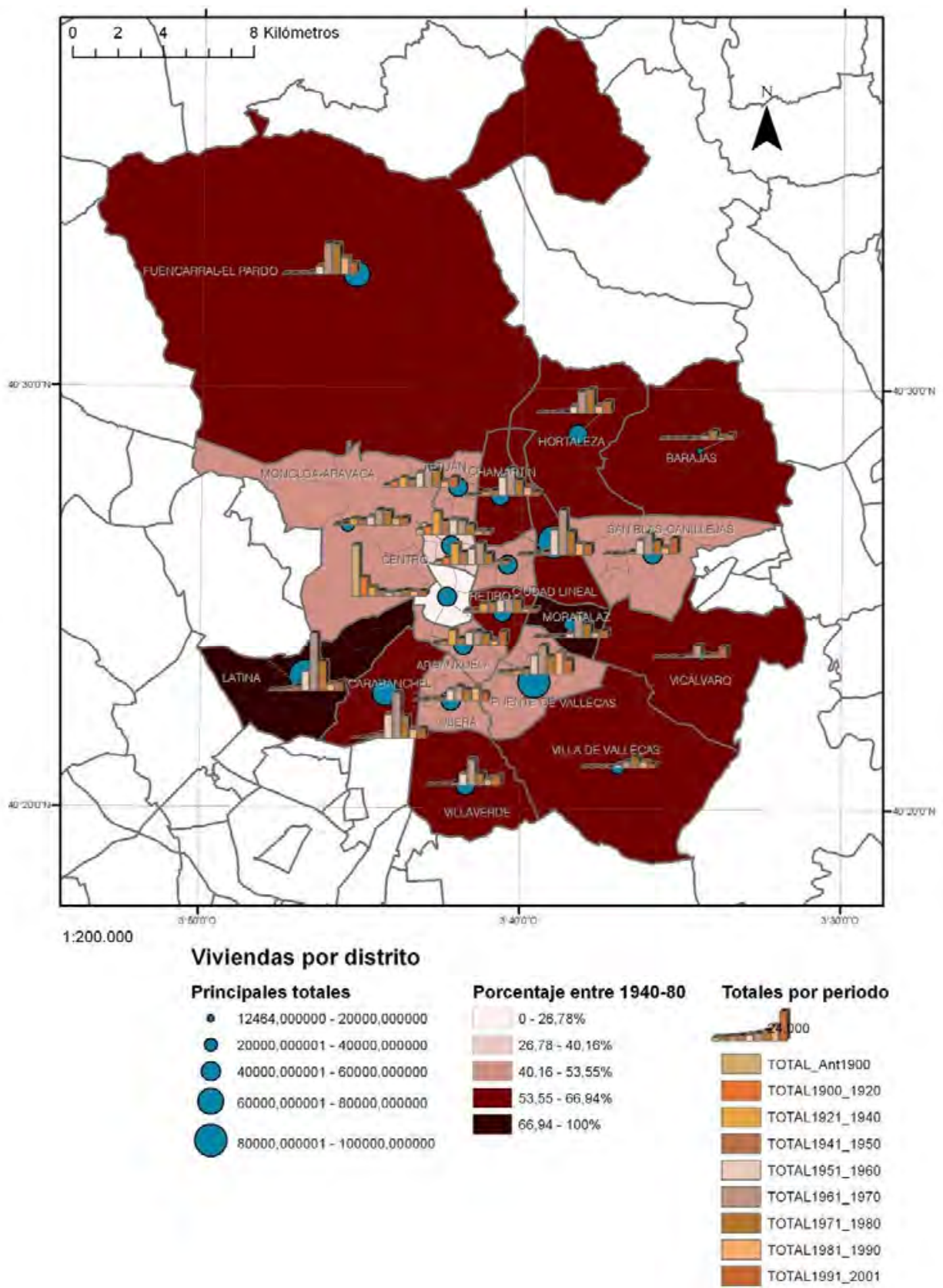

Figura 23. Distribución de viviendas por distritos y periodo de construcción en el municipio de Madrid. Datos INE 2001

\section{Viviendas anteriores a 1900}

En Madrid en el año 2001 el 3,38\% de las viviendas estaban situadas en edificios construidos antes del año 1900 (36.522 Uds.). De ellas, 26.157 (el 72\%) estaban en el distrito centro. El resto de las viviendas antiguas se distribuyen principalmente en Chamberí (2.972 Uds., 8\%). Salamanca (1.455 Uds.), Tetuán (1.103 Uds.), Puente de Vallecas (992 Uds.), Arganzuela (847) y Retiro (707) todavía conservaban algunas viviendas antiguas en 2001, pero siempre representan una cantidad inferior al $5 \%$ del 
total de viviendas construidas antes de 1900. En el resto de distritos la presencia de viviendas antiguas es anecdótica y son prácticamente inexistentes en Carabanchel, Usera, Moratalaz Villaverde, Vicálvaro y San Blas-Canillejas.

\section{Viviendas construidas durante el periodo de 1901 a 1940}

Del periodo de 1901 a 1940 se conservaban 92.357 viviendas en 2001 (un 8,55\% del total). Estas fueron construidas en los distritos Centro (16\%), y de los ensanches: Arganzuela (12\%), Salamanca (16\%) y Chamberí (20\%). Retiro (7 \%) y Tetuán (9\%) también conservan algunos desarrollos de esa época. Si se contemplan los dos periodos anteriores, en 2001 se contaba con 128.879 viviendas construidas antes de la Guerra Civil Española (12\% del total). La presencia de viviendas anteriores a la Guerra Civil es prácticamente despreciable en los distritos de la periferia.

Viviendas construidas durante el periodo de 1941 a 1980

Las viviendas del periodo 1941 a 1980, construidas en su mayoría durante la dictadura franquista, eran 739.639 unidades y suponían un $68,46 \%$ de las viviendas totales de Madrid en el año 2001. Este grupo de viviendas se sitúa principalmente en la periferia y presenta en general una baja calidad constructiva y térmica. A excepción del distrito centro, todos los demás distritos tienen más de un $50 \%$ de viviendas construidas en este periodo, y los distritos de Retiro, Chamartín, Fuencarral-El Pardo, Latina, Carabanchel, Moratalaz, Ciudad Lineal, Hortaleza, Villaverde y San Blas-Canillejas superan la media de la ciudad. La mayor concentración de viviendas de ese periodo en la ciudad se encuentra en el distrito de Latina que contiene el $10,48 \%$ de las unidades construidas.

\section{Viviendas construidas durante el periodo 1981 a 2001}

Las viviendas construidas después de la transición política suponían el 19'19\% de las viviendas de la ciudad en el año 2001, con 207.313 Uds. Se entiende que la calidad de la construcción de los edificios construidos en este periodo mejora desde el punto de vista del comportamiento térmico al incorporar las mejoras en la envolvente introducidas por la norma básica NBE CT 79. En la ciudad de Madrid, el distrito de Puente de Vallecas es el que cuenta con un mayor número de viviendas de este periodo, seguido de Fuencarral-El Pardo. 


\subsubsection{Vivienda de promoción pública producida durante el periodo 40-80}

Las áreas de promoción pública desarrolladas durante el franquismo, y especialmente las ubicadas en periferia, resultan de interés puesto que se trata de un parque edificado con pocos recursos y malas calidades constructivas que resultan en envolventes de bajo desempeño térmico (Oteiza, l. et al. 2018). Además de esto se considera que el hecho de haber sido promovidas por medios públicos confiere una responsabilidad al estado en las consecuencias que produce la ineficiencia energética desde su planeamiento. Sus problemas se han ido haciendo patentes a partir de la crisis energética de los años 70 , cuando todavía se estaban produciendo y actualmente puede representar el parque con mayores dificultades para el cumplimiento de las exigencias europeas en materia de eficiencia energética de la edificación.

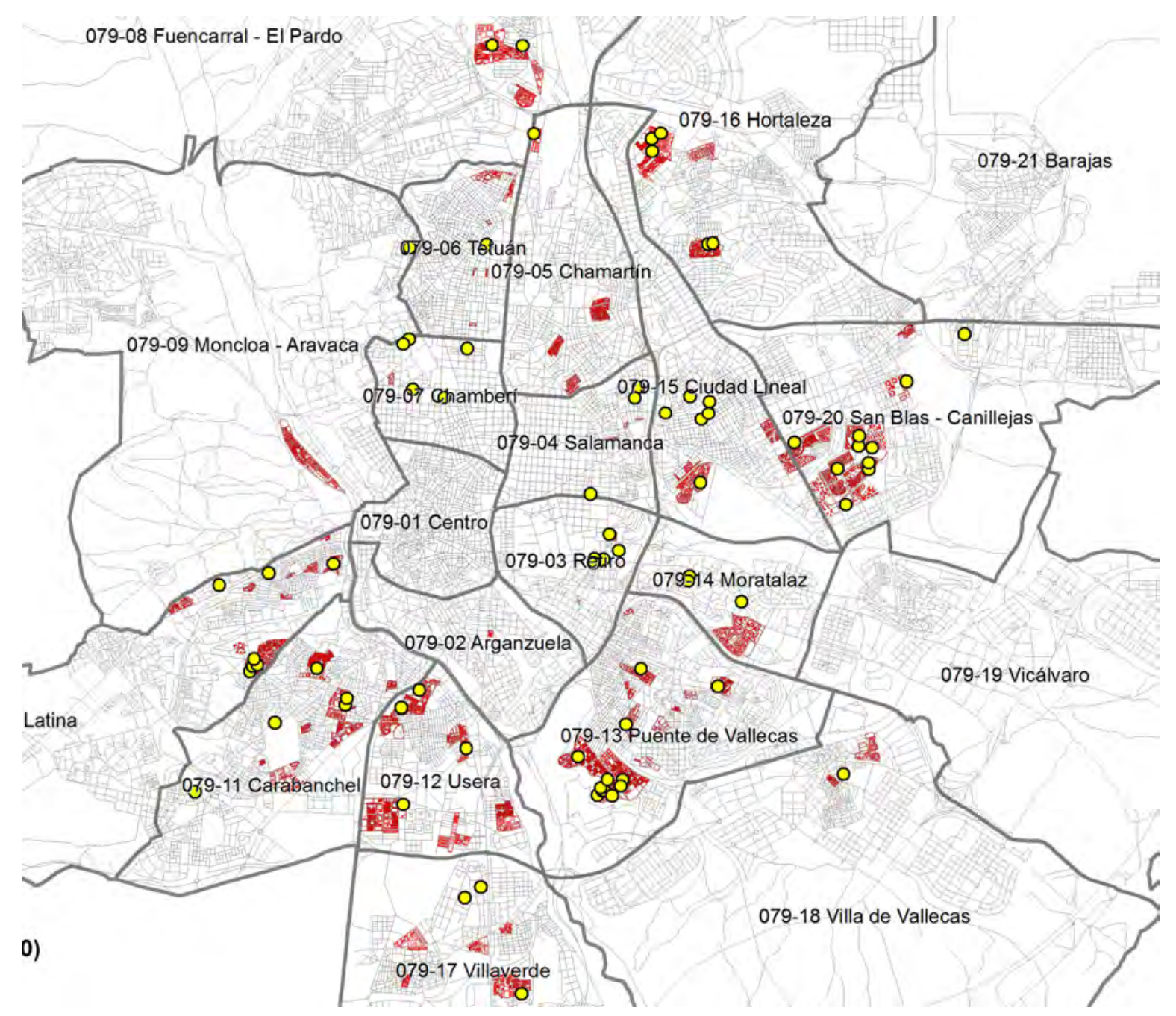

Figura 24. Muestra del proyecto REFAVIV (Oteiza, 2018) y barrios de promoción oficial (Moya 1983) 
Para la identificación de las promociones de vivienda de protección pública existentes producidas durante el periodo $40-80$ se ha utilizado la información contenida en el libro de Moya González "Barrios de promoción oficial, Madrid, 1939-1976: La política de promoción pública de vivienda" (1983), que abarca una muestra significativa de las principales promociones que se realizaron durante la dictadura franquista. En el plano (Figura 24) aparecen representadas en rojo las parcelas que contiene la muestra publicada. Se comprueba que el grueso está situado principalmente en áreas de la periferia del municipio de Madrid (Luis Moya González, Ezquiaga, y Inglés Musoles 1983). Otra fuente relevante de datos acerca de la producción pública de vivienda es el proyecto REFAVIV (Oteiza et al. 2016). En él se analizan las características de una muestra de 75 promociones de vivienda de protección pública en el municipio de Madrid. En el plano aparecen situados mediante puntos, coincidiendo en su gran parte con la localización de las promociones referenciadas (Oteiza, I. et al. 2018).

\subsubsection{Instalaciones térmicas}

Una vez localizadas las bolsas de viviendas ineficientes, en edificios con envolventes de mala calidad térmica, se pasa a incluir información acerca de las instalaciones de acondicionamiento térmico. La información estadística más detallada que ofrece el censo acerca de las instalaciones de las viviendas corresponde al año 2001. Se ha encontrado información acerca de las fuentes de energía y la idoneidad de las instalaciones de calefacción, de agua caliente sanitaria mediante producción centralizada y de la disponibilidad de instalaciones de refrigeración en los hogares.

\section{Viviendas sin calefacción}

En Madrid, en el año 2001, aproximadamente el 80\% de las viviendas (215.489 Uds.) tenían una instalación de calefacción adecuada, ya sea comunitaria o individual. No se han considerado instalaciones de calefacción adecuadas las que consisten en radiadores individuales conectados a la red eléctrica, ni braseros o aparatos de este tipo. Según los datos del Censo de 2011, las viviendas sin calefacción serían 189.810 Uds. (un 12\% menos). El equipamiento de las viviendas registra una tendencia al alza. 
Para cada sección censal se recopila el porcentaje de viviendas que carecen de una instalación de calefacción o las viviendas con instalación inadecuada. En la Figura 25 aparecen como zonas frías, en color azul, aquellas secciones censales que tienen un mayor porcentaje de viviendas sin instalación de calefacción. Se puede observar que las viviendas sin calefacción se ubican principalmente en arco sur, en el centro, en el corredor que va desde el centro hacia el norte y en otras promociones periféricas coincidentes en gran parte con los desarrollos de vivienda social construidos durante el periodo 40-80. Además se dibuja una coincidencia bastante exacta con los barrios vulnerables definidos por Hernández Aja et al.

A pesar de su falta de actualización, en este estudio se han utilizado los datos de disponibilidad de calefacción del Censo de 2001 por ser el único que presenta relación con las fuentes de energía utilizadas para abastecer este servicio. No se han encontrado fuentes más recientes que presenten el nivel de desagregación a la escala de la sección censal necesario para el desarrollo del presente trabajo. No ha quedado otro remedio que asumir el error del 12\% que refleja la actualización de los datos de 2011.

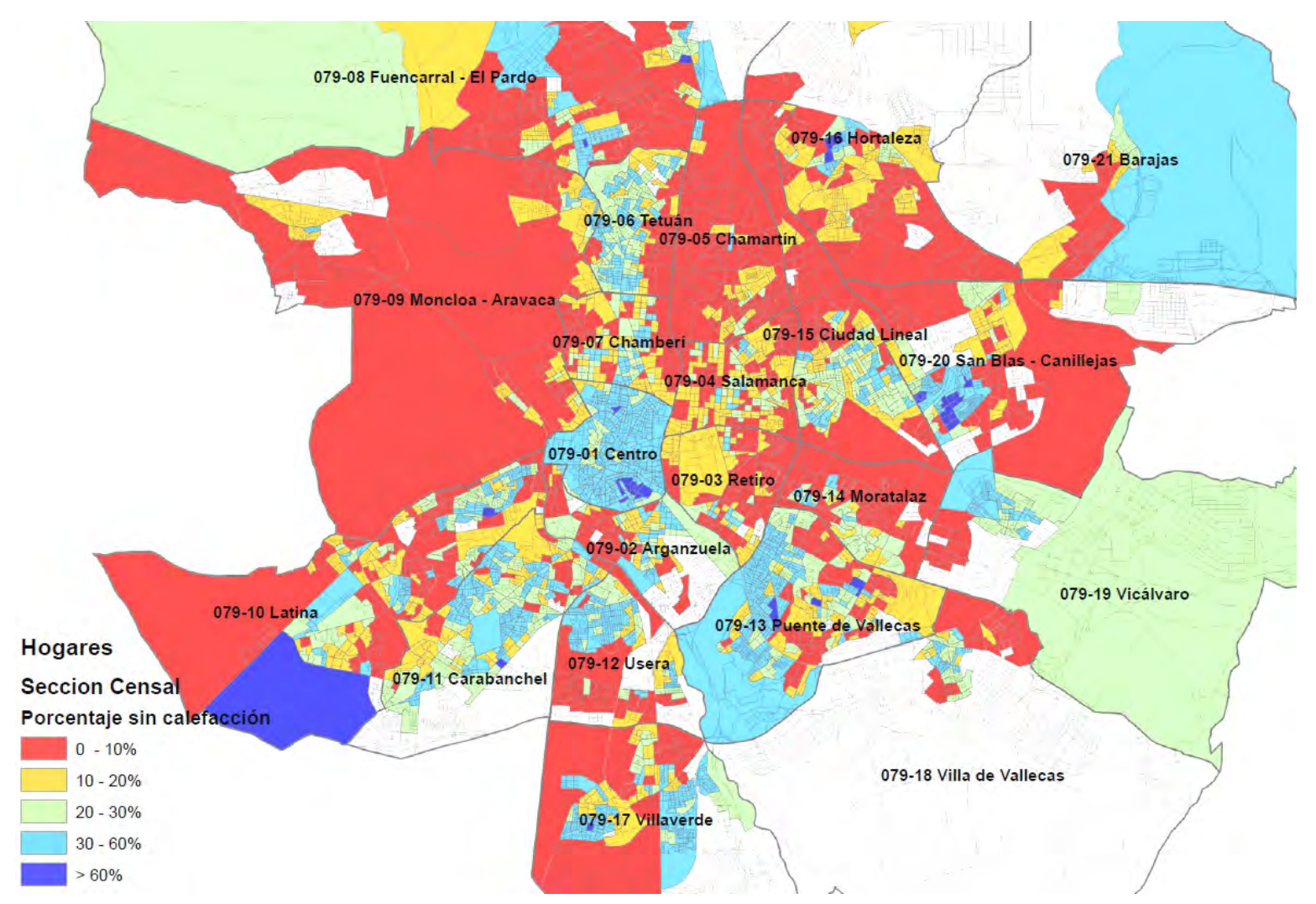

Figura 25. Porcentaje de viviendas sin calefacción por sección censal (Fuente: Censo INE 2001) 
Equipamiento de instalación de agua caliente sanitaria centralizada

El servicio de agua caliente sanitaria mediante caldera centralizada supone el $6 \%$ de los sistemas de ACS de España. Hay un claro predominio del tipo de sistemas individuales frente a los sistemas colectivos, no existiendo, por lo general, multiequipamiento (IDAE 2011b). El 73 \% de estos equipamientos se concentran en la zona continental del país. Se considera que un edificio tiene agua caliente central cuando dispone de una instalación fija y común que suministra agua caliente a todas o la mayor parte de las viviendas que contiene.

En el caso del municipio de Madrid, la media de edificios de vivienda que cuenta con instalación centralizada de ACS se sitúa en un 28,01\% en 2001 (134.873 Uds.), según la distribución espacial que aparece en la Figura 26. Se puede observar que la mayor parte de las viviendas que cuentan con este servicio se concentran en el arco norte y Retiro, excepto áreas de Tetuán y Hortaleza.

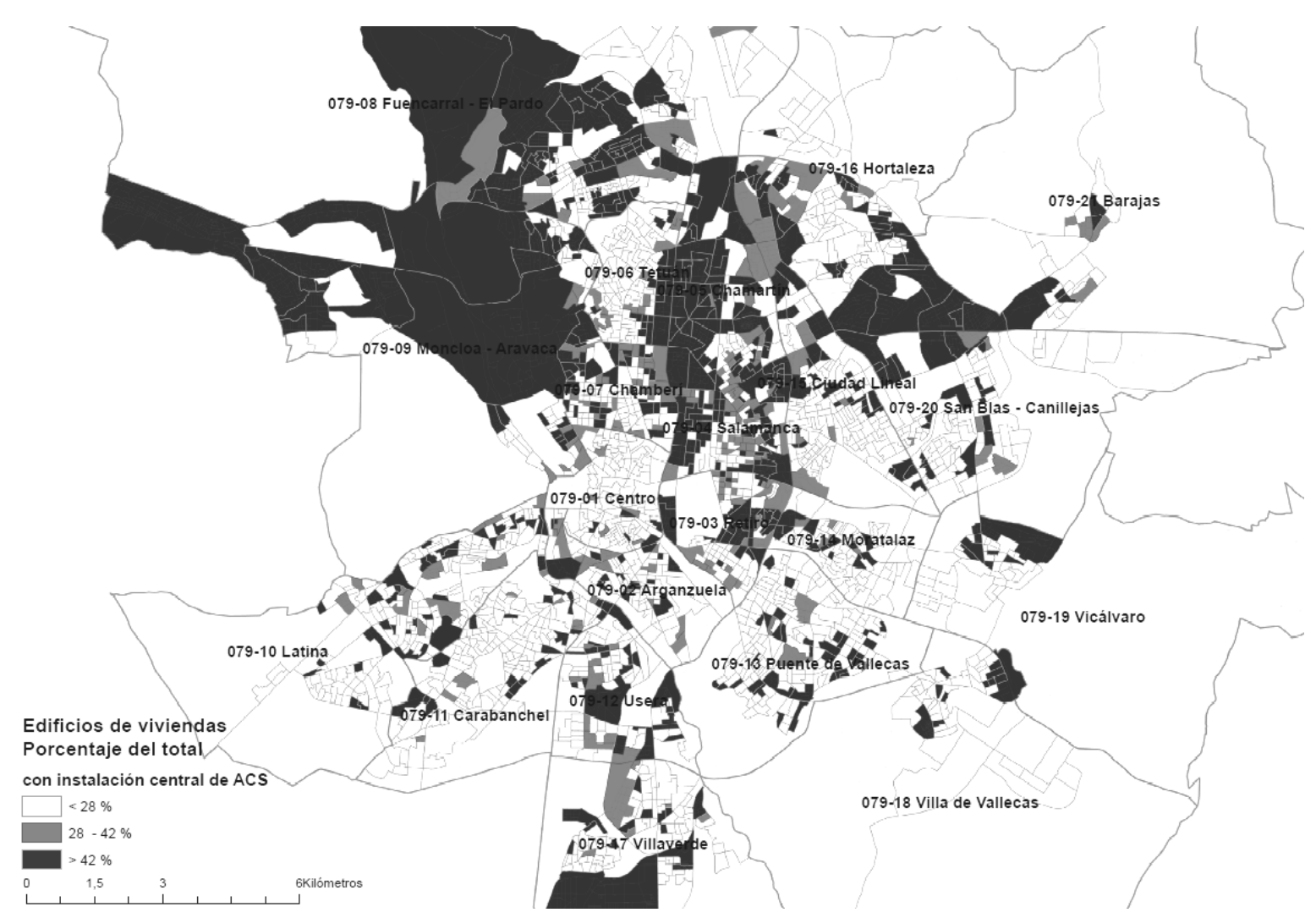

Figura 26. Porcentaje de edificios de viviendas con instalación de ACS centralizada por sección censal (Fuente: Censo INE 2001) 


\section{CAPÍTULO 1. ESTADO DEL ARTE}

\section{Existencia de instalación de refrigeración en las viviendas}

La instalación de sistemas de refrigeración ha pasado de ser un indicador de lujo en las viviendas a popularizarse paulatinamente. Se considera interesante analizar este indicador puesto que las perspectivas de cambio climático indican un incremento de temperaturas que puede implicar la necesidad de utilización de sistemas de refrigeración, que hasta este momento no han sido necesarios (Luxán García de Diego, Gómez Muñoz, y López Román 2015).

En el año 2001 la implantación de instalaciones de refrigeración en las viviendas familiares convencionales principales de Madrid era del 23,41\% de media (Figura 27). Es muy probable que este valor haya aumentado desde el último censo de muestra universal. Los datos del Censo de 2011 no incluyen esta información, pero si comparamos con los datos de 1991, el número de viviendas con aire acondicionado se duplicó entre 1991 y 2001 señalando una tendencia creciente en el uso de sistemas de refrigeración que implica el incremento del consumo de electricidad (Luxán García de Diego, Gómez Muñoz, y López Román 2015). Se observa una mayor implantación en el arco norte, con Chamartín a la cabeza.

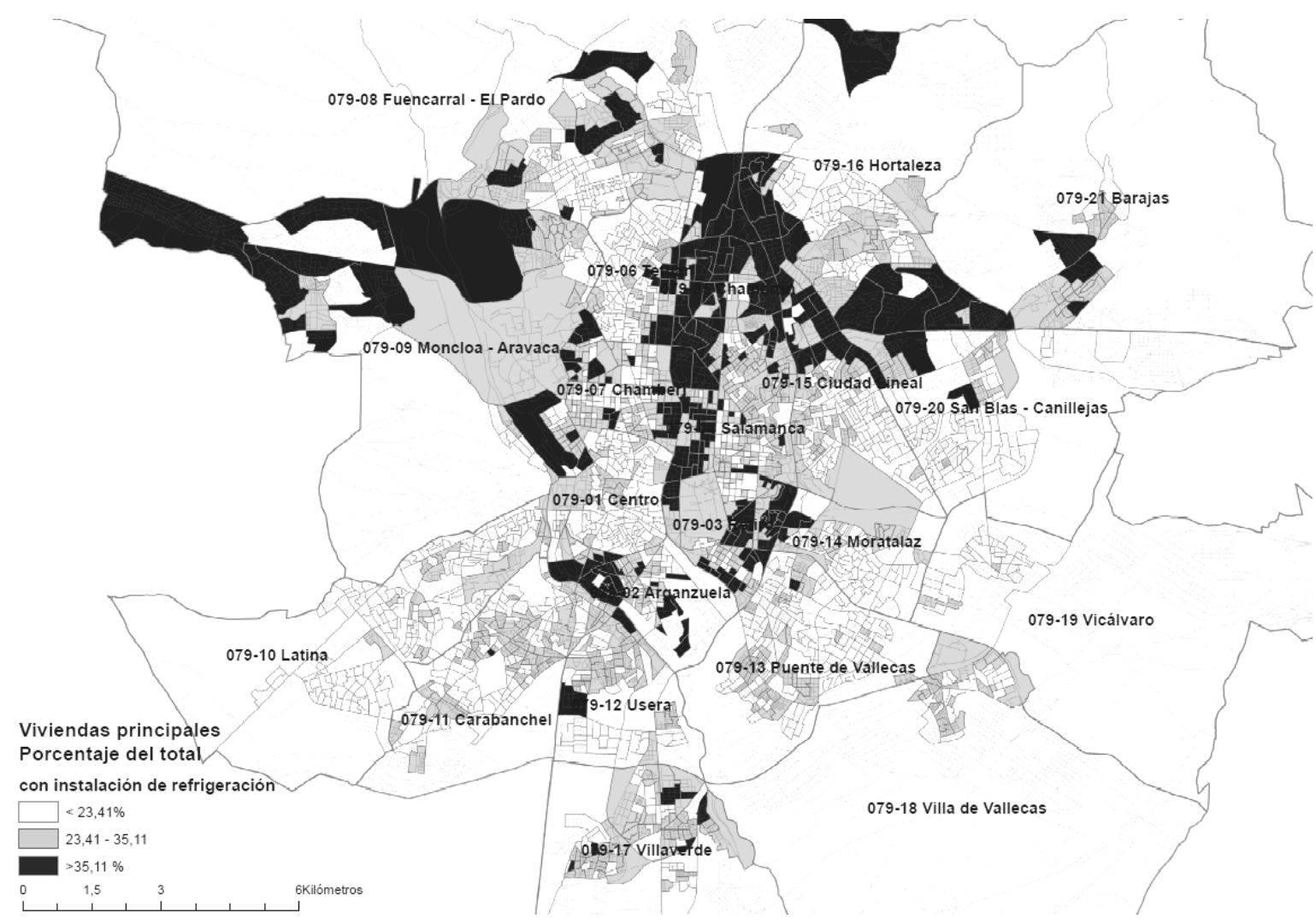

Figura 27. Porcentaje de viviendas con refrigeración por sección censal (Fuente: Censo INE 2001) 


\subsubsection{La vivienda vacía}

En los barrios en los que la vivienda vacía suponga un porcentaje importante de las viviendas principales, su análisis y cuantificación pueden ser determinantes a la hora de planificar la recuperación de edificios. La concentración de viviendas vacías puede tener implicaciones energéticas en múltiples aspectos de la regeneración urbana, tanto a la hora de plantear operaciones de rehabilitación de edificios como en las previsiones de consumos energéticos y periodos de amortización de la renovación térmica.

Los expertos en mercado inmobiliario consideran razonable y conveniente que exista un stock técnico (entre 3 y 5 por ciento) de viviendas desocupadas que facilite un más ágil funcionamiento de mercado (Vinuesa 2008). No obstante en Madrid se llevan superando estos valores al menos desde el año 1970 (Bahamonde Magro y Otero Carvajal 1989). En España la primera crisis inmobiliaria, en los años 70, comienza a repercutir en un momento de tasa de inflación más elevada, espectacular incremento del déficit comercial, alza de costes, notable crecimiento del déficit público, mayor intensidad en la caída de los sectores industriales y existencia de retraso en la toma de medidas correctoras. Los datos de viviendas vacías registrados en los tres censos aparecen representados en la Tabla 5 y Figura28.

En este caso, es resultado fue una importantísima caída de la demanda, debida a la moderación del crecimiento demográfico, a la reducción de los ingresos familiares reales y a los efectos del retraso de la independencia de los jóvenes. En 1981 había en Madrid 242.000 viviendas vacías (el 14\% del parque provincial frente el 9\% de 1970). (Bahamonde Magro y Otero Carvajal 1989).

A pesar de que han existido numerosas imprecisiones en el cómputo estadístico de las viviendas vacías, la información revela una situación anómala, con proporciones que multiplican varias veces el stock técnico deseable (Vinuesa 2008). Según afirma José Manuel Naredo, la metodología del Censo de 2011 ha contribuido a minimizar las viviendas infrautilizadas e inflar las principales, resultando funcional a la mitología inmobiliaria en vigor orientada a justificar el crecimiento y encubrir los excesos de la burbuja inmobiliaria (ignorando el uso ineficiente del stock) (Naredo 2014). 
Tabla 5. Viviendas vacías en el municipio de Madrid y su porcentaje con respecto de las principales (Censo INE 1991, 2001 y 2011)

\begin{tabular}{|l|l|l|l|}
\hline Censo & viviendas principales & viviendas vacías & \% vacías \\
\hline 1991 & 963.909 & 146.192 & 15,17 \\
\hline 2001 & 1.080 .306 & 178.377 & 16,51 \\
\hline 2011 & 1.320 .530 & 153.100 & 11,59 \\
\hline
\end{tabular}

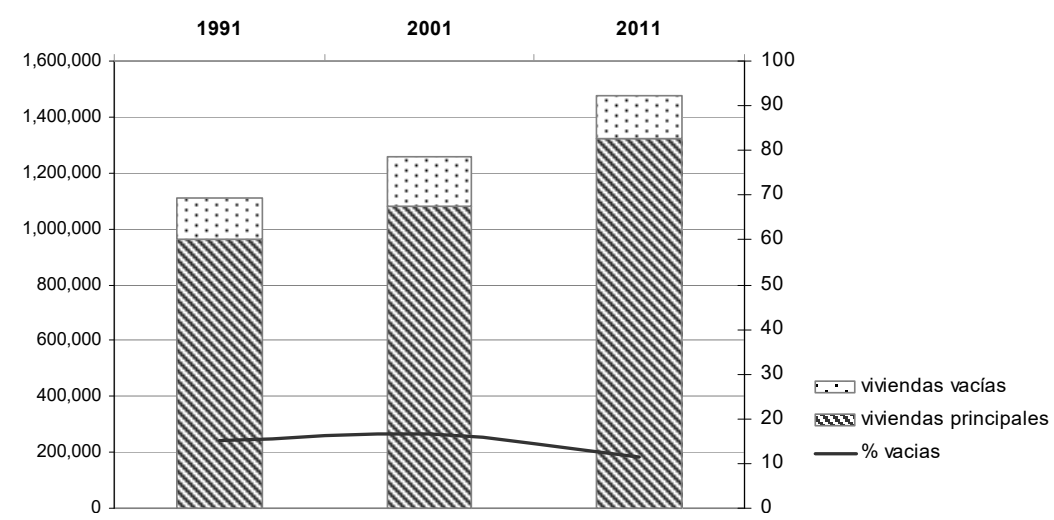

Figura 28. Viviendas vacías en el municipio de Madrid y su porcentaje con respecto de las principales (Censo INE 1991, 2001 y 2011)

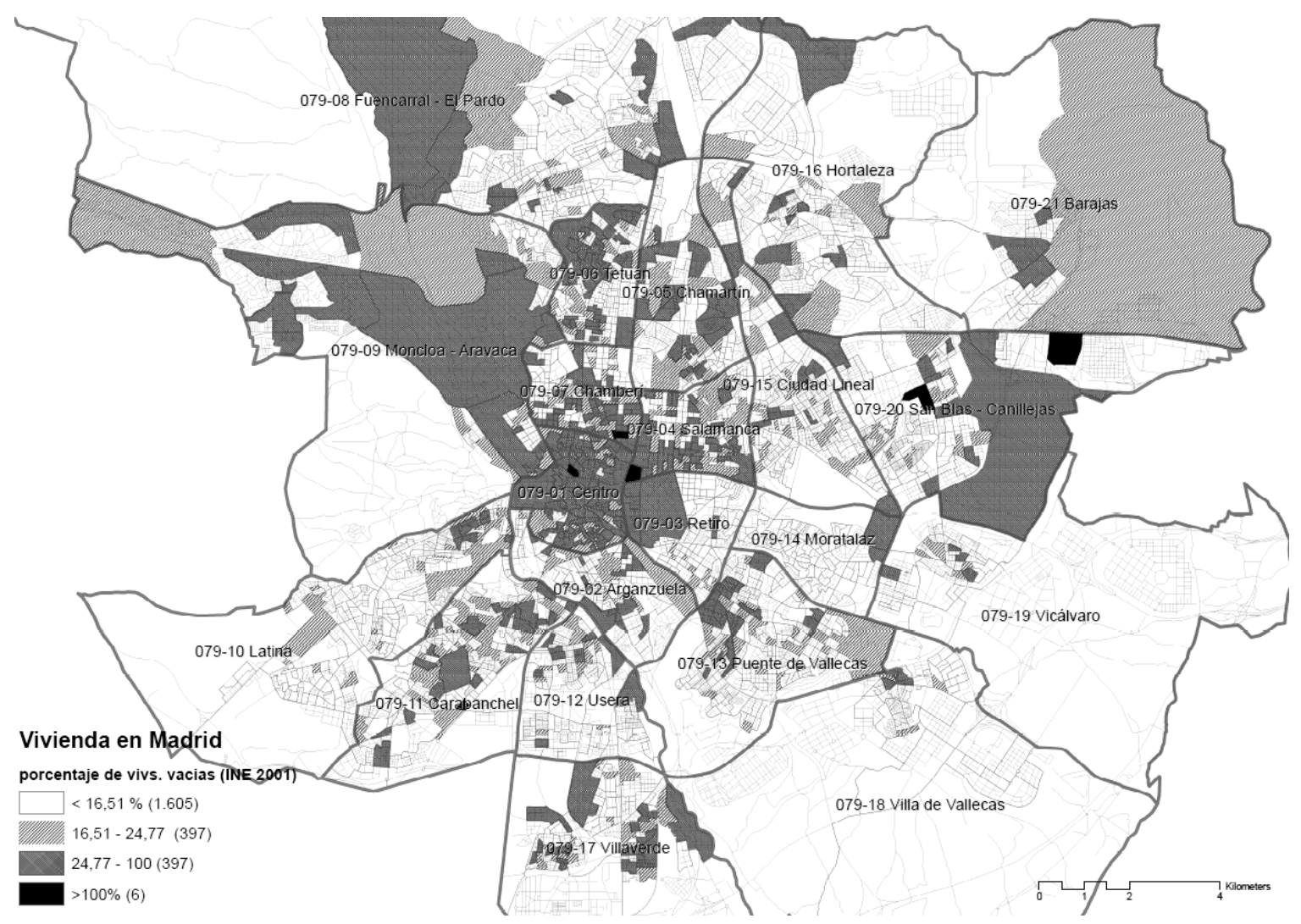

Figura 29. Porcentaje de viviendas vacías por sección censal (Fuente: Censo INE 2001) 
En 2001 el distrito con un mayor número de viviendas vacías era Centro (Figura 29). Los distritos con un menor número de viviendas vacías eran Retiro, Moratalaz, Villa de Vallecas, Vicálvaro y Barajas. La mayor proporción de vivienda vacía se encontraba en el distrito Centro y los valores menores de porcentaje de vivienda vacía, en los distritos de la periferia urbana. La distribución de la densidad de vivienda vacía era concéntrica, disminuyendo a medida que nos alejamos del centro, y parece afectar más al arco norte. Esta distribución espacial de la vivienda vacía resulta coherente con la tendencia descrita por autores especialistas en el estudio del parque de viviendas, indicando que es acaparada por la población de más renta, quedando el sector de la población más desfavorecido al margen del acceso a la vivienda (Rodríguez Alonso 2010).

\subsubsection{La edificación residencial}

Para el planeamiento de operaciones de rehabilitación energética de barrios se debe utilizar el edificio como unidad de actuación para solucionar los problemas de ineficiencia de todas las viviendas que lo componen, principalmente mediante la mejora de toda su envolvente. Se ha recopilado información estadística acerca de la antigüedad del parque edificado, de su estado de conservación y de su accesibilidad.

\subsubsection{Edificios construidos durante el periodo de 1940 a 1981}

El año de construcción de los edificios va a determinar en gran medida sus características constructivas. Como se ha estudiado, los edificios multifamiliares de viviendas producidos durante el periodo de 1940 a 1979 serían los mayores sumideros de energía de la edificación residencial española (Dalle et al. 2010; Albert Cuchí, Sweatman, y GTR 2012; WWF et al. 2017). Los estudios existentes de caracterización del parque residencial coinciden en que, a pesar de no contar con aislamiento térmico, las viviendas construidas en el periodo anterior a 1940 contienen en general soluciones constructivas tradicionales en sus envolventes, con una mejor respuesta bioclimática (Gómez Muñoz 2014; Ministerio de Fomento 2014). Sus fachadas, por ejemplo suelen estar construidas utilizando soluciones de mayor espesor y con mayor masa que las de los periodos posteriores, lo que hace que funcionen como acumulador térmico capaz de amortiguar las oscilaciones térmicas del clima exterior. 


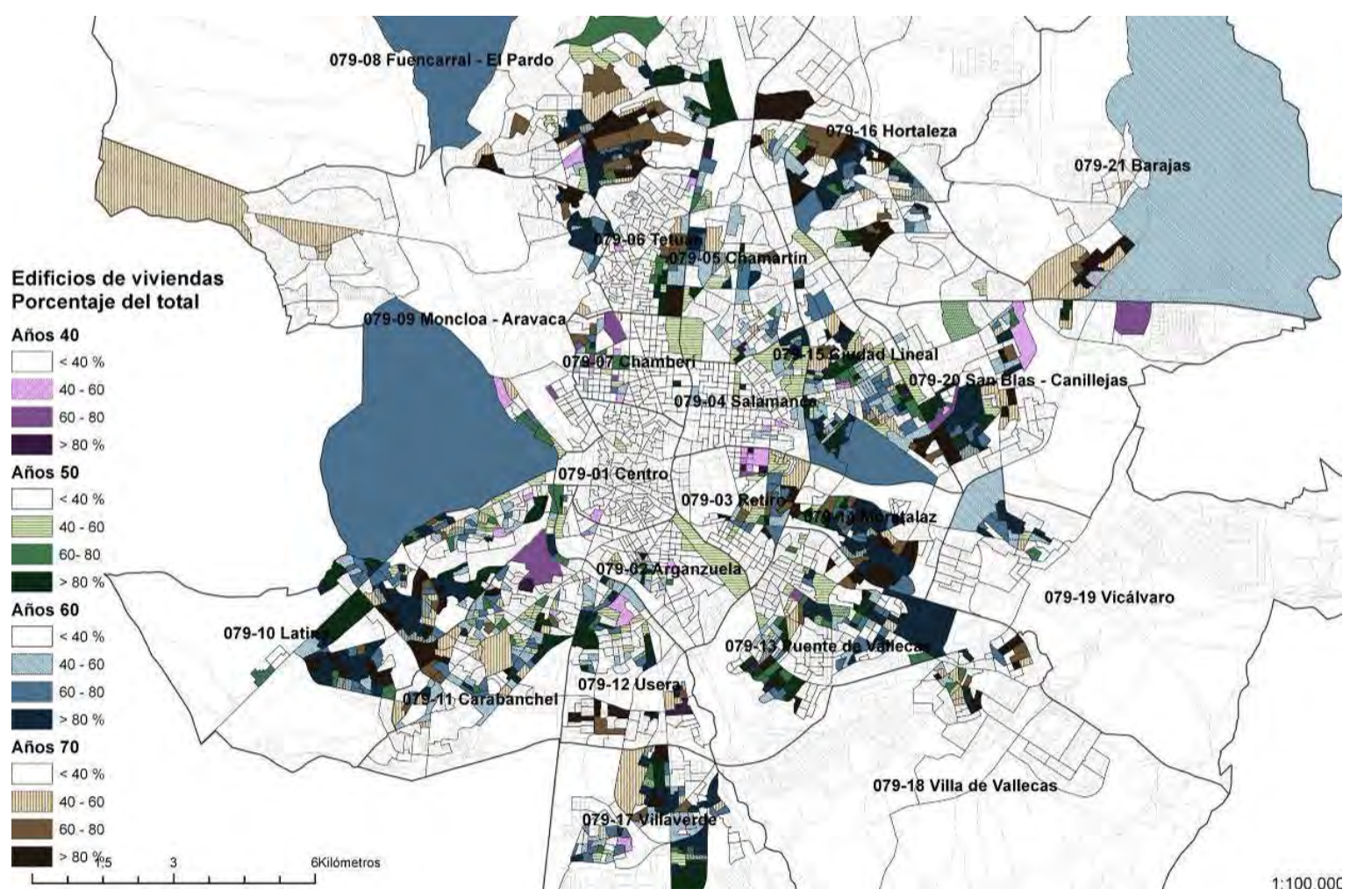

Figura 30. Edificios destinados a viviendas construidos durante el periodo 1940-80. Datos INE 2001

Se puede observar en la Figura 30, que durante este periodo se desarrolló de manera vertiginosa lo que ha pasado a ser la primera periferia de la ciudad, principalmente en un círculo concéntrico situado de forma contigua y por el exterior de la autopista de circunvalación M30, que también fue desarrollada durante ese periodo.

El número de edificios destinados principalmente a vivienda construidos durante el periodo de estudio (1940-1979) suponían, en el año 2001, el 62\% del total de la edificación residencia (Tabla 6)l. En el Censo de población y viviendas de 2011, tras la segunda burbuja inmobiliaria española de los años 90, estos edificios representaban el $56 \%$ del parque. Los edificios anteriores a 1979 suponían el 68\% sobre el total.

Tabla 6. Numero de edificios destinados principalmente a viviendas en el municipio de Madrid por periodos de construcción (Censo INE 2011)

\begin{tabular}{|l|l|l|l|l|l|l|l|l|l|l|}
\hline Total & $\begin{array}{l}\text { Antes } \\
\text { de } \\
\mathbf{1 9 0 0}\end{array}$ & $\begin{array}{l}\text { De } \\
\mathbf{1 9 0 0} \\
\mathbf{1 9 2 0}\end{array}$ & $\begin{array}{l}\text { De } \\
\mathbf{1 9 2 1} \\
\mathbf{1 9 4 0}\end{array}$ & $\begin{array}{l}\text { De } \\
\mathbf{1 9 4 1} \\
\mathbf{1 9 5 0}\end{array}$ & $\begin{array}{l}\text { De 1951 } \\
\text { a } 1960\end{array}$ & $\begin{array}{l}\text { De 1961 } \\
\text { a 1970 }\end{array}$ & $\begin{array}{l}\text { De 1971 } \\
\text { a 1980 }\end{array}$ & $\begin{array}{l}\text { De 1981 } \\
\text { a 1990 }\end{array}$ & $\begin{array}{l}\text { De 1991 } \\
\text { a 2001 }\end{array}$ & $\begin{array}{l}\text { de 2001 } \\
\text { a 2011 }\end{array}$ \\
\hline 129.085 & 3.600 & 3.480 & 7.854 & 8.089 & 21.939 & 25.572 & 16.958 & 13.273 & 17.307 & 11.013 \\
\hline $100 \%$ & $2,79 \%$ & $2,70 \%$ & $6,08 \%$ & $6,27 \%$ & $17,00 \%$ & $19,81 \%$ & $13,14 \%$ & $10,28 \%$ & $13,41 \%$ & $8,53 \%$ \\
\hline
\end{tabular}




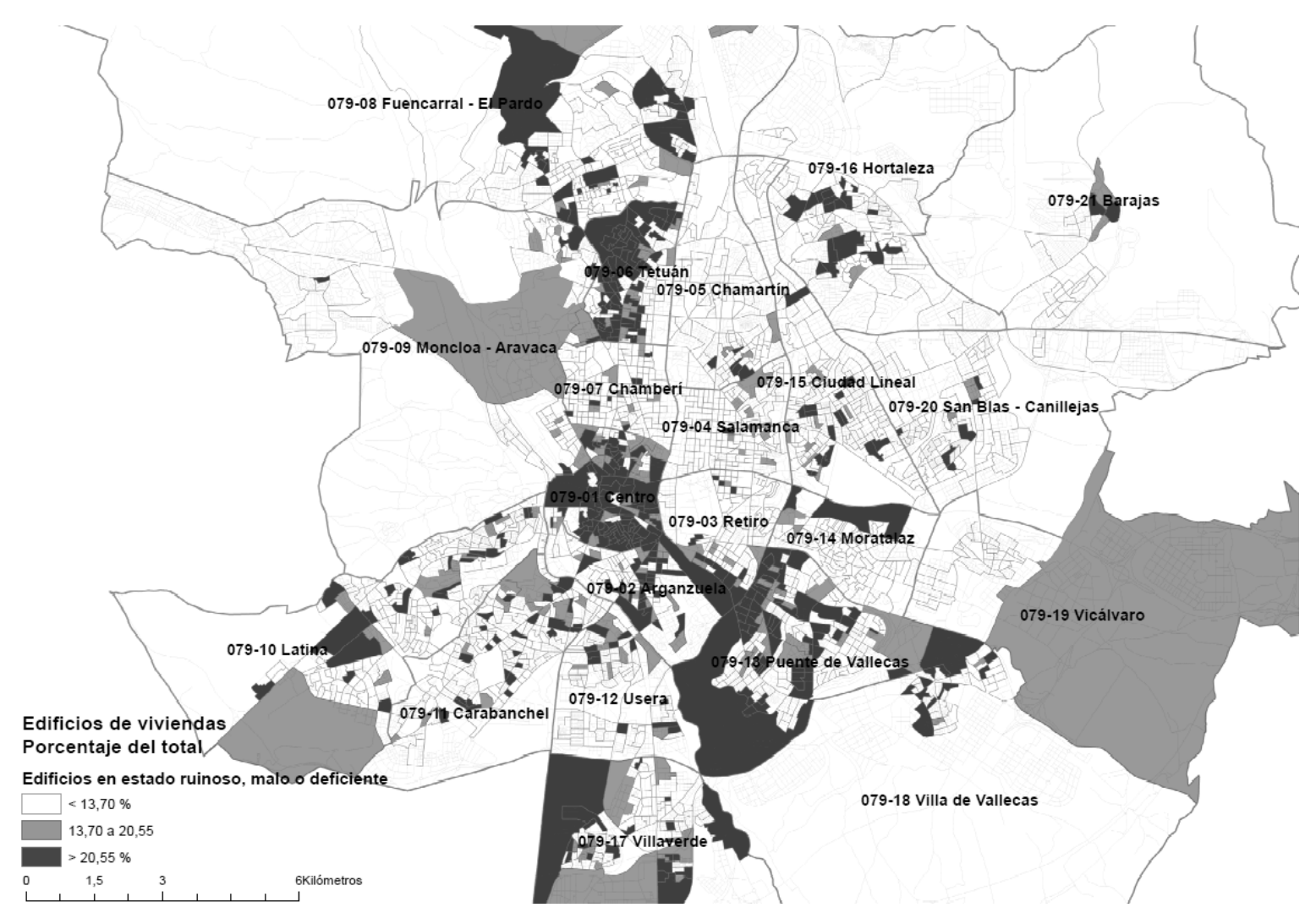

Figura 31. Edificios destinados a viviendas en estado ruinoso, malo o deficiente. Datos INE 2001

\subsubsection{Estado de la edificación}

Según los datos recogidos en el Censo del INE, en el año 2001 el 13'70 \% de los edificios destinados a vivienda de Madrid se encontraban en estado ruinoso, malo o deficiente. Se pueden considerar estos datos como un indicador de la necesidad de rehabilitación del parque residencial por motivos de mantenimiento y conservación.

Para estudiar su distribución espacial en la ciudad, se han identificado en el plano aquellas secciones censales que concentran un porcentaje de edificios en mal estado superior a la media y aquellos que superan el valor del $150 \%$ de la media para Madrid $(20,55 \%)$ (Figura 31).

Las zonas que contienen edificios deteriorados coinciden en gran medida con las zonas desarrolladas en el periodo 1940-80. Se concentran, además de en el centro de la ciudad, principalmente en el arco sur y en una línea que se extiende hacia el norte en los distritos de Tetuán y Fuencarral-El Pardo. 


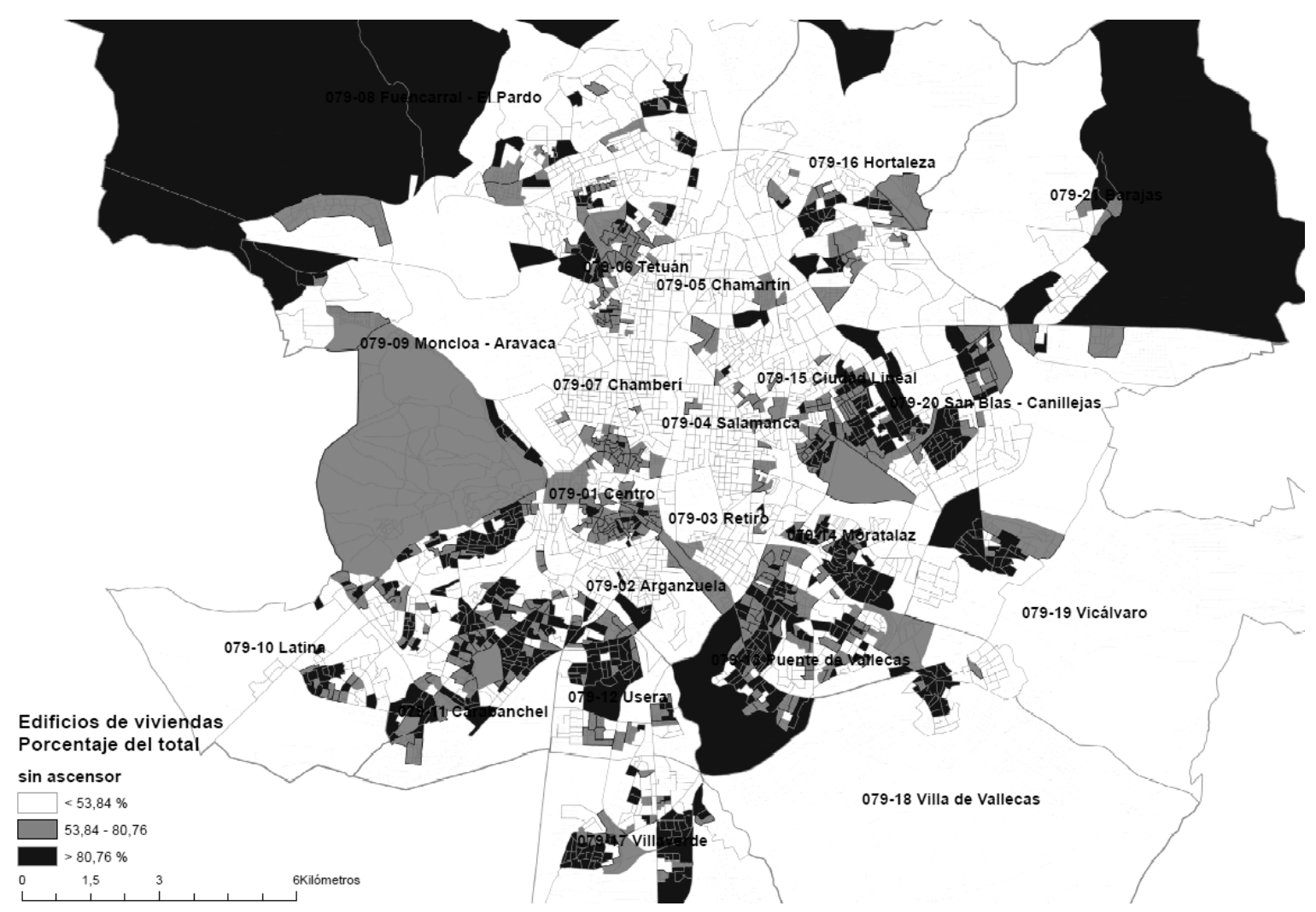

Figura 32. Edificios destinados a viviendas sin ascensor con cuatro o más plantas. Datos INE 2001

\subsubsection{Accesibilidad en la edificación residencial}

Una de las circunstancias habituales que motivan la rehabilitación de edificios de viviendas en altura es la necesidad de ascensor para mejorar la accesibilidad a las plantas altas. Es una intervención prioritaria que ha contado con varios programas de ayuda pública y supone dotar de un valor añadido a la edificación existente. Para fomentar su incorporación la normativa permite cierta flexibilidad a la hora de introducir modelos que no cumplan con las prescripciones mínimas exigibles a un edificio de nueva planta. Actualmente la industria desarrolla modelos de ascensor adaptados a las circunstancias que exige cada rehabilitación.

Además de la instalación de ascensores, la accesibilidad del edificio depende muchas veces del acceso hasta dicho ascensor. La construcción de rampas o la instalación de salvaescaleras u otros dispositivos mecánicos permite asegurar un uso adecuado de los elementos comunes para todas las personas, independientemente de su capacidad de movilidad y reduciendo su dependencia. 


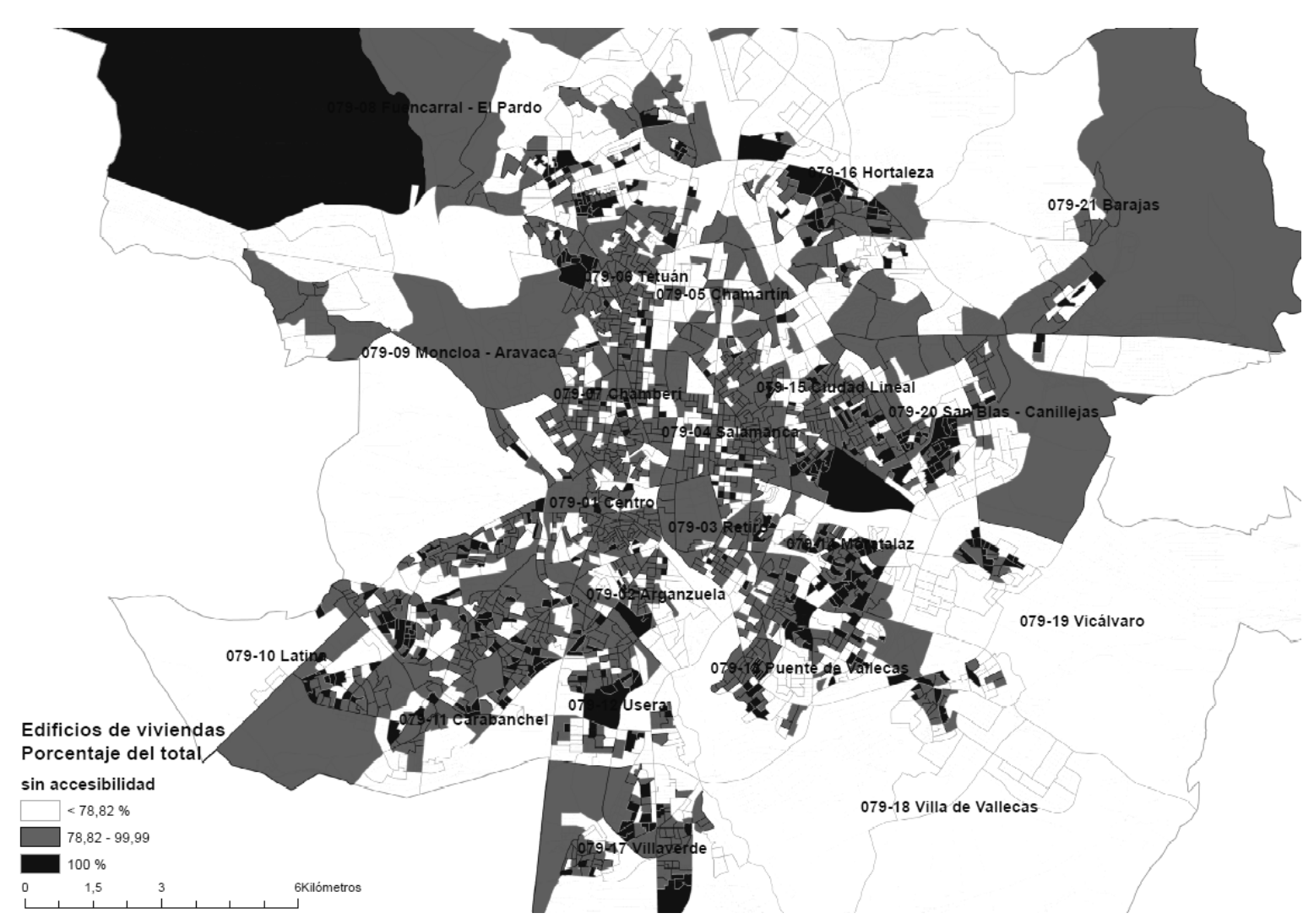

Figura 33. Edificios no accesibles destinados a viviendas. Datos INE 2001

Un primer empuje a la rehabilitación de los edificios residenciales viene dado por la modificación de la Ley 49/1960, de 21 de julio, sobre Propiedad Horizontal por la Ley 8/2013, de 26 de junio, de rehabilitación, regeneración y renovación urbanas. Esta ley introduce la novedad de que los trabajos y las obras que resulten necesarias para satisfacer la accesibilidad universal de personas con discapacidad y personas mayores, tendrán carácter obligatorio y no requerirán de acuerdo previo de la Junta de Propietarios, impliquen o no modificación del título constitutivo o de los estatutos, y vengan impuestas por las Administraciones Públicas o solicitadas a instancia de los propietarios.

Según los datos del Censo del INE, en 2001 había en Madrid 36.987 edificios de viviendas de cuatro o más plantas que carecían de ascensor, lo que suponía un $53 \%$ del total de la edificación residencial de estas características. En la estimación del Censo de 2011 la cifra ha descendido al 43\%, lo que indica que la instalación de ascensores avanza a buen ritmo, pero se sigue contando con una gran cantidad de edificios sin este servicio. En el plano (Figura 32) aparecen representados aquellas secciones censales que 


\section{CAPÍTULO 1. ESTADO DEL ARTE}

contienen un porcentaje de edificios de cuatro o más plantas sin ascensor que superan la media de la ciudad. Se puede apreciar que las zonas que cuentan con un mayor número de edificios sin ascensor coinciden en gran medida con los desarrollos de vivienda en las periferias de los años 40 al 80, además de en el centro histórico y el distrito de Tetuán.

En lo que respecta a la accesibilidad, se desprende del análisis de los datos del Censo INE de 2001 que en Madrid 106.307 edificios destinados a vivienda (el $79 \%$ del total) carecían de una accesibilidad adecuada, según la distribución espacial que aparece representada en el plano (Figura 33). En este caso, dada la gran cantidad de edificios que no estaban adaptados en 2001, se representan aquellas secciones que superan a la media y las que contienen un $100 \%$ de edificios de viviendas no accesibles. En la estadística del Censo de 2011 este valor representa el 76\% de los edificios, lo cual indica que las obras de accesibilidad se han producido en menor medida que la instalación de ascensores.

El problema de la accesibilidad en edificios residenciales aparece extendido por toda la ciudad desde el centro hasta las periferias. No obstante este alcanza sus puntos más negros en aquellas zonas de periferia desarrolladas durante el periodo del estudio (4080), que una vez más concentran los problemas de obsolescencia de la edificación residencial existente. Esto viene a sumar un motivo más de urgencia para la rehabilitación urbana de estas áreas.

\subsubsection{El patrimonio moderno}

A la hora de abordar la rehabilitación energética del parque edificado del periodo analizado, es necesario realizar una reflexión sobre la necesidad de la conservación del patrimonio moderno y abordar las posibilidades de mejora energética sin menoscabar su carácter. El objetivo es actualizar los edificios existentes a las nuevas exigencias en materia de habitabilidad, siempre desde el punto de vista del respeto y la conservación de sus valores arquitectónicos y urbanos. La rehabilitación de promociones de alto valor arquitectónico debe ser apoyada para su correcta conservación y la preservación de la memoria de la tipología de vivienda obrera y del conjunto de la sociedad industrial en la que los países europeos encuentran gran parte de sus raíces comunes (Tatjer, M. 2005). 


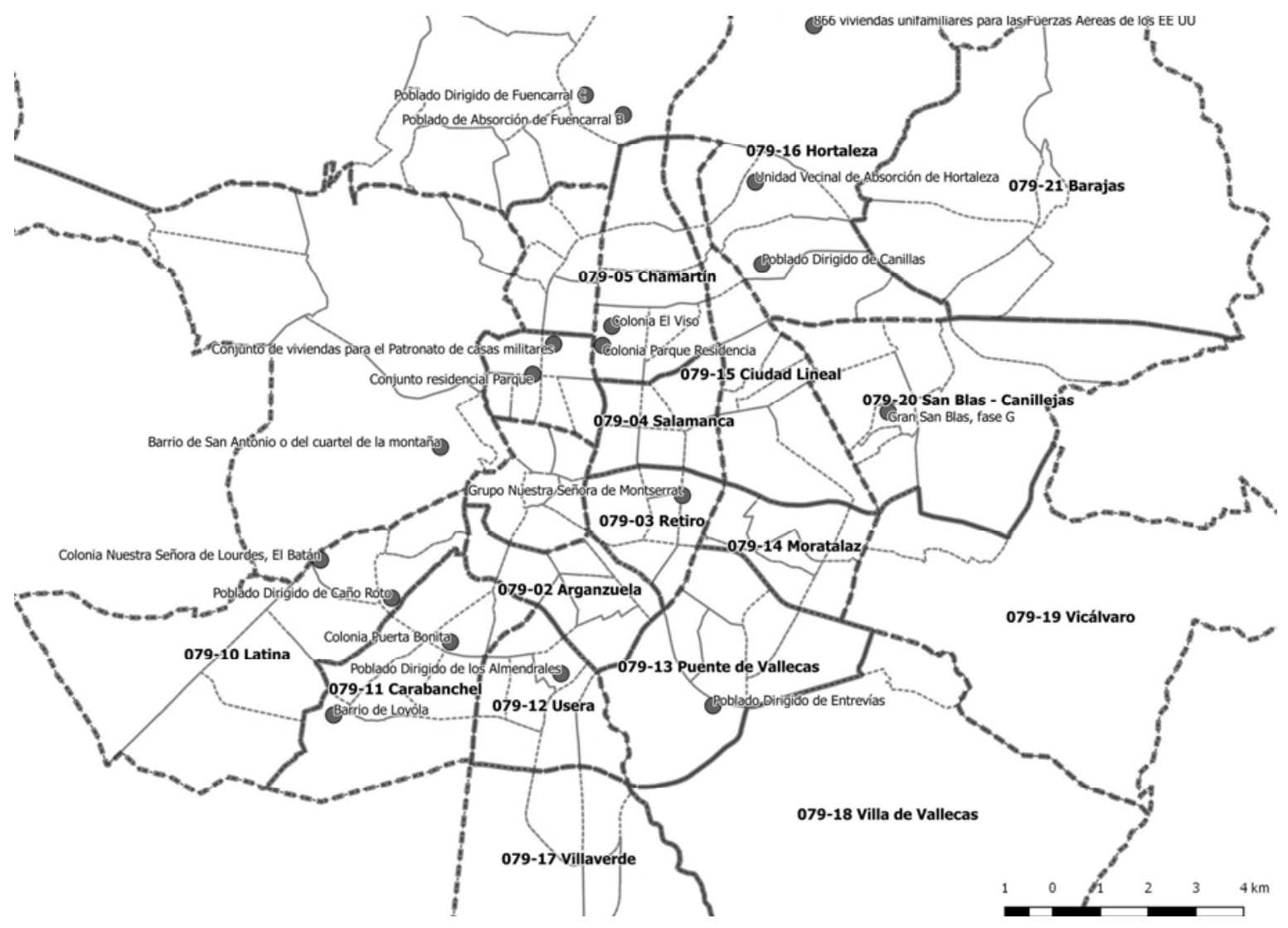

Figura 34. Conjuntos residenciales catalogados en el archivo "La vivienda Moderna". Fuente: DOCOMOMO

Para el caso de este estudio tienen especial interés aquellas promociones públicas ideadas o desarrolladas en Madrid durante los años 50. Se trata de los más tempranos e interesantes ejemplos de vivienda modesta de carácter moderno, construidos en la periferia madrileña (Esteban Maluenda 1999). Se producen en un momento en el cual la política de desarrollo de poblados se dirige a tratar de solucionar el problema de la inmigración masiva hacia la capital. La producción de estos desarrollos -como son Almendrales, Canillas, Caño Roto, Entrevías, Fuencarral, Manoteras, Orcasitas... -resulta en uno de los mejores capítulos de la arquitectura de vivienda social española por la capacidad resolver de forma racional el problema de la escasez de vivienda y de recursos bajo las premisas del Movimiento Moderno (Guillem González-Blanch 2013a).

Para avalar la selección de algunas de estas promociones se ha utilizado la catalogación realizada por la fundación DOCOMOMO Ibérico para la preservación de los edificios del Movimiento Moderno. Se han recopilado los datos de conjuntos residenciales incluidos en el registro "La Vivienda Moderna" del periodo 1925-1965 
(Centellas et al. 2009) (Figura 34). Las 18 promociones residenciales de estas características se han incorporado a la base de datos que alimenta el Modelo de Análisis de Datos Espaciales que alimenta este estudio, de manera que pueda prestarse especial atención a estos casos.

\subsubsection{5 Áreas de Madrid en las que se han promovido operaciones de rehabilitación urbana}

A partir de los años 80 se empieza a plantear el problema de mantenimiento de las áreas vulnerables de la ciudad, en la que residen los sectores de población con menor renta, que empiezan a mostrase deterioradas. A través del plan de remodelación de barrios, con un presupuesto de $1.800 .000 .000 €$, el municipio de Madrid rehabilita su periferia sureste, erradicando los asentamientos de infravivienda y vivienda pública en ruina. La Administración contó con la participación muy activa de las Asociaciones de Vecinos, afectó a 30 barrios de muy diferentes características y realojó a una población de alrededor de 150.000 personas procedentes de poblados chabolistas construidos por la población inmigrante de origen rural, viviendas provisionales públicas (UVAs, Poblados Mínimos, Agrícolas, de Absorción y Dirigidos) que habían sido construidas para alojar población chabolista, procedente del centro de la ciudad o sujetos a procesos de expropiación forzosa (Echenagusía 1996).

Durante el periodo 1992-2012 se desarrolla la rehabilitación de áreas mediante seis planes de vivienda en los que le estado financia la rehabilitación de áreas acordadas con las Comunidades Autónomas y los Ayuntamientos (Áreas de Rehabilitación Integral ARI). Las declaraciones de áreas comenzaron a realizarse sobre tejidos periféricos, para pasar a incluir ayudas específicas para áreas de cascos históricos A pesar de afectar a un número muy reducido de viviendas si se compara con la producción de obra nueva, ha permitido el desarrollo de planes complejos y una experiencia en materia de rehabilitación en áreas urbanas, con las que poder afrontar los retos de un nuevo ciclo que necesariamente pasará por la rehabilitación (A. Hernández Aja et al. 2015).

Las Áreas de Rehabilitación son zonas de la ciudad para las que el Ayuntamiento de Madrid, la Comunidad de Madrid y el Ministerio de Fomento, han suscrito un Convenio de colaboración con objeto de recuperar tanto el espacio público como las viviendas y edificios (Agustín Hernández Aja et al. 2010). 


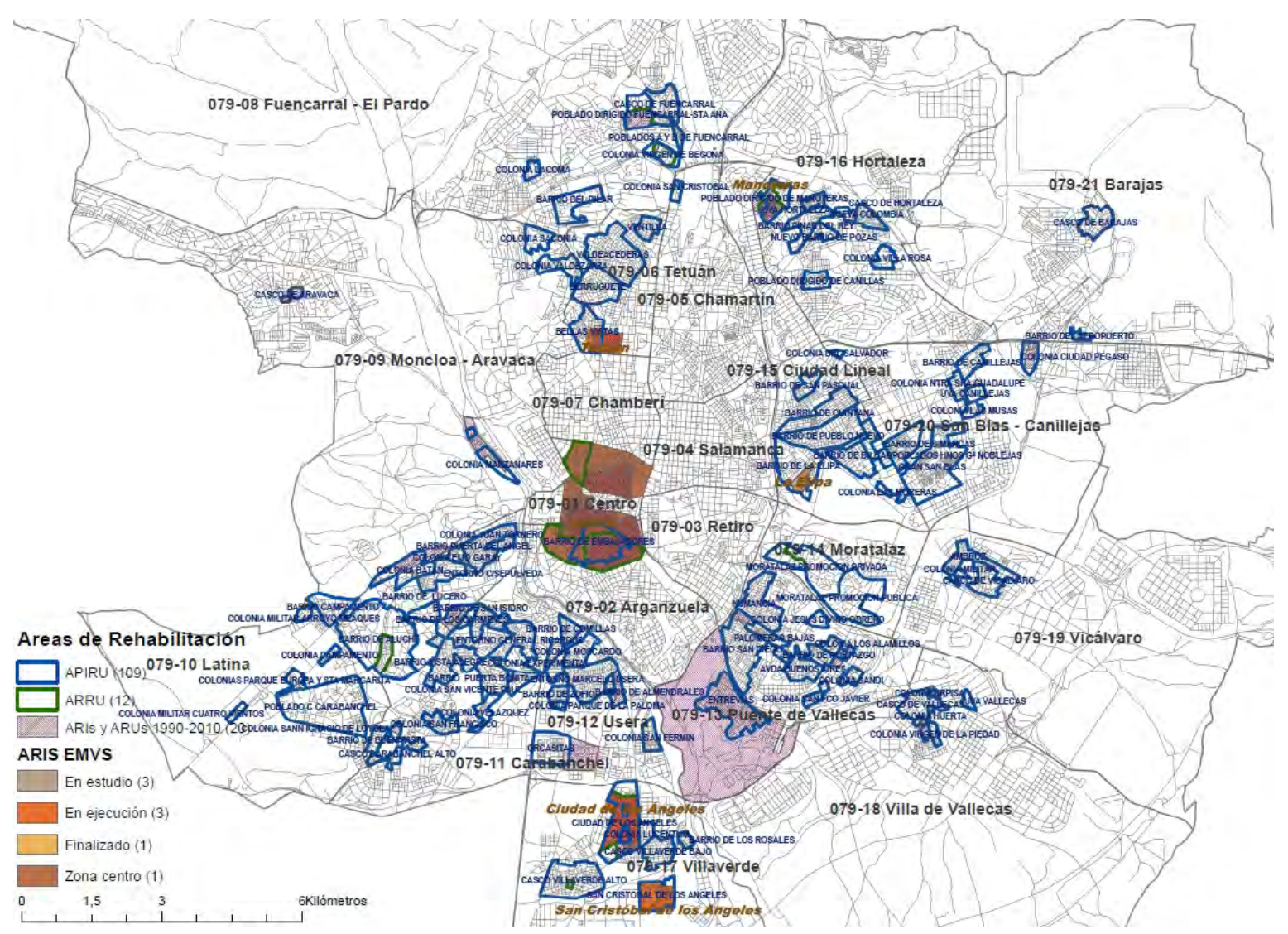

Figura 35. Áreas de Rehabilitación en Madrid. Fuente: Ayuntamiento de Madrid y Hernández Aja

En la Figura 35 se ha volcado información acerca de los tejidos residenciales señalados como Áreas de Rehabilitación para la intervención en su edificación por las administraciones públicas en el municipio de Madrid. Por una parte se ha utilizado los datos que ofrece la Empresa municipal de Vivienda y Suelo (EMVs) del Ayuntamiento en su página WEB. Por otra parte se ha volcado la información proveniente del Atlas de la Edificación Residencial a partir del trabajo Delimitación y digitalización de ARIs y ARUs en los Planes Estatales de Vivienda. "ARIs y ARUs 1990-2010", en la que aparecen los ARIs (Áreas de Rehabilitación Integral) y ARUs (Áreas de Renovación Urbana) financiados en los Planes Estatales de Vivienda y Rehabilitación.

Recientemente el Ayuntamiento, a través del Área de Gobierno de Desarrollo Urbano (Dirección General de Planificación Estratégica), delimitó las áreas definidas como Áreas Preferentes de Impulso a la Regeneración Urbana (APIRUS) en su el Plan MAD-RE (Madrid Recupera) para el fomento de la rehabilitación energética. Principalmente situadas entre la almendra central y los desarrollos periféricos más recientes, por primera vez se incluye 


\section{CAPÍTULO 1. ESTADO DEL ARTE}

la mejora de la eficiencia energética entre los objetivos principales para estos ámbitos (ver Apartado 1.2.1. Vulnerabilidad Urbana). Se perfilan estas áreas como los barrios prioritarios, con abundancia de vivienda social, construidos entre 1950 y 1980, con tipología mayoritaria de bloque abierto (Ayuntamiento de Madrid 2016).

El proyecto REFAVIV recopiló información -a través del trabajo de campo durante una serie de visitas a conjuntos residenciarles desarrollados mediante operaciones de promoción pública en el periodo 1940-80- acerca de la existencia una serie de barrios rehabilitados en los que han sido incluidas medidas de mejora de la eficiencia energética de manera generalizada para toda la edificación (Figura 36). En el proyecto se pudo constatar la incorporación de sistemas de aislamiento térmico por el exterior (SATE) para la mejora de las fachadas (Oteiza, I. et al. 2018). La mayor superficie rehabilitada incluida en el estudio corresponde a varias barriadas del Gran San Blas, rehabilitadas durante el Plan de Remodelación de Barrios en los años 80 .

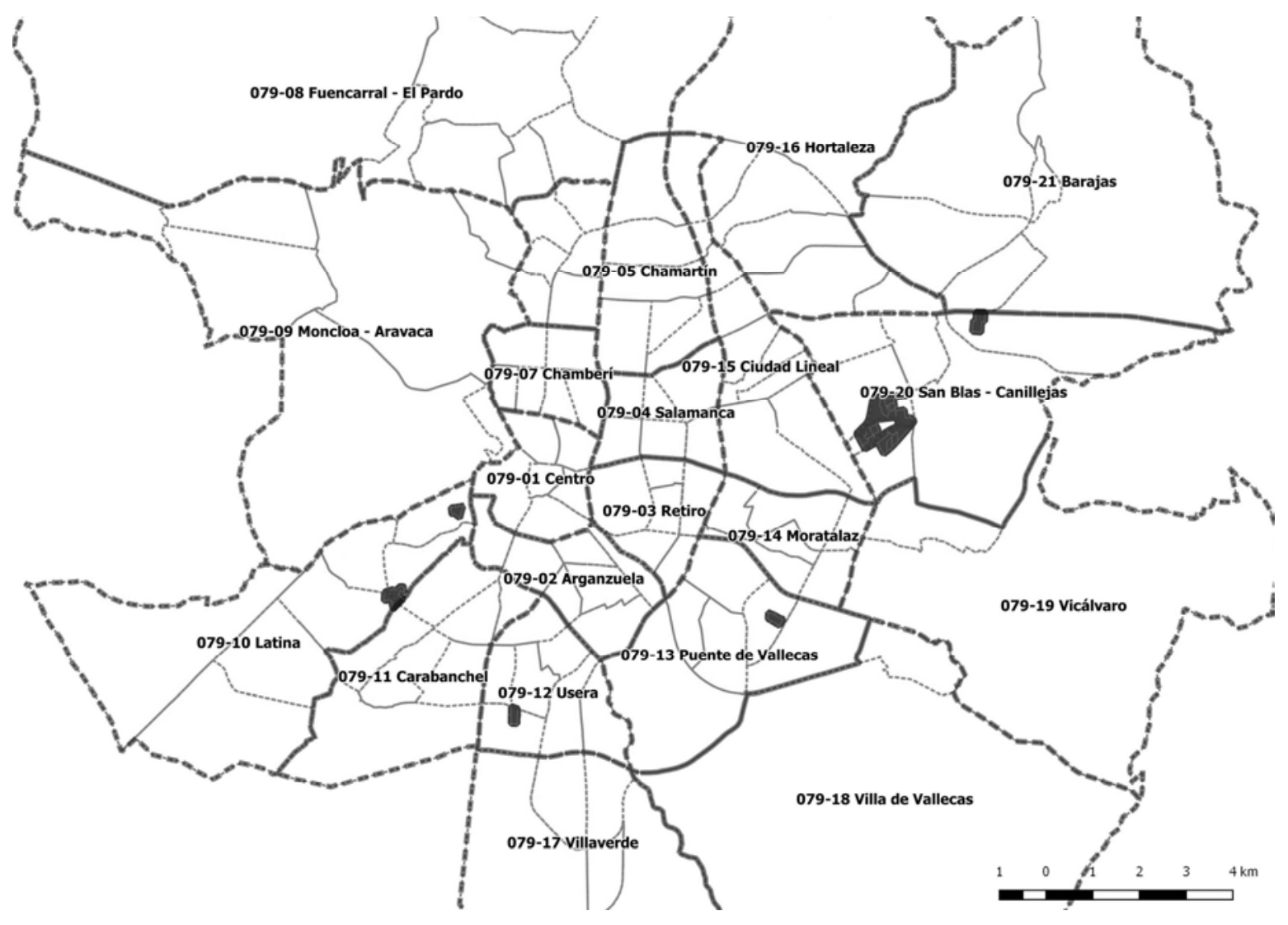

Figura 36. Áreas urbanas con fachadas rehabilitadas de forma masiva con aislamiento por el exterior (Oteiza et al. 2016) 


\subsection{CONSIDERACIONES PARA EL DESARROLLO DEL ESTUDIO}

En este CAPITULO se ha realizado la recopilación de una serie de informaciones de partida deducidas a partir de la revisión del estado del arte sobre la pobreza energética y el análisis de datos estadísticos relacionados. De la recopilación de esta información para el estudio de caso de la ciudad de Madrid se obtienen unas primeras impresiones acerca de las áreas que pueden ser susceptibles de contener bolsas de pobreza energética

La ciudad de Madrid contiene los diferentes vectores que son causa de pobreza energética. La edificación ineficiente es un problema generalizado que debe ser tenido en cuenta. Existe un alto porcentaje de viviendas que no cuentan con aislamiento térmico en toda la ciudad.

La pirámide de población apunta a una población cada vez más envejecida y por tanto vulnerable a las consecuencias de la pobreza energética. En los últimos años se ha producido un envejecimiento o movimiento de la población mayor en las zonas de la periferia urbana y un paulatino rejuvenecimiento de la población que habita zona centro. Desde el punto de vista de la falta de confort térmico por motivos de salud, las personas mayores y los niños son especialmente sensibles, y este tipo de actuaciones ofrece la oportunidad de mejorar su calidad de vida. Por otro lado, en el caso de las personas mayores para abordar las obras de rehabilitación son necesarios esquemas de financiación adaptados a su realidad psicológica y económica (Luxán García De Diego et al. 2017).

La edificación ineficiente es un vector de pobreza energética. Se ha recopilado información existente de los aspectos que afectan a la pobreza energética en varias fuentes de datos robustos. Se han recopilado indicadores con vistas a caracterizar los principales aspectos que determinan la vulnerabilidad energética de la edificación. Se trata de indicadores sobre la población, sobre la vivienda y sobre el estado actual del tipo de promoción, en la línea de las recomendaciones para una regeneración urbana integrada (RUI). El análisis de los indicadores urbanos muestra que existe una segregación espacial que marca diferencias entre el centro y la periferia, y dentro de esta, delimita zonas con características similares en el arco Sur-Sureste y el corredor que se extiende desde el centro hacia el Norte. Es en esta periferia urbana donde se sitúan las 
mayores bolsas de edificación ineficiente en barrios vulnerables. Los barrios más vulnerables se concentran en el arco Sur y contienen los ámbitos de menor renta, que presenta una tendencia descendente desde el Noroeste al Sureste.

Las viviendas son fundamentalmente en propiedad, y gran parte de ellas se construyeron en la década de los 60. Las viviendas sin calefacción y sin agua caliente centralizada se sitúan también en el arco Sur-Sureste, el centro, y el corredor que va desde el centro hacia el Norte, coincidiendo en gran parte con las áreas vulnerables. En cuanto a la densidad de viviendas vacías, es menor en estas zonas de periferia y aumenta en las zonas de mayor renta. Las zonas con edificaciones más deterioradas coinciden con las áreas desarrolladas durante el periodo de la dictadura. El problema de la accesibilidad está extendido en toda la ciudad, afectando a más de las tres cuartas partes de las viviendas, pero alcanza un mayor ratio en las zonas de periferia desarrolladas en el periodo de estudio.

El acceso universal a la energía es responsabilidad de las administraciones públicas a partir del momento en el que se define como una necesidad sin la cual la supervivencia se ve amenazada. Los crecientes estudios acerca de los efectos sobre la salud humana de la carencia de confort y de la mortalidad estacional asociada al clima están demostrando que la energía es una necesidad básica como lo es la alimentación, la vestimenta y la vivienda digna (Bouzarovski y Simcock 2017). Esta responsabilidad del estado se hace especialmente patente en la vivienda de promoción pública, que debe cubrir los estándares básicos de eficiencia, confort y ahorro de recursos que exige la actual normativa. Gran cantidad de áreas residenciales situadas en las zonas vulnerables fueron promovidas por el estado y algunas de ellas fueron concebidas con carácter temporal. Aunque la propiedad de muchas de ellas haya sido transferida a sus ocupantes, la calidad precaria de su construcción de partida unida a la dificultad para su mantenimiento hace que estas zonas concentren un mayor número de edificios en mal estado.

La vulnerabilidad energética de la edificación debe ser un indicador para priorizar las actuaciones. Las zonas que contienen edificios deteriorados coinciden en gran medida con las zonas desarrolladas en el periodo de 1940 a 1980. Son coincidentes también con áreas con un mayor porcentaje de edificios que no disponen de instalaciones de calefacción, y que no disponen de ascensor. El problema de la accesibilidad en edificios 
residenciales está extendido en toda la ciudad, si bien alcanza sus puntos más negros también en aquellas zonas de periferia desarrolladas durante el periodo 1940-80. La mejora de la accesibilidad es una condición indispensable para permitir el envejecimiento activo de sus habitantes y debe abarcar tanto ascensores como rampas o elementos salva escaleras. .

La intervención energética debe englobarse dentro de operaciones de Regeneración Urbana Integrada, ligada a otros aspectos de mejora de la edificación y su entorno urbano, que den solución a los principales problemas de obsolescencia existentes en las zonas degradadas. Estas políticas de ayudas públicas para la regeneración urbana integrada con componentes de mejora de la eficiencia energética deben priorizar a la población desfavorecida. Para lograrlo es necesario destinar recursos públicos para la rehabilitación del parque público de viviendas ineficientes, especialmente en aquellos casos en los que la población que los habita no puede afrontar el pago de las facturas energéticas, y por tanto tampoco está preparada para costear la rehabilitación energética. Es muy importante reducir los riesgos en las actuaciones de rehabilitación ya que resulta difícil encontrar segundas oportunidades. La difícil gestión y apuesta de las comunidades de propietarios en los edificios multifamiliares hacen necesarias actuaciones especialmente certeras. El seguimiento de estas mejoras antes y después de la actuación permitirá comprobar y verificar la correcta ejecución y las mejoras reales conseguidas. Tanto las buenas actuaciones como las actuaciones fallidas suponen un ejemplo para comunidades vecinas propagándose la experiencia dentro de los barrios.

La incorporación de la mejora de la envolvente en los planes de Regeneración Urbana Integrada debe ser el primer paso para la mejora de la eficiencia energética y la calidad del ambiente interior en las viviendas. Debido al deficiente desempeño de los cerramientos opacos verticales además de la falta de mantenimiento generalizado en los edificios de vivienda social, las medidas de mejora más apropiadas van dirigidas a la rehabilitación de la envolvente opaca de la edificación a la escala de barrio. Además, se genera una herramienta de apoyo para la resolución de diferentes lesiones constructivas y problemas de adecuación funcional (humedades, ruido, accesibilidad, etc.), y tiene una repercusión en la mejora de los espacios exteriores de estas zonas, a menudo degradados. Estos aspectos influyen sirviendo de alivio para diversos problemas sociales 


\section{CAPÍTULO 1. ESTADO DEL ARTE}

como son la pobreza energética o la mejora de la percepción de los barrios degradados, y ayudan a conseguir el objetivo del envejecimiento activo de la población. Por lo tanto, es necesario abordar con prioridad la adecuación del edificio de forma pasiva, mejorando el confort térmico en las viviendas, para después tratar de mejorar los rendimientos de las instalaciones y aparatos consumidores de energía, de forma que tengan que afrontar una

menor demanda. Una vez mejorados estos aspectos, la energía necesaria se podría obtener con la incorporación de fuentes de energía renovable. 


\section{CAPITULO 2. EVALUACIÓN ESTADÍSTICA DE LA POBREZA ENERGÉTICA A LA ESCALA DE LA CIUDAD}

“...deben adoptarse estrategias nacionales que contengan directrices claras y acciones específicas mensurables, y debe fomentarse el acceso igualitario a la financiación, en particular para los segmentos menos eficientes del parque inmobiliario nacional, para los consumidores en situación de pobreza energética, para las viviendas sociales...". Directiva (UE) 2018/844 (Parlamento Europeo y el Consejo de la Unión Europea 2018).

Del análisis de los factores descritos en el 0 , se desprende que la promoción de la rehabilitación pasa por una planificación que permitan delimitar aquellas áreas que deben ser prioritarias para la inversión pública utilizando criterios de justicia y equidad energética. Un análisis integral de la vulnerabilidad energética de la edificación residencial desde la sostenibilidad debe englobar aspectos sociales, medioambientales y económicos. Generalmente los edificios que requieren más actuaciones de rehabilitación serán aquellos de mayor antigüedad y deficiente calidad constructiva, situados en barrios desfavorecidos. Esta circunstancia deriva en unos mayores costes energéticos por persona y unidad de superficie habitable para la población vulnerable (M. Santamouris et al. 2007). En el presente CAPITULO se desarrolla una herramienta dirigida a detectar y analizar estas áreas, a través de nuevos indicadores. 


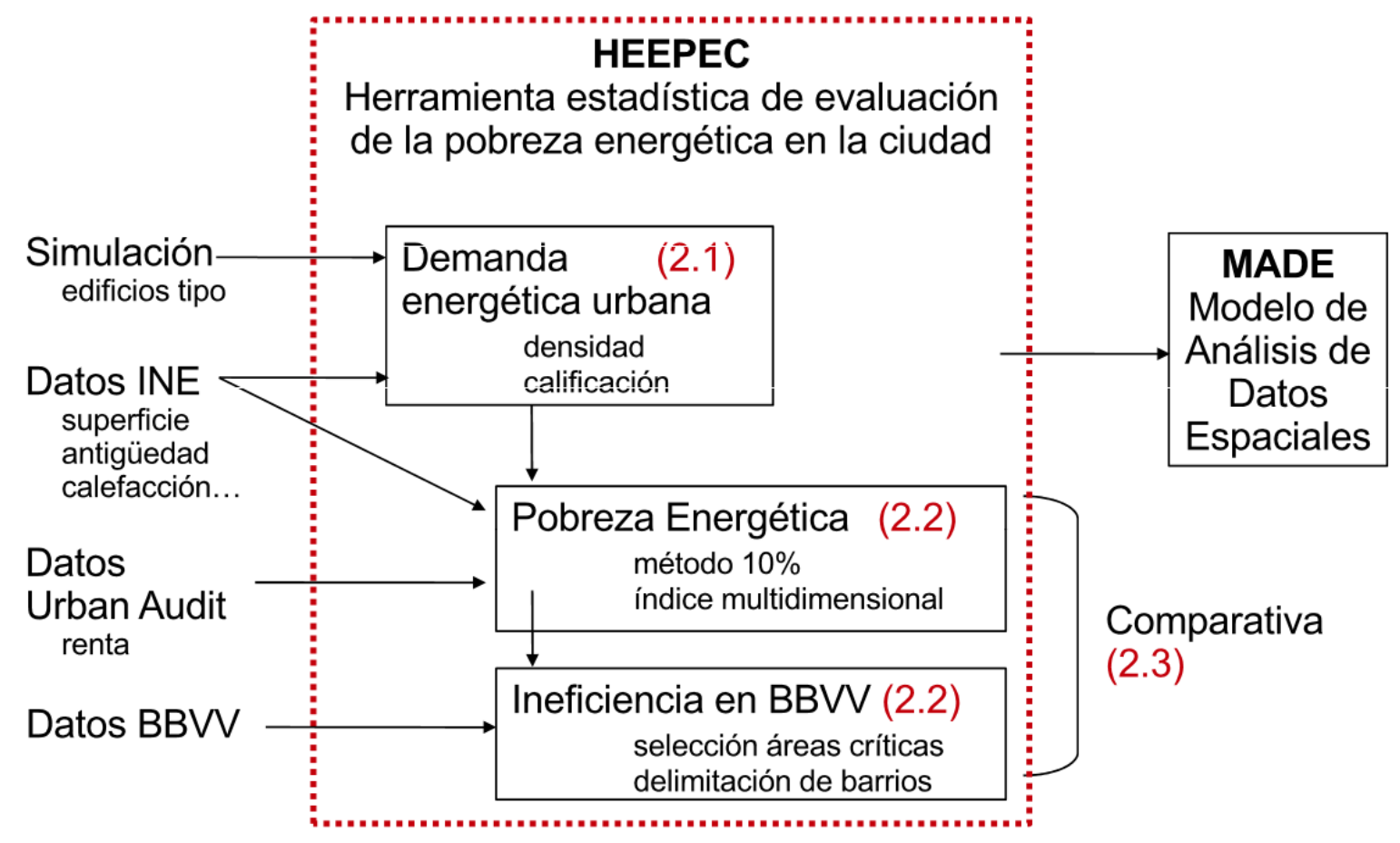

Figura 37. Esquema conceptual del desarrollo de la herramienta estadística de evaluación de la pobreza energética. Elaboración propia

En este capítulo se aplican los conceptos de pobreza energética y los datos estadísticos existentes en los censos, analizados en el Capítulo 1, para generar una herramienta útil para desarrollar nuevos indicadores urbanos que permitan analizar la eficiencia energética de la edificación residencial a la escala urbana desde un punto de vista integral que incluya los aspectos medioambientales, sociales y económicos (Figura 37). La herramienta posibilita la comparación de los cálculos energéticos con la información estadística existente relacionada con las características socioeconómicas de la población. Los resultados se vuelcan en el Modelo (MADE) para su posterior visualización y análisis. La metodología se va aplicando al estudio de caso de la ciudad de Madrid. Los datos estadísticos se han utilizado con el mayor detalle de desagregación posible con las fuentes utilizadas: la escala de la sección censal (INE 2001; 2011).

La herramienta HEEPEC procesa la información existente para la realización de cálculos que posibilitan la obtención de un mapa de las necesidades energéticas para calefacción de la edificación residencial. Esta información se pone en relación con aspectos sociales, medioambientales y económicos para la detección de la pobreza energética a la escala de la ciudad. Para ello se siguen los siguientes pasos: 
- En primer lugar se realiza una estimación gruesa de las necesidades energéticas de calefacción utilizando el método de simulación de edificios tipo y generalización de sus resultados a partir de datos estadísticos (É. Mata, Johnsson, y Sasic Kalagasidis 2011). Este proceso posibilita la identificación de las áreas urbanas que contienen bolsas de edificación ineficiente.

- Una vez obtenidas las necesidades energéticas de calefacción se procede a la estimación simplificada del resto de servicios energéticos básicos en cada sección censal de la ciudad. Utilizando datos de renta media del hogar se consigue realizar una estimación del riesgo de pobreza energética y su distribución en la ciudad. A partir de esta información es posible el desarrollo de un índice multidimensional que incorpora además otros aspectos sociales al análisis.

- Finalmente se identifican aquellas áreas de la ciudad donde se concentran los problemas y se realiza una selección de áreas críticas, con alto riesgo de pobreza energética. 


\subsection{LA DEMANDA ENERGÉTICA DE CALEFACCIÓN A ESCALA URBANA}

En este apartado se calcula un orden de magnitud aproximado de la demanda energética de calefacción del parque residencial de toda una ciudad, con información desagregada a la escala de la sección censal. El método está basado en la simulación energética de edificios tipo y la generalización de los resultados mediante datos estadísticos (É. Mata, Johnsson, y Sasic Kalagasidis 2011). El cruce de datos con el atlas de Vulnerabilidad Urbana permite obtener un primer listado de barrios vulnerables con baja eficiencia energética. A priori se puede considerar que estos barrios podrían ser también vulnerables a la pobreza energética por sumarse a su situación ya de por sí desfavorecida la presión energética causada por la mala calidad térmica de su edificación que redunda en mayores costes de calefacción para llegar a la temperatura de confort.

El objetivo principal en esta fase es localizar áreas urbanas vulnerables donde la edificación es ineficiente desde el punto de vista de sus necesidades de calefacción, a partir de datos estadísticos robustos. Esto permitirá clasificar toda la edificación residencial de una ciudad conforme a sus necesidades de rehabilitación energética. Para ello se han desarrollado dos indicadores a partir de los cálculos de demanda. Estos indicadores se calculan para la ciudad en su conjunto y para cada sección censal, y son replicable para barrios mediante la agrupación de los resultados por sección censal.

- Indicador de densidad energética (kWh/HA): Estimación del total de la demanda energética de calefacción de los edificios residenciales de una determinada área, repercutida por la superficie urbana que ocupa.

- Clasificación energética de demanda de calefacción urbana ( $\mathrm{kWh} / \mathrm{m} 2)$ : Estimación del total de la demanda energética de calefacción de los edificios residenciales de un área, repercutida por la superficie a acondicionar. Da lugar al valor unitario de demanda de calefacción y a una calificación energética (A-G), promedio de todos los edificios del área analizada.

Hasta el momento no se habían realizado representaciones gráficas del comportamiento energético de las ciudades basados en el estudio de la edificación como causa de vulnerabilidad energética. Se propone una imagen global de las necesidades 
energéticas de todos los barrios de la ciudad -desde el punto de vista de la demanda de calefacción- para facilitar el diagnóstico de la ciudad en su conjunto como organismo disipador de energía, y conseguir localizar las áreas con el parque más ineficiente.

\subsubsection{Método de cálculo}

En primer lugar se procede a la contabilización del número total de viviendas y la estimación de la superficie a acondicionar en cada barrio. Los datos analizados proceden de los Censos de Población y Viviendas del Instituto Nacional de Estadística (INE 2001; 2011). Se trata de una foto fija de la población, realizada en una fecha de referencia, obtenida por medio de la recolección de un cuestionario que cubre varios campos de interés y cuyos datos están protegidos por el secreto estadístico. Desde el punto de vista del trabajo estadístico, el territorio nacional se encuentra dividido en secciones censales, siendo esta la menor desagregación de datos accesibles de manera pública.

El siguiente paso es la clasificación de la superficie total de las viviendas a acondicionar en función de la calidad térmica de sus envolventes. Para ello se utilizan datos de antigüedad de la edificación, y se adjudican las características térmicas correspondientes a la normativa vigente en el momento de su construcción. La demanda de calefacción se caracteriza así según el periodo en valores unitarios mediante la asunción de los resultados obtenidos de simulaciones energéticas de edificios representativos del parque (edificios arquetipo o tipo). Para la caracterización de los rangos de la demanda energética de calefacción de los espacios residenciales por periodo de construcción en el clima de Madrid, ha sido necesario asumir que dicha demanda va a depender en gran medida de la capacidad de aislamiento térmico de la envolvente, más allá de otros aspectos que, aunque influyentes (orientación y factor de forma del edificio), lo son en menor medida en edificios con envolvente de bajo desempeño térmico. Existe una relación entre las características térmicas de los edificios (definidas por el periodo en el que están construidos) y unos rangos en los valores de su demanda energética de calefacción.

Con esta información es posible calcular los dos indicadores de demanda propuestos. Atribuyendo a la superficie a acondicionar los valores de la caracterización para cada período de construcción, se hace posible la estimación de la necesidad energética de 
calefacción total por sección censal en valores absolutos y de la densidad energética por superficie (Ha). Volviendo a repercutir los valores de demanda total por la superficie a acondicionar en cada sección censal, es posible obtener una calificación energética de la demanda de calefacción para cada barrio y para toda la ciudad, utilizando el procedimiento normativo habilitado para la obtención de la escala de clasificación energética para el clima de Madrid (IDAE 2011a).

Finalmente se procede a la identificación de los barrios vulnerables que contienen edificación de baja eficiencia energética mediante el cruce de los resultados con el Atlas de Vulnerabilidad Urbana de la ciudad de Madrid (Agustín Hernández Aja et al. 2018).

\subsubsection{Caracterización energética de la edificación}

Para la selección de indicadores capaces de caracterizar de forma aproximada la demanda de calefacción de la edificación residencial en áreas urbanas, se han considerado tres etapas. Por una parte se ha calculado la escala de certificación energética en el concepto de demanda de calefacción conforme al procedimiento oficial de etiquetado energético para el clima de Madrid. En segundo lugar se estima la demanda total para la superficie residencial de cada sección censal, adjudicando a la superficie de cada periodo el resultado obtenido en los edificios tipo correspondientes. En último lugar se calcula la demanda total para cada sección censal sumando estos valores y se obtiene la clase energética de cada una de ellas en función del valor medio de demanda repercutido por la superficie total a acondicionar.

\subsubsection{Valores de referencia para la escala de calificación energética de calefacción}

En este trabajo se ha caracterizado exclusivamente la demanda de calefacción. Para determinar la escala de calificación de los edificios existentes de Madrid se ha empleado el procedimiento oficial de calificación energética de España (IDAE 2009; 2011a). Dicho procedimiento se desarrolló como trasposición de las directivas europeas en materia de eficiencia energética de la edificación conforme a las directivas de etiquetado energético (Parlamento Europeo y el Consejo de la Unión Europea 2012; 2010). Se parte de las demandas de referencia para edificios nuevos y existentes para Madrid (Tabla 7). Se han considerado edificios residenciales en bloque, mayoritarios en la ciudad de Madrid. 
Tabla 7. Valores de demandas energéticas de referencia para edificios de nueva construcción y existentes en $\mathrm{kWh} / \mathrm{m}^{2}$ (IDAE 2011a)

\begin{tabular}{|l|l|l|l|l|l|l|}
\hline Edificios & $\begin{array}{l}\text { Calefacción } \\
\text { unifamiliar }\end{array}$ & $\begin{array}{l}\text { Calefacción } \\
\text { bloques }\end{array}$ & $\begin{array}{l}\text { Refrigeración } \\
\text { unifamiliar }\end{array}$ & $\begin{array}{l}\text { Refrigeración } \\
\text { bloque }\end{array}$ & $\begin{array}{l}\text { ACS } \\
\text { unifamiliar }\end{array}$ & $\begin{array}{l}\text { ACS } \\
\text { bloques }\end{array}$ \\
\hline Nuevos & 64,4 & 43,2 & 15,7 & 10,8 & 17,7 & 13,0 \\
\hline Existentes & 149,8 & 121,2 & 26,5 & 19,1 & 17,7 & 13,0 \\
\hline
\end{tabular}

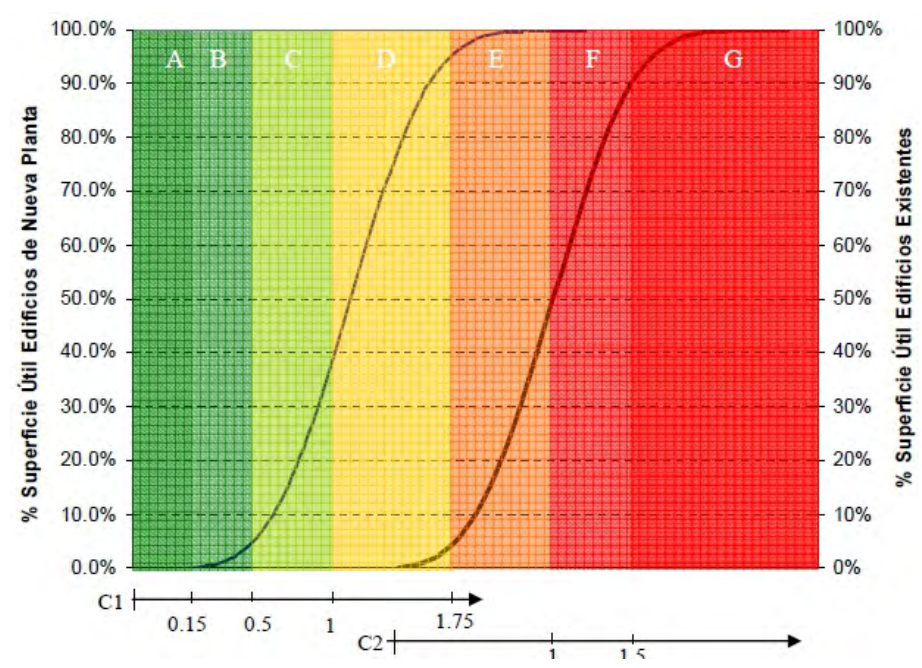

Figura 38. Clases de Energía a partir de los Índices de Calificación C1 y C2 (IDAE 2011a)

Tabla 8. Valores límite de clase en demanda de calefacción para viviendas en bloque en Madrid.

Elaboración propia a partir de (IDAE 2011a)

\begin{tabular}{|l|l|l|l|l|l|l|}
\hline Límite de Clase & R o R' & C1 & C2 & $\begin{array}{l}\text { Demanda de referencia } \\
\text { (kWh/m2) }\end{array}$ & $\begin{array}{l}\text { IEE } \\
\text { lo/lr }\end{array}$ & $\begin{array}{l}\text { Demanda límite } \\
\text { (kWh/m2) }\end{array}$ \\
\hline A & 1,7 & 0,15 & & 43,2 & 0,22 & 9,40 \\
\hline B & 1,7 & 0,5 & & 43,2 & 0,51 & 21,85 \\
\hline C & 1,7 & 1 & & 43,2 & 0,92 & 39,64 \\
\hline D & 1,7 & 1,75 & & 43,2 & 1,54 & 66,32 \\
\hline E & 1,1 & & 1 & 121,2 & 1,00 & 121,20 \\
\hline F & 1,1 & & 1,5 & 121,2 & 1,09 & 132,22 \\
\hline G & & & & 121,2 & & $\geq 132,22$ \\
\hline
\end{tabular}

El valor del límite de las fronteras entre clases se obtiene desnormalizando el índice de calificación energética (Figura 38). Para las clases A a D los límites de la escala se han establecido a partir del indicador energético normalizado que se define en el Real Decreto 47/2007, de 19 de enero, de Certificación de Eficiencia Energética de Edificios de Nueva Construcción. Se denomina índice de calificación energética de edificios nuevos 
(C1). Para las clases E, F y G se utilizan los criterios de normalización para los edificios existentes, que establecen un segundo índice de calificación (C2) (Figura 38, Tabla 8) (IDAE 2011a). Estos coeficientes dependen exclusivamente del límite entre clases considerado. El cociente $I_{0} / I_{R}$ representa el indicador de eficiencia energética: la relación entre la demanda del edificio objeto y la del edificio de referencia que cumple estrictamente con las exigencias del Código Técnico (CTE-DB-HE 2006). A partir de estos coeficientes se calculan los valores de corte para cada clase de demanda de calefacción.

El Indicador de eficiencia energética de calefacción se utiliza para comparar los edificios en materia de energía demandada para los servicios de calefacción por la edificación residencial en los barrios de Madrid. Como indicadores energéticos complementarios (también en base anual, y referidos a la unidad de superficie útil del edificio) el procedimiento de certificación permite complementar también los siguientes para hacer un análisis completo de todos los servicios energéticos existentes en las viviendas de forma simplificada. Para la estimación del resto de indicadores sería necesario continuar el desarrollo de la herramienta HEEPEC en ese sentido.

- Energía demandada por el edificio para otros servicios principales (en uso residencial son refrigeración y Agua Caliente Sanitaria).

- Desglose del consumo de energía primaria para los servicios principales del edificio

- Desglose de las emisiones de CO2 para los servicios principales del edificio.

El estudio se centra en la demanda de calefacción porque se asume que es altamente dependiente de las pérdidas energéticas que se producen a través de la envolvente en edificios de mala calidad térmica, como se pretende demostrar en este trabajo. La demanda de refrigeración en cambio, se ve altamente influenciada por otras circunstancias como son su ubicación y el entorno próximo. La orientación de sus fachadas, el tamaño de huecos o las obstrucciones solares repercuten en gran medida sobre ella, lo cual dificulta realizar una caracterización a partir de su clasificación por periodo de construcción, siendo necesario realizar análisis en detalle que permitan estudiar parámetros urbanos que influyen en el soleamiento. Por esta razón en este procedimiento se ha optado por comenzar la herramienta considerando exclusivamente el indicador de calefacción. 


\subsubsection{Simulación energética de edificios tipo}

Para la estimación de la demanda energética de calefacción a la escala urbana, se han utilizado resultados obtenidos a partir de la simulación de edificios representativos del parque (edificios tipo). Esta metodología se ha utilizado previamente en algunos trabajos para la determinación de los consumos del parque edificado en diferentes países europeos (Kavgic et al. 2010; Cheng y Steemers 2011; É. Mata, Kalagasidis, y Johnsson 2013; Tuominen et al. 2014; Serrano-Lanzarote et al. 2016; Loga, Stein, y Diefenbach 2016). Se trata de un análisis de abajo a arriba en el que se extrapolan los resultados obtenidos de una muestra de edificios, analizada en detalle, al resto del parque edificado (Figura 39). La generalización de los resultados se apoya en el uso de datos estadísticos de superficie de vivienda y periodo de construcción (INE 2001; 2011). El procedimiento para la estimación de la demanda de calefacción de los edificios tipo se desarrolla en profundidad en (Martín-Consuegra 2014).

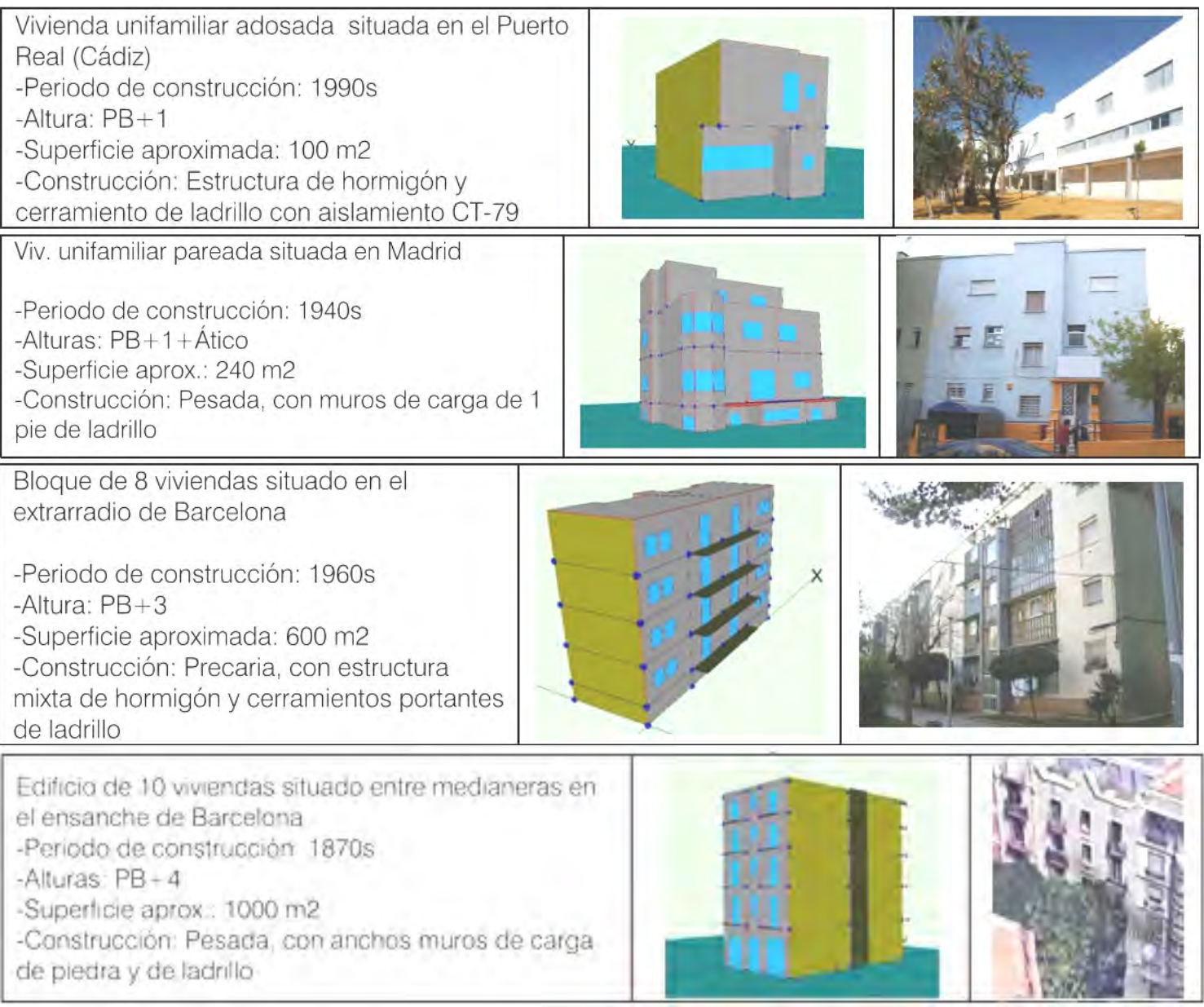

Figura 39. Características de los edificios tipo simulados en el clima de Madrid. Elaboración propia 
Se busca obtener valores de demanda de calefacción promedio de los edificios de cada periodo, definidos de acuerdo con la normativa vigente en materia de eficiencia energética en el momento de su construcción (NBE-CT-79 1979; CTE-DB-HE 2006; 2013). Se parte de la premisa de que todos los edificios anteriores a 1979 carecen de aislamiento térmico. Los resultados para los edificios tipo se obtienen mediante simulación energética dinámica horaria del año completo. Se ha utilizado la Herramienta Unificada LIDER-CALENER (HULC), desarrollada para el cumplimiento del Código Técnico de la Edificación, para la evaluación de la demanda energética. Para todos los edificios existentes se ha considerado la descripción operacional acorde con las premisas de la normativa de eficiencia energética española (CTE-DB-HE 2013) y una tasa de ventilación de una renovación de aire a la hora. Introduciendo datos reales de sus superficies, geometría y la definición constructiva de sus envolventes. Para la caracterización de los elementos de la envolvente se han tomado los valores de transmitancia térmica correspondientes a la normativa en vigor en el momento de su construcción. Para los edificios anteriores a 1979 se han calculado los valores de las soluciones reales de los edificios analizados utilizando el documento de apoyo (CTE DA DB-HE / 1 2015).

Se ha realizado una simulación energética para cada una de los 4 edificios analizados incluyendo en detalle toda su envolvente térmica. A continuación, se simulan estos mismos edificios sustituyendo los elementos de su envolvente por otros con las características de los 4 periodos de construcción analizados. En total se estima la demanda de 16 edificios tipo.

Tabla 9. Resultados de la simulación de edificios tipo en Madrid $\left(\mathrm{kWh} / \mathrm{m}^{2}\right)$. Elaboración propia

\begin{tabular}{|l|l|l|l|l|}
\hline \multirow{2}{*}{$\begin{array}{l}\text { TIPO DE EDIFICIO } \\
\text { *edificio original }\end{array}$} & \multicolumn{4}{l|}{ Demanda calefacción por periodo de construcción } \\
\cline { 2 - 5 } & $<1979$ & $\mathbf{1 9 7 9 - 2 0 0 6}$ & HE 2006 & HE 2013 \\
\hline $\begin{array}{l}\text { 1 Unifamiliar adosado años 90 } \\
\text { PB+1, calidad constructiva estándar }\end{array}$ & 122,89 & $79,13^{*}$ & 71,61 & 40,00 \\
\hline $\begin{array}{l}\text { 2 Unifamiliar aislada años 40 } \\
\text { PB+2, alta calidad constructiva }\end{array}$ & $109,90^{*}$ & 87,50 & 72,82 & 40,00 \\
\hline $\begin{array}{l}3 \text { Multifamiliar en bloque (1) años } 60 \\
\text { PB+3 baja calidad constructiva }\end{array}$ & $147,77^{*}$ & 97,23 & 79,11 & 52,00 \\
\hline $\begin{array}{l}5 \text { Multifamiliar en manzana cerrada } \\
\text { PB+4, construcción pesada <1900 }\end{array}$ & $116,53^{*}$ & 78,26 & 72,54 & 52,00 \\
\hline Variabilidad de resultados & $109-148$ & $78-97$ & $58-79$ & $40-52$ \\
\hline valor medio obtenido & 122,42 & 85,56 & 70,87 & 47,2 \\
\hline Porcentaje de reducción & $100,00 \%$ & $69,89 \%$ & $57,89 \%$ & $38,56 \%$ \\
\hline
\end{tabular}


La demanda de calefacción para los edificios de nueva construcción se ha tomado a partir de los valores tabulados para edificios residenciales (tabla 2.1 del CTE DB HE1) para la zona climática de invierno D (correspondiente a Madrid), teniendo en cuenta las superficies medias de las viviendas ( $150 \mathrm{~m} 2$ para unifamiliares y $80 \mathrm{~m} 2$ para viviendas en edificio multifamiliar). El edificio de referencia permite estimar el valor de demanda de calefacción que debería cumplir un edificio existente que se rehabilitase de manera integral para cumplir estrictamente con la normativa. Para el cálculo de la demanda de calefacción de los edificios construidos entre 1979 y 2006 se han tomado los valores de transmitancia térmica (K) establecidos en la NBE CT 79 para la zona climática $Y$, correspondiente al municipio de Madrid.

Se comprueba que los edificios que no poseen aislamiento ofrecen una mayor variabilidad en la horquilla de resultados de demanda de calefacción. Los factores que determinan esta variabilidad pueden ser la compacidad, la orientación, las obstrucciones solares, y la calidad constructiva. Los resultados obtenidos apuntan a una menor influencia de estos factores a medida que aumenta el aislamiento térmico en la envolvente térmica del edificio. La simplificación de incluir todos los edificios construidos con anterioridad a la entrada en vigor de la NBE CT 79 en el mismo grupo se considera por tanto aceptable para el objetivo del presente trabajo, consistente en la estimación de valores medios para cada sección censal. No obstante, a la hora de plantear soluciones concretas se hace necesario un estudio para cada edificio o conjunto.

\subsubsection{Establecimiento del valor unitario de demanda de calefacción por periodo}

Para la obtención del indicador de demanda unitario para cada periodo, se ha optado por adjudicar un valor de demanda energética promedio. Con el objetivo de armonizar los resultados con la escala de calificación energética para la edificación residencial de aplicación en España, se parte del valor máximo de la escala de certificación energética (Tabla 8), adjudicándolo a los edificios anteriores al año 1979. Esto va a permitir identificar con la peor clase energética a aquellas secciones censales en las cuales todos los edificios pertenecen a ese periodo. A partir de este valor estiman valores aproximados para cada periodo según el porcentaje de reducción que supone el valor medio obtenido de las simulaciones energéticas (Tabla 9). 
Tabla 10. Demanda de calefacción adoptada para cada periodo $\left(\mathrm{kWh} / \mathrm{m}^{2}\right)$. Elaboración propia

\begin{tabular}{|l|l|l|l|}
\hline Anterior a $\mathbf{1 9 7 9}$ & $\mathbf{1 9 7 9 - 2 0 0 6}$ & $\mathbf{2 0 0 6 - 2 0 1 3}$ & Posterior a 2013 \\
\hline 132,22 & 92,41 & 76,54 & 52 \\
\hline
\end{tabular}

\subsubsection{Datos estadísticos residenciales utilizados}

El cómputo de la superficie construida dedicada al uso residencial (Figura 40), registrada por el Censo de Población y Viviendas para cada municipio, permite cuantificar aproximadamente la superficie a acondicionar en las viviendas de la ciudad, de forma desagregada por sección censal y clasificada por periodo de construcción (Figura 41). La antigüedad de la edificación determinará en gran parte la necesidad de energía para acondicionar las viviendas durante el invierno. Otro factor a analizar será la densidad de vivienda, que permite estimar de forma aproximada un orden de magnitud de los valores de la demanda total para cualquier área de la ciudad, permitiendo un enfoque sobre las necesidades de infraestructuras de abastecimiento.

\subsubsection{Indicadores energéticos urbanos obtenidos}

La metodología propuesta hace posible estimar el orden de magnitud de la demanda energética total necesaria para mantener en situación de confort las viviendas de la ciudad de Madrid durante un periodo de invierno típico. Se asigna la demanda para cada unidad de superficie de vivienda, en función del periodo de construcción de los edificios en los que se ubican (Tabla 10). Según esta estimación, en el año 2001 era necesario un orden aproximado de $10.750 .000 \mathrm{MW}$ (924.333 kteps) de energía térmica total anual para calefactar toda la edificación residencial de la ciudad de Madrid de acuerdo con las condiciones de confort establecidas en la reglamentación vigente (CTE-DB-HE 2013).

Los resultados del análisis permiten visualizar los datos de las necesidades de calefacción a través de mapas a escala urbana para toda la ciudad de Madrid. Los diferentes puntos de vista a través de los cuales se puede visualizar la información de la eficiencia energética de áreas residenciales permiten distintos acercamientos al problema de la ineficiencia: el indicador de densidad energética (kWh/HA) nos habla de las necesidades totales de suministro, y la calificación energética nos ofrece información acerca de la calidad térmica de los edificios contenidos en el área de análisis. 


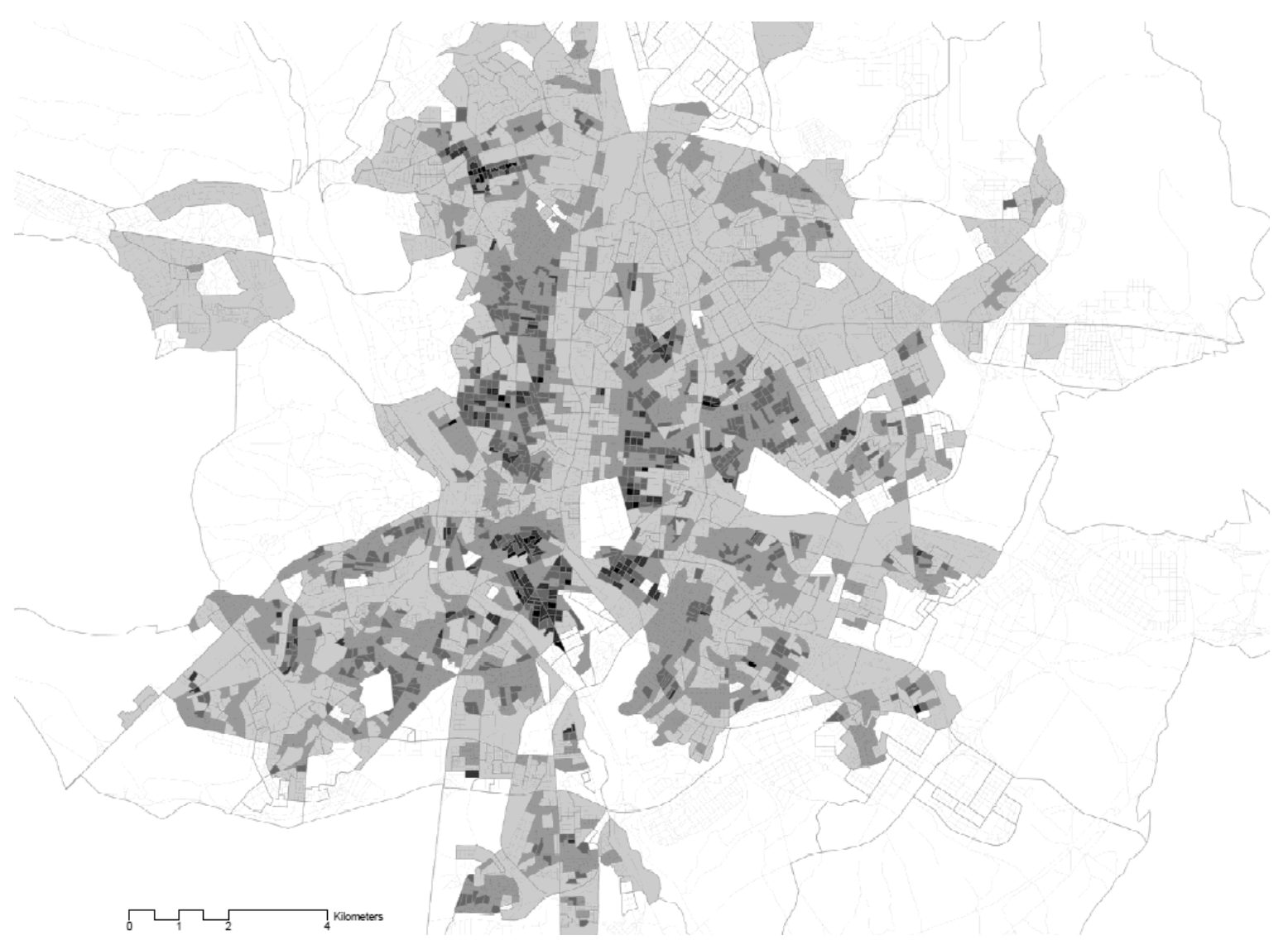

Figura 40. Densidad residencial por sección censal en Madrid (INE 2001)

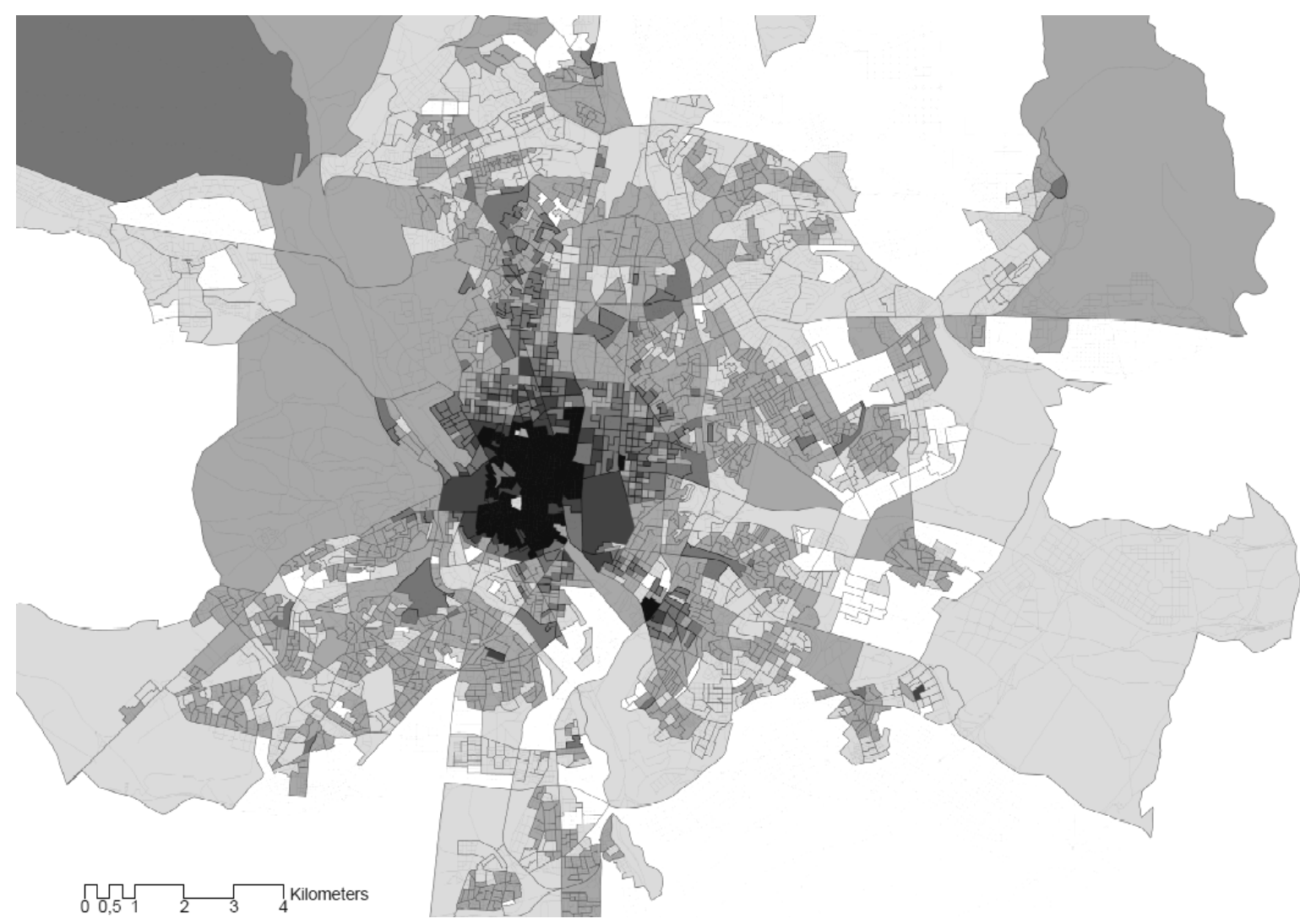

Figura 41. Antigüedad de los edificios de vivienda en Madrid (INE 2001) 


\subsubsection{Indicador de densidad de demanda energética de calefacción}

A partir de los datos de demanda energética totales estimados para la ciudad, se elabora un indicador de necesidades energéticas que permite situar geográficamente las zonas con la mayor demanda de calefacción. Se obtiene a partir de la repercusión de la demanda total anual de calefacción de todas las viviendas de cada área urbana que se analice, por la superficie urbana que ocupa (kWh año / Ha). Este indicador está influido por la calidad de la edificación, la densidad de vivienda y la superficie media de las mismas. El indicador representa la necesidad energética para calefacción y señala los barrios que precisan de un suministro energético mayor dentro de la ciudad. Además, es representativo de la energía disipada producida por la edificación en el caso de demandas satisfechas. Los valores obtenidos se representan mediante una herramienta informática de Sistemas de Información Geográfica para poder analizar su distribución en todas las secciones censales del municipio de Madrid (Figura 42). En el Anexo I.1 se reproducen estos resultados con mayor detalle.

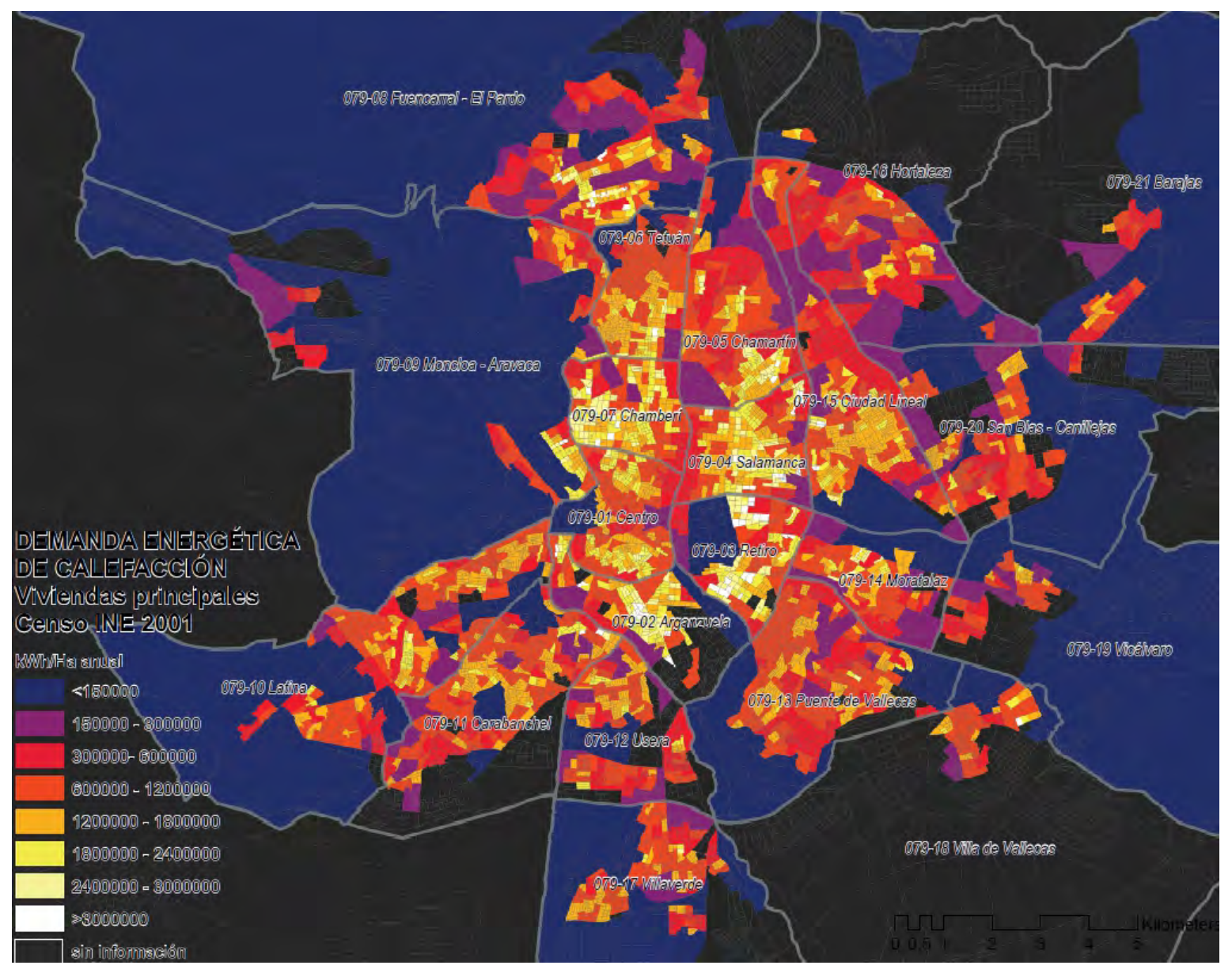

Figura 42. Densidad de demanda de calefacción (MWh/Ha). Elaboración propia 


\subsubsection{Calificación energética de demanda de calefacción por sección censal}

A partir de los datos de demanda totales y de la superficie habitable a calefactar, se puede deducir también un segundo indicador representativo de la calidad térmica media para las viviendas contenidas en cada sección censal (Figura 43). Para ello se repercuten los valores totales de demanda de calefacción obtenidos para todas las viviendas contenidas en cada sección censal por la superficie habitable total de las mismas. De esta forma se obtiene el valor del indicador de la clase en demanda energética de calefacción por unidad de superficie para cada una de ellas $\left(\mathrm{kWh}\right.$ año $\left./ \mathrm{m}^{2}\right)$. Dicho valor es calificado mediante una etiqueta energética ( $\mathrm{A}$ - F), de acuerdo con la clasificación propuesta por el procedimiento de calificación energética establecido para los edificios residenciales existentes (IDAE 2011a). Se trata de una trasposición de la Escala de calificación energética para edificios existentes a la dimensión urbana, que posibilita analizar la edificación en su conjunto y detectar los ámbitos de la ciudad en los que se concentran las bolsas de edificación más ineficiente.

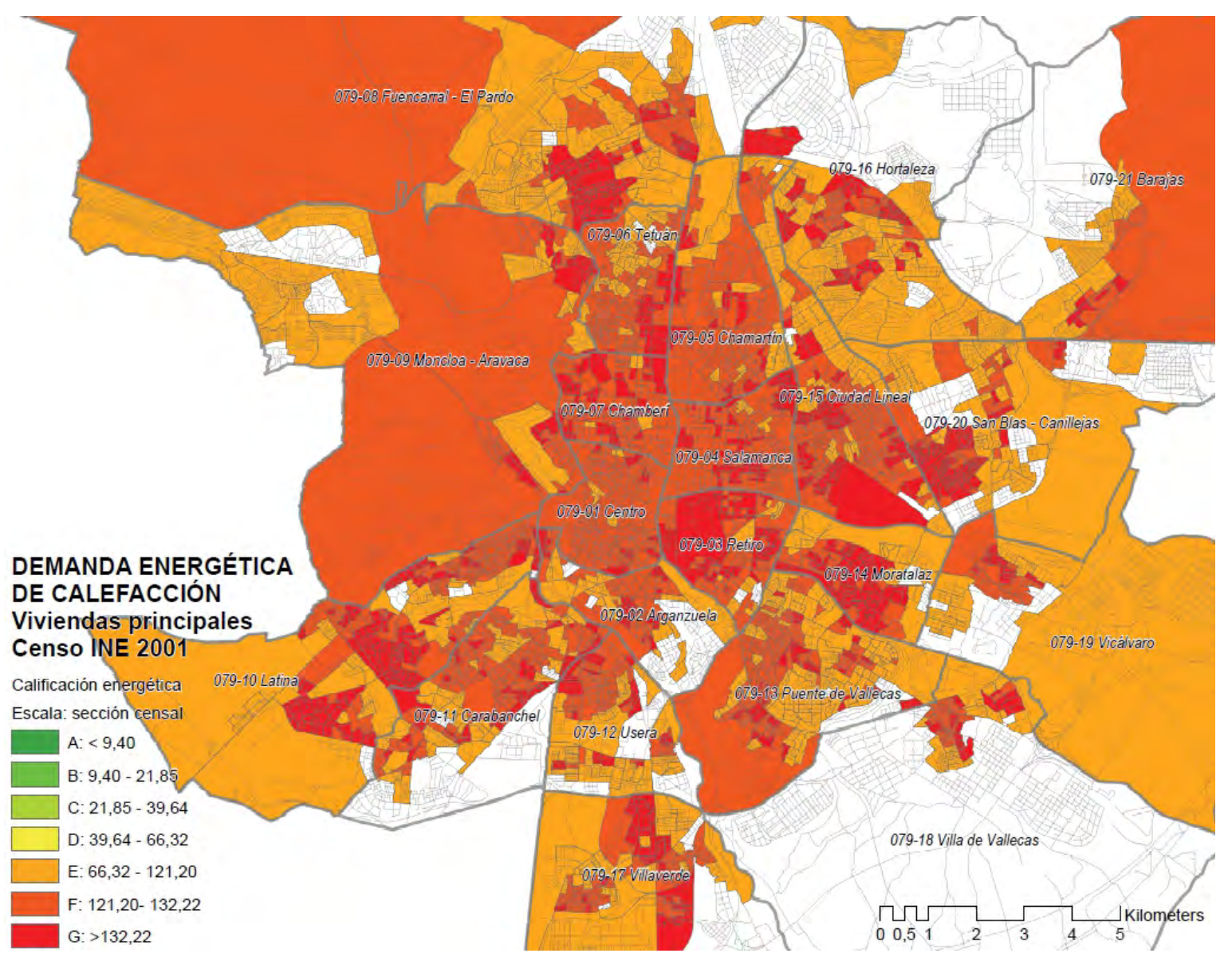

Figura 43. Calificación energética de demanda de calefacción residencial (kWh/m2). Elaboración propia 
Según la metodología propuesta, para la ciudad de Madrid se obtendría una demanda de calefacción media de 123,65 kWh/m2 al año, lo que le otorgaría una clase energética de demanda energética a la ciudad correspondiente a una etiqueta F. Este valor se asemeja bastante al ofrecido por el IDAE para edificios existentes en bloque multifamiliar para el clima de Madrid (Tabla 7 y Tabla 8). En el Anexo I.1.2 se detalla este resultado incluyendo datos actualizados del Censo de 2011.

\subsubsection{La clasificación energética de los Barrios Vulnerables}

La localización de los barrios vulnerables de la ciudad en los que existe edificación residencial ineficiente se consigue cruzando los datos de calificación energética obtenida para cada área urbana con los datos del Atlas de la Vulnerabilidad Urbana (Agustín Hernández Aja et al. 2015). De esta manera es posible realizar una primera clasificación básica del estado de los barrios vulnerables en lo referente a la eficiencia energética de la edificación residencial (Figura 44). No se aprecia relación significativa entre las zonas clasificadas como barrios vulnerables y la eficiencia energética de la edificación residencial, dándose diferentes niveles de calidad térmica de la edificación en diferentes barrios.

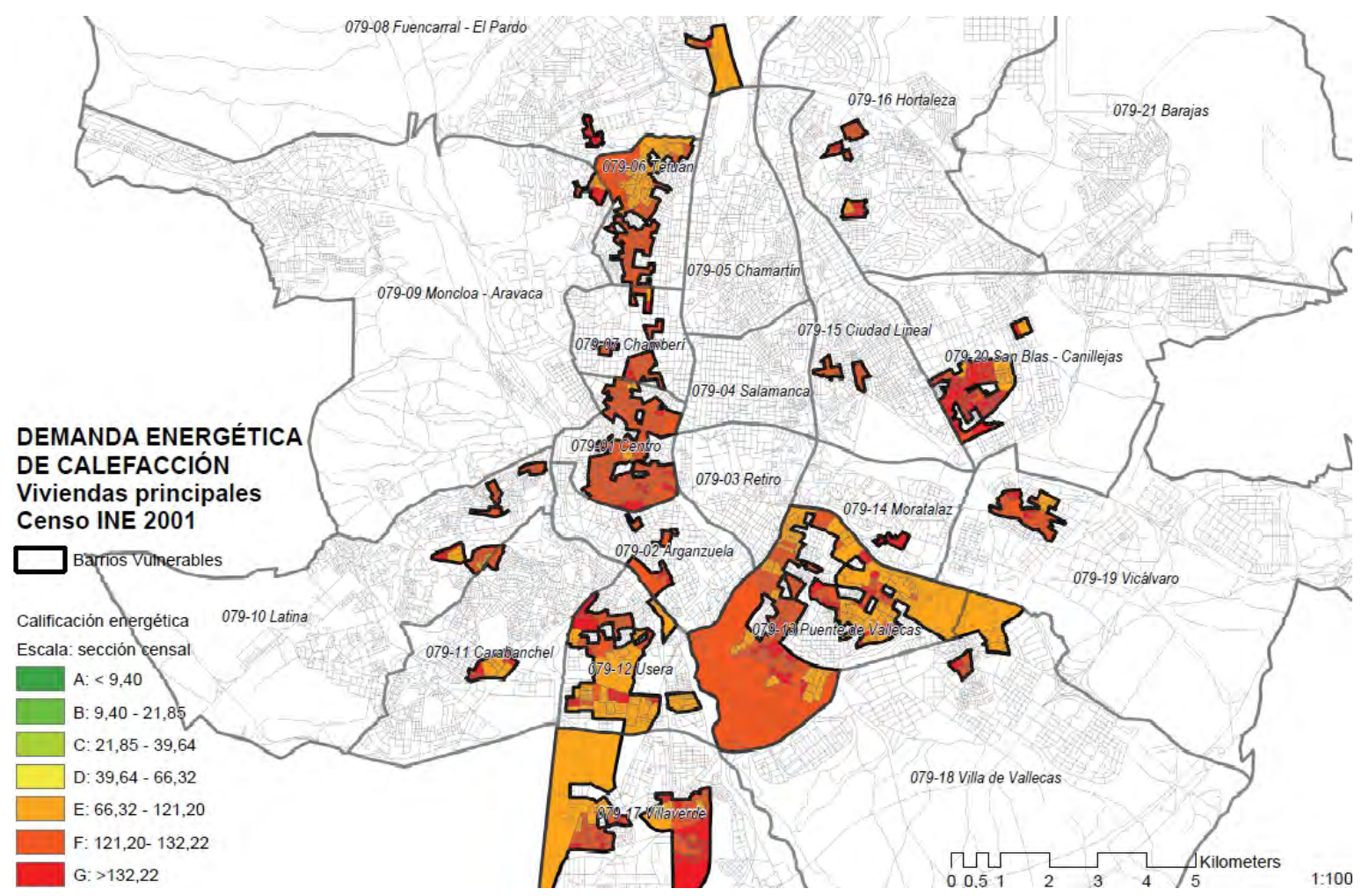

Figura 44. Calificación energética en los barrios vulnerables (2001). Elaboración propia 
Tabla 11. Listado de barrios vulnerables afectados por ineficiencia energética. Elaboración propia

\begin{tabular}{|c|c|c|}
\hline numDist & Distrito & Barrio Vulnerable afectado \\
\hline 1 & Centro & $\begin{array}{l}\text { Embajadores } \\
\text { Cortes } \\
\text { Justicia }\end{array}$ \\
\hline 2 & Arganzuela & La Chopera \\
\hline 7 & Chamberí & $\begin{array}{l}\text { Trafalgar } \\
\text { Ríos Rosas }\end{array}$ \\
\hline 8 & Fuencarral- el Pardo & $\begin{array}{l}\text { El Pilar } \\
\text { Valverde }\end{array}$ \\
\hline 9 & Aravaca - Moncloa & Valdezarza \\
\hline 10 & Latina & Lucero \\
\hline 11 & Carabanchel & $\begin{array}{l}\text { Puerta Bonita } \\
\text { Abrantes }\end{array}$ \\
\hline 12 & Usera & $\begin{array}{l}\text { Moscardo } \\
\text { Zofío } \\
\text { Almendrales } \\
\text { Orcasitas } \\
\text { Orcasur }\end{array}$ \\
\hline 13 & Puente de Vallecas & $\begin{array}{l}\text { Entrevías } \\
\text { San Diego } \\
\text { Palomeras Bajas } \\
\text { Palomeras Sureste } \\
\text { Portazgo } \\
\end{array}$ \\
\hline 14 & Moratalaz & Fontarrón \\
\hline 16 & Hortaleza & $\begin{array}{l}\text { Pinar del Rey } \\
\text { Canillas }\end{array}$ \\
\hline 17 & Villaverde & $\begin{array}{l}\text { San Andrés } \\
\text { San Cristóbal } \\
\text { Los Rosales } \\
\text { Los Ángeles } \\
\end{array}$ \\
\hline 18 & Villa de Vallecas & Casco Histórico de Vallecas \\
\hline 19 & Vicálvaro & $\begin{array}{l}\text { Ambroz } \\
\text { Casco Histórico de Vicálvaro }\end{array}$ \\
\hline 20 & San Blas-Canillejas & $\begin{array}{l}\text { Canillejas } \\
\text { Hellín } \\
\text { Simancas } \\
\text { Arcos } \\
\text { Amposta } \\
\end{array}$ \\
\hline
\end{tabular}

Los barrios vulnerables que contienen secciones censales con etiqueta energética $G$ aparecen representados en la Tabla 11. Este procedimiento se utiliza más adelante para la selección de barrios vulnerables e ineficientes y asociarlos con el Índice Multidimensional de Pobreza Energética (IMPE) (Apartado 2.2.2), que permite el análisis detallado de los barrios vulnerables e ineficientes. 


\subsection{DISTRIBUCIÓN DE LA POBREZA ENERGÉTICA EN MADRID}

A continuación se proponen dos métodos específicos para la detección de la pobreza energética mediante la combinación de los resultados de la demanda de calefacción realizada (Apartado 2.1) y los datos estadísticos socioeconómicos (Apartado 1.2) relacionados espacialmente. La comprobación del método se realiza mediante su aplicación al estudio de caso de la ciudad Madrid.

Se parte de la propuesta de un indicador cuantitativo sencillo, basado en la comparación de gastos e ingresos mediante la regla del 10\% (definida en el Apartado 1.1.5). En un segundo acercamiento se desarrolla un indicador multidimensional que incorpora datos estadísticos socioeconómicos relacionados con las causas y consecuencias de la pobreza energética.

\subsubsection{Método del $10 \%$}

El cálculo del indicador del $10 \%$ se realiza a partir de la incorporación en el modelo MADE de datos acerca de los precios de la energía y de la renta de los hogares por sección censal (Apartado 1.2.1). Para ello se realiza una estimación del coste que supone la factura energética para una vivienda media de Madrid en la cual se cumplen los estándares de confort, calculados a partir de la suposición de demandas satisfechas. A partir de la relación entre ambos cuerpos de datos se puede deducir la presión en la renta del hogar que tiene la factura energética y por tanto tener un indicador de Pobreza Energética para cada sección censal de la ciudad. La metodología se aplica al caso de la ciudad de Madrid (España). En el proceso de estimación del coste de los servicios energéticos por hogar se desentrama el peso que juegan los distintos factores que influyen en el mismo: la calidad de la construcción, las instalaciones térmicas más utilizadas, los tipos de suministro de energía empleados para satisfacer las necesidades del hogar y la estructura tarifaria del sector energético español.

El enfoque de este trabajo se dirige principalmente al consumo de energía en calefacción. Además se aborda también el gasto correspondiente a otros consumos energéticos domésticos de forma simplificada. 


\subsubsection{Método de cálculo}

Para el desarrollo de este método se entiende la pobreza energética como la confluencia de factores que llevan a un consumo de energía que se considera excesivo en relación con la renta disponible en los hogares. Se localizan las secciones censales en las que el gasto en facturas energéticas de las viviendas principales supone una proporción excesiva de los ingresos del hogar en base anual, de acuerdo con la definición clásica de pobreza energética. Para ello se comparan los datos de ingresos medios por hogar de cada sección (nivel de renta media), con el promedio del gasto equivalente en facturas energéticas en los hogares que contiene, estableciendo el umbral de la pobreza energética en el $10 \%$ de la renta.

\section{Consumo energético en calefacción estimado para la vivienda media en Madrid}

De acuerdo con el proyecto Sech-Spahousec (IDAE 2011b), en las viviendas de la zona centro de España la calefacción es el consumo energético mayoritario, representando el $55 \%$ del consumo total por vivienda. A partir de la demanda media de calefacción de cada clase (Tabla 7) ha sido posible caracterizar las necesidades energéticas de calefacción de forma simplificada para todas las viviendas de una sección censal (Apartado 2.1.4). Para el desarrollo de este indicador de demanda se asume la suposición de que todos los habitantes tienen derecho a la energía, es decir a unas condiciones de confort mínimas durante el invierno y por tanto que los hogares están a una temperatura adecuada.

El consumo se ha estimado a partir del cálculo de la demanda y de la información recopilada acerca del tipo de sistema utilizado para calefacción (información recopilada en el Apartado 1.2.2). Para los casos en los que la fuente de energía es el gas natural se ha considerado un rendimiento del $75 \%$ correspondiente al sistema más utilizado en la zona mediterránea continental de España: la caldera individual (IDAE 2011b). En el caso de que el sistema empleado para calefacción sea la electricidad por efecto Joule, se supone un rendimiento del $100 \%$ de manera conforme a lo establecido en el procedimiento de certificación energética de edificios existentes vigente (EFINOVATIC y CENER 2016). 
Tabla 12.Transformación de datos de demanda a consumo para calefacción para la vivienda media en Madrid. Elaboración propia a partir de datos (INE 2001; 2011)

\begin{tabular}{|l|l|l|l|l|l|l|}
\hline $\begin{array}{l}\text { Superficie } \\
\text { total }\left(\mathbf{m}^{\mathbf{2}}\right)\end{array}$ & $\begin{array}{l}\text { Viviendas } \\
\text { (Uds.) }\end{array}$ & $\begin{array}{l}\text { Sup } \\
\text { media } \\
\left(\mathbf{m}^{\mathbf{2}}\right)\end{array}$ & $\begin{array}{l}\text { Demanda CAL } \\
\text { unitaria anual } \\
\left(\mathbf{k W h} / \mathbf{m}^{\mathbf{2}}\right)\end{array}$ & $\begin{array}{l}\text { Demanda CAL } \\
\text { anual por } \\
\text { vivienda } \\
(\mathbf{k W h})\end{array}$ & $\begin{array}{l}\text { Consumo CAL } \\
\text { anual Electricidad } \\
(\mathbf{k W h})\end{array}$ & $\begin{array}{l}\text { Consumo CAL } \\
\text { anual gas natural } \\
(\mathbf{k W h})\end{array}$ \\
\hline 106.646 .084 & 1.320 .531 & 80,76 & 124,00 & 10.014 & 10.014 & 13.352 \\
\hline
\end{tabular}

Por tanto en estos casos el consumo se iguala a la demanda. Para hacer una estimación de una vivienda habitual se ha utilizado el valor medio de superficie de vivienda en Madrid de 80,76 m2, (INE 2011). Se obtienen por tanto datos de demanda y consumo por vivienda represados en la Tabla 12.

Siguiendo estos mismos pasos es posible hallar una estimación aproximada de los consumos energéticos de calefacción que tendrían las diferentes calidades energéticas conforme a las distintas clases de demanda (para la vivienda de tamaño medio), siendo la clase A la más eficiente y la G la que más energía demanda. Se calcula el consumo energético ( $\mathrm{kWh}$ anual) necesario para satisfacer la demanda energética para cada clase energética de la escala establecida en el procedimiento de certificación. En el caso de la clase energética $\mathrm{G}$ no es posible utilizar un valor medio, así que se ha utilizado el valor límite para caracterizar las viviendas que se encuentran en esa circunstancia, que son las de peor calidad térmica de la ciudad. Se calcula el consumo energético ( $\mathrm{kWh}$ ) necesario para satisfacer la demanda energética para cada clase energética de la escala establecida en el procedimiento de certificación (Tabla 13).

Tabla 13. Transformación de datos unitarios de demanda a consumo para cada clase en zona climática D (Madrid). Elaboración propia

\begin{tabular}{|l|l|l|l|}
\hline $\begin{array}{l}\text { Clase demanda } \\
\text { calefacción }\end{array}$ & $\begin{array}{l}\text { Demanda CAL unitaria } \\
\left(\mathbf{k W h} / \mathbf{m}^{\mathbf{2}}\right)\end{array}$ & $\begin{array}{l}\text { Demanda CAL total y } \\
\text { Consumo eléctrico total }(\mathbf{k W h})\end{array}$ & $\begin{array}{l}\text { Consumo gas total } \\
(\mathbf{k W h})\end{array}$ \\
\hline A & 9,40 & 759 & 1.012 \\
\hline B & 15,63 & 1.262 & 1.683 \\
\hline C & 30,75 & 2.483 & 3.311 \\
\hline D & 52,98 & 4.279 & 5.705 \\
\hline E & 93,76 & 7.572 & 10.096 \\
\hline F & 126,71 & 10.233 & 13.644 \\
\hline G & 132,22 & 10.678 & 14.237 \\
\hline
\end{tabular}


Coste de la energía para satisfacer la demanda de calefacción de las viviendas en Madrid

Para realizar una estimación del monto de facturación del consumo energético correspondiente al servicio de calefacción se tiene en cuenta el gasto en función del tipo de combustible empleado. De acuerdo con el Censo de 2001 (INE 2001) se comprueba (Tabla 14) que casi el 60\% de los hogares de la ciudad de Madrid emplean el gas natural, que resulta el combustible más económico en el momento del estudio. Un $20 \%$ de hogares emplea el suministro eléctrico para la calefacción y el resto de fuentes de energía (petróleo, madera, carbón) se consideran anecdóticos para una estimación gruesa.

La implantación del tipo de combustible para calefacción también está sujeta a una distribución espacial irregular en la ciudad. Se comprueba que en 2001 la mayor implantación del gas era en las periferias más externas del municipio, de reciente desarrollo (Figura 45). Se constata a su vez una mayor presencia de calefacción eléctrica en el centro de la ciudad y en las zonas periféricas del periodo 40-80. En el centro esto se debe a un factor de antigüedad de la edificación, construida en gran parte con anterioridad a la puesta en marcha de los sistemas de calefacción por fluidos. En el caso de las periferias, las políticas de poblados del periodo de 1940 a 1980 derivaron en la construcción de viviendas de calidad constructiva y prestaciones muy básicas que no incluían estos sistemas. Las viviendas del mismo periodo que se construían en los ensanches decimonónicos de la ciudad sí que contaban con servicio de calefacción, a menudo centralizado, utilizando la combustión continua generalmente con carbón, además de presentar mejores calidades constructivas en la envolvente (Oteiza, I. et al. 2018). En el momento de este estudio los quemadores de carbón han sido mayormente sustituidos. El porcentaje de hogares que utilizan otros combustibles distintos a la electricidad y al gas natural se han asimilado al porcentaje de hogares que utilizan suministro eléctrico.

Tabla 14. Combustible usado para calefacción por número de hogares (INE 2001)

\begin{tabular}{|l|l|l|l|l|l|l|l|}
\hline Gas & Electricidad & Petróleo & Madera & Carbón & Otros & No aplicable & TOTAL \\
\hline 640.321 & 220.904 & 144.224 & 3.808 & 41.837 & 4.368 & 24.844 & 1.080 .306 \\
\hline $59,27 \%$ & $20,45 \%$ & $13,35 \%$ & $0,35 \%$ & $3,87 \%$ & $0,40 \%$ & $2,30 \%$ & $100,00 \%$ \\
\hline
\end{tabular}



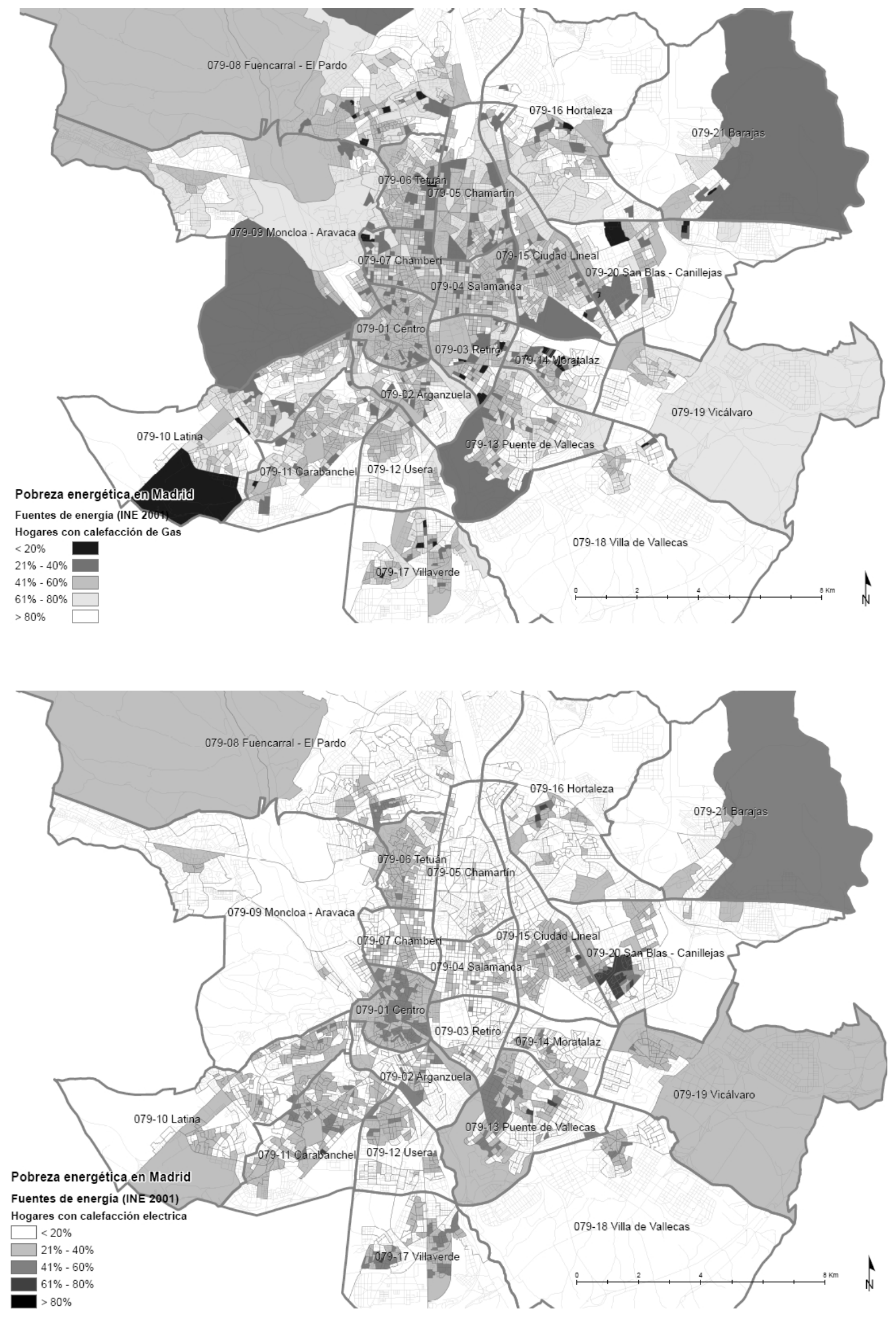

Figura 45. Implantación de calefacción (1) de gas y (2) eléctrica en el municipio de Madrid. Elaboración propia a partir de datos (INE 2001) 
Para la estimación del coste que suponen los consumos en los hogares se ha utilizado el método de cálculo del coste descrito en (C. Alonso, Martín-Consuegra, y Lucas 2013), utilizando la tarifa válida para consumidores domésticos. Se basa en la herramienta WEB "Comparador de Ofertas de Energía: Gas y Electricidad" habilitada por la Comisión Nacional de los Mercados y la Competencia de España que permite consultar las ofertas de gas natural disponibles para consumidores del grupo 3 (hasta 4 bares de presión) y ofertas de electricidad para consumidores en baja tensión (CNM 2017). En el caso de la electricidad se ha supuesto una potencia contratada de 3,30 Kw, tarifa eléctrica normal sin discriminación horaria y sin servicios adicionales. Se comprueba que el precio de la electricidad varía mucho según la compañía que oferte el servicio (de 1.620,13€ a $2.015,78 €$ en el momento de la consulta: julio de 2017). A modo de ejemplo se ha tomado un precio medio, de una suministradora muy establecida en el mercado español.

Se comprueba que el coste para mantener la vivienda en condiciones de confort empleando como combustible el gas natural estaría en torno a $883 €$ anuales, es decir 74 $€$ mensuales si se reparte el gasto a lo largo de todo el año. En el caso de la electricidad el

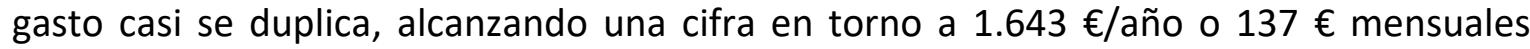
(Tabla 15).

Para poder asociar los consumos medios de cada sección censal y poder visualizar los datos mediante un Sistema de Información Geográfica (GIS) se calculan los costes de calefacción de cada sección censal conforme a las diferentes clases de la escala de calificación energética (Tabla 16 y

Tabla 17). Los cálculos están realizados en todo momento para una vivienda de tamaño medio en Madrid (superficie de $80,76 \mathrm{~m} 2$ ). En ambos casos las estimaciones indican que la estructura tarifaria española resulta en un coste por unidad de energía suministrada más elevado cuanto más bajo es el consumo energético. Para llegar al grado de confort estándar que marca la normativa, aquellos hogares eficientes cuya vivienda está clasificada como clase $A$, deben abonar un precio unitario por kWh que duplica aproximadamente el de la vivienda de clase $\mathrm{G}$ con grandes consumos energéticos. A su vez, los hogares que sufren situaciones de pobreza energética que restringen el uso de la energía para reducir costes se ven penalizados con un mayor precio del kWh. 
Tabla 15. Descomposición de la factura energética anual necesaria para calefactar una vivienda media en Madrid por tipo de suministro. Elaboración propia

\begin{tabular}{|c|c|c|c|c|c|c|c|}
\hline $\begin{array}{l}\text { Tipo de } \\
\text { energía }\end{array}$ & $\begin{array}{l}\text { Consumo } \\
\text { (kWh) }\end{array}$ & \begin{tabular}{|l|} 
Consumo \\
$(€)$
\end{tabular} & \begin{tabular}{|l|} 
Término fijo o \\
de potencia $(€)$ \\
\end{tabular} & $\begin{array}{l}\text { Impuesto } \\
\text { HC/elec (€) }\end{array}$ & $\begin{array}{l}\text { Subtotal } \\
\text { (€) }\end{array}$ & $\begin{array}{l}\text { IVA 21\% } \\
\text { (€) }\end{array}$ & \begin{tabular}{|l|} 
Total \\
(€/año)
\end{tabular} \\
\hline Gas & 13.352 & 597,21 & 101,40 & 31,24 & 729,86 & 31,24 & 883,13 \\
\hline Electricidad & 10.014 & $1.155,74$ & 135,82 & 66,03 & $1.357,59$ & 285,09 & $1.642,68$ \\
\hline
\end{tabular}

Tabla 16. Descomposición de la factura de gas para calefacción por clases para la zona climática D (Madrid). Elaboración propia

\begin{tabular}{|c|c|c|c|c|c|c|c|c|}
\hline clase & $\begin{array}{l}\text { Consumo } \\
\text { (kWh) }\end{array}$ & $\begin{array}{l}\text { Consumo } \\
(€)\end{array}$ & $\begin{array}{l}\text { Término } \\
\text { Fijo }(€)\end{array}$ & $\begin{array}{l}\text { Impuesto } \\
\mathrm{HC}(€)\end{array}$ & $\begin{array}{l}\text { Subtotal } \\
(€)\end{array}$ & $\begin{array}{l}\text { IVA 21\% } \\
(€)\end{array}$ & $\begin{array}{l}\text { Total } \\
\text { (€/año) }\end{array}$ & $\begin{array}{l}\text { Coste kWh } \\
\text { (€/kWh) }\end{array}$ \\
\hline A & 1.012 & 52,22 & 51,72 & 2,37 & 106,31 & 22,33 & 128,63 & 0,1271 \\
\hline B & 1.683 & 86,85 & 51,72 & 3,94 & 142,50 & 29,93 & 172,43 & 0,1025 \\
\hline C & 3.311 & 170,86 & 51,72 & 7,75 & 230,32 & 48,37 & 278,69 & 0,0842 \\
\hline D & 5.705 & 255,17 & 101,40 & 13,35 & 369,92 & 77,68 & 447,61 & 0,0785 \\
\hline$E$ & 10.096 & 451,58 & 101,40 & 23,62 & 576,60 & 121,09 & 697,69 & 0,0691 \\
\hline $\mathrm{F}$ & 13.644 & 610,27 & 101,40 & 31,93 & 743,60 & 156,16 & 899,76 & 0,0659 \\
\hline G & 14.237 & 636,80 & 101,40 & 33,31 & 771,51 & 162,02 & 933,53 & 0,0656 \\
\hline
\end{tabular}

Tabla 17. Descomposición de la factura de electricidad para calefacción por clases, zona climática D (Madrid). Elaboración propia

\begin{tabular}{|c|c|c|c|c|c|c|c|c|}
\hline clase & $\begin{array}{l}\text { Consumo } \\
\text { (kWh) }\end{array}$ & $\begin{array}{l}\text { Consumo } \\
\text { (€) }\end{array}$ & $\begin{array}{l}\text { Termino de } \\
\text { potencia }(€)\end{array}$ & $\begin{array}{l}\text { Impuesto } \\
\text { elec }(€)\end{array}$ & \begin{tabular}{|l} 
Subtotal \\
(€)
\end{tabular} & $\begin{array}{l}\text { IVA 21\% } \\
\text { (€) }\end{array}$ & $\begin{array}{l}\text { Total } \\
\text { (€/año) }\end{array}$ & $\begin{array}{l}\text { Coste kWh } \\
\text { (€/kWh) }\end{array}$ \\
\hline A & 759 & 87,60 & 135,82 & 11,42 & 234,84 & 49,32 & 284,15 & 0,3744 \\
\hline B & 1,262 & 145,65 & 135,82 & 14,39 & 295,86 & 62,12 & 357,99 & 0,2837 \\
\hline C & 2,483 & 286,57 & 135,82 & 21,60 & 442,98 & 93,24 & 537,22 & 0,2164 \\
\hline D & 4,279 & 493,85 & 135,82 & 32,19 & 661,86 & 138,99 & 800,85 & 0,1872 \\
\hline $\mathrm{E}$ & 7,572 & 873,90 & 135,82 & 51,62 & $1.061,34$ & 222,88 & $1.284,22$ & 0,1696 \\
\hline $\mathrm{F}$ & 10,233 & $1.181,01$ & 135,82 & 67,33 & $1.384,15$ & 290,67 & $1.674,82$ & 0,1637 \\
\hline G & 10,678 & $1.232,37$ & 135,82 & 69,95 & $1.438,14$ & 302,01 & $1.740,15$ & 0,1630 \\
\hline
\end{tabular}

En la zona climática continental de España, en la que se encuentra Madrid, los sistemas de calefacción centralizada en edificios multifamiliares están presentes en el 18\% de los hogares (IDAE 2011b). Dichos sistemas presentan mejores rendimientos que los de la caldera individual, lo que reduciría los costes energéticos. Las instalaciones de calefacción por distrito presentan balances todavía más efectivos en la gestión de los recursos energéticos, reduciéndose aun más los costes (Song, Li, y Wallin 2017). No 
obstante la implantación de estos últimos en la ciudad de Madrid se reduce a unos pocos casos anecdóticos, siendo conocidas las redes de la Ciudad Universitaria de Madrid, la Colonia de la Esperanza, el Barrio Altamira y la Meseta de Orcasitas. En el presente estudio las instalaciones colectivas no han sido tenidas en cuenta, asimilándose a los sistemas individuales, consiguiendo así el objetivo de desvelar los casos más críticos y simplificando la metodología.

\section{Estimación del consumo total de todos los servicios}

La metodología para la estimación de la pobreza energética empleada hace referencia al porcentaje de ingresos del hogar que representa el gasto total en facturas energéticas, y no solo el gasto en calefacción. Para poder comparar los valores de Renta con la factura, es necesario estimar cual sería el coste total de la misma añadiendo el resto de servicios. Además del 55\% de la energía utilizado en la calefacción para la zona centro, el resto de consumos se refiere a electrodomésticos $(17,6 \%)$, ACS $(17,4 \%)$, cocina $(6,5 \%)$, iluminación (2,6\%) y aire acondicionado (0,7\%) (IDAE 2011b).

Para el cálculo del consumo energético total se añade al coste del suministro de energía para calefacción el del resto de los servicios (Tabla 18), conforme a las estimaciones del IDAE (4403,7kWh). Para estos usos se ha considerado, de forma simplificada para todos los casos, que se utiliza la energía eléctrica. Estos valores se suman al consumo de energía para calefacción. Se entiende que en el caso de las viviendas con calefacción eléctrica no procede computar por segunda vez la cantidad correspondiente al término de potencia y por lo tanto se ha sumado únicamente este valor para la estimación de la factura correspondiente a las viviendas que se calefactan por gas.

La Tabla 19 representa los resultados de consumos energéticos totales anuales (para calefacción y resto de usos) para una vivienda media de Madrid (clase en demanda de calefacción F y superficie de 80,76 m2).

De la misma forma resulta posible calcular los costes totales, tanto energético como económico, para la vivienda media de cada clase de demanda de calefacción (Tabla 20). Se obtiene a partir de la adición del coste correspondiente a "resto de usos" al coste de suministro energético para calefacción calculado anteriormente. 
Tabla 18. Descomposición de la factura de electricidad para otros usos. Elaboración propia

\begin{tabular}{|c|c|c|c|c|c|c|c|}
\hline $\begin{array}{l}\text { Tipo de } \\
\text { calefacción }\end{array}$ & $\begin{array}{l}\text { Consumo } \\
(\mathrm{kWh})\end{array}$ & $\begin{array}{l}\text { Consumo } \\
(€)\end{array}$ & $\begin{array}{l}\text { Termino de } \\
\text { potencia }(€)\end{array}$ & $\begin{array}{l}\text { Impuesto } \\
\text { elec (€) }\end{array}$ & $\begin{array}{l}\text { Subtotal } \\
(€)\end{array}$ & $\begin{array}{l}\text { IVA 21\% } \\
\text { (€) }\end{array}$ & $\begin{array}{l}\text { Total } \\
\text { (€/año) }\end{array}$ \\
\hline Gas & 4.404 & 508,27 & 135,82 & 32,93 & 677,02 & 142,17 & 819,20 \\
\hline Eléctrica & 4.404 & 508,27 & 0 & 25,97 & 534,24 & 112,19 & 646,43 \\
\hline
\end{tabular}

Tabla 19. Consumo total para la vivienda media en Madrid. Elaboración propia

\begin{tabular}{|l|l|l|l|l|l|}
\hline $\begin{array}{l}\text { Tipo de } \\
\text { calefacción }\end{array}$ & $\begin{array}{l}\text { Consumo CAL } \\
(\mathbf{k W h})\end{array}$ & $\begin{array}{l}\text { Coste CAL } \\
(\boldsymbol{(})\end{array}$ & $\begin{array}{l}\text { Consumo Resto } \\
(\mathbf{k W h})\end{array}$ & $\begin{array}{l}\text { Coste Resto de usos } \\
(\boldsymbol{(})\end{array}$ & $\begin{array}{l}\text { Coste total } \\
(\boldsymbol{(})\end{array}$ \\
\hline Gas & 13.352 & 883,13 & 4.404 & 819,20 & $1.702,33$ \\
\hline Eléctrica & 10.014 & $1.642,68$ & 4.404 & 646,43 & $2.289,11$ \\
\hline
\end{tabular}

Tabla 20. Consumo total anual por vivienda por clase de demanda de calefacción según fuente de energía (1) gas y (2) eléctrica, para la zona climática D2 (Madrid). Elaboración propia

\begin{tabular}{|c|c|c|c|c|c|c|c|c|c|c|c|c|}
\hline \multicolumn{2}{|c|}{$\begin{array}{c}\text { CALEFACCIÓN DE } \\
\text { GAS } \\
\end{array}$} & \multicolumn{2}{|c|}{ Otros Usos } & \multicolumn{2}{|c|}{ TOTAL } & \multirow{2}{*}{$\begin{array}{c}\text { clase } \\
\text { CAL }\end{array}$} & \multicolumn{2}{|c|}{$\begin{array}{l}\text { CALEFACIÓN } \\
\text { ELECTRICA }\end{array}$} & \multicolumn{2}{|c|}{ Otros usos } & \multicolumn{2}{|c|}{ TOTAL } \\
\hline kWh & $€$ & kWh & $€$ & kWh & $€$ & & kWh & $€$ & kWh & $€$ & kWh & $€$ \\
\hline 1.012 & 129 & 4.404 & 819 & 5.416 & 948 & A & 759 & 284 & 4.404 & 646 & 5.163 & 931 \\
\hline 1.683 & 172 & 4.404 & 819 & 6.087 & 992 & B & 1.262 & 358 & 4.404 & 646 & 5.666 & 1.004 \\
\hline 3.311 & 279 & 4.404 & 819 & 7.715 & 1.098 & C & 2.483 & 537 & 4.404 & 646 & 6.887 & 1.184 \\
\hline 5.705 & 448 & 4.404 & 819 & 10.109 & 1.267 & D & 4.279 & 801 & 4.404 & 646 & 8.683 & 1.447 \\
\hline 10.096 & 698 & 4.404 & 819 & 14.500 & 1.517 & $E$ & 7.572 & 1.284 & 4.404 & 646 & 11.976 & 1.931 \\
\hline 13.644 & 900 & 4.404 & 819 & 18.048 & 1.719 & $\mathbf{F}$ & 10.233 & 1.675 & 4.404 & 646 & 14.637 & 2.321 \\
\hline 14.237 & 934 & 4.404 & 819 & 18.641 & 1.753 & G & 10.678 & 1.740 & 4.404 & 646 & 15.082 & 2.387 \\
\hline
\end{tabular}

Para la estimación del coste del consumo energético total de todas las viviendas de cada sección censal se ha tenido en cuenta la proporción de hogares con calefacción eléctrica y la de gas natural para cada una de ellas. El resto de fuentes de energía se han asimilado, de forma simplificada, a la de electricidad. Utilizando el procedimiento propuesto, es posible calcular el coste medio de la factura energética de manera detallada. La distribución de la factura media para cada sección censal aparece representada en el plano de la Figura 46. El análisis arroja unas diferencias importantes en el coste de las facturas de las áreas más eficientes (1509 € anuales) a las más ineficientes (2.224 € anuales). 


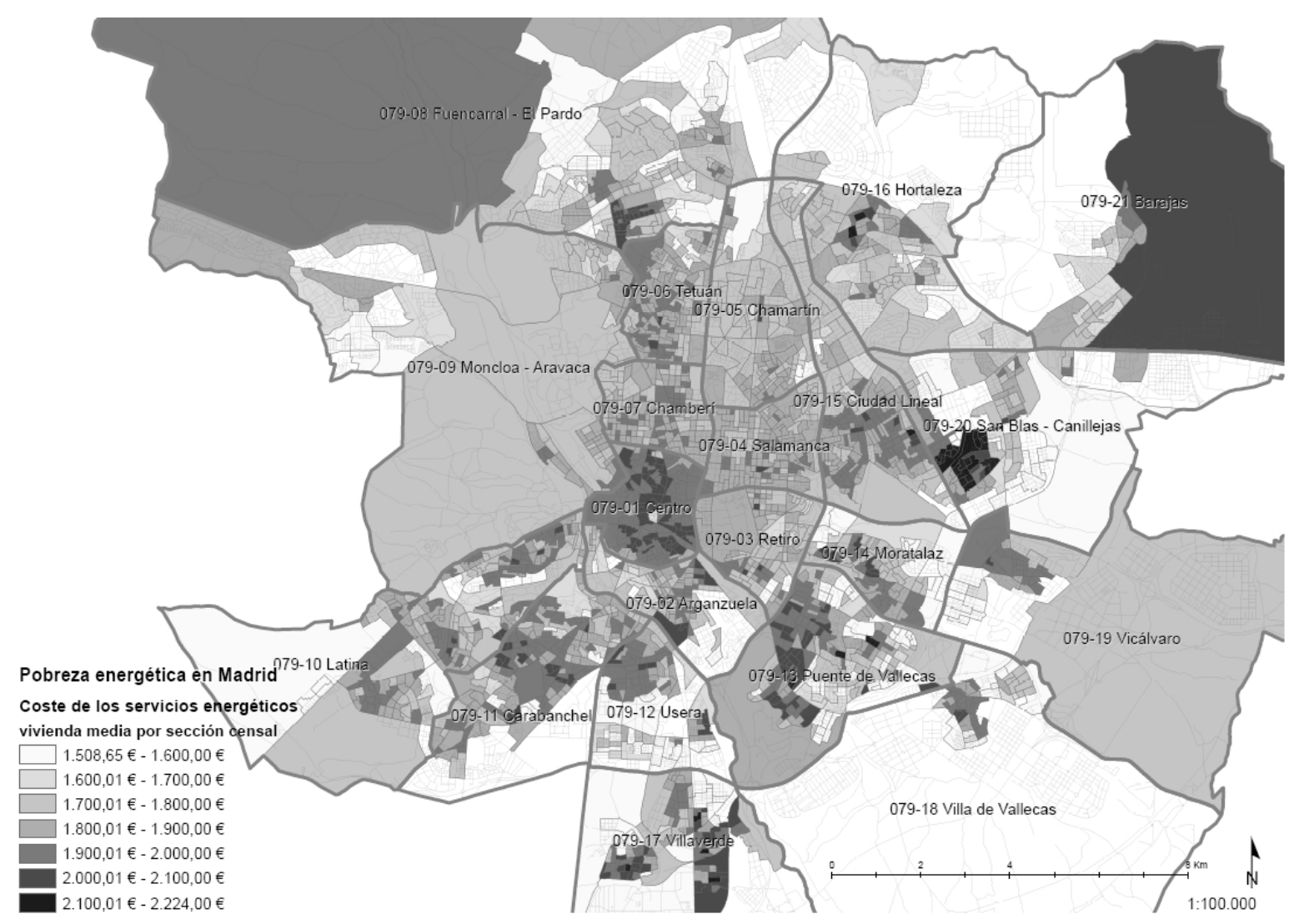

Figura 46. Distribución del coste anual del consumo energético residencial medio por sección censal. Elaboración propia

\section{Nivel de Renta}

Una vez se ha volcado en el modelo datos sobre el gasto energético medio necesario para conseguir unos servicios básicos de energía para cada sección censal, resulta necesario incorporar datos correspondientes al nivel de renta de los hogares. De los datos de renta existentes en la literatura para Madrid (Apartado 1.2.1), se ha utilizado el correspondiente al nivel de renta por tramos, por ser el único con suficiente detalle como para caracterizar las secciones censales (Ayuntamiento de Madrid 2018). Esto va a permitir establecer comparaciones con las estimaciones de demanda, consumo y precio de la energía realizados en el presente trabajo para la misma escala. Por debajo del tramo inferior (Tramo 1) se han incluido estimaciones para los valores de renta correspondientes al Salario Mínimo Interprofesional (SMI) descrito por el Ministerio de Empleo y Seguridad Social (EmpleoGob 2015), y a la Renta Mínima de Inserción (RMI) definida en el ámbito de la Comunidad Autónoma de Madrid (CAM 2017). 


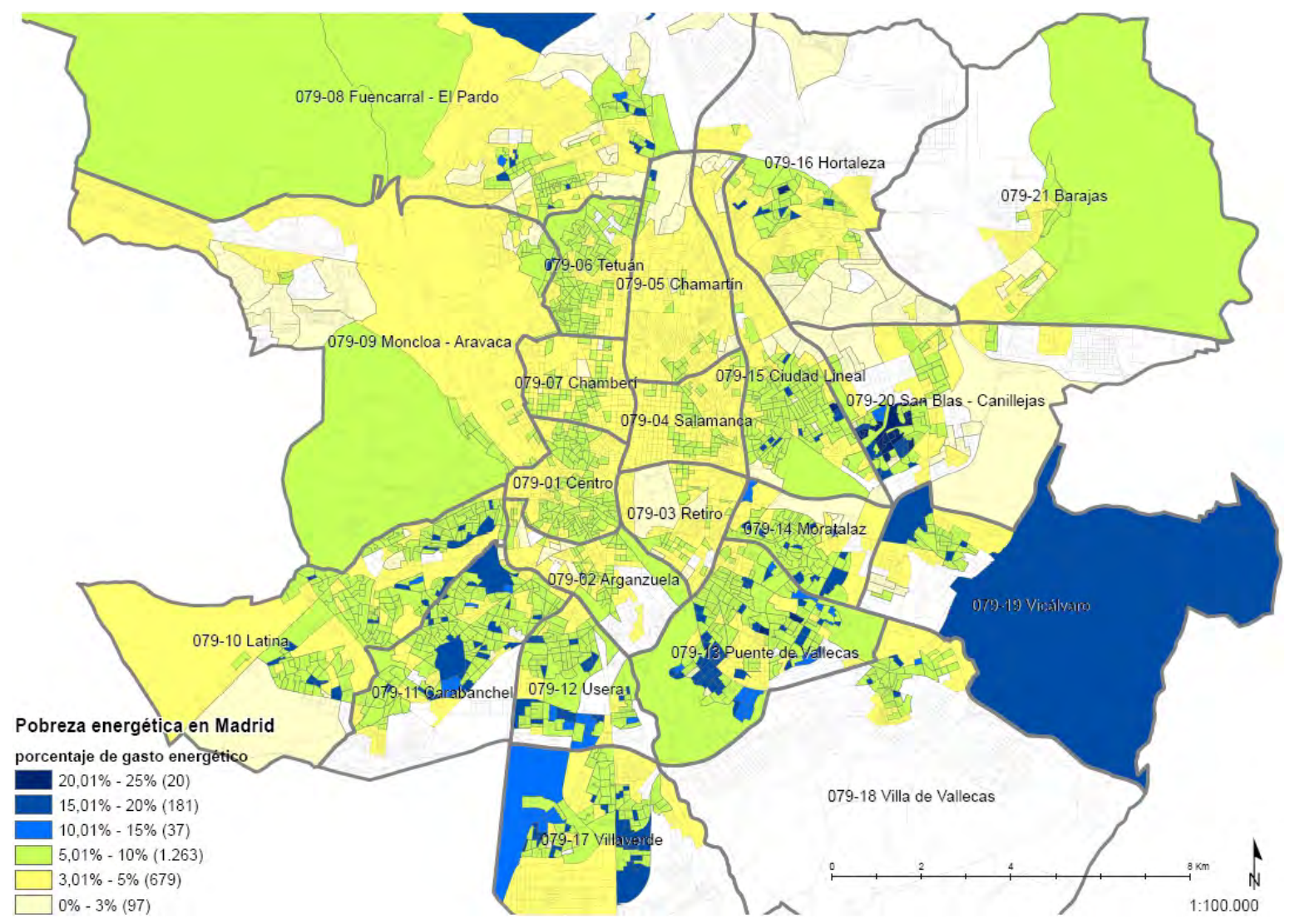

Figura 47. Mapa de la pobreza energética en Madrid. Elaboración propia

\subsubsection{Resultados de pobreza energética obtenidos mediante la regla del $10 \%$}

Finalmente se calcula la relación entre el valor medio del gasto en servicios energéticos de las viviendas principales y la renta media disponible por hogar, para cada sección censal. Para el contraste de los datos se han utilizado los valores medios de cada clase de demanda energética y los valores medios de cada tramo de renta. En lo que respecta a la etiqueta energética, para la clase $\mathrm{A}$ se ha utilizado el valor medio. Para la peor clase $(G)$ y el tramo de renta más alto, se ha optado por utilizar los límites inferiores, puesto que no es posible hacer estimaciones acerca del valor medio.

La Figura 47 representa el mapa de la pobreza energética de Madrid obtenido mediante la aplicación de la regla del 10\%. Quedan representadas las secciones censales conforme a una clasificación en 6 tramos y destacadas aquellas que superan el indicador de pobreza energética del $10 \%$. Para la representación en el mapa, se han considerado viviendas de tamaño medio y el precio por kWh necesario para satisfacer la demanda de calefacción correspondiente a la clase en demanda de cada sección censal, sumándole el coste para el consumo del "resto de usos" energéticos. 
En general, la almendra central aparece libre de pobreza energética, concentrándose el problema en áreas de periferia. A pesar de que la rehabilitación de la edificación en el centro ha incorporado sistemas de calefacción individual por gas natural en edificios de viviendas, esta implantación no supera aun el 50\%. No obstante, el área central no cae en problemas de pobreza energética por tener, en general, rentas más altas que las de la periferia. Los edificios de los ensanches decimonónicos de la ciudad, además de presentar mejores calidades constructivas en la envolvente, sí que suelen contar con servicio de calefacción, con mayor implantación de sistemas centralizados (Oteiza, I. et al. 2018). En las periferias en cambio, los niveles de renta más bajos, unidos a la mala calidad constructiva y una menor presencia de sistemas de calefacción apropiados derivan en unos mayores índices de pobreza energética. Destaca el caso de San Blas, con grandes extensiones de edificación residencial con la menor implantación de calefacción por gas de la ciudad.

En las tablas 21 y 22 se puede comprobar la presión del coste de la factura energética sobre los ingresos del hogar para cada clase en demanda de calefacción de la edificación residencial existente ( $A$ a $G$ ). Se marcan en rojo las situaciones en las que el coste de las facturas energéticas estaría superando el 10\% de los ingresos. Estos hogares quedarían del lado de la pobreza energética de acuerdo con esta regla. Se puede comprobar que tanto con la Renta Mínima de Inserción como con el Salario Mínimo Interprofesional no es posible mantener el hogar medio en situación de confort en ningún caso, ni siquiera en edificios de alta eficiencia energética. Para rentas situadas en el tramo 1 solamente quedan libres de situaciones de pobreza las viviendas más eficientes, de clasificación en demanda de calefacción A o B. Además, en los casos en los que la fuente de energía es eléctrica (Tabla 22), la situación empeora y las viviendas de peor calificación ( $F$ y G) que se encuentran en los tramos de renta 2 y 3 también entrarían en la clasificación de pobreza energética. Se ha estimado también el porcentaje de gasto considerando las rentas más bajas de cada tramo, comprobándose que no hay variaciones en las clases energéticas que entrarían en la situación de pobreza. La rehabilitación energética para lograr la calidad térmica definida a partir de las exigencias del Código Técnico de la Edificación de España (clase D o superior) no garantiza la erradicación de la pobreza energética en las secciones censales clasificadas en el tramo de renta más bajo, ni para los hogares que ingresan el SMI o sobreviven gracias a la RMI. 
Tabla 21.Porcentaje de los ingresos del hogar empleado para hacer frente al gasto con calefacción de GAS, según tramo de renta y clase de demanda. Elaboración propia

COSTE TOTAL ENERGÍA GAS (€/año)

\begin{tabular}{|c|c|c|c|c|c|c|c|c|c|c|}
\hline \multicolumn{4}{|c|}{ RENTA (€/año) } & $\mathbf{9 4 7 , 8 3}$ & $\mathbf{9 9 1 , 6 3}$ & $\mathbf{1 0 9 7 , 8 9}$ & $\mathbf{1 2 6 6 , 8 1}$ & $\mathbf{1 5 1 6 , 8 9}$ & $\mathbf{1 7 1 8 , 9 6}$ & $\mathbf{1 7 5 2 , 7 3}$ \\
\hline Min & Media & Max & Tramo & $\mathbf{A}$ & $\mathbf{B}$ & $\mathbf{C}$ & $\mathbf{D}$ & $\mathbf{E}$ & $\mathbf{F}$ & $\mathbf{G}$ \\
\hline 0 & $\mathbf{5 . 6 0 0}$ & & $\mathbf{R M I}$ & $17 \%$ & $18 \%$ & $20 \%$ & $23 \%$ & $27 \%$ & $31 \%$ & $31 \%$ \\
\hline 0 & $\mathbf{9 . 1 7 3}$ & & $\mathbf{S M I}$ & $10 \%$ & $11 \%$ & $12 \%$ & $14 \%$ & $17 \%$ & $19 \%$ & $19 \%$ \\
\hline 0 & $\mathbf{1 0 . 6 6 0}$ & 21.320 & $\mathbf{1}$ & $9 \%$ & $9 \%$ & $10 \%$ & $12 \%$ & $14 \%$ & $16 \%$ & $16 \%$ \\
\hline 21.321 & $\mathbf{2 2 . 2 9 0}$ & 23.260 & $\mathbf{2}$ & $4 \%$ & $4 \%$ & $5 \%$ & $6 \%$ & $7 \%$ & $8 \%$ & $8 \%$ \\
\hline 23.261 & $\mathbf{2 4 . 3 0 2}$ & 25.343 & $\mathbf{3}$ & $4 \%$ & $4 \%$ & $5 \%$ & $5 \%$ & $6 \%$ & $7 \%$ & $7 \%$ \\
\hline 25.344 & $\mathbf{2 6 . 5 8 3}$ & 27.823 & $\mathbf{4}$ & $4 \%$ & $4 \%$ & $4 \%$ & $5 \%$ & $6 \%$ & $6 \%$ & $7 \%$ \\
\hline 27.824 & $\mathbf{2 9 . 3 5 3}$ & 30.883 & $\mathbf{5}$ & $3 \%$ & $3 \%$ & $4 \%$ & $4 \%$ & $5 \%$ & $6 \%$ & $6 \%$ \\
\hline 30.884 & $\mathbf{3 2 . 7 2 2}$ & 34.560 & $\mathbf{6}$ & $3 \%$ & $3 \%$ & $3 \%$ & $4 \%$ & $5 \%$ & $5 \%$ & $5 \%$ \\
\hline 34.561 & $\mathbf{3 6 . 8 0 0}$ & 39.040 & $\mathbf{7}$ & $3 \%$ & $3 \%$ & $3 \%$ & $3 \%$ & $4 \%$ & $5 \%$ & $5 \%$ \\
\hline 39.041 & $\mathbf{4 2 . 3 1 0}$ & 45.580 & $\mathbf{8}$ & $2 \%$ & $2 \%$ & $3 \%$ & $3 \%$ & $4 \%$ & $4 \%$ & $4 \%$ \\
\hline 45.581 & $\mathbf{5 1 . 3 6 5}$ & 57.150 & $\mathbf{9}$ & $2 \%$ & $2 \%$ & $2 \%$ & $2 \%$ & $3 \%$ & $3 \%$ & $3 \%$ \\
\hline $\mathbf{5 7 . 1 5 1}$ & & & $\mathbf{1 0}$ & $\mathbf{2} \%$ & $\mathbf{2} \%$ & $2 \%$ & $\mathbf{2} \%$ & $3 \%$ & $3 \%$ & $3 \%$ \\
\hline
\end{tabular}

Tabla 22.Porcentaje de los ingresos del hogar empleado para hacer frente al gasto con calefacción ELECTRICA según tramo de renta y clase de demanda. Elaboración propia

\begin{tabular}{|c|c|c|c|c|c|c|c|c|c|c|}
\hline & & & & \multicolumn{7}{|c|}{ COSTE TOTAL ENERGÍA ELECTRICA (€/año) } \\
\hline \multicolumn{4}{|c|}{ RENTA (€/año) } & 930,58 & 1004,42 & 1183,65 & 1447,28 & 1930,65 & 2321,25 & 2386,58 \\
\hline Min & Media & Max & Tramo & A & B & $\mathbf{C}$ & D & $\mathbf{E}$ & $\mathbf{F}$ & G \\
\hline & 5.600 & & RMI & $17 \%$ & $18 \%$ & $21 \%$ & $26 \%$ & $34 \%$ & $41 \%$ & $43 \%$ \\
\hline & 9.173 & & SMI & $10 \%$ & $11 \%$ & $13 \%$ & $16 \%$ & $21 \%$ & $25 \%$ & $26 \%$ \\
\hline 0 & 10.660 & 21.320 & 1 & $9 \%$ & $9 \%$ & $11 \%$ & $14 \%$ & $18 \%$ & $22 \%$ & $22 \%$ \\
\hline 21.321 & 22.290 & 23.260 & 2 & $4 \%$ & $5 \%$ & $5 \%$ & $6 \%$ & $9 \%$ & $10 \%$ & $11 \%$ \\
\hline 23.261 & 24.302 & 25.343 & 3 & $4 \%$ & $4 \%$ & $5 \%$ & $6 \%$ & $8 \%$ & $10 \%$ & $10 \%$ \\
\hline 25.344 & 26.583 & 27.823 & 4 & $4 \%$ & $4 \%$ & $4 \%$ & $5 \%$ & $7 \%$ & $9 \%$ & $9 \%$ \\
\hline 27.824 & 29.353 & 30.883 & 5 & $3 \%$ & $3 \%$ & $4 \%$ & $5 \%$ & $7 \%$ & $8 \%$ & $8 \%$ \\
\hline 30.884 & 32.722 & 34.560 & 6 & $3 \%$ & $3 \%$ & $4 \%$ & $4 \%$ & $6 \%$ & $7 \%$ & $7 \%$ \\
\hline 34.561 & 36.800 & 39.040 & 7 & $3 \%$ & $3 \%$ & $3 \%$ & $4 \%$ & $5 \%$ & $6 \%$ & $6 \%$ \\
\hline 39.041 & 42.310 & 45.580 & 8 & $2 \%$ & $2 \%$ & $3 \%$ & $3 \%$ & $5 \%$ & $5 \%$ & $6 \%$ \\
\hline 45.581 & 51.365 & 57.150 & 9 & $2 \%$ & $2 \%$ & $2 \%$ & $3 \%$ & $4 \%$ & $5 \%$ & $5 \%$ \\
\hline 57.151 & & & 10 & $2 \%$ & $2 \%$ & $2 \%$ & $3 \%$ & $3 \%$ & $4 \%$ & $4 \%$ \\
\hline
\end{tabular}


El consumo anual medido en los estudios existentes (IDAE 2011b) para una vivienda media situada en la zona continental de España es de 9.786kWh (35,3 GJ/hogar) en las viviendas en bloque y de $19.658 \mathrm{kWh}$ (70,8 GJ/hogar) en las unifamiliares. Su correspondencia en consumo de calefacción ( $55 \%$ de la energía) sería de $5.382 \mathrm{kWh}$ en viviendas en bloque y de $10.812 \mathrm{kWh}$ en unifamiliares. Ambas cifras se sitúan por debajo de las estimaciones realizadas a partir de los valores medios de demanda para la vivienda en Madrid. El hecho de que las cifras de estimación de demanda energética, en base a las exigencias normativas, queden por encima de los consumos medidos por el IDAE podría indicar que al menos en las viviendas situadas en Madrid no se está satisfaciendo la exigencia en demanda, situándose por debajo del confort que prescribe la normativa. La pobreza energética es sin duda causante de este desfase, aunque no es el único factor. Se puede estar constatando que existe una privación voluntaria del confort por parte del usuario final, que prefiere ahorrar los costes derivados de la satisfacción del mismo para reducir gastos en el hogar y poder dedicar sus recursos a otros asuntos que considera prioritarios. Esto sucedería principalmente en las rentas medias y bajas. Otra posible interpretación sería que la estimación de las demandas energéticas por el procedimiento normativo esté sobredimensionando las necesidades para quedar, por así decirlo, del lado de la seguridad. Esta circunstancia no tiene mayor importancia cuando se trata de clasificar las viviendas conforme a la escala de calificación energética, que está distribuida mediante el mismo procedimiento de cálculo, pero en el momento en el que se comparan con datos de renta se puede generar incertidumbre en los resultados.

También hay que tener en cuenta que se están cruzando datos de diferentes fuentes y periodos: datos de la edificación (INE 2001) con datos de población (INE 2011), datos de renta (Ayuntamiento de Madrid 2017) y precios de la energía en el momento actual de la consulta (2017). La validez de los resultados depende de que la situación de la edificación existente se haya mantenido desde el último Censo de muestra universal, lo cual tiene sentido en los barrios que tienen edificios en mal estado y por tanto una mayor necesidad de ser rehabilitados. Además, para realizar este análisis se ha supuesto que los niveles de renta y su distribución espacial no han variado desde 2013 hasta el momento de la consulta de los precios de la energía, lo cual también tiene sentido para los barrios desfavorecidos, que han visto reducidos sus niveles de renta. 
Los cálculos están realizados para una vivienda de tamaño medio en Madrid (superficie de 80,76 m2), pero sería posible introducir en el análisis el tamaño de vivienda medio por sección censal, lo que lo haría el procedimiento más engorroso, pero tal vez más ajustado a la realidad. Previamente sería necesario analizar la variabilidad del tamaño medio de la vivienda para comprobar si difiere en los distintos barrios y distritos de la ciudad. Estudios recientes parecen indicar que esta variabilidad no resulta destacable (L. Moya González, Fernández Salgado, y Escamilla Valencia 2017) y por ello se ha optado por no introducir esta variable.

\subsection{2 Índice multidimensional de pobreza energética}

El uso de un determinado indicador para la cuantificación de la pobreza energética tiene una fuerte implicación en los resultados obtenidos. Resulta interesante el acercamiento de (Moore 2012), que refiere problemas a la hora de definir la pobreza energética solamente a partir del porcentaje de los ingresos que suponen las facturas. En su estudio sugiere la incorporación de otros factores de vulnerabilidad en el análisis, incluyendo un enfoque estándar de presupuestos familiares que permita discriminar las rentas más bajas (que en ningún caso van a poder hacer frente a sus costes energéticos) de las rentas altas con consumos energéticos disparados. En ese sentido, el indicador del 10 \% resulta en la inclusión de un elevado número de casos (Romero et al. 2014) y puede incluir las rentas altas con consumos energéticos excesivos que no se pueden considerar en situación de pobreza. Algunos autores han definido esta situación como "obesidad energética" (Gouveia, Seixas, y Long 2018). Para discriminar este tipo de casos parece necesario evaluar el riesgo de pobreza energética a través de un índice multidimensional compuesto que aborde sus causas y consecuencias socioeconómicas directamente en áreas desfavorecidas de las ciudades. Se trata de establecer, en los barrios de rehabilitación prioritaria señaladas por el Atlas de Barrios Vulnerables, aquellas zonas que presentan problemas de ineficiencia energética, con lo cual su situación de vulnerabilidad se ve agravada. Se aplica la metodología a la escala de la sección censal, para el estudio de los barrios vulnerables de la ciudad de Madrid.

Se tienen en cuenta tres aspectos principales derivados de las causas de la pobreza energética en los hogares ya abordados en el Capítulo 1: la ineficiencia energética de la 
edificación, la media de la renta por hogar y los costes de la factura energética. Se incorporan además los datos existentes acerca de la población mayor, doblemente afectada por las consecuencias de la pobreza energética por problemas de salud, y desmotivación en la inversión en eficiencia energética (Apartado 1.2.1).

Esta metodología se aplica a la escala de la sección censal, para el estudio de los barrios vulnerables, de manera que los datos puedan incorporarse al Modelo de Análisis de Datos Espaciales (MADE) para la totalidad del municipio.

\subsubsection{Estimación del Î́ndice Multidimensional de Pobreza Energética}

En primer lugar se detectan los barrios vulnerables que tienen problemas de ineficiencia energética en la edificación (Apartado 2.1). A partir de esta selección de áreas en las que estos problemas urbanos se solapan, se establece una segunda clasificación de la severidad del problema mediante la utilización de diferentes indicadores del riesgo de pobreza energética que componen un Índice Multidimensional.

\section{Inclusión de Barrios Vulnerables}

Para la delimitación de las áreas urbanas diagnosticadas como barrios desfavorecidos se utiliza la información del catálogo de barrios vulnerables realizado a partir del censo de 2011 (Agustín Hernández Aja et al. 2018), para el Ministerio de Fomento (Ministerio de Fomento y UPM 2017). Para delimitar el catálogo de barrios vulnerables se utilizan tres indicadores básicos: uno socio demográfico (el nivel de estudios, y concretamente la población sin estudios básicos completos, es decir, sin enseñanza secundaria obligatoria;

un indicador muy ligado a la inmigración desde el sur global y al envejecimiento), otro socioeconómico (el nivel de desempleo, muy ligado a la reta de los hogares) y otro residencial (el estado de conservación de la edificación).

\section{Ineficiencia energética de la edificación}

Las áreas que contienen la edificación más ineficiente se detectan a la escala de la sección censal utilizando el indicador de demanda energética de calefacción mediante el método desarrollado en el Apartado 2.1. Para la detección de grandes bolsas de edificación residencial obsoleta desde el punto de vista de su calidad térmica, se incluyen 
las áreas que han sido construida en su totalidad con anterioridad a la entrada en vigor de la norma (NBE-CT-79 1979).

\section{Solape de áreas vulnerables e ineficientes}

Mediante la visualización y análisis espacial de la información de ambas fuentes se obtiene el solape de secciones censales que se encuentran afectadas simultáneamente por los dos problemas: vulnerabilidad e ineficiencia (Figura 48).

Se detectan un total de 64 barrios y áreas estadísticas vulnerables que contienen bolsas de edificación ineficiente: 42 de estos barrios se corresponden con barrios con vulnerabilidad prolongada en el tiempo es decir, ya fueron declarados como barrios vulnerables en el Atlas de Barrios Vulnerables realizado con el censo de 2001 (Agustín Hernández Aja et al. 2015). Los 22 barrios restantes han sido detectados utilizando el censo de 2011 y se han denominado Áreas Estadísticas Vulnerables (Agustín Hernández Aja et al. 2018).

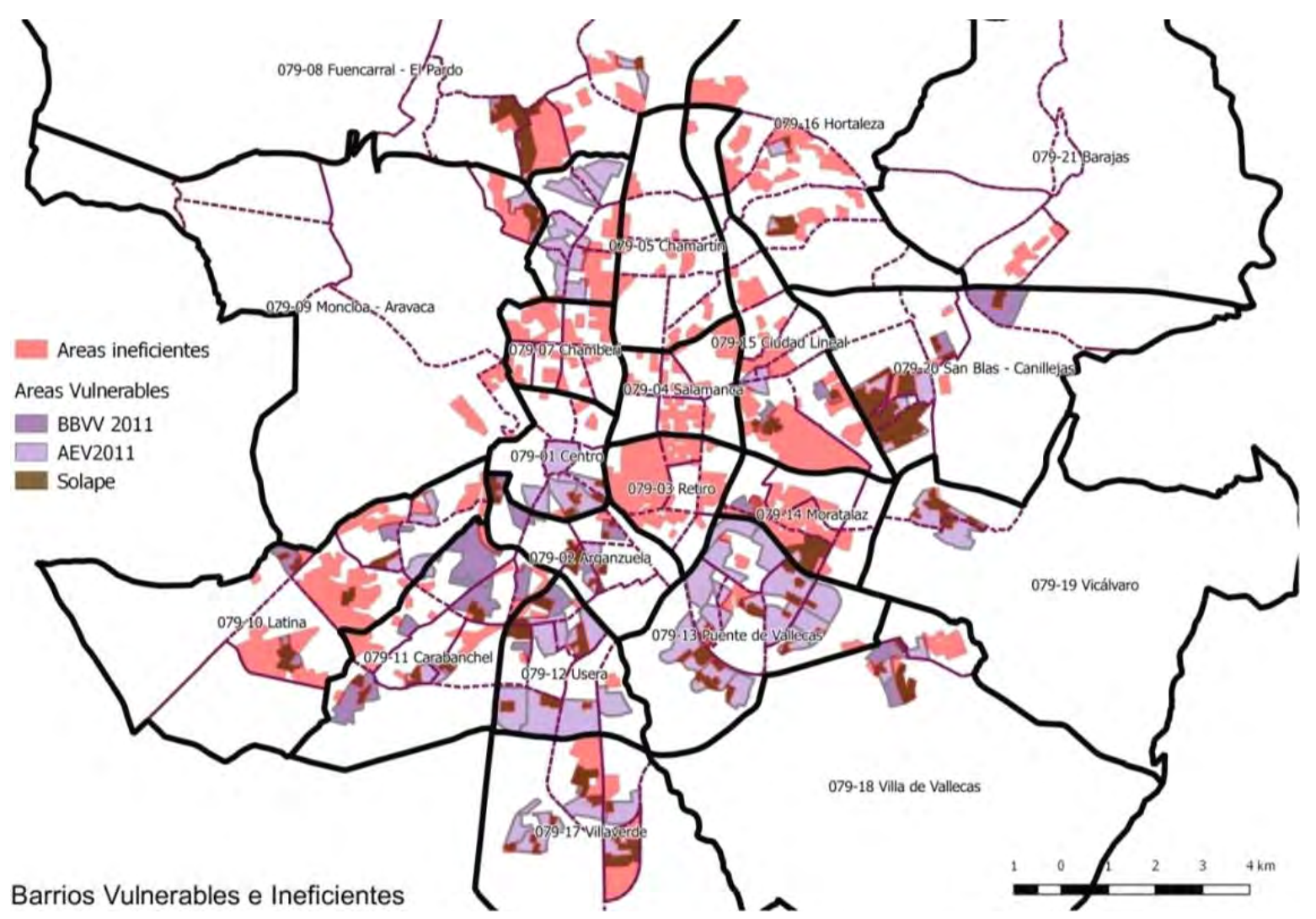

Figura 48. Áreas con edificación residencial ineficiente, barrios vulnerables y solape entre ellos. Elaboración propia. 
A partir de esta primera selección de barrios vulnerables con edificación ineficiente, se realizan operaciones básicas de comprobación de los resultados. Se eliminan las áreas donde se ha podido constatar que se ha producido una operación de rehabilitación energética generalizada en la edificación residencial (Apartado 1.2.3).

- Áreas de Rehabilitación (ARIs o ARUs) que han incluido mejoras de la eficiencia energética de la edificación (Agustín Hernández Aja et al. 2010). Con este criterio se han excluido los barrios de Orcasitas Este, 2807918, 2807924. La zona centro también se considera para su exclusión de las áreas más vulnerables desde el punto de vista de la energía, ya que ha sido objeto de fuertes inversiones en sucesivas operaciones de Regeneración Urbana Integral (ARIS de la zona centro Apartado 1.2.3). Además de esto, contiene una cantidad importante de edificación construida con anterioridad a 1940, generalmente con cerramientos de gran espesor y un mejor desempeño térmico que los desarrollos de 1940-80 situados principalmente en las periferias.

- También se han eliminado de la selección aquellos barrios en los que ha habido operaciones de rehabilitación urbana que han incluido la incorporación de aislamiento térmico por el exterior en toda su edificación según los estudios existentes basados en el análisis de muestras de promociones de vivienda pública (Oteiza, I. et al. 2018). En las visitas de campo realizadas en el proyecto REFAVIV se ha encontrado aislamiento térmico por el exterior en edificios anteriores a 1979 situados en los barrios de Hellín, Amposta y La Elipa. Se han mantenido áreas vulnerables donde, a pesar de haberse constatado mejora energética en algunos conjuntos, esta no ha afectado a todas las zonas con edificación ineficiente (Portazgo, Caño Roto, 280716) o se han rehabilitado puntualmente solo algunos de los edificios (Villaverde Alto, San Cristóbal).

Una vez realizadas todas estas operaciones espaciales en el MADE, se obtiene una selección de un total de 48 BBVV 2001 y AEV 2011 en los que se dan simultáneamente los problemas de vulnerabilidad urbana e ineficiencia energética. La delimitación de estas áreas aparece representada en la Figura 49. 


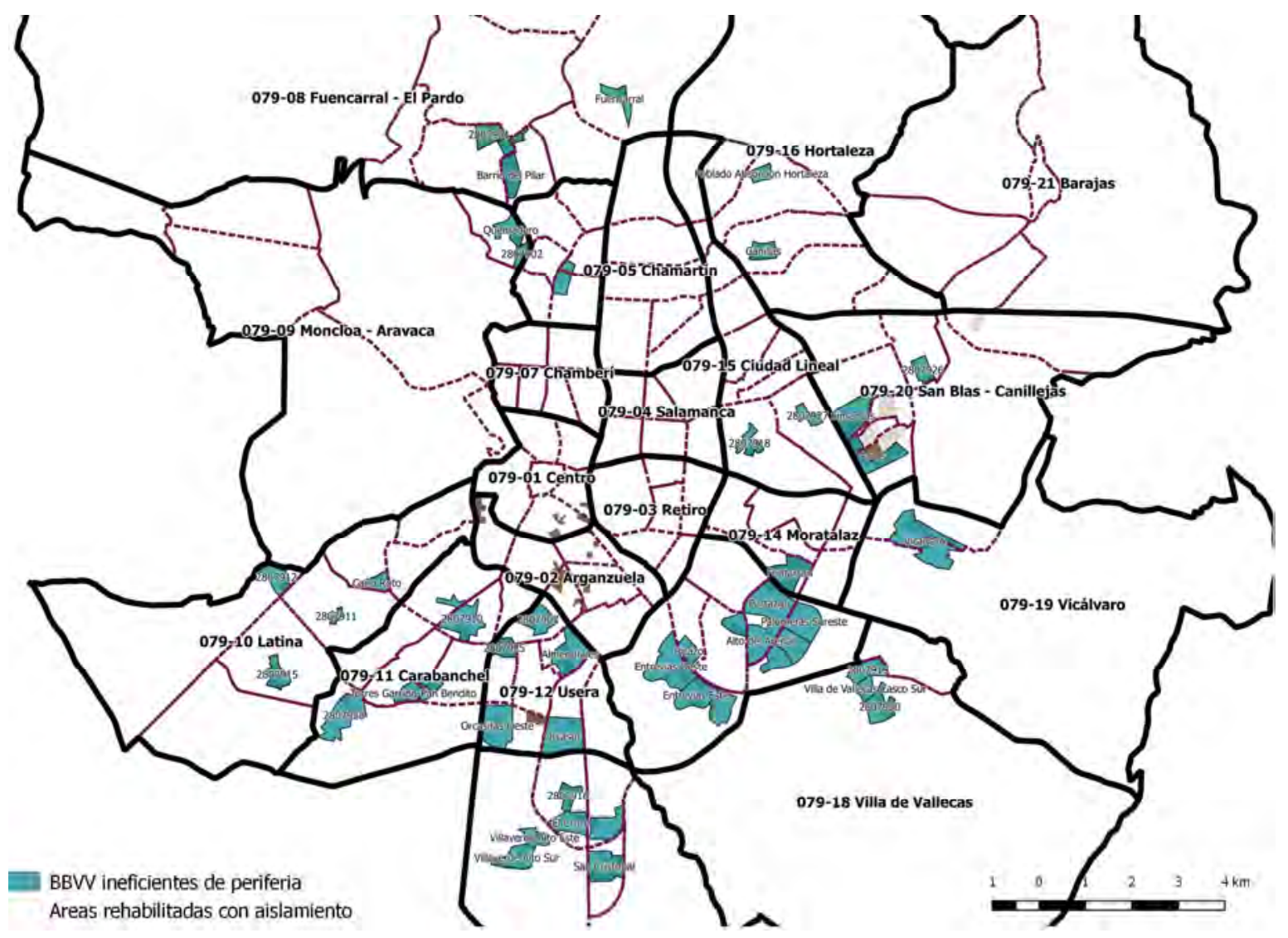

Figura 49. Barrios vulnerables ineficientes eliminando áreas rehabilitadas. Elaboración propia a partir de datos del Atlas de Barrios Vulnerables de España

\subsubsection{Indicadores socioeconómicos incorporados}

Se proponen una serie de indicadores para identificar y caracterizar la severidad del riesgo a situaciones de pobreza energética en las secciones censales pertenecientes a los barrios y áreas estadísticas vulnerables que contienen edificación ineficiente. Se trata de información proveniente de los censos de población y vivienda de 2001 y 2011 y del proyecto Urban Audit. Los indicadores se han seleccionado por estar relacionados con las causas de pobreza energética (ineficiencia de las instalaciones térmicas, altos precios de la energía y bajos ingresos). Además se incluye el indicador de la población mayor, por ser especialmente afectada por las consecuencias de la pobreza energética. En la Figura 50 se representa gráficamente la distribución en la ciudad de Madrid de cada uno de los cuatro indicadores que componen el índice desarrollado. Toda la información obtenida se vuelca en el Modelo de Análisis de Datos Espaciales (MADE) para su combinación con los datos de vulnerabilidad urbana. 


\section{Bajos ingresos en el hogar (Figura 50.1)}

Para la incorporación de este indicador se seleccionan las áreas que se encuentran dentro del tramo I de renta del hogar, en el que se clasifican las secciones censales con los menores ingresos en el proyecto Urban Audit a la escala de la sección censal (Ayuntamiento de Madrid 2018) (Apartado 1.2.1). Se utilizan datos de renta media por hogar, y no de renta per cápita, para referirse al problema de la pobreza energética, que está directamente asociado a la vivienda. De esta manera se pueden seleccionar los barrios vulnerables que contienen secciones censales que contienen las rentas más bajas.

\section{Altos precios: Costes energéticos elevados (Figura 50.2)}

Se determina el coste teórico de la factura energética media por sección censal en el supuesto de demandas de calefacción satisfechas obtenido previamente para la aplicación del método de la regla del 10\% (Apartado 2.2.1), a partir de datos de calidad de la edificación y tipo de suministro energético para calefacción. Según esa metodología, el coste anual del consumo energético residencial para una vivienda media en Madrid oscilaría entre 1.702€ y 2.289€ (calefacción de gas y eléctrica respectivamente). La media para la ciudad se situaría en $1.941 €$, considerando que el $59 \%$ de las calefacciones funcionan con gas (INE 2001). Se vuelca en el MADE la selección de las secciones censales que superan esta media, considerando que sus costes energéticos son elevados, o lo serían en el caso de pretender satisfacer las necesidades de confort establecidas en la normativa vigente (CTE-DB-HE 2013).

\section{Ineficiencia energética: Viviendas sin calefacción (Figura 50.3)}

Se incluye un indicador de ineficiencia en las instalaciones térmicas para caracterizar los barrios que cuentan con las peores condiciones de equipamiento de calefacción (Apartado 1.2.2). El censo de 2001 registra una media de un 20,25\% de viviendas sin sistemas de calefacción adecuados en la ciudad de Madrid (INE 2001). Se han seleccionado aquellas secciones censales que superan este valor medio en más de un $150 \%$ con respecto al valor medio de la ciudad, es decir, aquellas que contienen más de un $30,375 \%$ de viviendas sin calefacción 


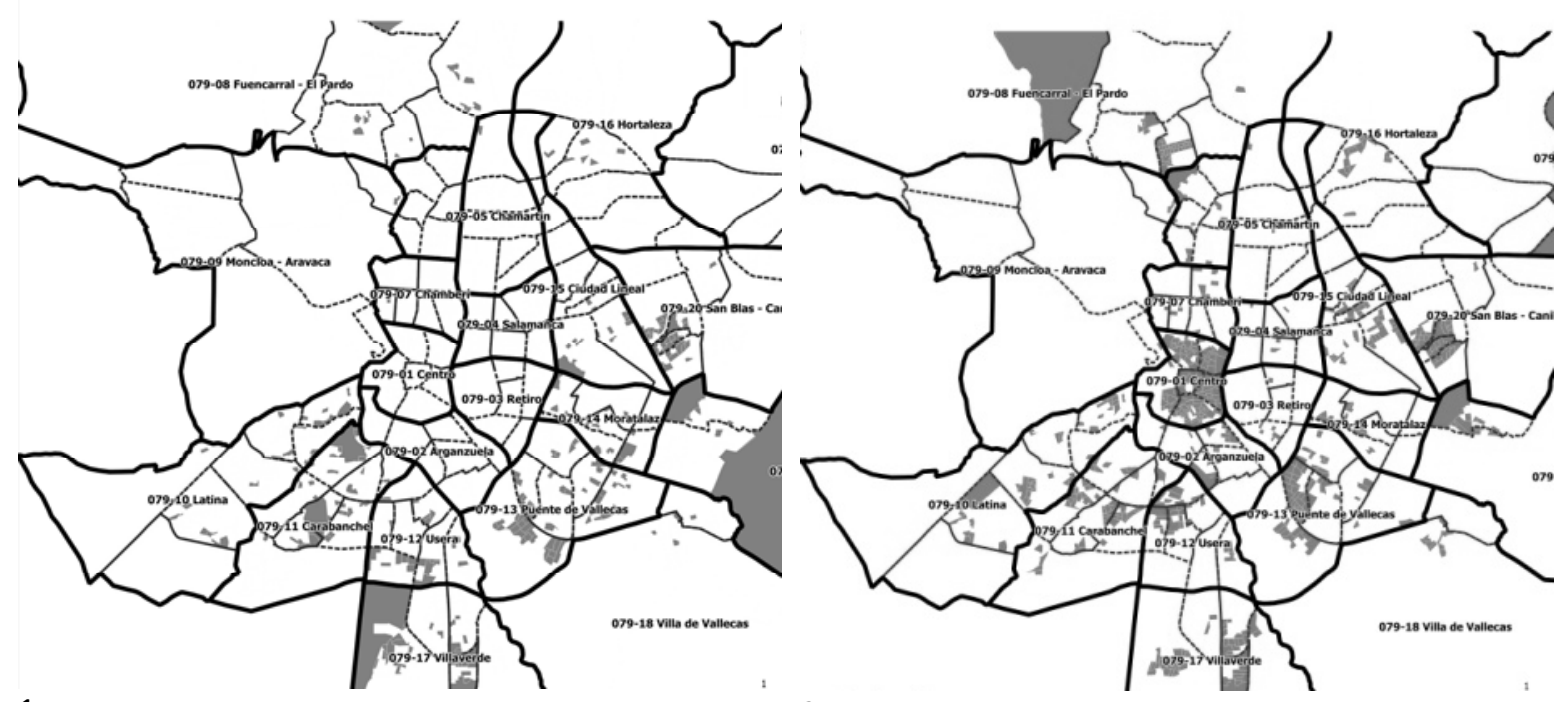

1

2

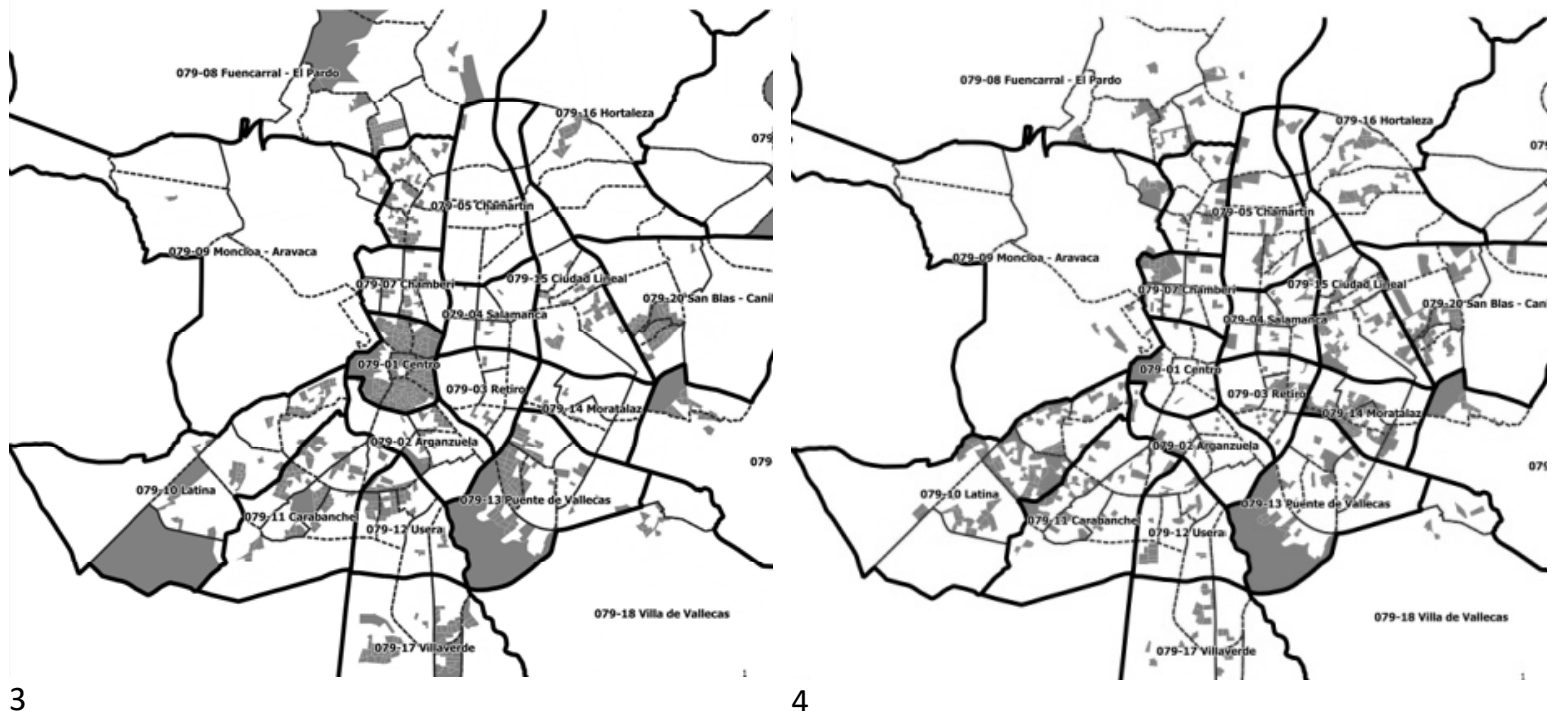

Figura 50. Distribución de los indicadores de: (1) bajos ingresos, (2) costes elevados, (3) sin calefacción y (4) población mayor. Elaboración propia

Población vulnerable: mayores de 65 (Figura 50.4)

En último lugar se detectan aquellas áreas de la ciudad en las cuales la vulnerabilidad energética se ve agravada por causa de un alto nivel de envejecimiento de la población. Los datos se han tomado del censo de población y viviendas de 2011 (INE 2011) (Apartado 1.2.1). Se incluyen las secciones censales que contienen más de un $150 \%$ de población mayor de 65 años con respecto de la media de la ciudad. En concreto, la media para Madrid en 2011 era del 19\% el indicador seleccionado se calcula en un $28,5 \%$ de población mayor. Las secciones censales que superan esa puntuación aparecen representadas en la Figura 50.4. 


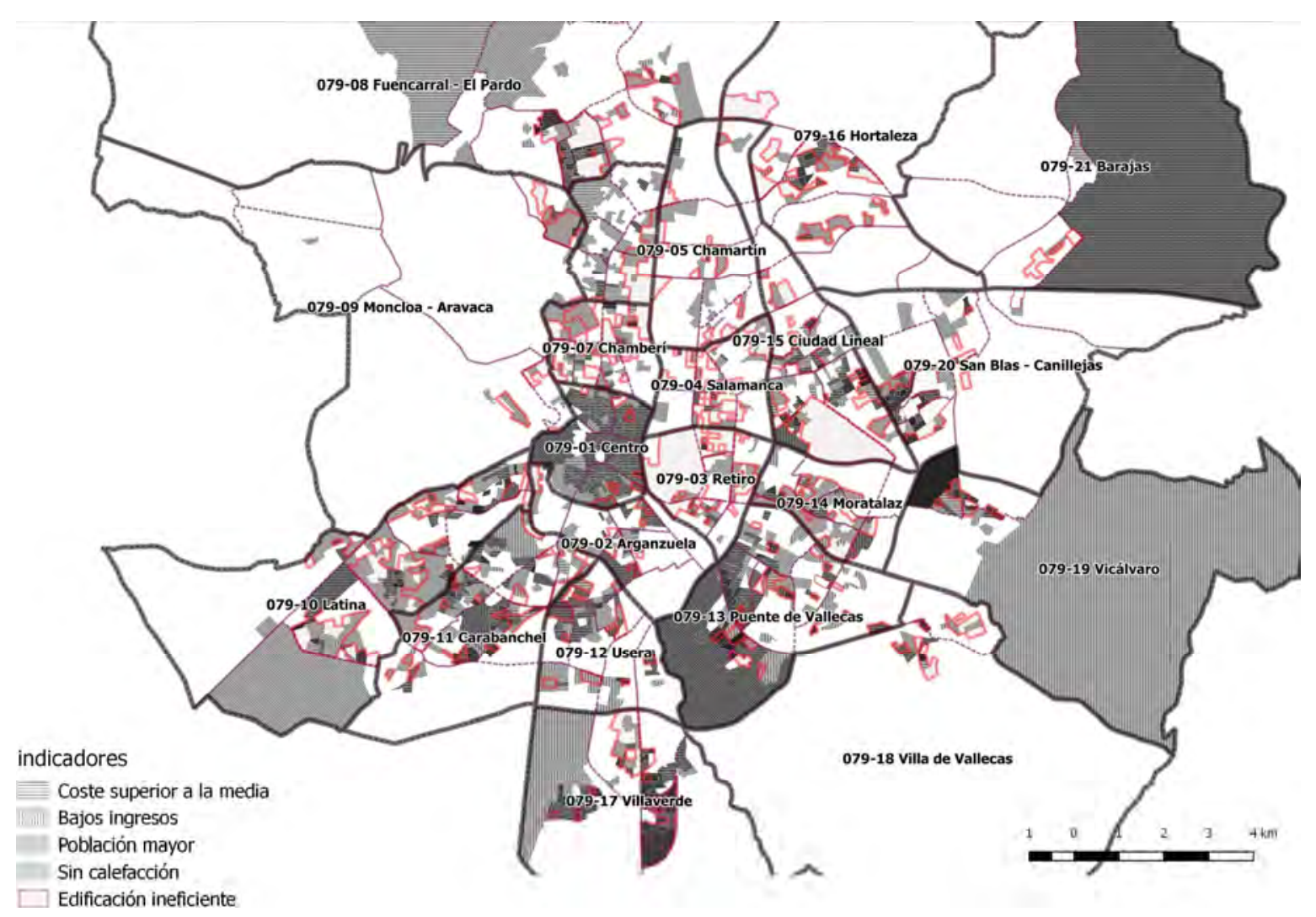

Figura 51. Edificación ineficiente e indicadores de severidad de la pobreza energética. Elaboración propia

\subsubsection{Composición del índice multidimensional de Pobreza Energética}

El índice propuesto incorpora en un solo análisis toda la información urbana recogida en los apartados anteriores. Engloba la mala calidad de la envolvente térmica de la edificación residencial, la falta de disponibilidad de instalaciones eficientes y, como consecuencia de ambos problemas, unos costes en facturas energéticas elevados para llegar a la situación de confort. Además contempla indicadores socioeconómicos tales como los bajos niveles de renta y el envejecimiento de la población. Esta información es filtrada a través de la delimitación de barrios y áreas vulnerables definida en el Catalogo de Barrios Vulnerables. De esta manera queda garantizada la selección de áreas deprimidas de la ciudad, descartando zonas donde se puedan estar produciendo fenómenos de obesidad energética.

Utilizando herramientas SIG se realizan operaciones de intersección de las áreas afectadas por los diferentes indicadores, para obtener el valor del índice multidimensional del riesgo de pobreza energética. Se clasifican los barrios vulnerables 
ineficientes conforme al mismo. Se obtiene un plano de la severidad del riesgo de pobreza energética para toda la ciudad, con cuatro gradaciones a añadir al problema de la ineficiencia de la envolvente de la edificación (Figura 51).

El distrito de Puente de Vallecas aparece como el más afectado. También hay concentración de los indicadores en San Blas-Canillejas, Vicálvaro, Villaverde, Carabanchel y zonas de Usera (Zofío). En el norte, barrio del Pilar y Peñagrande también tienen áreas con riesgo severo, así como Pinar del Rey en el noreste. El distrito centro, a pesar de aparecer afectado por altos costes en la factura energética y falta de instalaciones de calefacción, no tiene problemas extendidos de rentas bajas ni población vulnerable mayor de 65 años. Por estas razones se descarta el ámbito del centro como área de alto riesgo generalizado de pobreza energética. En los ensanches decimonónicos los indicadores de riesgo no aparecen con una presencia importante. No contienen áreas urbanas de tramos de rentas bajas. Además, estas áreas cuentan con mejor equipamiento de sistemas de calefacción que el centro y la periferia del $40-80$, lo que redunda en menores costes en la factura. El único iniciador que aparece de forma salpicada por toda la periferia y los ensanches es el de personas mayores. En ese sentido la información coincide con el indicador del 10\%, a partir del cual ninguno de los distritos de la almendra central se vería afectado de forma generalizada por problemas de pobreza energética.

Para todos los barrios vulnerables que contienen una alta concentración de edificación residencial ineficiente se obtiene una clasificación del riesgo de pobreza energética en función de la coexistencia de los diferentes indicadores socioeconómicos. Se hace un uso cualitativo de la información de los 4 indicadores de pobreza energética, que señalan las secciones censales que superan el umbral crítico para cada una de ellas. Se pasa a considerar que los barrios vulnerables con secciones censales que superan este umbral contienen el problema y obtienen una puntuación 1 en el riesgo de pobreza energética. Esto permite la catalogación conforme al índice multidimensional y la determinación de la severidad del riesgo de pobreza energética de cada uno ellos. En los casos en los que los cuatro indicadores se producen de manera simultánea en las mismas secciones censales, se ha añadido un indicador de solape, entendiendo que en estas secciones el riesgo es máximo (índice 5). 
Tabla 23. Severidad del riesgo de pobreza energética en los barrios vulnerables e ineficientes.

\section{Elaboración propia}

\begin{tabular}{|c|c|c|c|c|c|c|c|c|c|c|c|c|c|}
\hline ID & DENBV & POB & V_PR & IEST & IPAR & IVIV & BVTIP & rent & cost & sincal & may & sol & PEi \\
\hline 1 & Lérida-Castillejos & 9.930 & 4.725 & 6,5 & 20,3 & 24,9 & VIV & 0 & 0 & 1 & 1 & 0 & 2 \\
\hline 2 & 2807901 & 3.805 & 1.715 & 17,9 & 17,5 & 4,6 & EST & 1 & 1 & 1 & 1 & 1 & 5 \\
\hline 3 & Barrio del Pilar & 6.600 & 2.910 & 19,1 & 28,4 & 12,6 & EST & 0 & 1 & 1 & 1 & 0 & 3 \\
\hline 4 & Fuencarral & 3.890 & 1.630 & 16,5 & 20,8 & 0,0 & EST & 1 & 1 & 1 & 1 & 0 & 4 \\
\hline 5 & 2807923 & 3.835 & 1.625 & 6,3 & 11,2 & 17,7 & VIV & 0 & 0 & 0 & 1 & 0 & 1 \\
\hline 6 & 2807902 & 3.765 & 1.670 & 8,6 & 22,9 & 28,0 & VIV & 1 & 1 & 1 & 1 & 0 & 4 \\
\hline 7 & Quemadero & 5.655 & 2.585 & 17,2 & 30,1 & 1,6 & EST & 0 & 0 & 1 & 1 & 0 & 2 \\
\hline 8 & Caño Roto & 4.100 & 1.720 & 17,7 & 27,3 & 58,4 & EST VIV & 1 & 0 & 0 & 1 & 0 & 2 \\
\hline 9 & 2807911 & 4.920 & 1.935 & 10,8 & 44,1 & 0,0 & \begin{tabular}{|l|} 
PAR \\
\end{tabular} & 1 & 1 & 1 & 1 & 1 & 5 \\
\hline 10 & 2807912 & 5.430 & 2.410 & 16,7 & 23,3 & 1,9 & EST & 1 & 0 & 1 & 1 & 0 & 3 \\
\hline 11 & 2807915 & 7.775 & 3.175 & 17,6 & 22,4 & 9,1 & EST & 1 & 0 & 0 & 1 & 0 & 2 \\
\hline 12 & T. Garrido-P. Bendito & 10.420 & 3.825 & 16,4 & 31,7 & 24,4 & EST VIV & 1 & 1 & 1 & 1 & 0 & 4 \\
\hline 13 & Abrantes Sur & 3.710 & 1.490 & 17,5 & 39,5 & 15,5 & EST & 1 & 1 & 1 & 1 & 0 & 4 \\
\hline 14 & 2807910 & 14.160 & 5.985 & 12,5 & 22,3 & 18,7 & VIV & 1 & 1 & 1 & 1 & 1 & 5 \\
\hline 15 & 2807928 & 11.815 & 4.790 & 17,2 & 27,6 & 0,7 & EST & 0 & 1 & 1 & 1 & 0 & 3 \\
\hline 16 & Almendrales & 7.470 & 3.105 & 19,5 & 38,2 & 3,6 & EST & 1 & 0 & 1 & 1 & 0 & 3 \\
\hline 17 & 2807907 & 5.600 & 2.320 & 7,5 & 28,2 & 17,8 & VIV & 0 & 1 & 0 & 0 & 0 & 1 \\
\hline 18 & Orcasur & 6.515 & 2.295 & 17,1 & 32,2 & 1,0 & EST & 1 & 0 & 1 & 1 & 0 & 3 \\
\hline 19 & Orcasitas Oeste & 11.950 & 4.835 & 17,0 & 26,3 & 0,0 & EST & 1 & 0 & 0 & 1 & 0 & 2 \\
\hline 20 & 2807925 & 4.280 & 1.785 & 8,9 & 44,9 & 2,1 & PAR & 1 & 1 & 1 & 1 & 1 & 5 \\
\hline 21 & Entrevías Este & 7.875 & 2.875 & 23,7 & 25,6 & 21,5 & ESTVIV & 1 & 1 & 1 & 1 & 1 & 5 \\
\hline 22 & Entrevías Oeste & 16.270 & 6.730 & 19,7 & 29,2 & 10,0 & EST & 1 & 1 & 1 & 1 & 1 & 5 \\
\hline 23 & Pozo del Tío Raimundo & 4.065 & 1.475 & 23,2 & 37,4 & 0,0 & EST & 1 & 0 & 0 & 0 & 0 & 1 \\
\hline 24 & Picazo & 9.585 & 4.005 & 24,2 & 33,4 & 23,6 & ESTVIV & 1 & 1 & 1 & 1 & 1 & 5 \\
\hline 25 & Parque Azorín & 6.820 & 2.885 & 16,7 & 31,2 & 1,7 & EST & 1 & 1 & 1 & 1 & 0 & 4 \\
\hline 26 & Alto del Arenal & 5.515 & 2.235 & 19,5 & 35,2 & 11,6 & EST & 1 & 1 & 1 & 1 & 0 & 4 \\
\hline 27 & Palomeras 1-L. Buñuel & 12.035 & 4.710 & 21,2 & 26,3 & 1,9 & EST & 1 & 0 & 1 & 1 & 0 & 3 \\
\hline 28 & J. Palomeras-Villalobos & 12.245 & 4.655 & 16,9 & 30,2 & 0,4 & EST & 1 & 1 & 1 & 0 & 0 & 3 \\
\hline 29 & Palomeras Sureste & 12.040 & 4.595 & 17,7 & 28,7 & 2,4 & EST & 1 & 0 & 0 & 1 & 0 & 2 \\
\hline 30 & Portazgo & 10.105 & 4.165 & 19,5 & 24,5 & 14,5 & EST & 1 & 1 & 1 & 1 & 1 & 5 \\
\hline 31 & Fontarrón & 4.650 & 1.975 & 16,7 & 28,8 & 0,0 & EST & 1 & 1 & 0 & 1 & 0 & 3 \\
\hline 32 & 2807918 & 7.160 & 3.110 & 16,8 & 30,3 & 15,8 & EST & 1 & 1 & 1 & 1 & 0 & 4 \\
\hline 33 & 2807927 & 3.830 & 1.595 & 17,6 & 13,5 & 0,0 & EST & 0 & 0 & 1 & 1 & 0 & 2 \\
\hline 34 & P. Absorción Hortaleza & 4.380 & 1.745 & 20,6 & 35,5 & 26,3 & EST VIV & 1 & 1 & 1 & 1 & 0 & 4 \\
\hline 35 & Canillas & 3.900 & 1.835 & 19,5 & 22,0 & 11,1 & EST & 0 & 1 & 0 & 1 & 0 & 2 \\
\hline 36 & Villaverde Alto Sur & 12.535 & 5.140 & 18,3 & 32,4 & 9,5 & EST & 1 & 1 & 1 & 1 & 0 & 4 \\
\hline 37 & Villaverde Alto Este & 5.815 & 2.225 & 18,8 & 32,4 & 5,7 & EST & 1 & 1 & 1 & 1 & 0 & 4 \\
\hline 38 & El Cruce & 6.130 & 2.410 & 16,6 & 27,8 & 1,0 & EST & 1 & 0 & 1 & 1 & 0 & 3 \\
\hline 39 & Villaverde Bajo & 11.840 & 4.655 & 16,8 & 34,4 & 39,0 & EST & 1 & 1 & 0 & 1 & 0 & 3 \\
\hline 40 & San Cristóbal & 14.785 & 5.100 & 19,8 & 41,5 & 39,0 & EST VIV & 1 & 1 & 1 & 1 & 0 & 4 \\
\hline 41 & 2807916 & 5.555 & 2.470 & 16,6 & 26,0 & 1,6 & EST & 1 & 1 & 1 & 1 & 0 & 4 \\
\hline 42 & V. de Vallecas Casco S & 4.515 & 1.785 & 17,3 & 40,8 & 6,5 & EST & 0 & 1 & 1 & 1 & 0 & 3 \\
\hline 43 & 2807919 & 7.725 & 3.160 & 17,3 & 25,8 & 16,1 & EST & 1 & 1 & 1 & 0 & 0 & 3 \\
\hline 44 & 2807920 & 10.410 & 4.140 & 19,1 & 25,6 & 2,2 & EST & 1 & 1 & 1 & 1 & 1 & 5 \\
\hline 45 & Vicálvaro & 25.005 & 9.890 & 17,1 & 27,5 & 1,9 & EST & 1 & 1 & 1 & 1 & 1 & 5 \\
\hline 46 & Simancas & 7.965 & 3.515 & 18,3 & 27,4 & 6,2 & EST & 1 & 1 & 1 & 1 & 1 & 5 \\
\hline 47 & Arcos & 7.925 & 3.160 & 17,2 & 28,3 & 4,4 & EST & 1 & 0 & 1 & 1 & 0 & 3 \\
\hline 48 & 2807926 & 4.405 & 1.690 & 18,7 & 22,5 & 9,1 & EST & 0 & 0 & 0 & 0 & 0 & 0 \\
\hline \multicolumn{14}{|c|}{ LEYENDA } \\
\hline ID & Identificador & IEST & icador sin & estudios & & rent: & Rentas & & sol & \multirow{4}{*}{\multicolumn{4}{|c|}{$\begin{array}{l}\text { Solape indicadores } \\
\text { Índice Pobreza Energética }\end{array}$}} \\
\hline DENE & Denominación BV & IPAR & & & & cost & & & $\mathrm{PEi}$ & & & & \\
\hline РOB & Población & IVIV & dicador viv & ienda & & sincal & Sin calef & cción & & & & & \\
\hline V_PR & Viviendas Principales & BVTIP & po de Barr & o Vulner & rable & may & Persona: & mayores & & & & & \\
\hline
\end{tabular}




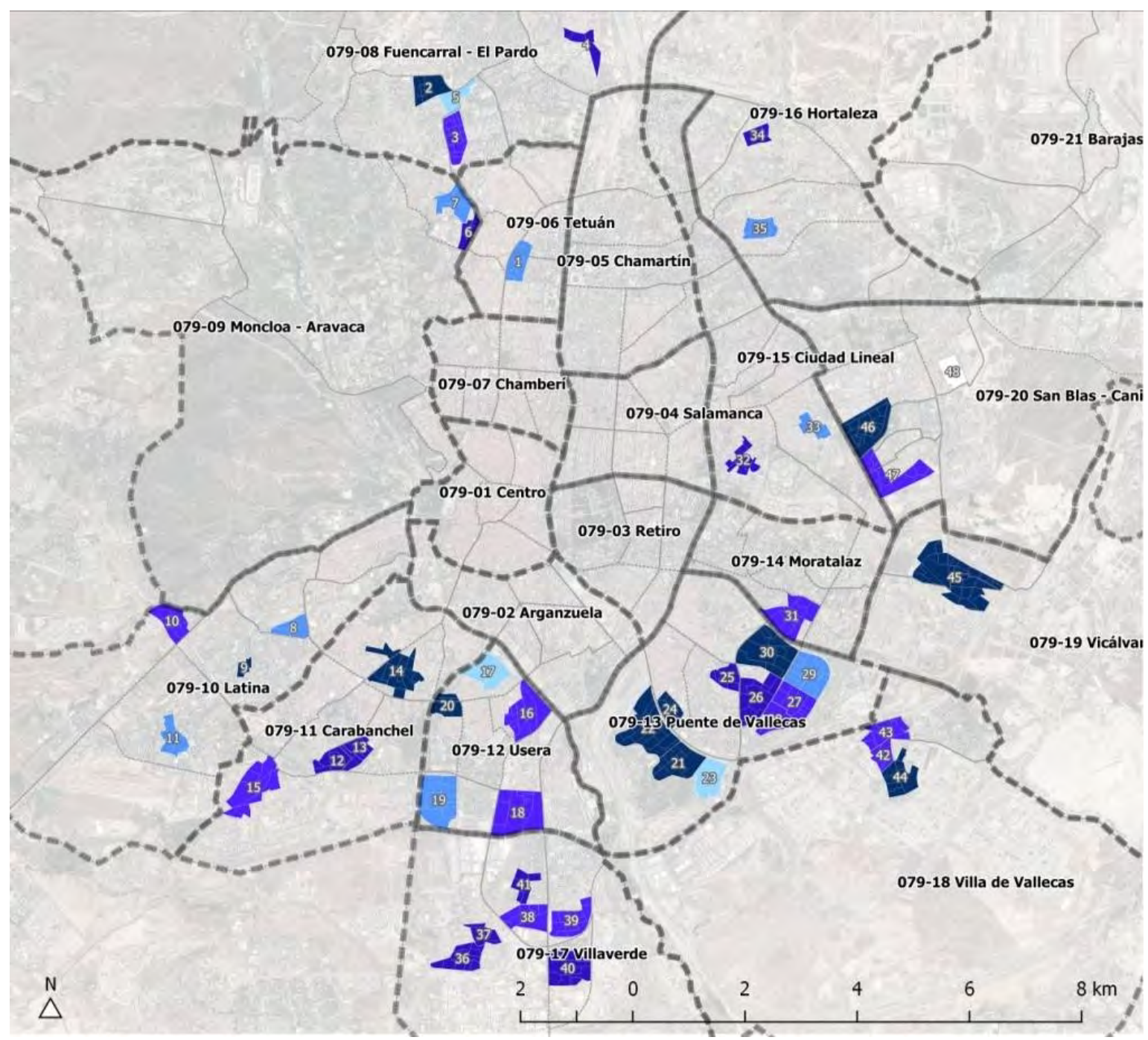

Figura 52. Detalle de la severidad de la pobreza energética en barrios vulnerables de la periferia. Elaboración propia

Como resultado se obtiene un listado de los 48 barrios vulnerables que contienen bolsas importantes de edificación ineficiente (edificios sin aislamiento térmico por estar construidos con anterioridad a 1979). Incluye datos de su población, número de viviendas, y los Indicadores Básicos de Vulnerabilidad Urbana: (1) porcentaje de población sin estudios, (2) porcentaje de población en paro y (3) carencias en las viviendas o porcentaje de viviendas en edificios en estado de conservación ruinoso, malo o deficiente. Para completar la información acerca de la Vulnerabilidad Urbana se resumen sus causas en el tipo de barrio vulnerable (BVTIP). Además, esta información se asocia a los indicadores que componen el Índice Multidimensional de Pobreza Energética descritos en este apartado (rentas bajas, costes energéticos elevados, porcentaje de 
viviendas sin calefacción y porcentaje de población mayor). La información se representa espacialmente en el plano de la (Figura 52) y los indicadores se detallan en la Tabla 23.

EI AEV 280796 (ID 48), del barrio de Canillejas, es el único área vulnerable 2011 que contiene edificación ineficiente en el que no se da ninguno de los 4 indicadores de pobreza energética (Tabla 23). La práctica totalidad de las áreas en las que se solapan los 4 indicadores de pobreza energética con edificación ineficiente pertenecen a barrios vulnerables, lo que indica que ambas problemáticas se encuentran relacionadas. Solamente 5 secciones censales con edificación ineficiente en las que se dan simultáneamente los 4 indicadores de pobreza energética no se encuentran incluidas en ningún barrio ni área estadística vulnerable (Tabla 24), con una población de 3.705 habitantes censados. Esta cifra supone el 3\% de los habitantes residentes en barrios vulnerables con los 4 indicadores solapados. Esto demuestra que la pobreza energética es un indicador relacionado con la vulnerabilidad urbana y se deben abordar ambos problemas de forma simultánea.

La visualización de los indicadores que componen el índice multidimensional de pobreza energética para cada barrio en detalle permite analizar la distribución espacial de los mismos e identificar la intersección de los factores de ineficiencia y pobreza energética con la máxima definición que permiten los datos estadísticos. Gracias a la tecnología GIS esta operación permite identificar bolsas de edificación afectada de manera simple, mediante la comparación con una foto aérea en la que aparezcan los edificios (Figura 53). La información de los 48 barrios vulnerables e ineficientes identificados (Tabla 23) se vuelca en un Atlas de pobreza energética en barrios vulnerables e ineficientes de Madrid, que contiene una ficha gráfica detallada que permite interpretar una distribución del riesgo en cada barrio (Anexo I.3.).

Tabla 24. Secciones censales afectadas que no pertenecen a ningún BBVV o AEV. Elaboración propia

\begin{tabular}{|l|l|}
\hline GEOCODIGO & residentes \\
\hline 2807911084 & 495 \\
\hline 2807915139 & 935 \\
\hline 2807915107 & 555 \\
\hline 2807910169 & 845 \\
\hline 2807915078 & 875 \\
\hline
\end{tabular}




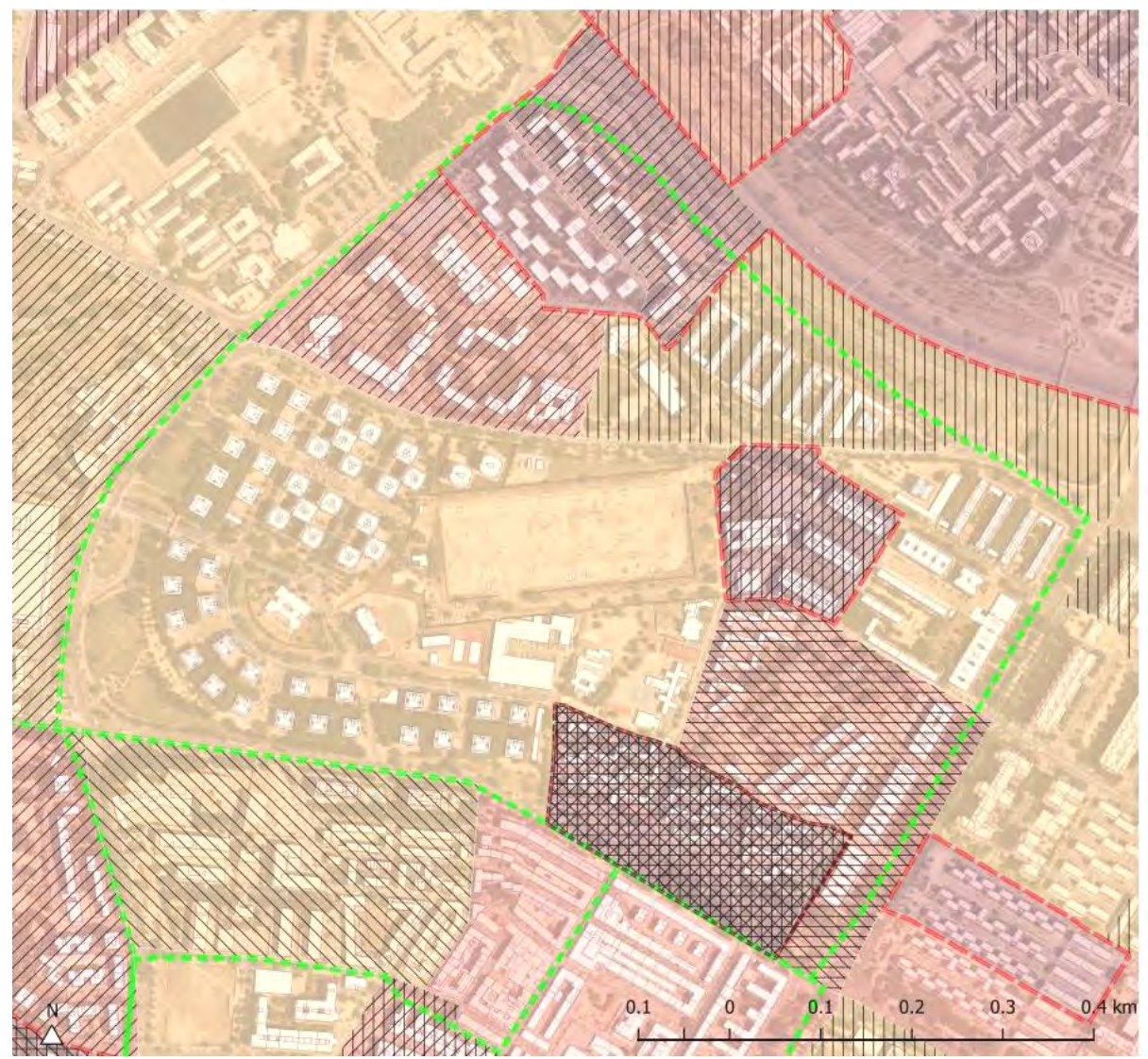

Pobreza Energética

L-i Barrio Vulnerable indicadores

11/ Rentas bajas

E Costes elevados

I' Sin calefacción

I// Población mayor

:--_ Solape indicadores

Demanda $(\mathrm{kWh} / \mathrm{m} 2$ año)

E: $66.3-121.2$

F: $121.2-132.2$

G: > 132.2

ㄱ. Tejido alta ineficiencia

Figura 53. Análisis multidimensional del riesgo de pobreza energética para el barrio de Portazgo.

Elaboración propia

\subsubsection{Barrios vulnerables ineficientes que contienen los 4 indicadores de pobreza energética}

Existen una serie de ámbitos urbanos donde se concentran los problemas. 23 de los 48 barrios vulnerables e ineficientes situados en la periferia de Madrid contienen los cuatro indicadores de riesgo de pobreza energética dentro del ámbito de su delimitación urbana (Tabla 25). En la Tabla 23 aparece resaltada en gris la información asociada a dichos barrios y en la Figura 52 aparecen identificados en el mapa de Madrid con los colores más oscuros. 15 de estas áreas se corresponden con barrios con vulnerabilidad prolongada en el tiempo (BBVV 2001 y 2011), mientras 8 son áreas identificadas como vulnerables solo a partir del último censo (AEVs 2011). Puente de Vallecas y Villaverde, ambos con seis barrios vulnerables afectados, son los distritos que presentan mayores extensiones de áreas en riesgo de pobreza energética. Estos barrios son los que se consideran en alto riesgo de pobreza energética. En su reforma se deben contemplar medidas de mejora de la eficiencia mediante procedimientos diseñados específicamente para esta población. 
Tabla 25. Información de los barrios vulnerables con 4 indicadores de pobreza energética solapados.

(Hernandez Aja et al. 2018)

\begin{tabular}{|l|l|l|l|l|l|l|l|l|}
\hline ID & DS & Barrio Admin & CODBV & DENBV & F_CREC & POB & VIVS & V_PR \\
\hline 2 & 8 & Peña Grande & 2807901 & 2807901 & & 3.805 & 1.955 & 1.715 \\
\hline 9 & 10 & Aluche & 2807911 & 2807911 & & 4.920 & 2.250 & 1.935 \\
\hline 14 & 11 & Opañel & 2807910 & 2807910 & & 14.160 & 7.230 & 5.985 \\
\hline 11 & 12 & Zofío Moscardo & 2807925 & 2807925 & & 4.280 & 2.150 & 1.785 \\
\hline 21 & 13 & Entrevías & 28079041 & Entrevías Este & Pr. Pub 40-60 & 7.875 & 3.585 & 2.875 \\
\hline 22 & 13 & Entrevías & 28079042 & Entrevías Oeste & Pr. Pub 40-60 & 16.270 & 7.680 & 6.730 \\
\hline 24 & 13 & San Diego & 28079048 & Picazo & Par. Perif & 9.585 & 4.625 & 4.005 \\
\hline 30 & 13 & Portazgo & 28079056 & Portazgo & Pr. priv 75-90 & 10.105 & 5.085 & 4.165 \\
\hline 44 & 18 & C.H. Vallecas & 2807920 & 2807920 & & 10.410 & 4.560 & 4.140 \\
\hline 45 & 19 & CH Vicálvaro-Ambroz & 28079038 & Vicálvaro & P. anex & 25.005 & 11.345 & 9.890 \\
\hline 46 & 20 & Simancas & 28079077 & Simancas & Pr. Pub 40-60 & 7.965 & 4.120 & 3.515 \\
\hline
\end{tabular}

\begin{tabular}{llllll}
\hline LEYENDA & & & & \\
ID & Identificador & F_CREC: & Forma de crecimiento & POB: & Población \\
DS & Distrito & Pr. Publ: & Promoción publica & VIVS: & Número de Viviendas \\
Barrio Admin & Barrio Administrativo & Pr. Priv: & Promoción privada & V_PR & Viviendas principales \\
CODBV: & Código Barrio Vulnerable & P. anex: & Pueblo anexionado & & \\
DENBV: & Denominación BV & Par. Perif ; & Parcelación periférica &
\end{tabular}

Existen algunos de estos barrios vulnerables que contienen los cuatro indicadores de pobreza energética solapados simultáneamente en las mismas secciones censales. Estas áreas aparecen resaltadas en la Tabla 23 con caracteres en negrita. Se ha considerado que se produce en estos casos un agravamiento de la presión provocada por la interacción de los vectores de riesgo y por tanto la máxima intensidad del riesgo de pobreza energética. Por esta razón se ha incluido el indicador de simultaneidad a la hora de componer el índice multidimensional, de manera que se pueda tener en cuenta cuales son los barrios que contienen secciones censales con estas características. Esta situación se produce en 11 barrios y áreas estadísticas vulnerables, y afecta a una población de 114.380 habitantes. El barrio de Simancas es el que contiene una mayor población censada en secciones en las que se solapan simultáneamente los cuatro indicadores de pobreza energética. 


\subsection{COMPARATIVA ENTRE MÉTODOS DE ANÁLISIS DE LA POBREZA ENERGÉTICA}

El indicador de demanda energética de calefacción por unidad de superficie habitable $(\mathrm{kWh} / \mathrm{m} 2)$ es adecuado para la caracterización de la calidad térmica de los edificios, de cara a detectar situaciones de vulnerabilidad energética asociada a la edificación. Posibilita la localización de la edificación en peores condiciones de la ciudad y la clasificación de los tejidos urbanos conforme a sus necesidades de energía.

El indicador de pobreza energética basado en la regla del $10 \%$ contempla la renta de los hogares, la calidad térmica de la edificación residencial y el coste de la factura energética a escala urbana, y permite localizar áreas desfavorecidas en grandes ciudades. En estas zonas se concentran las circunstancias que dificultan mantener la calidad del ambiente interior de las viviendas dentro de unos rangos aceptables. Estos rangos se definen en la normativa vigente. También se ha propuesto un índice que introduce una escala para cuantificar la severidad del problema conforme a otros aspectos socioeconómicos relacionados. La metodología se aplica en Madrid, obteniendo mapas en los que se puede visualizar la distribución espacial de aspectos relevantes de la vulnerabilidad y la pobreza energética en la ciudad.

La metodología permite estimar un valor aproximado del coste de la factura energética media de los hogares contenidos en cada área urbana. Los hogares contenidos en secciones censales clasificadas en el tramo de rentas más bajas (RMI, SMI y tramos 1 y 2), cuyas viviendas tienen clasificación energética de demanda de calefacción C, D, E, F y G se encuentran todas en riesgo de pobreza energética de acuerdo con la regla del $10 \%$. La fuente de energía es el factor que más influye en el precio del kilovatio hora (kWh), pero también existen otros factores como pueden ser el tipo de tarifa que se contrate y, en un mercado recientemente liberalizado como el español, influye la oferta de precios de cada empresa comercializadora (García 2006). En el caso de la energía eléctrica la potencia contratada que se suscriba también influye sensiblemente. La utilización de instalaciones de calefacción por energía eléctrica agrava el problema al resultar sensiblemente más elevada la factura energética resultante. 
Se demuestra que la estructura tarifaria española deriva en un coste mayor por kWh para los consumos energéticos más bajos. Esta situación penaliza tanto a los hogares que incorporan medidas de mejora de la eficiencia energética como a aquellos que se encuentran sufriendo situaciones de pobreza energética y carecen de recursos para hacer frente al costo de la energía suficiente como para lograr el confort en sus viviendas. Esto se traduce en que las rentas más bajas, que intentan reducir gastos mediante el ahorro de combustible, reciben una mayor presión en la factura a pesar de no satisfacer sus necesidades de confort. Además esta situación desincentiva a aquellos hogares pertenecientes a los niveles de renta más altos, que podría permitirse la inversión en la eficiencia energética pero no reciben estímulo puesto que la repercusión de las mejoras en la factura energética resulta amortiguada. La tarificación de precios de la energía hace además que, en el momento del presente estudio, la utilización de gas natural como combustible para la calefacción resulte sensiblemente más económico que la utilización de la calefacción eléctrica. Esta situación favorece la instalación de calderas de gas, normalmente individuales para cada vivienda, promoviéndose el agotamiento de combustibles fósiles no renovables y generando unas mayores emisiones de gases contaminantes y de efecto invernadero a la atmosfera, al menos en la ciudad y su entorno próximo, que además empeoran la calidad del aire exterior.

El catalogo de Barrios Vulnerables está recogiendo la práctica totalidad de las áreas en situación de riesgo de pobreza energética, al menos en la ciudad de Madrid. No obstante, no cuenta con ningún indicador de la eficiencia energética de la edificación. Teniendo en cuenta la importancia que está cobrando el problema de los costes energéticos en el hogar, sería interesante incorporar algún indicador, como los que se han propuesto en este trabajo. En el caso del municipio de Madrid, la pobreza energética resulta ser un fenómeno exclusivo de la periferia urbana. Se constata que se produce una acumulación de circunstancias causantes de la pobreza energética en los mismos barrios: demandas energéticas altas por mala calidad de la edificación, instalaciones de calefacción ineficientes mediante radiadores eléctricos y bajos niveles de renta. Estas áreas contienen una alta proporción de personas mayores. El estudio indica que la pobreza energética es una dimensión más de la vulnerabilidad urbana, mayoritariamente incluido en áreas vulnerables de la periferia urbana de la ciudad. 


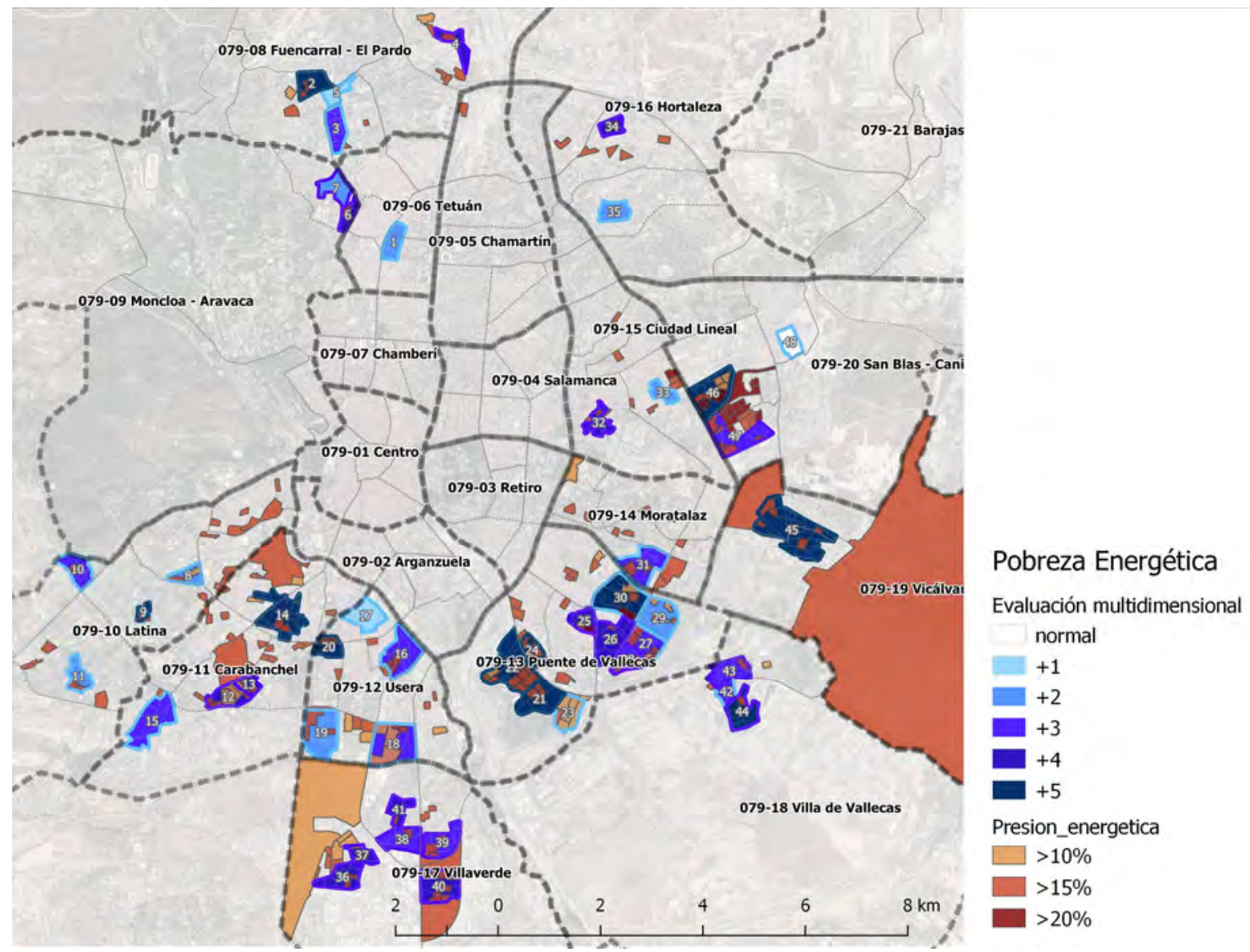

Figura 54. Comparativa con la metodología del 10\% con el análisis multidimensional. Elaboración propia

Si analizamos comparativamente los resultados de las dos metodologías desarrolladas en este trabajo (regla del $10 \%$ vs índice multidimensional), se pueden realizar algunas apreciaciones (Figura 54). La metodología del 10\% ofrece como resultado una mayor cantidad de áreas urbanas en riesgo de pobreza energética en sus datos de salida. Ninguna de las dos metodologías ofrece como resultado ninguna sección censal contenida en la almendra central de Madrid. Centro, Retiro, Salamanca y Chamberí serían distritos libres de riesgo de pobreza energética. Esto no quiere decir que dentro de estos distritos no puedan darse situaciones de pobreza energética, sino que el problema puede afectar a casos puntuales, y no se va a producir de forma generalizada. Todas las zonas más oscuras afectadas por elevados índices de pobreza energética multidimensional contienen áreas detectadas mediante el método del $10 \%$.

Llegado a este punto se considera que se han explotado al máximo las posibilidades que ofrecen los datos estadísticos para la detección del riesgo de pobreza energética. Una vez realizado el análisis urbano de su distribución de la pobreza energética a la 
escala de la sección censal se hace necesario ampliar la escala para analizar la edificación residencial existente en los barrios afectados. A través del estudio de los barrios en detalle se pretende desentramar los aspectos de la ineficiencia de la edificación que provocan una vulnerabilidad energética en las personas que la habitan. Para ello se ha juzgado necesario pasar a analizar en profundidad las posibilidades que ofrecen los datos catastrales. 



\section{CAPITULO 3. EVALUACIÓN ENERGÉTICA DE BARRIOS UTILIZANDO DATOS CATASTRALES}

El alto consumo de energía del sector de la edificación, el cambio climático local y la pobreza energética son los principales problemas encontrados en el entorno construido en Europa (Mat Santamouris 2016)

En el CAPITULO 2 se ha estimado la vulnerabilidad energética asociada a la edificación residencial para toda la ciudad a partir de modelos estadísticos de datos agregados obtenidos de los Censos, llegando a obtenerse un indicador de pobreza energética a escala urbana. Los modelos basados en la caracterización de muestras que representan la tipología edificatoria son una herramienta ampliamente utilizada hoy en día para la estimación de las necesidades energéticas del parque edificado. Estos métodos aportan información detallada de un conjunto de edificios existentes característicos de cada parque edificado y establecen conclusiones a partir de la generalización de los datos obtenidos. El principal problema de este acercamiento es que no es capaz de reproducir a pequeña escala toda la complejidad de la realidad de las ciudades, ya que no permiten incluir un número suficiente de casos estadísticamente representativos. La evaluación del potencial de nuestras ciudades debe hacerse de forma precisa para no desaprovechar los recursos existentes y al mismo tiempo no generar falsas expectativas que desincentivan a los usuarios y tienen un efecto perverso en la consecución de los objetivos de la Regeneración Urbana Integrada. En el presente capítulo se desarrolla un método para el análisis detallado de la edificación en los barrios. 


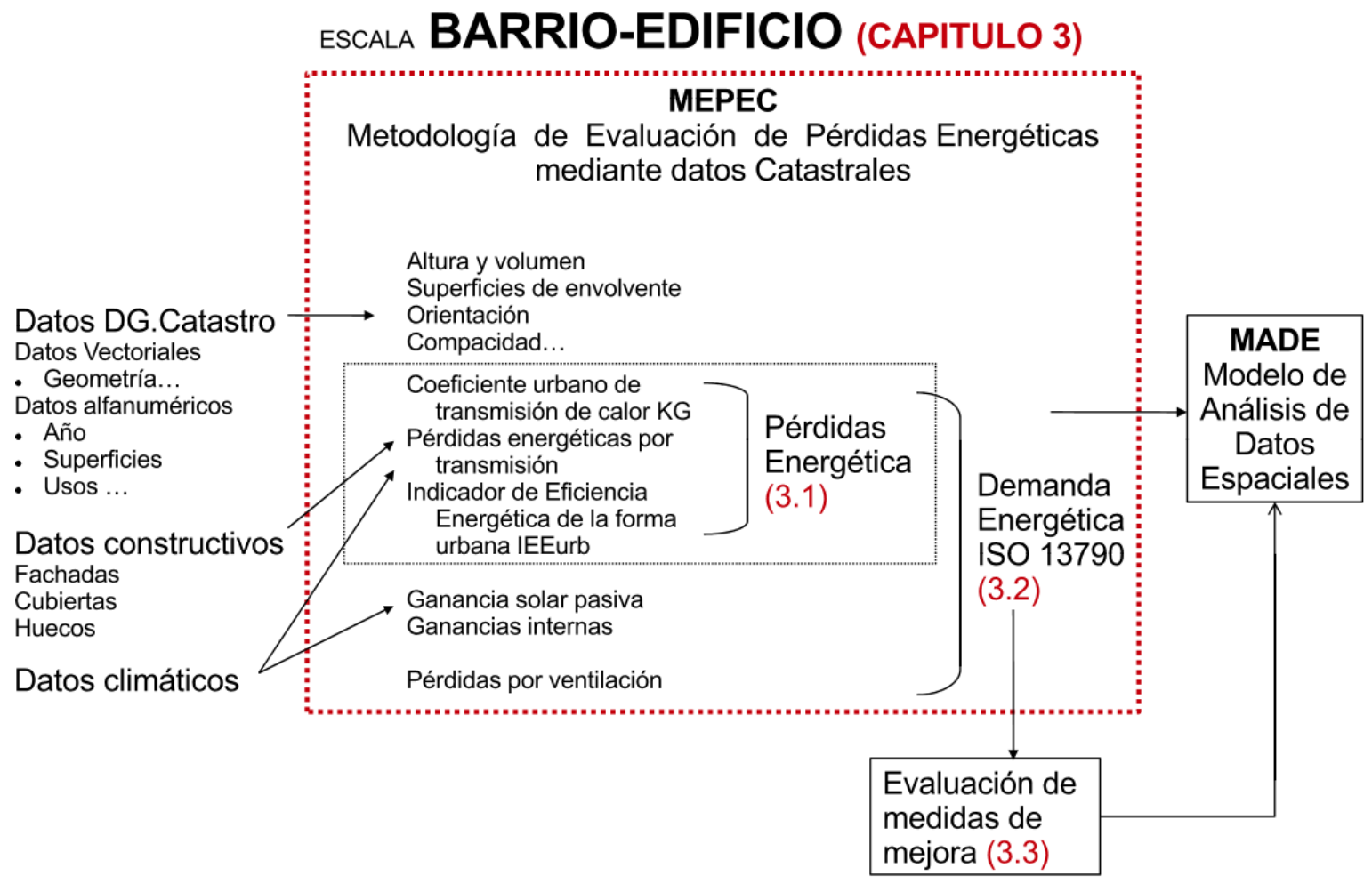

Figura 55. Esquema conceptual del desarrollo de la Metodología de Evaluación de Pérdidas Energéticas mediante Datos catastrales. Elaboración propia

Para ello, en el presente capítulo se describe el desarrollo de una herramienta de evaluación energética detallada para la edificación, a partir de la incorporación al MADE de cálculos energéticos realizados a partir de la información catastral (Figura 55). El volumen de información contenido en las bases de datos de Catastro permite abordar áreas urbanas completas. La incorporación de información catastral permite una gran exactitud en estos indicadores, ya que se obtienen a partir de la agregación de datos geométricos obtenidos edificio por edificio.

En origen, el enfoque de pobreza energética se centra principalmente en las necesidades energéticas de calefacción. En el caso de España, estas están consideradas como causantes de los mayores consumos energéticos del sector residencial. La metodología que se presenta está diseñada para cubrir este enfoque, que se centra en la evaluación de las pérdidas energéticas a través de la envolvente térmica. Este parámetro es óptimo para evaluar la calidad térmica de la edificación e incide directamente en la demanda energética de calefacción. Se trata por tanto de un indicador pasivo clave para 
la determinación de las necesidades de mejora, con objeto de reducir su vulnerabilidad energética y proponer soluciones efectivas a largo plazo para la pobreza energética.

Desde el punto de vista del urbanismo, la herramienta propuesta es capaz de calcular indicadores complejos, útiles para determinar la influencia de la forma urbana en las necesidades energéticas de la ciudad. 


\subsection{ESTIMACIÓN DE PÉRDIDAS ENERgÉtICAS A tRAVÉS DE DATOS CATASTRALES (MEPEC)}

Se propone una metodología de cálculo de las pérdidas energéticas a través de la envolvente de la edificación mediante la explotación masiva de datos catastrales a partir de herramientas informáticas de software libre disponibles en abierto. Los resultados permiten obtener información a escala de barrio acerca de la calidad térmica de la envolvente de la edificación, la dispersión de la energía conforme al clima de la ciudad a partir del cómputo de las pérdidas energéticas, y la eficiencia del tejido existente a partir del desarrollo de indicadores energéticos urbanos.

El objeto principal de este estudio es el desarrollo de una herramienta precisa, que facilite la incorporación de criterios de eficiencia energética en las operaciones de Regeneración Urbana Integrada para posibilitar el cumplimiento de los objetivos exigidos por las directivas europeas en materia de eficiencia energética y de eficiencia energética de la edificación (Parlamento Europeo y el Consejo de la Unión Europea 2002; 2010; 2012; 2018). En concreto, se pretende facilitar el diseño de estrategias para la rehabilitación de áreas urbanas con edificios ineficientes para dar respuesta a las obligaciones del Artículo 4 de la Directiva 2012/27/UE, que insta a los estados miembros a establecer una estrategia a largo plazo para movilizar inversiones en la renovación del parque nacional de edificios residenciales y comerciales. La herramienta que se presenta resulta útil para planificar las sucesivas actualizaciones de la ERESEE (Ministerio de Fomento 2017). Además, la actualización de la Directiva (UE) 2018/844 indica expresamente que las estrategias diseñadas por los estados miembros deben incluir planes específicos para combatir la pobreza energética. Para el diseño de estas estrategias es necesario poder evaluar cuantitativamente el estado actual de la edificación con objeto de ser precisos en la estimación de su potencial de mejora.

La generación de un sistema de datos espaciales a partir del tratamiento masivo de información catastral, abre una oportunidad para ampliar la escala en el estudio más allá de la unidad edificada y poder analizar áreas urbanas completas, con un nivel de precisión relevante. La incorporación en este sistema de datos acerca de la calidad 
térmica de la edificación existente permite desarrollar modelos energéticos del parque edificado mucho más exhaustivos que los obtenidos hasta el momento. Esto permite afinar en el diagnóstico del estado actual de nuestros barrios y evaluar el impacto de diferentes medidas para su mejora energética. Este cambio de escala aporta una aproximación que ayuda a cerrar la brecha que existe entre el análisis de las edificaciones aisladas y el comportamiento estadístico global de la ciudad. El trabajo que se presenta se ha podido realizar gracias a que la Comisión Permanente del Catastro de la Unión Europea trabaja en la unificación de los sistemas catastrales en Europa para la compatibilidad, el intercambio y la transparencia de la información (de Santis 2008). La digitalización, sistematización y publicación de datos catastrales facilita el desarrollo de actividades de investigación. En el caso de los estudios urbanos, la accesibilidad e interoperabilidad de los datos espaciales permiten integrar o relacionar datos geográficos contenidos en diferentes corpus de datos, proporcionando información clave para la toma de decisiones. Trabajos como el que aquí se presenta abren la posibilidad de desarrollo de herramientas europeas para la gestión del medio ambiente que se pueden volcar en el proyecto INSPIRE (Infraestructura para la Información Espacial en Europa) (Ratia 2d. C.). Además, en el caso del catastro español, es preciso señalar que la información que contiene ha sido elaborada por un equipo de arquitectos que ha sabido integrar datos exhaustivos de la edificación. Esto permite el análisis detallado de la misma, más allá de la función impositiva y de control de la propiedad de las parcelas, característica de los catastros.

Para la comprobación de la metodología se analizan los resultados obtenidos para un estudio de caso en un área de la periferia de Madrid que contiene edificación ineficiente y está declarado como barrio vulnerable. Contiene con toda probabilidad población viviendo en situación de pobreza energética. La metodología descrita es extrapolable a otras ciudades españolas y europeas, que cuenten con sistemas catastrales cada vez mas armonizados gracias al trabajo que lleva haciendo desde 2002 la Comisión Permanente del Catastro de la Unión Europea. 


\subsubsection{Las pérdidas energéticas de la edificación}

Para el desarrollo de herramientas que faciliten la incorporación de criterios de eficiencia energética de la edificación en las operaciones de Regeneración Urbana Integrada, se parte en primer lugar del objetivo de limitación de la demanda mediante la aplicación de los principios de diseño de la arquitectura solar pasiva. El enfoque para una rehabilitación solar pasiva de los barrios existentes implica que en temporada de invierno la demanda de calefacción se debe reducir básicamente limitando las pérdidas y promoviendo las ganancias solares. Para reducir la demanda de refrigeración en verano, se deben limitar las ganancias, por ejemplo mediante la protección solar, y promover las pérdidas mediante estrategias como la ventilación nocturna (García Arroyo 1983; F. Javier Neila 2009).

En lo que respecta al análisis del consumo energético del sector residencial de España, en el caso de la ciudad de Madrid, las mayores necesidades energéticas corresponden al acondicionamiento térmico para la calefacción, que supone aproximadamente un $55 \%$ del consumo total (IDAE 2011b). Las pérdidas energéticas han sido señaladas en diversos estudios como factores determinantes en la demanda de calefacción de los espacios domésticos (Kavgic et al. 2010). La limitación de estas pérdidas se considera la estrategia más urgente en este momento para la reducción del consumo energético de las ciudades.

Se persigue incorporar al Modelo para el Análisis de Datos Espaciales (MADE) una serie de indicadores de las características térmicas de la edificación para caracterizar la calidad térmica de las áreas urbanas. La parametrización del comportamiento bioclimático de los tejidos urbanos se realiza a partir de la caracterización geométrica y constructiva de la edificación que contienen. Esto permite la estimación del potencial de reducción de pérdidas a partir de la comparación de resultados en el estado actual con el de posibles estados reformados que incorporen medidas de mejora.

Para la validación de los resultados se ha aplicado la metodología al área urbana correspondiente al "Poblado de Canillas", incluido en el barrio de Canillas, distrito de Hortaleza de Madrid (España). La mayor parte de su edificación cuenta con una calificación energética en demanda de calefacción de las más bajas de acuerdo con la escala vigente para edificios existentes (IDAE 2011a), y está catalogado como barrio vulnerable en el Atlas de Barrios Vulnerables (Ministerio de Fomento y UPM 2017). 
Además, cuenta con varios conjuntos de edificación que han sido catalogados por su valor patrimonial en el registro del DOCOMOMO Ibérico (Centellas et al. 2009), con lo cual su conservación se considera de interés cultural.

\subsubsection{Procedimiento de cálculo}

La Metodología de Evaluación de Perdidas Energéticas (MEPEC), utiliza como fuentes las bases de datos del Catastro. El Catastro es el registro administrativo, dependiente del Ministerio de Hacienda y Función Pública, que contiene la descripción de los bienes inmuebles rústicos, urbanos y de características especiales (Figura 56). La inscripción en el mismo es obligatoria y gratuita y los datos no protegidos se pueden consultar en abierto. Los datos no protegidos comprenden toda la información contenida en el catastro, excepto la que se refiere a la titularidad u el valor catastral de los inmuebles (Sede Electrónica de Catastro 2011).

La explotación de estos datos permite un análisis a escala urbana de la edificación de manera pormenorizada para cada individuo (clasificado a través del código de referencia de su parcela catastral, REFCAT). Esto permite parametrizar aspectos de la morfología urbana que influyen en el comportamiento energético de los barrios (Jose Lao 2014; Liu y Sweeney 2012; Vartholomaios 2017). Para ello se han seguido las etapas que se resumen a continuación:

- Generación de modelos en tres dimensiones (2.5D) para barrios a partir de datos catastrales en formato vectorial (SHP).

- Caracterización geométrica. Cómputo de las superficies construidas por usos, del volumen edificado y las superficies de la envolvente térmica de cada edificación, asociadas a los diferentes usos contemplados en el catastro. A partir de la incorporación de datos alfanuméricos no protegidos (CAT) al modelo vectorial (SHP).

- Caracterización constructiva. Cálculo del indicador de calidad térmica de la envolvente: el Coeficiente Global de Transmisión de Calor $\mathrm{K}_{\mathrm{G}}\left(\mathrm{W} / \mathrm{m}^{2} \mathrm{~K}\right)$ para cada edificio, según (NBE-CT-79 1979); mediante la incorporación en el modelo de información acerca de las características térmicas de la edificación (véase Apartado 4.1). Se obtiene también un valor urbano para el barrio $K_{G u r b}$ 


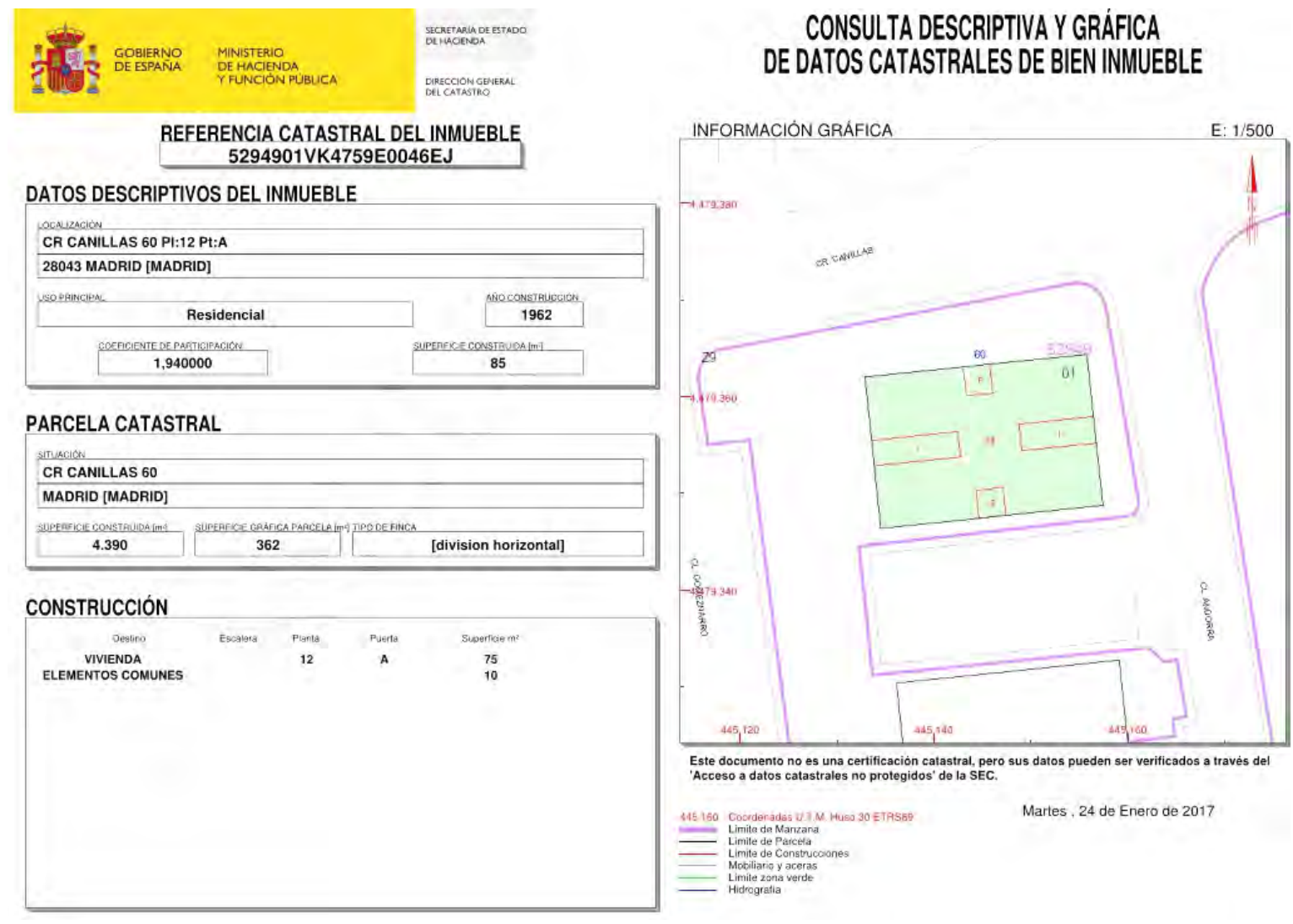

Figura 56. Ficha de salida de datos no protegidos de la consulta descriptiva y grafica de bienes inmuebles. Ejemplo de edifico en torre en el PD Canillas (Sede Electrónica de Catastro 2011)

- Estimación de pérdidas totales. Cálculos de la dispersión de la energía en la ciudad a partir de las pérdidas energéticas por transmisión $Q_{t}$ ( $k W h$ año) de cada edificación y para agrupaciones de estas. Se introducen datos climáticos de la localización por el método de los grados día (ISO 13790, 2008).

- Estimación de un Indicador de Eficiencia Energética de calefacción para cada edificio $\mathrm{IEE}_{\text {cal }}$ y para todo el tejido urbano $\mathrm{IEE}_{\mathrm{urb}}$; a partir de la ponderación de las pérdidas totales por el volumen de la edificación $\left(\mathrm{kWh} / \mathrm{m}^{3}\right.$ año).

\subsubsection{Descarga y procesado de los datos catastrales}

La Dirección General del Catastro pone a disposición de los ciudadanos una serie de servicios de descarga masiva de datos; en la Tabla 26 se recogen los servicios utilizados en este documento y se describe la descarga usada, el tipo de datos que se recibe, la fuente y una breve descripción del servicio ofrecido por la Sede Electrónica de Catastro (Sede Electrónica de Catastro 2011); cada uno de los servicios está documentado en su correspondiente epígrafe del portal web. 
Tabla 26.Servicios de descarga masiva (Sede Electrónica de Catastro)

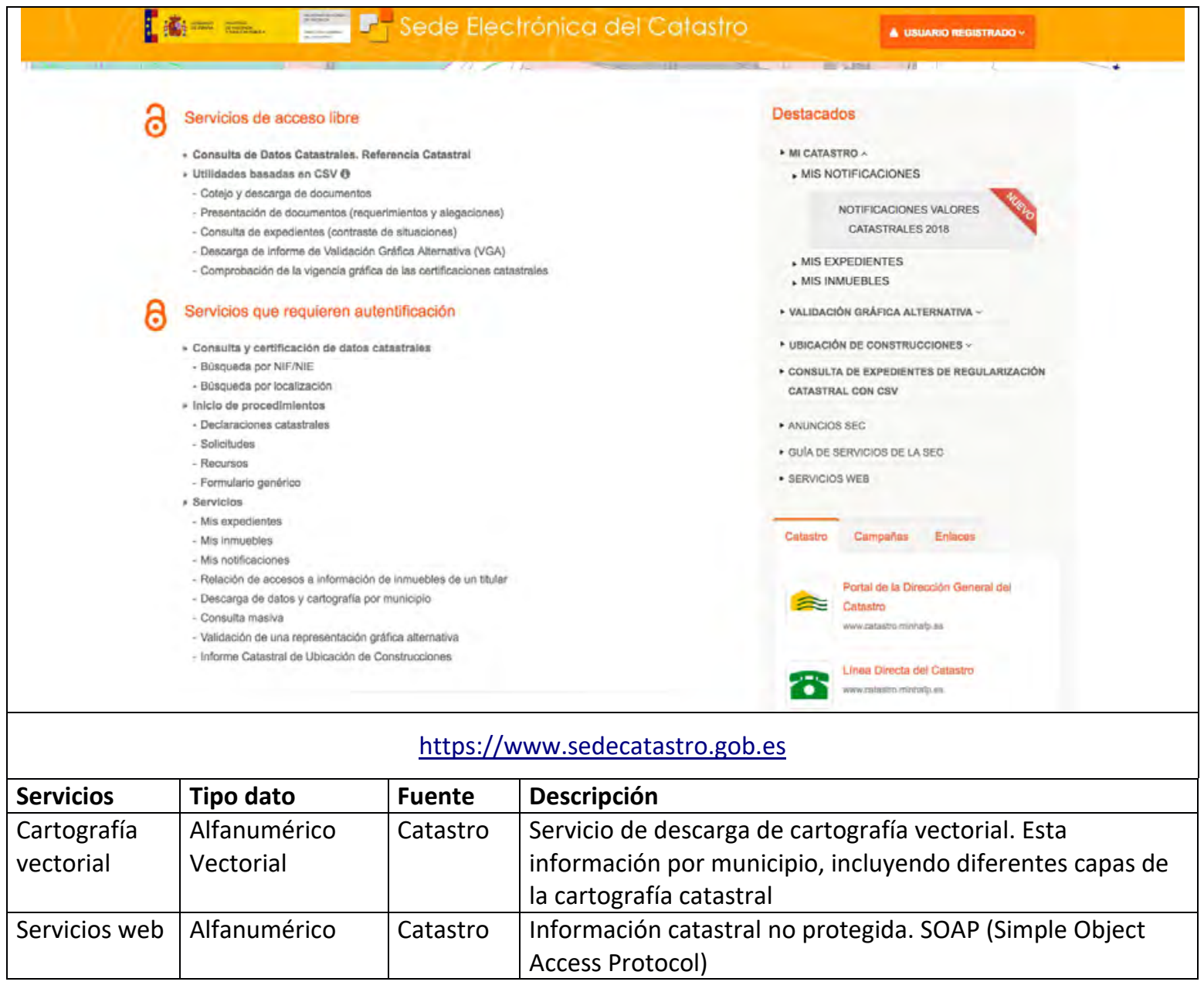

\subsubsection{Cartografía vectorial}

La Dirección General del Catastro ofrece la cartografía catastral en formato de imagen vectorial (Sede Electrónica de Catastro 2014). Esta información se proporciona por municipio en archivos Shapefile, incluyendo separadamente las diferentes capas de la cartografía catastral. Estas capas/tablas son:

- ALTIPUN. Puntos de altimetría con cota y puntos de las redes geodésicas y topográficas.

- CARVÍA. Descripción de los códigos de vías de comunicación e hidrografía.

- CONSTRU. Subparcelas urbanas que representan los volúmenes edificados dentro de una parcela.

- EJES. Ejes de elementos lineales.

- ELEMLIN. Elementos cartográficos lineales 
- ELEMPUN. Elementos cartográficos puntuales

- ELEMTEX. Rótulos del mapa

- ERRLIN. Tramos abiertos en el parcelario que se detectan en el momento de la carga. Son errores y no deberían existir.

- HOJAS. Hojas de división de la cartografía urbana.

- $\quad$ LIMITES. Límites administrativos.

- MAPA. Identificación de cada una de las zonas con cartografía diferente.

- MASA. Agrupaciones de parcelas (manzanas de urbana y polígonos de rústica)

- PARCELA. Parcelas catastrales.

- SUBPARCE. Subparcelas de cultivo.

El parcelario catastral se define mediante las capas/tablas: MASA, PARCELA, SUBPARCE y CONSTRU. El resto de tablas/capas son auxiliares o contienen otros elementos cartográficos, como mobiliario urbano, límites administrativos, etc. La capa/tabla CONSTRU incluye las subparcelas urbanas que representan los volúmenes edificados dentro de una parcela; La estructura de campos, más relevante en esta metodología, se definen en la Tabla 27.

REFCAT14 - REFCAT20 son los identificadores de parcela e inmueble definidos por Catastro.

- REFCAT14 / REFCAT. Referencia catastral de parcela tiene 14 caracteres únicos para cada parcela catastral. Dentro de una misma parcela catastral pueden existir diferentes inmuebles.

- REFCAT20. Referencia catastral de un inmueble tiene 20 caracteres. De estos 20 caracteres, los 14 primeros identifican la parcela cartográfica en la que se ubica y los otros 6 identifican el inmueble dentro de la parcela.

Tabla 27. Selección de atributos capa CONSTRU (Sede Electrónica de Catastro)

\begin{tabular}{|l|l|l|l|}
\hline NOMBRE CAMPO & TIPO DATO & LONG & DESCRIPCIÓN \\
\hline REFCAT & VARCHAR2 & 14 & Referencia catastral de parcela \\
\hline CONSTRU & VARCHAR2 & 16 & Alturas construidas \\
\hline NUMSYMBOL & NUMBER & 2 & Subparcelas con edificación identificadas con el valor 11 \\
\hline AREA & NUMBER & 10 & Superficie del elemento en metros cuadrados \\
\hline
\end{tabular}




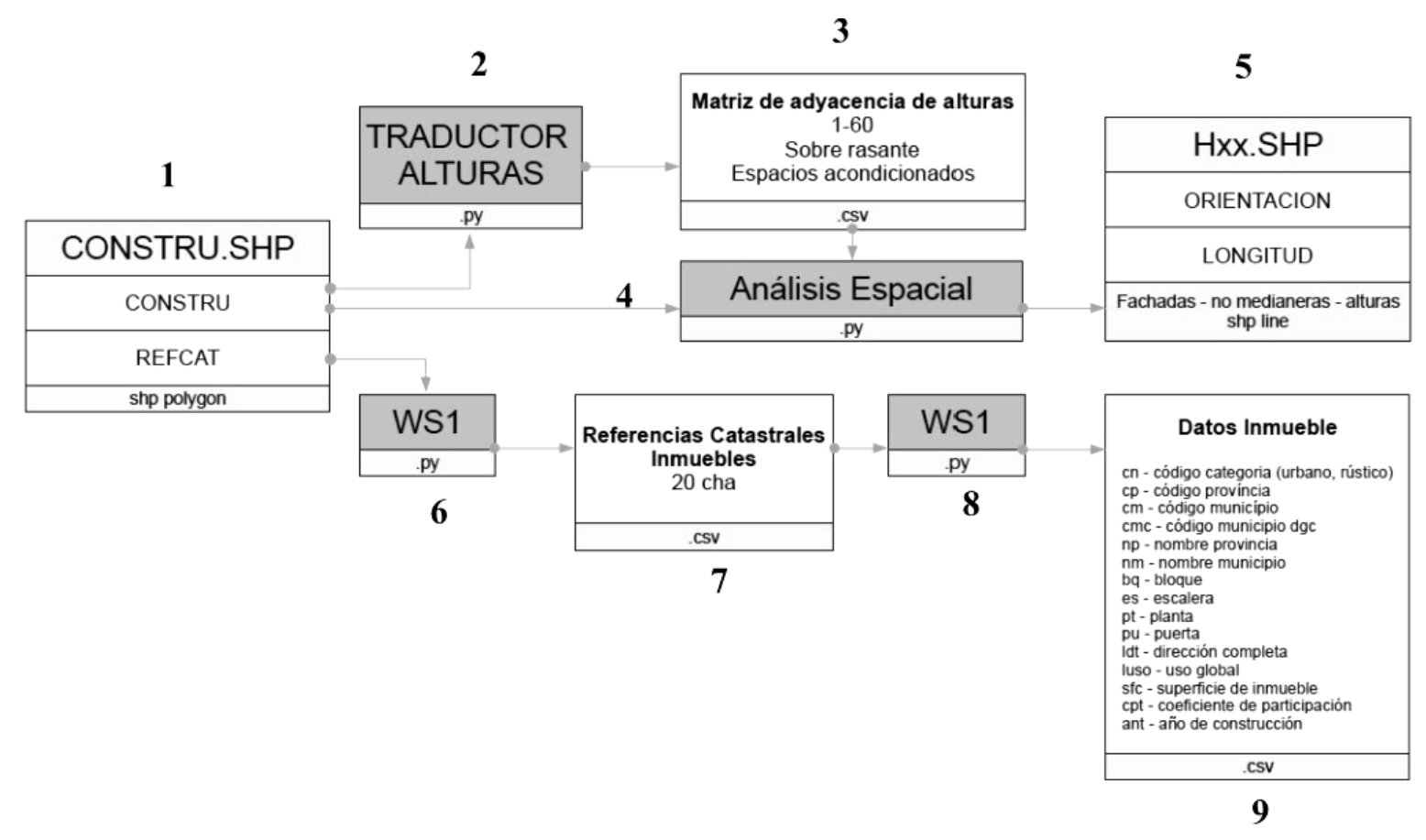

Figura 57. Diagrama de flujo para el programa MEPEC (Fernando de Frutos 2017)

\subsubsection{Servicios Web (WS)}

El servicio web da acceso a la consulta de datos catastrales no protegidos de un inmueble identificado por su referencia catastral. Los datos no protegidos de los inmuebles, (todos excepto titularidad y valor) son:

- PARCELA CATASTRAL. Localización, superficie gráfica y participación del inmueble.

- DATOS DESCRITIVOS DEL INMUEBLE. Referencia catastral, localización, clase (rural/urbano), uso principal, superficie construida (m2) y año de construcción.

- CONSTRUCCION. Uso principal, escalera, planta, puerta y superficie (m2)

\subsubsection{Descarga y procesamiento de datos}

Este apartado recoge la forma en que informática e información (Jiang 2011) se integran para la descarga, procesamiento y exploración de datos espaciales. La Figura 57 define el diagrama de flujos del programa informático que procesa la información catastral para obtener los datos de longitud de fachada por planta de la edificación y los datos por inmueble descritos anteriormente. Se ha usado Python como lenguaje de programación: 
- Módulo Pandas. (http://pandas.pydata.org) Pandas es un módulo de Python destinado al análisis de datos.

- Módulo GeoPandas. (http://geopandas.org/) GeoPandas facilita el trabajo con datos geoespaciales. GeoPandas extiende los tipos de datos utilizados por Pandas para permitir operaciones espaciales en tipos geométricos.

El campo CONSTRU descrito en el Apartado 3.1.3.1 de Cartografía Vectorial de la capa/tabla CONSTU.SHP (1) recoge los códigos de altura de las subparelas. Esto permite conformar la matriz de adyacencia de alturas (2-3) con las que mediante análisis espacial (4) se obtienen los datos de longitud de fachadas y orientación de cada registro edificado (5).

El campo REFCAT descrito en la capa/tabla CONSTU.SHP (1) recoge las referencias catastrales por parcela. Se consulta por cada una de ellas las referencias catastrales de los inmuebles (6-7) de las que obtenemos los datos por inmueble descritos en el Servicio Web (SW) (8-9).

\subsubsection{Caracterización geométrica de la edificación}

A partir del proceso de los datos catastrales (vectoriales y alfanuméricos) descargados, se concreta la caracterización geométrica de la edificación en el Modelo de Análisis de Datos Espaciales (MADE). La automatización del tratamiento de datos permite generar una ficha de información para cada individuo que se asocia a su referencia catastral. En ella se registran los valores correspondientes a los volúmenes edificados que contiene cada parcela. Para el desarrollo de la metodología MEPEC se han incluido en el Modelo las variables geométricas que influyen en el comportamiento energético de la edificación.

\subsubsection{Superficie residencial}

La superficie catastral de la edificación se obtiene para cada inmueble o recinto (REFCAT20) que esté contenido en cada parcela catastral (REFCAT14) que contiene edificación (campo: numsymbol 11). La estructura de los datos permite recopilar usos pormenorizados para cada inmueble. Para la evaluación energética se han escogido aquellos usos que precisan de acondicionamiento térmico de acuerdo con la normativa 
vigente (CTE-DB-HE 2013) y se excluyen aquellos recintos que están clasificados como zonas comunes, garajes, almacenes, etc. Se recoge a su vez la información del año de construcción contenida en la información catastral.

La salida de datos del MADE se puede volcar en una matriz (Tabla 28) que cruza los datos de superficies en función de sus variables Uso/Periodo (Thuvander 2008). La información acerca de los usos permite hacer estimaciones acerca de la complejidad urbana (MARM 2010). Además puede aportar información relevante para el estudio de la demanda energética en barrios completos en régimen horario y mediante la caracterización de perfiles de los diferentes usos de la edificación estacional (Fonseca y Schlueter 2015). Este acercamiento temporal se considera emergente en los modelos de estimación de la demanda energética y cobra especial importancia en la estimación de demandas pico para la modelización de sistemas de climatización por distrito y redes de suministro (Salisu y Ayinde 2016). Se pretende además que se pueda utilizar en trabajos futuros de predimensionado grueso para la instalación de energía solar renovable en el barrio y el trazado de sus redes de distribución.

En la aplicación de la metodología al estudio de caso del barrio de Canillas se observa que la mayor parte de la superficie está destinada a uso residencial (Figura 58) y la práctica totalidad de la superficie destinada a servicios fue desarrollada durante el periodo 40-80, y por tanto está contenida en edificios que no cuentan con ningún tipo de aislamiento térmico (Tabla 28).

Tabla 28. Matriz de superficie habitable (m2) por Uso y Periodo del PD Canillas. Elaboración propia

\begin{tabular}{|c|c|c|c|c|c|}
\hline Uso/Periodo & ant_1940 & 1940a1979 & 1980a2006 & post_2006 & TOTAL \\
\hline VIVIENDA & 392 & 104.327 & 28.795 & 1.237 & 134.751 \\
\hline COMERCIO & & 4.987 & 684 & & 5.671 \\
\hline ENSENANZA & & 6.708 & & & 6.708 \\
\hline SANIDAD & & 1.644 & & & 1.644 \\
\hline OCIO_HOSTEL & & 255 & & & 255 \\
\hline OFICINA & & 147 & & & 147 \\
\hline DEPORTIVO & & 1.610 & 27 & & 1.637 \\
\hline RELIGIOSO & & 895 & & & 895 \\
\hline INDUSTRIAL & & 29 & & & 29 \\
\hline OTROS_USOS & & 676 & & & 676 \\
\hline TOTAL & 392 & 121.278 & 29.506 & 1.237 & 152.413 \\
\hline
\end{tabular}




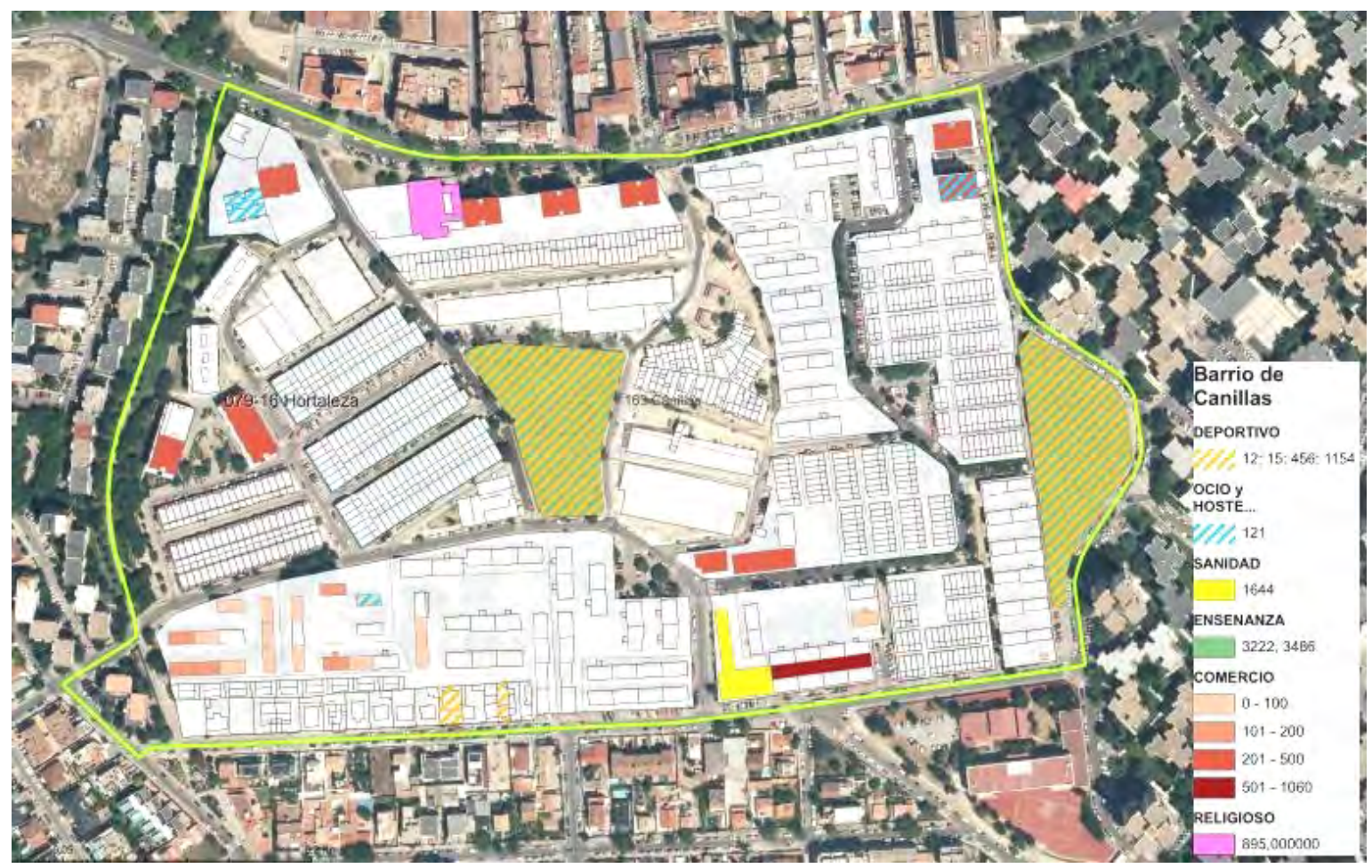

Figura 58. Visualización de la clasificación de otros usos distintos al residencial para el poblado de Canillas (m2). Elaboración propia

\subsubsection{Altura y volumen de la edificación}

Si bien actualmente existen modelos capaces de predecir la altura de la edificación basándose en modelos 2D (Biljecki, Ledoux, y Stoter 2017), en el caso de los datos catastrales es posible definir la volumetría de los elementos de la edificación con precisión a partir de atributo CONSTR asociado a la geometría 2D contenida en el SHP. Se desarrolla una programación Python (CONSTRU_ALTURAS.ipynb) que traduce cada uno de los códigos CONSTRU de alturas a una tabla con los atributos de niveles de planta desde H01 hasta H60 (número máximo de plantas en la ciudad de Madrid). El valor 1 significa que el elemento espacial existe en el nivel correspondiente y contiene un valor de superficie construida, uso pormenorizado asociado y año de construcción, entre otros. Para la obtención de la altura total de cada volumen edificado se computa el número de niveles con valor 1. Para este estudio solamente se ha tenido en cuenta la información acerca de la superficie edificada sobre rasante, si bien la codificación catastral describe también el número de plantas bajo rasante y su uso asociado. Se ha simplificado el estudio entendido que los espacios bajo rasante no son habitables y no cuentan con acondicionamiento térmico. La altura media de los edificios de un barrio se obtiene 
ponderando la altura de cada volumen edificado por la superficie ocupada por su huella en planta.

El volumen aproximado de la edificación se obtiene a partir de los datos de superficie y número de plantas. La información catastral contiene datos del número de plantas pero no del valor en $\mathrm{m}$ de la altura de planta. Para evaluar la potencia del método se ha adjudicado un valor estándar de la altura entre plantas de 3 metros para todos los casos, contando $30 \mathrm{~cm}$ de altura de forjado y 2,70 de altura libre (Modelo 2.5D). Se ha optado por la utilización de este valor simplificado, si bien un ajuste más preciso del modelo debe permitir introducir datos concretos para cada área urbana, puesto que su influencia en el cálculo del volumen acondicionado es relevante (Modelo 3D).

\subsubsection{Superficies de envolvente}

EI MADE parte de los datos de perímetro, área y altura del modelo vectorial contenido en la cartografía SHP de Catastro. A partir de la geometría de los registros accedemos a la orientación y longitud de cada una de las fachadas. Mediante un programa Python, que automatiza el proceso de datos (Fachadas_shp_polylines.ipynb), es posible almacenar la información en el registro de cada parcela catastral. La superficie bruta de fachadas se calcula a partir del perímetro de los polígonos del que contienen edificación y su correspondiente valor de altura. Para reconocer y sustraer las medianeras se definen las líneas 2D por alturas a través del centroide de los elementos línea; si dos líneas tienen un

mismo centroide $y$ pertenecen a distinta referencia catastral se definen como medianeras y no se computan. Este proceso permite analizar la relación entre volúmenes edificados contiguos de manera precisa para cada planta. Las paredes medianeras en contacto con el aire exterior se contabilizan como fachadas a efectos del intercambio de energía.

La función AZIMUTH define el ángulo perpendicular al sentido de los objetos de línea que componen cada polígono. La función ORIENTACION traduce el valor del ángulo azimut en su orientación ( $N$, SE S, SO, O, NO), que puede asociarse a cada una de las orientaciones de fachada (Tabla 29). Como datos salida se obtiene un archivo vectorial Shapefile de línea para cada una de las plantas que componen el barrio a analizar (Figura 59). Para la estimación estricta de las pérdidas energéticas que se presenta en este 
artículo, la información acerca de la orientación de las fachadas no resulta relevante. Se ha optado por la inclusión de esta información en el MADE puesto que se pretende utilizar este mismo modelo en el futuro para la estimación de las ganancias solares.

La superficie de la parte hueca de las fachadas se obtiene mediante la asociación de un porcentaje de huecos. A partir de este valor se puede deducir la superficie neta de la parte opaca. En este caso se ha optado por un valor medio simplificado del $16 \%$ para todas las orientaciones. El valor se ha obtenido a partir de datos de muestras de promociones de vivienda en bloque multifamiliar producidas en Madrid en el periodo 4080 (Oteiza, l. et al. 2018).

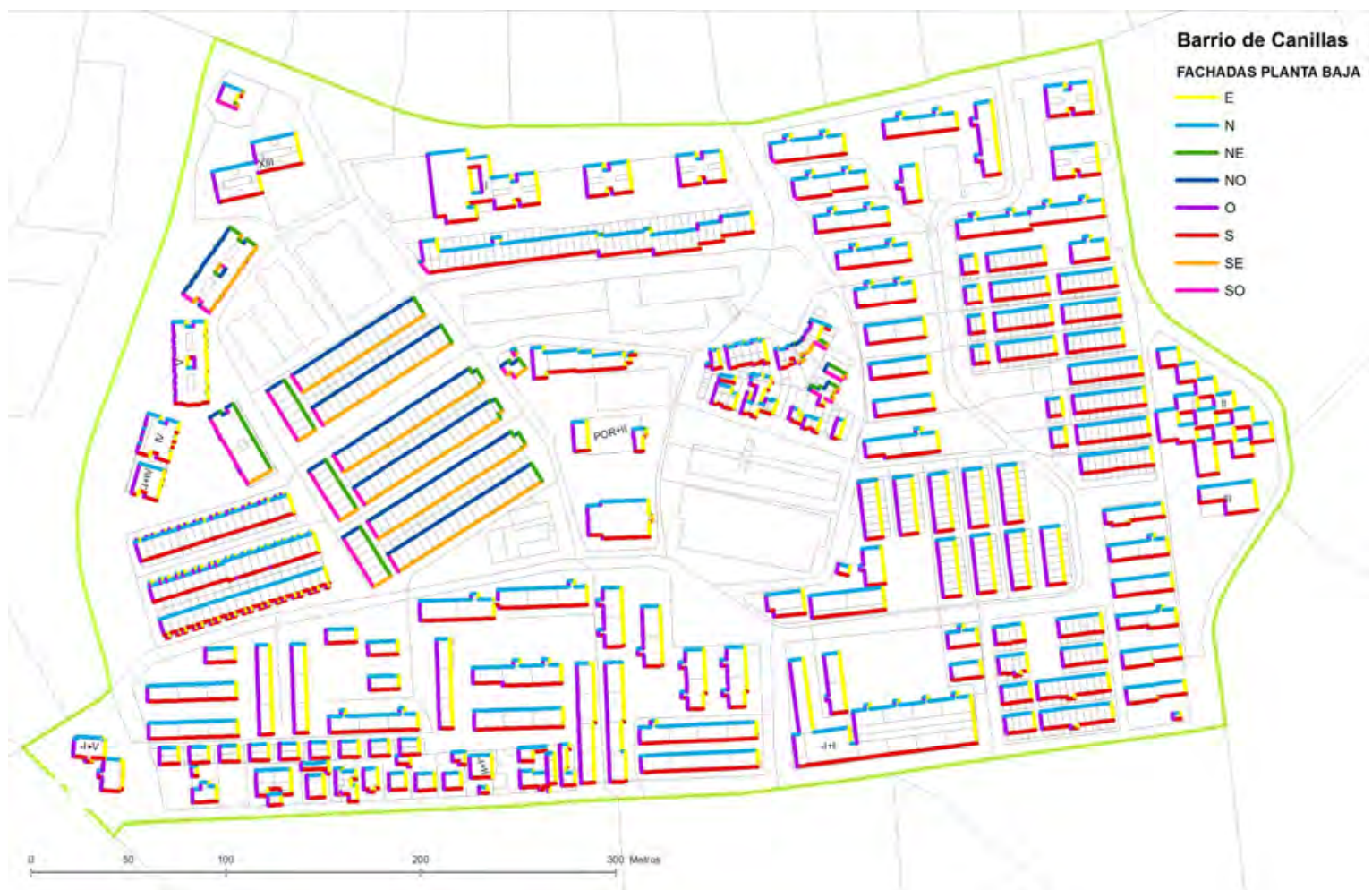

Figura 59. Cómputo de fachadas por orientaciones en el estudio de caso (planta baja). Elaboración propia

Tabla 29. Dimensiones de fachada obtenidas para el barrio de Canillas clasificadas por orientación

\begin{tabular}{|l|l|l|l|l|l|l|l|l|l|}
\hline Orientación & $\mathbf{E}$ & $\mathbf{N}$ & NE & NO & O & S & SE & SO & Total \\
\hline Long $(\mathrm{m})$ & 8.547 & 13.201 & 745 & 1.477 & 8.533 & 13.157 & 1.495 & 7678 & 47.926 \\
\hline Sup $(\mathrm{m} 2)$ & 25.642 & 39.604 & 2.237 & 4.433 & 25.600 & 39.472 & 4.486 & 2.304 & 143.778 \\
\hline$\%$ huecos & $16 \%$ & $16 \%$ & $16 \%$ & $16 \%$ & $16 \%$ & $16 \%$ & $16 \%$ & $16 \%$ & $16 \%$ \\
\hline Sup H (m2) & 4.103 & 6.337 & 358 & 709 & 4.096 & 6.315 & 717,83 & 369 & 23.004 \\
\hline Sup O (m2) & 21.539 & 33.267 & 1.879 & 3.724 & 21.504 & 33.156 & 3.769 & 1.935 & 120.773 \\
\hline
\end{tabular}


Tabla 30. Superficies de envolvente en PD Canillas, agrupadas por periodo (m2). Elaboración propia

\begin{tabular}{|l|l|l|l|l|l|}
\hline & Anterior a 1940 & $\mathbf{1 9 4 0 - 1 9 7 9}$ & $\mathbf{1 9 8 0 - 2 0 0 6}$ & $\mathbf{2 0 0 7 - 2 0 1 3}$ & TOTAL \\
\hline Sup. bruta fachada & 827 & 119.314 & 22.375 & 1.262 & 143.778 \\
\hline Sup. parte hueca & 132 & 19.090 & 3.580 & 202 & 23.005 \\
\hline Sup. parte opaca & 694 & 100.224 & 18.795 & 1.060 & 120.774 \\
\hline Sup. cubiertas & 526 & 36.037 & 12.142 & 411 & 49.116 \\
\hline Sup. suelo con aire & 0 & 497 & 432 & 0 & 930 \\
\hline Sup. resto de suelos & 526 & 35.539 & 11.710 & 411 & 48.186 \\
\hline TOTAL & 1.878 & 191.387 & 46.660 & 2.085 & 242.010 \\
\hline
\end{tabular}

La superficie de las cubiertas se equipara a la de la huella ocupada por la edificación, a partir de la suma de los valores de área de los polígonos de cada volumen construido. En cuanto a los suelos, la codificación de la configuración de los volúmenes edificados contenida en los datos catastrales permite distinguir soportales, porches y voladizos sobre forjados que están en contacto con el aire exterior. Esto permite distinguirlos de los que están a nivel de terreno y deducirlos.

EI MADE ofrece como datos de salida un resumen de las superficies de toda la envolvente térmica de la edificación (Tabla 30) obtenida a partir de la agregación de los datos de cada individuo, que tiene su propia ficha asociada a su código REFCAT.

\subsubsection{Otros indicadores geométricos urbanos}

Mediante ciertas operaciones sencillas es posible obtener indicadores útiles para caracterizar aspectos de la forma urbana que están relacionados con el comportamiento energético del tejido (Tabla 31). La información se obtiene a partir de los datos agregados de cada edificio existente. Se realiza una estimación precisa de la compacidad urbana, a partir del cociente entre el volumen acondicionado y la superficie de la envolvente térmica. El factor de forma urbano se expresa como el inverso de la compacidad.

\section{Ecuación 1. Compacidad (m3/m2)}

$\mathrm{C}=\mathrm{Vol} / \mathrm{S}_{\mathrm{env}}$

Donde:

Vol $=$ volumen de aire correspondiente a usos acondicionados $\quad\left(\mathrm{m}^{3}\right)$

$\mathrm{S}_{\text {env }}=$ Superficie total de la envolvente térmica 
Tabla 31. Indicadores geométricos para el barrio y para tres edificios tipo. Elaboración propia

\begin{tabular}{|l|l|l|l|l|l|l|}
\hline & $\begin{array}{l}\text { Sup. envolv } \\
(\mathbf{m} 2)\end{array}$ & $\begin{array}{l}\text { Huella ocupada } \\
(\mathbf{m} \mathbf{2})\end{array}$ & $\begin{array}{l}\mathbf{N}^{\mathbf{0}} \text { plantas } \\
\text { (ud) }\end{array}$ & $\begin{array}{l}\text { Altura media } \\
(\mathbf{m})\end{array}$ & $\begin{array}{l}\text { Volumen } \\
(\mathbf{m} 3)\end{array}$ & $\begin{array}{l}\text { Compacidad } \\
(\mathbf{m} 2 / \mathbf{m} 3)\end{array}$ \\
\hline Total Barrio Canillas & 243.317 & 49.769 & 3,22 & 9,65 & 480.253 & 1,97 \\
\hline 4994547VK4749F Torre & 5.380 & 346 & 13 & 39 & 13.647 & 2,54 \\
\hline 4992543VK4749D Bloque & 706 & 155 & 4 & 12 & 2.200 & 3,11 \\
\hline 5292448VK4759C Unif. & 170 & 35 & 2 & 6 & 209 & 1,23 \\
\hline
\end{tabular}

La compacidad es un factor determinante en el diseño solar pasivo de la edificación para la caracterización de las pérdidas energéticas y mediante el tratamiento de datos catastrales masivos es posible calcularla pormenorizadamente para áreas urbanas completas.

Teniendo en cuenta la superficie total del territorio que ocupa el barrio (en el caso de Canillas de $198.318 \mathrm{~m}^{2}$ ) es posible obtener valores de otros indicadores útiles para caracterizar el comportamiento energético de conjuntos urbanos, como son:

$\begin{array}{llll}\text { DNS } & 2,42 & \text { Densidad } & \text { (Volumen edif. / Área Total Barrio) } \\ \text { RSD } & 0,68 & \text { Densidad residencial } & \text { (Superficie de uso vivienda / A T B ) } \\ \text { EDF } & 0.77 & \text { Edificabilidad bruta } & \text { (Superficie construida / A T B) } \\ \text { BCR } & 0,25 & \text { Coeficiente de Ocupación } & \text { (Superficie ocupada / A T B) }\end{array}$

\subsubsection{Caracterización constructiva de la envolvente térmica}

El siguiente paso una vez caracterizada la geometría de la edificación, consiste en la introducción en el MADE de los datos correspondientes a las características constructivas de la envolvente térmica que separa los espacios habitados del ambiente exterior. Completando este paso el modelo contiene todos los datos imprescindibles para la caracterización energética de los edificios del barrio, como paso previo al cálculo de las pérdidas de calor en invierno. Para cada edificio se adjudican unas determinadas características constructivas representativas del periodo en que fue construido, de acuerdo con estudios existentes que han demostrado fuerte interdependencia entre consumo de energía, compacidad y antigüedad del edificio (Aksoezen et al. 2015). La información introducida se enlaza con la referencia catastral de cada parcela a partir de la variable "año de construcción". 
La necesidad de conocimiento acerca del consumo energético del sector edificación ha producido numerosos estudios en Europa dirigidos a la caracterización de la calidad térmica del parque edificado (E. Mata, Sasic Kalagasidis, y Johnsson 2014; Loga, Stein, y Diefenbach 2016). La caracterización de las soluciones constructivas de la envolvente de los edificios existentes de distintos periodos y ciudades de España se ha abordado en múltiples estudios (Santiago 2014; Begoña Serrano Lanzarote y Alejandra García Prieto 2011; Kurtz, Monzón, y López-Mesa 2015; Carmen Alonso 2015; Gómez Muñoz 2014). La segmentación del parque inmobiliario en los periodos propuestos (pre 1940, 1940 1979, 1980 2006, post 2007) se repite con pocas variaciones en los diferentes estudios. Esta clasificación de las envolventes por periodo de construcción es coherente con la adoptada por la Estrategia a largo plazo para la renovación energética de la edificación ERESEE 2014, diseñada para dar respuesta a los requerimientos Europeos (Ministerio de Fomento 2014). Esta estrategia señala como clúster de ineficiencia las áreas urbanas edificadas con anterioridad al año 1979. La obligación de incorporar criterios de eficiencia energética de la edificación no aparece hasta el año 1979 (NBE-CT-79 1979). Esto se traduce principalmente en la incorporación de aislamiento térmico en la envolvente y la mejora de los huecos de ventana. Para el caso de Madrid sabemos que los edificios construidos con anterioridad a la entrada de normativa de eficiencia energética representan el $56 \%$ de la arquitectura residencial. Para la inclusión de valores característicos de la envolvente de esta etapa se han utilizado valores obtenidos de estudios basados en muestras del parque edificado existente (Kurtz, Monzón, y LópezMesa 2015; Domínguez, Sendra, y Oteiza San José 2016; Oteiza, I. et al. 2018). Para generalizar los datos recopilados de la literatura se tiene en cuenta que la mayor parte de la edificación pre-1979 está producida durante el periodo 40-80, bajo modelos del urbanismo funcional que se repiten en las áreas de periferia de las ciudades de España. Los estudios consultados parecen indicar que existe poca variación en los sistemas constructivos utilizados, puesto que la construcción masiva de vivienda a partir del periodo de posguerra destinada a alojar a la población proveniente de la inmigración masiva, generó la homogeneización en la producción de ciudades (Rodríguez Lorite 2013). La incorporación de normativa específica para la Vivienda de Protección Oficial (Gobierno de España 1944; 1939) y la falta de industrialización de la construcción en la España de la dictadura contribuyeron a la estandarización de unas soluciones tipo. Estos 
condicionantes configuraron la morfología de gran parte de las áreas de los barrios de periferia, impulsados bajo las premisas de los desarrollos de promoción pública. Además, algunos autores concluyen que las diferencias entre las viviendas de protección pública y las viviendas libres no resultaron determinantes en muchos aspectos (L. Moya González, Fernández Salgado, y Escamilla Valencia 2017).

Después del año 1979 se van incorporando progresivamente en la edificación española normativas específicas de acondicionamiento térmico y eficiencia energética cada vez más exigentes (NBE-CT-79 1979; CTE-DB-HE 2006; 2013). Esta circunstancia hace que la caracterización constructiva sea más exacta a medida que las exigencias normativas y la experiencia del sector de la construcción van incorporando mejoras térmicas a la producción de vivienda. Para la caracterización de los cerramientos de estos periodos se han utilizado los valores correspondientes a las exigencias normativas en vigor en el año catastral de cada edificio. Hay que tener en cuenta que la caracterización basada en la normativa supone el cumplimiento de estas condiciones por parte de la edificación existente. La información se completa mediante la utilización de catálogos de soluciones por defecto desarrollados para los procedimientos de certificación energética de edificios existentes (EFINOVATIC y CENER 2015; Castaño et al. 2012). En lo que se refiere a la influencia de la localización de las áreas a analizar, a partir del año 1979 adquieren cada vez más influencia los condicionantes climáticos de la ubicación puesto que las exigencias se definen en función de las diferentes zonas climáticas de España, que se va realizando de forma más exhaustiva a medida que se va desarrollando la normativa.

Es preciso tener en cuenta que la caracterización del desempeño térmico basada en el año de construcción puede dar lugar a error en aquellos barrios en los que se hayan producido reformas urbanas integrales que hayan incluido mejoras de la eficiencia energética de la edificación. En Madrid las visitas de campo han permitido observar casos (como son varias promociones en Gran San Blas o en Caño Roto) en las que se ha incorporado aislamiento térmico por el exterior en los edificios peor la fecha de la reforma no ha sido incorporada a la base de datos del Catastro (Apartado 1.2.3). En otras ocasiones, la fecha Catastral incorpora las mejoras en la edificación con el objeto de añadir un valor de actualización a los inmuebles. En estos casos la herramienta actualiza los valores de la envolvente a la última fecha registrada. 
Tabla 32. Valores U en elementos de la envolvente de viviendas de Madrid (Gómez Muñoz, 2014)

\begin{tabular}{|l|l|l|l|l|}
\hline & Muros & Cubiertas & Suelos & Huecos \\
\hline Anteriores a 1940 & 2,0 & 2,5 & 2,0 & 5,0 \\
\hline Entre 1940 y 1960 & 2,5 & 2,5 & 2,0 & 5,0 \\
\hline Entre 1961 y 1980 & 2,5 & 2,5 & 2,0 & 4,5 \\
\hline Entre 1981 y 2006 & 1,6 & 1 & 1,4 & 3,5 \\
\hline Entre 2007 y 2010 & 0,66 & 0,38 & 0,49 & $1,90-3,50$ \\
\hline
\end{tabular}

Se caracteriza de forma simplificada la transmitancia térmica de las fachadas (incluyendo la parte hueca y la opaca), las cubiertas y los suelos de los edificios. La investigación realizada por (Gómez Muñoz 2014) aporta una primera caracterización completa de los valores de transmitancia térmica de los elementos de la envolvente de las viviendas de Madrid en base a la normativa vigente en cada periodo de construcción (Tabla 32).

\subsubsection{Fachadas parte opaca}

La fachada es el elemento con mayor superficie de pérdidas en los edificios de vivienda colectivos que albergan a la mayor parte de la población de Madrid y por tanto su caracterización es la más importante a la hora de evaluar las pérdidas energéticas. La caracterización de su parte opaca resulta relativamente sencilla puesto que se trata de elementos comunes a todo el edificio que salvo excepciones han sufrido por lo general pocas intervenciones importantes desde el punto de vista de su desempeño térmico.

\section{Valores de catálogo}

La Figura 60 representa una recopilación, a partir de diferentes fuentes, de los valores de catalogo de la transmitancia térmica de las fachadas de edificios residenciales de acuerdo con la normativa vigente en el momento de su construcción (Carmen Alonso 2015). Se concluye que la máxima dispersión se concentra en el periodo anterior a 1979. 


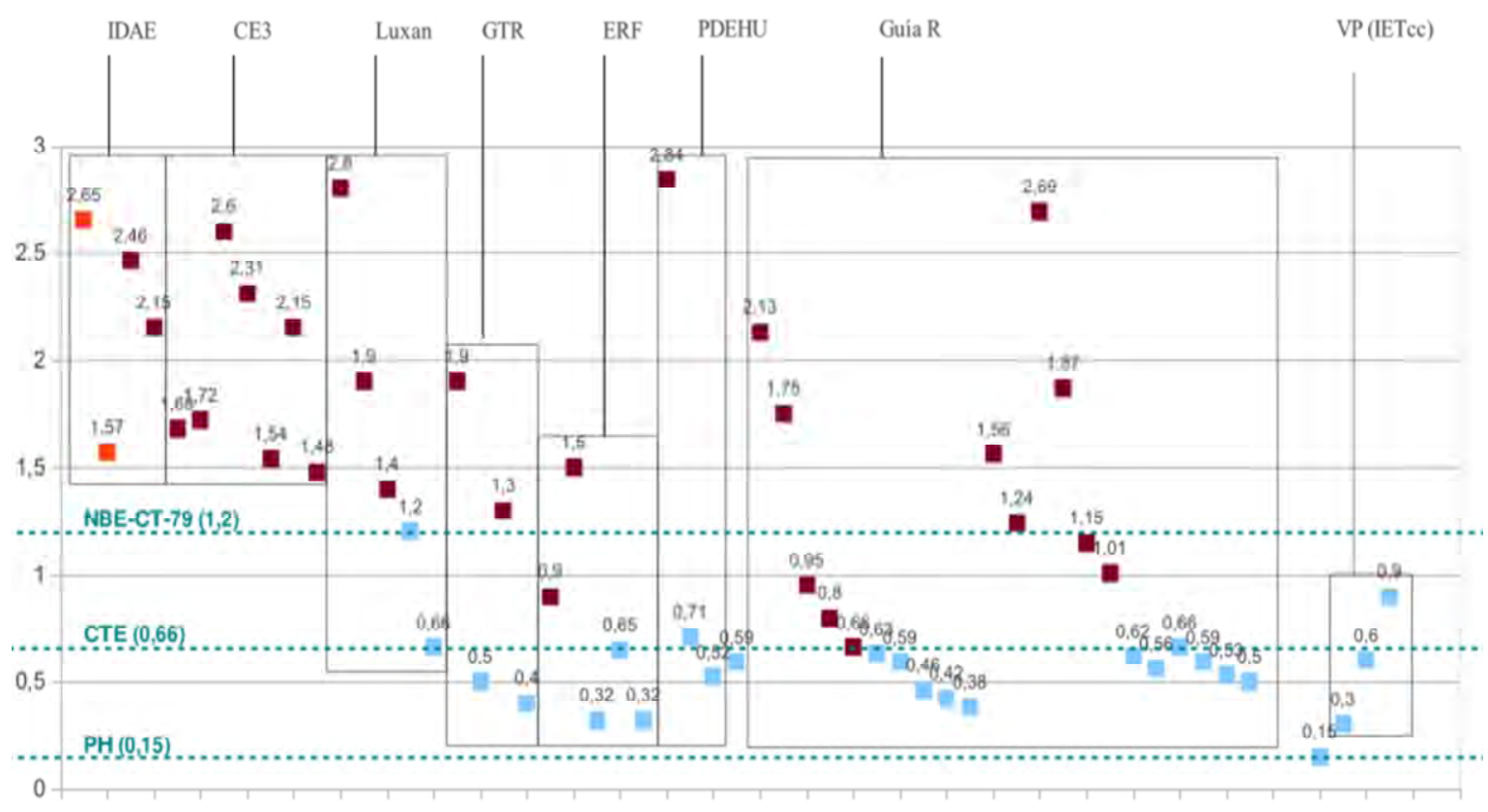

Figura 60. Valores de transmitancia térmica $(\mathrm{W} / \mathrm{m} 2 \mathrm{~K})$ empleados en diversos estudios para fachadas de Madrid (Alonso 2015)

Valores de estudios basados en muestras

Si se centra el análisis en el periodo del 40 al 80, los datos de la muestra de fachadas de 75 promociones de vivienda pública analizada en el proyecto REFAVIV (Oteiza, I. et al. 2018) obtenidos de la documentación original de proyecto arrojan los valores de transmitancia térmica que aparecen representados en la Tabla 33. Se observa una gran variabilidad en el desempeño térmico de las fachadas dependiendo de su calidad constructiva, de lo que se deduce que no todas las fachadas necesitarán el mismo tipo de solución de mejora. La práctica totalidad de las soluciones empleadas se ejecutaron con ladrillo y la diferencia de valores depende del tipo de pieza empleado (macizo, perforado, hueco), el espesor (un pie o medio pie) y del número de hojas ( 1 o 2 ). Los valores más bajos se corresponden con soluciones pioneras de dos hojas que incorporan entre ellas algún tipo de material aislante. Entre los aislantes que figuran en la documentación de los proyectos aparecen: fibra de vidrio (P.D Fuencarral, Colonia El Calero) lámina de corcho ( C/ Virgen María), poliestireno (Parcela J Gran San Blas) y hormigón celular (Unidad Vecinal 2 de Entrevías.

Para la evaluación de las fachadas a escala urbana se utilizan valores representativos medios. Los valores medios prorrateados de las diferentes fachadas de las promociones de Madrid aparecen reflejados en la Tabla 34. 
Tabla 33. Valores U de fachada de la muestra REFAVIV (Oteiza, I. et al. 2018)

\begin{tabular}{|c|c|c|c|c|}
\hline U fachada & Promociones & Edificios & Viviendas & Superficie \\
\hline 0,40 & 1 & 6 & 4.175 & 33.844 \\
\hline 0,50 & 1 & 36 & 3.480 & 226.896 \\
\hline 0,72 & 1 & 1 & 432 & 3.652 \\
\hline 0,93 & 1 & 7 & 432 & 15.200 \\
\hline 1,00 & 1 & 9 & 762 & 43.049 \\
\hline 1,07 & 1 & 7 & 432 & 3.948 \\
\hline 1,09 & 2 & 61 & 2.070 & 93.472 \\
\hline 1,10 & 1 & 26 & 7.416 & 99.951 \\
\hline 1,17 & 2 & 40 & 2.716 & 136.975 \\
\hline 1,18 & 1 & 16 & 493 & 76.002 \\
\hline 1,20 & 5 & 32 & 13.511 & 520.671 \\
\hline 1,24 & 6 & 65 & 2.649 & 58.050 \\
\hline 1,27 & 1 & 7 & 432 & 9.695 \\
\hline 1,29 & 1 & 43 & 1.098 & 77.896 \\
\hline 1,40 & 6 & 152 & 17.493 & 289.880 \\
\hline 1,46 & 1 & 1 & 1.240 & 13.928 \\
\hline 1,47 & 2 & 41 & 3.212 & 21.403 \\
\hline 1,50 & 4 & 11 & 4.260 & 57.880 \\
\hline 1,52 & 1 & 17 & 802 & 31.916 \\
\hline 1,60 & 5 & 146 & 4.064 & 440.053 \\
\hline 1,70 & 5 & 37 & 6.943 & 148.799 \\
\hline 1,80 & 8 & 140 & 16.306 & 1.216 .830 \\
\hline 1,90 & 3 & 51 & 6.245 & 716.370 \\
\hline 1,97 & 1 & 12 & 1.606 & 39.705 \\
\hline 2,10 & 2 & 41 & 2.662 & 64.467 \\
\hline 2,20 & 10 & 156 & 9.646 & 662.005 \\
\hline 2,70 & 1 & - & 639 & - \\
\hline- & 1 & 8 & 432 & 35.162 \\
\hline Total & 75 & 1.169 & 115.648 & 5.137 .699 \\
\hline
\end{tabular}

Tabla 34. Promedio de los valores de U del proyecto REFAVIV (Oteiza, I. et al. 2018)

\begin{tabular}{|l|l|}
\hline Prorrateo & Valor U medio \\
\hline por promociones & 1,56 \\
\hline por edificios & 1,55 \\
\hline por viviendas & 1,48 \\
\hline por superficie & 1,61 \\
\hline
\end{tabular}




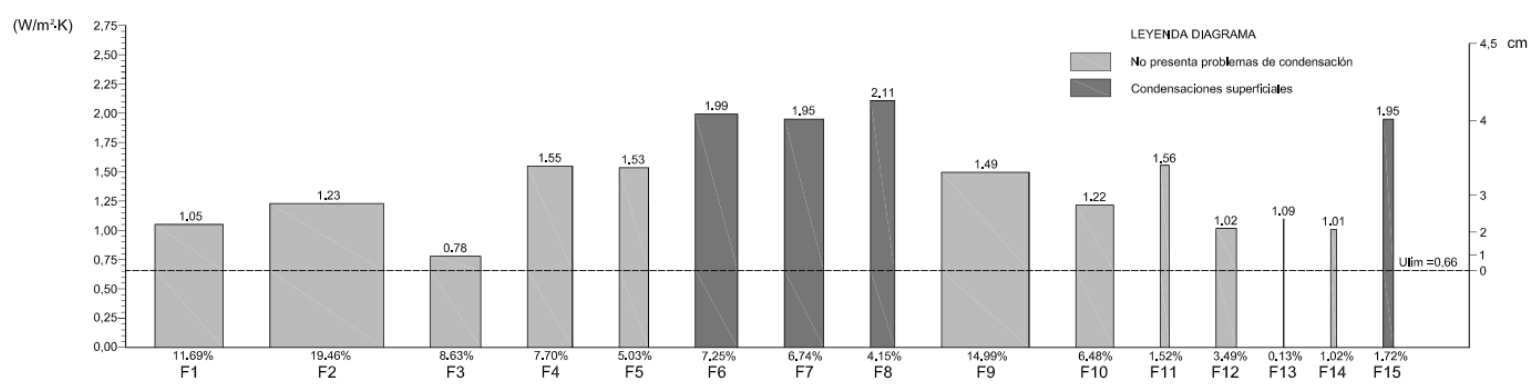

Figura 61. Transmitancia de fachadas de promociones de vivienda publica en Zaragoza (Kurtz 2015)

Un estudio similar realizado para el mismo periodo que analiza la vivienda pública de Zaragoza (Kurtz, Monzón, y López-Mesa 2015), ciudad que cuenta con características de severidad climática similares a las de Madrid según la clasificación climática vigente (CTEDB-HE 2013), permite observar que las fachadas se ejecutaron de manera muy similar. Las soluciones se repiten con bastante exactitud a excepción del adobe y del bloque de hormigón que no aparecen en Madrid. En el caso de Zaragoza en cambio no se ha observado ninguna solución que contenga aislamiento térmico (Figura 61).

\subsubsection{Caracterización de los huecos en fachada}

Para la estimación de las pérdidas a través de los elementos huecos es necesario caracterizar su superficie y su composición constructiva. La caracterización de la composición de la parte hueca de la envolvente se realiza de manera independiente y resulta más compleja que la de la parte opaca de las fachadas puesto su vida útil es más corta y se han ido produciendo sustituciones progresivamente. En los edificios de vivienda, generalmente con división horizontal de la propiedad, es habitual encontrarse con diferentes tipos de ventana para cada recinto o inmueble. Es por ello que la clasificación basada en el año de construcción resulta poco exacta para estos elementos, cada vez más difícil de encontrar en su estado original.

\section{Porcentaje de huecos por fachada}

La estimación de superficie de huecos se realiza a partir de un porcentaje de la superficie bruta de fachada y se descuenta de la superficie total para evaluarla con su propio valor de la transmitancia térmica, generalmente mayor por tratarse de la parte térmica. 
Tabla 35. Proporción de huecos en fachadas en promociones de vivienda social en el distrito de San Blas Canillejas (Madrid) (proyecto REFAVIV)

\begin{tabular}{|l|l|l|l|l|l|l|l|l|}
\hline Muestra & Promoción & $\begin{array}{l}\text { Norte } \\
(\mathbf{\%})\end{array}$ & $\begin{array}{l}\text { Este } \\
(\mathbf{\%})\end{array}$ & $\begin{array}{l}\text { SE } \\
(\mathbf{\%})\end{array}$ & $\begin{array}{l}\text { Sur } \\
(\%)\end{array}$ & $\begin{array}{l}\text { SO } \\
(\%)\end{array}$ & $\begin{array}{l}\text { Oeste } \\
(\%)\end{array}$ & PROM. \\
\hline 42 & P. D. de San Blas & 14,02 & 20,40 & 16,75 & - & 21,09 & - & 18,07 \\
\hline 43 & Parcela D y E . S. Blas & 16,48 & 0,00 & 28,16 & - & 0,00 & - & 14,88 \\
\hline 45 & Parcela F. Tipo 2. S. Blas & 15,53 & 0,00 & - & 23,48 & - & 0,00 & 13,00 \\
\hline 46 & Parcela G. & 0,00 & - & 26,78 & - & 0,00 & 17,53 & 14,77 \\
\hline 47 & Parcela G. S. Blas & 5,42 & - & 29,19 & 28,16 & 0,00 & - & 20,02 \\
\hline 49 & Parcela J. S. Blas & 10,06 & 18,68 & 10,06 & - & 18,68 & - & 15,81 \\
\hline 54 & 3a Fase Canillejas & 0,00 & 20,43 & 0,00 & - & 11,88 & - & 10,77 \\
\hline & PROMEDIO & 10,75 & 14,88 & 20,28 & 25,82 & 11,48 & 11,69 & $16 \%$ \\
\hline
\end{tabular}

*Los porcentajes de huecos de los cerramientos laterales de los bloques se han prorrateado al $50 \%$

Para una estimación a escala urbana es necesario, una vez más, encontrar unos valores medios generalizables para todos los edificios. Algunos estudios estiman entre 25 '5 y $29,3 \%$ de huecos en la fachada principal de edificios del movimiento moderno (Rodríguez Lorite 2013) si bien es necesario evaluar también los huecos a fachadas laterales y traseras y a patios interiores, que como norma general cuentan con menor superficie. En el caso de las promociones de vivienda pública de Zaragoza, el estudio de (Kurtz, Monzón, y López-Mesa 2015) concluye que salvo en dos casos excepcionales, los huecos representan entre el 17 y el $23 \%$ de las fachadas en los 21 Conjuntos Urbanos de Interés construidos en la posguerra.

En el proyecto REFAVIV se caracteriza pormenorizadamente el porcentaje de huecos en fachada mediante mediciones de los huecos de diferentes promociones de VPO en bloque multifamiliar del distrito de San Blas Canillejas (Madrid) a partir de los planos de los proyectos originales.

Valor $U$ de huecos y renovación de ventanas

Una vez estimada la superficie que ocupan los huecos es necesario conocer la composición constructiva en su estado actual para afinar la estimación de pérdidas energéticas a través de los mismos. Puesto que una gran parte de los huecos de fachada han sido remodelados por los usuarios, generalmente de forma independiente en cada vivienda, la evaluación de las características térmicas de los huecos debe ser objeto de estudios específicos. 
Tabla 36. Valores $U$ de catálogo $\left(\mathrm{W} / \mathrm{m}^{2} \mathrm{~K}\right)$ para soluciones constructivas de huecos habituales (con 20\% de marco) (Ministerio de Fomento 2011; EFINOVATIC y CENER 2015)

\begin{tabular}{|l|l|l|l|l|l|l|}
\hline & MARCO & Metálico & Metálico RPT & Madera & PVC & Doble Ventana \\
\hline VIDRIO & & 5,70 & 4,00 & 2,20 & 2,40 & 2.07 \\
\hline Sencillo & 5,70 & 5,70 & 5,36 & 5,00 & 5,04 & \\
\hline Doble & 3,30 & 3,78 & 3,44 & 3,08 & 3,12 & \\
\hline Doble BE & 2,40 & 3,06 & 2,72 & 2,36 & 2,40 & \\
\hline Doble ventana & 2.81 & & & & & $2,22^{*}$ \\
\hline
\end{tabular}

*Las dobles ventanas se estiman con carpinterías de aluminio sin RPT, una de ellas con vidrio simple y otra doble

Los valores de la transmitancia térmica de las soluciones de ventanas comprenden un número menor de soluciones posibles y varían menos que las de la envolvente opaca. En primer lugar se han recopilado los valores teóricos para las composiciones constructivas más frecuentes a partir del Catálogo de elementos Constructivos del CTE (Ministerio de Fomento 2011) y el procedimiento para la calificación energética de edificios existentes CEX (EFINOVATIC Y CENER 2015).

En cuanto a los valores obtenidos en estudios basados en muestras de la edificación existente, en el caso de las promociones de VPO de Zaragoza, nos encontramos con las siguientes conclusiones:

...se deduce que el $45 \%$ de las ventanas son sencillas de vidrio sencillo, de entre las que en torno al $27 \%$ son las originales de madera con más de 50 años representando el $12 \%$ del total aproximadamente. Asimismo se observa que el 37 \% son ventanas sencillas con unidades de vidrio aislante y el $18 \%$ son ventanas dobles con la ventana exterior de vidrio sencillo (Kurtz, Monzón, y López-Mesa 2015).

Para la muestra de vivienda social de Zaragoza, las ventanas originales que conservan carpinterías y vidrios sencillos tendrían valores $\mathrm{U}$ que oscilarían entre 4,3 y $5,7 \mathrm{~W} / \mathrm{m}^{2} \mathrm{~K}$ para marcos de madera o metálicos respectivamente. Las que han sido sustituidas incorporando doble acristalamiento aislante oscilarían entre 3,4 y $4,2 \mathrm{~W} / \mathrm{m}^{2} \mathrm{~K}$. Para las dobles ventanas se adjudican valores entre 1,23 y 1,4 W/m²K (Kurtz, Monzón, y LópezMesa 2015). 
En el caso de Madrid, y a través de visitas de campo ha sido posible recoger cierta información acerca de aspectos de los huecos que son apreciables mediante la inspección visual de la edificación, como son la instalación de dobles ventanas (Tabla 37), invernaderos en terrazas o protecciones solares (Oteiza, I. et al. 2018).

A partir de estos estudios se propone una valoración promedio del valor $U$ para los huecos de las viviendas del periodo 40-80 que incluya un porcentaje de huecos originales, un porcentaje de huecos sustituidos con vidrio sencillo (cuyas características térmicas se asimilan a las de los huecos originales), una parte de huecos sustituidos con doble acristalamiento aislante y finalmente un porcentaje de dobles ventanas (Tabla 38). Para el cómputo se ha tenido en cuenta que la carpintería más utilizada es la de aluminio.

Para los huecos de los edificios construidos en etapas posteriores se asumen los valores de transmitancia que les corresponden según la normativa aplicable de acuerdo con su año de construcción.

Tabla 37. Porcentaje de dobles ventanas en promociones analizadas en Madrid (proyecto REFAVIV)

\begin{tabular}{|l|l|l|}
\hline No Muestra & Promoción & Dobles ventanas (\%) \\
\hline 42 & P. D. de San Blas & 10,24 \\
\hline 43 & Parcela D y E . S. Blas & 3,71 \\
\hline 45 & Parcela F. Tipo 2. S. Blas & 1,21 \\
\hline 46 & Parcela G. & 1,19 \\
\hline 47 & Parcela G. S. Blas & 4,58 \\
\hline 49 & Parcela J. S. Blas & 6,44 \\
\hline 54 & 3a Fase Canillejas & 10,77 \\
\hline
\end{tabular}

Tabla 38. Valor promedio de transmitancia $\left(\mathrm{W} / \mathrm{m}^{2} \mathrm{~K}\right)$ en huecos (Oteiza, I. et al. 2018)

\begin{tabular}{|l|l|l|}
\hline & porcentaje & valor U \\
\hline Originales & $12 \%$ & 4,50 \\
\hline Sustituidos vidrio simple & $33 \%$ & 4,50 \\
\hline Sustituidos doble acristalamiento aislante & $37 \%$ & 3,44 \\
\hline Dobles ventanas & $18 \%$ & 2,22 \\
\hline Valor promedio & $100 \%$ & 3,70 \\
\hline
\end{tabular}




\subsubsection{Cubiertas}

La transmisión térmica a través de las cubiertas supone una parte importante del total de pérdidas en viviendas unifamiliares y otros edificios de poca altura. Además es un factor decisivo para garantizar el confort térmico en las plantas más altas de los edificios de residenciales multifamiliares, llegando a considerarse que habitar en estas plantas aumenta la vulnerabilidad energética dentro de un mismo edificio (Sánchez-Guevara Sánchez 2015).

El procedimiento simplificado para calificación energética de edificios existentes en España (EFINOVATIC y CENER 2016), utilizan los datos que aparecen reflejados en la Tabla 39 para los diferentes periodos.

En cuanto a los estudios basados en el muestreo de edificios, en el caso del estudio en Zaragoza, del periodo 40-80, nos encontramos con los siguientes valores de transmitancia térmica, correspondientes a cubiertas inclinadas (C1 a C7) y en mucha menor medida, cubiertas planas (C8 y C9). De toda la muestra, ninguna de las soluciones analizadas cuenta con aislamiento térmico (Figura 62).

En el proyecto REFAVIV, en las 75 promociones estudiadas del periodo $40-80$ en Madrid, se encontraron 12 tipos diferentes de cubiertas, que se han agrupado en función del tipo (plana o inclinada) y de la existencia o no de aislamiento térmico en la solución adoptada Tabla 40. La más numerosa en la muestra de VPO de Madrid es la solución plana sin aislamiento térmico. En resumen, el $60 \%$ de los edificios carecían de aislamiento térmico en cubierta y el 33\% incluía materiales aislantes. En las descripciones de proyecto se definen los materiales aislantes con los conceptos "manta aislante" y "mortero aireado".

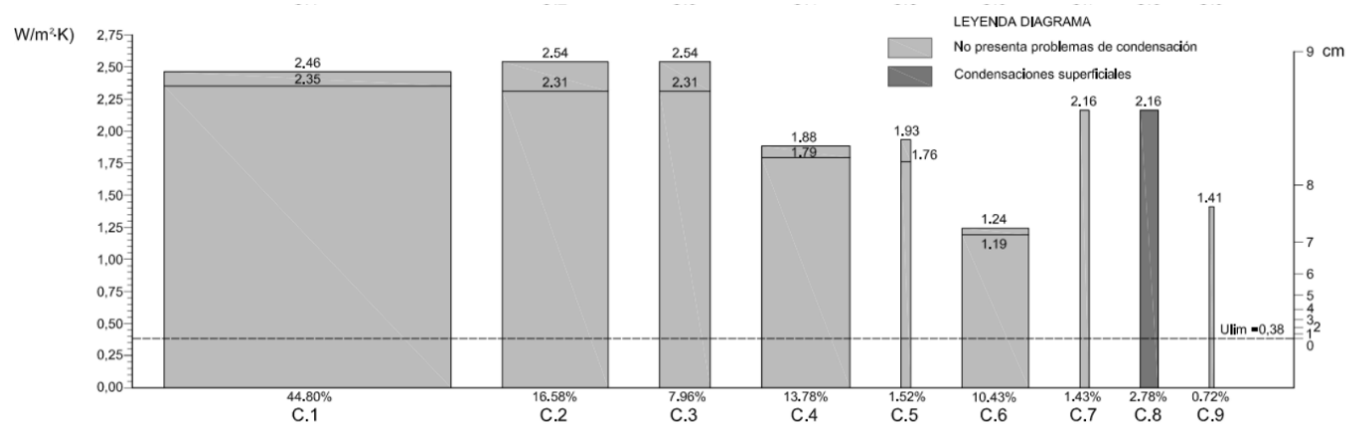

Figura 62. Valores $U\left(\mathrm{~W} / \mathrm{m}^{2} \mathrm{~K}\right)$ de cubiertas en Zaragoza (Kurtz et al., 2015) 
Tabla 39. Transmitancia Térmica de cubiertas $\left(\mathrm{W} / \mathrm{m}^{2} \mathrm{~K}\right)$ por periodo (EFINOVATIC y CENER 2016)

\begin{tabular}{|l|l|l|l|l|}
\hline & Ant. 1979 & $\mathbf{1 9 8 0 - 2 0 0 6}$ & $\mathbf{2 0 0 7 - 2 0 1 3}$ & 2014-post \\
\hline Cubierta plana & 2,17 & 0,9 & 0,38 & 0,22 \\
\hline Cubierta inclinada & 2,63 & 0,9 & 0,38 & 0,22 \\
\hline
\end{tabular}

Tabla 40. Soluciones de cubierta para la muestra de VPO (Oteiza et al. 2016)

\begin{tabular}{|l|l|l|l|l|l|l|}
\hline & Promociones & \% promo & Edificios & \% edif & Viviendas & \% vivs \\
\hline Plana sin AT & 35 & $47 \%$ & 601 & $51 \%$ & 53.633 & $46 \%$ \\
\hline Plana con AT & 18 & $24 \%$ & 330 & $28 \%$ & 40.024 & $35 \%$ \\
\hline Inclinada sin AT & 12 & $16 \%$ & 111 & $9 \%$ & 15.161 & $13 \%$ \\
\hline Inclinada con AT & 7 & $9 \%$ & 54 & $5 \%$ & 3.154 & $3 \%$ \\
\hline Sin información & 3 & $4 \%$ & 73 & $6 \%$ & 3.676 & $3 \%$ \\
\hline TOTAL & 75 & $100 \%$ & 1.169 & $100 \%$ & 115.648 & $100 \%$ \\
\hline
\end{tabular}

Tabla 41. Transmitancia Térmica de suelos $\left(\mathrm{W} / \mathrm{m}^{2} \mathrm{~K}\right.$ ) por periodo (EFINOVATIC y CENER 2015).

\begin{tabular}{|l|l|l|l|l|}
\hline & Ant. $\mathbf{1 9 7 9}$ & $\mathbf{1 9 8 0 - 2 0 0 6}$ & $\mathbf{2 0 0 7 - 2 0 1 3}$ & 2014-post \\
\hline Suelo con terreno & 1,0 & 1,0 & 0,66 & 0,27 \\
\hline Suelo con espacio no habitable & 2,0 & 1,2 & 0,49 & 0,49 \\
\hline Suelo con el exterior & 2,5 & 0,8 & 0,49 & 0,34 \\
\hline
\end{tabular}

La comparación de ambas muestras parece indicar una diferencia en las soluciones de cubiertas usadas en Madrid y Zaragoza, con una mayor incidencia de la cubierta inclinada en Zaragoza. Esta variabilidad geográfica corresponde probablemente a la mayor pluviometría registrada en el clima de Zaragoza.

\subsubsection{Suelos}

Para el cómputo de suelos esta metodología se limita a distinguir los suelos en contacto con el aire exterior de las soleras que apoyan sobre el terreno o en contacto con espacios no habitables. En la Tabla 41 se exponen los valores de catálogo de I herramienta de certificación energética de edificios existentes CE3X. Los estudios basados en la recogida de datos de muestras de edificios consultados no hacen especial referencia a los suelos. En el caso de Madrid resulta sencillo comprobar, a partir de la codificación de alturas en la información catastral, que los edificios construidos durante el periodo de 1940 a 1980 carecen en su mayor parte de espacios bajo rasante. 


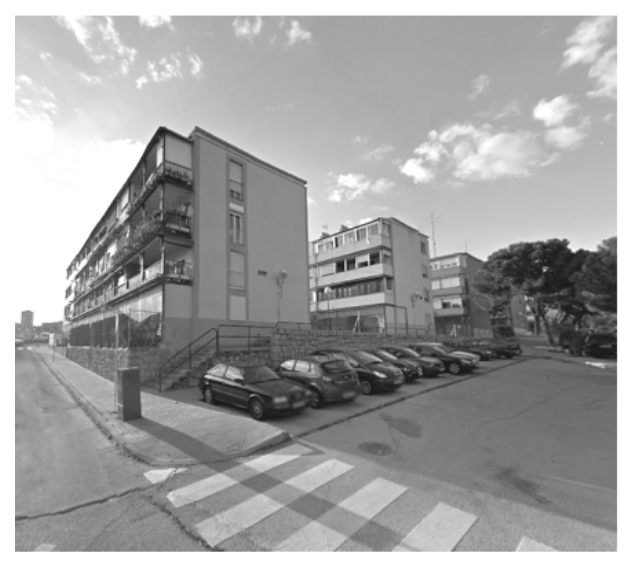

UTM: 40.462116, -3.647760 .

36 P.D.Canillas

Distrito: Hortaleza-Canillas

\section{DATOS DEL CONJUNTO}

Año: 1959 № viviendas: 1424 (791)

Superficie construida: $59695 \mathrm{~m}^{2}$

Superficie ocupada: $29304 \mathrm{~m}^{2}\left(13541 \mathrm{~m}^{2}\right)$

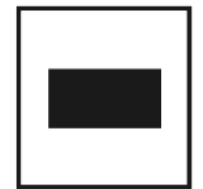

DATOS CONSTRUCTIVOS

\begin{tabular}{|l|l|l|}
\hline Fachada & $1 / 2$ pie+ ca 5cm+THS+ enlucido & F7 \\
\hline Cubierta & Plana. Asfáltica. & C6 \\
\hline Carpintería & Madera & $\mathrm{H} 2$ \\
\hline Vidrio & & \\
\hline P. solar & Persiana & P1 \\
\hline
\end{tabular}

Figura 63. Ficha de recogida de datos del Poblado Dirigido de Canillas (Oteiza, I. et al. 2018)

\subsubsection{Introducción de valores conocidos}

El modelo permite introducir valores reales para la transmitancia térmica de la envolvente en caso de que sean conocidas. Para la adjudicación de valores de la envolvente en el programa MEPEC para el estudio de caso del Barrio de Canillas, diseñado en los años 50, se cuenta con fichas de alguna de las promociones (Figura 63).

\subsubsection{Valores por defecto}

Para los barrios en los que no se conozcan las soluciones constructivas, el modelo MADE incorpora los valores de la Tabla 42. Se caracterizan de forma simplificada las fachadas (incluyendo la parte hueca y la opaca), las cubiertas y los suelos a través de su transmitancia térmica - valor $\mathrm{U}\left(\mathrm{W} / \mathrm{m}^{2} \mathrm{~K}\right)$.

Tabla 42. Valores de transmitancia térmica $(\mathrm{W} / \mathrm{m} 2 \mathrm{~K})$ adoptados para la envolvente por periodo y elemento constructivo. Elaboración propia

\begin{tabular}{|l|l|l|l|l|l|}
\hline & Fachada & Hueco & Cubierta & Suelo Exterior & Resto de suelos \\
\hline Ant 1940 & 2,00 & 3,70 & 2,67 & 2,50 & 1,00 \\
\hline $\mathbf{1 9 4 0 - 1 9 7 9}$ & 1,55 & 3,70 & 2,40 & 2,50 & 1,00 \\
\hline $\mathbf{1 9 8 0 - 2 0 0 6}$ & 1,20 & 3,50 & 1,00 & 1,20 & 1,00 \\
\hline 2007-post & 0,66 & 3,38 & 0,38 & 0,49 & 0,49 \\
\hline
\end{tabular}




\subsubsection{Indicadores de transmisión térmica y cómputo de pérdidas energéticas}

La asociación de los datos geométricos (Tabla 30) con las características constructivas (Tabla 42) posibilita determinar indicadores globales de la calidad térmica de cada edificio $K G_{u r b}\left(\mathrm{~W} / \mathrm{m}^{2} \mathrm{~K}\right)$. A partir de esos datos se pueden evaluar las pérdidas energéticas $Q_{t}(\mathrm{kWh})$ para cada edificio y de manera agrupada para barrios o tejidos urbanos completos. Además, se define un indicador global de eficiencia energética de la forma urbana $I E E_{u r b}\left(\mathrm{kWh} / \mathrm{m}^{3}\right)$ que se obtiene repercutiendo las pérdidas energéticas de todo un barrio por el volumen edificado a acondicionar.

\subsubsection{Coeficiente global de transmisión de calor del edificio y urbano $\mathrm{K}_{G}$ y $\mathrm{K}_{\mathrm{Gurb}}$}

Resulta posible caracterizar la calidad de la envolvente para cada edificio de forma simplificada a través el Coeficiente Global de Transmisión de Calor $K_{G \text {.. }}$ Para ello se pondera la transmitancia térmica $U\left(W / m^{2} K\right)$ de los elementos de la envolvente por la superficie de cada uno de ellos. Realizando el cálculo para todo el barrio, se obtiene el $\mathrm{KG}_{\text {urb }}$ (Ecuación 2).

\section{Ecuación 2. Coeficiente global de transmisión térmica urbano $\left(\mathrm{W} / \mathrm{m}^{2} \mathrm{~K}\right)$}

$K_{G u r b}=\Sigma U x A / \Sigma A$

Donde:

$A$ = área de superficie expuesta por elemento y periodo de construcción $\left(m^{2}\right)$

$\mathrm{U}=$ transmitancia térmica de la superficie expuesta de cada periodo $\left(\mathrm{W} / \mathrm{m}^{2} \mathrm{~K}\right)$

La operación se realiza para las fachadas (parte hueca y opaca), cubiertas y suelos mediante la asociación, a través del año de construcción correspondiente a la referencia catastral de cada edificio (REFCAT14) de las características térmicas de cada elemento de la envolvente. La Figura 64 representa el Coeficiente global de pérdidas $\mathrm{K}_{\mathrm{G}}$ estimado para cada edificación del estudio de caso. Los edificios de cada periodo responden a unas características térmicas diferenciadas. Se observa que la mayor parte del tejido urbano original, construido entre los años 1950 a 1980, presenta las peores condiciones de calidad térmica, siendo aun peores en aquellos edificios de menor compacidad (edificios en esquina, torres...). Se observa que la edificación de la parte oeste del barrio, sido sustituida durante el periodo 1990-2006, se comporta mejor que el resto. 


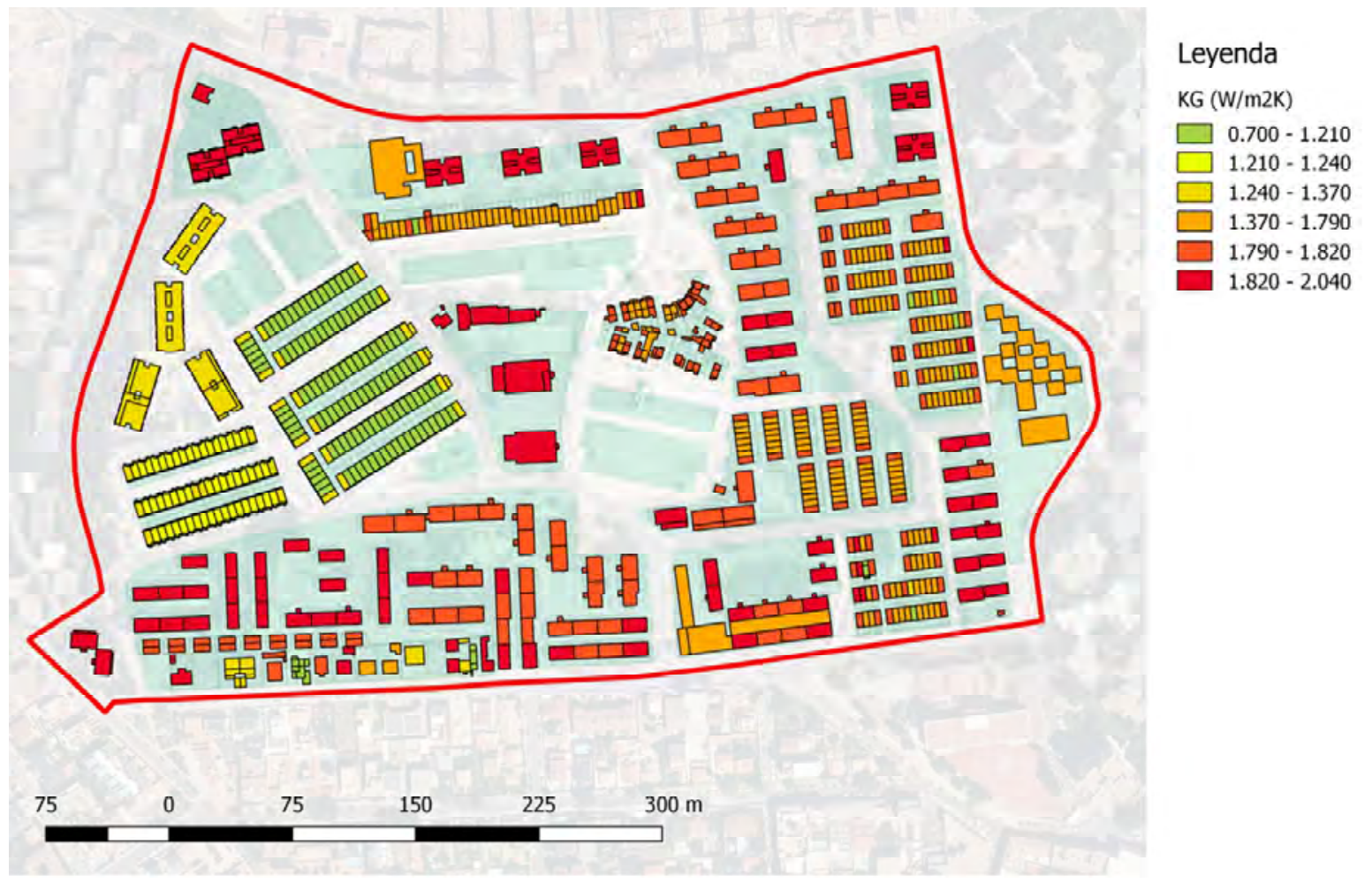

Figura 64. Visualización del coeficiente global de pérdidas $\mathrm{K}_{\mathrm{G}}\left(\mathrm{W} / \mathrm{m}^{2} \mathrm{~K}\right)$ para cada edificio del barrio. Elaboración propia

\subsubsection{Pérdidas energéticas por transmisión térmica a través de la envolvente}

Las pérdidas de calor a través de la envolvente se estiman a partir de la suma de las pérdidas transmitidas por conducción a través de los elementos opacos y las pérdidas por convección provocadas por la infiltración de aire a través de fallos de estanquidad. Este método sirve para caracterizar las que se producen por conducción. Para caracterizar las pérdidas por infiltraciones no deseadas es necesario realizar estudios de estanqueidad de las envolventes. Este aspecto se aborda de forma simplificada más adelante al estimar la demanda energética total de calefacción (Apartado 3.2.4).

Ecuación 3. Perdidas energéticas totales por transmisión (kW)

$Q_{t}=K_{\text {Gurb }} \times A_{\text {tot }} \times\left(T_{\text {int }}-T_{\text {out }}\right)$

Donde:

$A_{\text {tot }}=$ Área total de envolvente del barrio $\left(\mathrm{m}^{2}\right)$

$\mathrm{T}_{\text {int }}=$ Temperatura del ambiente interior (으)

$\mathrm{T}_{\text {out }}=$ Temperatura exterior $(\stackrel{\circ}{ } \mathrm{C})$ 
Para la estimación de las pérdidas energéticas totales anuales es necesario incluir en el MADE información relativa a las condiciones climáticas de la zona (Rodríguez-Soria et al. 2015). La diferencia de temperatura interior y exterior se puede estimar de forma simplificada utilizando el método de los grados día (GD) mediante la suma, a lo largo del periodo de invierno, de las diferencias de temperatura entre el valor base, $a$, y la temperatura media diaria, cuando esa temperatura es inferior a otro valor, $b$. En el presente estudio se ha realizado en base $15 / 15$ de manera coherente con el procedimiento descrito en la Norma (NBE-CT-79 1979). Los datos para el clima de Madrid aparecen en la Tabla 43. El método permite tener en cuenta los efectos del calentamiento global a través del cómputo de los grados día con datos climáticos actualizados(Gangolells y Casals 2012).

Los resultados de la aplicación del modelo al estudio de caso de Canillas apuntan a unas pérdidas energéticas anuales en torno a $13.967 .635 \mathrm{kWh}$ para la totalidad del barrio (Tabla 44), que inciden directamente sobre la demanda energética de calefacción. El análisis utilizando los datos para el escenario de calentamiento global apunta a una reducción de las pérdidas energéticas totales del 8,80 \% debido al cambio climático, lo que redundaría en una menor demanda energética.de calefacción.

Tabla 43. Grados día en base 15/15 anuales medios en la NBE CT 79 y actualización periodo 1981-2010 (Gangolells y Casals 2012)

\begin{tabular}{|l|l|l|l|l|}
\hline & \multicolumn{2}{|l|}{$\begin{array}{l}\text { NBE CT 79 classification based on mean } \\
\text { annual degree days based at 15c c }\end{array}$} & $\begin{array}{l}\text { Updated classification based on mean annual } \\
\text { degree days based at 15c (1981-2010) }\end{array}$ \\
\hline Madrid & $1.404,9$ & $\mathrm{D}$ & $1.281,3$ & $\mathrm{C}$ \\
\hline
\end{tabular}

Tabla 44. Resultados de pérdidas energéticas anuales (kWh/año), barrio de Canillas (torre 4994547VK4749F, bloque 4992543VK4749D y unifamiliar 5292448VK4759C). Elaboración propia

\begin{tabular}{|l|l|l|l|l|l|l|}
\hline & $\begin{array}{l}\text { Sup envolv. } \\
(\mathbf{m} \mathbf{)})\end{array}$ & $\begin{array}{l}\text { KG } \\
(\mathbf{W} / \mathbf{m} \mathbf{2 K})\end{array}$ & $\begin{array}{l}\text { UxA tot } \\
(\mathbf{W} / \mathbf{K})\end{array}$ & $\begin{array}{l}\text { Pérdidas } \\
(\mathbf{k W h})\end{array}$ & $\begin{array}{l}\text { Pérdidas CC } \\
(\mathbf{k W h})\end{array}$ & $\begin{array}{l}\text { IEE } \\
(\mathbf{k W h} / \mathbf{m 3})\end{array}$ \\
\hline Total Barrio de Canillas & 243.317 & 1,70 & 414.254 & 13.967 .635 & 12.738 .793 & 12.738 .793 \\
\hline 4994547VK4749F Torre & 5.381 & 1,87 & 10.056 & 339.061 & 309.231 & 309.231 \\
\hline 4992543VK4749D Bloque & 707 & 1,81 & 1.278 & 43.106 & 39.314 & 39.314 \\
\hline 5292448VK4759C Unif. & 170 & 1,81 & 308 & 10.387 & 9.473 & 9.473 \\
\hline
\end{tabular}




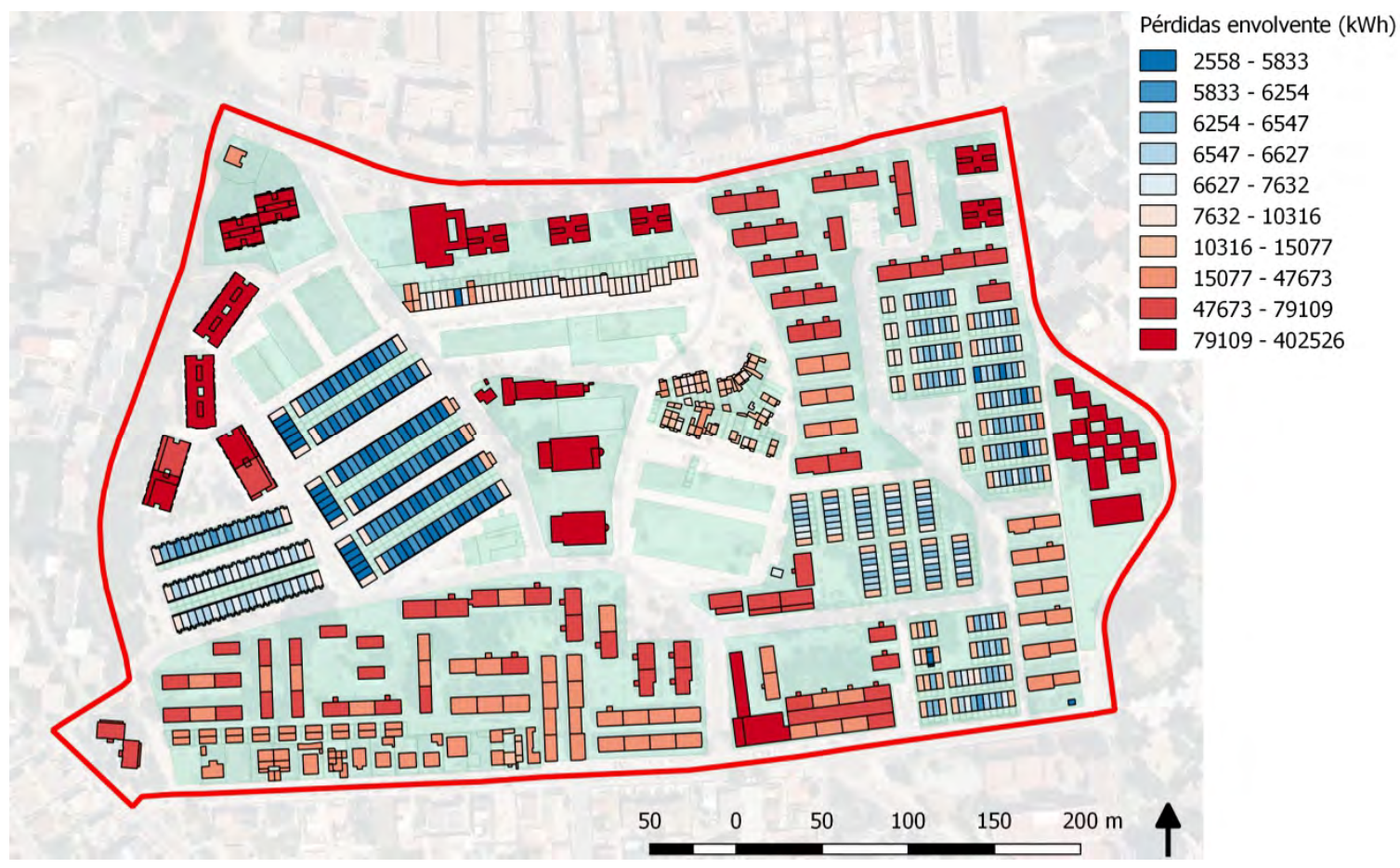

Figura 65. Pérdidas energéticas anuales (kWh) de la edificación del barrio de Canillas. Elaboración propia

En el estudio de caso se observa como los edificios residenciales en torre en altura presentan grandes pérdidas, seguidos de los bloques que varían de acuerdo con su compacidad (Figura 65). Los edificios de mayor tamaño presentan los mayores valores. Los edificios de otros usos (enseñanza, comercio, sanidad) presentan en general también altas pérdidas energéticas, lo que apunta a la necesidad de la mejora energética de su envolvente y a su inclusión en los planes de rehabilitación de áreas residenciales.

\subsubsection{Indicador de Eficiencia Energética de calefacción urbano}

Se considera Indicador de Eficiencia Energética de calefacción de un edificio (IEE $\left.\mathrm{E}_{\mathrm{cal}}\right)$ a la repercusión de las pérdidas totales a través de la envolvente por el volumen contenido en ella. Si esta operación se realiza a la escala urbana, se consigue un indicador de eficiencia energético urbano unitario (Ecuación 4).

Ecuación 4. Indicador de eficiencia energética urbano de calefacción ( $k W h / m 3)$

$\mathrm{IEE}_{\mathrm{urb}}=\mathrm{Q}_{\mathrm{t}} / \mathrm{V}$

Donde:

$\mathrm{Q}_{\mathrm{t}}=$ Pérdidas de calor por transmisión totales en el barrio $\quad(\mathrm{kWh})$

$V=$ Volumen de la edificación total del barrio $\quad\left(\mathrm{m}^{3}\right)$ 
Este indicador es un indicador óptimo para caracterizar la influencia de la morfología urbana en la dispersión de energía en la ciudad durante el periodo de calefacción. Engloba aspectos fundamentales del diseño bioclimático de los edificios, que se ve fuertemente influenciado por la trama urbana en la que se insertan y permite valorar la eficiencia energética de los tejidos. Contempla aspectos de la arquitectura (superficies, volumen, compacidad, orientaciones), incorpora datos de la envolvente tanto cuantitativos (superficies de intercambio) como cualitativos (características constructivas); e incluye las solicitaciones climáticas de la ubicación. Por todo ello este indicador parece idóneo para ser incluido en los Estándares de Calidad Urbana en el planeamiento de las ciudades (Agustín Hernández Aja 1995) para que incorporen aspectos de eficiencia energética.

Para el estudio de caso del barrio de Canillas se obtiene un valor IEE $_{\text {urb }}$ de 30,55 $\mathrm{kWh} / \mathrm{m}^{3}$. Las pérdidas por unidad de superficie habitable $\left(152.413 \mathrm{~m}^{2}\right)$ son de 91,64 $\mathrm{kWh} / \mathrm{m}^{2}$ año. Ambos valores resultan coherentes con las estimaciones de demanda energética para calefacción que contemplan los procedimientos de certificación energética para la edificación existente en el clima de Madrid (Zona climática D3 según CTE). Los resultados obtenidos para cada edificio del barrio se representan en la grafica de la Figura 66. El eje de abscisas corresponde a los valores del coeficiente $K_{G}$ Y el de ordenadas al $\mathrm{IEE}_{\mathrm{cal}}$ de cada edificio $\left(\mathrm{Q}_{\mathrm{t}} / \mathrm{V}\right)$.

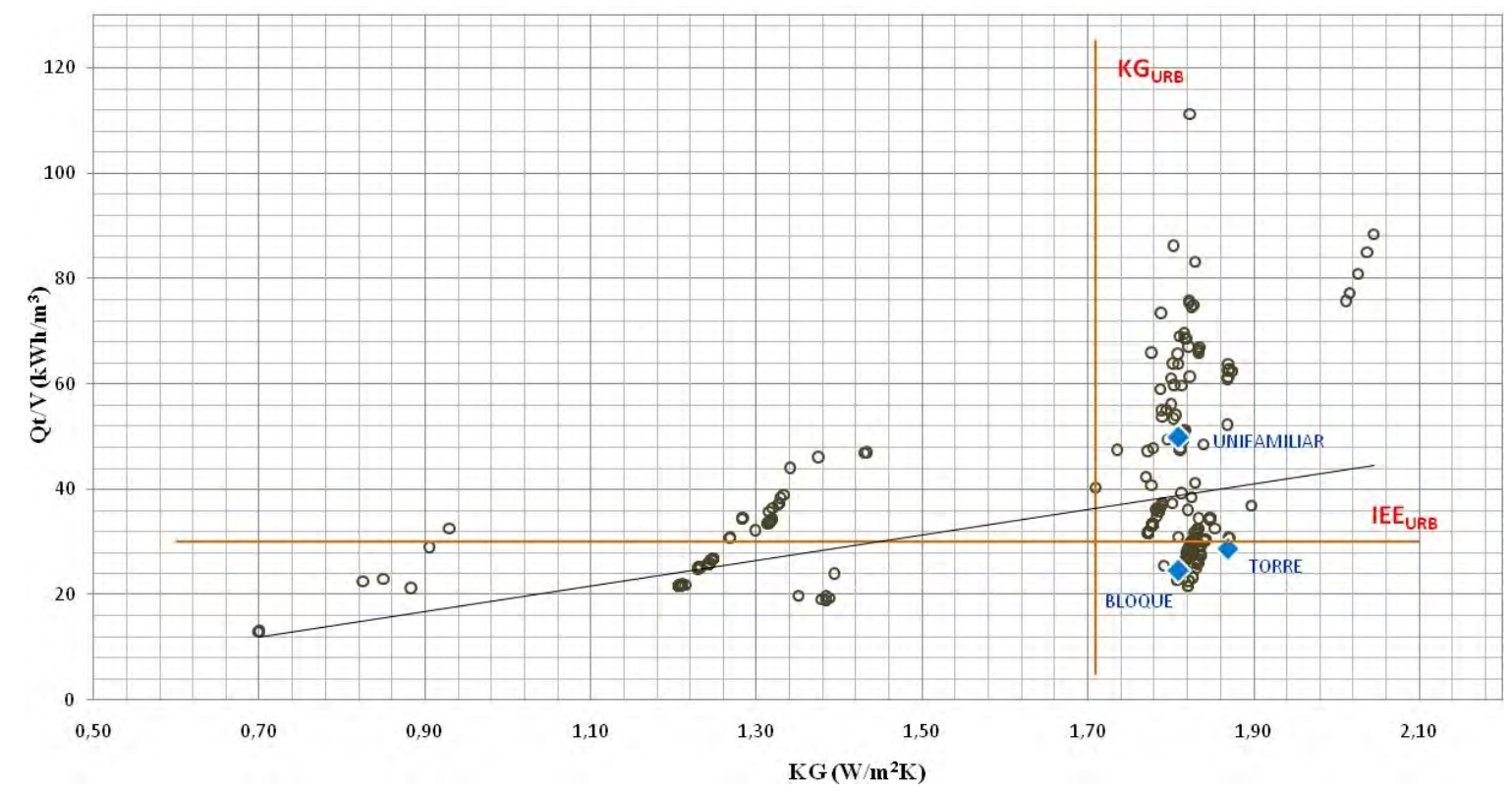

Figura 66. Indicador de eficiencia Energética IEE $\left(\mathrm{kWh} / \mathrm{m}^{3}\right)$ para la muestra analizada conforme a la calidad de la envolvente. Elaboración propia 
Los valores más bajos del $\mathrm{K}_{\mathrm{G}}$ se corresponden con edificios más recientes, con una mejor calidad térmica en sus envolventes y los de la derecha de la gráfica son edificios antiguos, sin aislamiento. Los valores urbanos aparecen en rojo: la línea horizontal representa el IEE $E_{u r b}$ y la vertical el valor de $K_{G u r b}$ para el barrio de PD Canillas. La línea de tendencia muestra cómo se van reduciendo las pérdidas con la mejora de la envolvente, a la vez que se reduce la variabilidad del $\mathrm{IEE}_{\mathrm{cal}}$. No obstante, existen algunos edificios antiguos (con valores $\mathrm{K}_{\mathrm{G}}$ altos), que presentan menores pérdidas que otros más modernos con mejores prestaciones en su envolvente. Esto apunta a que otros factores geométricos tienen mayor influencia en esos casos que la calidad constructiva.

Se comprueba que la necesidad de energía no depende solamente de la calidad térmica de los cerramientos de los edificios, sino que además se ve muy influida por el tejido urbano en el que se inserta. Los estudios de rehabilitación que se están realizando hasta el momento se centran básicamente en la mejora de las prestaciones térmicas de la envolvente según su periodo de construcción. Los resultados arrojados por la herramienta MEPEC apuntan a que la morfología puede ser muy relevante. Se hace necesario utilizar indicadores como el que se presenta aquí, que sean capaces evaluar el desempeño energético de los edificios contemplando aspectos morfológicos además de la calidad de la envolvente.

\subsubsection{La evaluación de la eficiencia energética mediante datos catastrales}

La reducción drástica de la demanda energética hasta niveles óptimos de rentabilidad, es la primera condición en la estrategia para conseguir edificios de alta eficiencia energética (Parlamento Europeo y el Consejo de la Unión Europea 2010). El diseño de herramientas que permitan controlar aspectos que influyen en la demanda es crucial para el correcto dimensionado de los planes de renovación del parque edificado ineficiente y la consecución de los objetivos del Artículo 4 de la Directiva 2012/27/UE de Eficiencia Energética, exigible a todos los estados miembros de la Unión Europea. La metodología presentada aquí profundiza en estas cuestiones al generar conocimiento acerca de las pérdidas energéticas a través de la envolvente de la edificación, que inciden directamente sobre la demanda de calefacción, además de servir para localizar los tejidos más ineficientes y caracterizarlos. 
Para una estimación de la demanda de energía total resulta necesario incorporar al MADE información acerca de las ganancias solares, además de un modelo de renovación de aire y una estimación de las cargas internas. El análisis de las fachadas por orientaciones facilitado por la herramienta MEPEC es suficiente para realizar una estimación simplificada de las posibilidades de captación de la radiación solar pasiva para el cálculo de la demanda de calefacción. En los estudios energéticos recientes del sector residencial español, los consumos energéticos para refrigeración representan un porcentaje bajo respecto del total. Esto puede deberse a la utilización de medidas pasivas para reducir la demanda de refrigeración. No obstante actualmente observan una tendencia al alza con la popularización de los sistemas de acondicionamiento térmico para refrigeración y es previsible que se vean aumentadas por la subida de temperaturas a consecuencia del cambio climático. Como línea de investigación futura se propone desarrollar un procedimiento detallado de estimación de la radiación solar incidente en todos los elementos de la envolvente y sobre el espacio público (MESOL, Figura 5). Utilizando la geometría del plano 2.5D construido a partir de datos vectoriales del catastro y construyendo la geometría del modelo solar a partir de datos climáticos de radiación anual en base horaria, es posible computar las obstrucciones solares de manera pormenorizada a la escala urbana.

El consumo de energía final estimado a partir de la demanda según (ISO 13790:2008 E) se puede predecir introduciendo en el modelo información de los sistemas de acondicionamiento térmico. Este tipo de estimación presenta incertidumbres cuando se cruza con datos reales de consumos energéticos monitorizados, con desviaciones que pueden llegar al 100\% (Roels 2016). Estas pueden ser causadas por múltiples variables que deben ser valoradas cuidadosamente. Algunas de ellas puede ser la variabilidad introducida por años de clima atípico, la utilización de patrones de uso que no se corresponden con la realidad de los usuarios de los edificios, o las demandas no satisfechas en casos de privación voluntaria del confort o en casos de pobreza energética.

Existen una serie de aspectos de la caracterización geométrica que influyen en la evaluación energética pero que no aparecen contenidos en la información catastral. Se trata de datos como son la altura de planta entre forjados, necesaria para calcular el volumen de aire a acondicionar; o los valores de superficies de los huecos acristalados. En 
el caso analizado se han completado mediante datos provenientes de estudios basados en muestras de la edificación existente (Oteiza et al. 2016). Según la necesidad de exactitud de cada análisis será necesario analizar tejidos urbanos de manera pormenorizada para incorporar valores exhaustivos en el Modelo.

La caracterización del desempeño térmico basada en el año de construcción puede dar lugar a error en aquellos barrios en los que se hayan producido reformas urbanas integrales que hayan incluido mejoras de la eficiencia energética de la edificación. Es por ello que, para conseguir certezas, se deba completar la evaluación basada en el análisis de datos masivos mediante su comprobación por medio de datos obtenidos en campañas o visitas de campo. En Madrid, las visitas de campo realizadas en el proyecto REFAVIV han permitido observar casos (como son varias promociones de gran cantidad de vivienda por ejemplo en Gran San Blas o en Caño Roto) en las que se han mejorado las fachadas incorporado sistemas de aislamiento térmico por el exterior en la edificación en operaciones de regeneración urbana en los años 80 (Oteiza, I. et al. 2018). En algunos casos (por ejemplo en San Blas) la fecha de reforma no ha sido incorporada a la base de datos del Catastro. La presente metodología puede perder exactitud en estos casos. No obstante, la información catastral es cada vez más rigurosa gracias al empleo de nuevas tecnologías en su elaboración. También se ha comprobado que en áreas urbanas producidas durante periodos de transición normativa $(1979,2006)$ es posible que se produzcan errores de concordancia entre la fecha de construcción registrada en catastro y la del proyecto, donde se define la normativa de aplicación (Martín-Consuegra 2014). En las áreas desarrolladas en esos periodos se pueden producir discordancias.

Además, hay que tener en cuenta que la caracterización basada en la normativa supone el cumplimiento de la misma por parte de la edificación realizada en cada periodo, situación de la cual no tenemos constancia a ciencia cierta. Para la caracterización genérica de las envolventes posteriores al año 1979 se presupone la inclusión de aislamiento térmico en cumplimiento de las normativas vigentes. Especialmente al principio de la obligación, la calidad de su ejecución pudo no haber sido la adecuada, y los materiales pueden haberse deteriorado a lo largo del tiempo. Las tecnologías de sistemas de aislamiento térmico para la edificación se han ido mejorando en lo que respecta a la calidad de su ejecución y la durabilidad de los materiales desde 
que se comienzan a instalar a gran escala tras la crisis energética de los años 70 , hasta nuestros días.

La situación de emergencia energética en la que se encuentra gran parte del tejido residencial español (y con probabilidad en gran parte del área mediterránea), hace que las prioridades se enfoquen hacia los edificios anteriores a 1979, que no cuentan con aislamiento térmico alguno, y que han sido señalados por los estudios existentes como clústeres de ineficiencia energética (de Santiago 2017). No obstante, también existen bolsas de edificación que, habiendo sido proyectadas conforme a los requisitos térmicos que incluyó por primera vez la Norma Básica de la Edificación (NBE-CT-79 1979), se encuentran en una situación muy alejada de los objetivos de las directivas europeas. En este trabajo se están excluyendo estos barrios. También se excluyen en un primer momento aquellos barrios que hayan contado con intervenciones de rehabilitación a escala urbana que haya incluido mejoras térmicas de la envolvente, puesto que dejan de considerarse los más vulnerables desde el punto de vista de la eficiencia energética. No obstante, después de cumplir los objetivos más urgentes de mejora, es probable que cobre gran importancia la obsolescencia de las áreas urbanas producidas desde los años 80 y hasta la entrada en vigor del CTE (CTE-DB-HE 2006). 


\subsection{DEMANDA ENERGÉtICA DE CALEFACCIÓN DE LOS BARRIOS RESIDENCIALES}

Las perdidas energéticas, estimadas hasta el momento, significan para la edificación residencial ineficiente, la variable de mayor impacto en la demanda energética de calefacción. Una vez conocidos estos valores es posible estimar la demanda total mediante la incorporación de información acerca de las perdidas por ventilación y las ganancias solares e internas. En este apartado se desarrolla la parte de la metodología dirigida a estimar el balance energético destinado a acondicionamiento térmico de la edificación a la escala de barrio durante el invierno. Los datos de radiación solar se han utilizado, además de para estimar las ganancias solares pasivas para el cálculo de la demanda de calefacción, para computar la radiación solar incidente en los elementos opacos. Esta información resulta útil de cara al predimensionado de posibles instalaciones de dispositivos de captación de energía solar térmica y fotovoltaica.

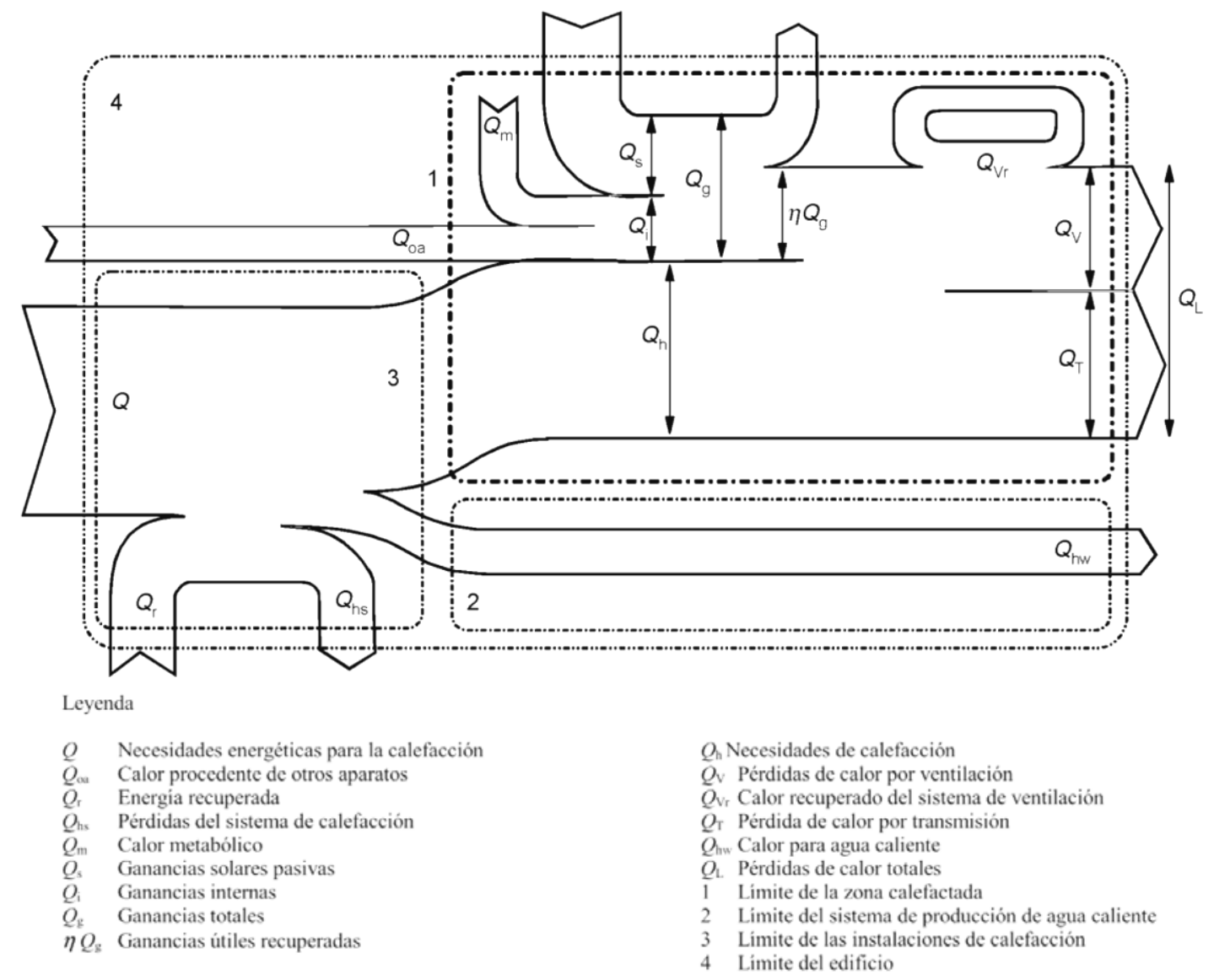

Figura 67. Balance energético de un edificio (ISO 13790, 2008) 
El procedimiento simplificado consiste en la estimación de las necesidades de energía a partir de la compensación del balance energético (Figura 67). Se han seguido los pasos de la norma (ISO 13790 2008) y se ha utilizado un predimensionado simplificado propuesto en estudios existentes basado en la misma (Ramírez Perea 2013). Se ha considerado que la demanda de energía para acondicionamiento térmico en temporada de invierno viene dada, de manera simplificada, por la Ecuación 5.

\section{Ecuación 5. Demanda energética de calefacción (kWh)}

$D_{C A L}=Q_{G}+Q_{i}-Q_{t}-Q_{v}$

Donde

$Q_{G}=$ Ganancias solares pasivas

$Q_{i}=$ Ganancias por cargas internas

$\mathrm{Q}_{\mathrm{t}}=$ Pérdidas de calor por transmisión

$\mathrm{Q}_{\mathrm{v}}=$ Pérdidas de calor por ventilación

Las pérdidas de calor se definen como la cantidad de calor que escapa de un edificio durante un periodo (que aquí se ha estimado anual). Engloba las perdidas por transmisión a través de la envolvente y las pérdidas por ventilación (filtración y ventilación). Las ganancias de calor representan la cantidad de calor que se genera o penetra en el edificio. Se incluyen las fuentes internas (calor suministrado por los ocupantes, y equipos y fuentes ajenas a los sistemas de calefacción o producción de agua caliente) y la captación de radiación solar mediante ventanas y otros dispositivos solares.

\subsubsection{Simplificaciones para el cálculo a escala urbana}

A partir de la información obtenida del proceso de datos catastrales a través del programa MEPEC, se realiza una estimación simplificada de la demanda energética de calefacción para cada unos de los edificios residenciales del barrio objeto de análisis. Para simplificar el proceso de manera que se pueda aplicar a gran escala para la evaluación de barrios enteros, se han admitido una serie de suposiciones:

- El cálculo de las pérdidas energéticas se realiza bajo la simplificación de que todos los edificios está siendo calentados a una temperatura interior constante. Se considera cada edificio como una sola zona térmica (cálculo monozona). 
- Se desprecian las zonas no calefactadas de los edificios residenciales, y por tanto la transferencia de calor entre ellas. Se han podido descontar las zonas no habitables registradas en Catastro, como zonas comunes, trasteros y garajes.

- Se evalúan las partes de la edificación sobre rasante.

- No se tiene en cuenta la capacidad de acumulación térmica de los cerramientos.

- Solo se tiene en cuenta el calor sensible, despreciándose el calor latente liberado en la condensación o absorbido por la evaporación. Se desprecia el agregado de energía que se consume en la acción de transformación cuando se está materializando un cambio de estado físico.

- El estudio está enfocado a analizar el problema de pobreza energética causada por la obsolescencia de la edificación y por tanto se centra en el cálculo de la demanda de calefacción. No se desarrolla la demanda de refrigeración si bien los datos recopilados pueden utilizarse en el futuro para ello

\subsubsection{Datos climáticos}

Para el cálculo de las pérdidas por ventilación se ha utilizado la información de los grados día anuales en base 15/15 (NBE-CT-79 1979) utilizando el mismo procedimiento, propuesto para las perdidas por transmisión (Apartado 3.1.6).

Para introducir en el modelo información referente a la radiación solar total mensual $\left(I_{m j}\right)$ o estacional $\left(I_{s j}\right)$ por unidad de superficie y orientación $(j)$ se han recopilado datos existentes considerando la latitud de Madrid 40.250 $\mathrm{N}$ y la influencia de la nubosidad a través de la aplicación online para el cálculo promedio de la radiación solar directa y difusa ofrecida por el Joint Research Center (JRC - European Comision 2017).

Para la estimación de ganancias es necesario conocer la irradiación solar incidente sobre las superficies verticales orientadas de las fachadas. Los valores se deducen a partir de la irradiación solar directa, global y difusa medidas en plano horizontal. La base de datos de radiación Climate-del JRC Photovoltaic Geographical Information System (PVGIS) (European Commission 2017) ofrece datos promedio de 2001 a 2012. Estos datos se han verificado para Madrid con la estimación realizada por CIEMAT para el mapa ADRASE, que incluye datos promedio a partir de información recopilada durante 33 años (CIEMAT s. f.) (Figura 68). 


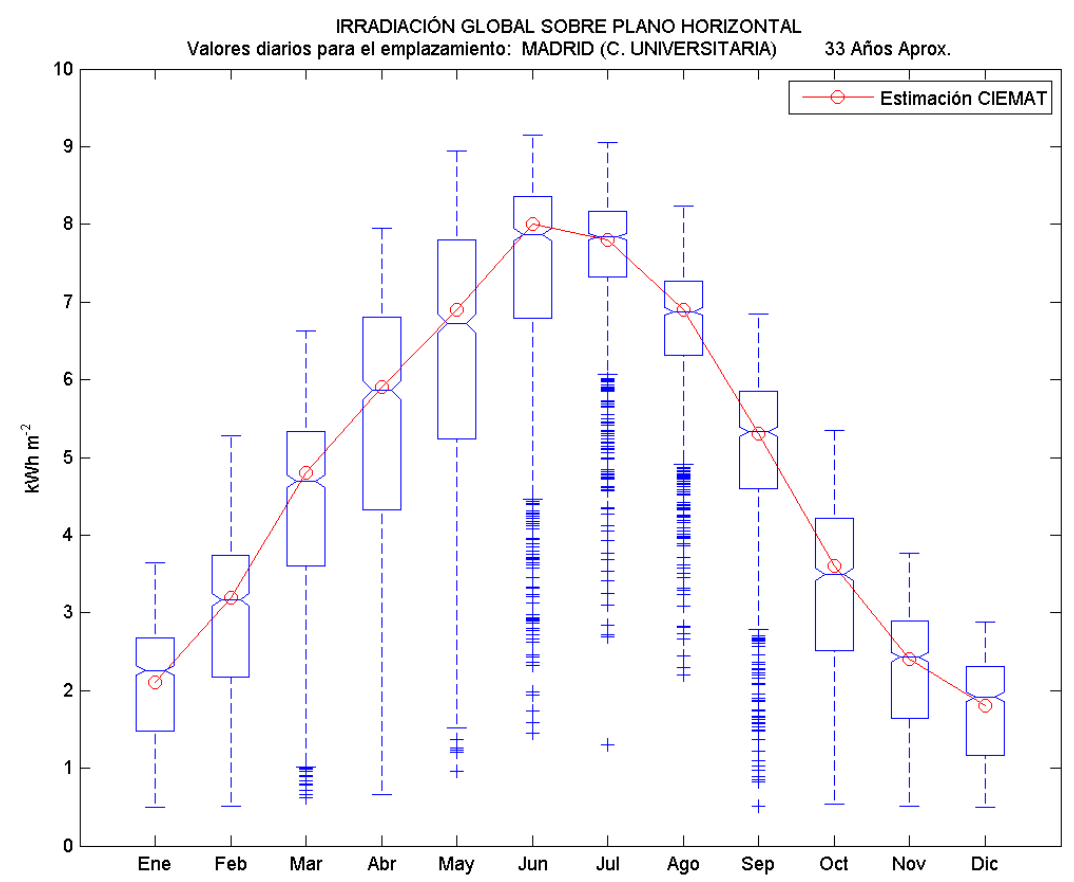

Figura 68. Validación de la estación de Marid Ciudad Universitaria para el mapa ADRASE (CIEMAT, n.d.)

Tabla 45. Datos medios de la radiación global recibida por unidad de superficie $(\mathrm{m} 2)$ recibidas para diferentes orientaciones (kWh/m2) por mes (JRC - European Comision, 2017)

\begin{tabular}{|l|l|l|l|l|l|l|}
\hline MES & HORIZONTAL & ESTE & SURESTE & SUR & SUROESTE & OESTE \\
\hline Ene & 64,5 & 41,7 & 86,4 & 114,0 & 87,1 & 42,3 \\
\hline Feb & 87,4 & 54,3 & 95,6 & 121,0 & 96,2 & 55,0 \\
\hline Mar & 145,4 & 88,2 & 122,0 & 137,0 & 122,0 & 88,9 \\
\hline Abr & 167,7 & 94,1 & 108,0 & 104,0 & 108,0 & 94,9 \\
\hline May & 205,8 & 110,0 & 107,0 & 87,9 & 108,0 & 111,0 \\
\hline Jun & 230,1 & 117,0 & 106,0 & 77,0 & 106,0 & 118,0 \\
\hline Jul & 248,9 & 126,0 & 117,0 & 86,3 & 117,0 & 127,0 \\
\hline Ago & 216,7 & 113,0 & 124,0 & 112,0 & 124,0 & 114,0 \\
\hline Sep & 160,8 & 89,7 & 121,0 & 132,0 & 122,0 & 91,1 \\
\hline Oct & 114,7 & 68,4 & 113,0 & 139,0 & 113,0 & 68,9 \\
\hline Nov & 71,7 & 44,3 & 88,8 & 117,0 & 90,0 & 45,4 \\
\hline Dic & 59,2 & 38,7 & 85,8 & 115,0 & 86,7 & 39,6 \\
\hline Gref & 856,5 & 445,7 & 468,0 & 407,3 & 469,0 & 450,1 \\
\hline Gcal & 916,4 & 539,7 & 806,6 & 934,9 & 811,0 & 546,0 \\
\hline ANUAL & 1772,9 & 985,4 & 1274,6 & 1342,2 & 1280,0 & 996,1 \\
\hline
\end{tabular}


La aplicación “PV Potential estimation (JRC - European Comision 2017) permite realizar estimaciones de la radiación media diaria por meses en todos los planos de la envolvente edificio. Se han considerado para la estimación de radiación incidente en la edificación las cubiertas y fachadas de orientación este, sureste, sur, suroeste y oeste (Tabla 45). La información se clasifica para los periodos de calefacción (invierno) y refrigeración (verano). Se han tenido en cuenta los meses de octubre a mayo para la temporada de calefacción y los meses de junio a septiembre para la de refrigeración, siguiendo la clasificación definida en la normativa vigente (CTE-DB-HE 2013).

\subsubsection{Ganancias de calor}

Las ganancias de calor incluyen una parte correspondiente a las ganancias solares $\left(Q_{G}\right)$ y otra cantidad correspondiente a las ganancias por cargas internas $\left(Q_{i}\right)$.

\subsubsection{Radiación solar incidente en la edificación}

El modelo incorpora una estimación gruesa para contabilizar la radiación solar incidente para cada edificio del barrio. Se estima para cada uno de los planos de la envolvente de la edificación que reciben radiación solar de manera significativa (cubiertas y fachadas orientadas a sur, este y oeste). La incidencia de la radiación sobre la parte hueca de las fachadas se computa como ganancia solar pasiva. La incidencia sobre la parte opaca se computa para la estimación de un indicador del potencial de captación de energía renovable. Para este cálculo se tienen en cuenta todos los edificios del barrio y se obtienen valores urbanos mediante el proceso de datos de todos ellos.

\section{El factor de corrección de sombra $\left(F_{s j}\right)$}

El factor de corrección de sombra $\left(\mathrm{F}_{\mathrm{sj}}\right)$ puede variar mucho en función de la morfología urbana. Algunos estudios incluyen aproximaciones a la obstrucción solar a partir de la relación entre el ancho de calle y la altura de la edificación (Urban Canyon Ratio) (Jose Lao 2014). Este método a priori parece poco apropiado para una parte importante de los tejidos de periferia, al menos en el caso de estudio de la ciudad de Madrid. En el caso de los tejidos de bloque abierto, los bloques se disponen libremente sin alineación al viario con lo cual el ancho de calle es muy variable. Para los desarrollos a partir de parcelación 
periférica, es la altura de la edificación la que no es constante. Otros factores que influyen son la obstrucción por la presencia de arbolado, si este es de hoja perenne o caduca, o la topografía.

Asimismo, se ha estimado la incidencia de la radiación solar a partir de parámetros simplificados, especialmente en lo que respecta a las obstrucciones solares. Para una evaluación pormenorizada de las ganancias, los porcentajes de huecos deben ir clasificados por orientación, puesto que les afectan factores de sombra diferenciados. Para ello serían necesarios estudios pormenorizados de los huecos de fachadas. Esta metodología no permite la estimación exacta de las obstrucciones solares en la escala de barrio, por lo que se propone incluir la reducción de la incidencia solar a partir de un factor de corrección por las sombras provocadas por el horizonte $\left(F_{h}\right)$. No se ha considerado el efecto de voladizos ni parasoles.

En este caso se han tomado los valores de referencia del 30\% de obstrucción de la radiación solar en fachadas Sur (se incluyen en este grupo las fachadas con orientación sureste y suroeste) y el $50 \%$ en las fachadas orientadas a este y oeste. Para la cubierta se ha considerado un factor de corrección de factor de sombra del $20 \%$, como forma de descontar la influencia de las obstrucciones solares causadas por otros edificios más altos, o de elementos como casetones, inclinaciones de cubierta, etc. Los resultados se ofrecen desglosados para las cubiertas y para las fachadas. La parte calculada para las fachadas se utiliza a su vez para la estimación de la radiación solar pasiva durante el invierno

\subsubsection{Ganancia solar pasiva durante el invierno}

La parte de radiación que penetra a través de los huecos de fachada durante el periodo de invierno se incluye en el balance energético para la estimación de la demanda energética de calefacción $\left(D_{C A L}\right)$. Estas ganancias de calor captadas a través de los elementos transparentes de la envolvente se aprovechan en forma de energía solar pasiva. Para contabilizar la cantidad de radiación que penetra la norma recomienda tener en cuenta una serie de factores influyentes (ISO 13790 2008). 
Superficie de los huecos $\left(A_{j}\right)$ en fachadas orientadas a sur, este y oeste.

El computo de las superficies que reciben una cantidad de radiación solar importante durante el invierno se ha realizado considerando las fachadas de orientación Sur, Este y Oeste y sus posiciones intermedias (sureste y suroeste). El modelo permite la introducción de la superficie de ventanas a partir de la variable del porcentaje de huecos por orientaciones o de manera prorrateada para todo el edificio. Para una evaluación simplificada, en el estudio de caso se ha considerado un $16 \%$ de huecos con respecto a la superficie bruta de fachadas, para todas las orientaciones.

La contabilización de la superficie expuesta a la radiación solar para cada fachada se consigue a partir de la salida de la herramienta MEPEC, que extrae de los registros vectoriales del catastro todos los datos de las superficies de envolvente clasificadas por orientación.

Factor de reducción por la carpintería $\left(F_{F j}\right)$.

Se contabiliza la parte del hueco compuesta por vidrio, transparente a la radiación solar descontando la parte ocupada por la carpintería. Este valor depende del tamaño del hueco y del tipo de material que conforma las carpinterías. En el caso de este estudio realizado para la escala urbana, no se llega a definir tanto detalle. Se ha considerado de forma simplificada que un $20 \%$ del hueco está ocupado por la carpintería para todos los casos.

\section{El factor solar del vidrio $\left(g_{j}\right)$}

Se utiliza para caracterizw5 la parte de la radiación solar que atraviesa el vidrio, descontando la parte reflejada y la parte absorbida por el mismo. Para el caso del vidrio estándar, la normativa contempla los valores de 0,85 para el vidrio sencillo y 0,75 para el doble acristalamiento aislante y dobles ventanas (CTE-DB-HE 2013). Se ha tomado este último valor, por ser el más frecuente en la muestra analizada en Madrid..

En resumen, una vez introducidos los valores propuestos para todos estos factores, se estima que el $10 \%$ de la radiación solar incidente sobre la superficie bruta de fachadas podría ser aprovechada para reducir la demanda de calefacción en concepto de energía solar pasiva si cada edificación se encontrase aislada. Si tenemos en cuenta el factor de 
corrección de sombra, que reduce la radiación incidente por las obstrucciones causadas por obstáculos del entorno, estos valores pasan a ser de aproximadamente del $5 \%$ en las fachadas este y oeste y del $7 \%$ en las fachadas a sur (Tabla 46). Para las orientaciones sureste y suroeste se adoptan los valores correspondientes al sur

Tabla 46. Resumen de valores adoptados para la aplicación de diferentes aspectos del factor solar.

Elaboración propia

\begin{tabular}{|c|c|c|c|c|c|c|}
\hline variable & ESTE & SURESTE & SUR & SUROESTE & OESTE & HORIZONTAL \\
\hline Área - \% huecos & \multicolumn{5}{|l|}{0.16} & - \\
\hline Fracción del marco - $F_{f j}$ & \multicolumn{5}{|l|}{0.8} & - \\
\hline Factor solar vidrio - $\mathrm{g}_{\mathrm{j}}$ & \multicolumn{5}{|l|}{0.75} & - \\
\hline subtotal & \multicolumn{5}{|l|}{0.096} & - \\
\hline Obstáculos remotos $-\mathrm{F}_{\mathrm{sj}}$ & 0.5 & 0.7 & 0.7 & 0.7 & 0.5 & 0.8 \\
\hline TOTAL $-F_{S}$ & 0.048 & 0.0672 & 0.0672 & 0.0672 & 0.048 & 0.8 \\
\hline
\end{tabular}

Tabla 47. Radiación solar incidente por periodo estacional para la edificación del barrio de Canillas. EP

\begin{tabular}{|l|l|l|l|l|l|}
\hline Elemento & Superficie (m2) & Invierno $(\mathbf{k W h})$ & Verano $(\mathbf{k W h})$ & anual $(\mathbf{k W h})$ & \% invierno \\
\hline Cubierta & 49.029 & 35.943 .657 & 33.595 .736 & 69.539 .393 & $52 \%$ \\
\hline Fachada E & 25.864 & 6.979 .290 & 5.763 .702 & 12.742 .992 & $55 \%$ \\
\hline Fachada O & 25.814 & 7.047 .270 & 5.809 .480 & 12.856 .749 & $55 \%$ \\
\hline Fachada S & 40.710 & 26.642 .098 & 11.606 .938 & 38.249 .036 & $70 \%$ \\
\hline Fachada SE & 4.930 & 2.783 .552 & 1.615 .053 & 4.398 .605 & $63 \%$ \\
\hline Fachada SO & 2.378 & 641.615 & 529.865 & 1.171 .480 & $55 \%$ \\
\hline Total fachadas & 99.696 & 44.093 .825 & 25.325 .038 & 69.418 .863 & $64 \%$ \\
\hline TOTAL & 148.725 & 80.037 .482 & 58.920 .774 & 138.958 .256 & $58 \%$ \\
\hline
\end{tabular}

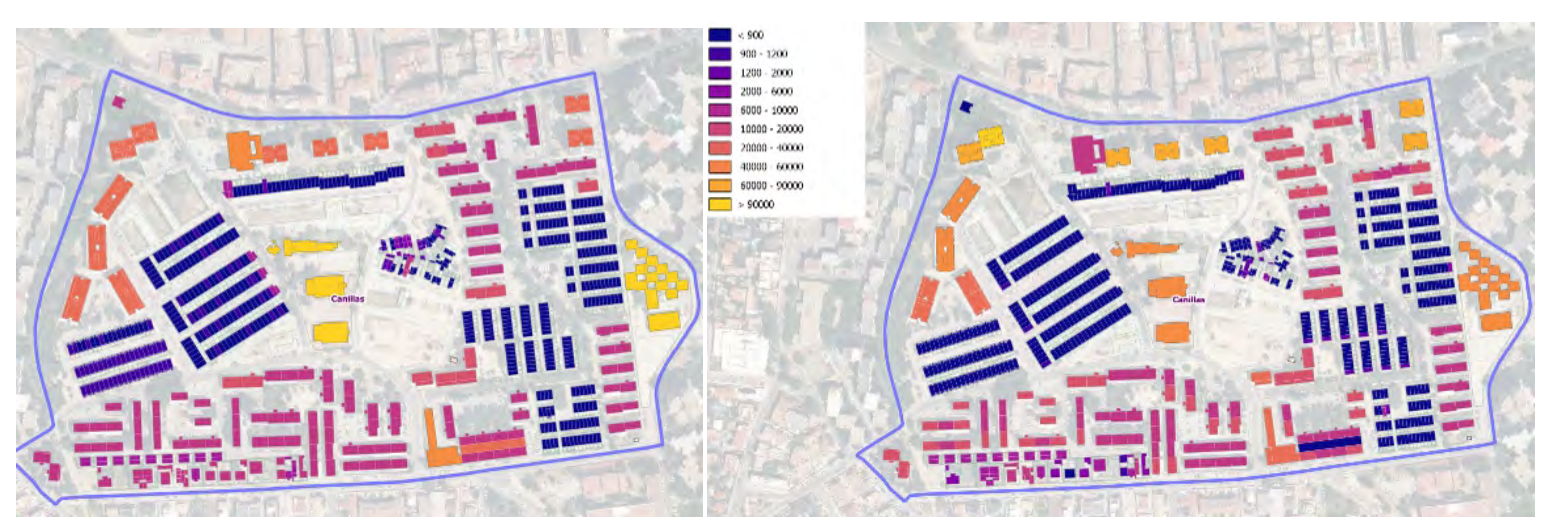

Figura 69. Radiación solar (kWh) incidente sobre (a) cubiertas y (b) fachadas, para los edificios del Canillas. Elaboración propia 
Radiación incidente y energía solar pasiva aprovechada

La aplicación del método en el estudio de caso arroja los siguientes resultados para las estimaciones de la radiación total incidente en la edificación del Poblado Dirigido de Canillas. Se obtienen para todos los edificios del barrio (residenciales y de uso terciario). Los valores totales para todo el barrio aparecen representados en la Tabla 47 los valores por edificio aparecen representados gráficamente en la Figura 69.

Durante el invierno ( 8 meses) se recibe el $58 \%$ de la radiación solar total anual sobre la envolvente. Esto indica que, a pesar de que la intensidad de la radiación solar es mayor en verano ( 4 meses), la mayor parte se recibe durante el periodo de calefacción, que es más prolongado. Este resultado apunta a que existen recursos solares disponibles en el periodo en el que la demanda de energía de los edificios es mayor.

El elemento que recibe la mayor cantidad de radiación solar es la cubierta, especialmente. Sumando la radiación incidente en el total de fachadas soleadas se obtienen valores anuales similares. Las cubiertas reciben cantidades de radiación similar en invierno que en verano, mientras las fachadas reciben el $64 \%$ de la radiación total durante el invierno. La fachada sur recibe el $70 \%$ de la radiación en invierno, siendo la más adecuada para la captación de la energía solar pasiva.

A partir de estos resultados se depura la parte de información correspondiente a edificios residenciales. Aplicando los factores solares estimados, representados en la Tabla 46, se obtienen una estimación de la radiación solar pasiva que es capaz de penetrar en el interior de cada edificio.

Tabla 48. Radiación solar anual incidente por elemento de la envolvente y periodo estacional para los edificios residenciales del barrio de Canillas

\begin{tabular}{|l|l|l|l|l|l|}
\hline Elemento & Superficie $\mathbf{( m 2})$ & Invierno $(\mathbf{k W h})$ & Verano $\mathbf{( k W h )}$ & anual $(\mathbf{k W h})$ & Pasiva invierno (kWh) \\
\hline Cubierta & 43,183 & $31,657,637$ & $29,589,689$ & $61,247,327$ & - \\
\hline Fachada E & 24,446 & $6,596,746$ & $5,447,785$ & $12,044,531$ & 316,644 \\
\hline Fachada O & 24,323 & $6,640,203$ & $5,473,911$ & $12,114,114$ & 318,730 \\
\hline Fachada S & 39,028 & $25,541,318$ & $11,127,370$ & $36,668,688$ & $1,716,377$ \\
\hline Fachada SE & 4,885 & $2,758,133$ & $1,600,305$ & $4,358,439$ & 185,347 \\
\hline Fachada SO & 2,648 & 714,433 & 590,000 & $1,304,433$ & 34,293 \\
\hline TOTAL & 138,513 & $73,908,470$ & $53,829,061$ & $127,737,531$ & $2,571,389$ \\
\hline
\end{tabular}


La radiación solar utilizada para el calentamiento solar pasivo representaría aproximadamente el $2 \%$ de la radiación solar total incidente en la edificación. La mayor parte de la energía es captada a través de la fachada sur, que es la que tiene una mayor superficie en el barrio (41\% de la superficie del total de las fachadas expuestas en el barrio). Esto sucede porque el diseño urbano en origen ha priorizado la orientación sur propiciando la captación solar. Se comprueba la validez del indicador urbano de porcentaje de superficie de fachada sur con respecto del total de todas las fachadas, para caracterizar de manera simplificada las posibilidades de aprovechamiento de la radiación solar.

\subsubsection{Ganancias internas}

El procedimiento empleado para el cálculo de la demanda contempla la producción de calor dentro de los edificios, a través de las cargas internas. Se tienen en cuenta las aportaciones metabólicas de los ocupantes y el consumo de energía de aparatos eléctricos y de iluminación artificial. Están directamente relacionadas con el número de personas que ocupan la vivienda y con el grado de equipamiento del hogar (Ecuación 6). Para la estimación de la demanda anual de calefacción se computa todo el periodo de invierno.

Ecuación 6. potencia media de las ganancias internas en espacios calefactados

$\mathrm{Q}_{\mathrm{i}}=\left[\Phi_{1, \mathrm{~h}}+(1-\mathrm{b}) \Phi_{1, \mathrm{u}}\right] \mathrm{t}=\Phi_{\mathrm{i}} \mathrm{t} \quad[\mathrm{kWh}$ año $]$

Donde:

$\Phi_{1, \mathrm{u}}=$ potencia media de las ganancias internas en espacios no calefactados

$\Phi_{1, \mathrm{u}}=$ potencia media de las ganancias internas

$b=$ factor de reducción

$\mathrm{t}$ = periodo de cálculo

Para realizar el cálculo simplificado para edificación residencial a la escala urbana, se ha considerado cada edificio como una sola zona térmica (cálculo monozona) no se han tenido en cuenta las ganancias internas en los espacios no calefactados. Se ha utilizado el valor estimado en el ANEXO K.2 (ISO 13790 2008) para las ganancias internas en edificios 
ocupados de forma continua (por ejemplo residenciales), $4 \mathrm{~W} / \mathrm{m} 2$. Si consideramos solamente el periodo de invierno, con el objetivo de incluirlos en el cálculo de la demanda de calefacción, esta cifra se corresponde aproximadamente con $\Phi_{\mathrm{i}}=23 \mathrm{kWh}$ por cada $\mathrm{m}^{2}$ habitable, para toda la temporada. Para la incorporación de estas cargas internas en el Modelo de Análisis de Datos Espaciales (MADE), se han considerado los valores registrados por los datos catastrales correspondientes al área habitable dedicados al uso vivienda, descontando los usos no habitables (zonas comunes, garajes, trasteros)..

\subsubsection{Estimación de las perdidas energéticas totales}

Para el cómputo de las perdidas energéticas totales se añade a las pérdidas energéticas por transmisión a través de la envolvente $\left(Q_{t}\right)$ una estimación de las perdidas por ventilación.

\subsubsection{Pérdidas por transmisión a través de la envolvente}

Las pérdidas por transmisión $\left(Q_{t}\right)$ son, especialmente en los edificios anteriores al año 1979, la principal causa de la ineficiencia energética de la edificación. Se han obtenido de manera pormenorizada para cada elemento de la envolvente y edificio a través de la metodología MEPEC en la etapa anterior (Apartado 3.1).

\subsubsection{Pérdidas por ventilación}

Seguidamente se complementan esos resultados con la información de pérdidas por ventilación, necesaria para la estimación de la demanda energética de calefacción. La ventilación es una de las variables que mas dependen del comportamiento de los usuarios de cada vivienda y por lo tanto son difíciles de generalizar. Asimismo, las infiltraciones de aire no deseadas están relacionadas con la estanqueidad de cada vivienda y dependen en gran parte de su estado de conservación. Se pretende realizar una estimación gruesa que permita contemplar la influencia de estos factores en el total de la demanda de calefacción. Una primera referencia de la renovación de aire en una vivienda se puede estimar a partir del caudal mínimo de ventilación necesario por 
motivos de confort e higiene. La norma ISO 13790 propone un estándar mínimo de 0,3 renovaciones por hora.

Se ha considerado que la mayor parte de las viviendas de Madrid no cuentan con sistemas de ventilación forzada, y que renuevan el aire a través de la ventilación natural, despreciándose la influencia de los sistemas mecánicos. La norma propone en estos casos unos valores en función del número de fachadas expuestas (una o más de una) y el nivel de exposición al viento del edificio (sin exposición, moderada, elevada) y de la estanqueidad (baja, media, alta). Los valores que corresponden a una exposición moderada oscilan entre 0,5 y $0,9 \mathrm{R} / \mathrm{h}\left[\mathrm{m}^{3} / \mathrm{h}\right]$.. En el caso de la normativa española, la Herramienta unificada LIDER-CALENER (HULC) (CTE 2017) propone un valor por defecto para los edificios residenciales de 0,63 renovaciones por hora. Esto se correspondería en la norma ISO con un edificio de estanqueidad media con más de una fachada expuesta, situado en una zona de clase de exposición moderada. El caudal de aire a través del espacio calefactado $(\tilde{V})$ se ha supuesto a partir de este valor y de los datos de volumen de la edificación obtenidos del catastro (Ecuación 7). En este caso de aplicación para los edificios residenciales, se ha utilizado el volumen calculado a partir de la superficie habitable y se ha considerado una altura libre media de $2,75 \mathrm{~m}$.

\section{Ecuación 7. Caudal de aire a través del espacio calefactado (Ṽ)}

$$
\tilde{V}=0,63 \mathrm{Vol} / \mathrm{h} \quad\left[\mathrm{m}^{3} / \mathrm{h}\right]
$$

Donde:

Vol $=$ Volumen de aire $\left[\mathrm{m}^{3}\right]$

El coeficiente de pérdida de calor por ventilación $\left(H_{v}\right)$ se obtiene de:

Ecuación 8. Coeficiente de pérdida de calor por ventilación (Hv) [Wh/K]

$H_{v}=\rho_{a} C_{a} \tilde{V} \quad[W h / K]$

Donde:

$\rho_{\mathrm{a}} \mathrm{c}_{\mathrm{a}}$ Calor específico del aire en volumen (se ha tomado $0,34 \mathrm{Wh} / \mathrm{m}^{3} \mathrm{~K}$ )

$\tilde{V}=$ Caudal de aire a través del espacio calefactado $\left[\mathrm{m}^{3} / \mathrm{h}\right]$ 
Las pérdidas totales por ventilación (Qv) se obtienen de:

\section{Ecuación 9. Pérdidas totales por ventilación $\left(Q_{v}\right)[k W h$ año]}

$Q_{\mathrm{v}}=H_{\mathrm{v}}\left(T_{\mathrm{i}}-T_{\mathrm{e}}\right) t \quad[\mathrm{kWh}$ año $]$

Donde:

$H_{v}=$ Coeficiente de pérdida de calor por ventilación $(\mathrm{Hv})[\mathrm{Wh} / \mathrm{K}]$

$T_{\mathrm{i}}-T_{\mathrm{e}}=$ Diferencia de temperatura exterior e interior $[\stackrel{\circ}{\circ}]$

$\mathrm{t}=$ periodo de cálculo [año]

\subsubsection{Resultados de demanda energética de calefacción}

Los resultados se obtienen a través del balance energético de las pérdidas y ganancias de calor mediante el método descrito en el Apartado 3.2.1 Se obtienen valores particularizados para cada edificio y un valor medio urbano ponderado.

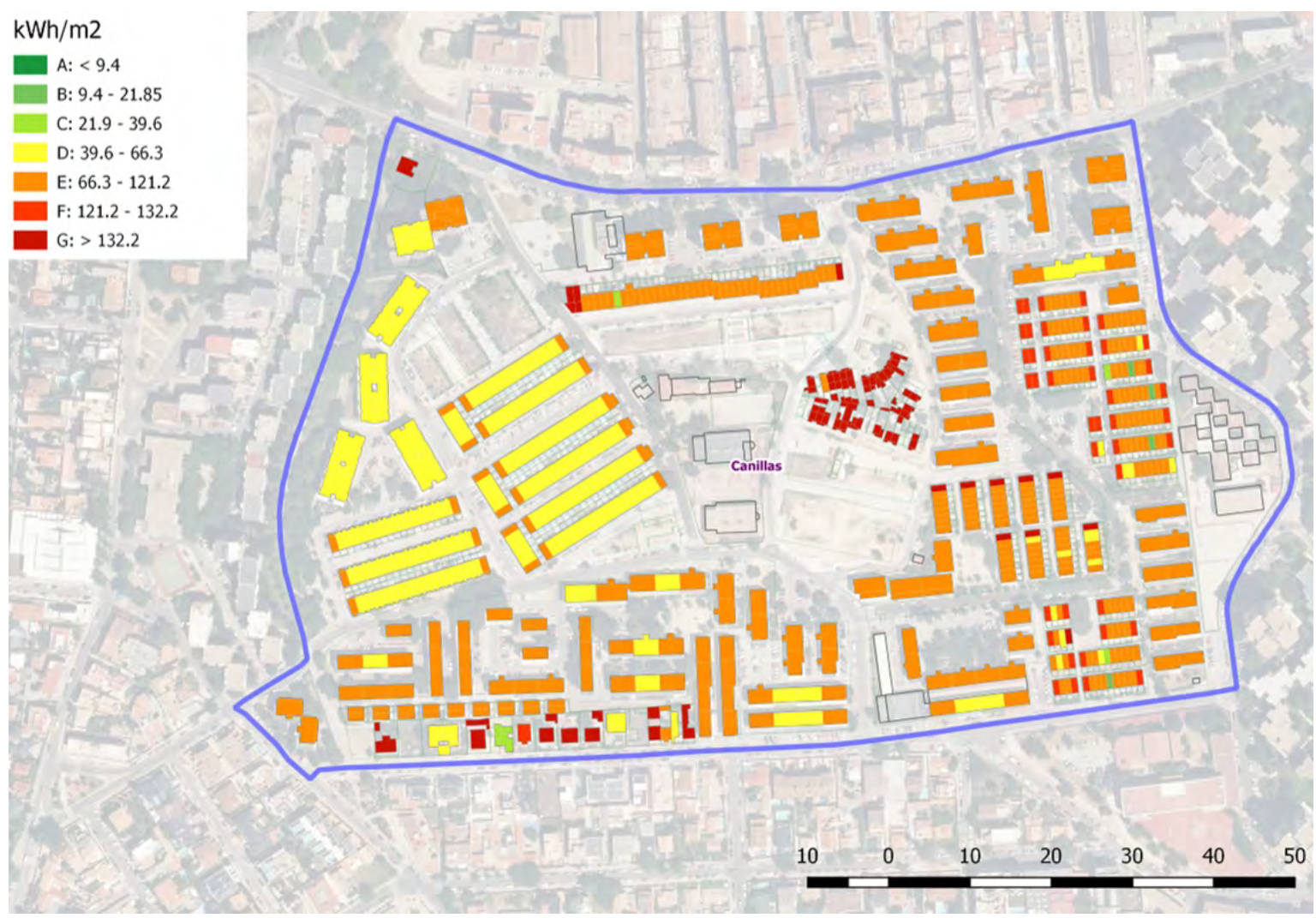

Figura 70. Demanda energética de calefacción $(\mathrm{kWh} / \mathrm{m} 2)$ para cada edifico residencial del barrio de Canillas. Elaboración propia 
Tabla 49. Estimación de la demanda para el periodo de calefacción en el Poblado Dirigido de Canillas. Elaboración propia

\begin{tabular}{|l|l|l|l|}
\hline Concepto & variable & valor & unidades \\
\hline Pérdidas por transmisión & $\mathrm{Q}_{t}$ & 13.069 .405 & kWh año \\
\hline Pérdidas ventilación & $\mathrm{Q}_{\mathrm{v}}$ & 2.683 .825 & $\mathrm{kWh}$ año \\
\hline Ganancias solares & $\mathrm{Q}_{\mathrm{s}}$ & 2.565 .811 & $\mathrm{kWh}$ año \\
\hline Ganancias internas & $\mathrm{Q}_{\mathrm{i}}$ & 3.148 .482 & $\mathrm{kWh}$ año \\
\hline Demanda de calefacción & $\mathrm{D}_{\text {cal }}$ & 10.038 .936 & kWh año \\
\hline
\end{tabular}

Los resultados del balance energético permiten comprobar, para el barrio de Canillas, la hipótesis de que las pérdidas energéticas a través de la envolvente suponen el aspecto que tiene una mayor incidencia sobre el total de la demanda de calefacción. Se demuestra que la intervención sobre la envolvente resulta prioritaria para mejorar la eficiencia energética de la edificación.

Al incluir la contabilidad de la energía solar pasiva en la demanda, se soporta con mayor contundencia la evidencia de que existen edificios anteriores a 1979 sin aislamiento pero con una menor demanda energética es decir, con un mejor comportamiento bioclimático, que otros edificios posteriores con envolventes de mejores prestaciones, pero con una peor compacidad y/o orientación (Figura 70). 


\subsection{EVALUACIÓN DE MEDIDAS DE MEJORA DE LA ENVOLVENTE}

Hasta el momento se ha logrado realizar un modelo energético del parque residencial existente utilizando datos catastrales e información constructiva a partir de bases de datos de estudios basados en muestras y de la normativa. Se ha identificado la calidad térmica de cada edificio a partir de la estimación de las pérdidas energéticas a través de la envolvente y se ha podido cuantificar su demanda de calefacción.

Una vez constituido este modelo, resulta posible modificar sus parámetros para simular escenarios de mejora de la envolvente y evaluar sus implicaciones y resultados a escala urbana. Se desarrolla un procedimiento para la incorporación de medidas de mejora, la estimación del coste económico de la inversión inicial necesaria para ponerlas en marcha y la evaluación de su impacto a través de los beneficios obtenidos sobre la eficiencia energética.

Para la selección de medidas de mejora se analiza la literatura existente referente a la mejora de los aspectos pasivos de la eficiencia energética de la edificación dirigidos a la reducción de la demanda, que se refieren a la mejora de la envolvente térmica. Se analizan los catálogos de medidas de mejora que recomiendan documentos oficiales de certificación de edificios existentes (Castaño et al. 2012; MIYABI y CENER 2012), así como de estudios independientes (Luxán García De Diego et al. 2017; WWF et al. 2017). Al tratarse de una intervención a escala de barrio, se ha considerado que se deben elegir soluciones de mejora que se puedan realizar desde el exterior de los edificios, para así tratar de reducir en la medida de lo posible la afectación al uso de las viviendas. Una recopilación de las posibles medidas sería:

- El aumento del nivel de aislamiento en muros de fachada (parte opaca)

- Aumento del nivel de aislamiento en cubiertas

- Aumento del nivel de aislamiento en suelos

- La modificación o sustitución de acristalamientos y carpinterías

- Instalación o modificación de protecciones solares

Las propuestas de mejora deben ser dimensionadas en función de las características de la edificación a rehabilitar, a partir de la clasificación de las envolventes por periodo 
de construcción. La metodología se aplica, para su validación, al estudio de caso del barrio de Canillas. Se propone actuar sobre los edificios del periodo de construcción anterior a 1979, señalados como clúster de ineficiencia (Apartado 1.2.3). De esta manera se abordan las necesidades más urgentes. Además, el análisis se realiza para dos escalas: la totalidad del área administrativa del barrio de Canillas (162), y una escala más pequeña correspondiente al barrio vulnerable del Poblado Dirigido de Canillas. El objeto es analizar aspectos acerca de la idoneidad en la selección de la escala de la intervención.

\subsubsection{Medidas de mejora propuestas}

El estudio se ha centrado en la envolvente opaca. Se plantea una rehabilitación a escala urbana de los elementos comunes de la envolvente de los edificios (fachadas, suelos, cubiertas) que omite la parte hueca. La razón es que se ha observado que una parte importante de las ventanas de los condominios residenciales con división horizontal han sido ya sustituidas de manera individual por parte de sus propietarios (Apartado 3.1.5). Por esta razón se ha considerado de mayor interés abordar las mejoras de la envolvente opaca, que presentan un gran potencial de mejora. Las ventanas, modificadas en una parte de las viviendas, de manera desigual dentro de un mismo edificio, se han considerado como un elemento asociado a la vivienda y se excluyen de una intervención urbana.

Se definen las características técnicas de las propuestas de mejora. Las prestaciones que se obtengan después de la rehabilitación deben ser, al menos, las exigidas por la reglamentación vigente para los edificios existentes (CTE-DB-HE 2013). No obstante, para el análisis que se presenta, se han escogido mejoras más profundas.

\subsubsection{Aislamiento térmico en fachadas, parte opaca}

La intervención en fachadas se considera prioritaria puesto que se trata del elemento de la envolvente con una mayor superficie en los edificios multifamiliares y en especial en los bloques habituales en la edificación de las periferias anteriores a 1979. Su rehabilitación consigue el mayor impacto en la reducción de la demanda de calefacción (Carmen Alonso 2015). Es una medida orientada a reducir el intercambio energético en las épocas con peores condiciones térmicas exteriores, principalmente en invierno, 
aunque también se observa una incidencia en verano, al reducirse el calor aportado a través de los muros, especialmente cuando estos tienen poca masa y presentan una baja inercia térmica. Consiste en la adición de una capa de material aislante a su parte opaca para la reducción de la transmitancia térmica en los cerramientos exteriores opacos verticales. Las pérdidas energéticas por transmisión a través de muros se reduce proporcionalmente a la disminución del coeficiente global de la misma (Castaño et al. 2012). Se modifica el aspecto a las fachadas existentes y aumenta el espesor del muro hacia el exterior, lo que hace necesaria una licencia de obras. Además es necesario tomar la precaución de tratar las jambas y dinteles en los huecos, lo que puede reducir su superficie efectiva. Una ventaja de este sistema es que se consigue reducir considerablemente los puentes térmicos en frentes de forjado, pilares en fachada y huecos. En los conjuntos catalogados por su interés patrimonial se hace necesario valorar cuidadosamente que la incorporación de mejoras no menoscabe sus características arquitectónicas.

\subsubsection{Adición de aislamiento térmico en cubiertas}

Esta medida consiste en añadir una capa de aislamiento térmico a las cubiertas existentes. La cubierta es el elemento constructivo de la envolvente que soporta mayores solicitaciones térmicas, por lo que su reparación resulta una práctica habitual. Resolver adecuadamente el techo de los edificios tiene una fuerte incidencia en las condiciones de confort de los usuarios y de higiene de las viviendas de la última planta. Estas se encuentran afectadas por los intercambios de calor a través de la cubierta que generalmente son mayores por metro cuadrado que en fachadas (Luxán García De Diego et al. 2017). Además es el elemento con más presencia de humedades por filtraciones y condensación, lo que agrava el deterioro del edificio y puede provocar un efecto directo sobre la salud de los usuarios.

Una vez más se analizan mejoras a acometer por el exterior para evitar la intervención dentro de las viviendas. En este elemento, la actuación por el exterior resulta especialmente interesante cuando el estado actual de la cubierta precise de reparaciones destacables, por ejemplo cuando el sistema de impermeabilización esté deteriorado, o sea necesario sustituir el material de cobertura (Castaño et al. 2012). En el caso de la 
rehabilitación de barrios vulnerables, la falta de mantenimiento de la edificación puede ser habitual y la reparación de las cubiertas se presenta como una oportunidad para la resolución de otros problemas además de la ineficiencia energética. Es necesario atender al sobrepeso que significa la aplicación de soluciones en la cubierta.

\subsubsection{Adición de aislamiento térmico en suelos}

Una parte de las pérdidas energéticas que se registran en un edificio se produce a través de los suelos. Estos separan el volumen acondicionado del terreno, o de espacios no acondicionados en la parte baja del edificio. Además, la temperatura superficial del suelo puede ser muy inferior a la temperatura ambiente, lo que provoca falta de confort por "radiación fría" y riesgo de condensaciones superficiales. Esta medida consiste en añadir una nueva capa de aislamiento térmico a los suelos existentes.

Al plantear las soluciones para el aislamiento de suelos, se recomienda valorar las posibilidades económicas, físicas y técnicas para realizarlo, ya que en algunas circunstancias, como en las cámaras ventiladas, el acceso puede ser complicado. La reducción del coeficiente global es prioritaria en suelos de locales habitables y puede ser secundaria para suelos que estén en contacto con locales comerciales, garajes, etc. 


\section{Mejora 1. Sistema de Aislamiento Térmico por el exterior convencional}

Se propone un SATE a base de poliestireno expandido (EPS) (Figura 71). Esta medida está ampliamente extendida actualmente y es de las soluciones de aislamiento térmico en fachada con un coste más bajo.

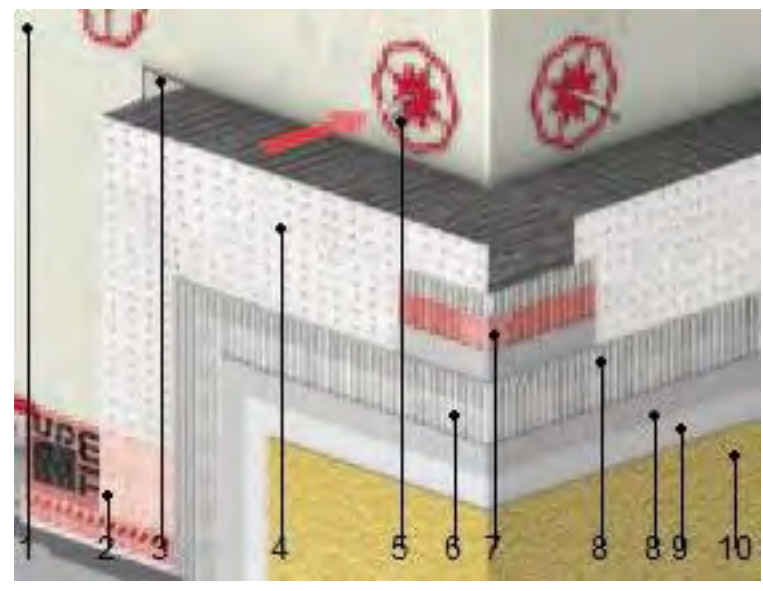

LEYENDA

1:Soporte.

2:Perfil de arranque con malla incorporada.

3:Mortero adhesivo para fijación del aislamiento.

4:Aislamiento.

5:Fijación mecánica.

6:Malla de refuerzo.

7:Perfil de esquina con malla incorporada.

8:Mortero base.

9:Imprimación.

10:Mortero de acabado.

Fuente: Baumit. CYPE 2018

Figura 71. Sistema de Aislamiento térmico por el exterior para fachada con EPS (CYPE 2018)

La descripción de la solución comercial de la que se han tomado los datos para la evaluación de esta la medida es la siguiente:

Rehabilitación energética de fachada, mediante aislamiento térmico por el exterior, con el sistema OpenSystem "BAUMIT", con DITE - 09/0256, compuesto por: panel rígido de poliestireno expandido, OpenReflect "BAUMIT", de $100 \mathrm{~mm}$ de espesor, con revestimiento reflectante de color blanco, fijado al soporte con mortero adhesivo KlebeSpachtel W (OpenContact) "BAUMIT" y fijaciones mecánicas con taco de expansión y clavo de polipropileno Espiga Universal STR U $2 G$ "BAUMIT"; capa de regularización de mortero adhesivo KlebeSpachtel W (OpenContact) "BAUMIT", armado con malla de fibra de vidrio antiálcalis, Star Tex "BAUMIT", de $4 \times 4 \mathrm{~mm}$ de luz de malla, de $145 \mathrm{~g} / \mathrm{m}^{2}$ de masa superficial y $0,5 \mathrm{~mm}$ de espesor; capa de acabado de revestimiento hidrófugo, NanoporTop "BAUMIT", de color blanco, acabado Fine 1,0, sobre imprimación, UniPrimer "BAUMIT", incolora, impermeable al agua de lluvia y permeable al vapor de agua. Solución constructiva con sello de calidad: Documento de Idoneidad Técnica Europeo DITE. 
Mejora 2. Sistema de aislamiento de fachada por el exterior de bajo impacto ambiental

Además de la solución convencional, se analiza una solución a base de materiales de bajo impacto ambiental. El coste de la inversión inicial de esta mejora es mayor que la solución anterior, pero presentaría otros beneficios para la reducción del impacto ambiental de la rehabilitación que se podrían evaluar a través de un Análisis de Ciclo de Vida.

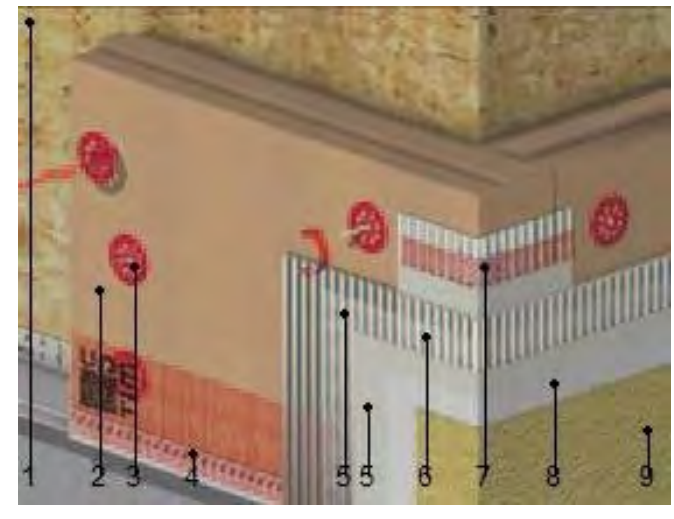

Figura 72. Sistema de aislamiento térmico por el exterior para fachadas, a base de fibras de madera (CYPE 2018)

Se ha incorporado al paquete una solución comercial con la siguiente descripción:

Rehabilitación energética de fachada, mediante aislamiento térmico por el exterior, con el sistema NatureSystem "BAUMIT", con DITE - 09/0305, compuesto por: panel rígido de fibras de madera, DiffuTherm "BAUMIT", de 100 mm de espesor, fijado al soporte con fijaciones mecánicas con espiga especial para madera 6H "BAUMIT"; capa de regularización de mortero adhesivo MultiContact "BAUMIT", armado con malla de fibra de vidrio antiálcalis, Star Tex "BAUMIT", de $4 \times 4 \mathrm{~mm}$ de luz de malla, de $145 \mathrm{~g} / \mathrm{m}^{2}$ de masa superficial y $0,5 \mathrm{~mm}$ de espesor; capa de acabado de revestimiento hidrófugo, NanoporTop "BAUMIT", de color blanco, acabado Fine 1,0, sobre imprimación, UniPrimer "BAUMIT", incolora, impermeable al agua de lluvia y permeable al vapor de agua. 


\section{Mejora 3. Aislamiento térmico por el exterior en cubierta plana}

En el caso de las cubiertas planas tradicionales el material aislante se sitúa debajo del material impermeabilizante, en su rehabilitación el orden de estas dos capas se invierte, conformando una cubierta plana invertida. Al invertir las posiciones convencionales de impermeabilización y aislamiento térmico, la durabilidad de la impermeabilización aumenta notablemente.

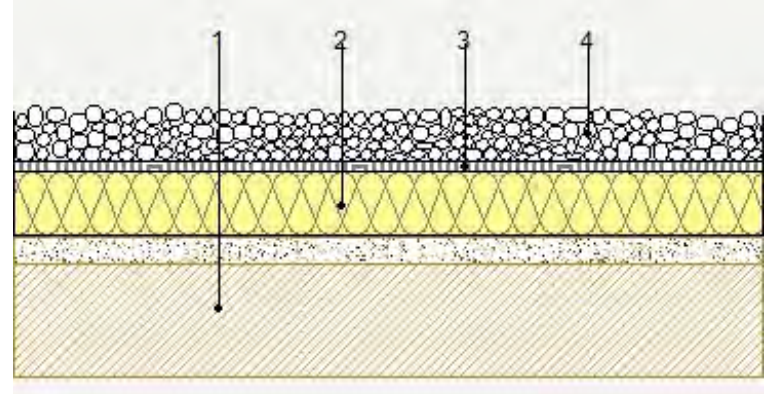

1:Cubierta existente.

2:Aislamiento.

3:Capa separadora.

4:Protección.

Fuente: CYPE 2018

Figura 73. Aislamiento de cubierta con XPS y protección de grava (CYPE 2018)

Para la introducción de los datos técnicos de esta mejora se han tomado los valores declarados por una solución comercial con la siguiente descripción:

Rehabilitación energética de cubierta plana no transitable, con la membrana impermeabilizante en buen estado de conservación, mediante la incorporación de aislamiento termo acústico por el exterior de la cubierta, formado por panel rígido de poliestireno extruido Ursa XPS NV L "URSA IBÉRICA AISLANTES", de $120 \mathrm{~mm}$ de espesor, resistencia a compresión >= $500 \mathrm{kPa}$; capa separadora de geotextil no tejido compuesto por fibras de poliéster unidas por agujeteado, (200 $\left.\mathrm{g} / \mathrm{m}^{2}\right)$; y protección con capa de $10 \mathrm{~cm}$ de canto rodado de 16 a $32 \mathrm{~mm}$ de diámetro. 


\section{Mejora 4. Aislamiento térmico por el exterior en cubierta plana ajardinada extensiva}

Se incluye también la valoración de la inversión inicial necesaria para la implantación de cubiertas ajardinadas como solución alternativa.

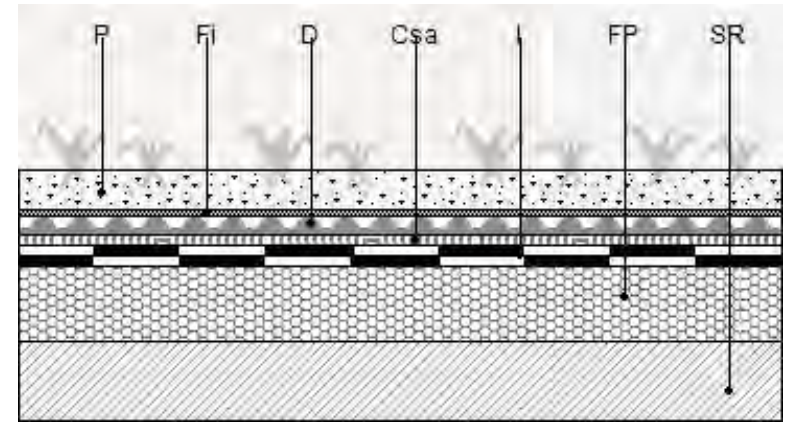

LEYENDA

P:Protección.

Fi: Capa filtrante.

D: Capa drenante.

Csa: Capa separadora bajo protección.

I: Impermeabilización.

FP: Formación de pendientes.

SR: Soporte resistente.

Fuente: CYPE 2018

Figura 74. Sistema de cubierta verde extensiva con aislamiento de XPS (CYPE 2018)

Se ha evaluado la mejora a través de una solución comercial con la siguiente descripción:

Cubierta plana transitable, no ventilada, ajardinada extensiva (ecológica), sistema Sedum Tapizante "ZINCO", compuesta de: formación de pendientes: arcilla expandida, de granulometría comprendida entre 2 y $10 \mathrm{~mm}$ y $350 \mathrm{~kg} / \mathrm{m}^{3}$ de densidad, vertida en seco y consolidada en su superficie con lechada de cemento, con espesor medio de $10 \mathrm{~cm}$, acabado con capa de regularización de mortero de cemento, industrial, M-5 de $4 \mathrm{~cm}$ de espesor; impermeabilización bicapa adherida: lámina de betún modificado con elastómero SBS, LBM(SBS)-30-FV y lámina de betún modificado con elastómero SBS, LBM(SBS)-50/G-FP, totalmente adheridas con soplete, sin coincidir sus juntas; membrana anti raíces flexible de polietileno de baja densidad, WSF 40 "ZINCO", de color negro; capa separadora bajo protección: manta protectora y retenedora SSM 45 "ZINCO", formada por geotextil de poliéster y polipropileno, con una masa superficial de 470 $\mathrm{g} / \mathrm{m}^{2}$; capa drenante y retenedora de agua: módulo Floradrain FD 25-E "ZINCO"; capa filtrante: filtro sistema SF "ZINCO", formado por un geotextil de fibras de polipropileno; capa de protección: sustrato Zincoterra Sedum "ZINCO", de $80 \mathrm{~mm}$ de espesor, plantas con cepellón plano, Zinco Sedum Mix "ZINCO". 


\section{Mejora 5. Aislamiento térmico por el exterior en cubierta inclinada}

La incorporación de aislamiento por el exterior en cubiertas existentes inclinadas es una medida que supone mayor complejidad que en las cubiertas planas, puesto que implica la retirada y reposición del material de cobertura. En Cubiertas inclinadas el aislamiento por el exterior permite la recuperación de los espacios no habitables bajo cubierta (desvanes, cámaras ventiladas) siempre y cuando sea posible cumplir con el resto de condiciones de habitabilidad. En estos casos y en aquellos en los que el material de cobertura este deteriorado, esta solución resulta de mayor rentabilidad.

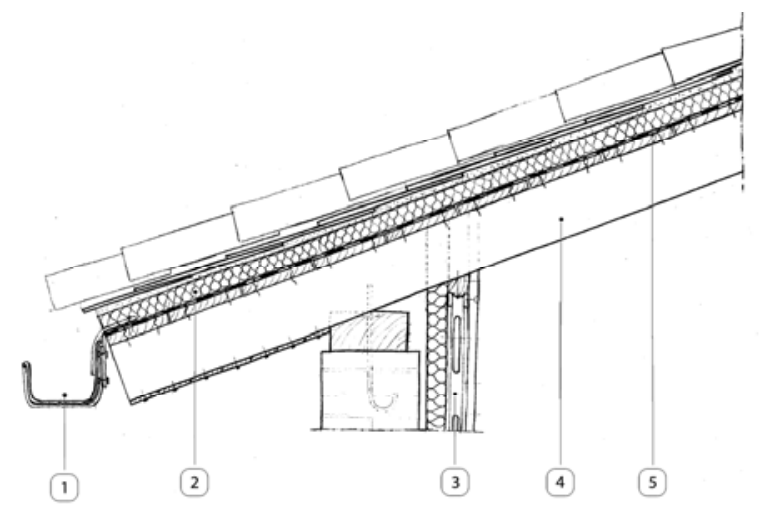

LEYENDA

1- Canalón

2- Aislante térmico

3- Elemento de cierre envolvente vertical

4- Pares de madera vistos

5- Impermeabilización

Fuente: V. Sánchez Ramos

Figura 75. Aislamiento térmico de cubierta inclinada por el exterior(Fuente: Virginia Sánchez Ramos 2012)

En el presente estudio se ha incluido una solución existente en el mercado, con la descripción:

Rehabilitación energética de cubierta inclinada con una pendiente media del 30\% a menos de 20 $m$ de altura, mediante la incorporación de aislamiento termo acústico por el exterior de la cubierta, formado por panel semirrígido de lana de roca volcánica Rockplus -E- 220 "ROCKWOOL", según UNE-EN 13162, no revestido, de $120 \mathrm{~mm}$ de espesor, colocado entre rastreles de madera, fijado mecánicamente al soporte; previo desmontaje de la capa de cobertura de teja cerámica curva, colocada con mortero, con medios manuales y carga manual sobre camión o contenedor; barrera de vapor adherida al soporte, bajo el aislante; colocación de la impermeabilización sobre el aislante; y cobertura de teja cerámica mixta, color rojo, $43 \times 26 \mathrm{~cm}$, fijada con tornillos rosca-madera sobre rastreles de madera, formando una cámara de aire ventilada por encima del aislamiento. 


\subsubsection{Mejora 6. Aislamiento térmico por el exterior de forjados con lana mineral}

La herramienta MEPEC empleada para el cómputo de superficies de suelos permite distinguir, a partir de los datos catastrales, aquellos suelos que están en contacto con el aire exterior, como son los soportales o porches. Estos suelos son los más afectados por el intercambio de calor con el exterior. Se ha propuesto esta medida para mejorar su calidad térmica.

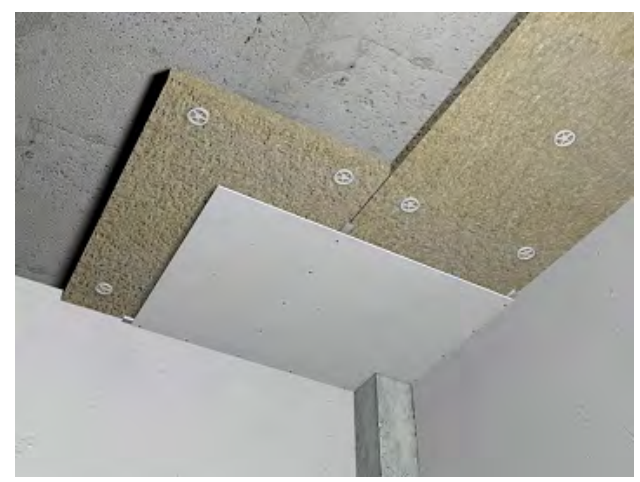

LEYENDA

1- Panel aislante de lana de roca

2- Fijación metálica

3- Falso techo de placa de yeso

laminado

Fuente: CYPE 2018

Figura 76. Sistema de aislamiento de suelos en contacto con el aire exterior con Lana Mineral (MW) (CYPE 2018)

La mejora propuesta se encuentra en fácilmente en el mercado y ofrece la siguiente descripción:

Rehabilitación energética mediante el sistema "ROCKWOOL" de aislamiento termo acústico por el interior, bajo el forjado plano, mediante la colocación de panel semirrígido de lana de roca volcánica Rockcalm -E- 211 "ROCKWOOL", según UNE-EN 13162, no revestido, de $80 \mathrm{~mm}$ de espesor, fijado mecánicamente; falso techo continuo adosado liso $(12,5+27+27)$, con una placa de yeso laminado A / UNE-EN 520 - 1200 / longitud / 12,5 / con los bordes longitudinales afinados, fijada a maestras separadas $1000 \mathrm{~mm}$ entre ejes y fijadas al forjado o elemento soporte mediante anclajes directos; y dos manos de pintura plástica, color blanco, acabado mate, textura lisa, (rendimiento: 0,1 l/ $\mathrm{m}^{2}$ cada mano); previa aplicación de una mano de imprimación a base de copolímeros acrílicos en suspensión acuosa. 


\subsubsection{Costes de la inversión inicial}

El volcado de los datos referidos a la envolvente en el MADE, hacen posible realizar de forma sencilla una planificación de las mediciones y el orden de magnitud de la inversión que resulta necesaria para la incorporación de la mejora de la envolvente térmica de la edificación en los planes de rehabilitación urbana. Se trata de un procedimiento simplificado en el que se computan exclusivamente los costes de la inversión inicial. No se han computado los costes de mantenimiento, ni de reposición a largo plazo.

El cálculo de los costes de cada una de las medidas destinadas a la reducción de las pérdidas parte de la estimación del presupuesto de ejecución material (PEM) que incluye el precio de los materiales, la mano de obra, maquinaria y medios auxiliares. Los precios unitarios de ejecución material de las mejoras, se han obtenido utilizando el software "Generador de precios de la construcción", de libre copia y distribución, desarrollado y actualizado por CYPE Ingenieros. Se trata de una herramienta informática que permite obtener precios (para obra nueva, rehabilitación y espacios urbanos) con las previsiones de costes ajustadas al máximo a la realidad (Tabla 50) (Castell Herrera, Miñana Giner, y Signes Orovay 2018). A partir de este presupuesto se obtienen los costes para una rehabilitación promovida por la administración pública (coste macroeconómico) y para una rehabilitación de promoción privada (coste microeconómico).

Además, los valores estimados de la mano de obra se utilizan para calcular el potencial de generación de empleo que tiene la ejecución de las obras descritas en el cómputo de beneficios sociales (Apartado 3.3.3.4). 
Tabla 50. Ficha ejemplo de precios descompuestos para una solución de aislamiento de fachada por el exterior. Fuente: CYPE Ingenieros 2018

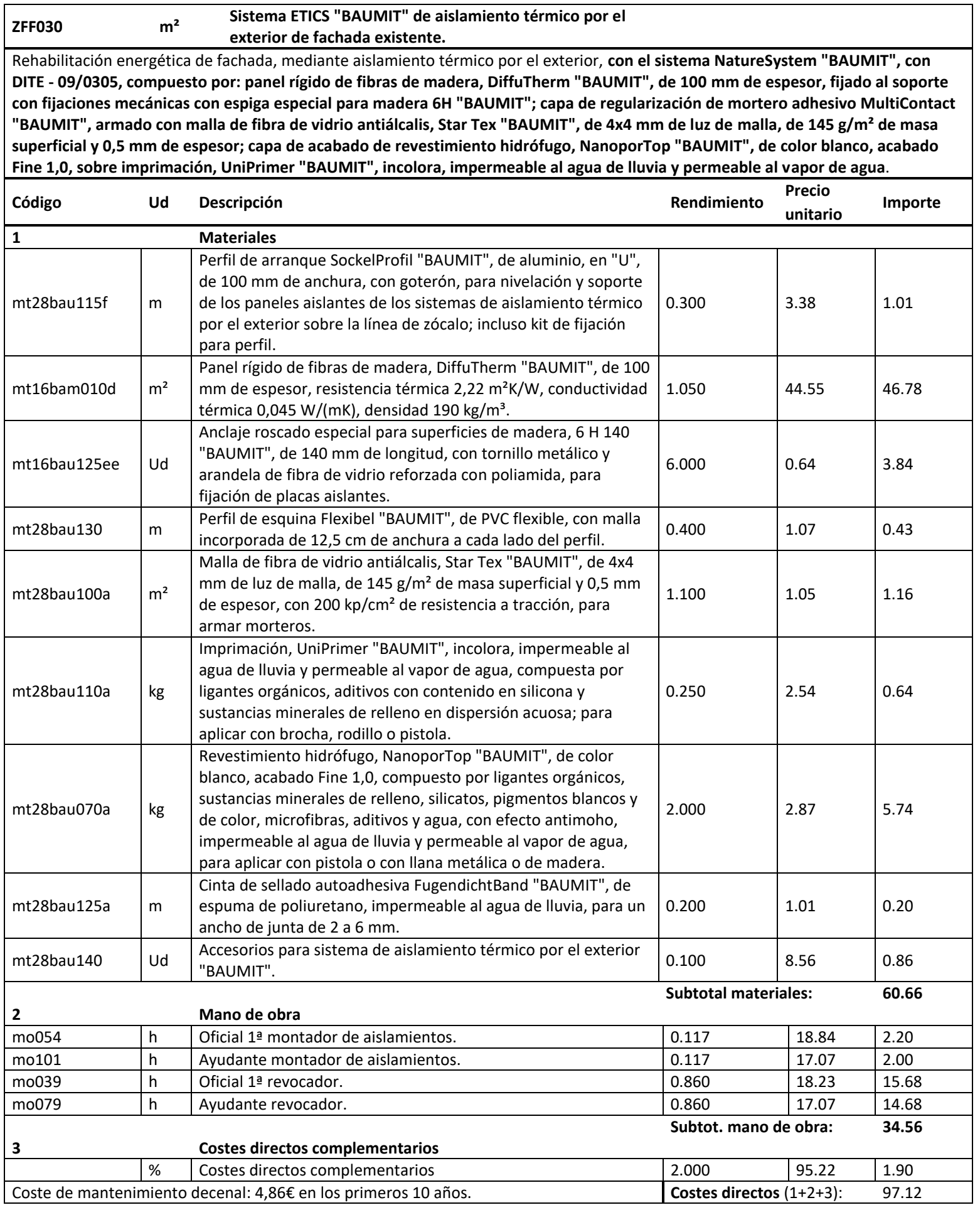




\subsubsection{El volumen de las obras incide en el coste de la inversión}

Desde el punto de vista económico, una de las ventajas que presenta la rehabilitación de barrios completos con respecto a la suma de la rehabilitación edificio por edificio es la reducción de los costes de ejecución. Para cuantificar esta diferencia se utiliza la herramienta de cálculo desarrollada por CYPE a partir de la Base de Precios de la Construcción para la zona centro. Se dimensiona el volumen de obra a partir de dos estudios de caso: el de un bloque individual tipo del Poblado Dirigido de Canillas y el de la intervención para todos los edificios del Poblado Dirigido.

Los posibles ahorros de costos por trabajar en escala de barrio vendrían dados por la estandarización de soluciones constructivas y el mayor volumen de compras, que se producen tanto en rehabilitación como en obra nueva. Teniendo en cuenta que depende del volumen de la obra y de los plazos de ejecución (que influirían en los costos de maquinaria), puede haber una horquilla de ahorro entre $0 \%$ y el $20 \%$.

\section{Rehabilitación para un bloque individual}

Se definen las características de la obra para la rehabilitación energética de un solo edificio residencial multifamiliar en bloque típico de la construcción anterior a 1979, en el barrio de Canillas. Las características de la obra (Tabla 51) se utilizan para la estimación de los precios unitarios, tanto de materiales como de mano de obra y de maquinaria y los rendimientos de la mano de obra.

Tabla 51. Características de la obra para un solo bloque (CYPE 2018)

\begin{tabular}{|l|l|}
\hline -Superficie de la intervención : $620,00 \mathrm{~m}^{2}$ & - Mercado : \\
-Superficie de la planta tipo : $155,00 \mathrm{~m}^{2}$ & Crecimiento \\
-Número de plantas sobre rasante : 4 & sostenido (normal) \\
-Número de plantas bajo rasante : 0 & - Situación : Aislada \\
-Dificultad de acceso : Limitado & - Tipo de proyecto : \\
-Almacenamiento de materiales y escombros : & Edificio \\
Reducido & plurifamiliar \\
-Transporte de materiales : Transporte manual & - Distancia a \\
-Presencia de usuarios y mobiliario : Presencia & vertedero \\
permanente de usuarios & autorizado: 50,00 \\
-Estado de conservación del edificio : Regular & km \\
-Grado de intervención : Parcial & \\
-Dificultad de ejecución : Moderada & \\
\hline
\end{tabular}




\section{Rehabilitación a escala de barrio}

Se estiman también los costes unitarios de ejecución material de las medidas de mejora en el caso en el que la rehabilitación se realice para todos los edificios obsoletos del barrio del Poblado Dirigido de Canillas. En la escala de barrio se han definido los parámetros correspondientes a un volumen de obra equivalente a la intervención sobre toda la edificación construida con anterioridad a la entrada en vigor de la norma (NBE-CT79 1979); un total de 432 edificios entre viviendas unifamiliares, bloques multifamiliares y torres en altura. Se contempla también la intervención sobre edificios terciarios con envolventes térmicas obsoletas (colegio, instituto, centro de salud...).

Las características de la obra seleccionada para los precios unitarios, tanto de materiales como de mano de obra y de maquinaria y los rendimientos de la mano de obra son las siguientes:

Para el estudio de caso del Barrio de Canillas, el ahorro estimado que se obtiene con un volumen de obra correspondiente a la rehabilitación de todos los edificios del barrio anteriores a 1979 sería de un $12,4 \%$ con respecto del coste que supondría la rehabilitación de cada uno de los edificios individualmente. Estos valores son coherentes con los publicados en otros estudios previos.

Buscar la economía de escala, con operaciones grandes, para incentivar a las empresas privadas a participar y disminuir, en más de un 10\% el coste de la rehabilitación (Santiago 2014).

Tabla 52. Características de la obra para la intervención a escala de barrio (CYPE 2018)

\begin{tabular}{|l|l|}
\hline -Superficie de la intervención : $120.000,00 \mathrm{~m}^{2}$ & - Mercado : \\
-Superficie de la planta tipo : $30.000,00 \mathrm{~m}^{2}$ & Crecimiento \\
-Número de plantas sobre rasante : 4 & sostenido (normal) \\
-Número de plantas bajo rasante : 0 & - Situación : Aislada \\
-Dificultad de acceso : Limitado & - Tipo de proyecto : \\
-Almacenamiento de materiales y escombros : & Edificio plurifamiliar \\
Reducido & - Distancia a vertedero \\
-Transporte de materiales : Transporte manual & autorizado : 50,00 \\
-Presencia de usuarios y mobiliario : Presencia & $\mathrm{km}$ \\
permanente de usuarios & \\
-Estado de conservación del edificio : Regular & \\
-Grado de intervención : Parcial & \\
-Dificultad de ejecución : Moderada & \\
\hline
\end{tabular}

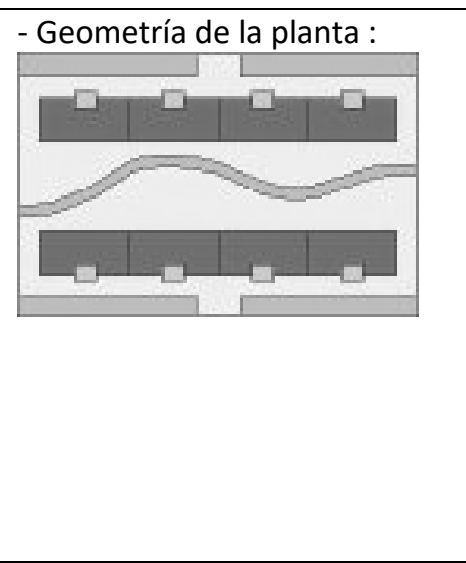


Tabla 53. Presupuesto unitario de ejecución material $(€)$ de las medidas evaluadas en función de la escala de la actuación (CYPE 2018)

\begin{tabular}{|l|l|l|l|}
\hline Solución & PEM escala bloque $\left(€ / \mathrm{m}^{2}\right)$ & PEM escala barrio $\left(€ / \mathrm{m}^{2}\right)$ & Ahorro obtenido \\
\hline SATE_EPS10 & 80.12 & 71.34 & $14 \%$ \\
\hline SATEmadera10 & 112.86 & 97.12 & $17 \%$ \\
\hline CUB_XPS12_grava & 58.63 & 48.69 & $8 \%$ \\
\hline CUB_XPS12_verde & 133.50 & 123.03 & $12 \%$ \\
\hline SUELO_MW8 & 41.76 & 36.75 & $14 \%$ \\
\hline
\end{tabular}

\subsubsection{Presupuesto de ejecución material de las obras}

A partir de los datos recopilados de la base de datos utilizada por el generador de precios de la construcción para cada una de las mejoras propuestas, se obtiene un presupuesto unitario de ejecución material (Tabla 53). Las características de la obra se definen por una parte para la escala de la edificación aislada (PEM bloque), y también para una actuación a escala de barrio (PEM barrio).

De este modo se estima la reducción de costes que supone, para cada una de las mejoras, al implementar las mejoras al aumentar el volumen de obra de la escala del edificio a la del barrio. Mediante la ampliación de la escala se consiguen ahorros de entre el 8 y el $17 \%$ en función de la medida de mejora a aplicar. En el estudio de caso, generalizable a otros barrios de la periferia de Madrid, las fachadas suponen el elemento constructivo de mayor superficie sobre la que se debe actuar. Para las dos medidas contempladas, el ahorro por el aumento del volumen de obra supondría entre el 14 y el $17 \%$ del PEM. Se comprueba que los ahorros se producen básicamente en el precio unitario de adquisición de los materiales. En cambio, la mano de obra necesaria no se ve reducida con el aumento de la escala, teniendo la intervención a escala de barrio un potencial de generación de empleo muy similar a la rehabilitación edificio por edificio.

\subsubsection{Estimación del coste unitario de la inversión para la incorporación de mejoras}

Para la estimación del coste total de la inversión inicial, es necesario incorporar una serie de gastos generados durante el proceso. Se han estimado los costes utilizando procedimientos descritos en la metodología existente para el cálculo del coste óptimo para los requerimientos de eficiencia energética en edificios en España (Ministerio de 
Fomento 2013b). Este procedimiento aborda el problema desde dos perspectivas: el cálculo de la rentabilidad óptima en términos macroeconómicos para los estados, y la financiera (microeconómica) para el estudio de la rentabilidad para inversores (Comisión Europea 2012). Para el cálculo del coste desde una perspectiva macroeconómica se han tenido en cuenta los siguientes conceptos, que se estiman en función de porcentajes del PEM:

- Seguridad y Salud en la obra

- Control de Calidad

- Gastos Generales de la Contrata

- Beneficio Industrial de la Contrata

- Honorarios técnicos

- Coste de Visados Colegiales

El subtotal que se obtiene de la inclusión de estos conceptos para la contratación y ejecución de las obras aparece en la Tabla 54. Los costes se calculan desglosados por precio unitario para cada una de las medidas de mejora. Se trata de cantidades libres de tasas e impuestos, por lo que podría asimilarse a la inversión necesaria para realizar operaciones de rehabilitación de promoción pública.

Tabla 54. Estimación de costes unitarios $\left(€ / \mathrm{m}^{2}\right)$ en escenario macroeconómico. Elaboración propia

\begin{tabular}{|l|l|l|l|l|l|l|l|}
\hline \multirow{2}{*}{ Solución } & Escala & PEM unitario & $\begin{array}{l}\text { SyS_CC } \\
\mathbf{4 \%}\end{array}$ & $\begin{array}{l}\text { Contrata } \\
\mathbf{1 9 \%}\end{array}$ & $\begin{array}{l}\text { HonTEC } \\
\mathbf{1 4 \%}\end{array}$ & $\begin{array}{l}\text { Visado } \\
\mathbf{0}, \mathbf{5} \%\end{array}$ & $\begin{array}{l}\text { Subtotal } \\
\text { MACRO }\end{array}$ \\
\hline \multirow{2}{*}{ SATE_EPS10 } & bloque & 80.12 & 3.20 & 15.22 & 11.22 & 0.40 & 110.17 \\
\cline { 2 - 8 } & barrio & 71.34 & 2.85 & 13.55 & 9.99 & 0.36 & 98.09 \\
\hline \multirow{2}{*}{ SATEmadera10 } & bloque & 112.86 & 4.51 & 21.44 & 15.80 & 0.56 & 155.18 \\
\cline { 2 - 8 } & barrio & 97.12 & 3.88 & 18.45 & 13.60 & 0.49 & 133.54 \\
\hline \multirow{2}{*}{ CUB_XPS12_grava } & bloque & 58.63 & 2.35 & 11.14 & 8.21 & 0.29 & 80.62 \\
\cline { 2 - 8 } & barrio & 48.69 & 1.95 & 9.25 & 6.82 & 0.24 & 66.95 \\
\hline \multirow{2}{*}{ CUB_XPS12_verde } & bloque & 133.50 & 5.34 & 25.37 & 18.69 & 0.67 & 183.56 \\
\cline { 2 - 8 } & barrio & 123.03 & 4.92 & 23.38 & 17.22 & 0.62 & 169.17 \\
\hline \multirow{2}{*}{ SUELO_MW8 } & bloque & 41.76 & 1.67 & 7.93 & 5.85 & 0.21 & 57.42 \\
\cline { 2 - 8 } & barrio & 36.75 & 1.47 & 6.98 & 5.15 & 0.18 & 50.53 \\
\hline
\end{tabular}


Para conocer el precio final que tendría la rehabilitación energética en un escenario microeconómico o financiero para un inversor, es necesario tener en cuenta los costes de licencias e impuestos Tabla 55. Se han calculado dos opciones para el Impuesto sobre el Valor Añadido, incluyendo un escenario con el IVA reducido. Este supuesto correspondería a la aplicación de incentivos fiscales a la rehabilitación de edificios, experiencia que ya se ha aplicado en periodos anteriores para fomentar la rehabilitación. A modo de ejemplo, en el caso de una comunidad de propietarios que rehabilitar la fachada de su edificio incorporando un SATE, el precio unitario a pagar con un IVA del $21 \%$ sería de $135,70 € / \mathrm{m} 2$ (123.59 €/m2 para un IVA reducido). Esta misma medida de mejora supondría un coste de $98.09 € / \mathrm{m} 2$ en un escenario macroeconómico en una operación de regeneración urbana integrada de promoción pública para la recuperación de un barrio vulnerable.

Para la estimación del coste total de la incorporación de mejoras energéticas en una operación de promoción pública para la rehabilitación del estudio de caso de Canillas, se han tomado los costes correspondientes a las mejoras de menor coste: la instalación de un SATE en las fachadas, la incorporación de aislamiento en una cubiertas planas con protección de grava y el aislamiento de suelos en contacto con el aire exterior (Tabla 55).

Tabla 55. Estimación de coste total unitario $\left(€ / \mathrm{m}^{2}\right)$ para un escenario financiero. Elaboración porpia

\begin{tabular}{|l|l|l|l|l|l|l|l|}
\hline \multirow{2}{*}{ Solución } & Escala & $\begin{array}{l}\text { Subtotal } \\
\text { MACRO }\end{array}$ & $\begin{array}{l}\text { Licencias } \\
\mathbf{3} \%\end{array}$ & $\begin{array}{l}\text { IVA } \\
\mathbf{2 1 \%}\end{array}$ & $\begin{array}{l}\text { IVA } \\
\text { reducido } \\
\mathbf{1 0 \%}\end{array}$ & TOTAL & $\begin{array}{l}\text { TOTAL } \\
\text { reducido }\end{array}$ \\
\hline \multirow{2}{*}{$\begin{array}{l}\text { SATE_EPS10 } \\
\text { SATE_EPS10 }\end{array}$} & bloque & 110.17 & 2.40 & 23.13 & 11.02 & 135.70 & 123.59 \\
\cline { 2 - 7 } & barrio & 98.09 & 2.14 & 20.60 & 9.81 & 120.83 & 110.04 \\
\hline \multirow{2}{*}{ SATEmadera10 } & bloque & 155.18 & 3.39 & 32.59 & 15.52 & 191.16 & 174.09 \\
\cline { 2 - 8 } & barrio & 133.54 & 2.91 & 28.04 & 13.35 & 164.50 & 149.81 \\
\hline \multirow{2}{*}{ CUB_XPS12_grava } & bloque & 80.62 & 1.76 & 16.93 & 8.06 & 99.30 & 90.44 \\
\cline { 2 - 8 } & barrio & 66.95 & 1.46 & 14.06 & 6.69 & 82.47 & 75.10 \\
\hline \multirow{2}{*}{ CUB_XPS12_verde } & bloque & 183.56 & 4.01 & 38.55 & 18.36 & 226.12 & 205.92 \\
\cline { 2 - 8 } & barrio & 169.17 & 3.69 & 35.52 & 16.92 & 208.38 & 189.77 \\
\hline \multirow{2}{*}{ CUB_XPS12_inclin } & bloque & $144.02 €$ & $3.14 €$ & $30.24 €$ & $14.40 €$ & $177.40 €$ & $161.56 €$ \\
\cline { 2 - 8 } & barrio & $130.14 €$ & $2.84 €$ & $27.33 €$ & $13.01 €$ & $160.31 €$ & $146.00 €$ \\
\hline \multirow{2}{*}{ SUELO_MW8 } & bloque & 57.42 & 1.25 & 12.06 & 5.74 & 70.73 & 64.41 \\
\cline { 2 - 8 } & barrio & 50.53 & 1.10 & 10.61 & 5.05 & 62.25 & 56.69 \\
\hline \multirow{2}{*}{ TOLDOS } & bloque & 400.66 & 8.74 & 84.14 & 40.07 & 493.54 & 449.47 \\
\cline { 2 - 8 } & barrio & 344.04 & 7.51 & 72.25 & 34.40 & 423.79 & 385.95 \\
\hline
\end{tabular}




\subsubsection{Beneficios medioambientales, sociales y económicos}

La estimación de los beneficios obtenidos por la mejora de la eficiencia energética de la edificación es un tema largamente debatido en múltiples estudios (Apartado 1.1.7). Estos beneficios se deben evaluar de forma integral a partir de los distintos aspectos de la teoría del desarrollo sostenible. Además del aumento de la calidad térmica de la edificación que redunda en la reducción del impacto ambiental de la misma, se producen beneficios sociales en la salud y generación de empleo y económicos por la reducción de los costes en las facturas energéticas. La herramienta desarrollada en este trabajo permite la cuantificación de algunos de estos impactos.

\subsubsection{La mejora de la calidad de la envolvente}

El principal objetivo de la rehabilitación energética que se aborda en este estudio es la mejora de la calidad térmica de la edificación. Esta operación reduce la demanda energética y produce un aumento del valor de la construcción. La mejora de las prestaciones térmicas de los elementos constructivos que se obtiene mediante la incorporación de las medidas se caracteriza a través de su transmitancia térmica en estado reformado $\left(U_{E R}\right)$. A partir de los valores originales recopilados en la caracterización constructiva de la edificación existente (Apartado 3.1.5), se estiman las características térmicas resultantes de la incorporación de las mejoras (Tabla 56). Para ello se ha utilizado el método de cálculo de la transmitancia térmica definido en el CTE para Cerramientos en contacto con el aire exterior (CTE DA DB-HE / 1 2015). Se estima la resistencia térmica total $\mathrm{R}$ de cada componente suponiendo que están constituidos por capas térmicamente homogéneas.

Se ha previsto la rehabilitación energética de todos los edificios anteriores a 1979 conforme a los valores de la Tabla 56. Se contempla la mejora de la fachada, la cubierta y los suelos en contacto con el aire exterior. Todos los valores superan los mínimos propuestos por el CTE para la definición del edificio de referencia que determina las exigencias aplicables para la rehabilitación de edificios existentes (CTE-DB-HE 2013). En el estudio de caso, la mayor parte de las cubiertas son planas: se ha descartado la evaluación del tipo y se han adoptado los mismos valores para todas. 
Tabla 56. Mejora de la transmitancia obtenida mediante la aplicación de las mejoras.

Elaboración propia

\begin{tabular}{|l|l|l|l|l|l|l|l|}
\hline ubicación & solución & $\begin{array}{l}\text { U EA } \\
\left(\mathbf{W} / \mathbf{m}^{2} \mathbf{K}\right)\end{array}$ & $\begin{array}{l}\lambda \\
(\mathbf{W} / \mathbf{m K})\end{array}$ & $\begin{array}{l}\text { Espesor } \\
(\mathbf{m})\end{array}$ & $\begin{array}{l}\text { R térmica } \\
\left(\mathbf{m}^{2} \mathbf{K} / \mathbf{W}\right)\end{array}$ & $\begin{array}{l}\text { U_ER } \\
\left(\mathbf{W} / \mathbf{m}^{2} \mathbf{K}\right)\end{array}$ & $\begin{array}{l}\text { Ulim_CTE* } \\
\left(\mathbf{W} / \mathbf{m}^{2} \mathbf{K}\right)\end{array}$ \\
\hline \multirow{2}{*}{ Fachada } & SATE_EPS10 & 1.55 & 0.031 & 0.10 & 3.23 & 0.26 & 0.66 \\
\cline { 2 - 8 } & SATEmadera10 & 1.55 & 0.045 & 0.10 & 2.22 & 0.35 & 0.66 \\
\hline \multirow{2}{*}{ Cubierta } & CUB_XPS12_grava & 2.40 & 0.036 & 0.12 & 3.33 & 0.27 & 0.38 \\
\cline { 2 - 8 } & CUB_XPS12_verde & 2.40 & 0.036 & 0.12 & 3.33 & 0.27 & 0.38 \\
\hline \multirow{2}{*}{ Suelo ext } & SUELO_MW8 & 2.50 & 0.035 & 0.08 & 2.29 & 0.37 & 0.49 \\
\hline
\end{tabular}

A partir de estos valores es posible calcular la reducción de las pérdidas energéticas a través de la envolvente que supone la intervención. Estas pérdidas inciden directamente en la demanda de energía del edificio (ISO 13790 2008), y por tanto se puede computar como ahorros en el consumo. Para la transformación de la reducción de la demanda en consumo de energía final, se tienen en cuenta, una vez más, los factores de conversión por rendimiento de las instalaciones térmicas del $100 \%$ en la calefacción eléctrica y del $75 \%$ en el gas natural.

\subsubsection{Beneficios económicos}

Se ha comentado que algunos de los beneficios económicos obtenidos son el aumento del valor del inmueble y los ahorros en facturas energéticas. El presente procedimiento permite calcular el ahorro en facturas energéticas en el caso de demandas satisfechas. Para ello se propone una estimación simplificada de los precios de la energía ( $k W h)$. Se han utilizado los precios para la vivienda media calculados para la detección de áreas urbanas en riesgo de pobreza energética mediante la regla dl 10\% (Apartado 2.2.1). Se tiene en cuenta el tipo de energía (electricidad o gas natural) y que incluyen el consumo (kWh; $€$ ) los costes por término fijo o de potencia y los impuestos (HC; elec; IVA) (Tabla 57).

Tabla 57. Coste anual de la factura energética necesaria para calefacción en una vivienda media en Madrid por tipo de suministro. Elaboración propia y EUROSTAT 2017

\begin{tabular}{|l|l|l|l|l|l|}
\hline $\begin{array}{l}\text { Tipo de } \\
\text { energía }\end{array}$ & $\begin{array}{l}\text { Implantación } \\
(\%)\end{array}$ & $\begin{array}{l}\text { Consumo } \\
(\mathbf{k W h})\end{array}$ & $\begin{array}{l}\text { Total } \\
(€ / \text { año) }\end{array}$ & $\begin{array}{l}\text { Precio Unitario } \\
(€ / \text { kWh })\end{array}$ & $\begin{array}{l}\text { Precio EUROSTAT 2017 } \\
(€ / \text { kWh })\end{array}$ \\
\hline Gas & 59,27 & 13.352 & 883,13 & 0,066 & 0,067 \\
\hline Electricidad & 40,73 & 10.014 & $1.642,68$ & 0,164 & 0,230 \\
\hline
\end{tabular}


En el caso del precio del gas natural para uso doméstico, los costes estimados para la vivienda media en Madrid son coincidentes con la información publicada en la UE (EUROSTAT 2017). Para el caso de la electricidad, el precio de EUROSTAT para España es un $29 \%$ más elevado que el calculado mediante la metodología propuesta en este trabajo para Madrid (CNM 2017). Se han tomado las estimaciones propias entendiendo que introducen variables correspondientes al caso concreto de Madrid y además estiman el ahorro económico obtenido quedando del lado de la seguridad. Para los cálculos simplificados, se considera que el coste del mix energético (60\% gas y $40 \%$ electricidad) utilizado para calefacción de viviendas en Madrid en 2017 sería de aproximadamente 0,1 $€ /$ kWh.

Una estimación exhaustiva del ahorro de costes en la factura energética requiere de un análisis profundo a partir de datos de medidores de consumo, además sería necesario generar un escenario dinámico en el que se tenga en cuenta la fluctuación del precio de la energía a lo largo de los años (Ministerio de Fomento 2013b). En este caso se ha simplificado el cálculo como si el escenario fuera estático, quedando una vez más del lado de la seguridad puesto que el escenario europeo actual es de precios energéticos al alza (De Vita et al. 2016).

\subsubsection{Beneficios medioambientales}

El modelo desarrollado permite calcular de forma sencilla dos indicadores para estimar la reducción de impactos ambientales que supone la operación. Por un lado la reducción en el agotamiento de recursos por el descenso del consumo de energía primaria no renovable. Además permite evaluar el impacto sobre el cambio climático que se produciría por la reducción de emisiones de $\mathrm{CO}_{2}$ en el medioambiente. Estos indicadores se pueden obtener para el caso de demandas satisfechas.

Para la estimación de estos indicadores el método aplica factores de conversión a energía final y primaria, y emisiones de $\mathrm{CO}_{2}$ asociadas. En el estudio de caso se han aplicado valores obtenidos de estudios existentes (Ministerio de Fomento 2013b). Se han aplicado estos factores sobre los cálculos de demanda realizados por la herramienta desarrollada. 
Tabla 58. Factores de conversión adoptados para el gas natural y electricidad. Elaboración propia

\begin{tabular}{|c|c|c|c|c|}
\hline $\begin{array}{l}\text { Fuente de } \\
\text { energía }\end{array}$ & $\begin{array}{l}\text { Energía final } \\
\left(\mathbf{k W h}_{\text {final }} / \mathbf{k W h} \mathbf{h}_{\text {demCal }}\right)\end{array}$ & $\begin{array}{l}\text { Energía primaria no } \\
\text { renovable } \\
\left(\mathbf{k W h} h_{\text {primaria }} / \mathbf{k W h}_{\text {final }}\right)\end{array}$ & $\begin{array}{l}\text { Emisiones de } \mathrm{CO}_{2} \\
\left(\mathrm{kgCO}_{2} / \mathrm{kWh}_{\text {final }}\right)\end{array}$ & $\begin{array}{l}\text { Acumulado } \\
\left(\mathrm{kgCO}_{2} / \mathrm{kWh}_{\text {demCAL }}\right)\end{array}$ \\
\hline gas natural & 1.333 & 1.070 & 0.201 & \\
\hline electricidad & 1.000 & 2.464 & 0.399 & \\
\hline $\operatorname{mix}$ & 1.200 & 1.628 & 0.280 & 0.547 \\
\hline
\end{tabular}

\subsubsection{Beneficios sociales: indicador de generación de empleo}

El método de estimación del potencial de generación de empleo es similar a la elaboración del presupuesto a partir de mediciones de la envolvente. En este caso, en lugar de coste unitario, se introducen valores de mano de obra necesaria en los distintos oficios que intervienen en la ejecución de cada unidad de obra. En el estudio de caso se han sumado el número total de horas de trabajo de todos los oficios necesarios para la ejecución de cada partida para las soluciones elegidas (Tabla 59).

Los valores unitarios de cada solución se introducen en el modelo como variables de entrada, lo que permite estimar el total de horas de trabajo que se necesitan en función del cómputo de superficies de cada elemento de la envolvente de todos los edificios, realizado mediante la herramienta MEPEC.

Tabla 59. Computo de horas de trabajo necesarias para la ejecución de mejoras.

Fuente CYPE ingenieros

\begin{tabular}{|c|c|c|c|}
\hline Solución & Oficio & $\begin{array}{l}\text { Horas trabajadas } \\
\left(\mathrm{H} / \mathrm{m}^{2}\right)\end{array}$ & $\begin{array}{l}\text { Total horas de } \\
\text { trabajo }\left(\mathrm{H} / \mathrm{m}^{2}\right)\end{array}$ \\
\hline SATE_EPS10 & $\begin{array}{l}\text { Oficial 1a montador de aislamientos. } \\
\text { Ayudante montador de aislamientos } \\
\text { Oficial 1a revocador } \\
\text { Ayudante revocador. }\end{array}$ & $\begin{array}{l}0.117 \\
0.117 \\
0.86 \\
0.86\end{array}$ & 1.954 \\
\hline CUB_XPS12_grava & $\begin{array}{l}\text { Oficial 1a construcción } \\
\text { Ayudante construcción. } \\
\text { Oficial 1a montador de aislamientos. } \\
\text { Ayudante montador de aislamientos. }\end{array}$ & $\begin{array}{l}0.137 \\
0.137 \\
0.114 \\
0.114\end{array}$ & 0,502 \\
\hline SUELO_MW8 & $\begin{array}{l}\text { Oficial 1a montador. } \\
\text { Ayudante montador. } \\
\text { Oficial 1a pintor. } \\
\text { Ayudante pintor. } \\
\text { Oficial 1a montador de aislamientos. } \\
\text { Ayudante montador de aislamientos. }\end{array}$ & $\begin{array}{l}0.293 \\
0.108 \\
0.170 \\
0.020 \\
0.113 \\
0.113\end{array}$ & 0.817 \\
\hline
\end{tabular}




\subsubsection{Comparación de costes y beneficios}

A continuación se comparan las necesidades de inversión inicial para la rehabilitación residencial a la escala urbana con el potencial de reducción de la demanda de calefacción de la edificación. Para ello se realiza una estimación de los costes de las obras de mejora y se compara con los resultados del cálculo de las pérdidas energéticas generando un modelo que incluye los parámetros característicos de la envolvente después de la rehabilitación. Se estima un periodo de amortización teórico a partir del cociente entre el coste y la reducción de pérdidas obtenida. La intención de esta operación es establecer comparaciones del impacto de las mejoras de distintos tipos de edificación, y no se pretende obtener cifras realistas en cuanto a ahorros económicos.

La herramienta de cálculo diseñada se puede aplicar a cualquier área urbana definida sobre la cartografía del catastro por una poligonal cerrada, a partir del recorte de las referencias catastrales que contiene. Para la validación del proceso y valorar la escala idónea de la intervención y la potencia del método de cálculo, se analizan los resultados a dos escalas: para el Poblado Dirigido de Canillas y también para una superficie urbana mayor, correspondiente al total del área administrativa del Barrio de Canillas (Figura 77).

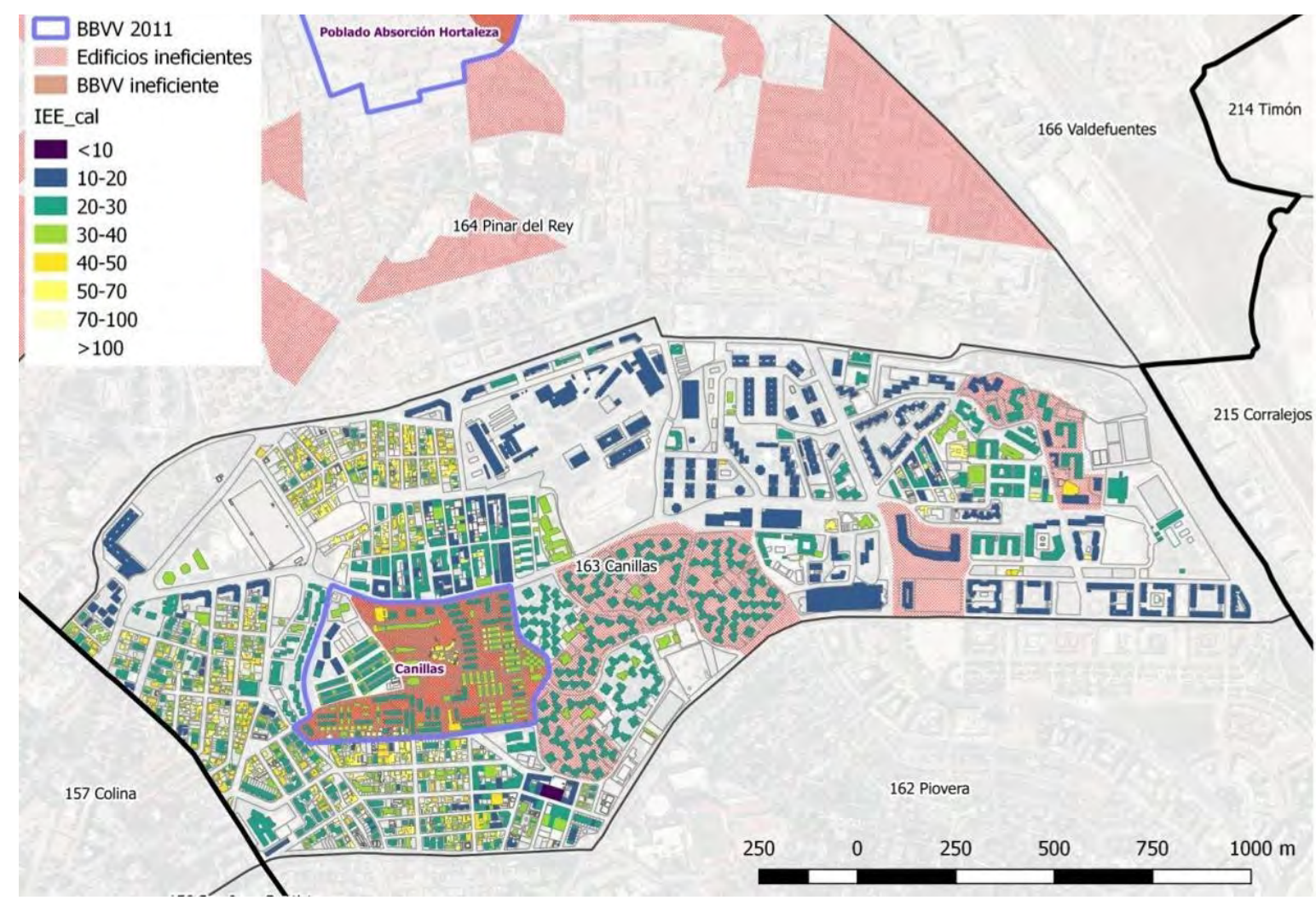

Figura 77. Edificación en el barrio administrativo de Canillas. IEEcal (kWh/m3). Elaboración propia 
La intervención en la envolvente para todos los edificios construidos con anterioridad al año 1979 para la totalidad del barrio administrativo de Canillas, tendría un coste aproximado de 95.104.660 € (Tabla 60). A través de la intervención, se conseguiría una reducción de pérdidas energéticas de $52.844 .024 \mathrm{kWh}$ anuales. Esto significaría, de acuerdo con el mix energético actual en Madrid, una reducción de 63.412.829 kWh al año de energía final y una reducción de 28.905.681 toneladas de $\mathrm{CO}_{2}$ al año, en el caso de demandas satisfechas. Esto significa la reducción del 59\% del total de las pérdidas (140.931.282 kWh) en los edificios intervenidos (1.220 Uds.), lo que se traduce en la reducción del 37\% de las pérdidas totales de energía de la edificación del barrio (2.019 edificios). La operación supone la intervención sobre un área total de envolvente de 1.457.384 $\mathrm{m}^{2}$, incluyendo $808.956 \mathrm{~m}^{2}$ de fachada opaca, $247.170 \mathrm{~m}^{2}$ de cubierta y 2.274 $\mathrm{m}^{2}$ de suelos en contacto con el aire exterior. En la Tabla 60 se representa la cuantificación de la reducción de las pérdidas energéticas mediante la comparación del Estado Actual (Figura 77) con el Estado Reformado a dos escalas y para edificios tipo.

La repercusión de la inversión en la reducción de la demanda de calefacción, para la totalidad de la edificación del barrio de Canillas, presenta una relación lineal con un factor de 0,55 kWh anuales de reducción de pérdidas por cada euro invertido o lo que es lo mismo, la reducción anual de cada kWh supone una inversión de 1,82€ (Figura 78). El edificio en el que la rehabilitación resulta más rentable es el bloque, seguido del unifamiliar y en último lugar la torre.

Tabla 60. Resultados para el total del barrio administrativo de Canillas, para el BBVV del Poblado Dirigido de Canillas, y para cada tipo de edificio. Elaboración propia

\begin{tabular}{|c|c|c|c|c|c|c|}
\hline Escala & $\begin{array}{l}\text { Perdidas EA } \\
\text { (kWh año) }\end{array}$ & $\begin{array}{l}\text { Pérdidas ER } \\
\text { (kWh año) }\end{array}$ & $\begin{array}{l}\text { Reducción } \\
\text { pérdidas (kWh) }\end{array}$ & $\begin{array}{l}\text { Reducción } \\
\text { pérdidas (\%) }\end{array}$ & Coste $(€)$ & $\begin{array}{l}\text { Coste } \\
\text { del } \\
\text { kWh }\end{array}$ \\
\hline Total barrio Canillas & $143,710,318$ & $90,866,294$ & \multirow{2}{*}{$52,844,024$} & 37 & \multirow{2}{*}{$96,013,490$} & \multirow{2}{*}{1.82} \\
\hline Anteriores a 1979 & $89,357,343$ & $36,513,319$ & & 59 & & \\
\hline PD Canillas & $14,220,845$ & $7,094,038$ & \multirow{2}{*}{$7,126,808$} & 50 & \multirow{2}{*}{$12,521,263$} & \multirow{2}{*}{1,76} \\
\hline Anteriores a 1979 PD & $12,012,440$ & $4,885,632$ & & 60 & & \\
\hline $\begin{array}{l}\text { Edificio en torre } \\
\text { 4994547VK4749F }\end{array}$ & 339,075 & $142,924.01$ & 196,151 & 58 & 409,438 & 2,09 \\
\hline $\begin{array}{l}\text { Edificio en bloque } \\
\text { 4992543VK4749D }\end{array}$ & 43,105 & $17,476.77$ & 25,628 & 59 & 43,051 & 1,68 \\
\hline $\begin{array}{l}\text { Vivienda unifamiliar } \\
\text { 5292448VK4759C }\end{array}$ & 10,388 & 4,228 & 6,160 & 59 & 10,589 & 1,72 \\
\hline
\end{tabular}




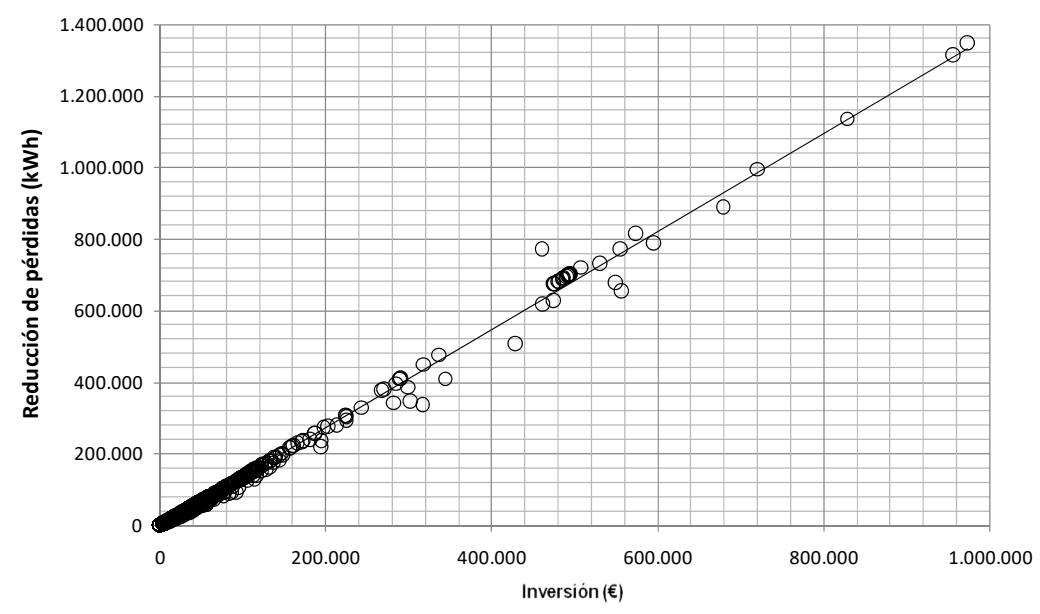

Figura 78. Reducción de pérdidas asociadas al coste de la inversión inicial por edificio. Elaboración propia

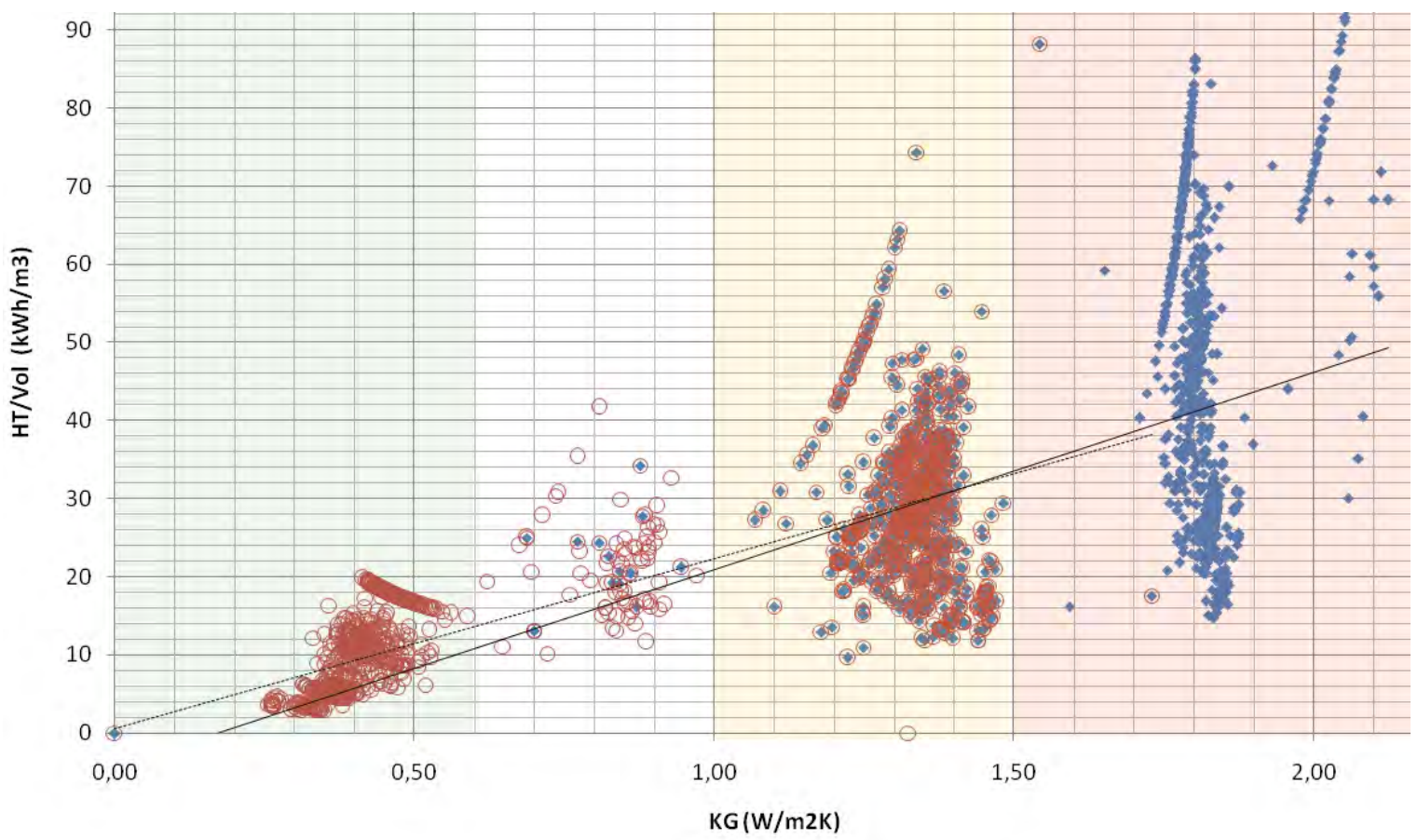

Figura 79. Representación de los coeficientes $\mathrm{K}_{\mathrm{G}}$ contra IEE $\mathrm{E}_{\mathrm{cal}}\left(\mathrm{Q}_{\mathrm{t}} / \mathrm{vol}\right)$ en los 2019 edificios del Barrio de Canillas, antes (azul) y después (rojo) de la rehabilitación. Elaboración propia
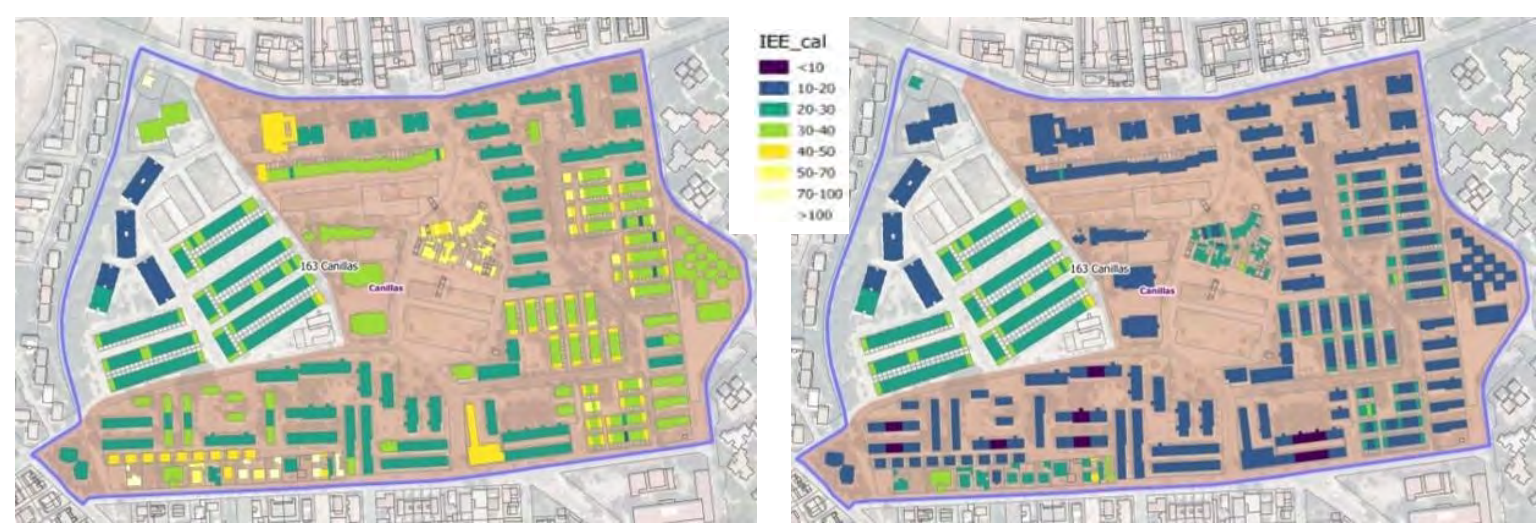

Figura 80. Perdidas por unidad de volumen edificado (IEE $\mathrm{Eal}_{\text {cal }}$ asociadas a la edificación del PD Canillas, antes y después de la rehabilitación. Elaboración propia 
La Figura 79 clasifica todos los edificios del barrio administrativo de Canillas en su Estado Actual, y en aquellos anteriores a 1979 se representa también su Estado Reformado. Se representan los resultados del indicador de eficiencia energética en demanda de calefacción ( $\mathrm{EE}_{\mathrm{cal}}=\mathrm{Q}_{\mathrm{t}} / \mathrm{vol}$ ) clasificados conforme al indicador de la calidad térmica de sus envolventes (Coeficiente Global de Transmisión Térmica $\mathrm{K}_{\mathrm{G}}$ ). Los edificios existentes aparecen representados por un punto y los reformados con un círculo. En este estudio no se ha contemplado la mejora de los edificios posteriores a 1979 y por tanto estos aparecen representados con los dos símbolos (EA=ER).

El análisis de la gráfica permite deducir que la calidad térmica de la envolvente $\left(\mathrm{K}_{\mathrm{G}}\right)$ clasifica claramente los edificios en cuatro grupos. Los edificios anteriores a $1979\left(K_{G}>1.6\right.$ $\mathrm{W} / \mathrm{m}^{2} \mathrm{~K}$ ) son los de peor calidad térmica. Su Indicador de Eficiencia Energética de calefacción varía entre 15 y $90 \mathrm{kWh} / \mathrm{m}^{3}$. Los edificios construidos entre 1979 y 2006 (NBE-CT-79 1979) tienen sus $\mathrm{K}_{\mathrm{G}}$ aproximadamente entre 1 y $1.5 \mathrm{~W} / \mathrm{m}^{2} \mathrm{~K}$ y su $\mathrm{IEE}_{\mathrm{cal}}$ varía entre 10 y $70 \mathrm{kWh} / \mathrm{m}^{3}$. Los edificios construidos durante el periodo de vigencia del CTE $\left(0.6<\mathrm{K}_{\mathrm{G}}<1\right)$ aparecen en la franja blanca $\left(10<\mid \mathrm{EE}_{\mathrm{ca}}<40 \mathrm{kWh} / \mathrm{m}^{3}\right)$. Tras la intervención, la mayor parte de los edificios anteriores a 1979 pasan a ser los de mayor calidad $\left(\mathrm{K}_{\mathrm{G}}<0.6\right.$ $\left.\mathrm{W} / \mathrm{m}^{2} \mathrm{~K}\right)$, variando su $\mathrm{IEE}_{\mathrm{cal}}$ entre 2 y $20 \mathrm{kWh} / \mathrm{m}^{3}$. Las pérdidas energéticas se reducen drásticamente en los edificios intervenidos. A medida que se refuerza la envolvente, se reduce proporcionalmente la variabilidad del $\mathrm{IEE}_{\mathrm{cal}}$. Se puede comprobar, desde el punto de vista del comportamiento bioclimático de la edificación, que la calidad térmica no es el único factor influyente en las pérdidas, pero si se consigue reducir la influencia de otras variables mediante su mejora.

El tamaño de la intervención para todo el barrio administrativo completo es excesivo y supone un coste que se aproxima a los $100 \mathrm{M} €$. La intervención a la escala del poblado dirigido supone el $13 \%$ de la inversión del total del barrio administrativo. Si la operación de rehabilitación energética se circunscribe al ámbito del PD Canillas, se conseguiría una reducción de pérdidas anuales de $7.126 .808 \mathrm{kWh}$, lo que significa el $60 \%$ de las pérdidas de los edificios intervenidos y el $50 \%$ de las pérdidas totales del Poblado. Las emisiones de $\mathrm{CO}_{2}$ se reducirían en 3.898 ton al año. En la Figura 80 se representan los valores del $\mathrm{IEE}_{\text {cal }}$ de cada edificio antes y después de la rehabilitación. Y en la Figura 81 el coste de la inversión por edificio. 

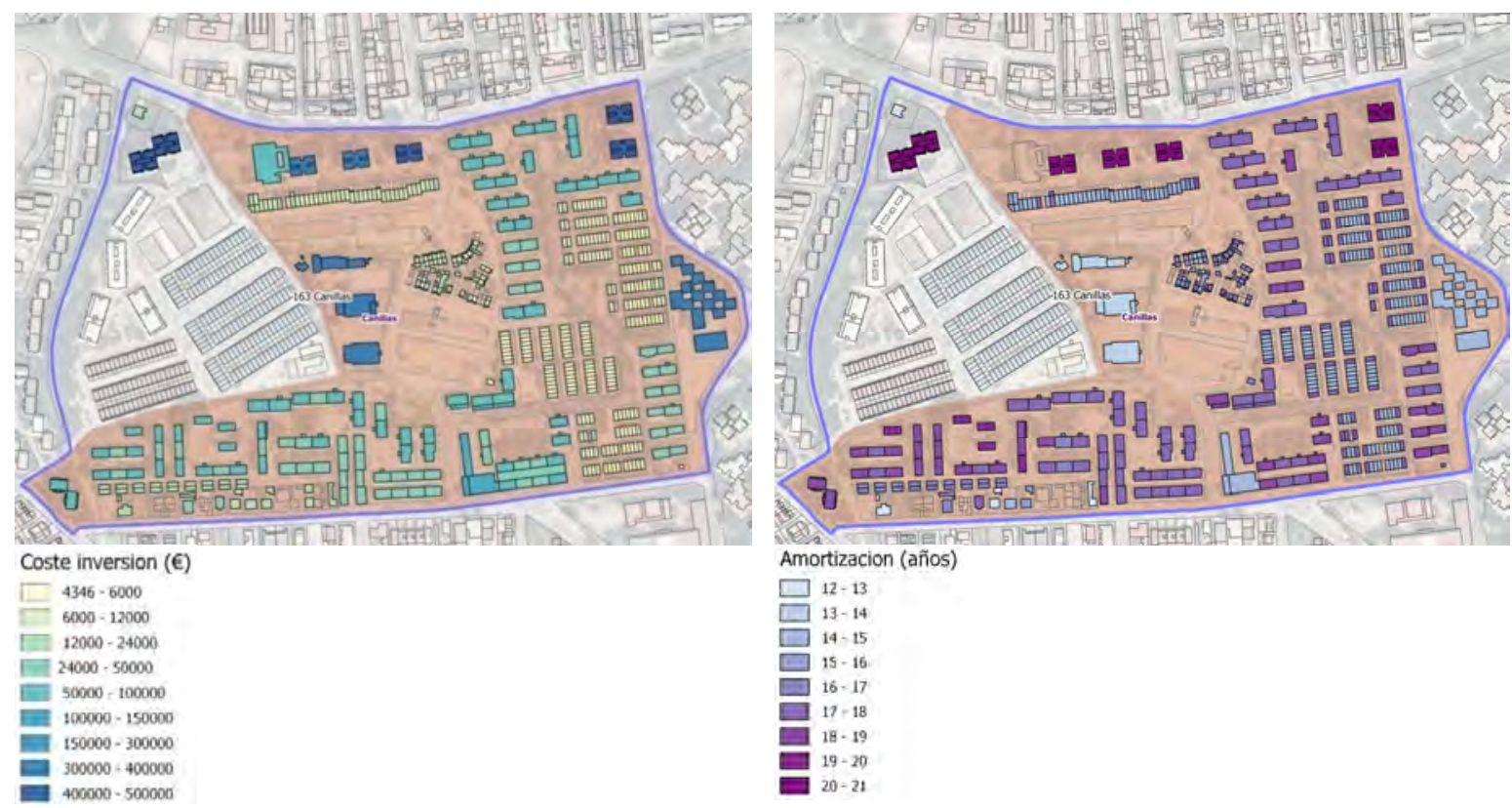

Figura 81. Coste de inversión (€) y periodo de amortización teórico (años) para los edificios intervenidos. Elaboración propia

La escala de la intervención en el ámbito del Poblado Dirigido resulta abarcable para un plan de regeneración del barrio, afectando a 432 edificios construidos con anterioridad a 1979, de los 647 totales del poblado. La superficie total de envolvente intervenida asciende a unos $194.950 \mathrm{~m}^{2}$ (suelos en contacto con el exterior $481 \mathrm{~m}^{2}$, cubiertas $36.447 \mathrm{~m}^{2}$ y fachadas $102.526 \mathrm{~m}^{2}$ ) con un coste de la inversión inicial de $12.521 .263 €$.

En el caso de que las demandas de calefacción de la edificación del barrio fueran satisfechas, La estimación del ahorro en las facturas energéticas ascendería 7.245.329 € anuales, lo que permitiría una amortización de la inversión en 17 años. Este valor corresponde a un escenario estático en el que no hubiera variaciones en el precio de la energía. Los periodos de amortización estimados son coherentes con los de estudios anteriores:

El coste de la inversión inicial de las reformas profundas se puede recuperar completamente tras 20 años de ahorro de energía (con el 5\% de coste de financiación) (Tragopoulos y Sweatman 2012).

Los edificios que más rápido amortizan su inversión son los unifamiliares, que presentan unas peores condiciones de partida. También los edificios terciarios del barrio presentan un periodo de amortización teórico relativamente corto con respecto al resto 
de la muestra. La amortización es en este caso menor en los edificios en los que la cubierta tiene un gran peso respecto del total de la superficie de envolvente (vivienda unifamiliar y terciarios). Esto es así porque se trata de un barrio con cubiertas planas y se ha optado por valorar la solución más económica (del orden de $60 € / \mathrm{m}^{2}$ ). En caso de instalación de cubiertas verdes, o en el caso de que hubiera que intervenir sobre cubiertas inclinadas, el coste de intervención en cubiertas aumentaría y el periodo de amortización subiría. La solución adoptada para la fachada, del orden de $100 € / \mathrm{m}^{2}$, es la que tiene un mayor coste de las adoptadas y por tanto los edificios en torre tienen un mayor periodo de retorno.

La documentación gráfica producida para el estudio de caso del Poblado Dirigido de Canillas se recoge en el Anexo II. 


\section{CAPITULO 4. ANÁLISIS DE RESULTADOS}

El modelo propuesto (MADE) permite identificar los barrios en riesgo de pobreza energética utilizando los resultados de una herramienta estadística (HEEPEC, CAPITULO 2). También permite analizar las causas del problema que van asociadas a la edificación y al urbanismo usando los resultados obtenidos a partir del proceso de datos catastrales (MEPEC CAPITULO 3). De esta manera es posible plantear soluciones desde una óptica integradora que incorpora las problemáticas sociales y la eficiencia energética de la edificación.

En el presente capítulo se analizan los resultados de la investigación para el estudio de caso de Madrid. Para ello se cruzan los datos recopilados en las diferentes escalas del análisis, desde la ciudad hasta el edificio, para establecer conclusiones acerca de las posibilidades de solución al problema de la vulnerabilidad energética causada por la edificación, para la reducción de la pobreza energética. Estas soluciones se plantean desde una lógica bioclimática priorizando la actuación en la envolvente para reducir la demanda energética de los edificios obsoletos en barrios vulnerables y enfrentar así el problema de la dependencia energética. 


\section{CAPÍTULO 4. ANÁLISIS DE RESULTADOS}

Esta parte del trabajo se centra en la comprobación y análisis comparado de los datos de salida del MADE, aplicado a una serie de barrios vulnerables e ineficientes que han sido seleccionados en el CAPITULO 2. El análisis de los resultados obtenidos se realiza en cuatro etapas:

- En primer lugar se analizan los datos en bruto del estado actual de la edificación de los 11 barrios vulnerables de Madrid con mayor puntuación en el índice multidimensional de riesgo de pobreza energética (IMPE) (Figura 82, Tabla 62). Se visualizan estos barrios a través de su indicador de eficiencia en demanda de calefacción, y se caracterizan las necesidades de cada uno a través de la selección de una serie de variables influyentes.

- En segundo lugar se analiza la demanda energética de la edificación residencial de los barrios que contienen tejidos de morfología homogénea que son característicos de la periferia urbana de Madrid. Para una clasificación general de la morfología urbana de estos tejidos se utiliza la información del Plan General de Ordenación Urbana (Ayuntamiento de Madrid 1997) que regula las normas que son de aplicación en cada área.

- Seguidamente se formula un escenario mejorado que contempla la rehabilitación de la envolvente opaca de los edificios residenciales anteriores al año 1979. Se analizan los costes y beneficios de la operación.

- Para finalizar, se comparan los resultados de demanda de calefacción obtenidos mediante la herramienta HEEPEC usando datos estadísticos y simulación energética (Apartado 2.1) con el método detallado MEPEC, que utiliza datos catastrales y la norma (ISO 13790 2008) (Apartado 3.2). Para la validación de los resultados de la estimación estadística se agrupan los datos catastrales correspondientes a las secciones censales de cada barrio.

La explotación de los resultados de cada fase se vuelca en fichas de barrio que resumen la información de distintos aspectos medioambientales, sociales y económicos de la operación, permitiendo valorar soluciones integrales al problema de la ineficiencia energética. Estas fichas se recogen en el Anexo III. 


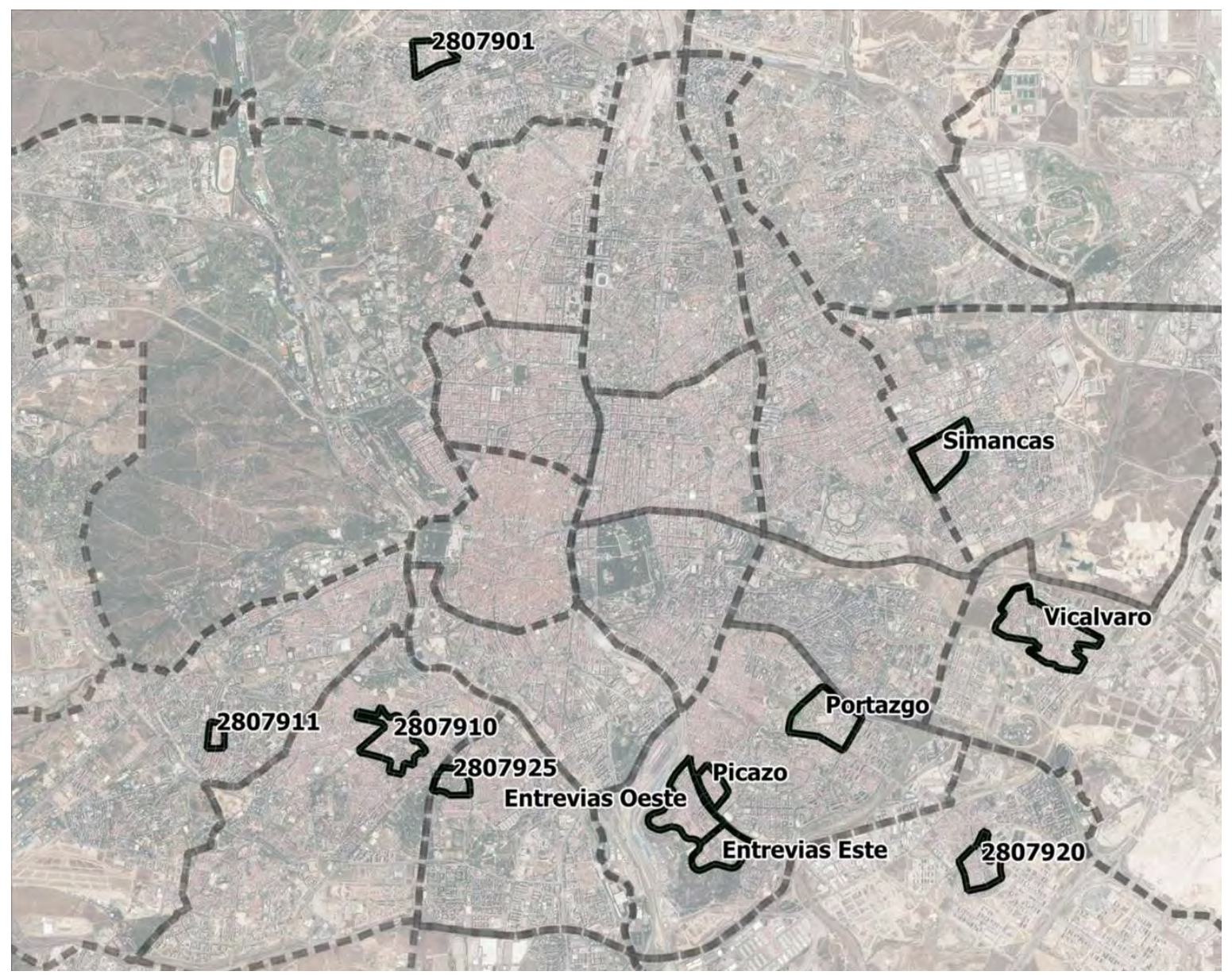

Figura 82. Ubicación de la muestra de 11 barrios en riesgo crítico de pobreza energética. Elaboración propia 


\subsection{CARACTERIZACIÓN TÉRMICA DE LOS BARRIOS EN RIESGO DE POBREZA ENERGÉTICA}

Para la comprobación del método se toma una muestra de barrios vulnerables que presentan un mayor índice de riego de pobreza energética de acuerdo con el análisis multidimensional del Apartado 2.2.2. Se extraen del modelo los resultados obtenidos a partir de los datos de salida. El procedimiento diseñado permite ampliar la escala del análisis de la sección censal (a partir de datos estadísticos) a la de la edificación (a partir de los datos catastrales) y poner toda la información en relación.

La agregación de los datos catastrales al modelo permite caracterizar pormenorizadamente la eficiencia energética de la envolvente térmica de los edificios de los barrios seleccionados en lo que respecta a las pérdidas por transmisión. Para ello se recopilan una serie de indicadores obtenidos mediante la herramienta MEPEC. Estos indicadores son variables influyentes en la demanda de calefacción y son necesarias para una estimación simplificada de la misma.

Tabla 61. Variables utilizadas para la caracterización energética de barrios. Elaboración propia

\begin{tabular}{|c|c|c|}
\hline Variable & Descripción & Unidades \\
\hline anho & Año de construcción & \\
\hline AREAtot & Superficie ocupada & $\mathrm{m}^{2}$ \\
\hline VOL_EDIF & Volumen edificado & $m^{3}$ \\
\hline A_CON & Superficie construida & $\mathrm{m}^{2}$ \\
\hline ALT_MED & Altura media de la edificación & $\mathrm{m}$ \\
\hline N_PLA & Número medio de plantas & no \\
\hline A_ENV_TOT & Área de envolvente total & $m^{2}$ \\
\hline KG & Coeficiente global de transmisión térmica & $\mathrm{W} / \mathrm{m}^{2} \mathrm{~K}$ \\
\hline P_KW & Pérdidas energéticas totales por conducción & kWh año \\
\hline A_HAB & Superficie habitable & $\mathrm{m}^{2}$ \\
\hline VIVIENDA & Superficie habitable de vivienda & $\mathrm{m}^{2}$ \\
\hline IEEurb & Indicador de eficiencia energética en demanda de calefacción & $\mathrm{kWh} / \mathrm{m}^{3}$ año \\
\hline COMP & Compacidad & $\mathrm{m}^{3} / \mathrm{m}^{2}$ \\
\hline radTOTanual & Radiación total sobre la envolvente al año & kWh año \\
\hline pasTOTinv & Radiación solar pasiva total captada a través de huecos & kWh año \\
\hline
\end{tabular}


Para la extracción de todas las referencias catastrales contenidas en los barrios a analizar, se ha utilizado como capa de recorte la delimitación de los barrios y áreas estadísticas vulnerables correspondientes al catálogo de barrios vulnerables de 2011 (Agustín Hernández Aja et al. 2018). Se seleccionan barrios con edificación ineficiente que tienen el mayor riesgo de pobreza energética en el IMPE (Apartado 2.2.2). Para el caso del Área Estadística Vulnerable 2807911, en el barrio de Aluche, se ha modificado la delimitación existente en el catálogo, ampliándola para incluir tejidos de características similares. El AEV 2807910, en el barrio de Opañel, tiene una delimitación que no resulta clara. En ella los indicadores de pobreza energética aparecen dispersos y solamente se solapan en un área reducida. Los datos de su edificación se han utilizado para el análisis general de la muestra, pero se desestima este ámbito para el análisis pormenorizado

\subsubsection{Análisis general de áreas afectadas}

Para lograr una visión general se analizan los datos en bruto de la muestra estadística extraída del modelo. Se procesan los 11 barrios vulnerables con mayor riesgo de Pobreza Energética (Tabla 62). Según los datos estadísticos, estos contienen una población de 114.380 habitantes (aproximadamente el 4\% del total de Madrid) (INE 2011). En estos barrios existen un total aproximado de 54.845 viviendas, de las cuales 46.740 son principales (el $85 \%$ del total). Según el Censo de 2011, en la ciudad, de las 1.530 .957 viviendas totales alrededor del $86 \%$ de ellas son principales: 1.320.531. La población en Madrid es de 3.198.645 habitantes y el tamaño medio del hogar es de 2,42 habitantes por vivienda. En los 11 barrios en riesgo de pobreza energética, el tamaño medio del hogar es de 2.45 hab/viv., superando ligeramente los valores municipales. Se recopilan datos de vivienda totales y principales. Se considera que las viviendas principales son las que albergan a la población (hogares). Para la estimación de las necesidades de rehabilitación a escala de barrio se tiene en cuenta el número total de viviendas, incluidas las clasificadas como secundarias y viviendas vacías.

Los barrios de los que se tiene información corresponden a crecimientos periféricos urbanos, en gran parte son promociones públicas de los años 1940 a 1960, otros pertenecientes a poblaciones anexionadas (Vicálvaro y Villa de Vallecas), tejidos anteriores de parcelación periférica y alguna promoción privada del 1975 al 1990. 
Tabla 62. Población y viviendas en los 11 barrios analizados (Hernández Aja et al., 2018)

\begin{tabular}{|c|c|c|c|c|c|c|c|}
\hline Distrito & Barrio admin & DENBV & CODBV & F_CREC & РОВ & VIVS & V_PR \\
\hline 8 & Peñagrande & 2807901 & 2807901 & Prom. 60-75 & 3,805 & 1,955 & 1,715 \\
\hline 10 & Aluche & 2807911 & 2807911 & Prom. 60-75 & 4,920 & 2,250 & 1,935 \\
\hline 11 & Opañel & 2807910 & 2807910 & Periferia mixta & 14,160 & 7,230 & 5,985 \\
\hline 12 & Zofío- Moscardó & 2807925 & 2807925 & Ciudad jardín & 4,280 & 2,150 & 1,785 \\
\hline 13 & Entrevías & Entrevías Este & 28079041 & Prom. Pub 40-60 & 7,875 & 3,585 & 2,875 \\
\hline 13 & Entrevías & Entrevías Oeste & 28079042 & Prom. Pub 40-60 & 16,270 & 7,680 & 6,730 \\
\hline 13 & San Diego & Picazo & 28079048 & Par. Perif & 9,585 & 4,625 & 4,005 \\
\hline 13 & Portazgo & Portazgo & 28079056 & Prom. priv 75-90 & 10,105 & 5,085 & 4,165 \\
\hline 18 & Villa de Vallecas & 2807920 & 2807920 & Pueblo anexionado & 10,410 & 4,560 & 4,140 \\
\hline 19 & Vicálvaro & Vicálvaro & 28079038 & Pueblo anexionado & 25,005 & 11,345 & 9,890 \\
\hline 20 & Simancas & Simancas & 28079077 & Prom. Pub 40-60 & 7,965 & 4,120 & 3,515 \\
\hline TOTAL & & & & & 114,380 & 54,585 & 46,740 \\
\hline $\begin{array}{l}\text { Leyenda: } \\
\text { DENBV } \\
\text { POB }\end{array}$ & $\begin{array}{l}\text { enominación de barrio vv } \\
\text { oblación }\end{array}$ & $\begin{array}{l}\text { COL } \\
\text { VIV }\end{array}$ & $\begin{array}{l}\text { Código } \\
\text { Viviend }\end{array}$ & $\begin{array}{l}\text { rrio vulnerable } \\
\text { ales }\end{array}$ & $\begin{array}{l}\text { :CREC } \\
\text { IPR }\end{array}$ & $\begin{array}{l}\text { na de crecin } \\
\text { endas princi }\end{array}$ & $\begin{array}{l}\text { iento } \\
\text { oales }\end{array}$ \\
\hline
\end{tabular}

Tabla 63. Estadísticos descriptivos para 15 variables de 6808 edificios en 11 barrios vulnerables. Elaboración propia

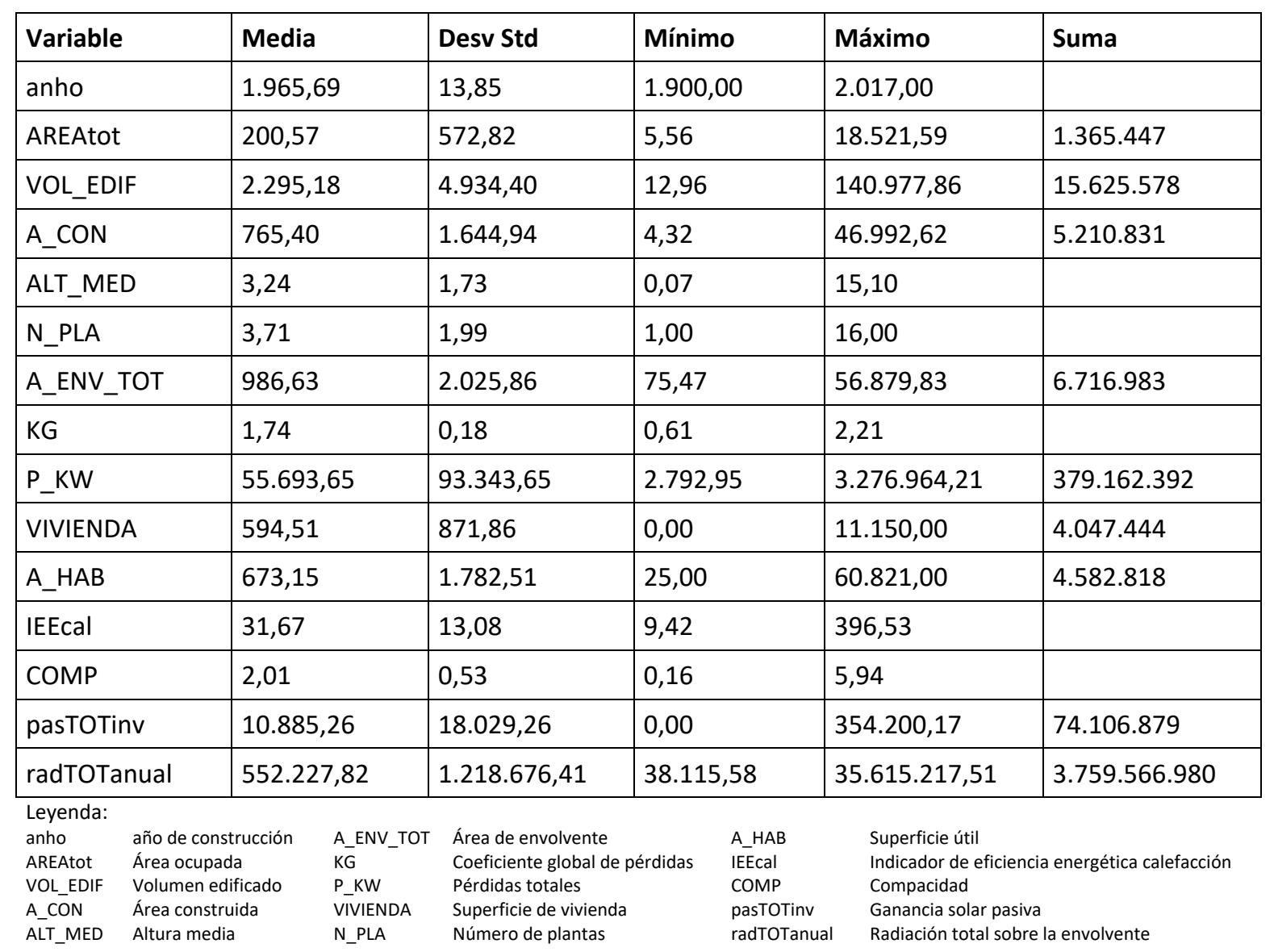


Se agregan al Modelo de Análisis de Datos Espaciales los datos de salida arrojados por la herramienta MEPEC. La visualización en el plano vectorial ofrecido en la Oficina Virtual del Catastro de la distribución espacial de las variables permite la comprobación de la coherencia de los cálculos. Para el análisis de los datos de muestreo se ha utilizado el programa de software libre PSPP 1.2.0-g0fb4db, de GNU GENERAL PUBLIC LICENSE Copyright (C) 2007 patrocinado por Free Software Foundation, Inc. En concreto, para este análisis general, se ha empleado las funcionalidades de estadística descriptiva.

La muestra comprende un total de 6808 edificios, correspondientes a los usos registrados en el catastro como habitables y por tanto con necesidades de acondicionamiento térmico. El año de construcción oscila entre 1900 y 2017, con la media en el año 1966. Por esta razón se puede suponer que los barrios en riesgo de pobreza energética contienen una gran cantidad de edificación sin aislamiento térmico: en concreto los resultados arrojan que un total de 5,800 edificios, el $85 \%$ de la muestra, fueron construidos con anterioridad al año 1979. Este valor queda sensiblemente por encima de la media de la ciudad de Madrid, que en el censo de 2011 registró un 68\% de edificios residenciales anteriores a 1979. Este resultado permite corroborar la hipótesis de que la población en riesgo de pobreza energética habita mayoritariamente en los barrios con la edificación más ineficiente y mayores necesidades de rehabilitación.

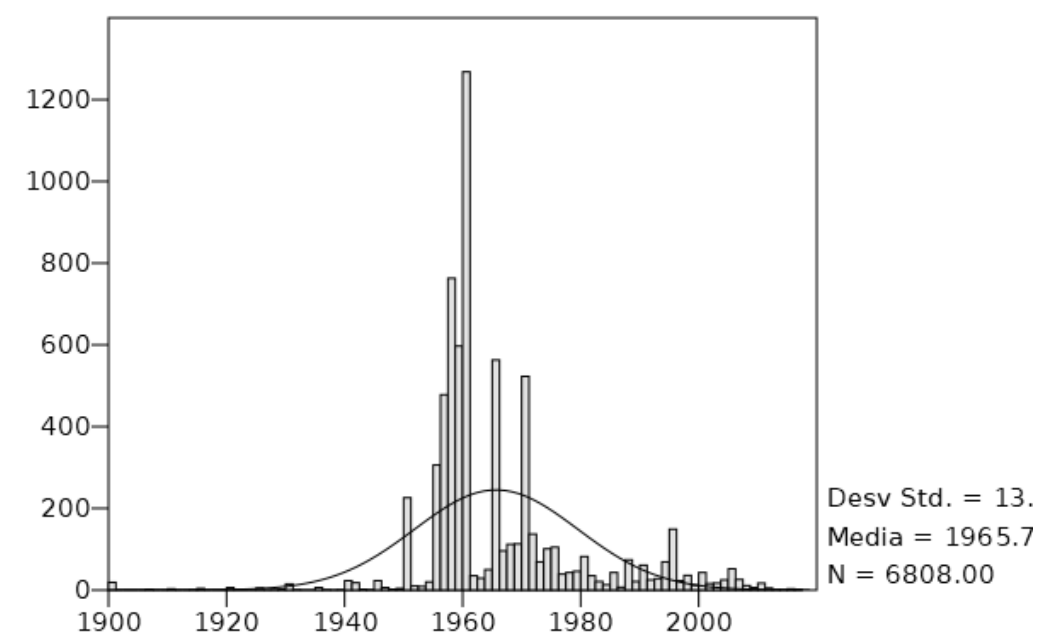

Figura 83. Histograma de frecuencias de la variable "año de construcción" de la edificación de la muestra. Elaboración propia 


\section{CAPÍTULO 4. ANÁLISIS DE RESULTADOS}

Los gráficos que relacionan la variable "año de construcción" con otras variables (superficie de vivienda, altura media, compacidad, coeficiente global de pérdidas $\mathrm{K}_{\mathrm{G}}$, indicador de eficicencia energética $\mathrm{IEE}_{\mathrm{cal}}$ y radiación solar pasiva) demuestran que se trata de una variable influyente en todas ellas excepto en la radiación solar pasiva. Resulta especialmente influyente en el $\mathrm{K}_{\mathrm{G}}$, superficie, altura y en el IEE $\mathrm{E}_{\mathrm{cal}}$ (Figura 84).

La edificación contiene una superficie construida total de $5.210 .831 \mathrm{~m}^{2}$, y su superficie acondicionada es de $4.582 .818 \mathrm{~m}^{2}$ de los cuales $4.047 .444 \mathrm{~m}^{2}$ corresponden al uso vivienda (88\%). Se trata de barrios principalmente residenciales. La superficie media de la huella de la edificación en planta de los edificios es de $200 \mathrm{~m}^{2}$, la superficie construida media de $765 \mathrm{~m}^{2}$ y el área habitable media de $673 \mathrm{~m}^{2}$, de los cuales la superficie habitable residencial es de $595 \mathrm{~m}^{2}$ (88\%).
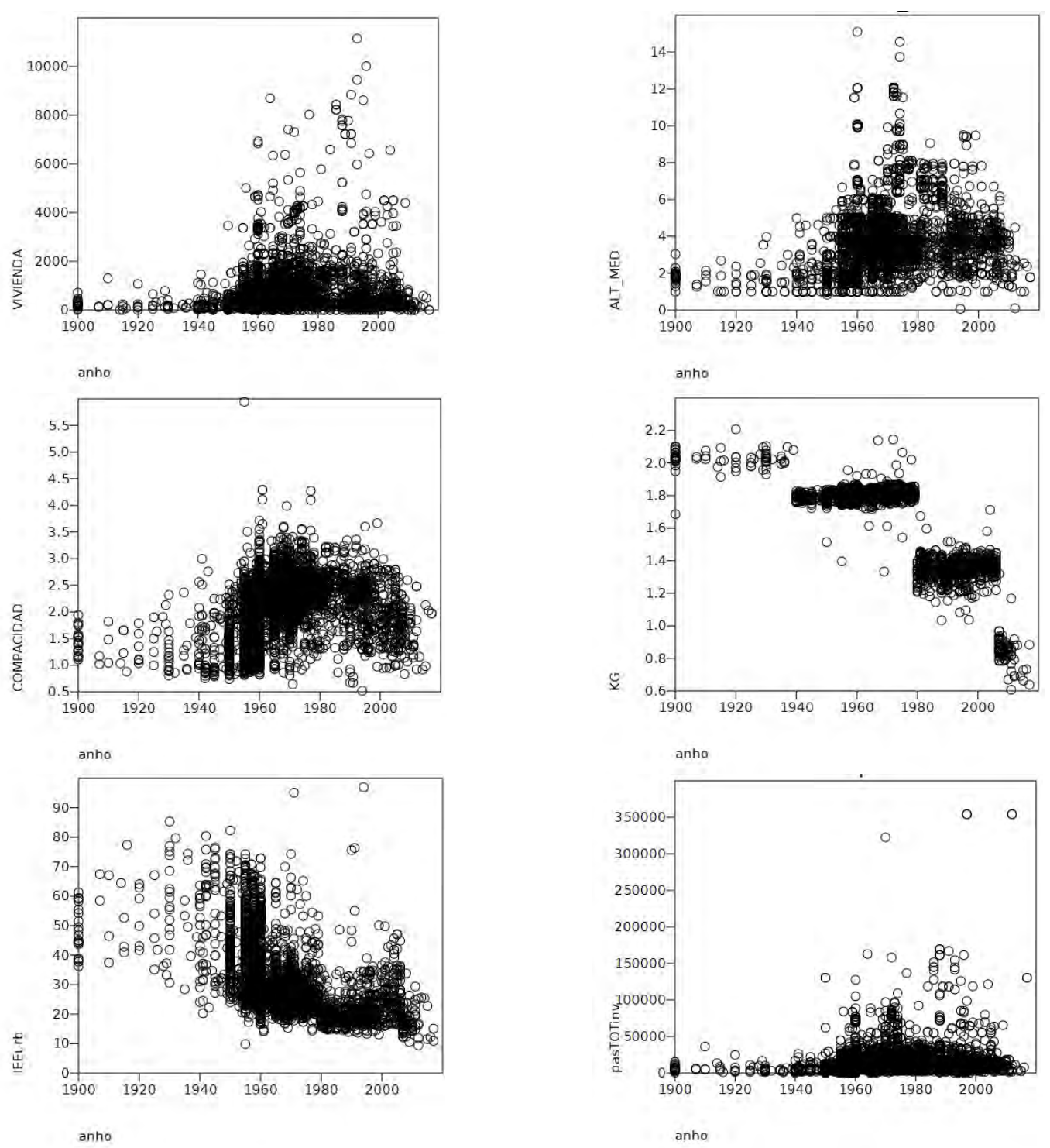

Figura 84. Gráficos de puntos de año de construcción contra las variables VIVIENDA, ALT_MED, COMP, KG, IEE y pasTOTinv para los 11 barrios. Elaboración propia 

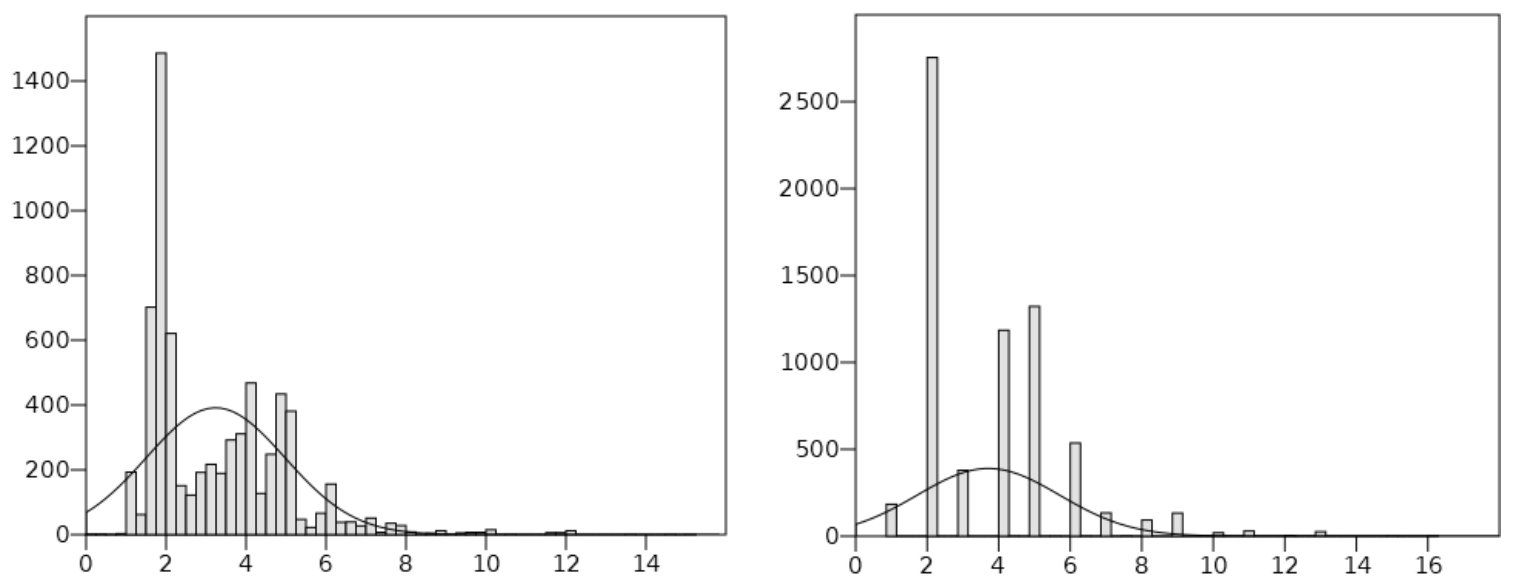

Figura 85. Histograma de frecuencias de las variables (1) altura media y (2) número de plantas. Elaboración propia

Para la estimación de la altura media de la edificación (ALT_MED) la herramienta prorratea la altura de cada uno de los volúmenes que componen cada edificio por la superficie de su huella en planta. Se ha utilizado una altura entre forjados de $3 \mathrm{~m}$ y $2.70 \mathrm{~m}$ de altura libre entre forjados. Se obtiene que la altura media de la edificación es de 3.24 plantas (Figura 85). La tipología de la edificación de estos barrios comprende un gran número de edificios de poca altura, que se corresponden en su mayor parte con viviendas unifamiliares y un grupo menos numeroso de edificios terciarios. Un grupo también muy numeroso de edificios de 4-5 plantas correspondientes a viviendas en bloque multifamiliar, que contienen múltiples viviendas. Los edificios en altura son menos numerosos, siendo la altura máxima de 16 plantas. La estructura de la información contenida en los datos catastrales no permite estimar con fiabilidad el número de viviendas. En este estudio los datos de vivienda se incorporan a la escala de la sección censal a partir del censo de 2011 utilizando los datos volcados por HEEPEC en el MADE (Tabla 62).

El área de envolvente total es de $6.716 .983 \mathrm{~m}^{2}$ con un valor medio del Coeficiente Global de Transmisión Térmica $\left(\mathrm{K}_{\mathrm{G}}=1,74 \mathrm{~W} / \mathrm{m}^{2} \mathrm{~K}\right)$, lo que refleja una mala calidad térmica de la edificación generalizada, correspondiente en su mayor parte a edificios sin aislamiento térmico en su envolvente (Figura 82). Esto se traduce en grandes pérdidas energéticas por transmisión (333.662.905 kWh anuales). La compacidad media de la edificación de estos barrios es de $2 \mathrm{~m}^{3} / \mathrm{m}^{2}$, con un indicador de eficiencia energética de calefacción ( $\left(\mathrm{EE}_{\mathrm{cal}}\right)$ de $32 \mathrm{kWh}$ de pérdidas anuales por cada $\mathrm{m}^{3}$ de volumen edificado. 


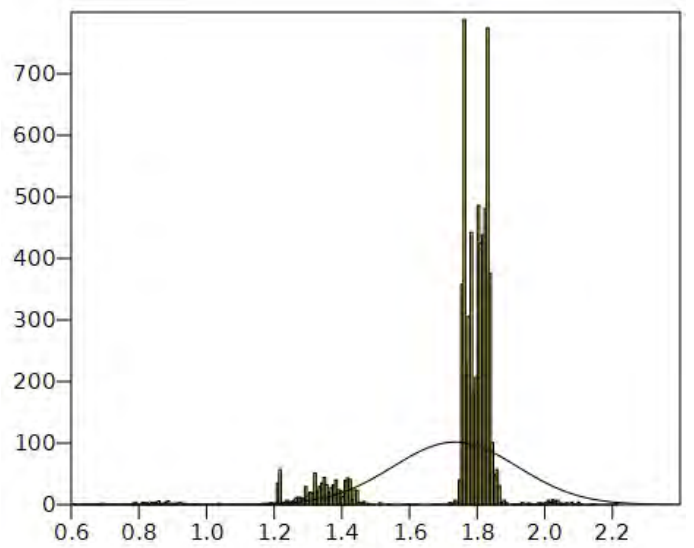

Figura 86. Histograma de frecuencias para el Coeficiente Global de Transmisión Térmica KG. Elaboración propia

La envolvente de la edificación recibe unos 3.312.131 MWh de radiación solar en un año promedio, de la cual el 56\% incidiría durante el invierno (8 meses). La superficie total en cubierta de los barrios analizados es de $1.365 .447 \mathrm{~m} 2$, que estaría recibiendo una radiación solar entorno a los 1.674.430 MWh al año, de la cual el 52\% incide durante el periodo de invierno. El resto de la radiación se recibe en su mayor parte por las fachadas, principalmente orientadas a sur, pero también en menor medida en fachas a este y oeste. De esta radiación se puede estar aprovechando aproximadamente el $2 \%$ en forma de energía solar pasiva a través de las ventanas (65.287kWh).

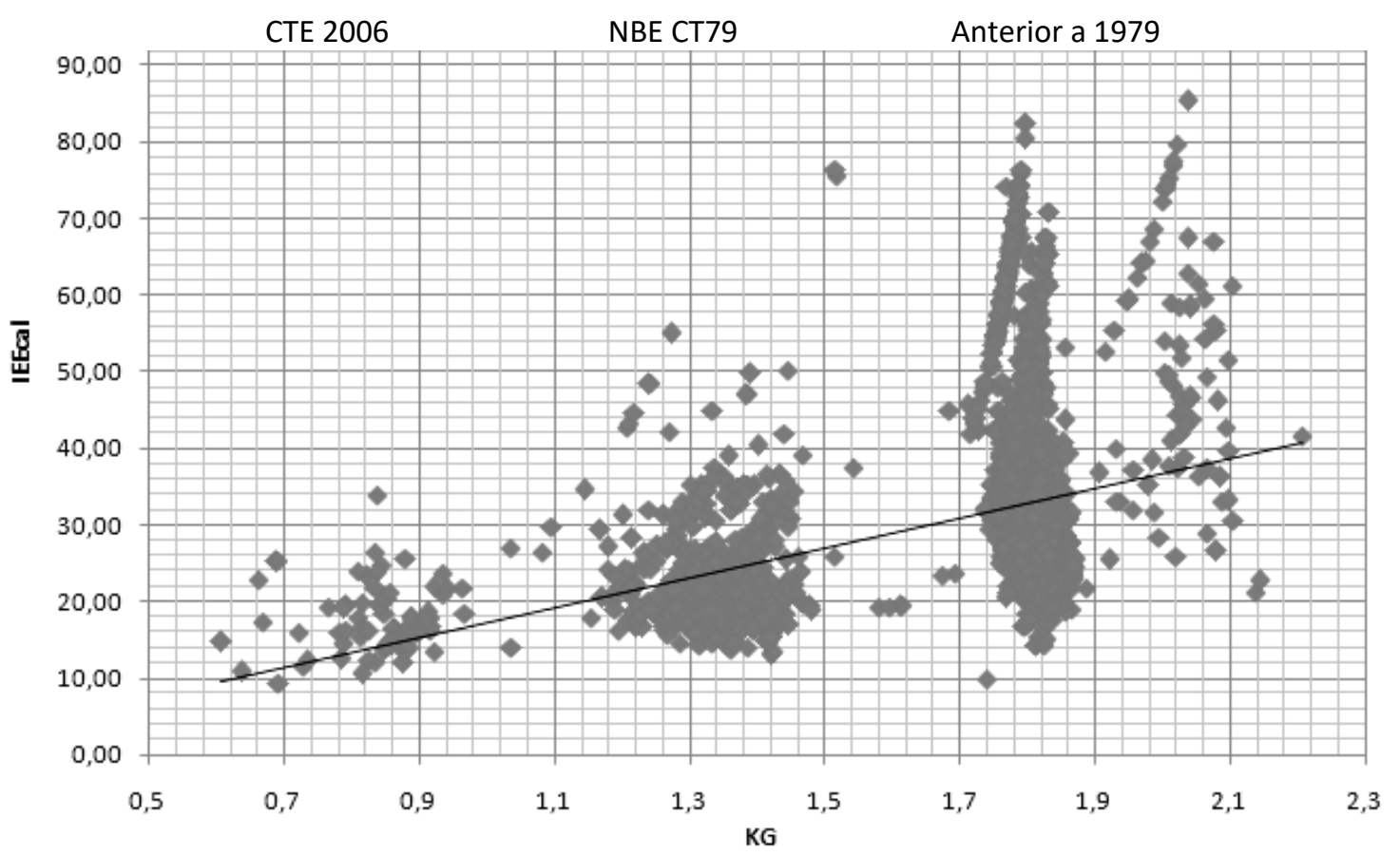

Figura 87. Ploteado de resultados de $\mathrm{K}_{\mathrm{G}}$ contra $I E E_{\mathrm{cal}}\left(\mathrm{Q}_{\mathrm{t}} / \mathrm{V}\right)$ de los 6808 edificios existentes en los 11 barrios analizados. Elaboración propia 


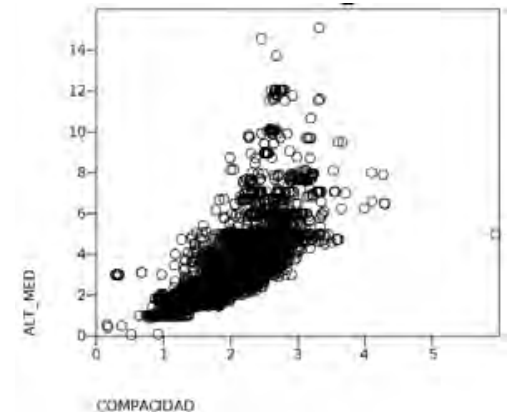

COMPACDAD

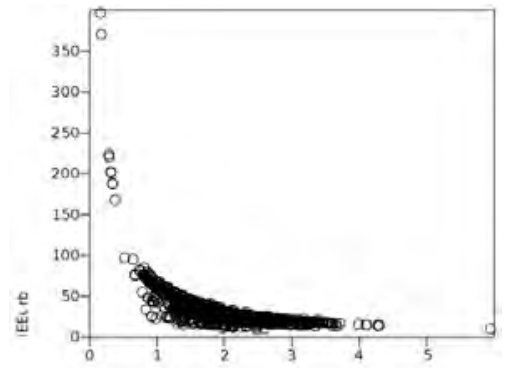

compacidad

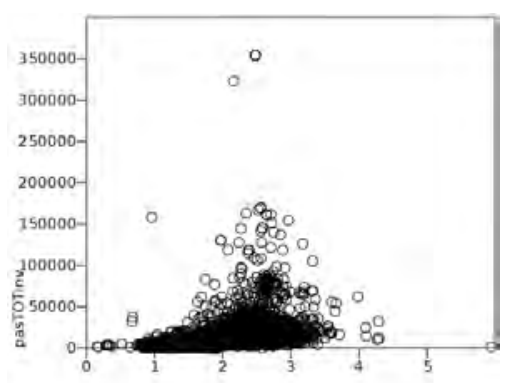

COMPACIOAD

Figura 88. Graficos de puntos de compacidad contra altura media, indicador de eficiencia energetica y radiacion solar pasiva. Elaboración propia

La distribución de las pérdidas energéticas en función de la calidad de la envolvente (Figura 87) presenta un comportamiento similar al del PD Canillas utilizado para la validación de la herramienta MEPEC (Figura 66). Utilizando una muestra mayor se confirma la agrupación de los edificios en tres grandes grupos, según la normativa vigente en el periodo en el que fueron construidos, que reducen la desviación de sus pérdidas energéticas por unidad de volumen a medida que disminuye su coeficiente $K_{G}$.

Se comprueba que el $\mathrm{IEE}_{\mathrm{urb}}$ y la compacidad son excelentes indicadores del comportamiento energético pasivo de los barrios, ya que presentan buen ajuste en sus relaciones (lineales o no) con las variables influyentes en la demanda energética.

\subsubsection{Análisis por barrios}

Se utiliza la misma herramienta estadística para analizar los datos de salida para cada caso particular, de manera que sea posible la comparación entre ellos. Se visualizan los resultados de salida la herramienta MEPEC mediante una herramienta la GIS de software libre (QGIS Desktop). Esta información se cruza con las normas zonales reguladoras de la edificación del planeamiento vigente en Madrid (Ayuntamiento de Madrid 1997) para identificar los tejidos urbanos existentes en cada uno de los barrios analizados. En la Tabla 64 se vuelcan los valores de los resultados de las variables geométricas clasificados para cada uno de los 10 barrios seleccionados (Tabla 62). Los valores máximo y mínimo para cada variable aparecen resaltados. En la Tabla 65 se presentan resultados de variables energéticas y en la Figura 85 se cruza la información del indicador $\mathrm{IEE}_{\mathrm{cal}}$ de cada edificio con las normas zonales. 
Tabla 64. Datos resumen para los 10 barrios: variables geométricas. Elaboración propia

\begin{tabular}{|l|l|l|l|l|l|l|l|}
\hline Barrio & $\begin{array}{l}\text { Área } \\
\left(\mathrm{m}^{2}\right)\end{array}$ & $\begin{array}{l}\text { A_CON } \\
\left(\mathrm{m}^{2}\right)\end{array}$ & $\begin{array}{l}\text { A_HAB } \\
\left(\mathrm{m}^{2}\right)\end{array}$ & $\begin{array}{l}\text { ALTmed } \\
(\mathrm{m})\end{array}$ & $\begin{array}{l}\text { Volumen } \\
\left(\mathrm{m}^{3}\right)\end{array}$ & $\begin{array}{l}\text { A_ENV } \\
\left(\mathrm{m}^{2}\right)\end{array}$ & $\begin{array}{l}\text { COMP } \\
\left(\mathrm{m}^{3} / \mathrm{m}^{2}\right)\end{array}$ \\
\hline Peñagrande & 51.889 & 207.880 & 165.051 & 4,58 & 623.640 & 245.301 & 2,46 \\
\hline Aluche & 33.007 & 197.525 & 185.551 & $\mathbf{5 , 8 8}$ & 592.576 & 200.736 & $\mathbf{2 , 9 1}$ \\
\hline Zofío-Mosc. & 56.604 & 173.072 & 171.086 & 5,27 & 519.216 & 242.097 & 2,12 \\
\hline Entrevías & 95.536 & 327.175 & 293.029 & 2,48 & 981.525 & 475.680 & 1,73 \\
\hline Entrevías & 205.949 & 720.136 & 593.715 & 2,49 & 2.160 .230 & 985.085 & 1,87 \\
\hline Picazo & 91.933 & 297.725 & 225.157 & 3,18 & 893.174 & 407.708 & 2,08 \\
\hline Portazgo & 98.531 & 460.072 & 389.666 & 4,60 & 1.380 .215 & 561.090 & 2,21 \\
\hline $\begin{array}{l}\text { Villa de } \\
\text { Vallecas }\end{array}$ & 104.291 & 421.675 & 347.264 & 3,83 & 1.264 .866 & 526.905 & 2,20 \\
\hline Vicálvaro & $\mathbf{3 5 0 . 3 5 3}$ & $\mathbf{1 . 1 9 3 . 1 8 4}$ & $\mathbf{1 . 1 0 0 . 1 3 4}$ & 3,67 & $\mathbf{3 . 5 7 4 . 7 7 0}$ & $\mathbf{1 . 5 4 6 . 6 7 4}$ & 2,11 \\
\hline Simancas & 126.683 & 555.400 & 474.239 & 3,44 & 1.665 .707 & 715.144 & 1,89 \\
\hline Total & 1.214 .777 & 4.553 .844 & 3.944 .892 & 3,24 & 13.655 .918 & 5.906 .419 & 2,01 \\
\hline
\end{tabular}

Tabla 65. Datos resumen para los 10 barrios: variables energéticas. Elaboración propia

\begin{tabular}{|l|l|l|l|l|l|}
\hline Barrio & Año & $\begin{array}{l}\text { KG } \\
\left(\mathrm{W} / \mathrm{m}^{2} \mathrm{~K}\right)\end{array}$ & $\begin{array}{l}\text { P_KW } \\
(\mathrm{MW} \text { año })\end{array}$ & $\begin{array}{l}\text { IEEcal } \\
\left(\mathrm{kW} / \mathrm{m}^{3}\right)\end{array}$ & $\begin{array}{l}\text { RAD/Vol } \\
\left(\mathrm{kWh} / \mathrm{m}^{3}\right)\end{array}$ \\
\hline Peñagrande & 1965 & 1,78 & 14.121 & 27,11 & 226,55 \\
\hline Aluche & 1965 & $\mathbf{1 , 8 3}$ & 12.383 & 22,13 & 189,39 \\
\hline Zofío- Moscardó & 1961 & 1,79 & 12.981 & 30,56 & 266,50 \\
\hline Entrevías & 1962 & 1,77 & 27.078 & $\mathbf{3 6 , 1 9}$ & $\mathbf{2 6 8 , 4 7}$ \\
\hline Entrevías & 1965 & 1,72 & 55.846 & 32,66 & 252,61 \\
\hline San Diego-Picazo & 1967 & 1,72 & 24.083 & 29,60 & 257,04 \\
\hline Portazgo & 1972 & 1,70 & 30.164 & 28,88 & 221,12 \\
\hline Villa de Vallecas & 1980 & 1,63 & 28.261 & 27,42 & 234,63 \\
\hline Vicálvaro & 1959 & 1,74 & 84.744 & 31,92 & 249,00 \\
\hline Simancas & 1960 & 1,76 & 41.819 & 34,85 & 233,76 \\
\hline Total & 1966 & 1,74 & 331.481 & 31,67 & 242,54 \\
\hline
\end{tabular}

Peñagrande - NZ 3.1.a

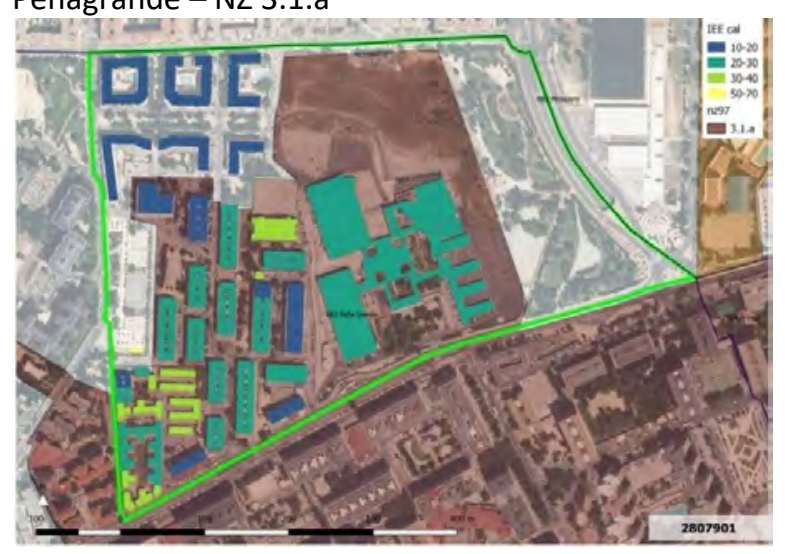

Aluche - NZ 3.1.a

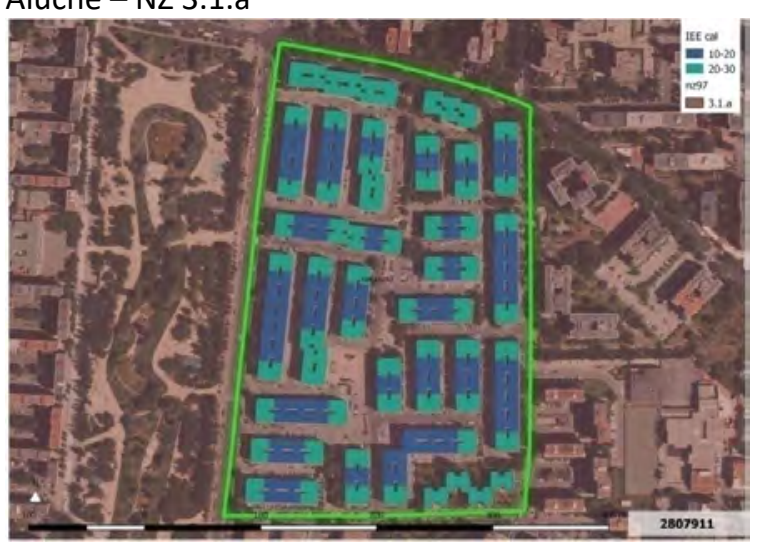


Zofío - Moscardó - NZ 3.1.a

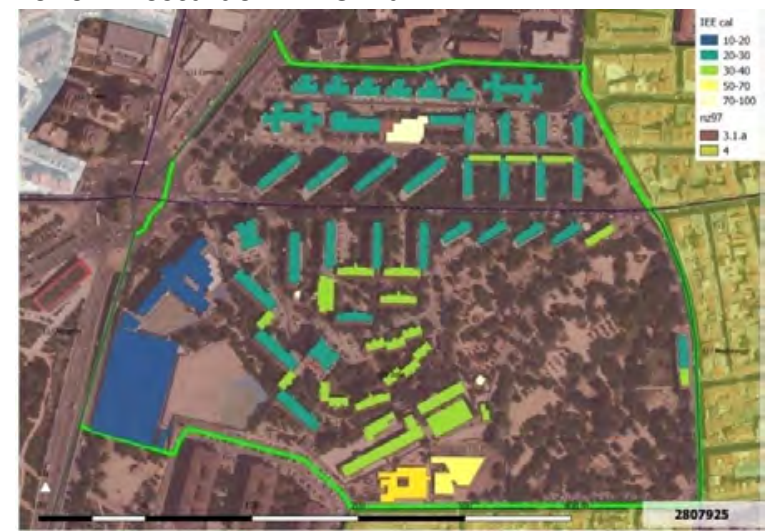

Entrevías Oeste-NZ:3.1.a/4/API-Promo.púb40-60

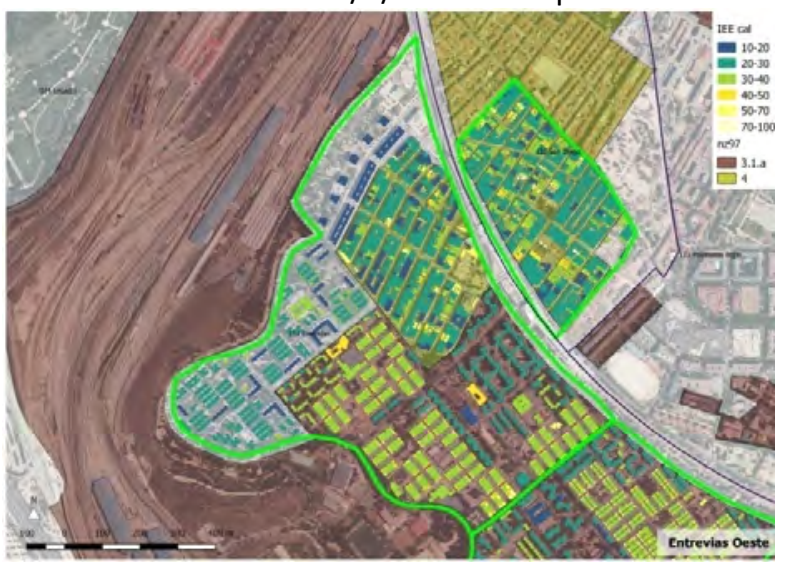

Portazgo - NZ 3.2 - Promoción privada 75-90

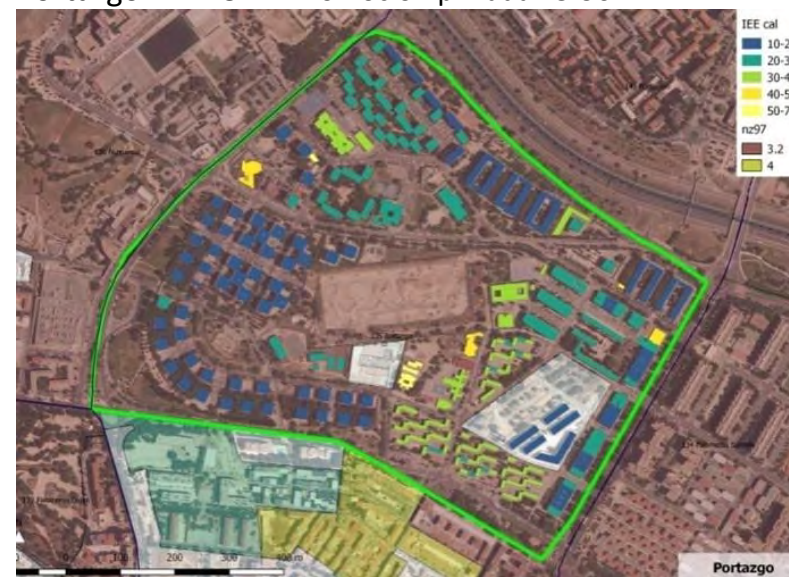

Vicálvaro - NZ 3.1.a / 4 / 8.3 -Pueblo anexionado

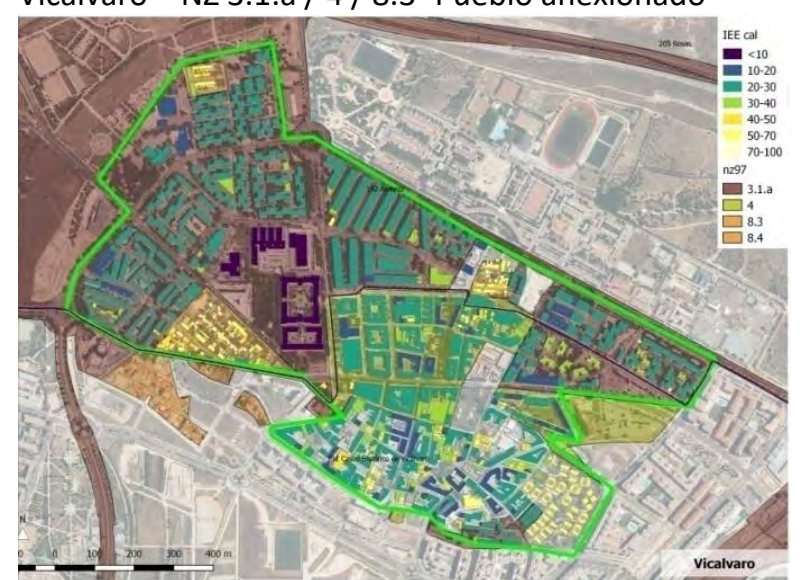

Entrevías Este-NZ 3.1.a- Promoción Publica 40-60

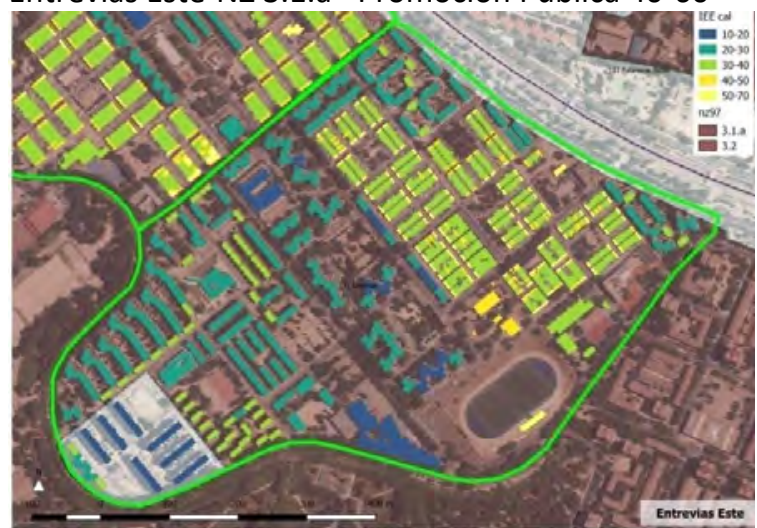

Picazo - San Diego - NZ 4 - Parcelación periférica

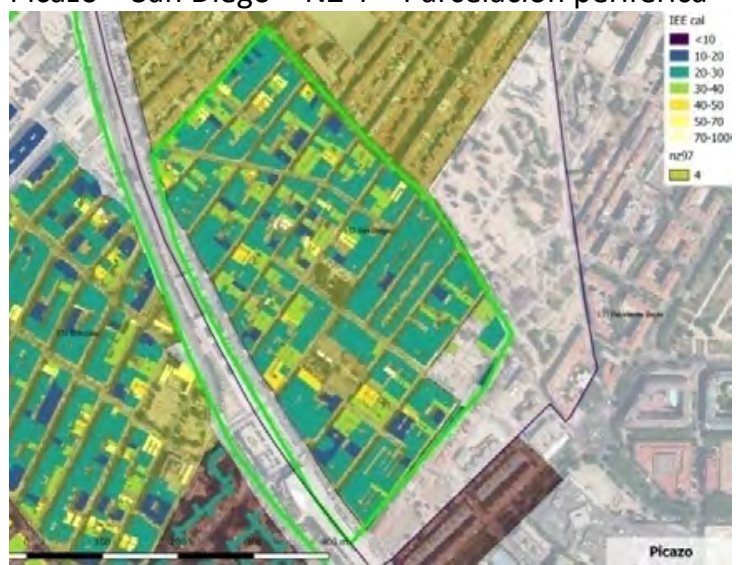

Casco Histórico de Vallecas - NZ 3.1.a / 4

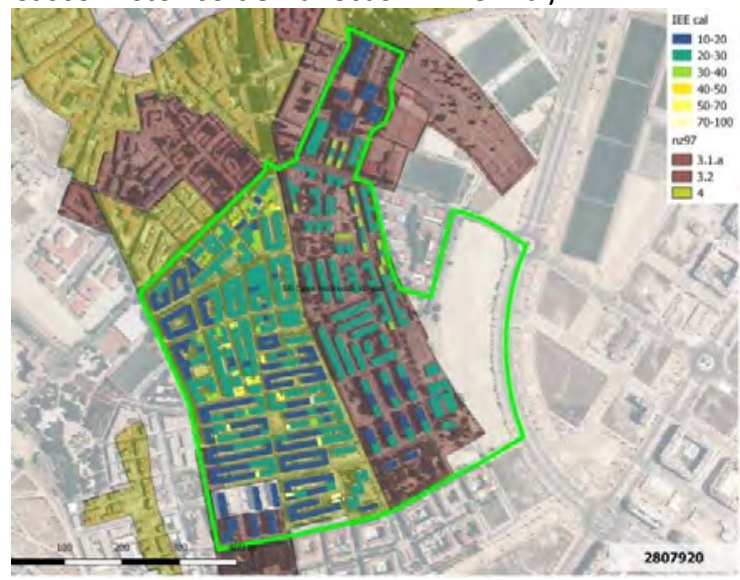

Simancas- NZ 3-1-a / 3.2-Promoción pública 40-60

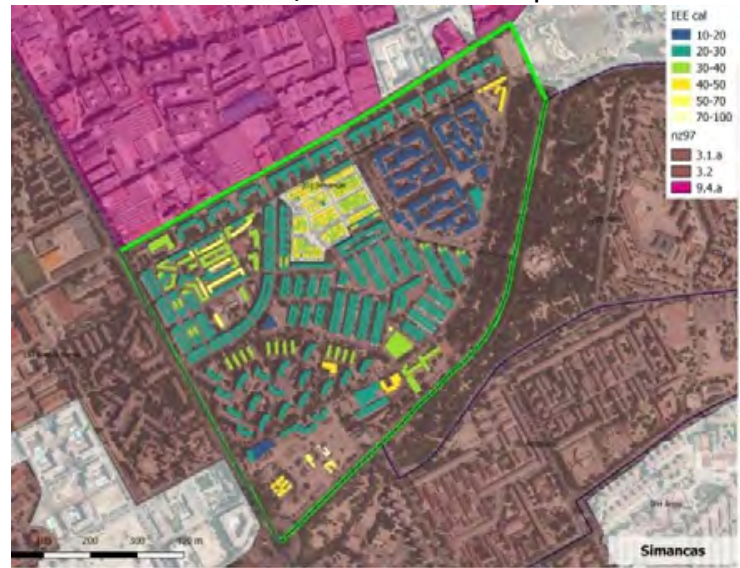

Figura 89. IEEcal y normas zonales en los 10 barrios seleccionados. Elaboración propia 
7 de los 10 barrios se corresponden con áreas homogéneas en la Norma Zonal (Figura 89). En su mayor parte se trata de barrios con morfología de Volumetría Específica (NZ 3.1.a y NZ 3.2), con edificios de bloque abierto. Picazo es la única zona homogénea regulada por la norma de Manzana Cerrada (NZ 4), constituido en su totalidad por tejidos de parcelación periférica. Casco Histórico de Vallecas y Entrevías Oeste presentan tejidos muy variados, con diferentes características. Combinan tejidos regulados por la NZ 3 con otros por la NZ 4. En el casco histórico de Vicálvaro además hay zonas reguladas por la NZ 8. Peñagrande, Entrevías, y Vicálvaro contienen además áreas de planeamiento específico significativas, que se salen de las normas generales.

Los peores valores en el IEEcal se observan claramente en las viviendas unifamiliares. A continuación las áreas reguladas por la Norma Zonal 4 de Manzana Cerrada, debido a que se corresponden en estos barrios con tejidos de parcelación periférica, con edificios medianeros de distintas alturas que generan amplias superficies de envolvente en contacto con el aire exterior. Las zonas de Volumetría Específica, formadas principalmente por tejidos de bloque abierto, presentan la mayor variabilidad en los indicadores de eficiencia energética, dependiendo principalmente a las variables de compacidad (COMP) y calidad de la envolvente (KG).

En el AEV 2807925 (Zofío - Moscardo) se han detectado errores importantes en el registro de los datos catastrales. En concreto, en la capa vectorial se han encontrado fallos en la codificación de las alturas (campo CONSTRU) y en el tipo de construcción (NUMSYMBOL). Estos errores se detectan fácilmente al visualizar los resultados del MADE y establecer su comparación con la imagen de satélite. La herramienta desarrollada aquí permite también detectar estos errores y puede ser útil para la corrección del Catastro.

\subsubsection{Tejidos urbanos característicos de áreas en riesgo de pobreza energética}

Uno de los objetivos del análisis de la eficiencia energética de los barrios es analizar el comportamiento e influencia de la morfología urbana a través del estudio de tejidos representativos de las áreas en riesgo de pobreza energética. En el caso de Madrid, se trata de crecimientos urbanos situados en la periferia urbana. A partir de la muestra de 10 barrios en alto riesgo de pobreza energética, se han seleccionado los barrios que 
contienen tejidos urbanos homogéneos característicos de esta periferia (bloque abierto, poblados dirigidos, parcelación periférica y pueblo anexionado). Tras el análisis de la información detallada, se han seleccionado los siguientes ejemplos:

Tejido de bloque abierto: barrio de Aluche (2807911). Es un barrio con características muy homogéneas. Prácticamente edificado en una única operación, el año de construcción medio es 1965 con poca desviación (3,2 años) en la edad de los edificios. Es el barrio de menor extensión de todos los analizados $(9,38 \mathrm{Ha})$, y se corresponde en su totalidad con un área homogénea de bloque abierto de $20 \mathrm{~m}$ de fondo, con patios interiores (4 viviendas por planta). El ámbito está regulado por la norma zonal de volumetría específica (NZ 3.1.a). Tiene la mayor altura media de todos los barrios (5.88 plantas) y una alta densidad residencial $\left(2,10 \mathrm{~m}^{2} / \mathrm{m}^{2}\right)$, la mayor de la muestra. Todos los edificios son residenciales, contando con escasos servicios dentro del ámbito

Poblado de Entrevías. Con una superficie de 39,46 Ha, representa a los barrios de promoción pública de los años 40-60. La ordenación de la zona de Entrevías es resultado de un plan redactado por Sáenz de Oiza y Sierra para la construcción de dos poblados sociales, uno de absorción y otro dirigido. El Plan Parcial de Entrevías, de 1963, ordena áreas de vivienda de bloque abierto. En el proceso de Remodelación de Barrios, que comienza en los 80, se incorporan el Poblado de Absorción de la Viña (ejecutado en los 90), y la UVA de Entrevías. La normativa es homogénea correspondiente a la NZ 3.1.a. Contiene un área de planeamiento del PGOU vigente (1997) dentro del ámbito “API 13.12 - Entrevías 2". Las áreas del Poblado Dirigido, de estructura racionalista, están compuestas por vivienda unifamiliar de dos plantas en hilera agrupadas en dos hileras enfrentadas con una calle peatonal de acceso. El resto de la trama de Entrevías está formada por bloque abierto lineal y en $\mathrm{H}$. Es el barrio de la muestra con la altura media más baja de la muestra (2,48 plantas) y una baja compacidad $\left(1,73 \mathrm{m3} / \mathrm{m}^{2}\right)$, debido al gran número de viviendas unifamiliares que contiene. La densidad residencial es también la más baja de la muestra, de $0,75 \mathrm{~m}^{2} / \mathrm{m}^{2}$

Parcelación periférica: barrio de Picazo. Se ha elegido este ámbito urbano por ser un barrio conformado por un área homogénea con las características de la parcelación periférica (NZ 4), de 17,46 Ha de superficie. La tipología corresponde a edificación entre medianeras. La trama urbana, muy compacta de manzanas alargadas y calles estrechas 


\section{CAPÍTULO 4. ANÁLISIS DE RESULTADOS}

en pendiente, tiene origen en los crecimientos populares de principios de finales del XIX y principios del siglo XX. A partir de los años 50, Vallecas es anexionado a Madrid y se va sustituyendo la edificación original por edificios de mayor altura (3-4 plantas). Actualmente, el año de construcción medio de la edificación es 1972 y la altura media de 3.2 plantas. Con una densidad residencial de $1,68 \mathrm{~m}^{2} / \mathrm{m}^{2}$, su valor de compacidad urbana, de $2,08 \mathrm{~m}^{3} / \mathrm{m}^{2}$, se sitúa dentro del valor promedio.

Pueblo anexionado: barrio de Vicálvaro. Se trata del barrio vulnerable con edificación más antigua de la muestra (1959). De origen rural, municipio anexionado a Madrid en 1951, en los años 60 sufre un fuerte desarrollo urbanístico. Con $97 \mathrm{Ha}$, es el ámbito de mayores dimensiones estudiado en la muestra: incluye el casco histórico de Vicálvaro, una zona de bloque abierto y la colonia Valderribas, de viviendas pareadas y aisladas, con protección ambiental. Presenta la mayor variabilidad en sus tejidos (NZ 3.1.a, 4 y 8.3) de toda la muestra, además de varias áreas de planeamiento del PGOU vigente (1997). Con una densidad residencial de $0,91 \mathrm{~m}^{2} / \mathrm{m}^{2}$ contiene varias tipologías de vivienda: El casco mantiene la estructura urbana de manzana irregular y calles estrechas propia de su origen rural, alguna persistencia de viviendas unifamiliares de principios del S XX Y bloques de bajo más cuatro alturas construidos a partir de los 60 . 


\subsection{DEMANDA RESIDENCIAL DE CALEFACCIÓN EN LOS TEJIDOS CARACTERÍSTICOS}

Se ofrecen los resultados detallados de las demandas de calefacción de los edificios residenciales de los barrios compuestos por tejidos urbanos homogéneos (Aluche, Entrevías Este, Picazo y Vicálvaro) en su estado actual. Además de las variables recopiladas anteriormente acerca de la envolvente y volumen de toda la edificación de los barrios, para los edificios residenciales se ha podido caracterizar la demanda energética de calefacción introduciendo los patrones de uso promedio para la vivienda, tal y como se desarrolla en el Apartado 3.2.1.

En este punto se depuran los datos que no se corresponden con edificios residenciales. Para limitar la selección a los edificios residenciales se filtran los usos pormenorizados del catastro para seleccionar aquellos registros que contienen valores en la variable VIVIENDA. Ha sido necesario eliminar de forma manual los edificios terciarios en los cuales existe una pequeña proporción de la superficie habitable que está destinada a vivienda. Es el caso, por ejemplo, de los colegios que contienen una vivienda para conserjería. Para la representación de la demanda energética unitaria se considera la superficie habitable total.

\subsubsection{Eficiencia energética en el estado actual}

Para conocer las características más relevantes de cada uno de los tejidos seleccionados, se calculan las correlaciones existentes entre los valores calculados de demanda energética de calefacción y las variables geométricas y energéticas que influyen sobre dicha demanda (Tabla 66). Se obtienen dichas correlaciones para el valor absoluto de la demanda anual total ( $\mathrm{kWh}$ ) (correspondiente a la energía necesaria para el servicio de calefacción durante la temporada de invierno) y para los valores unitarios de demanda energética ponderados por la superficie a acondicionar $\left(\mathrm{kWh} / \mathrm{m}^{2}\right)$. 
Tabla 66. Correlaciones entre la demanda de calefacción total $(\mathrm{kWh})$ y unitaria $\left(\mathrm{kWh} / \mathrm{m}^{2}\right)$ y variables influyentes en tejidos característicos. Elaboración propia

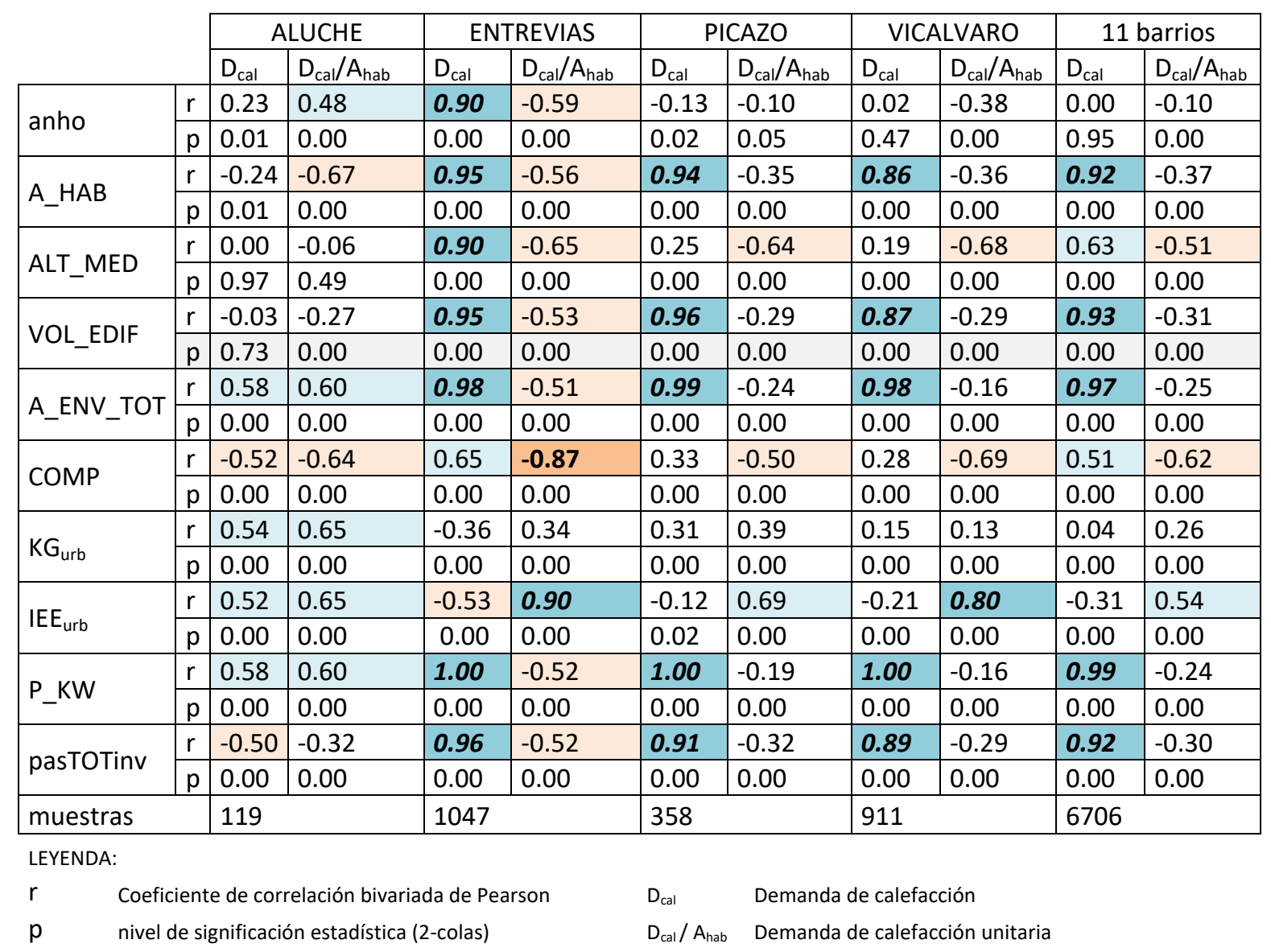

La Tabla 66 representa las correlaciones entre las variables influyentes y la demanda total y unitaria. Las correlaciones significativas aparecen resaltadas con un sombreado de color, más oscuro a medida que aumenta la significación del coeficiente de correlación. Se representan en azul las que presentan correlación directa y en rojo las variables que presentan correlación inversa. Para el total de los diez barrios, las variables que presentan una mayor correlación significativa con la demanda son la compacidad, el IEE $\mathrm{Ial}_{\mathrm{c}}$ (correlación directa) y la altura (correlación inversa), por ese orden.

La variable del coeficiente global de pérdidas energéticas ( $K_{\text {Gurb }}$ ) se suele utilizar habitualmente para caracterizar la eficiencia energética de la edificación a la escala urbana y está directamente relacionada con el periodo de construcción de los edificios. No obstante, solamente presenta niveles de correlación media-alta con la demanda energética unitaria de calefacción en el barrio de Aluche. En el resto de ámbitos, la altura, la compacidad y el $\mathrm{IEE}_{\mathrm{cal}}$ presentan una mayor correlación. EI IEE $\mathrm{E}_{\mathrm{cal}}$ es un excelente 
indicador de la demanda energética unitaria en estos barrios en los que las pérdidas energéticas por transmisión son elevadas, especialmente en Entrevías y Vicálvaro.

En Entrevías, la variable COMPACIDAD presenta alta correlación inversa con la demanda energética, probablemente porque la gran cantidad de edificios de vivienda unifamiliar existentes en el barrio genera una mayor demanda energética unitaria, como indica que la variable altura (ALT_MED) esté fuertemente correlacionada con la demanda de calefacción en este barrio.

La radiación solar pasiva presenta fuerte correlación significativa con la demanda energética total en todos los barrios excepto en Aluche, donde es moderada. En cuanto a la correlación con la demanda energética unitaria, esta es inversa en todos los casos y moderadamente significativa en el caso de Entrevías. Se podría concluir que la captación solar pasiva puede ser una alternativa para compensar las pérdidas energéticas producidas en áreas de edificación de baja compacidad. No obstante, las pérdidas energéticas son el factor más influyente en la demanda en los edificios sin aislamiento térmico. En el barrio del PD Canillas las ganancias solares no llegan al $20 \%$ de las pérdidas por transmisión (Apartado 3.2.5), lo que hace imposible compensar estas pérdidas sin intervenir en la envolvente opaca.

A continuación se describen las características pormenorizadas para algunos barrios vulnerables que presentan alto riesgo de pobreza energética (valor 5 en el Índice Multidimensional de pobreza energética). Se han seleccionado aquellos barrios que presentan una morfología uniforme, representativa de los tejidos característicos de la periferia urbana (Aluche, Entrevías Este, Picazo y Vicálvaro). Se presentan los resultados del balance energético y la demanda de calefacción. Para el caso de Aluche se presenta también como ejemplo la ficha de salida del MADE correspondiente a los resultados de barrio (Figura 92). Las fichas de barrio de los cuatro casos de estudio se pueden consultar en el ANEXO III. 


\subsubsection{Aluche - Tejido de bloque abierto}

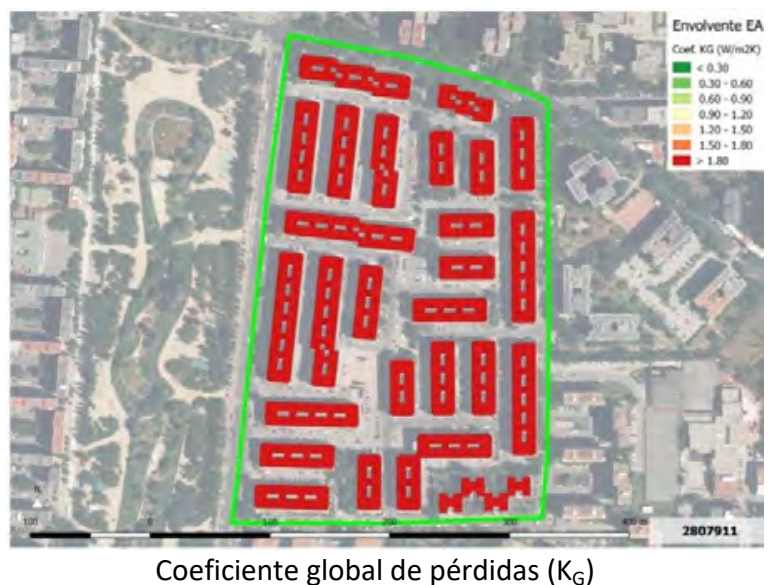

Coeficiente global de pérdidas $\left(\mathrm{K}_{\mathrm{G}}\right)$

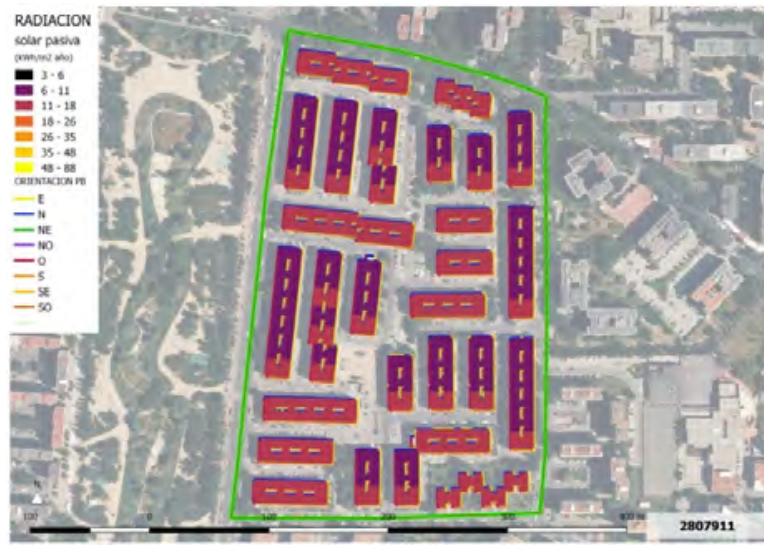

Radiación solar pasiva por unidad de superficie habitable
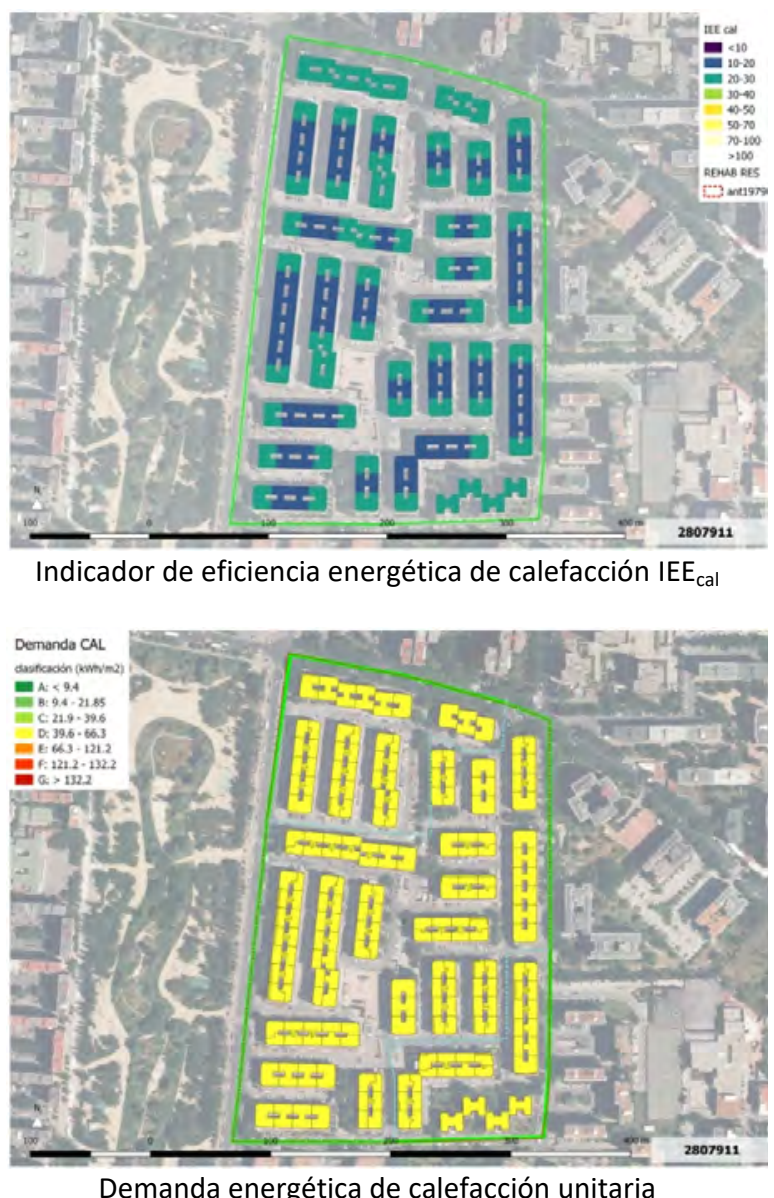

Demanda energética de calefacción unitaria

Figura 90. Indicadores energéticos de la edificación en el AEV 2807911 del barrio de Aluche. Elaboración propia

En el ámbito de este Área Estadística Vulnerable (2807911), todos los edificios presentan un comportamiento energético similar. Los edificios en esquina se desvían de la media por registrar mayores pérdidas energéticas a través de su envolvente, debido a que esta presenta una superficie mayor de fachadas que los edificios entre medianeras. Aunque tiene los peores valores de calidad de la envolvente de toda la muestra $\left(K_{G}=1,83\right.$ $\left.\mathrm{W} / \mathrm{m}^{2} \mathrm{~K}\right)$, el efecto de su alta compacidad $\left(2,91 \mathrm{~m}^{3} / \mathrm{m}^{2}\right)$ hace que se obtenga el valor más bajo de todos los barrios en el indicador $\operatorname{IEE}_{\text {urb }}\left(22,83 \mathrm{kWh} / \mathrm{m}^{3}\right)$. El cómputo de las pérdidas de calor por transmisión a través de la envolvente resulta reducido en relación con el volumen que encierra la edificación.

En lo que respecta a las ganancias solares, se trata del barrio con menor cantidad de radiación solar pasiva incidente por unidad de superficie habitable $\left(12,15 \mathrm{kWh} / \mathrm{m}^{2}\right)$. Esto 
es debido a una mala orientación de la mayor parte de los bloques, que se desarrollan en el eje norte-sur. Las ganancias solares suponen el $18 \%$ de las pérdidas energéticas. Se comprueba que la radiación solar incide con mayor impacto en los bloques con orientación sur (que se desarrollan en el eje este-oeste), no obstante, al ser bloques con 4 viviendas por planta, las viviendas no son pasantes. Estas presentan solamente una de las dos orientaciones y son las que quedan orientadas al sur las que aprovechan esta energía, generando un problema de inequidad energética dentro del propio edificio. Las cubiertas reciben una radiación solar directa en invierno de $24.160 .20 \mathrm{kWh}\left(130 \mathrm{kWh} / \mathrm{m}^{2}\right.$ habitable) y un total al año de 46.741.189 kWh.

La demanda energética de calefacción total es de $9.462 \mathrm{MWh}$ anuales, y la demanda unitaria es de $51 \mathrm{kWh} / \mathrm{m}^{2}$ año, lo que se corresponde con una letra $D$ en la clasificación energética de demanda de calefacción. Esta presenta correlación inversa media-alta con el área habitable y la compacidad y correlación directa media-alta con el $\mathrm{K}_{\mathrm{G}}$ y el IEE $\mathrm{Erb}_{\text {. }}$

Tabla 67. Balance energético para el periodo de invierno en Aluche. Elaboración propia

\begin{tabular}{|l|l|l|l|}
\hline variable & concepto & MWh año & Balance energético \\
\hline $\mathrm{Q}_{\mathrm{t}}$ & Pérdidas por transmisión & 12.359 \\
\hline $\mathrm{Q}_{\mathrm{v}}$ & Pérdidas por ventilación & 3.685 \\
\hline $\mathrm{G}_{\mathrm{s}}$ & Ganancias solares & 2.260 \\
\hline $\mathrm{G}_{\mathrm{i}}$ & Ganancias internas & 4.323 \\
\hline $\mathrm{D}_{\mathrm{cal}}$ & Demanda de calefacción & 9.462 \\
\hline
\end{tabular}
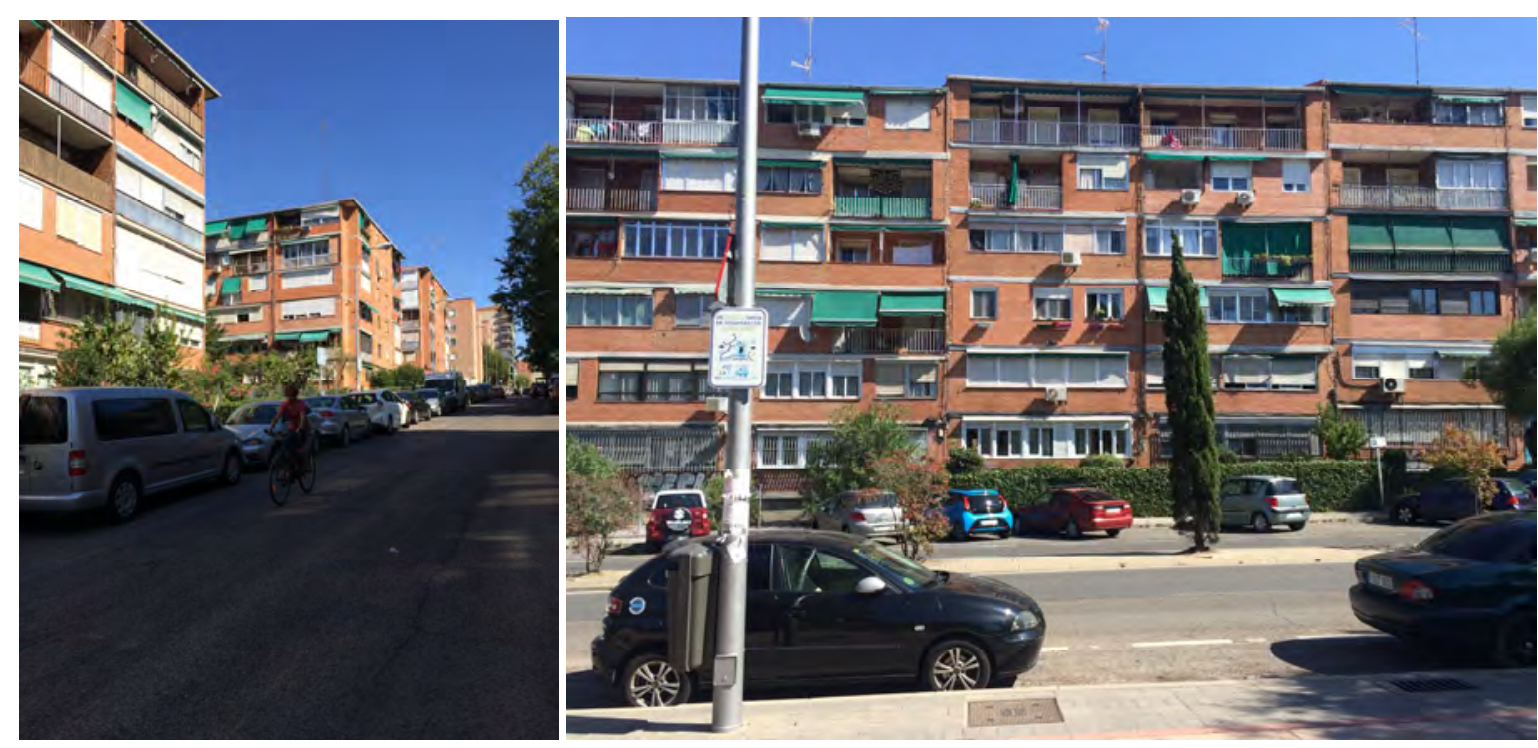

Figura 91. Imagenes del barrio de Aluche. Elaboración propia 
Distrito 10 - LATINA

VULNERABILIDAD URBANA

AEV 2011 PARO: 44,11\%

Denominación: 2807911

\section{RESUMEN URBANO}

$\begin{array}{lc}\text { Viv. principales } & 2,250 \text { ud. } \\ \text { Sup Hab Res } & 144,777 \mathrm{m2} \\ \text { Vivmedia } & 64 \mathrm{m2} \\ \text { Población } & 4,920 \text { pers. } \\ \text { Tamaño hogar } & 2.19 \text { pers/viv }\end{array}$

FORMA DE CRECIMIENTO

Tejido de bloque abierto, años 60

NORMAZONAL PG97

\section{POBREZA ENERGÉTICA_INDICADORES}

\begin{tabular}{ccccccc|} 
COSTE & RENTA & SIN CAL & MAYORES & SOLAPE & \multicolumn{1}{c|}{ RIESGO } \\
1 & 1 & 1 & 1 & 1 & $\mathbf{5}$ & Situación \\
& & & & & &
\end{tabular}

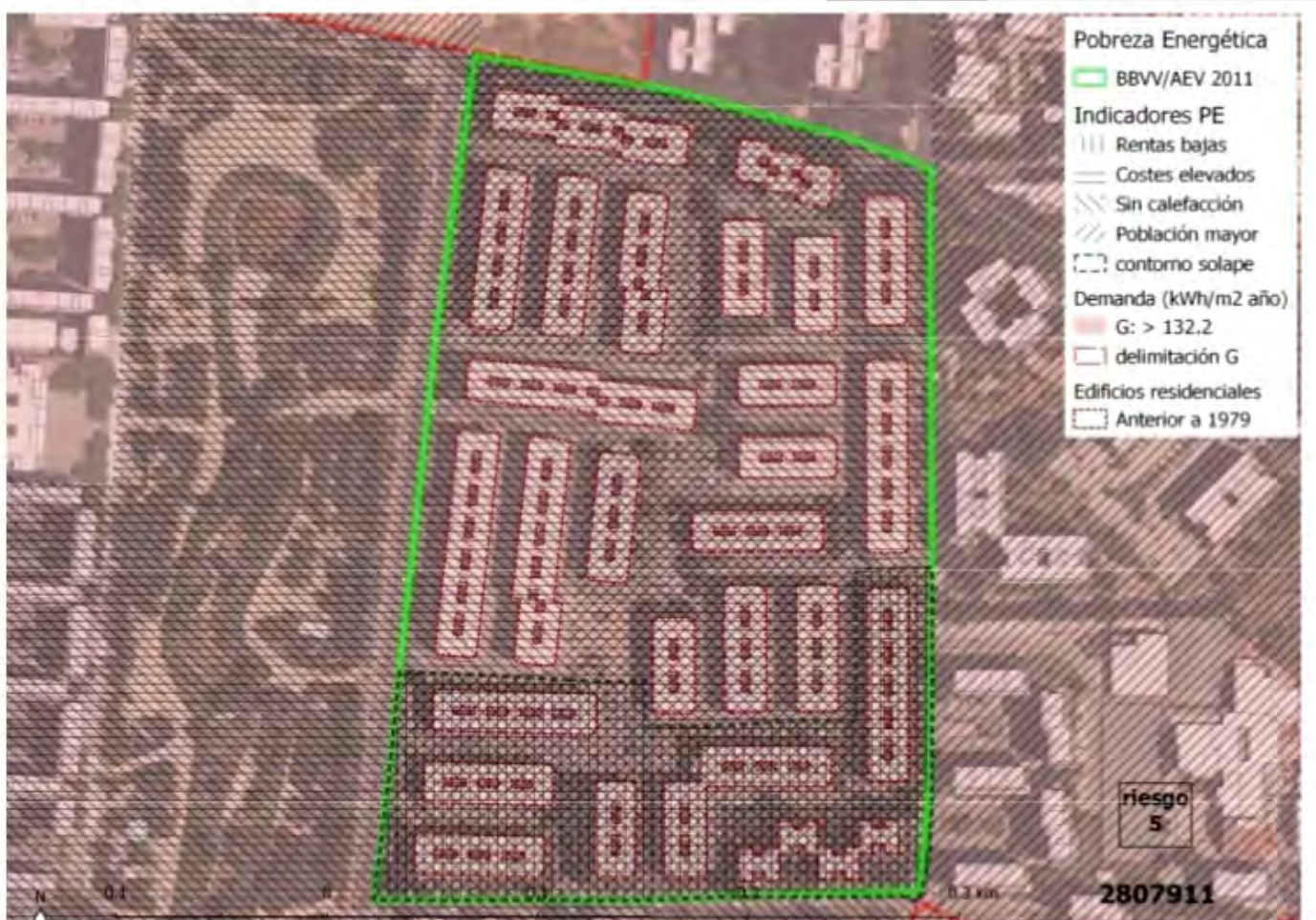

\section{RESUMEN EDIFICACIÓN}

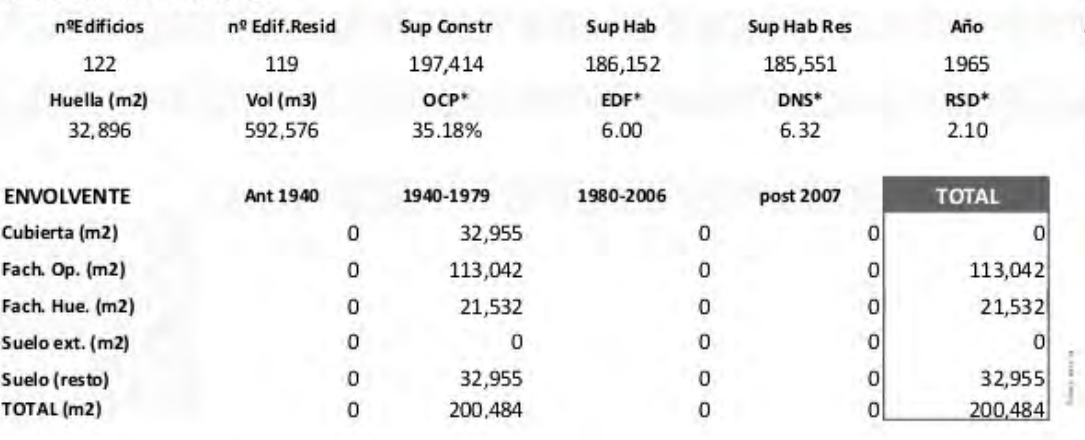

DATOS CATASTRALES

$\begin{array}{cc}\text { Alt MAX (pl) } & \text { Alt. Med. (pl) } \\ 7.00 & 6.00 \\ \text { COMP } & \text { Esbeltez(m/m2) } \\ 2.96 & 0.07\end{array}$

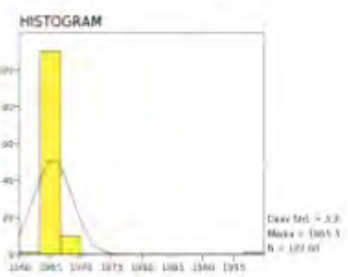

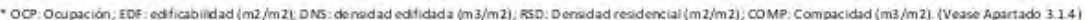


Barrio administrativo: 104 - ALUCHE

\begin{tabular}{|c|c|c|c|c|c|c|}
\hline PÉRDIDAS & minimo & media & maximo & desviación st & TOTAL & HERRAMIENTA MEPEC \\
\hline KG & 1.33 & 1.83 & 1.84 & 0.05 & \multirow{3}{*}{$12,383,326$} & $\mathrm{~W} / \mathrm{m} 2 \mathrm{~K}$ \\
\hline Qt & 6,173 & 101,503 & 122,998 & 15,662 & & kWh anual \\
\hline IEE (Qt/vol) & 19.62 & 22.13 & 72.56 & 8.01 & & $\mathrm{~kW} / \mathrm{m} 3$ \\
\hline RADIACIÓN SOLAR & superficie & $\mathrm{kWh} / \mathrm{m} 2 \mathrm{INV}$ & INVIERNO & Qs Solar pasiva & $k W h / m 2$ VER & VERANO \\
\hline Cubierta & 32,955 & 916 & $24,159,970$ & & 857 & $22,580,766 \mathrm{kWh}$ año \\
\hline Fach $\mathrm{S}$ & 28,079 & 935 & $18,375,740$ & $1,234,867$ & 407 & $8,005,604$ kWh año \\
\hline Fach SE & 46 & 807 & 25,973 & 1,737 & 468 & $15,070 \mathrm{kWh}$ año \\
\hline Fach so & 45 & 811 & 25,547 & 1,727 & 469 & $14,774 \mathrm{kWh}$ año \\
\hline Fach E & 41,079 & 540 & $11,085,168$ & 532,094 & 446 & $9,154,455$ kWh año \\
\hline Fach 0 & 37,417 & 546 & $10,214,841$ & 490,310 & 450 & $8,420,696$ kWh año \\
\hline Superficie TOTAL & 139,621 & TOT inv & $63,887,238$ & $2,260,735$ & TOT ver & $48,191,364 \mid \mathrm{kWh}$ año \\
\hline
\end{tabular}

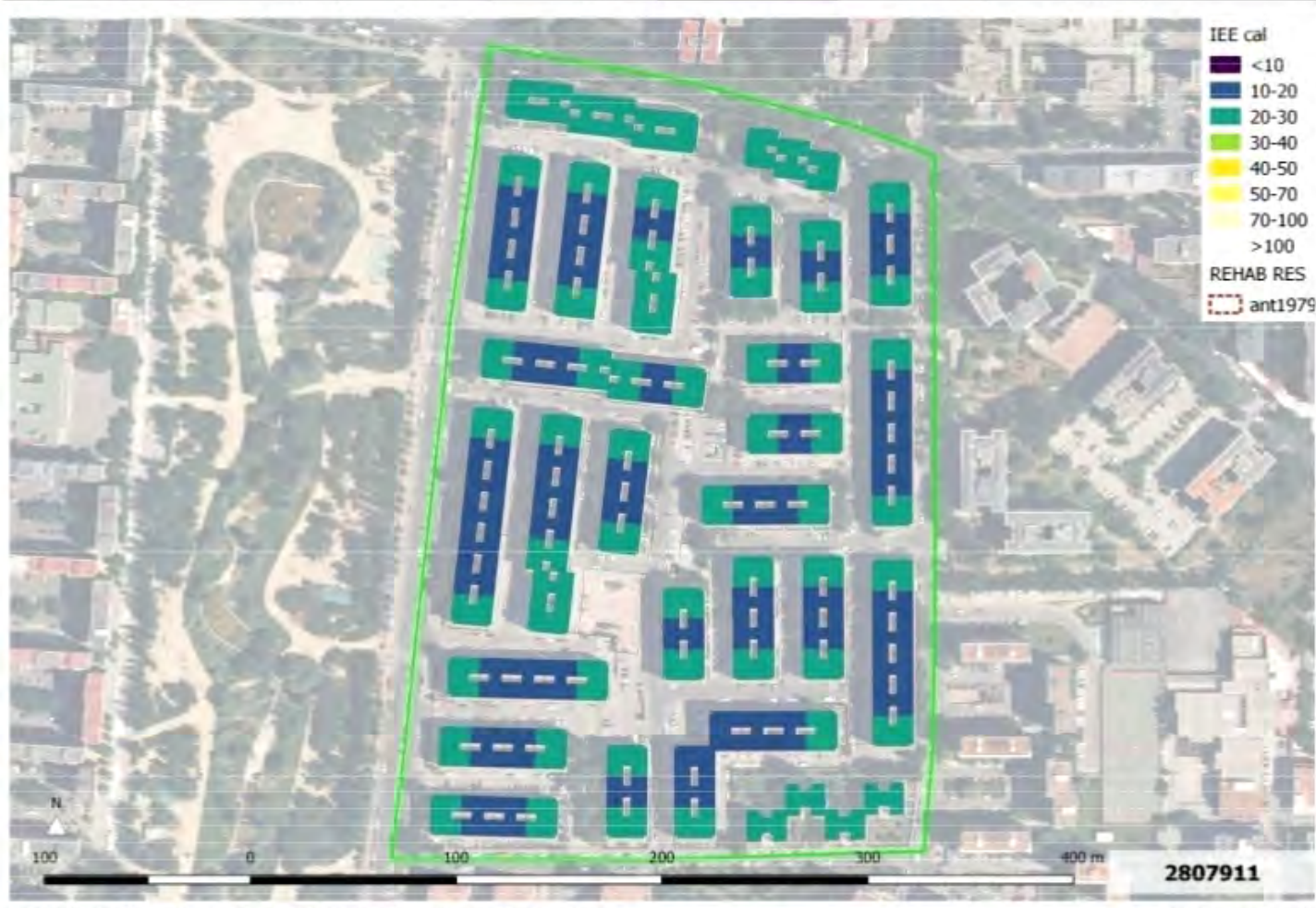

ESTADO ACTUAL: Demanda de calefacción de edificios residenciales

\begin{tabular}{|c|c|c|c|c|c|}
\hline \multicolumn{2}{|c|}{ PÉRDIDAS } & \multicolumn{2}{|c|}{ GANANCIAS } & \multicolumn{2}{|c|}{ BALANCE } \\
\hline Qt Transmisión & Qv Ventilación & Qi Internas & QS Solar pas & Demanda (kWh) & Unit (kWh/m2) \\
\hline $12,359,341$ & $3,685,294$ & $4,323,338$ & $2,260,735$ & $9,460,562$ & 50.82 \\
\hline
\end{tabular}

REHABIUTACIÓN

ESTADO REFORMADO: Aislamiento de envolvente opaca en edificios anteriores a 1979

\begin{tabular}{|c|c|c|c|c|c|}
\hline REHAB & Elemento & Coste INV (€) & Empleo (Horas) & Qt $(\mathrm{kWh} / \mathrm{m} 2)$ & RED tonCO2 \\
\hline$n^{2}$ edificios & Cubierta & $2,202,401$ & 16,514 & $3,974,144$ & 4,587 \\
\hline 119 & Fach. Op. & $11,080,662$ & 220,732 & Reducción & $54,77 \%$ \\
\hline$\%$ ant 1979 & Suelo ext. & 0 & 0 & Demanda (kWh) & Unit (kWh/m2) \\
\hline \multirow[t]{3}{*}{$100 \%$} & \multirow[t]{3}{*}{ TOTAL } & $13,283,063$ & \multirow[t]{2}{*}{237,246} & $1,075,365$ & 5.78 \\
\hline & & & & Dcal/RadCUBinv = & $4.45 \%$ \\
\hline & & Amortización & 16 años & Ahorro Demanda & $88.63 \%$ \\
\hline
\end{tabular}
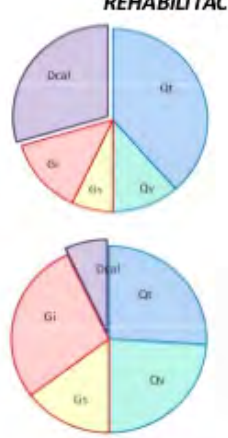

Fig: balance energético EA y ER

Figura 92. Ficha de salida de resultados para barrio. Caso de Aluche (Anexo III). Elaboración propia 


\subsubsection{Entrevías Este - Poblado de promoción pública del periodo 40-60}

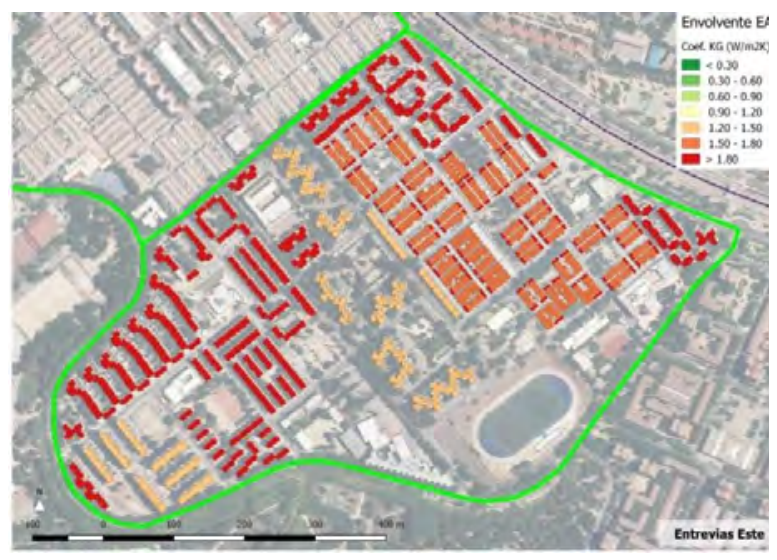

Coeficiente global de pérdidas $\left(\mathrm{K}_{\mathrm{G}}\right)$

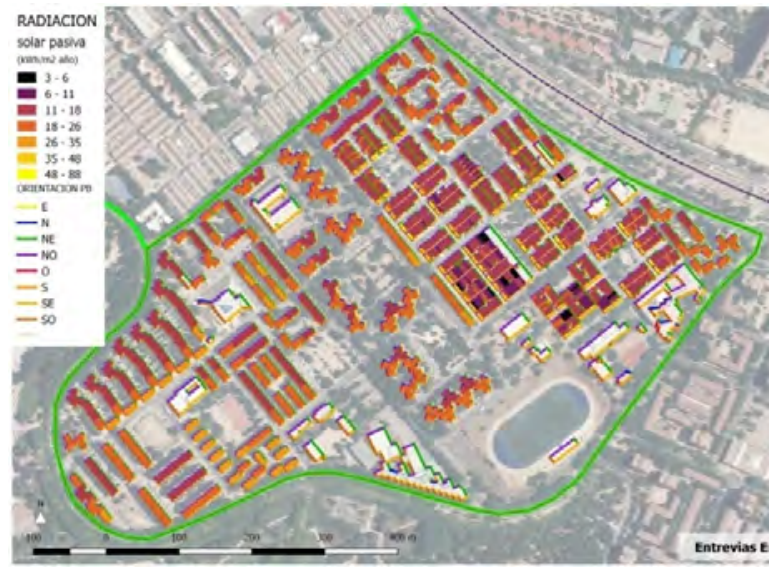

Radiación solar pasiva por unidad de superficie habitable

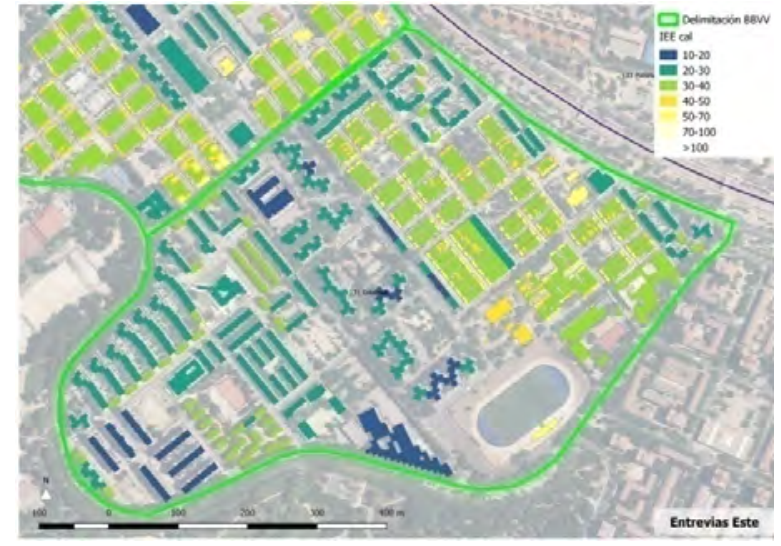

Indicador de eficiencia energética de calefacción $\mathrm{IEE}_{\mathrm{cal}}$

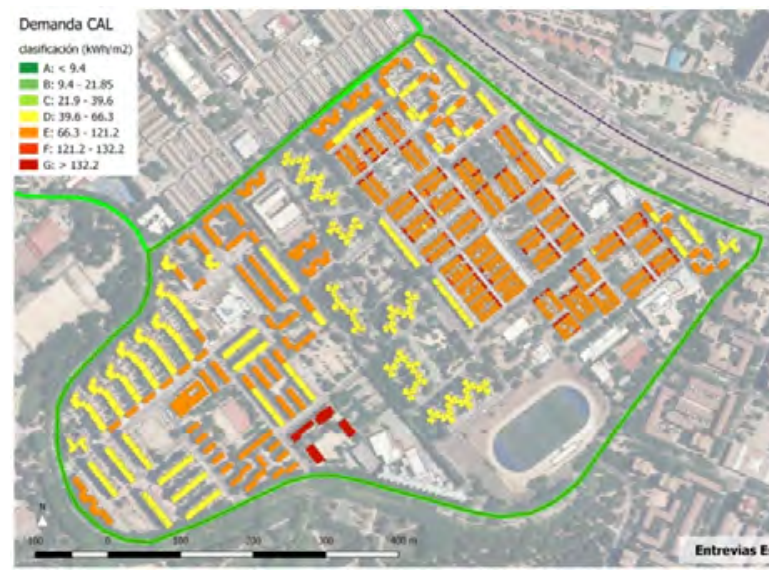

Demanda energética de calefacción unitaria

Figura 93. Indicadores energéticos de la edificación en el barrio de Entrevías Este. Elaboración propia

La calidad de la envolvente en este barrio (Tabla 65) se encuentra ligeramente por debajo de la media de los 10 barrios vulnerables $\left(\mathrm{K}_{\mathrm{G}}=1,77 \mathrm{~W} / \mathrm{m}^{2} \mathrm{~K}\right)$, a pesar de contener áreas con edificación posterior a 1979 que cuenta con aislamiento térmico. Tiene el peor valor promedio del indicador de eficiencia energética urbano de toda la muestra $\left(\mathrm{IEE}_{\mathrm{urb}}=\right.$ $\left.36,19 \mathrm{kWh} / \mathrm{m}^{3}\right)$, por tanto se genera una alta demanda para compensar las fuertes pérdidas a través de su envolvente. Esto es debido a su baja compacidad $\left(1,25 \mathrm{~m}^{3} / \mathrm{m}^{2}\right)$, variable que presenta una fuerte correlación inversa con la demanda energética unitaria de calefacción en este barrio. La altura media del barrio es de 2,48 plantas a pesar de contener edificios de hasta 10 plantas, lo que indica que existe un alto número de viviendas unifamiliares en este ámbito, causa principal de su baja compacidad y de sus altas pérdidas energéticas. En cuanto a la radiación solar incidente en la envolvente, es la 
más alta de la muestra. Las cubiertas reciben 69.111.222 kWh durante el invierno y un total al año de $133.705 .026 \mathrm{kWh}$. Recibe también los mayores valores de radiación solar pasiva en invierno de la muestra: $22,60 \mathrm{kWh} / \mathrm{m}^{2}$, por lo que las viviendas mejor orientadas reducen considerablemente su demanda energética. Las ganancias solares suponen el $25 \%$ de las pérdidas energéticas.

La demanda energética de calefacción total es de $18.337 \mathrm{MWh}$ anual, y la demanda unitaria es de $63 \mathrm{kWh} / \mathrm{m}^{2}$ año, lo que se corresponde con una letra E en la clasificación energética de demanda de calefacción. Esta presenta correlación inversa alta con la compacidad y media con la altura: los edificios menos compactos y de menor altura son los que más demandan. Presenta correlación directa alta con el IEE $\mathrm{Erb}_{\text {, }}$

Tabla 68. Balance energético para el periodo de invierno en Entrevías Este. Elaboración propia

\begin{tabular}{|l|l|l|}
\hline variable & concepto & MWh año \\
\hline $\mathrm{Q}_{t}$ & Pérdidas por transmisión & 24.245 \\
\hline $\mathrm{Q}_{\mathrm{v}}$ & Pérdidas por ventilación & 5.193 \\
\hline $\mathrm{G}_{\mathrm{s}}$ & Ganancias solares & 5.009 \\
\hline $\mathrm{G}_{\mathrm{i}}$ & Ganancias internas & 6.092 \\
\hline $\mathrm{D}_{\mathrm{cal}}$ & Demanda de calefacción & 18.337 \\
\hline
\end{tabular}

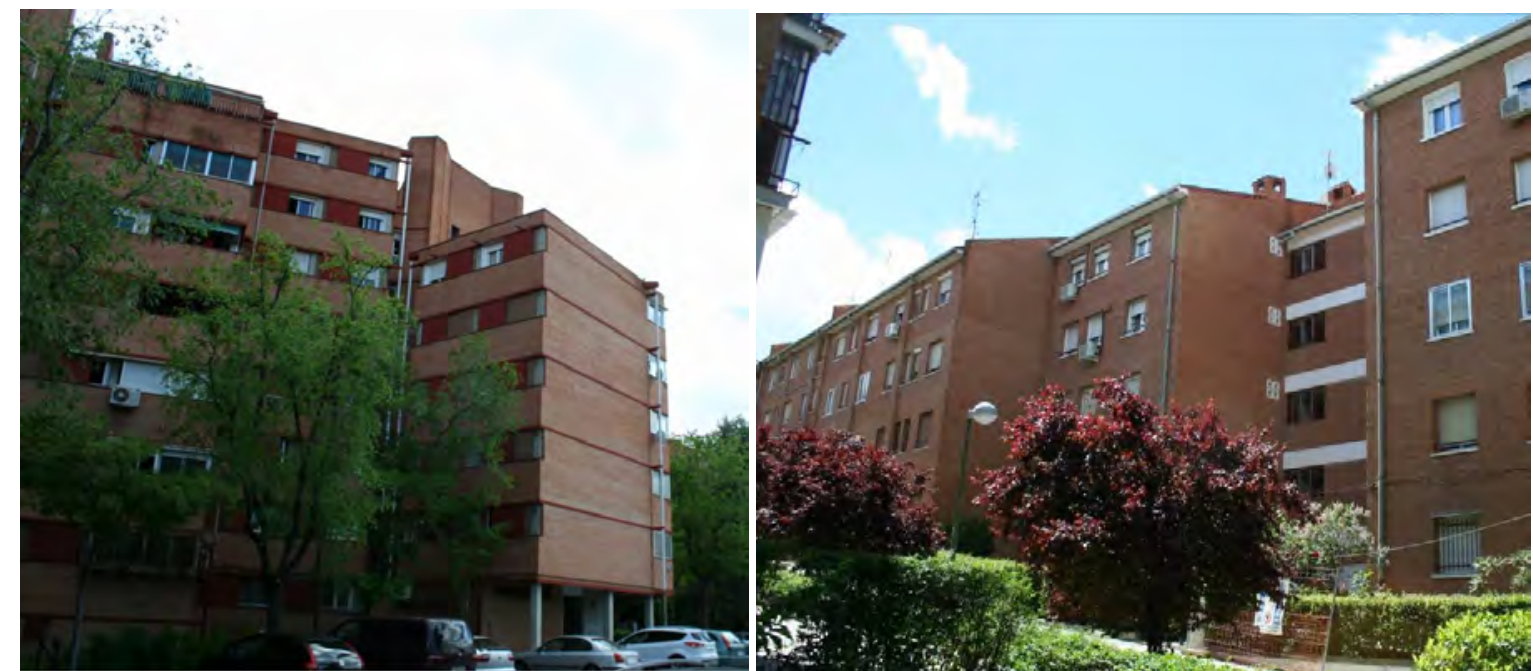

Figura 94. Edificios multifamiliares de las unidad vecinal 5 y 2 en Entrevías Este (Proyecto REFAVIV) 


\subsubsection{Picazo - Tejido de parcelación periférica}
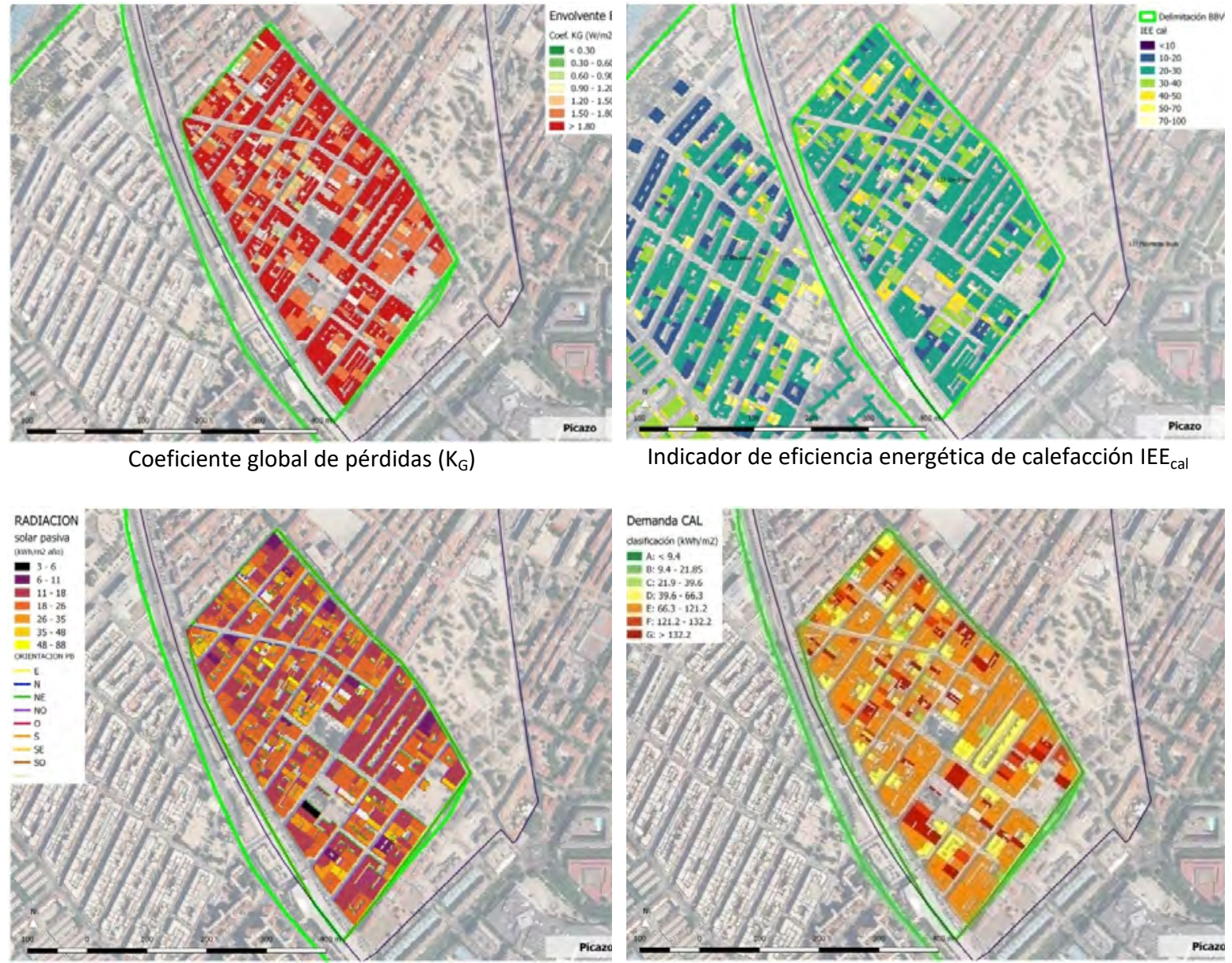

Radiación solar pasiva por unidad de superficie habitable

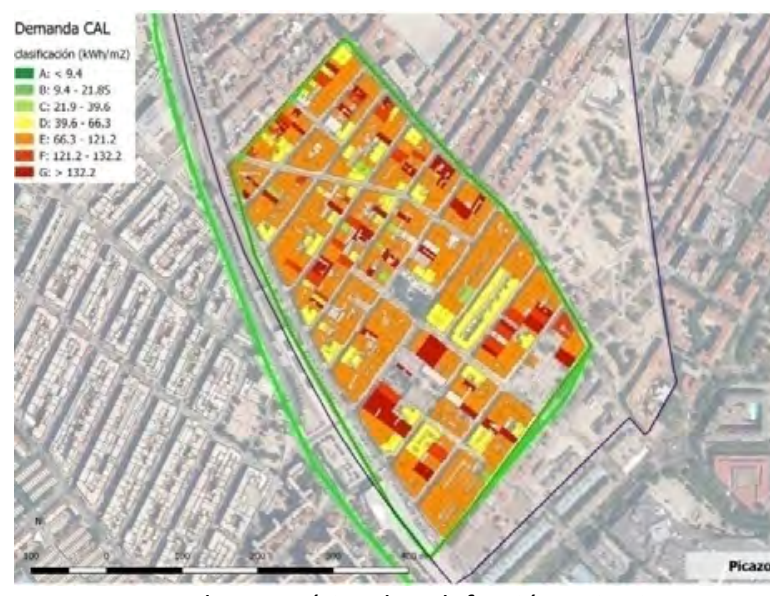

Demanda energética de calefacción unitaria

Figura 95. Indicadores energéticos de la edificación en el barrio de Picazo. Elaboración propia

A pesar de contar con una deficiente calidad constructiva característica de todos los barrios de periferia analizados, este ámbito presenta un coeficiente global de pérdidas a través de la envolvente algo mejor que la media $\left(1,72 \mathrm{~W} / \mathrm{m}^{2} \mathrm{~K}\right)$. Esto se debe a que contiene una cierta cantidad de edificios que se han ido sustituyendo. Esta mejora de la calidad no supone una reducción en las pérdidas energéticas a través de la envolvente, que registran un alto impacto en la demanda. Esto es debido a la existencia de numerosas medianeras entre los edificios. El indicador de eficiencia energética es de $29,60 \mathrm{kWh} / \mathrm{m}^{3}$, cercano a la media de los 10 barrios vulnerables. Los valores de compacidad son ligeramente mayores que la media $\left(2,08 \mathrm{~m}^{3} / \mathrm{m}^{2}\right)$. Su altura media es de 3,18 plantas y el impacto de la radiación solar pasiva en invierno es medio-bajo $(19,44$ $\mathrm{kWh} / \mathrm{m}^{2}$ ), ya que la mayor parte de la radicación se recibe en cubiertas (65.714.054 kWh 
en invierno y $142.487 .416 \mathrm{kWh}$ anuales). Las ganancias solares en este barrio suponen un $18 \%$ de las pérdidas por transmisión.

La demanda energética total de $18.741 \mathrm{MWh}$ se reparte en la superficie habitable en unos $83 \mathrm{kWh} / \mathrm{m}^{2}$, lo que corresponde con una clase $E$ en demanda de calefacción. Esta demanda presenta correlación directa media-alta con el $\mathrm{IEE}_{\mathrm{cal}}$ y correlación inversa media-alta con la altura: los edificios bajos son los que más demandan.

Tabla 69. Balance energético para el periodo de invierno en Picazo. Elaboración propia

\begin{tabular}{|l|l|l|l|}
\hline variable & concepto & MWh año & Balance \\
\hline $\mathrm{Q}_{t}$ & Pérdidas por transmisión & 23.864 \\
\hline $\mathrm{Q}_{v}$ & Pérdidas por ventilación & 4.392 \\
\hline $\mathrm{G}_{\mathrm{s}}$ & Ganancias solares & 4.363 \\
\hline $\mathrm{G}_{\mathrm{i}}$ & Ganancias internas & 5.152 \\
\hline $\mathrm{D}_{\mathrm{cal}}$ & Demanda de calefacción & 18.741 \\
\hline
\end{tabular}
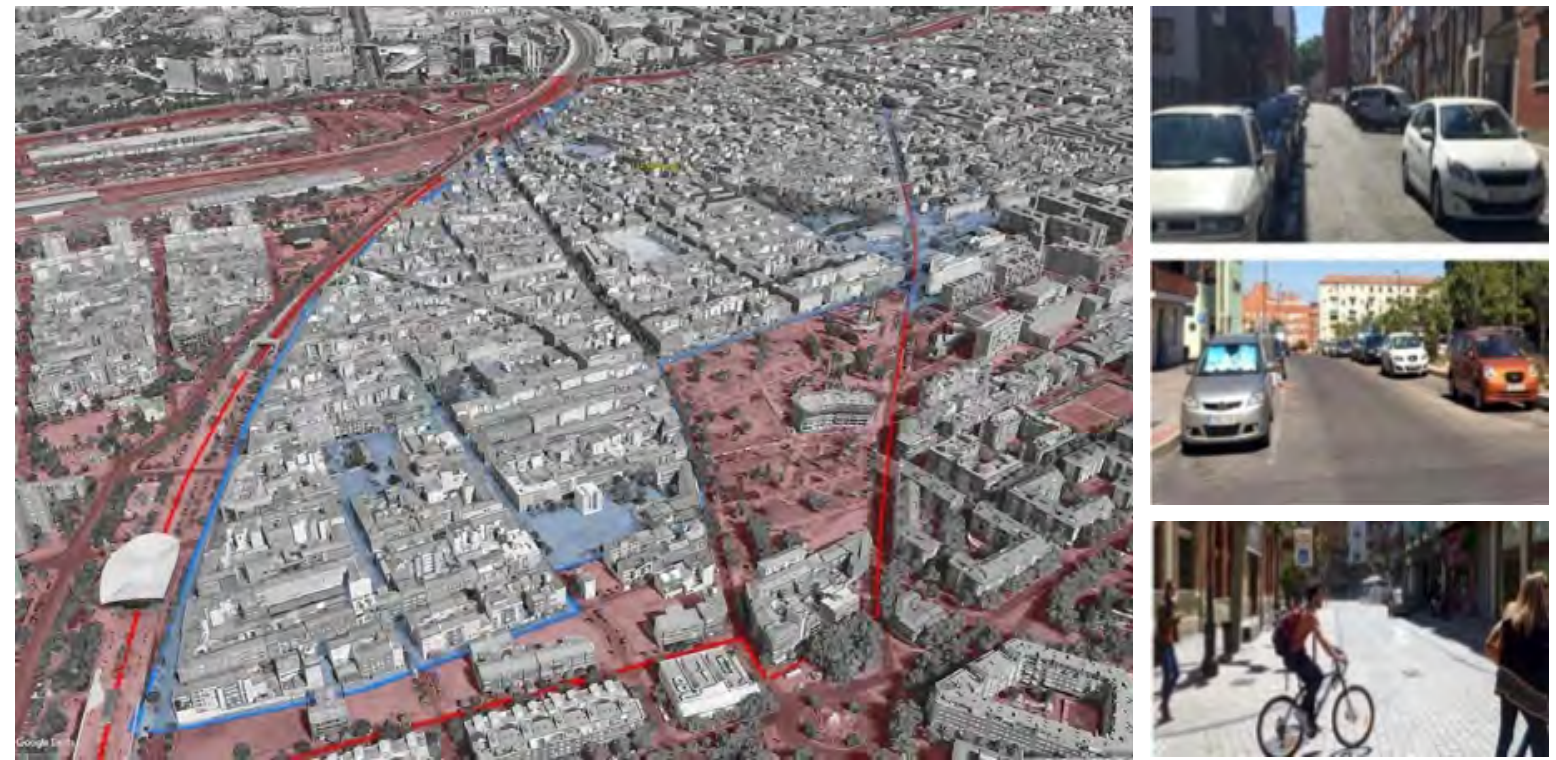

Figura 96. Imágenes del APIRU del Barrio de San Diego, que contiene el Barrio Vulnerable de Picazo. Fuente: proyecto Madrid Regenera (Ayuntamiento de Madrid) 


\subsubsection{Vicálvaro - Poblado anexionado a Madrid}

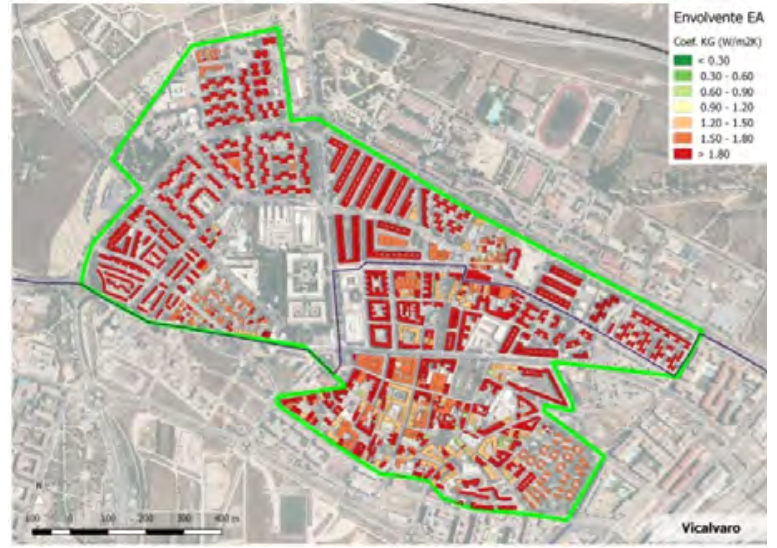

Coeficiente global de pérdidas $\left(\mathrm{K}_{\mathrm{G}}\right)$

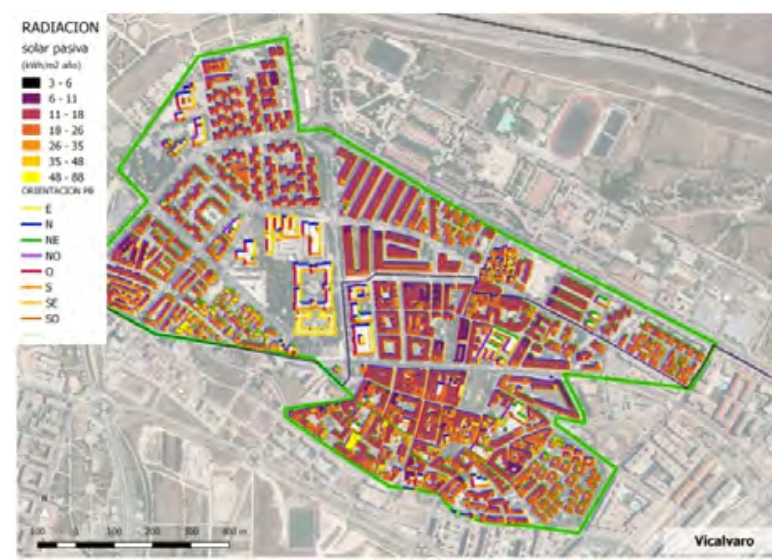

Radiación solar pasiva por unidad de superficie habitable

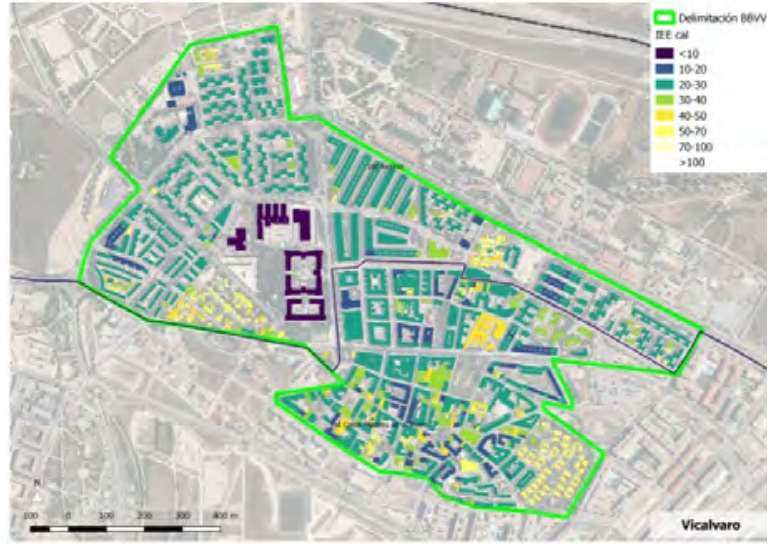

Indicador de eficiencia energética de calefacción IEE $\mathrm{Eal}_{\mathrm{c}}$

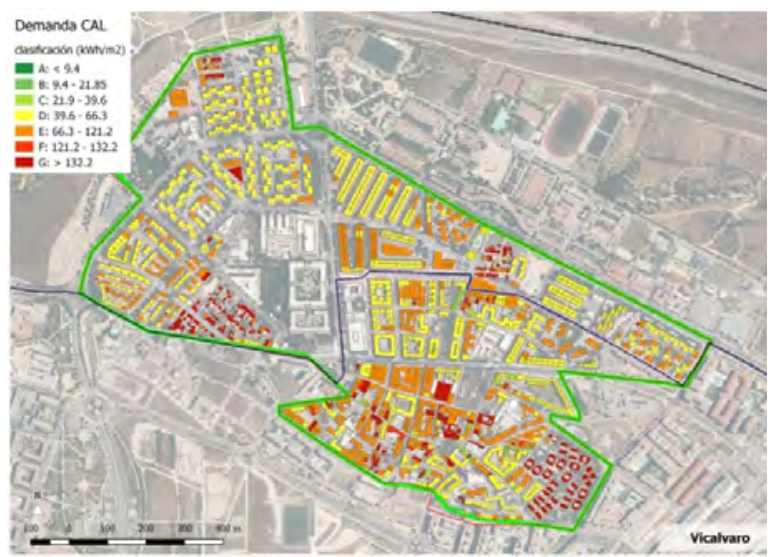

Demanda energética de calefacción unitaria

Figura 97. Indicadores energéticos de la edificación en el barrio de Vicálvaro. Elaboración propia

Este poblado anexionado es el ámbito más antiguo de la muestra y contiene edificios muy diferentes y de distintos periodos. En lo que respecta a la calidad constructiva de la envolvente tiene el valor medio del coeficiente global de pérdidas de la muestra de los 10 barrios en riesgo de pobreza energética analizados $\left(\mathrm{K}_{\mathrm{G}}=1,74 \mathrm{~W} / \mathrm{m}^{2} \mathrm{~K}\right)$. La compacidad está ligeramente por encima de la media $\left(2,11 \mathrm{~m}^{3} / \mathrm{m}^{2}\right)$. La radiación solar pasiva es de 14,17 $\mathrm{kWh} / \mathrm{m}^{2}$ y supone un $19 \%$ de las pérdidas por transmisión. Presenta tres tejidos diferentes en los cuales los peores valores de demanda energética corresponden con las áreas de vivienda unifamiliar seguidos de la parte correspondiente al casco histórico. 
La demanda anual total de calefacción es de 9,790 MWh y la unitaria de $51 \mathrm{kWh} / \mathrm{m}^{2}$, correspondiente a una clase D. La demanda unitaria presenta correlación media-alta con el indicador de eficiencia energética de calefacción $\left(\mathrm{IEE}_{\mathrm{urb}}=31,92 \mathrm{kWh} / \mathrm{m}^{3}\right)$. También presenta correlación inversa media-alta con la altura $(3,4$ plantas de media, con una altura máxima de 13 plantas) y la compacidad $\left(2,31 \mathrm{~m}^{3} / \mathrm{m}^{2}\right)$.

Tabla 70. Balance energético para el periodo de invierno en Vicálvaro. Elaboración propia

\begin{tabular}{|l|l|l|}
\hline variable & concepto & MWh año \\
\hline $\mathrm{Q}_{\mathrm{t}}$ & Pérdidas por transmisión & 72.752 \\
\hline $\mathrm{Q}_{\mathrm{v}}$ & Pérdidas por ventilación & 16.188 \\
\hline $\mathrm{G}_{\mathrm{s}}$ & Ganancias solares & 13.619 \\
\hline $\mathrm{G}_{\mathrm{i}}$ & Ganancias internas & 18.990 \\
\hline $\mathrm{D}_{\mathrm{cal}}$ & Demanda de calefacción & 56.330 \\
\hline
\end{tabular}
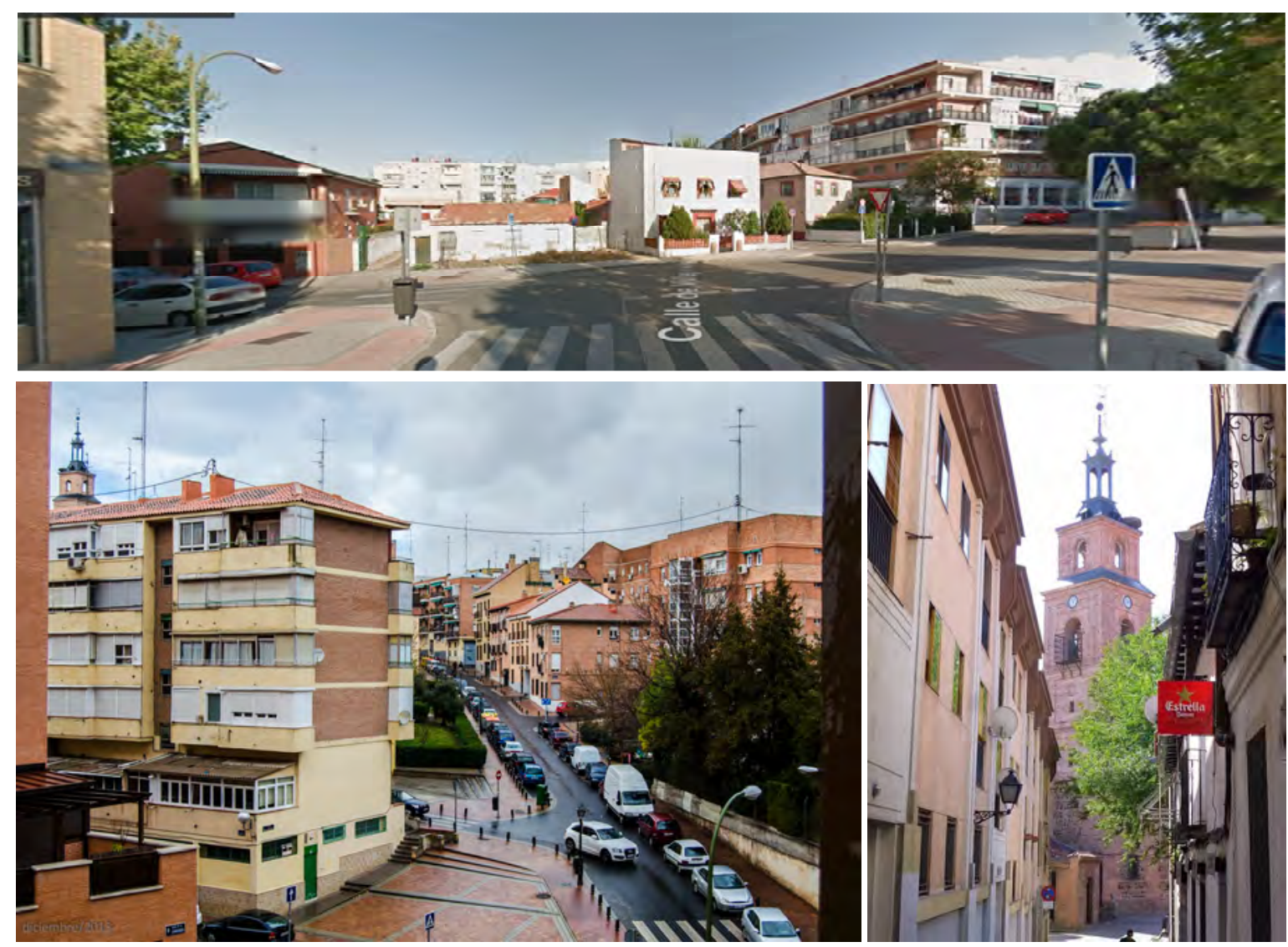

Figura 98. Imágenes del Casco Histórico de Vicálvaro (Google, Wikiwand) 


\subsection{MEJORA DE LA EDIFICACIÓN RESIDENCIAL}

Se evalúa el impacto conseguido a través de una operación de mejora de la calidad térmica de la edificación obsoleta utilizando la herramienta MEPEC aplicada a los cuatro barrios vulnerables en riesgo de pobreza energética que se corresponden con tejidos urbanos característicos de la periferia (Aluche, Entrevías, Picazo y Vicálvaro). Se analiza el potencial de mejora de la envolvente opaca mediante la incorporación de aislamiento térmico en fachadas, cubiertas y suelos en contacto con el aire exterior, en los edificios residenciales anteriores al año 1979 (marcados en rojo en la Figura 99). Se estiman los costes de la inversión inicial que supone la intervención. También se cuantifican los beneficios previstos tras la rehabilitación energética: su impacto en la reducción de las pérdidas energéticas a través de la envolvente y la demanda de calefacción resultante y los impactos ambientales evitados. Además se estiman las necesidades de mano de obra para su ejecución siguiendo el método desarrollado en el apartado 3.3.
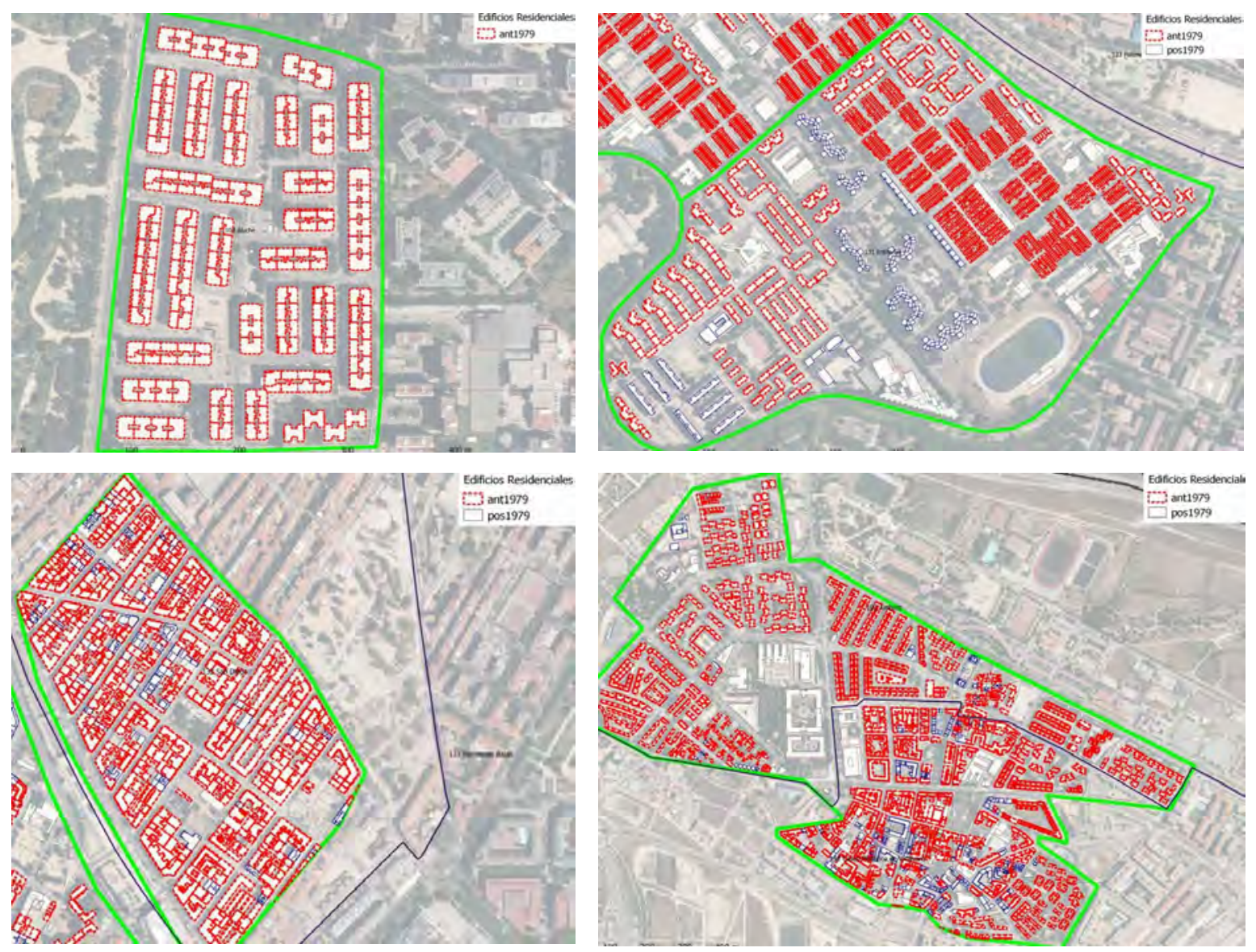

Figura 99. Edificios anteriores a 1979 (en rojo) incluidos en el análisis para su rehabilitacion. Elaboración propia 


\subsubsection{Beneficios medioambientales}

Para cada una de las soluciones propuestas se obtienen las pérdidas energéticas en el estado reformado para todos y cada uno de los edificios construidos con anterioridad a 1979, y a partir de este valor se obtiene su demanda energética de calefacción. Se entiende que la reforma no afecta a los huecos de fachada y por tanto los valores de pérdidas a través de las ventanas y las ganancias solares no se ven modificados. También las pérdidas por ventilación y ganancias internas se han mantenido constantes, entendiendo que no hay variaciones en los patrones de uso de los edificios antes y después de la intervención.

El impacto de las mejoras se evalúa mediante el cómputo de la reducción de pérdidas energéticas totales por transmisión $\left(Q_{t}\right)$, el efecto sobre el Indicador de Eficiencia Energética urbano ( $\mathrm{IEE}_{\mathrm{urb}}$ ), la demanda y sobre la reducción de emisiones de $\mathrm{CO}_{2}(\mathrm{Tabla}$ 71). Se obtiene también la clase en demanda de calefacción para cada edificio del barrio y para el conjunto del tejido urbano.

Tabla 71. Impacto medioambiental de la mejoras de la edificación residencial. Elaboración propia

\begin{tabular}{|c|c|c|c|c|c|}
\hline \multirow[t]{2}{*}{ Var } & \multirow[t]{2}{*}{ Descripción } & \multicolumn{4}{|c|}{ Resultados por barrio } \\
\hline & & Aluche & Entrevías este & Picazo & Vicálvaro \\
\hline \multirow{2}{*}{$\begin{array}{l}\text { Qt } \\
\text { (kWh) }\end{array}$} & $\begin{array}{l}\text { Pérdidas por } \\
\text { transmisión EA }\end{array}$ & 12.359 .341 & 24.245 .345 & 23.864 .427 & 72.751 .612 \\
\hline & $\begin{array}{l}\text { Pérdidas por } \\
\text { transmisión ER }\end{array}$ & 3.974 .144 & 10.965 .714 & 8.162 .503 & 26.211 .115 \\
\hline$\%$ & Reducción perdidas & $67,85 \%$ & $54,77 \%$ & $65,80 \%$ & $63,97 \%$ \\
\hline$\left(\right.$ ton $\left.\mathrm{CO}_{2}\right)$ & Reducción emisiones & 4.587 & 7.264 & 8.589 & 25.458 \\
\hline \multirow{2}{*}{$\begin{array}{l}\text { Dcal } \\
\text { (kWh) }\end{array}$} & Demanda EA & 9.461 .669 & 18.337 .407 & 18.740 .536 & 56.330 .136 \\
\hline & Demanda ER & 1.076 .473 & 5.057 .775 & 3.038 .612 & 9.789 .639 \\
\hline \multirow{2}{*}{$\begin{array}{l}\text { Dcal/Shab } \\
\left(\mathrm{kWh} / \mathrm{m}^{2}\right)\end{array}$} & Demanda unitaria EA & $50,99 \mathrm{D}$ & $69,51 \mathrm{E}$ & $84,75 \mathrm{E}$ & $69,1 \mathrm{E}$ \\
\hline & Demanda unitaria ER & $5,80 \mathrm{~A}$ & 19,17 B & 13,74 B & 12,01 B \\
\hline & Reducción demanda & $88,62 \%$ & $72,42 \%$ & $83,79 \%$ & $82,62 \%$ \\
\hline & $\begin{array}{l}\text { Balance energético en } \\
\text { el estado reformado }\end{array}$ & & & & \\
\hline & Edificios intervenidos & 119 & 1.002 & 298 & 798 \\
\hline & Edificios totales & 119 & 1.047 & 358 & 915 \\
\hline & \% intervención & $100 \%$ & $96 \%$ & $81 \%$ & $87 \%$ \\
\hline
\end{tabular}


Tabla 72. Ejemplos de edificios candidatos a Edificios de Consumo Casi Nulo. Elaboración propia

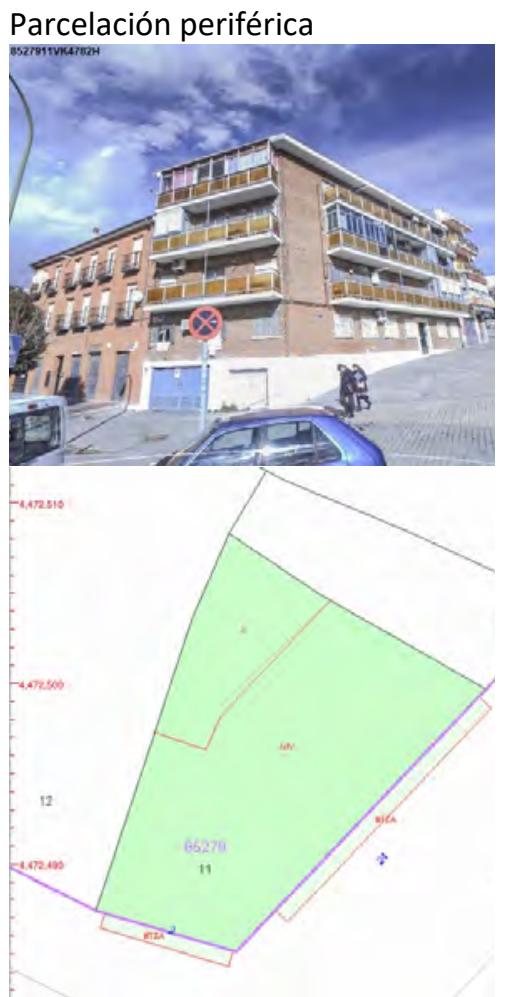

REFCAT 8527911VK4782H

Edificio medianero en esquina Vicálvaro

Dcal: $E A=51,83 ; E R=0,05 \mathrm{kWh} / \mathrm{m} 2$

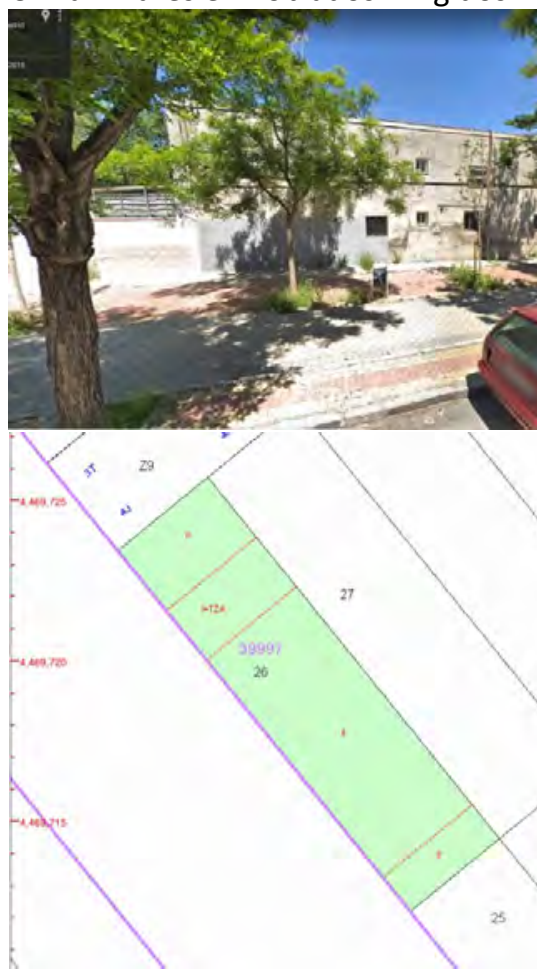

REFCAT 3999726VK4639H

Unifamiliar en hilera, esquina Entrevías

Dcal EA=126,06; ER=0,00 (kWh/m2)
Tejidos de bloque abierto

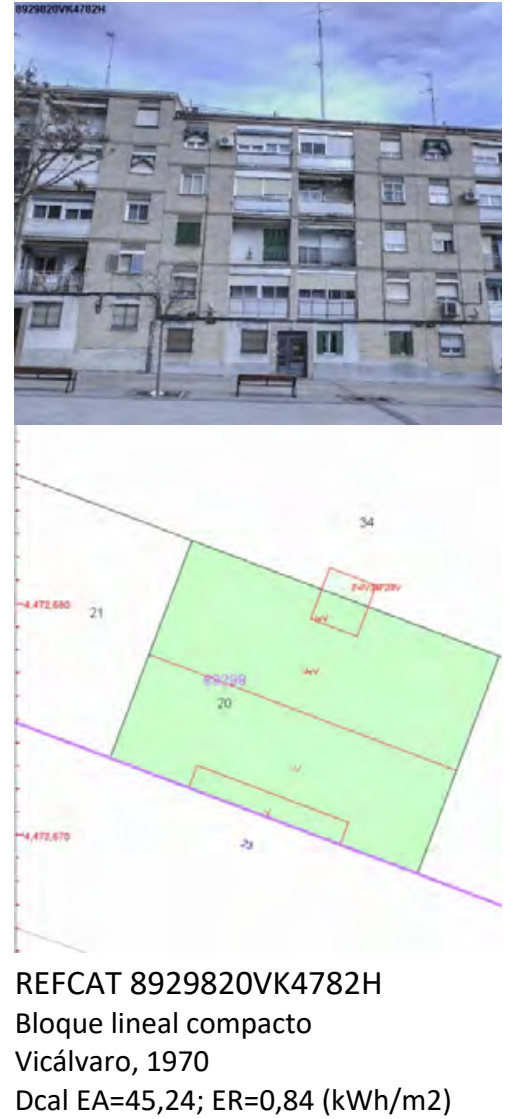

Los resultados permiten comprobar que el potencial de reducción de la demanda energética por la limitación de las pérdidas a través de la envolvente $\left(Q_{t}\right)$ es muy elevado: entre el $55 \%$ y el $68 \%$ de reducción de las pérdidas totales según el barrio. Para los barrios analizados, la reducción de la demanda oscila entre el 72\% (Entrevías Este) y el 89\% (Aluche). Al reducirse drásticamente las pérdidas, el balance energético resulta equilibrado a través de las ganancias.

Cuanto mayor es la reducción de pérdidas a través de la envolvente, más influyente resulta el comportamiento del usuario en la demanda de calefacción resultante, puesto que comienzan a pesar las variables de Pérdidas energéticas por ventilación $\left(Q_{v}\right)$ y Ganancias Internas $\left(Q_{\mathrm{i}}\right)$. También el comportamiento del usuario es un factor decisivo en el aprovechamiento de las ganancias solares $\left(\mathrm{G}_{\mathrm{s}}\right)$.

En el total de la muestra de los 4 barrios existen al menos 59 edificios que llegarían a cubrir la totalidad de su demanda energética de calefación mediante los aportes solares despues de la intervención (Tabla 72). Muchos otros tendrían demandas de calefacción 
muy bajas. Su tipología se corresponde con viviendas unifamiliares en los poblados dirigidos, edificios multifamiliares en esquina (con dos fachadas soleadas) en áreas de parcelación periférica y algunos bloques exentos de alta compacidad. Todos son edificios que contienen amplias fachadas de orientación sur, sureste y suroeste, con lo que el aprovechamiento de la energía solar pasiva resulta favorable. Se trata de edificios situados en areas degradadas, con alta probabilidad de contener hogares en riesgo de pobreza energética que mediante la rehabilitación de sus envolventes podrían funcionar de forma pasiva en invierno, manteniendo la temperatura de confort sin necesidad de consumo de energía. Para lograr el éxito de la operación son necesarios estudios complementarios que contemplen la demanda de refrigeración. El objetivo sería su redución mediante la incorporacion de medidas pasivas dirigidas a fomentar las perdidas de calor y la reducción de las ganancias durante el verano. Estos edificios son candidatos idoneos para una rehabilitación energética dirigida a lograr edificios de consumo casi nulo. Mediante su rehabilitación se conseguiría eliminar la vulnerabilidad energética que la edificación genera en sus ocupantes y se podrían solucionar problemas de pobreza energética, facilitando la consecución de los estándares de confort.

\subsubsection{Aspectos económicos}

Utilizando las mediciones de la envolvente y los precios de la construcción actualizados en el momento de la intervención resulta posible realizar un presupuesto del coste de la inversión inicial para la intervención en los edificios residenciales ineficientes de cada barrio. En este caso se han utilizando precios de la construcción consultados en el año 2018 según la metodología descrita en el Apartado 3.3.2.

Para la evaluación del impacto de la inversión se comparan los costes con los beneficios obtenidos en la reducción de las pérdidas energéticas por transmisión y en la demanda de calefacción. Se obtiene el indicador de la reducción de pérdidas por cada euro invertido y un periodo de amortización teórico que sería válido para aquellos casos en los que las necesidades de confort estén cubiertas. Este no es el caso de los hogares en situación de pobreza energética, que restringen el uso de energía por no poder hacer frente a los costes que supone la factura energética necesaria para llegar al confort, por lo que los cálculos de la amortización se deben utilizar con cautela. 
Tabla 73. Costes de la intervención. Elaboración propia

\begin{tabular}{|l|l|l|l|l|}
\hline Elemento & Resultados por barrio & \multicolumn{2}{l|}{} \\
\hline & Aluche & Entrevías este & Picazo & Vicálvaro \\
\hline Cubierta $(€)$ & $2,202,401$ & $4,198,214$ & $5,234,507$ & $14,143,062$ \\
\hline Fachada $(€)$ & $11,080,662$ & $15,022,039$ & $16,567,935$ & $54,105,362$ \\
\hline Suelo exterior (€) & 0 & 850 & 14,19 & 63,240 \\
\hline TOTAL (€) & $13,283,063$ & $19,221,103$ & $21,816,640$ & $68,311,664$ \\
\hline Coste por sup. construida S/R (€/m2) & 67.28 & 58,78 & 72.90 & 57.25 \\
\hline Coste por sup. habitable (€/m2) & 71.36 & 65.59 & 96.45 & 62.09 \\
\hline Repercusión (kWh/€) & 0.63 & 0.69 & 0.72 & 0.68 \\
\hline Periodo amortización teórico (años) & 15.84 & 14.47 & 14.68 & 13.89 \\
\hline
\end{tabular}

El análisis económico de los resultados de los costes de la inversión inicial y de la reducción en la factura energética se considera complementario y debe tomarse con suma precaución, ya que presenta serias incertidumbres. Los cálculos son altamente dependientes de la variabilidad de los precios de la construcción y la volatilidad del coste por kWh de la factura energética. Esto no permite utilizar estos resultados como evidencias científicas, solo se calculan a título orientativo. Sería necesario un análisis específico sobre el tema. Solamente permiten la comparación entre los edificios de la muestra y no son extrapolables a otros casos.

Los costes de la inversión inicial se han estimado para unas obras para un barrio de tamaño medio y un nivel de complejidad de ejecución media, correspondiente a los edificios de tipo bloque abierto. En los casos en los que las condiciones de trabajo sean complejas o en los que la edificación sea singular, sería necesario un estudio de detalle para ajustar los precios. Por ejemplo, en los barrios de parcelación periférica, con numerosas medianeras en contacto con el aire exterior, la instalación de medios auxiliares resulta más compleja que en las áreas de bloque abierto y esto podría suponer un incremento del precio de la solución de mejora de fachada en esos casos.

La repercusión de la inversión en la reducción de pérdidas energéticas oscila entre 0,62 y $0,72 \mathrm{kWh}$ de ahorro anual por cada euro invertido. El barrio en el que se consigue la mayor reducción de pérdidas por cada euro invertido es Picazo y el de menor repercusión Aluche, que cuenta de partida con una mejor $\mathrm{IEE}_{\text {urb }}$ y calificación en demanda energética. Los periodos de retorno, en el caso de demandas satisfechas y de 
que se congelase la situación actual en cuanto a costes energéticos oscilarían entre los 14 y los 16 años. El coste por unidad de superficie construida sobre rasante rehabilitada estaría alrededor de los $58 € / \mathrm{m} 2$ o de los $73 € / \mathrm{m} 2$ de superficie habitable de vivienda.

\subsubsection{Beneficios sociales por el potencial de creación de empleo}

Se calcula la mano de obra que sería necesaria para la ejecución de los trabajos de rehabilitación en los edificios seleccionados para cada barrio, siguiendo el procedimiento descrito en el Apartado 3.3.3. El modelo permite obtener datos acerca de las necesidades de mano de obra para la rehabilitación de los edificios afectados a partir de la información obtenida en la base de datos de precios de la construcción para el cálculo de su presupuesto de ejecución material. Para ello se utilizan las mediciones de la envolvente de la edificación arrojadas por la herramienta MEPEC que ya se han utilizado para la estimación del presupuesto de ejecución material. A partir de la variable "Horas de Trabajo" se obtienen el número de jornadas laborales de 8 horas, y los años de contrato de operarios suponiendo 225 días de trabajo anuales (Tabla 74). Las horas calculadas se corresponden con la suma total de horas de trabajo de los diferentes oficios: oficiales y ayudantes de montador de aislamiento, revocador, pintura, etc (Tabla 59). La información se obtiene desglosada para cada uno de los edificios intervenidos, y para el total de cada barrio.

Tabla 74. Estimación del impacto en la creación de empleo de la rehabilitación de los barrios analizados. Elaboración propia

\begin{tabular}{|l|l|l|l|l|}
\hline Elemento & \multicolumn{4}{l}{ Resultados por barrio } \\
\hline & Aluche & Entrevías este & Picazo & Vicálvaro \\
\hline Cubierta (Horas) & 16.514 & 31.479 & 39.249 & 106.047 \\
\hline Fachada (Horas) & 220.732 & 299.246 & 330.041 & 1.077 .805 \\
\hline Suelo exterior (horas) & 0 & 14 & 230 & 1.023 \\
\hline TOTAL (horas) & 237.246 & 330.739 & 369.520 & 1.184 .874 \\
\hline Días (8h) & 29.668 & 41.342 & 46.190 & 148.109 \\
\hline Semanas (40h) & 5.931 & 8.268 & 9.238 & 29.622 \\
\hline Años (225 días) & 132 & 184 & 205 & 658 \\
\hline
\end{tabular}




\section{CAPÍTULO 4. ANÁLISIS DE RESULTADOS}

Si la realización de las obras de rehabilitación energética de la envolvente opaca se planificara para ser ejecutada durante un año, serían necesarios 132 contratos de trabajo en Aluche (1.11 por edificio rehabilitado), 184 en Entrevías (0.19 por edificio), 205 en Picazo (0.85) y 658 en Vicálvaro (0.95).

Se comprueba que la rehabilitación de fachadas es la actuación de mejora que genera una mayor necesidad de mano de obra. Los planes de regeneración urbana con componente de mejora energética deben situar las fachadas opacas como elemento central, especialmente cuando se aborden barrios de edificios multifamiliares. El resto de elementos se deben incluir para evitar desequilibrios, puentes térmicos y por razones de equidad energética, como por ejemplo en el caso de las viviendas situadas en bajocubierta, sometidas a mayores solicitaciones térmicas que generan una mayor demanda tanto de calefacción como de refrigeración. 


\subsection{COMPARATIVA DE RESULTADOS OBTENIDOS CON DATOS ESTADÍSTICOS Y CATASTRALES}

En el trabajo desarrollado en esta tesis doctoral se han diseñado dos métodos para evaluar la demanda energética de calefacción en áreas urbanas. La primera, desarrolla en el CAPÍTULO 2, está basada en datos estadísticos acerca de la antigüedad y la superficie de vivienda y se apoya en la generalización de los resultados de la simulación energética de edificios tipo. La escala de este análisis es la de mayor desagregación que permite la utilización de datos del Censo: la sección censal. Esta escala permite el cruce de datos socioeconómicos posibilitando el análisis de la pobreza energética en la ciudad. El segundo método, desarrollado en el CAPITULO 3, incorpora la información contenida en el Catastro acerca de la edificación. Permite ampliar la escala para analizar el edificio y se consigue realizar una estimación simplificada de la demanda de calefacción utilizando la norma (ISO 13790 2008).

La estimación de la demanda energética detallada de los barrios a partir del proceso de datos catastrales, permite agrupar y contrastar la información a la escala de la sección censal y para el ámbito del barrio. Esta agrupación de resultados de los edificios en valores promedio para las secciones censales que los contienen posibilita su comparación con las estimaciones realizadas para estas mismas secciones censales mediante el método realizado a partir de datos estadísticos. En la Tabla 75 se vuelcan los resultados obtenidos utilizando cada método para los cuatro barrios vulnerables de tejidos urbanos característicos. Al analizar los valores registrados de superficies habitables en los censos y en Catastro, se comprueba que, exceptuando el barrio de Entrevías Este - en el cual los valores coinciden- el catastro computa una mayor superficie habitable, entre un $15 \%$ (Picazo) y un $20 \%$ (Aluche y Vicálvaro) superiores a los datos estadísticos. En el glosario de términos del Censo de Población y Viviendas de 2001, se define la superficie útil de la vivienda con la siguiente descripción:

Clasificación por intervalos de la superficie útil de la vivienda, medida en el interior de los muros exteriores de la vivienda, no comprendiendo los sótanos, desvanes, trasteros y buhardillas no habitables. Tampoco se incluyen las terrazas abiertas ni los jardines. Con valores: Hasta $30 \mathrm{m2}$, 30 a 45 m2, 46 a 60 m2, 61 a 75 m2,...., Más de 180m2. (INE 2001). 
En el caso de los datos Catastrales, se registran superficies construidas totales de cada inmueble, definido por su referencia catastral de veinte dígitos. La clasificación de usos permite descontar al total la parte correspondiente a usos no habitables (elementos comunes, garajes, trasteros, etc.). Aún así, quedarían por descontar las superficies ocupadas por los elementos constructivos (fachadas, elementos estructurales, tabiquería, etc.). El valor censal se acerca más al concepto de superficie acondicionada, no obstante la información se ofrece en valores medios por tramos para cada sección censal, lo que introduce un elemento de incertidumbre. Los valores catastrales son muy ajustados a la realidad. La implicación de la utilización de uno u otro valor para el cálculo energético son difíciles de valorar, algunos autores utilizan un factor del 20\% para transformar la superficie útil en construida en edificios multifamiliares (González-Vallejo et al. 2015).

Tabla 75. Comparación de resultados para ambos métodos en los barrios afectados. Elaboración propia

\begin{tabular}{|c|c|c|c|c|c|}
\hline Datos estadísticos & unidades & Aluche & Entrevías Este & Picazo & Vicálvaro \\
\hline Sup urbana & $\mathrm{Ha}$ & 9.38 & 39.46 & 17.46 & 96.65 \\
\hline Viviendas & Uds. & 2,250 & 2,875 & 4,005 & 9,890 \\
\hline Población & Habs. & 4,920 & 7,875 & 9,585 & 25,005 \\
\hline Sup útil & $\mathrm{m}^{2}$ & 144,777 & 262,039 & 188,980 & 653,043 \\
\hline Demanda Total & kWh & $19,142,415$ & $33,833,120$ & $24,763,761$ & $84,569,461$ \\
\hline Densidad energética & $\mathrm{kWh} / \mathrm{Ha}$ & $2,040,769$ & 857,403 & $1,418,314$ & 875,007 \\
\hline Demanda unitaria & $\mathrm{kWh} / \mathrm{m}^{2}$ & 132.22 & 129.11 & 131.04 & 129.50 \\
\hline Etiqueta HEEPEC & A-B-C-D-E-F-G & G & $F$ & F & $\mathbf{F}$ \\
\hline Datos catastrales & unidades & Aluche & Entrevías Este & Picazo & Vicálvaro \\
\hline Sup construida & $\mathrm{m}^{2}$ & 197,414 & 326,971 & 299,242 & $1,193,184$ \\
\hline Sup residencial & $\mathrm{m}^{2}$ & 185,551 & 263,821 & 221,136 & 815,041 \\
\hline Demanda Total & kWh & $9,461,669$ & $18,337,407$ & $18,740,536$ & $56,330,136$ \\
\hline Densidad energética & $\mathrm{kWh} / \mathrm{Ha}$ & $1,008,707$ & 464,709 & $1,073,341$ & 582,826 \\
\hline Demanda unitaria & $\mathrm{kWh} / \mathrm{m}^{2}$ & 50.99 & 69.51 & 84.75 & 69.11 \\
\hline Etiqueta MEPEC & A-B-C-D-E-F-G & D & E & E & E \\
\hline Comparativa & unidades & Aluche & Entrevías Este & Picazo & Vicálvaro \\
\hline Sup habitable & Desviación \% & $22 \%$ & $1 \%$ & $15 \%$ & $20 \%$ \\
\hline Demanda total & Desviación \% & $-102 \%$ & $-85 \%$ & $-32 \%$ & $-50 \%$ \\
\hline Demanda unitaria & Desviación \% & $-159 \%$ & $-86 \%$ & $-55 \%$ & $-87 \%$ \\
\hline
\end{tabular}


En lo que respecta a la demanda energética total, la generalización de resultados de la simulación de edificios tipo mediante datos estadísticos de los censos demuestra sobredimensionar claramente la demanda energética en todos los casos. El caso de Aluche presenta la desviación más llamativa, siendo el error de un 100\% superior en los resultados obtenidos mediante datos estadísticos. Le sigue el barrio de Entrevías Este con un $86 \%$ de desviación y Vicálvaro con un $50 \%$. En el caso del barrio de Picazo, la diferencia es más asumible (32\%).

Cuando se trata de calcular los valores unitarios de demanda de calefacción por superficie habitable, las diferencias en el computo de superficies y de estimación de la demanda total se multiplican, generando diferencias aun mayores en la calificación energética de los edificios de las muestras analizadas. La desviación es especialmente llamativa en el barrio de Aluche, que registra un valor un $159 \%$ superior en el método de estimación estadístico. Para el ajuste del modelo estadístico serían necesarios estudios pormenorizados atendiendo a las siguientes variables:

- Estudios específicos de las pérdidas por renovación de aire $\left(Q_{v}\right)$ en lo que respecta a las infiltraciones y a los hábitos de ventilación. En la actualidad se necesita generar conocimiento en este ámbito. Los edificios residenciales españoles suelen ventilarse de forma natural, sin sistemas de ventilación mecánica. Para la estimación de los caudales de aire es necesaria información ajustada como la altura en el edificio, las temperaturas ambientales, la exposición a los vientos dominantes, y la configuración constructiva (Meiss, Feijó-Muñoz, y Padilla-Marcos 2016). En lo que respecta a las infiltraciones no deseadas, la investigación avanza en la caracterización de la estanqueidad de las envolventes (Fernández-Agüera et al. 2019).

- El ajuste de las cargas internas $\left(Q_{i}\right)$ debidas a la ocupación, patrones de uso, iluminación artificial y utilización de equipos y electrodomésticos en los usos residenciales. Investigaciones previas indican que los valores de cálculo adoptados por la normativa en la herramienta de simulación para la estimación de demandas no siempre se corresponden con la realidad observada por estudios de monitorización de casos reales (Carmen Alonso 2015). 


\section{CAPÍTULO 4. ANÁLISIS DE RESULTADOS}

Para que estas variables se pudieran introducir en el modelo, sería necesario introducir valores representativos a la escala urbana. En la actualidad no se ha encontrado literatura existente que caracterice esos valores, por lo que se identifica aquí un ámbito de investigación para el futuro.

En el Anexo III se presentan fichas para la rehabilitación energética de barrios que contiene el resumen de los resultados arrojados en las diferentes fases de la metodología desarrollada. Se ha recopilado la información referente a los cuatro barrios examinados en detalle que se corresponden con tejidos urbanos característicos de áreas urbanas en riesgo de pobreza energética (Aluche, Entrevías Este, Picazo y Vicálvaro). En estas fichas se vuelcan indicadores relevantes provenientes de la información contenida en el Modelo de Análisis de Datos Espaciales. La información se obtiene mediante los procedimientos desarrollados en las diferentes fases de esta tesis, tal y como se explica en los CAPITULOS 2 y 3. La ficha-resumen recoge la siguiente información:

- Datos administrativos (Ayuntamiento de Madrid).

- Normativa urbanística de aplicación (PGOUM 1997).

- Datos acerca de los problemas de vulnerabilidad urbana en el ámbito (Atlas de Barrios Vulnerables).

- Estimaciones acerca de la demanda energética de calefacción a partir de datos estadísticos desagregados a la escala de la sección censal.

- Valoración del riesgo de Pobreza Energética (INE 2001 y 2011, Proyecto Urban Audit).

- Datos geométricos y urbanísticos (no de edificios, ocupación, edificabilidad, densidad...) calculados a partir del cruce de los datos catastrales con información estadística (Catastro, INE 2001 y 2011).

- Datos de la envolvente de la edificación del barrio, clasificados por elemento y por periodo de construcción (Catastro).

- Estimación de datos de eficiencia energética mediante la herramienta MEPEC.

- Pérdidas energéticas a través de la envolvente de todos los edificios del barrio.

- Incidencia de la radiación solar en la envolvente (fachadas por orientación y cubiertas). 
- Potencial de captación de energía solar pasiva que es capaz de captar la edificación residencial.

- Demanda energética de calefacción de la edificación residencial.

- Estimación de costes e impactos de las obras de reforma para la mejora de la envolvente de la edificación residencial anterior al año 1979. 



\section{CONCLUSIONES}

Se ha desarrollado la conceptualización de un Modelo de Análisis de Datos Espaciales (MADE) a escala urbana que contiene información precisa de la ineficiencia energética de la edificación residencial y sus consecuencias socioeconómicas asociadas. EI MADE permite planificar estrategias de rehabilitación en la ciudad desde la óptica de la equidad energética. Para ello es capaz de manejar información estadística de los Censos e información catastral acerca de la edificación. Además incorpora información de otras fuentes relevantes para el análisis de su vulnerabilidad energética, en concreto:

- Censos de Población y Viviendas (INE 1991; 2001; 2011)

- Oficina Virtual del Catastro (Sede Electrónica de Catastro 2011)

- Catálogo de Barrios Vulnerables de España (Agustín Hernández Aja et al. 2018)

- Indicadores Urban Audit para Ciudades (Ayuntamiento de Madrid 2018)

- Proyecto REFAVIV (Oteiza et al. 2016)

- Normas del Plan General de Ordenación Urbana (Ayuntamiento de Madrid 1997)

- Registro de la fundación DOCOMOMO Ibérico (Centellas et al. 2009)

- Atlas de la Edificación Residencial en España (Ministerio de Fomento 2013a)

- Barrios de promoción oficial (Luis Moya González, Ezquiaga, y Inglés Musoles 1983) 
Por primera vez se logra la integración en un solo análisis de las bases de datos del Catastro y de los Censos de Población y Viviendas para el análisis de la eficiencia energética del parque edificado. Se ha logrado el objetivo de realizar un método que permita la comparación los datos de los registros que contienen una mayor información de la edificación residencial del país.

El desarrollo de este modelo facilita la incorporación de criterios de eficiencia energética en las operaciones de Regeneración Urbana Integrada. Permite trazar estrategias dirigidas a la reducción de los consumos, la dependencia energética, las emisiones de $\mathrm{CO}_{2}$ y la contaminación en las ciudades, contribuyendo a amortiguar el agotamiento de recursos energéticos fósiles y el cambio climático. También servirá para mejorar la calidad del ambiente interior en los espacios habitados, obteniendo una repercusión positiva en la salud de las personas que los ocupan, mediante la mejora pasiva de la edificación. Como resultado de la mejora de la eficiencia de la edificación en el caso de barrios vulnerables, se lograría además el alivio de situaciones de pobreza energética (Atanasiu, Kontonastou, y Mariottini 2014).

Para su validación, se ha aplicado el modelo para el diagnóstico detallado de las necesidades de rehabilitación energética en áreas en riesgo de pobreza energética de la ciudad de Madrid. Se ha comprobado que la herramienta desarrollada es de utilidad para el diseño de "acciones específicas y mensurables y promover el acceso igualitario a la financiación para los consumidores que sufren pobreza energética y para las viviendas sociales" tal y como especifica la última revisión de la Directiva 2018/844/UE del Parlamento Europeo y del Consejo, de 30 de mayo de 2018, por la que se modifica la Directiva 2010/31/UE relativa a la eficiencia energética de los edificios y la Directiva 2012/27/UE relativa a la eficiencia energética (Parlamento Europeo y el Consejo de la Unión Europea 2018). En concreto, las directivas apuntan al diseño de estrategias para la rehabilitación de áreas urbanas con edificios ineficientes e insta a los estados miembros a establecer una estrategia a largo plazo para movilizar inversiones en la renovación del parque nacional de edificios residenciales y comerciales. Para el diseño de estas estrategias ha sido necesario evaluar cuantitativamente el estado actual de la edificación con objeto de ser precisos en la medición de sus envolventes y la estimación de su potencial de mejora. La actuación en barrios vulnerables ineficientes permite cumplir con 
el doble objetivo de combatir la pobreza energética al tiempo que se da cumplimiento a las directivas europeas.

La herramienta se compone de diversos métodos de evaluación cuyos resultados se vuelcan en un único Modelo de Análisis de Datos Espaciales capaz de integrar información desde varias escalas. La geolocalización de la información se ha realizado principalmente mediante dos identificadores espaciales: (1) por un lado se utiliza la Referencia Catastral de 14 dígitos para asociar la información relativa a la edificación y (2) para la escala urbana se utiliza la sección censal como unidad que presenta el mayor nivel de desagregación estadística posible. La visualización de los resultados mediante Sistemas de Información Geográfica permite obtener una visión global de la distribución de las problemáticas analizadas para toda la ciudad. Además permite ampliar la escala para analizar en detalle las áreas de interés y cuantificar las necesidades energéticas desde la evaluación pormenorizada de la edificación. Este proceso concluye en el desarrollo de indicadores para la caracterización de los barrios.

Se ha calculado la demanda energética de calefacción para cada edificio residencial de los barrios en riesgo de pobreza energética y se han identificado una serie de indicadores complementarios para la caracterización del comportamiento pasivo de los edificios y mediante su agrupación, para barrios enteros. Se comprueba que en estos barrios existe un porcentaje de edificios obsoletos sensiblemente mayor a la media de la ciudad, construidos con anterioridad al año 1979.

El coeficiente global de pérdidas energéticas $\left(\mathrm{K}_{\mathrm{G}}\right)$ es un buen indicador de la calidad térmica de la envolvente de un edificio y permite estimar una horquilla de variabilidad de las necesidades energéticas para calefacción de un edificio. A partir de esta suposición se desarrolla el método de cálculo de la demanda para áreas urbanas utilizando datos estadísticos y la simulación energética de edificios tipo (CAPITULO 2). No obstante, el análisis pormenorizado utilizando datos catastrales (CAPITULO 3) demuestra que la calidad térmica de la envolvente no es el indicador que más influye en la demanda energética de calefacción, a pesar de ser el más utilizado para definir los estudios de rehabilitación energética hasta el momento. Esto se demuestra por la baja correlación que presenta esta variable $\left(\mathrm{K}_{\mathrm{G}}\right)$ con la demanda energética unitaria de calefacción $\left(D_{\mathrm{cal}} / \mathrm{S}_{\mathrm{hab}}\right)$ en la mayor parte de los tejidos urbanos analizados. Existe una influencia 
importante de otras variables relacionadas con la morfología urbana que inciden sobre las necesidades de energía. Factores como la altura media, la compacidad y el indicador de pérdidas energéticas por unidad de volumen edificado (IEE $\mathrm{urb}_{\mathrm{rb}}$ ) presentan mayores niveles de correlación con la demanda de calefacción. La orientación está fuertemente correlacionada con la demanda en las áreas que reciben cantidades importantes de energía solar pasiva en invierno (de los casos analizados, el Poblado Dirigido de Entrevías es el más beneficiado por esta variable).

Se ha constatado que, a través de la rehabilitación energética de la envolvente en operaciones de barrio, se puede reducir de manera muy importante la demanda de calefacción a escala urbana (del 72 al 89\% adoptando las soluciones propuestas en este estudio). Se identifican algunos casos de edificios en los que es posible conseguir edificios solares pasivos que tengan una demanda de calefacción muy reducida o incluso cercana a cero. Se trata de los edificios que cuentan con alta compacidad y una buena orientación de partida. En estos casos la mejora de las prestaciones de la envolvente es un paso definitivo para frenar el derroche energético y para la consecución de edificios de consumo casi nulo. En general, y especialmente estos casos, será necesario realizar los estudios pertinentes para controlar la demanda energética de refrigeración durante los meses de verano, ya que la consecución de edificios pasivos depende de ambos factores. La herramienta permite identificar también los casos en los que la reducción demanda no consigue llegar a valores deseables y para ellos se pueden proponer medidas más ambiciosas, por ejemplo incluir mayores espesores de aislamiento en los elementos más débiles de la envolvente.

\section{La identificación de la ineficiencia y la pobreza energética en la ciudad}

Se ha conseguido el objetivo de desarrollar un método de detección de la pobreza energética que incluye la consideración de la eficiencia de las viviendas a través del concepto de vulnerabilidad energética asociada a la edificación. El método es replicable para todo el país y completa una carencia detectada en los indicadores de pobreza energética utilizados habitualmente, que no habían contemplado aspectos relacionados con la edificación hasta el momento. 
Se ha obtenido una estimación de la demanda de calefacción a la escala de la ciudad aplicando el método de cálculo desarrollado en el CAPITULO 2, que consiste en la generalización de los resultados de la simulación energética de edificios tipo a partir de datos estadísticos. La calificación energética en demanda de calefacción para uso residencial en la ciudad de Madrid sería de clase F. La necesidad de energía térmica es de unos 924.333 kteps (10.752.274 MWh) para poder mantener las viviendas en situación de confort durante todo un invierno típico. El valor aproximado del potencial de mejora de la demanda energética mediante la rehabilitación de la edificación se estima en un $46 \%$ si se consigue subir la calificación en dos letras (D), hasta el estándar mínimo exigido por el CTE. Esto supondría una notable mejora del confort y la reducción de los consumos energéticos y emisiones contaminantes, lo que redundaría en una sensible mejora del medio ambiente urbano. En este caso la demanda de energía térmica se reduciría a unos 495.918 kteps (5.767.530 MWh).

Se ha calculado la demanda energética de calefacción de áreas urbanas y se han determinado indicadores de pobreza energética a partir de datos estadísticos. A partir del solapamiento de los anteriores indicadores se han podido definir las áreas en situación de vulnerabilidad energética en toda la ciudad. Las zonas de rehabilitación prioritaria se perfilan en aquellos barrios vulnerables periféricos cuya edificación tiene unas características que la hacen menos eficiente. Se comprueba la hipótesis obtenida de la literatura existente, que apunta hacia las áreas de periferia que contienen edificación residencial multifamiliar construida entre los años 40 y 80 . En Madrid el área de periferia que produce el mayor derroche de energía en calefacción corresponde al Barrio del Pilar, que representa el mayor sumidero de energía de la ciudad, con alta densidad de vivienda y condiciones constructivas precarias. Destacan también por sus densidades energéticas el Barrio de la Concepción y el de Ventas, Comillas, Santa Eugenia, Peñagrande y Marroquina. También se perfilan como grandes dispersoras de energía en la ciudad las zonas de los primeros ensanches decimonónicos, por su alta densidad de vivienda construida en un alto porcentaje con anterioridad a la entrada en vigor de la norma NBE CT 79. Destacan los barrios de Pacífico, Ibiza, Arapiles y Acacias/La Chopera. Estas zonas contienen en general una edificación de mejor calidad que en las periferias y mejores equipamientos de calefacción que no se ha tenido en cuenta al incluir todos los edificios anteriores a 1979 en un mismo rango. Por estas razones su intervención es prioritaria 
desde el punto de vista medioambiental, pero no presentan la problemática social existente en los barrios vulnerables periféricos producidos durante el periodo del 40-80.

La hipótesis de que las personas desfavorecidas habitan los edificios más ineficientes no se ha demostrado. No se aprecia una relación directa entre las zonas clasificadas como barrios vulnerables y la eficiencia energética de la edificación residencial, ya que se dan circunstancias muy distintas de calidad térmica de la edificación en los diferentes barrios vulnerables (Figura 44). No todos los barrios vulnerables de la ciudad contienen edificación ineficiente. Aunque comparten la dificultad añadida que supone la promoción de la rehabilitación en barrios con escasez de recursos, es de suponer que aquellos en los que la ineficiencia energética supone un agravante a los problemas de vulnerabilidad urbana presentarán mayores riesgos para la salud causados por largos periodos en situación de falta de confort.

Se han detectado aquellas áreas en las que la población sufre alta probabilidad de encontrarse en situación de pobreza energética de acuerdo con la regla del $10 \%$. Se trata de la identificación de las secciones censales en las que el valor medio del coste de la factura energética supera el $10 \%$ de la media de ingresos en el hogar. Para tratar de discriminar aquellos casos en los que se estuvieran produciendo altos consumos energéticos pero los ingresos del hogar fueran elevados, se ha desarrollado un índice multidimensional que incorpora otros criterios socioeconómicos. El criterio de selección de áreas vulnerables a la pobreza energética a partir del solape multidimensional de indicadores de riesgo en barrios vulnerables con edificación ineficiente -(1) bajos ingresos, (2) elevados costes energéticos, (3) instalaciones inadecuadas y (4) población mayor- resulta efectivo para afinar el criterio de gastos e ingresos. Este índice multidimensional se perfila como un método valido para la delimitación de áreas en riesgo de pobreza energética al incorporar criterios sociales a los meramente económicos. En función de la cantidad de factores agravantes que inciden en un mismo ámbito urbano, permite valorar la severidad del problema. La máxima severidad se ha detectado en aquellas áreas que contienen los cuatro factores agravantes coincidentes en las mismas secciones censales, obteniendo una serie de barrios donde la problemática se puede considerar crítica. No obstante, llama la atención como en el distrito de Villaverde, que contiene amplias superficies y numerosa población afectada por los 
distintos indicadores de pobreza energética -en barrios como San Cristóbal o San Andrésno aparece ningún barrio con el riesgo máximo porque no se llegan a solapar los indicadores en la misma sección censal. Se concluye que el criterio de simultaneidad, si bien permite identificar áreas críticas y debe ser tenido en cuenta como agravante, no es definitivo a la hora de identificar a todos los barrios en riesgo de pobreza energética. En ese sentido se recomienda incluir en los planes de emergencia contra la pobreza energética todos los barrios que obtengan una puntuación de 4 o 5 en el índice multidimensional. El listado de estos ámbitos aparece en la Tabla 23. La información gráfica acerca de estos ámbitos aparece en el Atlas de Pobreza Energética en Barrios Vulnerables e Ineficientes de Madrid recogido en el Anexo I.3.

Tampoco se demuestra la hipótesis de que la rehabilitación energética sea una herramienta capaz de erradicar la pobreza energética por sí sola. Los resultados obtenidos apuntan a reducciones drásticas de la demanda de calefacción mediante la intervención en la envolvente opaca en barrios enteros (Tabla 71). A pesar de la sustancial mejora de la situación, el análisis de los costes y beneficios (regla del 10\%) concluye que incluso en edificios con etiqueta energética $A$, con la actual estructura tarifaria, no es posible salir de la pobreza energética con el Salario Mínimo Interprofesional o con la Renta Básica de Inserción (tablas 21 y 22). Por lo tanto, se demuestra la necesidad de incluir medidas sociales diseñadas para aliviar las necesidades energéticas de los hogares sin recursos como es el bono social. En cualquier caso la cuantía necesaria para subvencionar estas ayudas resultará muy reducida tras la rehabilitación energética.

Los 11 barrios en los que se dan todos los indicadores del riesgo de Pobreza Energética simultáneamente contienen a una población de 114.380 habitantes, tienen su parque de viviendas mayormente ocupado, con un porcentaje de viviendas principales (86\%), por encima de la media de Madrid (78\%). También tienen, en general, un menor porcentaje de viviendas vacías. El tamaño medio del hogar es alto, se trata de barrios con una ocupación por encima de los valores medios de Madrid. Por tanto se evidencia que la intervención en estos barrios vulnerables va a significar altos beneficios para una gran cantidad de población. 


\section{Del Método de Evaluación de Pérdidas Energéticas a partir de Catastro}

La aplicación de las técnicas de programación para el análisis de Sistemas Complejos (Big Data) aplicado a la Ciencia de Datos Urbanos (Urban Data Science) abre la vía para la automatización del proceso de datos y realizar estudios que incluyan amplias áreas de análisis. Esto permite recoger información muy exacta de la eficiencia energética de la edificación en tejidos urbanos complejos, superando las simplificaciones de los análisis basados en muestras de edificios representativos. El tratamiento de las bases de datos de información catastral permite nuevos niveles de detalle en los estudios urbanos que eran imposibles hasta el momento de la publicación de estos datos en abierto. En ese sentido se valora muy positivamente el trabajo de la Comisión Permanente del Catastro de la Unión Europea a favor de la transparencia de los datos existentes en estos registros públicos.

Utilizando estos datos catastrales se ha desarrollado un procedimiento detallado para el diseño de estrategias de rehabilitación energética que permite una cuantificación teórica de la transferencia de calor por conmducción a través de la envolvente de la edificación (MEPEC). Se ha podido definir un indicador de eficiencia energética pasiva para tejidos urbanos que engloba aspectos del urbanismo y la arquitectura (las dimensiones, orientación y forma de los edificios y su disposición urbana) y aspectos constructivos (la calidad de los elementos de la envolvente, el porcentaje de huecos). Este indicador es útil para detectar áreas prioritarias de edificación ineficiente y dentro de ellas define cuales son los edificios más vulnerables. De los resultados se desprende que los aspectos geométricos tienen una gran influencia en las pérdidas energéticas, además de los aspectos constructivos en los cuales se focaliza normalmente la atención.

El volumen de los datos demuestra ser eficaz para el diagnóstico de las necesidades a la escala de barrio. La potencia en el manejo de datos de las aplicaciones para Big Data abre la posibilidad de su aplicación a escala municipal y, a partir de la adición de municipios, hacer estimaciones de las necesidades a escala estatal.

A partir de los resultados de este método se han estimado indicadores para la caracterización de la eficiencia energética a la escala urbana. Algunos de estos parámetros pueden incorporarse en los Estándares de Calidad Urbana de las ciudades españolas (Agustín Hernández Aja 1995) para que estos índices puedan incluir 
información acerca de la eficiencia energética de los tejidos urbanos. En concreto la metodología propuesta hace posible determinar, a partir de resultados pormenorizados para cada edificio, los datos agrupados por barrios de al menos los siguientes factores influyentes:

- Superficie acondicionada -por usos $\left(\mathrm{m}^{2}\right)$

- Superficie y orientación de cada elemento de la envolvente $\left(\mathrm{m}^{2}\right)$

- Altura $(\mathrm{m})$ y volumen $\left(\mathrm{m}^{3}\right)$ de la edificación

- Compacidad $\left(\mathrm{m}^{3} / \mathrm{m}^{2}\right) /$ Factor de Forma $\left(\mathrm{m}^{2} / \mathrm{m}^{3}\right)$

- Densidad:

- Bruta

○ RSD (Residencial Surface Density): Densidad residencial

- FAR (Floor/Area ratio). Ocupación

- BCR (Building Coverage Ratio). Edificabilidad

- $\mathrm{K}_{\mathrm{Gurb}}$ Coeficiente de Transmisión Térmica Global Urbano $\left(\mathrm{W} / \mathrm{m}^{2} \mathrm{~K}\right)$

- $\mathrm{Q}_{\mathrm{t}}$ Perdidas energéticas totales por edificios, barrios, usos, ... (kWh)

- $\mathrm{IEE}_{\mathrm{urb}}$ Indicador de Eficiencia Energética urbano $\left(\mathrm{kWh} / \mathrm{m}^{3}\right)$

- Dcal Demanda de calefacción total y unitaria, por edificio residencial y para barrios residenciales

- Radiación solar incidente en la envolvente (fachadas este-sur-oeste y cubiertas)

Se verifica, para los barrios estudio de caso, que las fachadas son el elemento que provoca las mayores pérdidas energéticas de toda la edificación. La cubierta significa el elemento más débil de la envolvente, pero computa una menor cantidad de pérdidas en valor absoluto porque su superficie es menor que la de las fachadas. Esto es debido a que la edificación residencial en Madrid se organiza principalmente en multifamiliares en altura. De la edificación residencial, solamente el tipo unifamiliar registra las mayores pérdidas en la cubierta. Los suelos son los elementos con menores pérdidas, en el estudio de caso representan la mitad de las pérdidas de la cubierta. A pesar de que su superficie bruta es prácticamente la misma, la transmisión térmica a través de los mismos es menor. Los suelos en contacto con el aire exterior son los más débiles, pero apenas representan el $2 \%$ del total de suelos. Además, están contenidos en la edificación más moderna, con lo que el desempeño térmico de estos elementos se presume de mejor 
calidad que los de periodos anteriores a la normativa NBE CT 79. Para un mejor ajuste del modelo es necesario avanzar en la caracterización de los huecos en fachada, puesto que las ventanas son elementos de vida útil relativamente corta para la escala de la edificación y no pueden caracterizarse a partir del periodo de construcción. Para una caracterización pormenorizada del estado actual de los huecos de fachada es necesario un trabajo de campo con más profundidad en los barrios a analizar.

Se ha podido aumentar notablemente la resolución de los estudios energéticos a escala urbana, que hasta la fecha se han realizado a partir de la utilización de datos estadísticos agregados proveniente de los Censos de Población y Vivienda para definir clústeres de ineficiencia. Esto permite mayor nivel de resolución en el análisis urbano con respecto de estudios anteriores. La información catastral permite utilizar el edificio como unidad de análisis, contando con una ficha de datos energéticos para cada edificio (individuo) asociado a su referencia catastral. Además, si el tratamiento de la información catastral se agrupa a la escala de la sección censal, se posibilita la comparación de ambos cuerpos de datos. A modo de ejemplo: agregando al modelo datos estadísticos de población por sección censal es posible obtener información relevante para un análisis socio-económico de las necesidades de energía por persona, grupos de edad, nivel de estudios, etc.

\section{La demanda energética de calefacción en los barrios}

Se confirma la hipótesis de que la demanda de calefacción es un indicador adecuado para caracterizar situaciones de vulnerabilidad energética en viviendas, edificios y zonas urbanas. Los estándares de confort supuestos por la normativa no tienen en cuenta la variabilidad de los hábitos energéticos de los usuarios, pero demuestran su utilidad a la hora de establecer comparaciones objetivas entre unas edificaciones y otras.

Del análisis realizado se desprende que la intervención en la envolvente opaca es una medida prioritaria para reducir drásticamente la demanda de calefacción en los barrios ineficientes. La intervención en fachadas es prioritaria desde el punto de vista de la reducción de la demanda y la intervención en cubiertas para mejorar el confort en las plantas altas de edificios multifamiliares y la reducción de la demanda en viviendas unifamiliares y edificios terciarios. 
La ciudad de periferia en bloque de 4 a 6 alturas presenta las características más eficientes en cuanto a la conservación de la energía por su alta compacidad. Esta compacidad se ve influenciada por el fondo del bloque. El impacto de la rehabilitación energética de la envolvente en estos edificios es muy alto, con las soluciones planteadas se consigue reducir la demanda de calefacción hasta límites muy bajos, en muchos casos, en los que la orientación es adecuada, los valores llegan a ser cercanos a cero. La equidad energética se puede empezar a plantear desde el momento en el que se decide incorporar un aislamiento térmico en la edificación. A modo de ejemplo, en estas áreas de bloque abierto con cuatro viviendas por planta de una sola orientación (como en el caso de Aluche) se podría compensar la diferencia de incidencia de radiación solar de la que se benefician las viviendas con orientación sur, aumentando el espesor de aislamiento térmico en las viviendas de orientación norte, que no reciben radiación solar, para así equilibrar el balance energético entre pérdidas y ganancias. Este análisis se debería acompañar de un estudio de la obstrucción solar entre los bloques, que podría estar afectando en algunos bloques a las plantas más bajas a pesar de contar con una orientación sur.

Los tejidos con morfología de parcelación periférica presentan un alto potencial de reducción de la demanda si se interviene, además de en las fachadas, en los muros medianeros en contacto con el aire exterior. Los costes en estas intervenciones se pueden ver incrementados por la dificultad añadida de instalar medios auxiliares sobre las cubiertas contiguas. Esta operación se debe realizar con garantías para la adecuada conservación de las mismas. El análisis de costes se debe afinar para estos casos particulares.

Para las áreas con tejidos unifamiliares la intervención es absolutamente necesaria. La baja compacidad de estos edificios hace que sus demandas energéticas de calefacción sean las más elevadas de la muestra, especialmente en las viviendas con tres fachadas: pareadas o en esquina en las hileras, y los unifamiliares exentos. Estos resultados son coherentes con los obtenidos por el proyecto SPAHOUSEC del IDAE. En los casos en los que la orientación sur, la radiación solar pasiva compensa en parte las pérdidas, y mediante la rehabilitación energética se pueden lograr edificios que se comporten de forma pasiva en el periodo de invierno. En los casos en los que la compacidad es muy 
baja o en aquellos unifamiliares con mala orientación, es posible que las medidas de mejora necesiten ser más ambiciosas que las planteadas en este estudio. Serán necesarios estudios pormenorizados para estos casos. En cualquier caso la intervención en cubiertas es una medida prioritaria para los edificios residenciales anteriores a 1979.

Los barrios de tejidos mixtos que contienen áreas con diferentes tipos de trama urbana, como es el caso de Vicálvaro o Entrevías Este, necesitan una definición pormenorizada de los distintos ámbitos en función de la tipología edificatoria que contienen. Se deben dividir los barrios en ámbitos de ordenamiento homogéneo. Los tipos recurrentes que se han encontrado en este estudio son áreas de unifamiliares, de parcelación periférica y tejidos de bloque abierto. Estos últimos también se pueden clasificar en función de su morfología, en función del ancho del bloque, y si las viviendas que contienen son pasantes o tienen una sola orientación.

La estimación de demandas energéticas mediante la generalización de resultados de edificios tipo por medio de datos estadísticos demuestra un error de sobredimensionado importante en gran parte de los casos. En el Apartado 2.1 se ha estimado mediante simulación energética la demanda de los edificios, catalogando los anteriores a 1979 de manera genérica como clase G. Al realizar los cálculos de manera pormenorizada para cada edificio, se constata que esta clasificación se corresponde con los edificios de esta época que tienen peores condiciones urbanas (principalmente una compacidad baja y poca incidencia de la radiación solar). Los edificios muy compactos y con buena orientación pueden presentar una clasificación energética de demanda de calefacción de hasta clase D, equiparables a otros edificios construidos en el periodo 1979-2006, o incluso llegando en algún caso a cumplir con las exigencias del Código Técnico de la Edificación (CTE-DB-HE 2006) en lo que respecta a la demanda de calefacción. La metodología de datos catastrales resulta mucho más exacta y debería usarse en los planes de rehabilitación integral para una estimación ajustada de la demanda energética a la escala de barrio. Los resultados de ambos procedimientos solamente se aproximan para el caso del tejido de parcelación periférica analizado. No obstante, el método estadístico demuestra su utilidad para la localización de áreas ineficientes.

Los planes de rehabilitación energética deben incluir medidas para la mejora de los edificios terciarios además de los residenciales ya que se ha detectado que disipan 
grandes cantidades de energía. Dentro de estos, los edificios que tienen un uso parcial (escolares, administrativos, comercios...) no generan tanta demanda como las viviendas, aunque si grandes pérdidas a través de la envolvente. Los mayores consumidores serían los edificios terciarios de uso $24 \mathrm{H}$ (sanitarios, hoteles).

\section{La rehabilitación de las envolventes, sus costes y beneficios}

La comparación de los resultados arrojados por la herramienta MEPEC acerca de las pérdidas energéticas a través de la envolvente en el modelo del estado actual, con diferentes escenarios mejorados, ha permitido estimar el potencial de reducción de la demanda de calefacción en distintos tejidos urbanos. El modelo permite introducir información de la transmitancia térmica de distintas soluciones para cada elemento de la envolvente (fachada opaca, ventanas, cubiertas y suelos). Introduciendo datos unitarios del coste de las mejoras, se puede aproximar el orden de magnitud de la inversión total necesaria para mejorar la envolvente en operaciones de rehabilitación energética de barrios. Puesto que la definición de los $\mathrm{NZEB}^{3}$ para cada país europeo se concreta a través de la metodología del coste óptimo, el trabajo que aquí se presenta resulta de utilidad para definir aspectos de demanda energética en la definición del concepto de "Barrios de Energía Casi Nula (BECN)". También se obtiene una información útil para el diseño de infraestructuras de abastecimiento de energía, y sistemas de calefacción por distrito.

Se ha comprobado, utilizando herramientas específicas para el cálculo de costes de la construcción, que el presupuesto de ejecución material se reduce en más de un $10 \%$ cuando se amplía suficientemente la escala de la actuación con respecto al coste que supondría la rehabilitación de cada uno de los edificios de manera individual. En concreto, la intervención para la rehabilitación energética a la escala de un barrio de tamaño medio, como es el Poblado Dirigido de Canillas, que comprenda la mejora de la envolvente de todos los edificios anteriores a 1979, supone un ahorro del $12,4 \%$. La reducción de los costes se produce básicamente en el precio unitario de adquisición de

${ }^{3}$ Nearly zero energy building, en español: edificio de consumo casi nulo 
los materiales. En cambio, la mano de obra necesaria no se ve reducida con el aumento de la escala, teniendo la intervención a escala de barrio un potencial de generación de empleo muy similar a la rehabilitación edificio por edificio.

En caso de demandas energéticas de calefacción satisfechas, el retorno de la intervención se puede definir, para la totalidad de la edificación del barrio de Canillas, de manera lineal en 0,55 kWh anuales de reducción de pérdidas por cada euro invertido. Este indicador es útil para estimar el potencial de mejora de la inversión en medidas pasivas y poder así comparar su rentabilidad con otras medidas dirigidas a la mejora de la eficiencia energética de la edificación como son la mejora del rendimiento de las instalaciones térmicas, y la instalación de energías renovables. El retorno de la inversión promedio para el barrio se puede estimar en unos 18 años, suponiendo que se mantienen los precios actuales de la energía (opción conservadora). La reducción anual de emisiones de $\mathrm{CO}_{2}$ que se conseguiría mediante la rehabilitación energética se puede estimar de manera simplificada en $0.547 \mathrm{kgCO}_{2}$ por cada $\mathrm{kWh}$ de reducción de pérdidas conseguido.

La repercusión de la rehabilitación energética en la generación de empleo es de 132 contratos anuales de trabajo para los bloques de Aluche (1.11 contratos por edificio rehabilitado), 184 contratos en Entrevías, con múltiples edificios unifamiliares intervenidos (0.19 por edificio rehabilitado), 205 en el área de edificación discontinua en tejido de parcelación periférica de Picazo (0.85 por edificio) y 658 en el pueblo anexionado de Vicálvaro (0.95 por edificio).

Todas las estimaciones basadas en este modelo teórico se han realizado bajo la suposición de demandas de calefacción satisfechas. Esta situación resulta dudosa en un barrio con altos indicadores de riesgo de pobreza energética, en el que existen altas probabilidades de que los ingresos del hogar sean insuficientes para cubrir las demandas energéticas. Por esta razón, los resultados se deben utilizar con gran cautela en la estimación del ahorro en las facturas. Para conseguir una estimación más precisa resulta necesario calibrar el modelo mediante datos reales de consumos energéticos. Es de suponer que dichos consumos, y por tanto los ahorros derivados de la rehabilitación energética, serán menores en barrios con alto riesgo de pobreza energética, donde el consumo de energía se puede ver reducido debido a que los elevados costes de la 
energía se traducen en demandas no satisfechas. Dicho esto, los periodos de amortización estimados en este trabajo son coherentes con los de estudios anteriores.

Tras la rehabilitación energética de las envolventes del parque mas obsoleto, edificado con anterioridad a 1979, quedará un grupo de edificios construidos durante el periodo de vigencia de la NBE CT 79 (1980-2006) que pasará a ser la nueva bolsa de ineficiencia. La rentabilidad de su posible intervención irá cobrando fuerza a medida que se vayan produciendo los escenarios previstos de aumento en los precios de la energía. Estos edificios quedan muy lejos de cumplir con las exigencias europeas.

Desde el punto de vista de la conservación del patrimonio edificado, la modificación del aspecto exterior de los paramentos de la edificación podría entrar en conflicto en ciertos casos con el valor patrimonial de la arquitectura. No es habitual que los edificios del periodo del 40 al 80 estén incluidos en el catálogo de edificios protegidos (Ayuntamiento de Madrid s. f.), pero la incorporación de algunas de estas promociones en el archivo "La Vivienda Moderna" del catálogo de DOCOMOMO (Centellas et al. 2009) y el interés que suscita el valor patrimonial de ciertas experiencias como legado del Movimiento Moderno, ha generado estudios para su recuperación e integración en la ciudad (Fernández Nieto 2006; Guillem González-Blanch 2013b; Díez de Pablo 2015), con el objetivo de poner en valor sus valores urbanos y arquitectónicos.

\section{Energía solar para los barrios}

En el clima de Madrid, la mayor parte de la radiación solar total que incide sobre la envolvente a lo largo del año se recibe durante el periodo de calefacción, que se contabiliza de 8 meses, frente al periodo de refrigeración, considerado en 4 meses. Esta radiación incide principalmente en las fachadas sur, sureste y suroeste. En el periodo de invierno es en el cual se producen los mayores consumos energéticos del sector residencial en Madrid, causados principalmente por el gasto en calefacción. No obstante, de toda la radiación solar incidente en la envolvente, tan solo un $2 \%$ está siendo aprovechando para el calentamiento solar pasivo. En ese sentido, se recomienda incluir en las normas zonales la posibilidad de permitir la apertura de ventanas en fachadas orientadas a sur para reducir la demanda de calefacción mediante el incremento de la captación solar pasiva. Para ello será necesario un análisis pormenorizado que incluya la 
evaluación del impacto de la medida en la demanda de refrigeración. Los resultados también apuntan a la idoneidad de las instalaciones de energía solar en fachadas soleadas orientadas a sur, para priorizar la producción de energía renovable durante el invierno, cuando la incidencia solar es perpendicular a estas fachadas.

La consecución de Barrios de Energía Casi Nula implica la necesidad de introducir la generación de energía limpia destinada a calefacción y otros servicios, lo que implica reducir el uso de gas natural y otros combustibles fósiles. En ese sentido, el aprovechamiento de la energía solar en invierno tiene sentido en una ciudad como Madrid. La demanda energética de calefacción representa entre un 22\% (Vicálvaro) y un 39\% (Aluche) de la radiación solar total incidente durante el periodo de invierno en las cubiertas (kWh). Dado que la radiación solar sobre las cubiertas es menor en los meses en los que la demanda de calefacción es mayor, parece difícil que se pueda cubrir la demanda mediante la producción. Después de la rehabilitación de la envolvente propuesta, la demanda pasaría a suponer entre el 4-5\% de la radiación en Aluche, Picazo y Vicálvaro, y en torno al 7\% en Entrevías Este. Estos valores hacen suponer que la producción de energía renovable de manera distribuida es una oportunidad factible para cubrir las necesidades energéticas en los barrios rehabilitados, lo que permitirá generar recursos propios en las áreas vulnerables que, conectadas a una red de distribución, pueden ser compartidos conforme a las necesidades y potencial de distintos barrios.

\section{La participación del usuario}

A menudo se cita la concienciación y la información al consumidor como imprescindibles para lograr ahorros energéticos en el hogar. Si bien el usuario final tiene un margen para poner en práctica hábitos de vida dirigidos a mejorar el confort y reducir el consumo, la situación de derroche en la edificación anterior a 1979 causada por la obsolescencia térmica de sus envolventes deja poco margen de actuación. El peso de las pérdidas energéticas a través de la envolvente se demuestra tan disparado que la capacidad de influencia del consumidor final es proporcionalmente reducida. El estudio demuestra que una vez rehabilitados los edificios para la mejora de su envolvente opaca, el factor que más determinará el consumo energético de los edificios será el comportamiento del usuario. Se habrá solucionado el principal problema de derroche de 
energía y se abrirá la vía para el control de la situación a través del empoderamiento de los habitantes. Los hábitos de ventilación y las estrategias de aprovechamiento de la energía solar pasiva, además del control sobre las cargas internas, serán determinantes. A partir de ese momento la concienciación y la formación de la sociedad tendrá sentido para la consecución de los objetivos ambientales marcados por las directivas europeas.

La estructura tarifaria española para el consumidor doméstico redunda actualmente en mayores precios por kWh en la factura energética para los que menos consumen. Esto ocurre tanto en la factura de la electricidad como para el gas natural. Esta situación también desincentiva el ahorro energético y la inversión en eficiencia energética, además de penalizar a la población de bajos ingresos. La inversión en eficiencia energética a la escala de barrio para mejorar la calidad térmica de la envolvente opaca reduce considerablemente los consumos energéticos necesarios para mantener los hogares en situación de confort. Se trata de una condición necesaria, no obstante, en hogares sin ingresos no es posible reducir el coste de la factura energética por debajo del $10 \%$ por muy eficiente que sea la vivienda. La reducción de tarifas a los pequeños consumidores al tiempo que se penalizan los consumos excesivos, puede ser una motivación directa para suscitar el interés de los usuarios en la eficiencia energética, traducida en ahorros económicos. 



\section{LÍNEAS DE INVESTIGACIÓN ABIERTAS}

La Norma (ISO 13790 2008), en su anexo A de aplicación a edificios existentes, indica que las necesidades energéticas de estos edificios se deben evaluar con la máxima precisión posible a partir de datos registrados, facturas o mediciones. Además se deben tener en cuenta datos climáticos reales y condiciones interiores reales. La información desarrollada aquí se puede emplear para una clasificación de la edificación y tiene su potencia en la posibilidad de evaluar grandes cantidades de edificios. Para estimaciones reales, es necesario completar estos datos con mediciones basadas en la observación científica. En ese sentido, se está desarrollando en el Instituto Eduardo Torroja de ciencias de la construcción, por parte del Grupo de Investigación de Sistemas Constructivos y Habitabilidad en la Edificación, el proyecto Habita_RES: Nueva herramienta integrada de evaluación para áreas urbanas vulnerables. Hacia la autosuficiencia energética y a favor de un modelo de habitabilidad biosaludable, cuyo Investigador Principal es Ignacio Oteiza, codirector de la presente Tesis. Con el objetivo de mejorar las condiciones de habitabilidad y salud de la población a partir de la reducción de la dependencia energética en barrios vulnerables en el marco de la Regeneración Urbana Integrada, el proyecto contempla campañas de monitorización in situ del confort y el consumo de un conjunto de viviendas situadas en barrios vulnerables. La obtención de información empírica permitirá calibrar los modelos energéticos de los barrios con datos de casos reales, y mediante la generalización de esta información afinar la predicción de los consumos que resultarían tras la rehabilitación energética y los ahorros económicos obtenidos. El Modelo desarrollado en esta tesis permitirá recoger estos datos y gestionarlos. 
Un siguiente paso que resulta necesario para completar el modelo generado en este trabajo es la incorporación de la demanda energética de refrigeración. Esta necesidad va ganando importancia en el actual contexto de cambio climático que está aumentando la frecuencia y duración de las de calor y aumentando las temperaturas medias en verano en una buena parte de las ciudades europeas. Si bien en Madrid el consumo de energía para refrigeración sigue siendo poco significativo de acuerdo con los estudios existentes que permiten desagregar los diferentes servicios energéticos del hogar, las altas temperaturas registradas en el interior de las viviendas hacen necesario abordar el problema. Mediante la herramienta en su estado actual es posible realizar una estimación muy gruesa de los barrios que tienen un mayor riesgo de calentamiento en verano. Para ello se podría analizar las variables influyentes en la cantidad de radiación recibida por la envolvente en periodo de verano, a partir de la evaluación de áreas de fachadas soleadas y superficies de cubierta. No obstante, la demanda de refrigeración no presenta una gran dependencia de la calidad de la envolvente, siendo determinada en mayor parte por factores distintos que deben ser objeto de estudios particularizados. Estos estudios deberán centrarse en una definición más precisa de la superficie de huecos por orientación, además de profundizar en el fenómeno de las obstrucciones solares que supone cada trama urbana y la vegetación, además de otros factores. Para ello sería interesante desarrollar una segunda herramienta complementaria a MEPEC que aproveche la definición volumétrica del catastro para definir un modelo de cálculo de la radiación solar. Esta herramienta, que se ha denominado MESOL, tendría una integración sencilla en el modelo desarrollado.

La estimación de la radiación solar incidente en las envolventes se ha realizado en base estacional - para todo el invierno- con el objetivo de obtener un orden de magnitud de la radiación solar pasiva que permita realizar estimaciones de la demanda de calefacción de los edificios residenciales. El modelo propuesto permite un análisis mensual de la radiación solar incidente en cubiertas que permita conocer el potencial de captación de energía solar renovable de manera comparada con la demanda mensual de calefacción. Esta información resulta imprescindible para el dimensionado de instalaciones de energía solar, puesto que los meses más fríos, con mayor demanda, son los que tienen un menor aporte de radiación solar en las cubiertas. En ese sentido el MADE permite también computar la radiación solar incidente en fachada sur que, como 
se ha visto, es mayor en los meses de invierno que en los de verano. Para este fin el desarrollo de la herramienta MESOL también podría resultar de enorme utilidad.

Otro avance interesante para el perfeccionamiento del MADE es sin duda la inclusión de un módulo de Análisis de Ciclo de Vida para una evaluación de las propuestas de mejora de la envolvente que nos permita optar por soluciones que produzcan el menor impacto ambiental posible. La incorporación de datos ambientales de los productos y sistemas constructivos para la rehabilitación energética permitirá evaluar la idoneidad ambiental de unas soluciones frente a otras, desde una óptica medioambiental más amplia, y a lo largo de toda su vida útil. Esto permite incluir una evaluación de impactos ambientales como son el agotamiento de recursos, el cálculo de la energía incorporada y/o emisiones de $\mathrm{CO}_{2}$ asociadas a la extracción de materias primas, fabricación de materiales, transporte y puesta en obra de las soluciones constructivas. La metodología desarrollada permite la incorporación sencilla de información medioambiental de las unidades de obra. Además de todo esto, las opciones de rehabilitación producen una menor cantidad de residuos que en las operaciones de sustitución por obra nueva. La inclusión de estos aspectos permitirá comparar la idoneidad ambiental de la rehabilitación frente a la sustitución por obra nueva de manera objetiva y mensurable. Esto permite completar la evaluación energética y el análisis del impacto ambiental de la rehabilitación mediante la inclusión de perspectivas a largo plazo (Gómez Muñoz 2014).

Una vez completada la foto fija del stock inmobiliario que compone el Modelo, sería interesante incorporar una nueva dimensión al mismo, de manera que pase a tener en cuenta la variable temporal. De esta manera se podría ampliar la potencia del método para lograr realizar modelos predictivos que introduzcan variaciones en sus parámetros en función de su evolución en el tiempo. Algunos ejemplos de estas variables son la variación de la climatología causada por el cambio climático, la evolución de los precios de la energía, el coste de mantenimiento de los edificios o la variabilidad de los costes de la construcción. El desarrollo de este modelo espacio-temporal también serían de utilidad para la evaluación de esquemas de financiación y amortización de la inversión. Otra aplicación totalmente diferente de la inclusión de la variable temporal podría ser la introducción de información sobre la capacidad de acumulación de energía de la edificación a través de su masa térmica, contemplando los efectos de amortiguación y 
retardo en la gestión del calor. Para esto la norma (ISO 13790 2008) propone un método simplificado cuya aplicación permitiría obtener una estimación gruesa de la influencia de la inercia térmica de los materiales contenidos en la edificación existente. 


\section{BIBLIOGRAFIA}

ACER/CEER. 2017. «ACER/CEER : Annual Report on the Results of Monitoring the Internal Electricity and Natural Gas Markets in 2015 : Key Insights and Recommendations.» Website. 14 de noviembre de 2017. https://publications.europa.eu/en/publication-detail/-/publication/333ef52a-c9ca-11e78e69-01aa75ed71a1/language-en/format-PDF.

Aksoezen, Mehmet, Magdalena Daniel, Uta Hassler, y Niklaus Kohler. 2015. «Building age as an indicator for energy consumption». Energy and Buildings 87 (enero): 74-86. https://doi.org/10.1016/j.enbuild.2014.10.074.

Alonso, C., F. Martín-Consuegra, y P. Lucas. 2013. «Consideraciones socioeconómicas para la rehabilitación energética de edificios». En . Instituto Eduardo Torroja. https://dialnet.unirioja.es/servlet/articulo?codigo=4589608\&info=resumen\&idioma=SPA.

Alonso, C., I. Oteiza, F. Martín-Consuegra, y B. Frutos. 2017. «Methodological proposal for monitoring energy refurbishment. Indoor environmental quality in two case studies of social housing in Madrid, Spain». Energy and Buildings $155 \quad$ (Supplement $\quad$ C): 492-502. https://doi.org/10.1016/j.enbuild.2017.09.042.

Alonso, Carmen. 2015. «Rehabilitación energética de fachadas: Propuesta metodológica para la evaluación de soluciones innovadoras, basándose en el diagnóstico de viviendas sociales construidas entre 1940 y $1980 »$. Escuela Técnica Superior de Ingeniería Agronómica, Alimentaria y de Biosistemas: Universidad Politécnica de Madrid.

Andreadis, Georgios, Susan Roaf, y Tapas Mallick. 2013. «Tackling fuel poverty with building-integrated solar technologies: The case of the city of Dundee in Scotland». Energy and Buildings 59 (abril): 310-20. https://doi.org/10.1016/j.enbuild.2012.11.032.

Aranda, Juan, Ignacio Zabalza, Andrea Conserva, y Gema Millán. 2017. "Analysis of Energy Efficiency Measures and Retrofitting Solutions for Social Housing Buildings in Spain as a Way to Mitigate Energy Poverty». Sustainability 9 (10): 1869. https://doi.org/10.3390/su9101869.

Aristondo, Oihana, y Eneritz Onaindia. 2018. "Counting energy poverty in Spain between 2004 and 2015». Energy Policy 113 (febrero): 420-29. https://doi.org/10.1016/j.enpol.2017.11.027.

Atanasiu, B., E. Kontonastou, y F. Mariottini. 2014. «Alleviating fuel poverty in the eu. Investing in home renovation, a sustainable and inclusive solution». Buildings Performance Institute Europe. http://bpie.eu/uploads/lib/document/attachment/60/BPIE_Fuel_Poverty_May2014.pdf.

Ayala, Amaia de, Ibon Galarraga, y Joseph V. Spadaro. 2016. «The price of energy efficiency in the Spanish housing market». Energy Policy $94 \quad$ (Supplement $\quad$ C): $16-24$. https://doi.org/10.1016/j.enpol.2016.03.032.

Ayuntamiento de Madrid. 1997. «PGOUM 97. Plano de ordenación». 1997. https://datos.madrid.es/portal/site/egob/menuitem.c05c1f754a33a9fbe4b2e4b284f1a5a0/?vgne xtoid=98fca5b5cfbac510VgnVCM2000001f4a900aRCRD\&vgnextchannel=374512b9ace9f310VgnV CM100000171f5a0aRCRD\&vgnextfmt=default.

- - - 2016. «Plan municipal en Áreas Preferentes de Impulso a la Regeneración Urbana (APIRU) para mejorar la accesibilidad y el confort interior». Área de gobierno de desarrollo urbano sostenible.

- - 2017. «Renta neta media de los hogares (Urban Audit)». 2017. http://www.madrid.es/portales/munimadrid/es/Inicio/El-Ayuntamiento/Estadistica/Areas-deinformacion-estadistica/Economia/Renta/Renta-neta-media-de-los-hogares-Urban-Audit?vgnextfmt=default\&vgnextoid=65e0c19a1666a510VgnVCM1000001d4a900aRCRD\&vgnextchann el=ef863636b44b4210VgnVCM2000000c205a0aRCRD.

- - 2018. «Renta neta media de los hogares (Urban Audit)». 2018. https://www.madrid.es/portales/munimadrid/es/Inicio/El-Ayuntamiento/Estadistica/Areas-de- 
informacion-estadistica/Economia/Renta/Renta-neta-media-de-los-hogares-Urban-Audit/?vgnextoid=65e0c19a1666a510VgnVCM1000001d4a900aRCRD\&vgnextchannel=ef863636b44b42 10VgnVCM2000000c205a0aRCRD.

- - - s. f. "Catálogo de edificios protegidos.» Portal de datos abiertos del Ayuntamiento de Madrid. $\begin{array}{lllll}\text { Accedido } & 6 & \text { de } & \text { noviembre } & \end{array}$ https://datos.madrid.es/portal/site/egob/menuitem.c05c1f754a33a9fbe4b2e4b284f1a5a0/?vgne xtoid=86833de141e0e510VgnVCM2000001f4a900aRCRD\&vgnextchannel=374512b9ace9f310Vgn VCM100000171f5a0aRCRD\&vgnextfmt=default.

Bahamonde Magro, Ángel, y Luis Enrique Otero Carvajal. 1989. «Madrid, de territorio fronterizo a región metropolitana». En La organización territorial del Estado, editado por Juan Pablo Fusi Aizpurúa, Espasa Calpe, 517-616. Madrid, España.

Ballester Díez, F. 1996. «Meteorología y salud. La relación entre la temperatura ambiental y la mortalidad». Revista Española de Salud Pública 70 (3): 251-59.

Begoña Serrano Lanzarote, y Alejandra García Prieto. 2011. «Informe de Evaluación del Edificio Comunitat Valenciana (IEE.CV) - Generalitat Valenciana». Instituto Valenciano de la Edificación. http://www.habitatge.gva.es/web/vivienda-y-calidad-en-la-edificacion/informe-de-evaluaciondel-edificio.

Berger, Tania, y Andrea Höltl. 2019. "Thermal insulation of rental residential housing: Do energy poor households benefit? A case study in Krems, Austria». Energy Policy 127 (abril): 341-49. https://doi.org/10.1016/j.enpol.2018.12.018.

Biljecki, Filip, Hugo Ledoux, y Jantien Stoter. 2017. "Generating 3D city models without elevation data». $\begin{array}{llllll}\text { Computers, Environment and Urban Systems } 64 & \text { (Supplement } & \text { C): } & \text { 1-18. }\end{array}$ https://doi.org/10.1016/j.compenvurbsys.2017.01.001.

Boardman, Brenda. 1991. Fuel poverty: from cold homes to affordable warmth. London; New York: Belhaven Press.

--- 2010. Fixing Fuel Poverty: Challenges and Solutions. Routledge. https://doi.org/10.4324/9781849774482.

Bouzarovski, Stefan. 2018. «The European Energy Divide». En Energy Poverty: (Dis)Assembling Europe's Infrastructural Divide, editado por Stefan Bouzarovski, 75-107. Cham: Springer International Publishing. https://doi.org/10.1007/978-3-319-69299-9_4.

Bouzarovski, Stefan, y Saska Petrova. 2015. «A global perspective on domestic energy deprivation: Overcoming the energy poverty-fuel poverty binary». Energy Research \& Social Science 10 (noviembre): 31-40. https://doi.org/10.1016/j.erss.2015.06.007.

Bouzarovski, Stefan, y Neil Simcock. 2017. «Spatializing energy justice». Energy Policy 107 (agosto): 640-48. https://doi.org/10.1016/j.enpol.2017.03.064.

Bradshaw, Jonathan, y Sandra Hutton. 1983. «Social policy options and fuel poverty». Journal of Economic Psychology 3: 249-66.

Brunner, Karl-Michael, Markus Spitzer, y Anja Christanell. 2012. «Experiencing fuel poverty. Coping strategies of low-income households in Vienna/Austria». Energy Policy, Special Section: Fuel Poverty Comes of Age: Commemorating 21 Years of Research and Policy, 49 (octubre): 53-59. https://doi.org/10.1016/j.enpol.2011.11.076.

CAM. 2017. ORDEN 1003/2017, de 7 de junio, del Consejero de Políticas Sociales y Familia, por la que se aprueba el modelo normalizado de solicitud de prestación económica de Renta Mínima de Inserción de la Comunidad de Madrid y se ordena su publicación. Vol. Consejería de Políticas Sociales $\mathrm{y}$ Familia. http://www.madrid.org/cs/Satellite?c=CM_ConvocaPrestac_FA\&cid=1109168955327\&definicion= Prestaciones+Sociales\&idListConsj=1109265444710\&pagename=ComunidadMadrid\%2FEstructura \&tipoServicio=CM_ConvocaPrestac_FA. 
Capros, P., L. Mantzos, N. Tasios, A. De Vita, y N. Kouvaritakis. 2010. «EU energy trends to 2030- UPDATE 2009». Luxembourg: Publications Office of the European Union: European Comission. Directorate General for Energy and the Directorate - General for Climate Action.

Cáritas. 2014. «VI Informe FOESSA sobre exclusión y desarrollo social en España». http://www.foessa.org/publicaciones_periodicas.aspx.

Castaño, E., M. Hernández, L.F. Rodríguez, P. López, I. Ruelas, S. Álvarez, J.L. Molina, et al. 2012. «Guía de recomendaciones de eficiencia energética; certificación de edifcios existentes CE3». IDAE. Instituto para la Diversificación y Ahorro de la Energía.

Castaño-Rosa, Raúl, Jaime Solís-Guzmán, y Madelyn Marrero. 2018. «A Novel Index of Vulnerable Homes: Findings from Application in Spain». Indoor and Built Environment, marzo, 1420326X18764783. https://doi.org/10.1177/1420326X18764783.

Castell Herrera, Vicente, Vicente Miñana Giner, y Javier Signes Orovay. 2018. «Generador de precios de la construcción en Madrid.» 2018.

Centellas, Miguel, Carmen Jordá, Susana Landrove, y Docomomo Ibérico. 2009. La vivienda moderna: registro DOCOMOMO ibérico, 1925-1965. Barcelona]; [Madrid: Fundación Caja de Arquitectos: Fundación DOCOMOMO ibérico ; Gobierno de España, Ministerio de Vivienda.

CEPCO. 2015. «Informe de Coyuntura Económica». Confederación Española de Asociaciones de Fabricantes de Productos de Construcción.

CESE Comité Económico y Social Europeo. 2010. «DICTAMEN del Comité Económico y Social Europeo sobre el tema "La pobreza energética en el contexto de la liberalización y de la crisis económica" (Dictamen exploratorio)».

Cheng, Vicky, y Koen Steemers. 2011. «Modelling Domestic Energy Consumption at District Scale: A Tool to Support National and Local Energy Policies». Environmental Modelling \& Software 26 (10): 118698. https://doi.org/10.1016/j.envsoft.2011.04.005.

CIEMAT. s. f. «ADRASE - Acceso a datos de radiación solar de España - Mapa zona Península». Accedido 17 de diciembre de 2018. http://adrase.com/acceso-a-los-mapas/mapa-zona-peninsula.html.

CNM. 2017. «Comisión Nacional de los Mercados y la Competencia. Comparador de Ofertas de Energía: Gas y $\quad$ Electricidad». 2017. https://comparadorofertasenergia.cnmc.es/comparador/index.cfm?js=1\&e=N.

Comisión Europea. 2012. Directrices que acompañan al Reglamento Delegado (UE) $n{ }^{\circ} 244 / 2012$ de la Comisión, de 16 de enero de 2012 , que complementa la Directiva 2010/31/UE del Parlamento Europeo y del Consejo, relativa a la eficiencia energética de los edificios, estableciendo un marco metodológico comparativo para calcular los niveles óptimos de rentabilidad de los requisitos mínimos de eficiencia energética de los edificios $y$ de sus elementos. https://eurlex.europa.eu/legal-content/ES/ALL/?uri=CELEX:52012XC0419(02).

- - 2 2016. «Nuevo Paquete de Medidas: Energía limpia para todos los europeos». https://www.hispacoop.com/home/index.php/energia/358-nuevo-paquete-de-medidas-energialimpia-para-todos-los-europeos.

CTE. 2017. «Herramienta unificada LIDER-CALENER (HULC)». marzo de 2017. https://www.codigotecnico.org/index.php/menu-recursos/menu-aplicaciones/282-herramientaunificada-lider-calener.html.

CTE DA DB-HE / 1. 2015. Documento de Apoyo al Documento Básico DB-HE Ahorro de energía Código Técnico de la Edificación. DA DB-HE / 1 Cálculo de parámetros característicos de la envolvente.

CTE-DB-HE. 2006. Código técnico de la Edificación. Documento Básico HE Ahorro de energía.

- - 2013. Código Técnico de la Edificación. Documento Básico HE Ahorro de energía. BOE 12/09/2013.

Cuchí, A., Arcas, J., y A. Pagés-Ramon. 2017. «Estudio de la distribución del consumo energético residencial para la calefacción en España». Ministerio de Fomento. https://www.fomento.gob.es/NR/rdonlyres/53E31468-1B09-4123-A05BOFBEB86B858E/149686/201804_Estudio_distribucion_consumo_energetico_res.pdf. 
Cuchí, A., y P. Sweatman. 2012. «Informe GTR 2012. UNA VISIÓN-PAÍS PARA EL SECTOR DE LA EDIFICACIÓN EN ESPAÑA. Plan de Acción Para Un Nuevo Sector de La Vivienda». Madrid: Grupo de Trabajo sobre Rehabilitación (GTR).

Cuchí, Albert, Peter Sweatman, y GTR. 2012. GTR'S 2012 Report: A National Perspective on Spain's Building Sector : Action Plan for a New Housing Sector. Madrid: Green Building Council España.

Dalle, Mathieu, M. López Quero, G. Arregui Portillo, C. Avilés Palacios, L. Buendía García, B. Estrada López, A. Marco Marco, B. Medialdea García, M. Medialdea García, y E. Méndez Bértolo. 2010. "La generación de empleo en la rehabilitación y modernización energética de edificios y viviendas». Instituto Sindical de Trabajo, Ambiente y Salud (ISTAS), 198.

De Vita, A, N Tasios, S Evangelopoulou, N Forsell, K Fragiadakis, P Fragkos, S Frank, et al. 2016. EU Reference Scenario 2016: Energy, Transport and GHG Emissions : Trends to 2050. Luxembourg: Publications Office. http://bookshop.europa.eu/uri?target=EUB:NOTICE:MJ0115793:EN:HTML.

Díaz, J., R. Carmona, I. J. Mirón, M. Y. Luna, y C. Linares. 2019. «Time trends in the impact attributable to cold days in Spain: Incidence of local factors». Science of The Total Environment 655 (marzo): $305-$ 12. https://doi.org/10.1016/j.scitotenv.2018.11.254.

Díez de Pablo, Ainhoa. 2015. "La vivienda social como patrimonio urbano: análisis de la patrimonialización de tres Barrios de Promoción Oficial madrileños». Phd, E.T.S. Arquitectura (UPM). http://oa.upm.es/39877/.

Domínguez, Samuel, Juan José Sendra, y Ignacio Oteiza San José. 2016. La envolvente energética de la vivienda social en el periodo 1939-1979. Caso de Sevilla. Monografías. IETcc. Madrid: CSIC.

Dresner, Simon, y Paul Ekins. 2006. «Economic instruments to improve UK home energy efficiency without negative social impacts». Fiscal Studies 27 (1): 47-74.

Dubois, Ute. 2012. «From targeting to implementation: The role of identification of fuel poor households». Energy Policy, Special Section: Fuel Poverty Comes of Age: Commemorating 21 Years of Research and Policy, 49 (octubre): 107-15. https://doi.org/10.1016/j.enpol.2011.11.087.

Echenagusía, J. 1996. «Un ejemplo de participación y renovación urbana: la remodelación de barrios en Madrid (España)». Biblioteca Ciudades para un Futuro más Sostenible. Concurso de Buenas Prácticas patrocinado por Dubai. http://habitat.aq.upm.es/bpes/onu/bp258.html.

ECOSERVEIS. 2010. Guia pràctica: Com actuar davant la pobresa energètica. Detecció, avaluació $i$ seguiment (2a edició - 2010). https://issuu.com/ecoserveis/docs/guia_pobresa_energetica_2ed.

EFINOVATIC, y CENER. 2015. "Manual de fundamentos técnicos de calificación energética de edificios existentes CE3X».

- - . 2016. "Guía IDAE: Manual de usuario de califcación energética de edifcios existentes CE3X».

EmpleoGob. 2015. Real Decreto 1171/2015, de 29 de diciembre, por el que se fija el salario mínimo interprofesional para 2016. http://noticias.juridicas.com/base datos/Fiscal/565513-rd-1171-2015de-29-dic-salario-minimo-interprofesional-para-2016.html.

Endres, D. 2009. «From wasteland to waste site: The role of discourse in nuclear power's environmental injustices». Local Environment 14 (10): 917-37. https://doi.org/10.1080/13549830903244409.

EPOV. 2017. «EU Energy Poverty Observatory». EU Energy Poverty Observatory. 19 de septiembre de 2017. https://www.energypoverty.eu/eu-energy-poverty-observatory.

Esteban Maluenda, Ana María. 1999. «La vivienda social española en la década de los 50: Un paseo por los poblados dirigidos de Madrid». Cuaderno de Notas, 1999. http://polired.upm.es/index.php/cuadernodenotas/article/view/805.

European Commission. 2017. «JRC Photovoltaic Geographical Information System (PVGIS)». 2017. http://re.jrc.ec.europa.eu/pvgis.html.

European Commission, y Directorate-General for Energy. 2010. EU Energy Trends to 2030: Update 2009. Luxembourg: EUR-OP. 
European Environment Agency. 2017. «Urban Audit». External Data Reference. 2017. https://www.eea.europa.eu/data-and-maps/data/external/urban-audit-database.

European Parliament and UE Council. 2010. Directive 2010/31/EU of the European Parliament and of the Council of 19 May 2010 on the Energy Performance of Buildings. 153. Vol. OJ L. http://data.europa.eu/eli/dir/2010/31/oj/eng.

- - . 2018. Directive 2018/844 of the European Parliament and of the Council of 30 May 2018 Amending Directive 2010/31/EU on the Energy Performance of Buildings and Directive 2012/27/EU on Energy Efficiency (Text with EEA Relevance). 156. Vol. OJ L. http://data.europa.eu/eli/dir/2018/844/oj/eng.

European Union. 2017. «Methodological manual on city statistics. 2017 edition». Luxembourg: Publications Office of the European Union, 2017.

EUROSTAT. 2017. «Energy prices in 2017 Household energy prices in the EU down compared with 2016». EUROSTAT News Release, 29 de noviembre de 2017. 180/2017.

- - . 2019. «Electricity price statistics - Statistics Explained». https://ec.europa.eu/eurostat/statisticsexplained/index.php/Electricity_price_statistics.

- - - s. f. "European Union Statistics on Income and Living Conditions». Accedido 30 de enero de 2019. https://ec.europa.eu/eurostat/web/microdata/european-union-statistics-on-income-and-livingconditions.

Fahmy, E. 2011. "The definition and measurement of fuel poverty», 2011. https://scholar.googleusercontent.com/scholar?q=cache:-

W5vxrAwOKOJ:scholar.google.com/+\%22Fahmy,+E.,+2011.+The+definition+and+measurement+of +fuel+poverty.+A+briefing+paper+to+inform+consumer+focus\%E2\%80\%99s+submission+to+the+ Hills+fuel+poverty+review,+University+of+Bristol.\%22\&hl=es\&as_sdt=0,5.

Fahmy, E., D. Gordon, y D. Patsios. 2011. «Predicting fuel poverty at a small-area level in England». Energy Policy 39 (7): 4370-77. https://doi.org/10.1016/j.enpol.2011.04.057.

Fernández Durán, Ramón. 2008. El crepúsculo de la era trágica del petroleo. Virus.

Fernández Nieto, María Antonia. 2006. «Las colonias del hogar del empleado : la periferia como ciudad». Phd, E.T.S. Arquitectura (UPM). http://oa.upm.es/4621/.

Fernández-Agüera, Jesica, Samuel Domínguez-Amarillo, Carmen Alonso, y Fernando Martín-Consuegra. 2019. "Thermal comfort and indoor air quality in low-income housing in Spain: The influence of airtightness and occupant behaviour». Energy and Buildings 199 (septiembre): 102-14. https://doi.org/10.1016/j.enbuild.2019.06.052.

Fonseca, Jimeno A., y Arno Schlueter. 2015. «Integrated Model for Characterization of Spatiotemporal Building Energy Consumption Patterns in Neighborhoods and City Districts». Applied Energy 142 (marzo): 247-65. https://doi.org/10.1016/j.apenergy.2014.12.068.

Freed, Michael, y Frank A. Felder. 2017. «Non-energy benefits: Workhorse or unicorn of energy efficiency programs?» The Electricity Journal 30 (1): 43-46. https://doi.org/10.1016/j.tej.2016.12.004.

Fuerst, Franz, Patrick McAllister, Anupam Nanda, y Peter Wyatt. 2015. «Does energy efficiency matter to home-buyers? An investigation of EPC ratings and transaction prices in England». Energy Economics 48 (marzo): 145-56. https://doi.org/10.1016/j.eneco.2014.12.012.

Gangolells, Marta, y Miquel Casals. 2012. «Resilience to Increasing Temperatures: Residential Building Stock Adaptation through Codes and Standards». Building Research \& Information 40 (6): 645-64. https://doi.org/10.1080/09613218.2012.698069.

García Arroyo, Arturo. 1983. Bases para el diseño solar pasivo: equipo de ahorro de energía en la edificación. Madrid: Instituto Eduardo Torroja de la Construcción y del Cemento, Consejo Superior de Investigaciones Científicas.

García, Luis Alberto Rasines. 2006. «The liberalisation of the Spanish gas market». Energy Policy 34 (13): 1630-44. https://doi.org/10.1016/j.enpol.2004.12.013. 
Gillard, Ross, Carolyn Snell, y Mark Bevan. 2017. «Advancing an energy justice perspective of fuel poverty: Household vulnerability and domestic retrofit policy in the United Kingdom». Energy Research \& Social Science 29 (julio): 53-61. https://doi.org/10.1016/j.erss.2017.05.012.

Gobierno de España. 1939. "Ley de 19 de abril de 1939 de Régimen de protección a la vivienda y creando el Instituto Nacional de la Vivienda». https://sede.fomento.gob.es/NR/rdonlyres/5FDF13C3-732F44D5-B44E-824A17A993F5/104324/L_190439.pdf.

-- - 1944. ORDEN DE 29 DE FEBRERO DE 1.944, POR LA QUE SE ESTABLECEN LAS CONDICIONES HIGIÉNICAS MÍNIMAS QUE HAN DE REUNIR LAS VIVIENDAS. Boletín Oficial del Estado. Vol. BOE núm. 61, de 1 de marzo de 1944.

- - - 2013. «Ley 8/2013, de 26 de junio, de rehabilitación, regeneración y renovación urbanas». B.O.E.

Gómez Muñoz, Gloria. 2014. «Método de análisis diacrónico para la intervención en el alojamiento con criterios ecológicos. El caso de Madrid 1940-2100». Phd, E.T.S. Arquitectura (UPM). http://oa.upm.es/30897/.

González-Vallejo, P., J. Solís-Guzmán, R. Llácer, y M. Marrero. 2015. "La construcción de edificios residenciales en España en el período 2007-2010 y su impacto según el indicador Huella Ecológica». Informes de la Construcción 67 (539): 111. https://doi.org/10.3989/ic.14.017.

Gosztonyi, Á., A. Dobbins, A. Bajomi, S. Tirado, M. Groote, F. Anagnostopoulos, E. Lakatos, M. Tamás, y K. Csiba. 2019. Energy Handbook. https://www.academia.edu/30117359/Energy_Poverty_Handbook.

Gouardères, F. 2019. «El mercado interior de la energía». Fichas temáticas sobre la Unión Europea | Parlamento Europeo. http://www.europarl.europa.eu/factsheets/es/home.

Gouveia, João Pedro, Júlia Seixas, y Gavin Long. 2018. «Mining households' energy data to disclose fuel poverty: Lessons for Southern Europe». Journal of Cleaner Production 178 (marzo): 534-50. https://doi.org/10.1016/j.jclepro.2018.01.021.

Greenpeace. 2008. «Posición de Greenpeace sobre la liberalización del mercado de la electricidad en la UE». archivo-es.greenpeace.org/espana/Global/espana/report/other/posici-n-de-greenpeacesobre-l.pdf.

Großmann, K., A. Bierwirth, S. Bartke, T. Jensen, S. Kabisch, C. Von Malottki, I. Mayer, y J. Rügamer. 2014. «Energetic retrofit: Considering socio-spatial structures of cities». GAlA 23 (4): 309-12. https://doi.org/10.14512/gaia.23.4.5.

Guillem González-Blanch, María del Puig. 2013a. «Tipología de vivienda en los poblados dirigidos de renta limitada: Madrid 1956-1959». Phd, E.T.S. Arquitectura (UPM). East=-3.7037901999999576; north=40.4167754; name=Madrid, Comunidad de Madrid, España. http://oa.upm.es/20288/.

- - - 2013b. "Tipología de vivienda en los poblados dirigidos de renta limitada : Madrid 1956-1959». Phd, E.T.S. Arquitectura (UPM). http://oa.upm.es/20288/.

Healey, J. D. 2004. «Housing, Fuel Poverty and Health: A Pan-European Analysis». EU Fuel Poverty Network, 2004. http://fuelpoverty.eu/resources/housing-fuel-poverty-and-health-a-pan-europeananalysis/.

Healy, John D. 2003. "Excess winter mortality in Europe: a cross country analysis identifying key risk factors». Journal of epidemiology and community health 57 (10): 784-89.

Helge Sigurd Næss-Schmidt, Martin Bo Westh Hansen, y Carl von Utfall Danielsson. 2012. «Multiple benefits of investing in energy efficient renovation of buildings». Copenhagen Economics. http://www.copenhageneconomics.com/publications/publication/multiple-benefits-of-investingin-energy-efficient-renovation-of-buildings.

Hernández Aja, A., Á Matesanz Parellada, I. Rodríguez-Suárez, y C. García Madruga. 2015. «Evolución de las políticas de rehabilitación en Áreas de Rehabilitación Integrada en España (1978-2012)». Informes de la Construcción 67 (Extra-1): 024. https://doi.org/10.3989/ic.14.057. 
Hernández Aja, Agustín. 1995. "Análisis de los estándares de calidad urbana en el planeamiento de las ciudades españolas». Cuadernos de Investigación Urbanística $0 \quad$ (11). http://polired.upm.es/index.php/ciur/article/view/225.

- - . 2007. "Áreas vulnerables en el centro de Madrid». Cuadernos de Investigación Urbanística, n. ${ }^{\circ} 53$. http://polired.upm.es/index.php/ciur/article/view/268.

- - . 2011. "Análisis urbanístico de barrios desfavorecidos: catálogo de áreas vulnerables españolas». Cuadernos de Unvestigación http://polired.upm.es/index.php/ciur/article/view/233.

Hernández Aja, Agustín, Ángela Matesanz Parellada, Carolina García Madruga, J. Alguacil Gómez, J. Camacho Gutiérrez, y C. Fernández Ramírez. 2015. Atlas de barrios vulnerables de España: 12 ciudades 1991-2001-2006. Madrid: Ministerio de Fomento. Instituto Juan de Herrera.

Hernández Aja, Agustín, Ángela Matesanz Parellada, Elena Moreno García, Iván Rodríguez Suárez, y Carolina García Madruga. 2010. «Delimitación y digitalización de ARIs y ARUs en los Planes Estatales de Vivienda». En Atlas de la edificación residencial en España 2001 y 2011. Metodología, contenidos y créditos. Ministerio de Fomento.

Hernández Aja, Agustín, Raquel Rodríguez Alonso, Iván Rodríguez Suárez, José Manuel Gómez Giménez, Isabel González García, Rafael Córdoba Hernández, Julio Alguacil Gómez, Javier Camacho Gutierrez, Fernando Carmona Mateos, y Sergio Jaramillo Cáceres. 2018. Barrios vulnerables de las grandes ciudades españolas. 1991/ 2001/ 2011. Madrid: E.T.S. Arquitectura (UPM). http://oa.upm.es/51015/.

Herrera, Joan. 2019. "Acceso a los datos de consumo, clave para gestionar la demanda de energía». eldiario.es, 2019. https://www.eldiario.es/tribunaabierta/Acceso-consumo-gestionar-demandaenergia_6_866923323.html.

Hills, John. 2012. "Getting the measure of fuel poverty: Final Report of the Fuel Poverty Review». Centre for Analysis of Social Exclusion, The London School of Economics and Political Science. London: Department of Energy and Climate Change (DECC), 237.

Hiteva, Ralitsa, y Benjamin Sovacool. 2017. «Harnessing social innovation for energy justice: A business model perspective». Energy Policy 107 (agosto): 631-39. https://doi.org/10.1016/j.enpol.2017.03.056.

Hyland, Marie, Ronan C. Lyons, y Seán Lyons. 2013. "The value of domestic building energy efficiency evidence from Ireland». Energy Economics 40 (noviembre): 943-52. https://doi.org/10.1016/j.eneco.2013.07.020.

IDAE. 2009. «Escala de calificación energética para edificios de nueva construcción». Instituto para la Diversificación y Ahorro de la Energía. Ministerio de Vivienda. http://www.minetad.gob.es/energia/desarrollo/EficienciaEnergetica/CertificacionEnergetica/Doc umentosReconocidos/OtrosDocumentos/Calificaci\%C3\%B3n\%20energ\%C3\%A9tica.\%20Viviendas/ Escala_\%20calif_energetica.pdf.

- - . 2011a. «Escala de calificación energética para edificios existentes». Instituto para la Diversificación y Ahorro de la Energía. Ministerio de Fomento. http://www.minetad.gob.es/energia/desarrollo/EficienciaEnergetica/CertificacionEnergetica/Doc umentosReconocidos/OtrosDocumentos/Calificaci\%C3\%B3n\%20energ\%C3\%A9tica.\%20Viviendas/ Escala_Calif\%20_Edif\%20_Existentes_accesible.pdf.

- - - 2011b. «Proyecto SECH-SPAHOUSEC. Análisis del consumo energético del sector residencial en España. Informe Final». Instituto para la Diversificación y Ahorro de Energía. www.idae.es/uploads/documentos/documentos_informe_spahousec_acc_f68291a3.pdf.

- - . 2016. «Programa de Ayudas para la Rehabilitación Energética de Edificios existentes (Programa PAREER-CRECE)». 2016. https://www.idae.es/ayudas-y-financiacion/para-rehabilitacion-deedificios-programa-pareer/programa-de-ayudas-para-la.

- - - 2019. "SPAHOUSEC II: Análisis estadístico del consumo de gas natural en las viviendas principales con calefacción individual». Instituto para la Diversificación y Ahorro de Energía. 
https://idae.es/publicaciones/spahousec-ii-analisis-estadistico-del-consumo-de-gas-natural-en-lasviviendas.

IEA. 2014. Capturing the Multiple Benefits of Energy Efficiency. Executive Summary. International Energy Agency. https://doi.org/10.1787/9789264220720-en.

INE. 1991. «Censo de Población y Viviendas de 1991». Instituto Nacional de Estadística.

- - - 2001. «Censo de Población y Viviendas de 2001». Instituto Nacional de Estadística. http://www.ine.es/censo2001/.

- - 2011. "Censo de Población y Viviendas de 2011». Instituto Nacional de Estadística. http://www.ine.es/censos2011_datos/cen11_datos_inicio.htm.

- - 2017. «Encuesta de condiciones de vida». Instituto Nacional de Estadística. https://www.ine.es/dyngs/INEbase/es/operacion.htm?c=Estadistica_C\&cid=1254736176807\&me nu=ultiDatos\&idp=1254735976608.

ISO 13790. 2008. UNE EN ISO 13790 : 2011 / ENERGY PERFORMANCE OF BUILDINGS - CALCULATION OF ENERGY USE FOR SPACE HEATING AND COOLING (ISO 13790:2008). https://infostore.saiglobal.com/en-gb/standards/une-en-iso-13790-201133778_SAIG_AENOR_AENOR_73811/.

Jenkins, Kirsten, Darren McCauley, Raphael Heffron, Hannes Stephan, y Robert Rehner. 2016. «Energy justice: A conceptual review». Energy Research \& Social Science 11 (enero): 174-82. https://doi.org/10.1016/j.erss.2015.10.004.

Jiang, Bin. 2011. "A Short Note on Data-Intensive Geospatial Computing». En Information Fusion and Geographic Information Systems, editado por Vasily V. Popovich, Christophe Claramunt, Thomas Devogele, Manfred Schrenk, y Kyrill Korolenko, 5:13-17. Berlin, Heidelberg: Springer Berlin Heidelberg. https://doi.org/10.1007/978-3-642-19766-6_2.

Jose Lao. 2014. Anàlisi dels teixits urbans des de l'òptica energètica - Àrea metropolitana de Barcelona. Barcelona Regional. http://www.amb.cat/web/medi-ambient/actualitat/publicacions/.

José Santamarta, y Llorenç Serrano. 2009. «Evolución de las emisiones de GEI en España (1990-2008) por I REVE -». CCOO. https://www.evwind.com/2009/05/22/evolucion-de-las-emisiones-de-gei-enespana-1990-2008-por-jose-santamarta-y-llorenc-serrano/.

JRC - European Comision. 2017. «PV potential estimation utility». Photovoltaic Geographical Information System - Interactive Maps. 2017. http://re.jrc.ec.europa.eu/pvgis/apps4/pvest.php\#.

Kavgic, M., A. Mavrogianni, D. Mumovic, A. Summerfield, Z. Stevanovic, y M. Djurovic-Petrovic. 2010. «A review of bottom-up building stock models for energy consumption in the residential sector». Building and Environment 45 (7): 1683-97. https://doi.org/10.1016/j.buildenv.2010.01.021.

Kerr, Niall, Andy Gouldson, y John Barrett. 2018. «Holistic narratives of the renovation experience: Using Qmethodology to improve understanding of domestic energy retrofits in the United Kingdom». Energy Research \& Social Science 42 (agosto): 90-99. https://doi.org/10.1016/j.erss.2018.02.018.

Kolokotsa, D., y M. Santamouris. 2015. «Review of the indoor environmental quality and energy consumption studies for low income households in Europe». Science of The Total Environment 536 (diciembre): 316-30. https://doi.org/10.1016/j.scitotenv.2015.07.073.

Kurtz, F., M. Monzón, y B. López-Mesa. 2015. «Obsolescencia de la envolvente térmica y acústica de la vivienda social de la postguerra española en áreas urbanas vulnerables. El caso de Zaragoza». Informes de la Construcción 67 (Extra-1): 021. https://doi.org/10.3989/ic.14.062.

Lelkes, Orsolya, y Eszter Zólyomi. 2010. «Housing Quality Deficiencies and the Link to Income in the EU». Policy Briefs. Viena: European Centre for Social Welfare Policy and Research, marzo, 20.

Liddell, C., y C. Guiney. 2015. «Living in a Cold and Damp Home: Frameworks for Understanding Impacts on Mental Well-Being». Public Health. 2015. https://doi.org/10.1016/j.puhe.2014.11.007.

Liddell, Christine, y Chris Morris. 2010. "Fuel poverty and human health: A review of recent evidence». Energy Policy, The Role of Trust in Managing Uncertainties in the Transition to a Sustainable 
Energy Economy, Special Section with Regular Papers, 38 (6): 2987-97. https://doi.org/10.1016/j.enpol.2010.01.037.

Liu, Xiaochen, y John Sweeney. 2012. «Modelling the Impact of Urban Form on Household Energy Demand and Related CO2 Emissions in the Greater Dublin Region». Energy Policy 46 (julio): 359-69. https://doi.org/10.1016/j.enpol.2012.03.070.

Loga, Tobias, Britta Stein, y Nikolaus Diefenbach. 2016. "TABULA Building Typologies in 20 European Countries-Making Energy-Related Features of Residential Building Stocks Comparable». Energy and Buildings 132 (noviembre): 4-12. https://doi.org/10.1016/j.enbuild.2016.06.094.

Luxán García de Diego, Margarita de, G. Gómez Muñoz, y Emilia López Román. 2015. «Cuentas energéticas no habituales en edificación residencial». Informes de la construcción 67 (1): 9-.

Luxán García De Diego, Margarita, Carmen Sánchez-Guevara Sánchez, Emilia Román López, María del Mar Barbero Barrera, y Gloria Gómez Muñoz. 2017. Re-habilitación exprés para hogares vulnerables. Soluciones de bajo coste. Madrid, España: Fundación Gas Natural Fenosa. http://www.fundaciongasnaturalfenosa.org/publicacion/re-habilitacion-expres-hogaresvulnerables-soluciones-coste/.

Madlener, R., y Y. Sunak. 2011. «Impacts of urbanization on urban structures and energy demand: What can we learn for urban energy planning and urbanization management?» Sustainable Cities and Society 1 (1): 45-53. https://doi.org/10.1016/j.scs.2010.08.006.

MARM. 2010. «Sistema municipal de indicadores de sostenibilidad urbana».

Martín-Consuegra, F. 2014. «Vulnerabilidad energética asociada a la edificación. Estudio de caso para la periferia urbana del sur de Madrid». Territorios en formación, n. ${ }^{\circ}$ 6: 105-18.

Martín-Consuegra, F., C. Alonso, y B. Frutos. 2015. «La regeneración urbana integrada y la declaración de Toledo». Informes de la Construcción 67 (Extra-1): nt002. https://doi.org/10.3989/ic.14.084.

Martín-Consuegra, F., C. Alonso, B. Frutos, y M. Olaya. 2015. «User utility as the financial justification for low energy refurbishment». En https://www.researchgate.net/publication/306262777_User_utility_as_the_financial_justification _for_low_energy_refurbishment.

Martínez Parra, D. 2019. «¿Hemos Salido de La Crisis?: Necesitamos Un Cambio de Políticas Económicas y de Empleo».

Mata, E., A. Sasic Kalagasidis, y F. Johnsson. 2014. "Building-Stock Aggregation through Archetype Buildings: France, Germany, Spain and the UK». Building and Environment 81 (noviembre): 270-82. https://doi.org/10.1016/j.buildenv.2014.06.013.

Mata, Érika, Filip Johnsson, y Angela Sasic Kalagasidis. 2011. A Bottom-up Model for Energy, Carbon and Costs Assessment of Building Stocks. http://publications.lib.chalmers.se/publication/136191-abottom-up-model-for-energy-carbon-and-costs-assessment-of-building-stocks.

Mata, Érika, Angela Sasic Kalagasidis, y Filip Johnsson. 2013. «A Modelling Strategy for Energy, Carbon, and Cost Assessments of Building Stocks». Energy and Buildings 56 (enero): 100-108. https://doi.org/10.1016/j.enbuild.2012.09.037.

McCabe, Annie, Dorina Pojani, y Anthony Broese van Groenou. 2018. «The application of renewable energy to social housing: A systematic review». Energy Policy 114 (marzo): 549-57. https://doi.org/10.1016/j.enpol.2017.12.031.

Meiss, A., J. Feijó-Muñoz, y M. A. Padilla-Marcos. 2016. «Evaluación, diseño y propuestas de sistemas de ventilación en la rehabilitación de edificios residenciales españoles. Estudio de caso». Informes de la Construcción 68 (542): 148. https://doi.org/10.3989/ic.15.101.

Ministerio de Fomento. 2011. «Catálogo de Elementos Constructivos del CTE». https://itec.cat/cec/.

2013a. «Análisis de las características de la edificación residencial en España (2001). A nivel nacional y por comunidad autónoma». 
- - - 2013b. «Report on cost optimal calculations and comparison with the current and future energy performance requirements of buildings in Spain». Version 1.0. Dirección General de Arquitectura, Vivienda y Suelo.

- - . 2014. «ERESEE 2014. Estrategia a largo plazo para la rehabilitación energética en el sector de la edificación en España». Secretaría de Estado de Infraestructuras, Transporte y Vivienda. https://www.fomento.gob.es/el-ministerio/planes-estrategicos/estrategia-a-largo-plazo-para-larehabilitacion-energetica-en-el-sector-de-la-edificacion-en-espana.

- - - 2017. «ERESEE 2017. Actualización de la estrategia a largo plazo para la rehabilitación energética en el sector de la edificación en España». Secretaría de Estado de Infraestructuras, Transporte y Vivienda. https://www.fomento.gob.es/el-ministerio/planes-estrategicos/estrategia-a-largo-plazopara-la-rehabilitacion-energetica-en-el-sector-de-la-edificacion-en-espana.

Ministerio de Fomento, y UPM. 2017. "Atlas Urbano para el "Observatorio de la Vulnerabilidad Urbana"».

MITECO. 2019. «Estrategia nacional contra la Pobreza Energética 2019-2024».

MIYABI, y CENER. 2012. "Guía de recomendaciones de eficiencia energética; certificación de edificios existentes CE3X». IDAE. Instituto para la Diversificación y Ahorro de la Energía.

Moore, Richard. 2012. «Definitions of fuel poverty: Implications for policy». Energy Policy, Special Section: Fuel Poverty Comes of Age: Commemorating 21 Years of Research and Policy, 49 (octubre): 19-26. https://doi.org/10.1016/j.enpol.2012.01.057.

Moreno Jiménez, Antonio. 2003. La distribución espacial de la renta en la Comunidad de Madrid: análisis y aplicaciones. Madrid: Instituto de Estadística de la Comunidad de Madrid.

Moss, Joseph L., Kieron J. Doick, Stefan Smith, y Mehdi Shahrestani. 2018. «Influence of evaporative cooling by urban forests on cooling demand in cities». Urban Forestry \& Urban Greening, agosto. https://doi.org/10.1016/j.ufug.2018.07.023.

Moya González, L., C. Fernández Salgado, y F. Escamilla Valencia. 2017. «Evolución del tamaño de la vivienda de promoción pública y su comparación con el resto del parque residencial construido en Madrid entre 1940-2010». Informes de la Construcción 69 (545): 178.

Moya González, Luis, José María Ezquiaga, y Fernando Inglés Musoles. 1983. Barrios de promoción oficial, Madrid 1939-1976: la política de promoción pública de vivienda. Madrid: Colegio Oficial de Arquitectos de Madrid.

Naredo, J. M. 2014. «Discontinuidad y peculiaridad de los datos de vivienda del "censo" de 2011. El censo de 2011 en el marco de la experiencia censal en España». Universidad Carlos III, Dep. de Análisis Social.

NBE-CT-79. 1979. NBE-CT-79. Condiciones Térmicas de los Edificios. Presidencia del Gobierno. Madrid.

Neila, F. Javier. 2009. Arquitectura bioclimática en un entorno sostenible. Madrid: Editorial Munilla-Leria.

Neila, F.J., Sánchez-Guevara, Román López, López Moreno, Núñez Peiró, Redondas Marrero, de Luxán, y Gómez Muñoz. 2017. «Proyecto MODIFICA. MOdelo predictivo - edificios - Isla de Calor urbanA». http://abio-upm.org/project/modifica/.

Nolay et al. 2009. «Diagnosis de Las Causas y de Las Consecuencias de Pobreza Energética En Bélgica, Francia, Italia, España y Reino Unido». EPEE project. WP2-Deliverable 5. Intelligent Energy Europe. European Commission. /energy/intelligent/projects/en/projects/epee.

Núñez Peiró, Miguel, Emilia Román, Carmen Sánchez-Guevara, y Francisco Javier Neila. 2016. «Hacia un modelo dinámico para la isla de calor urbana de Madrid = Towards a Dynamic Model for the Urban Heat Island of Madrid.» Anales de Edificación 2 (1): 49-58. https://doi.org/10.20868/ade.2016.3198.

Oteiza, I., C. Alonso, F. Martín-Consuegra, A. Blazquez, T. Cuerdo, J. Monjo, M. González, et al. 2016. «Proyecto REFAVIV. Rehabilitación energética de la fachada de viviendas sociales, con productos innovadores con Documento de Idoneidad Técnica (DIT, DITE). Impacto económico, social y ambiental». 
Oteiza, I., Carmen Alonso, Fernando Martín-Consuegra, Juan Monjo, Mariam González Moya, y Alberto Buldón. 2018. La envolvente energética de la vivienda social. El caso de Madrid en el periodo 19391979. Monografías del IETcc. Serie Arquitectura. Madrid: Instituto Eduardo Torroja de ciencias de la construcción.

Parlamento Europeo y el Consejo de la Unión Europea. 2002. Directiva 2002/91/CE del Parlamento Europeo y del Consejo de 16 de diciembre de 2002, relativa a la eficiencia energética de los edificios. https://es.scribd.com/document/70373949/Directiva-2002-91-CE-EFICIENCIA-ENERGETICA-DELOS-EDIFICIOS.

- - . 2010. Directiva 2010/31/UE del Parlamento Europeo y del Consejo, de 19 de mayo de 2010, relativa a la eficiencia energética de los edificios. http://www.gradhermetic.ma/docs/Directiva_2010-13EC_EPBD.pdf.

- - - 2012. Directiva 2012/27/UE del Parlamento Europeo y del Consejo, de 25 de octubre de 2012, relativa a la eficiencia energética, por la que se modifican las Directivas 2009/125/CE y 2010/30/UE, y por la que se derogan las Directivas 2004/8/CE y 2006/32/CE Texto pertinente a efectos del EEE.

-- - 2018. Directiva (UE) 2018/844 Del Parlamento Europeo y Del Consejo, de 30 de Mayo de 2018, Por La Que Se Modifica La Directiva 2010/31/UE Relativa a La Eficiencia Energética de Los Edificios y La Directiva 2012/27/UE Relativa a La Eficiencia Energética (Texto Pertinente a Efectos Del EEE). 156. Vol. OJ L. http://data.europa.eu/eli/dir/2018/844/oj/eng.

Pérez Mayo, J. 2004. La dimensión territorial de la pobreza y la privación en España. Fundación Alternativas. Estudios de progreso. https://docplayer.es/13146669-La-dimension-territorial-de-la-pobreza-y-laprivacion-en-espana.html.

Pisello, Anna Laura. 2017. "State of the art on the development of cool coatings for buildings and cities». Solar Energy 144 (marzo): 660-80. https://doi.org/10.1016/j.solener.2017.01.068.

Pittau, Francesco, Laura E. Malighetti, Giuliana lannaccone, y Gabriele Masera. 2017. «Prefabrication as Large-scale Efficient Strategy for the Energy Retrofit of the Housing Stock: An Italian Case Study». Procedia Engineering, International High-Performance Built Environment Conference - A Sustainable Built Environment Conference 2016 Series (SBE16), iHBE 2016, 180 (enero): 1160-69. https://doi.org/10.1016/j.proeng.2017.04.276.

PNUD. 2016. "Objetivos de Desarrollo Sostenible». enero de 2016. https://www.undp.org/content/undp/es/home/sustainable-development-goals.html.

Poortinga, Wouter, Sarah E Rodgers, Ronan A Lyons, Pippa Anderson, Chris Tweed, Charlotte Grey, Shiyu Jiang, Rhodri Johnson, Alan Watkins, y Thomas G Winfield. 2018. "The Health Impacts of Energy Performance Investments in Low-Income Areas: A Mixed-Methods Approach». Public Health Research 6 (5): 1-182. https://doi.org/10.3310/phr06050.

Ramírez Perea, P. 2013. «Los Números Gordos de La Demanda de Climatización En Viviendas». Madrid. https://issuu.com/rpp.arquitectos/docs/20131231_numeros_gordos_demanda_cli.

Ratia, Jarmo. 2d. C. «Cadastres as Focuses on Environmental Protection». En . Granada, España.

Rodríguez Lorite, I. 2013. "Urbanización descontextualizada y condiciones locales. Cinco casos de estudio en España / Decontextualized urbanization and local conditions. Five case study in Spain». Territorios en formación 0 (5): 101-16.

Rodríguez-Soria, Beatriz, Javier Domínguez-Hernández, José M. Pérez-Bella, y Juan J. del Coz-Díaz. 2015. "Quantitative Analysis of the Divergence in Energy Losses Allowed through Building Envelopes». Renewable and Sustainable Energy Reviews 49 (septiembre): 1000-1008. https://doi.org/10.1016/j.rser.2015.05.002.

Roels, Staf. 2016. «EBC Annex 58 Reliable Building Energy Performance Characterisation Based on Full Scale Dynamic Measurements». https://www.kuleuven.be/bwf/projects/annex58/summary.htm.

Romero, J. C., P. Linares, X. López Otero, X. Lavandeira, y A. Pérez Alonso. 2014. «Pobreza Energética en España Análisis económico y propuestas de actuación». Vigo: Economics for Energy. 
Romero Rodríguez, Laura, José Sánchez Ramos, MCarmen Guerrero Delgado, José Luis Molina Félix, y Servando Álvarez Domínguez. 2018. "Mitigating energy poverty: Potential contributions of combining PV and building thermal mass storage in low-income households». Energy Conversion and Management 173 (octubre): 65-80. https://doi.org/10.1016/j.enconman.2018.07.058.

Saaroni, H., J. H. Amorim, J. A. Hiemstra, y D. Pearlmutter. 2018. «Urban Green Infrastructure as a tool for urban heat mitigation: Survey of research methodologies and findings across different climatic regions». Urban Climate 24 (junio): 94-110. https://doi.org/10.1016/j.uclim.2018.02.001.

Salisu, Afees A., y Taofeek O. Ayinde. 2016. «Modeling Energy Demand: Some Emerging Issues». Renewable $\begin{array}{lllll}\text { and Sustainable Energy } & \text { Reviews }\end{array}$ https://doi.org/10.1016/j.rser.2015.10.121.

Sánchez Suarez, C. 2019. «De la vulnerabilidad energética al derecho a la energía». Ecologistas en Acción. https://www.ecologistasenaccion.org/?p=115365.

Sánchez-Guevara, Carmen, Anna Mavrogianni, y Fco. Javier Neila. 2017. «On the Minimal Thermal Habitability Conditions in Low Income Dwellings in Spain for a New Definition of Fuel Poverty». Building and Environment 114 (marzo): 344-56. https://doi.org/10.1016/j.buildenv.2016.12.029.

Sánchez-Guevara, Carmen, Ana Sanz Fernández, y Agustín Hernández Aja. 2015. "Income, Energy Expenditure and Housing in Madrid: Retrofitting Policy Implications». Building Research \& Information 43 (6): 737-49. https://doi.org/10.1080/09613218.2014.984573.

Sánchez-Guevara Sánchez, Carmen. 2015. «Propuesta metodológica de evaluación de la pobreza energética en España: indicadores para la rehabilitación de viviendas». Phd, E.T.S. Arquitectura (UPM). http://oa.upm.es/39928/.

Santamouris, M., K. Kapsis, D. Korres, I. Livada, C. Pavlou, y M. N. Assimakopoulos. 2007. «On the relation between the energy and social characteristics of the residential sector». Energy and Buildings 39 (8): 893-905. https://doi.org/10.1016/j.enbuild.2006.11.001.

Santamouris, Mat. 2016. "Innovating to zero the building sector in Europe: Minimising the energy consumption, eradication of the energy poverty and mitigating the local climate change». Solar Energy, Special issue: Progress in Solar Energy, 128 (abril): 61-94. https://doi.org/10.1016/j.solener.2016.01.021.

Santiago, E. de. 2014. "La estrategia para la rehabilitación energética en el sector de la edificación residencial en España: metodología y principales resultados». Ciudad y territorio: Estudios territoriales, 2014

Santis, Antonio de. 2008. «Cadastral information system: a resource for the E.U. policies». Roma: Agenzia del Territorio.

Sanz Fernández, Ana. 2012. "La vulnerabilidad energética asociada a la movilidad motorizada». Territorios en formación 0 (3): 129-45.

Schleich, Joachim. 2019. «Energy efficient technology adoption in low-income households in the European Union - What is the evidence?» Energy Policy 125 (febrero): 196-206. https://doi.org/10.1016/j.enpol.2018.10.061.

Sede Electrónica de Catastro. 2011. "Servicios web libres del catastro». Dirección General de Catastro. http://www.catastro.minhap.gob.es/ws/Webservices_Libres.pdf.

- - - 2014. "Modelo de Datos de Cartografía Vectorial. Formato shapefile 2014 - manual descriptivo». Dirección General de Catastro. http://www.catastro.minhap.es/ayuda/manual_descriptivo_shapefile.pdf.

Serrano-Lanzarote, Begoña, Leticia Ortega-Madrigal, Alejandra García-Prieto-Ruiz, Laura Soto-Francés, y Victor-Manuel Soto-Francés. 2016. "Strategy for the Energy Renovation of the Housing Stock in Comunitat Valenciana (Spain)». Energy and Buildings, Towards an energy efficient European housing stock: monitoring, mapping and modelling retrofitting processes, 132 (noviembre): 11729. https://doi.org/10.1016/j.enbuild.2016.06.087. 
Skumatz, Lisa A. 2015. «Efficiency Programs' Non-Energy Benefits: How States Are Finally Making Progress in Reducing Bias in Cost-Effectiveness Tests». The Electricity Journal 28 (8): 96-109. https://doi.org/10.1016/j.tej.2015.09.008.

Song, Jingjing, Hailong Li, y Fredrik Wallin. 2017. "Cost Comparison Between District Heating and Alternatives During the Price Model Restructuring Process». Energy Procedia, 8th International Conference on Applied Energy, ICAE2016, 8-11 October 2016, Beijing, China, 105 (Supplement C): 3922-27. https://doi.org/10.1016/j.egypro.2017.03.813.

Sovacool, Benjamin K., y Michael H. Dworkin. 2015. «Energy justice: Conceptual insights and practical applications». $\quad$ Applied $\quad$ Energy $142 \quad$ (marzo): https://doi.org/10.1016/j.apenergy.2015.01.002.

Sustainable Energy Authority Of Ireland. 2015. «KORE Warmer Homes Scheme. Free Upgrades for Eligible Homes». http://www.seai.ie/grants/home-energy-grants/free-upgrades-for-eligible-homes/.

Tatjer, M. 2005. «La vivienda obrera en España de los siglos XIX y XX: de la promoción privada a la promoción pública». Scripta Nova. Revista electrónica de Geografía y Ciencias Sociales IX (194 (23)).

Teller-Elsberg, Jonathan, Benjamin Sovacool, Taylor Smith, y Emily Laine. 2016. «Fuel poverty, excess winter deaths, and energy costs in Vermont: Burdensome for whom?» Energy Policy 90 (marzo): 81-91. https://doi.org/10.1016/j.enpol.2015.12.009.

The Energy Commission. 1979. "The patterns of domestic energy consumption and the growth of prices in relation to consumers' income and expenditure 1966-1977 Energy». HMSO Commission Paper 2. London.

Thomson, Harriet, Neil Simcock, Stefan Bouzarovski, y Saska Petrova. 2019. «Energy poverty and indoor cooling: An overlooked issue in Europe». Energy and Buildings 196 (agosto): 21-29. https://doi.org/10.1016/j.enbuild.2019.05.014.

Thomson, Harriet, y Carolyn Snell. 2013. «Quantifying the prevalence of fuel poverty across the European Union». Energy Policy, Special Section: Transition Pathways to a Low Carbon Economy, 52 (enero): 563-72. https://doi.org/10.1016/j.enpol.2012.10.009.

Thuvander, Liane. 2008. Towards Environmental Informatics for Building Stocks. A Conceptual Model for an Environmental Building Stock Information System. Chalmers Publication Library (CPL). Forskningspublikationer från Chalmers Tekniska Högskola. VDM. http://publications.lib.chalmers.se/publication/104105-towards-environmental-informatics-forbuilding-stocks-a-conceptual-model-for-an-environmental-buildi.

Tirado, S., L. Jiménez, J. L. López, J. Martín, y E. Perero. 2014. «Pobreza energética en España. Análisis de tendencias». España.

Tirado, S., Jiménez Meneses, L., López Fernández, J.L., Perero Van Hove, E., Irigoyen Hidalgo, V., y Savary, P. 2016. «Pobreza, vulnerabilidad y desigualdad energética. Nuevos enfoques de análisis». Asociación de Ciencias Ambientales. Madrid.

Tirado, S., Jiménez Meneses, López Fernández, y Irigoyen Hidalgo. 2018. «Pobreza energética en España. Hacia un sistema de indicadores y una estrategia de actuación estatales». Madrid: Asociación de Ciencias Ambientales.

Tirado, S., J. L. López Fernández, y P. Martín García. 2012. «Pobreza Energética en España. Potencial de Generación de empleo derivado de la rehabilitación energética de viviendas». Asociación de Ciencias Ambientales, ACA, Madrid.

Tod, Angela, y Harriet Thomson. 2016. «Health Impacts of Cold Housing and Energy Poverty». Energy Poverty Handbook, 39-56.

Tragopoulos, Georgios, y Peter Sweatman. 2012. «Retos y oportunidades de financiación para la rehabilitación energética de viviendas en España». WWF/Adena. 
Tuominen, Pekka, Riikka Holopainen, Lari Eskola, Juha Jokisalo, y Miimu Airaksinen. 2014. "Calculation Method and Tool for Assessing Energy Consumption in the Building Stock». Building and Environment 75 (mayo): 153-60. https://doi.org/10.1016/j.buildenv.2014.02.001.

UPV. 2016. "PROJECTE DE MAPA DE LA POBRESA ENERGÈTICA PER A L'AJUNTAMENT DE VALÈNCIA». Institut Universitari de Recerca d'Enginyeria Energètica. Universitat Politècnica de València.

Vartholomaios, Aristotelis. 2017. «A parametric sensitivity analysis of the influence of urban form on domestic energy consumption for heating and cooling in a Mediterranean city». Sustainable Cities and Society 28 (enero): 135-45. https://doi.org/10.1016/j.scs.2016.09.006.

Vinuesa, Julio. 2008. "La vivienda vacía en España: un despilfarro social y territorial insostenible». Scripta Nova: revista electrónica de geografía y ciencias sociales, n. ${ }^{\circ}$ 12: 35.

Walker, Gordon, y Rosie Day. 2012. «Fuel poverty as injustice: Integrating distribution, recognition and procedure in the struggle for affordable warmth». Energy Policy, Special Section: Fuel Poverty Comes of Age: Commemorating 21 Years of Research and Policy, 49 (octubre): 69-75. https://doi.org/10.1016/j.enpol.2012.01.044.

Weber, Ines, y Anna Wolff. 2018. «Energy efficiency retrofits in the residential sector - analysing tenants' cost burden in a German field study». Energy Policy 122 (noviembre): 680-88. https://doi.org/10.1016/j.enpol.2018.08.007.

Wicks, M. 1978. Old and cold: hypothermia and social policy. London: Heinemann Educational Books.

Wilkinson, Paul, Sam Pattenden, Ben Armstrong, Astrid Fletcher, R Sari Kovats, Punam Mangtani, y Anthony J McMichael. 2004. "Vulnerability to Winter Mortality in Elderly People in Britain: Population Based Study». BMJ 329 (7467): 647. https://doi.org/10.1136/bmj.38167.589907.55.

Wurtz, Frédéric, y Benoît Delinchant. 2017. "“Smart buildings" integrated in "smart grids": A key challenge for the energy transition by using physical models and optimization with a "human-in-the-loop" approach». Comptes Rendus Physique, Demain l'énergie, 18 (7): 428-44. https://doi.org/10.1016/j.crhy.2017.09.007.

WWF, Isabela Velázquez, Carlos Verdaguer, Alfonso Sanz, y Gloria Gómez. 2017. «Rehabilitación energética de viviendas Como mejorar la calidad de vida y combatir el cambio climático». Madrid, España. http://awsassets.wwf.es/downloads/RehabilitacionEnergeticaViviendas_\%28completo\%29.pdf. 


\section{INDICE DE FIGURAS}

Figura 1. Visados de rehabilitación y reforma 2000 al 2014. Fuente Ministerio de Fomento (CEPCO, 2015). .8

Figura 2. Esquema conceptual del Modelo de Análisis de Datos Espaciales (Thuvander, 2008) .21

Figura 3. Diagrama conceptual de la metodología propuesta. Elaboración propia .23

Figura 4. Visualización del soporte de información geométrica del MADE. Ejemplo de barrios vulnerables e ineficientes en Puente de Vallecas (Madrid). Elaboración propia.

Figura 5. Diagrama de flujos de entradas y salidas de información en el Modelo de Análisis de Datos Espaciales propuesto. Elaboración propia.

Figura 6. Viviendas principales por año de construcción en España. Fuente INE 2011 .37

Figura 7. Evolución 2004-2011 de la tasa de riesgo de pobreza por edad. Fuente: UNICEF a partir de datos de la ECV, INE. Datos provisionales para 2011.

Figura 8. El pico de la producción mundial. Fuente: Ramón Fernández Durán. .41

Figura 9. Tasas de desconexión en diferentes países de la UE (ACER/CEER 2017) 45

Figura 10. Cálculo de la brecha de pobreza energética. Fuente: J. HILLS. Final report of the Fuel Poverty Review, 2012. .50

Figura 11. Comparación de indicadores de pobreza energética en 5 países Europeos. Fuente: EPEE project

Figura 12.Porcentaje de personas que no pueden permitirse mantener su vivienda a una temperatura adecuada, con retraso en el pago de recibos (excluidos alquiler e hipoteca) y con goteras, humedades o podredumbre en su vivienda (España, 2004-2010). Proyecto REPEX.

Figura 13.Pirámides de población española en 2009 y estimaciones hasta 2049. Fuente: Instituto Nacional de Estadística

Figura 14. Impactos en costes y precios de la electricidad. Escenario base. Fuente: (European Commission y Directorate-General for Energy 2010)

Figura 15. Cruce de datos de vulnerabilidad urbana en Madrid, de las dos metodologías existentes. Elaboración propia

Figura 16.Distribución de la renta per cápita en Madrid capital en 1997 por secciones censales y por distritos (Moreno Jiménez 2003)

Figura 17. Indicador de renta disponible bruta municipal per cápita (Base 2010) Euros. Elaboración propia a partir del Banco de datos municipal y zonal Almudena, Instituto de Estadística de la Comunidad de Madrid . .74

Figura 18. Distribución de la renta por tramos en Madrid (Urban Audit 2013) .......................................75

Figura 19. Renta media del hogar por distritos en 2013 y 2014 (Ayuntamiento de Madrid).........................76

Figura 20. Edad de la población por tramos. Fuente Censos INE 1991, 2001 y 2011...................................77

Figura 21. Evolución de la distribución de la población mayor de 65 años. Censos (INE 1991; 2001; 2011)..78

Figura 22. Porcentaje de población menor de 16 años por sección censal en el Censo del INE 2011 ............79

Figura 23. Distribución de viviendas por distritos y periodo de construcción en el municipio de Madrid. Datos INE 2001

Figura 24. Muestra del proyecto REFAVIV (Oteiza, 2018) y barrios de promoción oficial (Moya 1983).........84

Figura 25. Porcentaje de viviendas sin calefacción por sección censal (Fuente: Censo INE 2001) .................86

Figura 26. Porcentaje de edificios de viviendas con instalación de ACS centralizada por sección censal (Fuente: Censo INE 2001) 
Figura 27. Porcentaje de viviendas con refrigeración por sección censal (Fuente: Censo INE 2001)

Figura 28. Viviendas vacías en el municipio de Madrid y su porcentaje con respecto de las principales

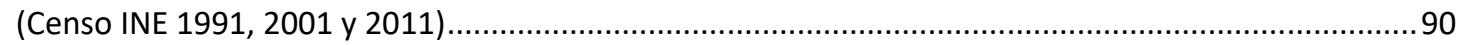

Figura 29. Porcentaje de viviendas vacías por sección censal (Fuente: Censo INE 2001) .............................90

Figura 30. Edificios destinados a viviendas construidos durante el periodo 1940-80. Datos INE 2001..........92

Figura 31. Edificios destinados a viviendas en estado ruinoso, malo o deficiente. Datos INE 2001 ...............93

Figura 32. Edificios destinados a viviendas sin ascensor con cuatro o más plantas. Datos INE 2001 .............94

Figura 33. Edificios no accesibles destinados a viviendas. Datos INE 2001.............................................95

Figura 34. Conjuntos residenciales catalogados en el archivo "La vivienda Moderna". Fuente: DOCOMOMO

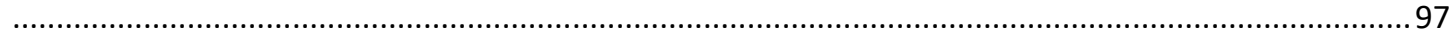

Figura 35. Áreas de Rehabilitación en Madrid. Fuente: Ayuntamiento de Madrid y Hernández Aja .99

Figura 36. Áreas urbanas con fachadas rehabilitadas de forma masiva con aislamiento por el exterior (Oteiza et al. 2016) 100

Figura 37. Esquema conceptual del desarrollo de la herramienta estadística de evaluación de la pobreza energética. Elaboración propia 106

Figura 38. Clases de Energía a partir de los Índices de Calificación C1 y C2 (IDAE 2011a)..... 111

Figura 39. Características de los edificios tipo simulados en el clima de Madrid. Elaboración propia ..........113

Figura 40. Densidad residencial por sección censal en Madrid (INE 2001) .............................................117

Figura 41. Antigüedad de los edificios de vivienda en Madrid (INE 2001) ..................................................117

Figura 42. Densidad de demanda de calefacción (MWh/Ha). Elaboración propia 118

Figura 43. Calificación energética de demanda de calefacción residencial (kWh/m2). Elaboración propia.119

Figura 44. Calificación energética en los barrios vulnerables (2001). Elaboración propia..... 120

Figura 45. Implantación de calefacción (1) de gas y (2) eléctrica en el municipio de Madrid. Elaboración propia a partir de datos (INE 2001)......

Figura 46. Distribución del coste anual del consumo energético residencial medio por sección censal. Elaboración propia 131

Figura 47. Mapa de la pobreza energética en Madrid. Elaboración propia 132

Figura 48. Áreas con edificación residencial ineficiente, barrios vulnerables y solape entre ellos. Elaboración propia.

Figura 49. Barrios vulnerables ineficientes eliminando áreas rehabilitadas. Elaboración propia a partir de datos del Atlas de Barrios Vulnerables de España

Figura 50. Distribución de los indicadores de: (1) bajos ingresos, (2) costes elevados, (3) sin calefacción y (4) población mayor. Elaboración propia

Figura 51. Edificación ineficiente e indicadores de severidad de la pobreza energética. Elaboración propia

Figura 52. Detalle de la severidad de la pobreza energética en barrios vulnerables de la periferia. Elaboración propia

Figura 53. Análisis multidimensional del riesgo de pobreza energética para el barrio de Portazgo. Elaboración propia

Figura 54. Comparativa con la metodología del 10\% con el análisis multidimensional. Elaboración propia152

Figura 55. Esquema conceptual del desarrollo de la Metodología de Evaluación de Pérdidas Energéticas mediante Datos catastrales. Elaboración propia. 156 
Figura 56. Ficha de salida de datos no protegidos de la consulta descriptiva y grafica de bienes inmuebles.

Ejemplo de edifico en torre en el PD Canillas (Sede Electrónica de Catastro 2011)..........................162

Figura 57. Diagrama de flujo para el programa MEPEC (Fernando de Frutos 2017) ..................................165

Figura 58. Visualización de la clasificación de otros usos distintos al residencial para el poblado de Canillas (m2). Elaboración propia ..168

Figura 59. Cómputo de fachadas por orientaciones en el estudio de caso (planta baja). Elaboración propia 170

Figura 60. Valores de transmitancia térmica $(\mathrm{W} / \mathrm{m} 2 \mathrm{~K})$ empleados en diversos estudios para fachadas de Madrid (Alonso 2015) .176

Figura 61. Transmitancia de fachadas de promociones de vivienda publica en Zaragoza (Kurtz 2015) .......178

Figura 62. Valores $\mathrm{U}\left(\mathrm{W} / \mathrm{m}^{2} \mathrm{~K}\right)$ de cubiertas en Zaragoza (Kurtz et al., 2015) .............................................182

Figura 63. Ficha de recogida de datos del Poblado Dirigido de Canillas (Oteiza, I. et al. 2018) ..... 184

Figura 64. Visualización del coeficiente global de pérdidas $K_{G}\left(W / m^{2} K\right)$ para cada edificio del barrio. Elaboración propia 186

Figura 65. Pérdidas energéticas anuales (kWh) de la edificación del barrio de Canillas. Elaboración propia .188

Figura 66. Indicador de eficiencia Energética IEE $\left(\mathrm{kWh} / \mathrm{m}^{3}\right)$ para la muestra analizada conforme a la calidad de la envolvente. Elaboración propia ..189

Figura 67. Balance energético de un edificio (ISO 13790, 2008) .194

Figura 68. Validación de la estación de Marid Ciudad Universitaria para el mapa ADRASE (CIEMAT, n.d.) 197

Figura 69. Radiación solar (kWh) incidente sobre (a) cubiertas y (b) fachadas, para los edificios del Canillas. Elaboración propia.

.201

Figura 70. Demanda energética de calefacción $(\mathrm{kWh} / \mathrm{m} 2)$ para cada edifico residencial del barrio de Canillas. Elaboración propia. 206

Figura 71. Sistema de Aislamiento térmico por el exterior para fachada con EPS (CYPE 2018) .212

Figura 72. Sistema de aislamiento térmico por el exterior para fachadas, a base de fibras de madera (CYPE 2018)

Figura 73. Aislamiento de cubierta con XPS y protección de grava (CYPE 2018) 214

Figura 74. Sistema de cubierta verde extensiva con aislamiento de XPS (CYPE 2018). .215

Figura 75. Aislamiento térmico de cubierta inclinada por el exterior(Fuente: Virginia Sánchez Ramos 2012)

Figura 76. Sistema de aislamiento de suelos en contacto con el aire exterior con Lana Mineral (MW) (CYPE 2018)

Figura 77. Edificación en el barrio administrativo de Canillas. IEEcal (kWh/m3). Elaboración propia .229

Figura 78. Reducción de pérdidas asociadas al coste de la inversión inicial por edificio. Elaboración propia

Figura 79. Representación de los coeficientes $K_{G}$ contra $I E E_{c a l}\left(Q_{t} /\right.$ vol) en los 2019 edificios del Barrio de Canillas, antes (azul) y después (rojo) de la rehabilitación. Elaboración propia......

Figura 80. Perdidas por unidad de volumen edificado ( $\mathrm{IEE}_{\mathrm{cal}}$ ) asociadas a la edificación del PD Canillas, antes y después de la rehabilitación. Elaboración propia

Figura 81. Coste de inversión (€) y periodo de amortización teórico (años) para los edificios intervenidos. Elaboración propia

Figura 82. Ubicación de la muestra de 11 barrios en riesgo crítico de pobreza energética. Elaboración propia 
Figura 83. Histograma de frecuencias de la variable "año de construcción" de la edificación de la muestra. Elaboración propia

Figura 84. Gráficos de puntos de año de construcción contra las variables VIVIENDA, ALT_MED, COMP, KG, IEE y pasTOTinv para los 11 barrios. Elaboración propia

Figura 85. Histograma de frecuencias de las variables (1) altura media y (2) número de plantas. Elaboración propia

Figura 86. Histograma de frecuencias para el Coeficiente Global de Transmisión Térmica KG. Elaboración propia

Figura 87. Ploteado de resultados de $\mathrm{K}_{\mathrm{G}}$ contra $\mathrm{IEE}_{\mathrm{cal}}\left(\mathrm{Q}_{\mathrm{t}} / \mathrm{V}\right)$ de los 6808 edificios existentes en los 11 barrios analizados. Elaboración propia.

Figura 88. Graficos de puntos de compacidad contra altura media, indicador de eficiencia energetica y radiacion solar pasiva. Elaboración propia

Figura 89. IEEcal y normas zonales en los 10 barrios seleccionados. Elaboración propia 247

Figura 90. Indicadores energéticos de la edificación en el AEV 2807911 del barrio de Aluche. Elaboración propia

Figura 91. Imagenes del barrio de Aluche. Elaboración propia..............................................................255

Figura 92. Ficha de salida de resultados para barrio. Caso de Aluche (Anexo III). Elaboración propia..........257

Figura 93. Indicadores energéticos de la edificación en el barrio de Entrevías Este. Elaboración propia ....258

Figura 94. Edificios multifamiliares de las unidad vecinal 5 y 2 en Entrevías Este (Proyecto REFAVIV)........259

Figura 95. Indicadores energéticos de la edificación en el barrio de Picazo. Elaboración propia 260

Figura 96. Imágenes del APIRU del Barrio de San Diego, que contiene el Barrio Vulnerable de Picazo. Fuente: proyecto Madrid Regenera (Ayuntamiento de Madrid)

Figura 97. Indicadores energéticos de la edificación en el barrio de Vicálvaro. Elaboración propia .............262

Figura 98. Imágenes del Casco Histórico de Vicálvaro (Google, Wikiwand) ....

Figura 99. Edificios anteriores a 1979 (en rojo) incluidos en el análisis para su rehabilitacion. Elaboración propia 


\section{INDICE DE TABLAS}

Tabla 1. Valores medios de la distribución de la población por edades para el municipio de Madrid. Fuente

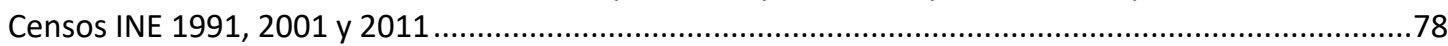

Tabla 2. Número de viviendas por clases en el municipio de Madrid (INE 2001) .....................................80

Tabla 3. Detalle del régimen de tenencia de vivienda principal en Madrid (INE 2001) ...............................80

Tabla 4. Distribución de viviendas principales de Madrid por periodo y distrito (INE 2001) .........................80

Tabla 5. Viviendas vacías en el municipio de Madrid y su porcentaje con respecto de las principales (Censo

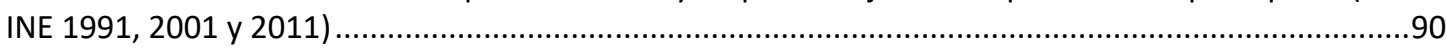

Tabla 6. Numero de edificios destinados principalmente a viviendas en el municipio de Madrid por periodos de construcción (Censo INE 2011)

Tabla 7. Valores de demandas energéticas de referencia para edificios de nueva construcción y existentes en $\mathrm{kWh} / \mathrm{m}^{2}$ (IDAE 2011a)

.111

Tabla 8. Valores límite de clase en demanda de calefacción para viviendas en bloque en Madrid. Elaboración propia a partir de (IDAE 2011a) ...............................................................................111

Tabla 9. Resultados de la simulación de edificios tipo en Madrid $\left(\mathrm{kWh} / \mathrm{m}^{2}\right)$. Elaboración propia...............114

Tabla 10. Demanda de calefacción adoptada para cada periodo $\left(\mathrm{kWh} / \mathrm{m}^{2}\right)$. Elaboración propia ................116

Tabla 11. Listado de barrios vulnerables afectados por ineficiencia energética. Elaboración propia...........121

Tabla 12.Transformación de datos de demanda a consumo para calefacción para la vivienda media en Madrid. Elaboración propia a partir de datos (INE 2001; 2011)

.124

Tabla 13. Transformación de datos unitarios de demanda a consumo para cada clase en zona climática D (Madrid). Elaboración propia .124

Tabla 14. Combustible usado para calefacción por número de hogares (INE 2001). 125

Tabla 15. Descomposición de la factura energética anual necesaria para calefactar una vivienda media en Madrid por tipo de suministro. Elaboración propia .128

Tabla 16. Descomposición de la factura de gas para calefacción por clases para la zona climática D (Madrid). Elaboración propia

Tabla 17. Descomposición de la factura de electricidad para calefacción por clases, zona climática D (Madrid). Elaboración propia .128

Tabla 18. Descomposición de la factura de electricidad para otros usos. Elaboración propia ....................130

Tabla 19. Consumo total para la vivienda media en Madrid. Elaboración propia 130

Tabla 20. Consumo total anual por vivienda por clase de demanda de calefacción según fuente de energía (1) gas y (2) eléctrica, para la zona climática D2 (Madrid). Elaboración propia .130

Tabla 21.Porcentaje de los ingresos del hogar empleado para hacer frente al gasto con calefacción de GAS, según tramo de renta y clase de demanda. Elaboración propia

Tabla 22.Porcentaje de los ingresos del hogar empleado para hacer frente al gasto con calefacción ELECTRICA según tramo de renta y clase de demanda. Elaboración propia

Tabla 23. Severidad del riesgo de pobreza energética en los barrios vulnerables e ineficientes. Elaboración propia.

Tabla 24. Secciones censales afectadas que no pertenecen a ningún BBVV o AEV. Elaboración propia ......147

Tabla 25. Información de los barrios vulnerables con 4 indicadores de pobreza energética solapados. (Hernandez Aja et al. 2018)

Tabla 26.Servicios de descarga masiva (Sede Electrónica de Catastro) 163 
Tabla 27. Selección de atributos capa CONSTRU (Sede Electrónica de Catastro).

Tabla 28. Matriz de superficie habitable $(\mathrm{m} 2)$ por Uso y Periodo del PD Canillas. Elaboración propia .........167

Tabla 29. Dimensiones de fachada obtenidas para el barrio de Canillas clasificadas por orientación ..........170

Tabla 30. Superficies de envolvente en PD Canillas, agrupadas por periodo (m2). Elaboración propia....... 171

Tabla 31. Indicadores geométricos para el barrio y para tres edificios tipo. Elaboración propia ..................172

Tabla 32. Valores $U$ en elementos de la envolvente de viviendas de Madrid (Gómez Muñoz, 2014) ..........175

Tabla 33. Valores $U$ de fachada de la muestra REFAVIV (Oteiza, I. et al. 2018) ........................................177

Tabla 34. Promedio de los valores de U del proyecto REFAVIV (Oteiza, I. et al. 2018).............................177

Tabla 35. Proporción de huecos en fachadas en promociones de vivienda social en el distrito de San Blas Canillejas (Madrid) (proyecto REFAVIV)

Tabla 36. Valores $U$ de catálogo $\left(\mathrm{W} / \mathrm{m}^{2} \mathrm{~K}\right.$ ) para soluciones constructivas de huecos habituales (con $20 \%$ de marco) (Ministerio de Fomento 2011; EFINOVATIC y CENER 2015) 180

Tabla 37. Porcentaje de dobles ventanas en promociones analizadas en Madrid (proyecto REFAVIV) ....... 181

Tabla 38. Valor promedio de transmitancia $\left(\mathrm{W} / \mathrm{m}^{2} \mathrm{~K}\right.$ ) en huecos (Oteiza, I. et al. 2018) .............................181

Tabla 39. Transmitancia Térmica de cubiertas $\left(\mathrm{W} / \mathrm{m}^{2} \mathrm{~K}\right.$ ) por periodo (EFINOVATIC y CENER 2016).............183

Tabla 40. Soluciones de cubierta para la muestra de VPO (Oteiza et al. 2016) ...........................................183

Tabla 41. Transmitancia Térmica de suelos $\left(\mathrm{W} / \mathrm{m}^{2} \mathrm{~K}\right)$ por periodo (EFINOVATIC y CENER 2015)................183

Tabla 42. Valores de transmitancia térmica $(\mathrm{W} / \mathrm{m} 2 \mathrm{~K})$ adoptados para la envolvente por periodo y elemento constructivo. Elaboración propia.

Tabla 43. Grados día en base 15/15 anuales medios en la NBE CT 79 y actualización periodo 1981-2010 (Gangolells y Casals 2012)

Tabla 44. Resultados de pérdidas energéticas anuales ( $\mathrm{kWh} / \mathrm{año}$ ), barrio de Canillas (torre 4994547VK4749F, bloque 4992543VK4749D y unifamiliar 5292448VK4759C). Elaboración propia ...187

Tabla 45. Datos medios de la radiación global recibida por unidad de superficie $(\mathrm{m} 2)$ recibidas para diferentes orientaciones (kWh/m2) por mes (JRC - European Comision, 2017)......

Tabla 46. Resumen de valores adoptados para la aplicación de diferentes aspectos del factor solar. Elaboración propia 201

Tabla 47. Radiación solar incidente por periodo estacional para la edificación del barrio de Canillas. EP... 201

Tabla 48. Radiación solar anual incidente por elemento de la envolvente y periodo estacional para los edificios residenciales del barrio de Canillas....

Tabla 49. Estimación de la demanda para el periodo de calefacción en el Poblado Dirigido de Canillas. Elaboración propia 207

Tabla 50. Ficha ejemplo de precios descompuestos para una solución de aislamiento de fachada por el exterior. Fuente: CYPE Ingenieros 2018

Tabla 51. Características de la obra para un solo bloque (CYPE 2018) 220

Tabla 52. Características de la obra para la intervención a escala de barrio (CYPE 2018) 221

Tabla 53. Presupuesto unitario de ejecución material $(€)$ de las medidas evaluadas en función de la escala de la actuación (CYPE 2018)

Tabla 54. Estimación de costes unitarios $\left(€ / \mathrm{m}^{2}\right)$ en escenario macroeconómico. Elaboración propia .........223

Tabla 55. Estimación de coste total unitario $\left(€ / \mathrm{m}^{2}\right)$ para un escenario financiero. Elaboración porpia .......224

Tabla 56. Mejora de la transmitancia obtenida mediante la aplicación de las mejoras. Elaboración propia 
Tabla 57. Coste anual de la factura energética necesaria para calefacción en una vivienda media en Madrid por tipo de suministro. Elaboración propia y EUROSTAT 2017 ......................................................226

Tabla 58. Factores de conversión adoptados para el gas natural y electricidad. Elaboración propia ............228

Tabla 59. Computo de horas de trabajo necesarias para la ejecución de mejoras. Fuente CYPE ingenieros ..228

Tabla 60. Resultados para el total del barrio administrativo de Canillas, para el BBVV del Poblado Dirigido de Canillas, y para cada tipo de edificio. Elaboración propia ..........................................................230

Tabla 61. Variables utilizadas para la caracterización energética de barrios. Elaboración propia .................238

Tabla 62. Población y viviendas en los 11 barrios analizados (Hernández Aja et al., 2018) ........................240

Tabla 63. Estadísticos descriptivos para 15 variables de 6808 edificios en 11 barrios vulnerables.

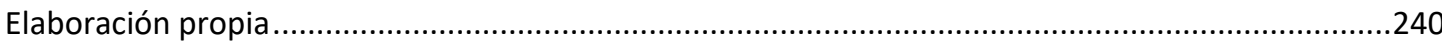

Tabla 64. Datos resumen para los 10 barrios: variables geométricas. Elaboración propia...........................246

Tabla 65. Datos resumen para los 10 barrios: variables energéticas. Elaboración propia ...........................246

Tabla 66. Correlaciones entre la demanda de calefacción total $(\mathrm{kWh})$ y unitaria $\left(\mathrm{kWh} / \mathrm{m}^{2}\right)$ y variables influyentes en tejidos característicos. Elaboración propia ..........................................................252

Tabla 67. Balance energético para el periodo de invierno en Aluche. Elaboración propia ..........................255

Tabla 68. Balance energético para el periodo de invierno en Entrevías Este. Elaboración propia ................259

Tabla 69. Balance energético para el periodo de invierno en Picazo. Elaboración propia...........................261

Tabla 70. Balance energético para el periodo de invierno en Vicálvaro. Elaboración propia .......................263

Tabla 71. Impacto medioambiental de la mejoras de la edificación residencial. Elaboración propia...........265

Tabla 72. Ejemplos de edificios candidatos a Edificios de Consumo Casi Nulo. Elaboración propia .............266

Tabla 73. Costes de la intervención. Elaboración propia........................................................................268

Tabla 74. Estimación del impacto en la creación de empleo de la rehabilitación de los barrios analizados. Elaboración propia .269

Tabla 75. Comparación de resultados para ambos métodos en los barrios afectados. Elaboración propia.272 
